This report was prepared as an account of work sponsured by an agency of the llated States Government. Neither the United States Ciovernment nor any agency thereof, nor any of their employees, makes any warranty, express or implied. ur ussumes any legal liability or respensibility for the accuracy, completeness, or usefulness of any information. apparatus. nroduct, ur process disclosed, or represents that its use would not iniringe privately owned rights. Reference herein to any specific commercial product, process, or service by trade name. Irademark. manufacturer, or otherwise does not necessarily constitute or impiy its endorsement, recommendation, or favoring by the United States Government or any agency thereof. The views and opinions of authors expressed herein do not necessarily state or reflect those of the United States Government or any agency thereof.

UCRL- -53702

DE87 014322

\title{
Spent Fuel Test-Climax: An Evaluation of the Technical Feasibility of Geologic Storage of Spent Nuclear Fuel in Granite Final Report
}

Compiled by:

W. C. Patrick

Manuscript date: March 30, 1986

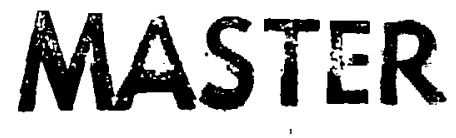

\section{LAWRENCE LIVERMORE NATIONAL LABORATORY University of California - Livermore, California • 94550}




\section{Foreword and Acknowledgments}

From the development of the text concept in lanuary 1978 to the writing of this final report. the Spent Fuel Test-Climax (SFT-C) has spanned 8 years and involved hundreds of scientists, engineers, and craftsmen in many organizations. During that time, those of us assuciated with the project had the pleasure of witnessing tine successful achievement of all the engineering and scientific objectives of the test. Perha os more importantly: we saw an increased public awe areness of the need fur nuclear energy and for a mears of saidely and reliably disposing of the assuciated wastes. Some 10,000 people from all walks of life th.roughout the L.S. and 22 foreign countries visited the test facility. Most went away with a more objective view of nuclear waste disposal than when they arrived.

Because the SFT - C Nas officially completed in FY 1485 and only very limited funding remains to finish up the remaining reports, it was not possible to assemble a complete team to write this report. Instead, it was assembled and edited by one person, but builds heavily on the FY 1993 project interim report in several technical areas. Although the responsibility for the inaterial presented here rests with the author, the important contributions of the following people are acknowledged: L. Ballou, T. Butkovich, R. Carlson. W' Durham, H. Ganow, G. Hage, E. Majer. D. Montan. R. Nyholm, N. Rector, F.J. Ryerson, H. Weiss, D. Wilder, and $\mathrm{l}$. Yow, Jr.

Nost of the scientists and enginaers who worked on the SFT - C have published formal reports and journal articles, providing a lasting record of their ufforts. However, many others filled roles vital to the success of the project, but that did not lend themselves to public documentation. Although it is not possible to properly acknowledge the contributions of each of these participants, those individuals and organizations whose efforts were keys to the success of the project are recognized here.

The SFT-C was funded as part of the U.S. Department of Energy (DOE) Nevada Nuclear Waste Storage Investigations (NNWSI) Project. Originally part of the National Waste Terminal Storage Program, it was conducted under the auspices of the Office of Civilian Radioactive Waste Management following passage of the Nuclear Waste Policy Act of 1982, which went into effect in January 1983. When the SFT - C was initiated, the DOE Project Manager was Robert Nelson. Beginning in June of 1982, Dr. Donald Vieth served as Manager of the Waste Management Project Office (WMPO) in Nevada. Mr. Mitch Kunich was WMPO's cognizant engineer and was intimately involved in all aspects of the SFT $-C t_{2}$ iroughout the development and execution of the test.

Facility engineering and construction were the responsibility of Holmes and Narver (general architect and engineering). Fenix and Scisson (architect and engineering services for mining and drilling), and Reynolds Electrical and Engineering Company (REECo) (construrcion). Special acknowledgment is extended to the late G.W. Adair, who served as superintendent throughout the construction and during the early storage phase, and to the REECo crew who provided continuous subsurface access and experimental support far beyond the normal requirements. Members of this crew included (at various times): L. Ala, J. Campbell, L. Cheney, D. Daffer, G. Frye, C. Halstead, and G. Medina. Appreciation is also extended to $H$. Allen, T. Clapp, D. Hansen, R. Murphy, and W. Smyth who provided special drilling support for stress measurements and geological characterization.

Spent fuel encapsulation was accomplished at the engine maintenance, assembly, and disassembly (EMAD) facility with a highly skilled Westinghouse team managed by D.C. Durrill. T. Cross was the project engineer with key responsibility for all hardware provided by Westinghouse. The accomplishments of his team were essential in preparing nuclear waste for emplacement less than two years from the date of authorization of the SFT-C. C. Balmgren coordinated and was the principal contributor to the test Safety Assessment Document.

A large suite of instrumentation was critical to the successful achievement of the technical objectives of the test. EG\&G-Las Vegas personnel filled a vital role in this area. Laboratory calibrations and recommendations regarding transducer selection were provided by $R$. Noyes and J. Pelles. In the field, B. Bailey, D. Jackson, W. Webb, and R. Seivert provided support for instrument installation, calibration. troubleshooting, and remedial actions.

Several colleagues at I.LNL deserve special recogrition as well, including: $M$. Mayr in construction management and coordination; R. Hasbrouck in control systems for spent-fuel handling; I. Duncan. I. House, and 6 . Wright in development of the spent-fuel handling system; W. Brough, R. Nvholm, $N$. Rector and $R$. Stager in data acyuisition system and instrumentation support: the late $N$ Cotter, M. Higuera, $W$. Richardson, and $L$. Rogers in data processing; 1 . Button as Operations Coardinator 
throughout the spent-fuel emplacement ano exchange uperations; T. Moran, K. Raschke, T. Roy, and T. Straume in Health and Sattety and I Beiriger. P'Burklund, T. Cates, R. Neurath, D. Peifer, J. Scarafiotti, F. Schumacher. and B. Sellick for electronice and mechancial technican support.

From te'st concept to find report. werall technical guidance for the SFT-6 has been provided by L. Ramspott. His insights and direction during the active phase of test development and execution, and his patience during the period of preparing final reports is gratefully acknowledged. I also extend my thanks and special recognition to L. Ballou. As Task Director for the SFT-C through April 1983, he was responsible for many of the engineering and test design concepts which led to the surcessful execution of the SFT-C. as reported here.

This manuscript represents uncountable hourn of effort on the part of 5 . Gonzales. Her irord processing skills, careful attention to details, and perseverance in working with the author are gratefully acknowledged. Editorial services were capably provided by M. Donohue and S. Stull, with help from B. Strack, I. Avde, and S. Wander.

Finally I thank F. Coffman. IT Corporation, for allowing me to complete this report after joining his company: 


\section{Contents}

Abstract

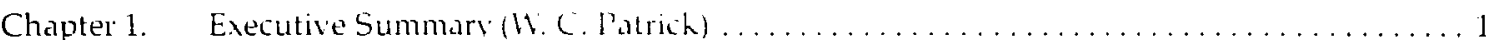

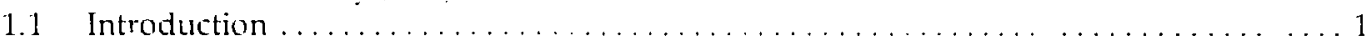

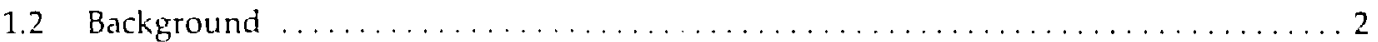

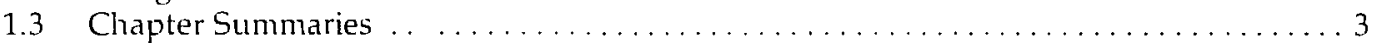

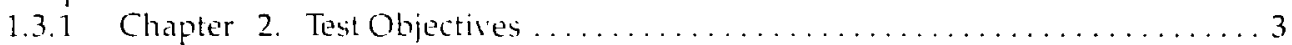

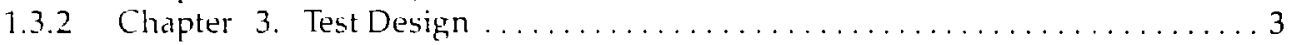

1.3.3 Chapter 4. Site Characterization and Geologic Investigations . . . . . . . 4

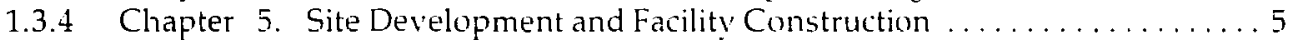

1.3.5 Chapter 6. Spent-Fuel Characterization ...................... 5

1.3.6 Chapter 7. Spent-Fuel Handling System ..................... 5

1.3.7 Chapter 8. Safety Assessment .......................... 6

1.3.8 Chapter 9. Selection, Deployment, and Performance of Instruments .....6 6

1.3.9 Chapter 10. Data Acquisition and Management Systems . . . . . . . . . . . 6

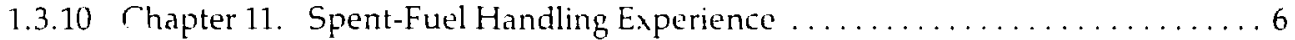

1.3.11 Chapter 12. Thermal Sources . . . . . . . . . . . . . . . . . . . . . . 7

1.3.12 Chapter 13. Heat Transfer Analyses and Measurements . . . . . . . . . . 7

1.3.13 Chapter 14 Ventilation System Analyses and Measurements . . . . . . . . . . 7

1.3.14 Chapter 15. Radiation Transport Calculations and Measurements . . . . . . . . . 7

1.3.15 Chapter 16. Rock Mechanical Response Calculations and Measurements . . .8

1.3.16 Chapter 17. Acoustic Emission and Wave Propagation Monitoring ........ 8

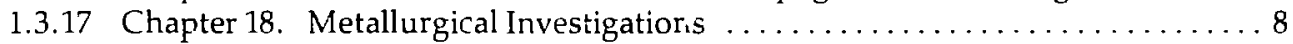

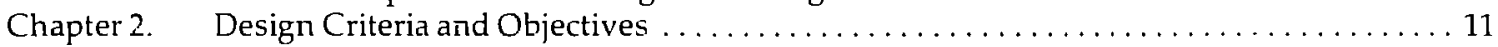

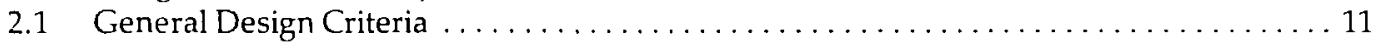

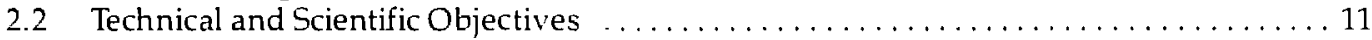

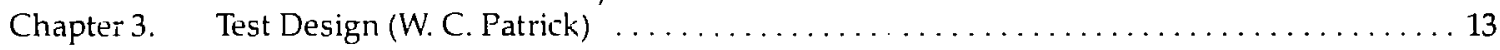

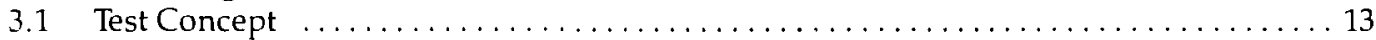

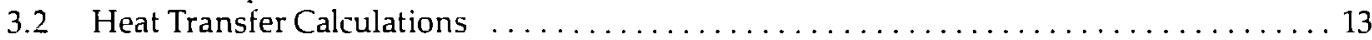

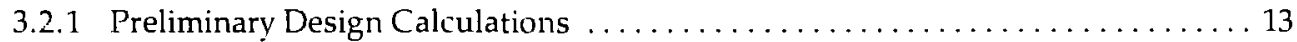

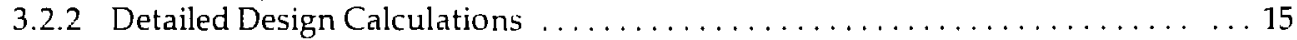

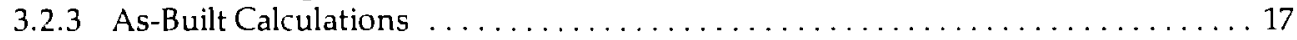

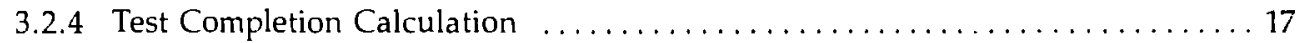

3.2 .5 Post-Test Calculations . . . . . . . . . . . . . . . . . . . . . . . . . . . . 19

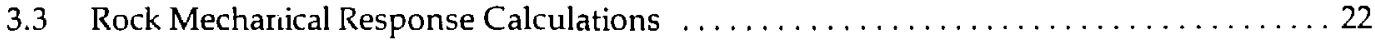

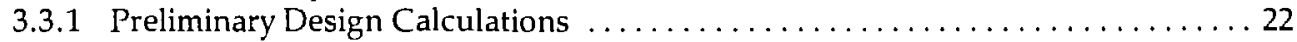

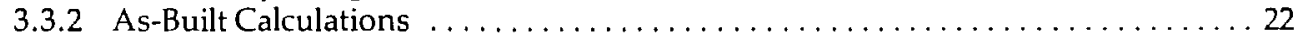

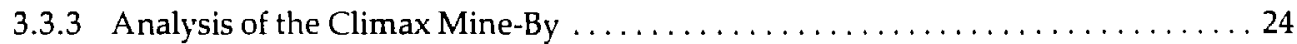

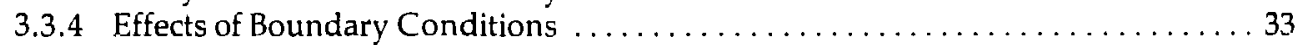

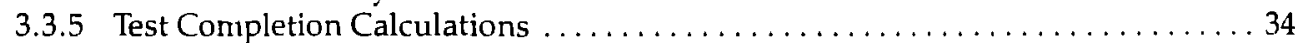

3.3.6 Post-Test Thermomechanical Calculations . . . . . . . . . . . . . . . . . . . . 34

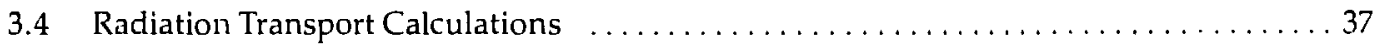

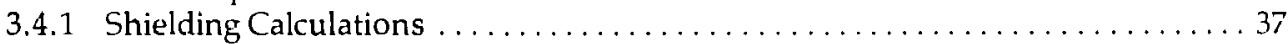

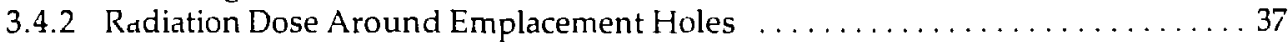

Chapter 4. Site Characterization and Geclogic Investigations $\ldots \ldots \ldots \ldots \ldots \ldots \ldots \ldots \ldots \ldots \ldots 4$

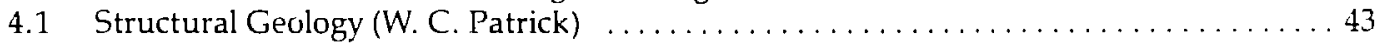

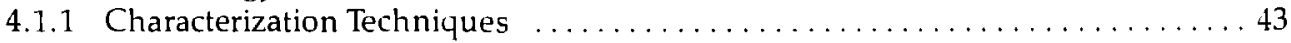

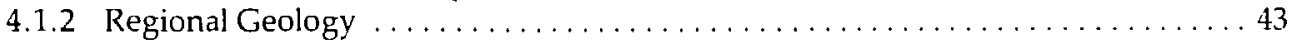

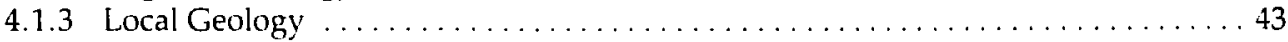

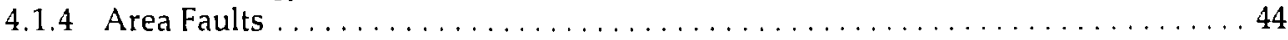

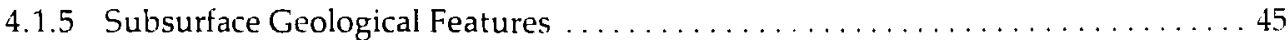

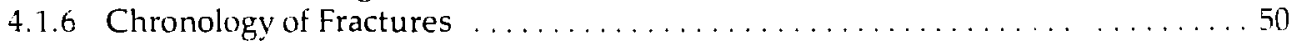

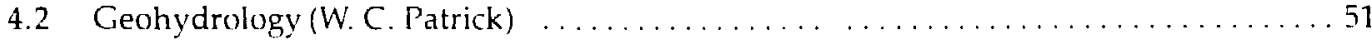

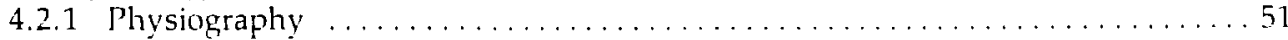




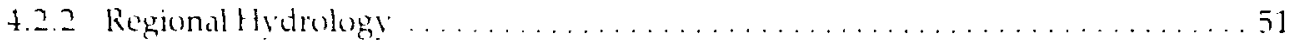

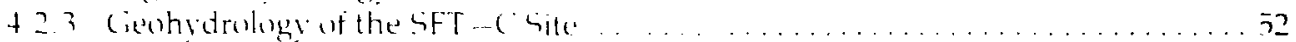

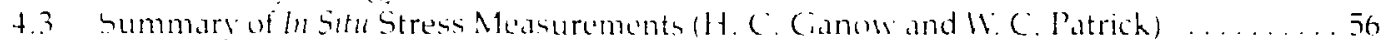

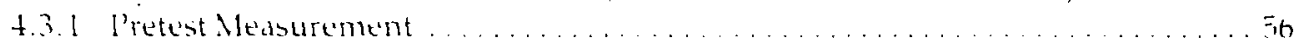

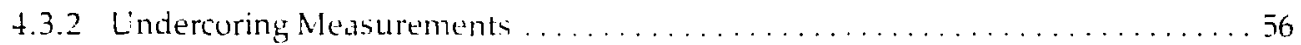

4.3 .3 Post-Test Measurements . . . . . . . . . . . . . . . . . . . . . . . 57

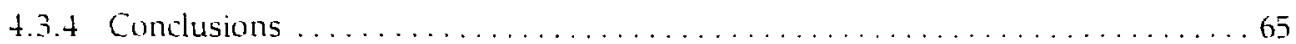

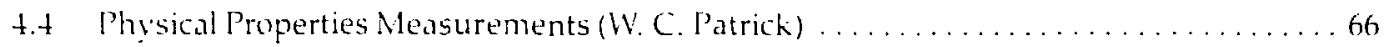

4.4 Laboratory Studies of Thermomechanical Properties $\ldots \ldots \ldots \ldots \ldots \ldots \ldots .70$

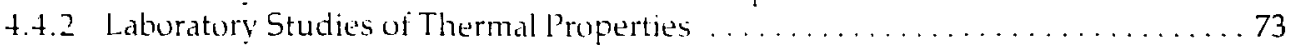

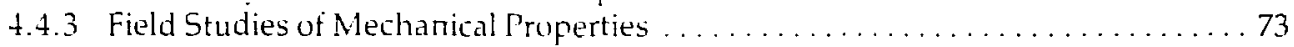

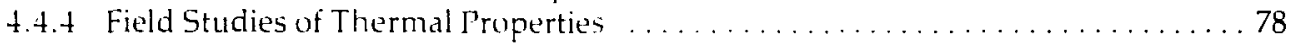

4.4 .5 Field Studies of Permeability . . . . . . . . . . . . . . . . . . 79

4.5 Mineralogical and Petrological Studies of Climax Pretest Cores (F. J. Ryerson) . . . . 79

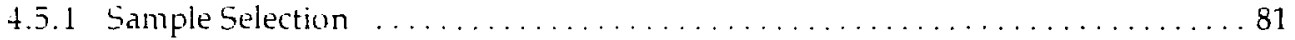

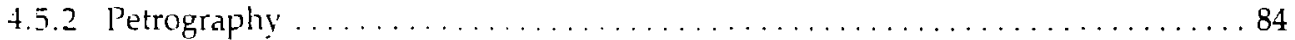

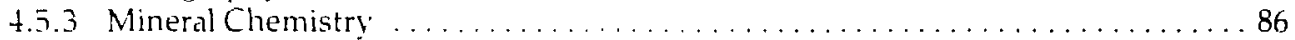

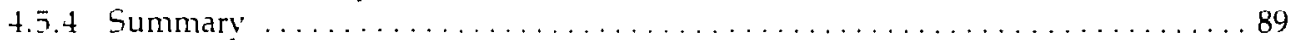

4.6 Radiation and Thermal Effects (W. B. Durham, F. J. Rverson, and W. C. Patrick) ... . . 89

4.6 .1 Effects on Mechanical Properties . . . . . . . . . . . . . . . . . . . . . 89

4.6.2 Microfracture Analysis of Laboratory-Irradiated Climax Core . . . . . . . . . . 90

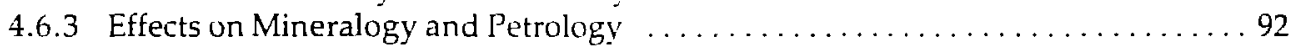

4.6.4 Physical and Chemical Changes Due to Heating $\ldots \ldots \ldots \ldots \ldots \ldots \ldots$

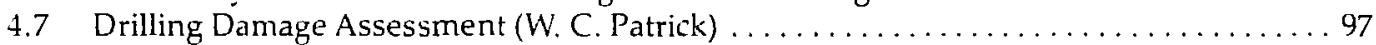

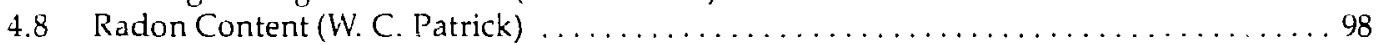

Chapter 5. Site Development and Construction of the Facility (W. C. Patrick) . . . . . . . . . 101

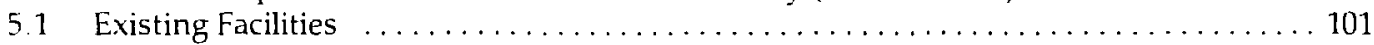

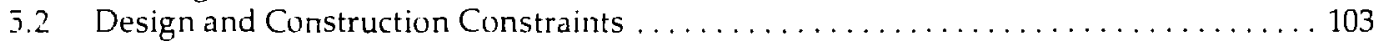

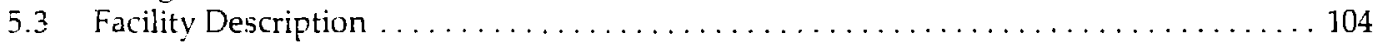

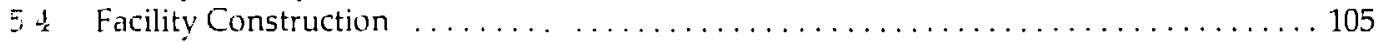

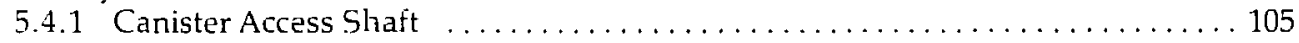

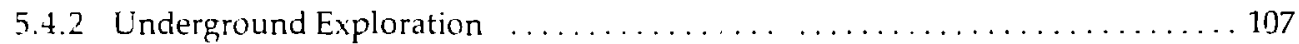

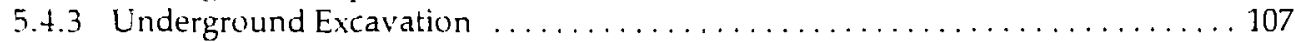

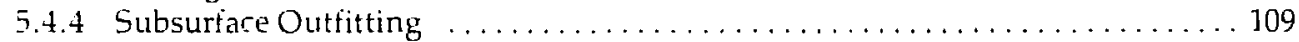

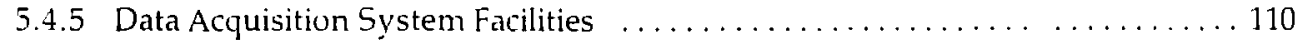

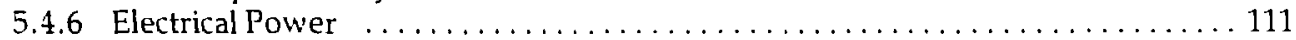

5.4 .7 Ventilation . . . . . . . . . . . . . . . . . . . . . . . . . . . . . 111

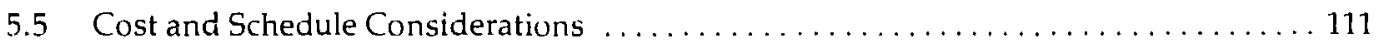

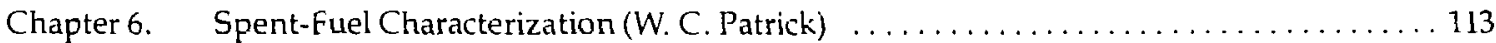

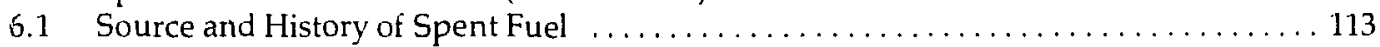

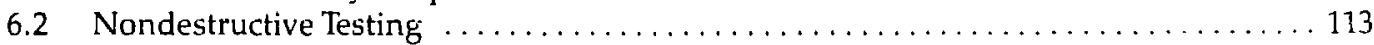

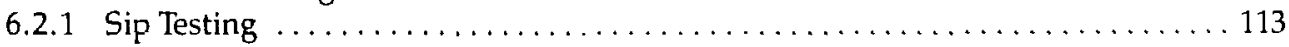

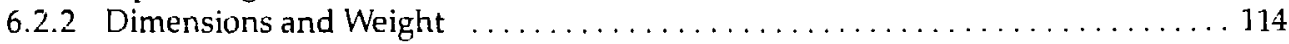

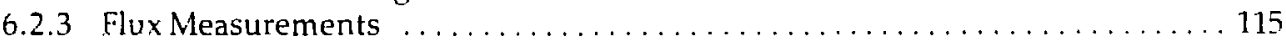

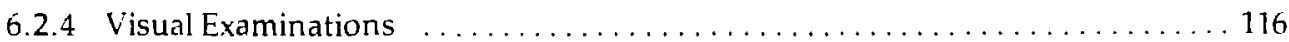

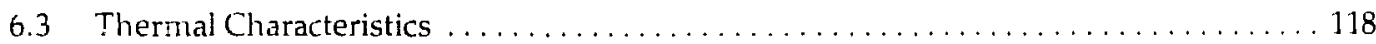

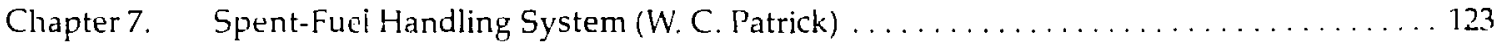

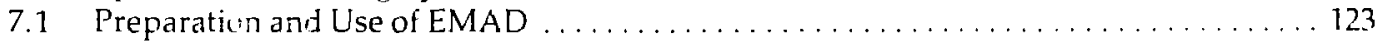

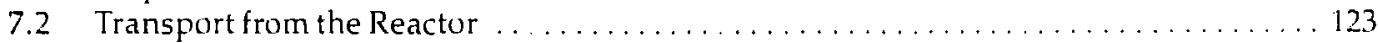

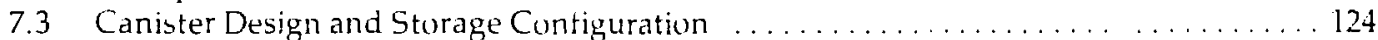

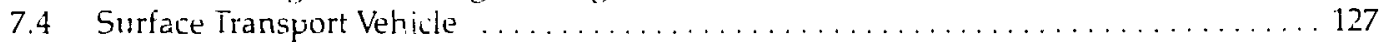

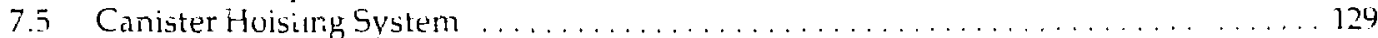

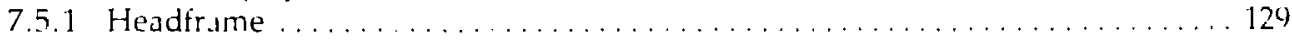

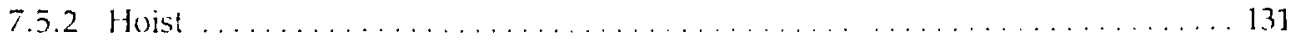

7.5 .3 Hois Cable . . . . . . . . . . . . . . . . . . . . . . . . 131 
7.5 .4 Emergency Brake $\lambda$ ssembly . . . . . . . . . . . . . . . . . . . . . . 131

7.5 .5 Cirapple Assembly . . . . . . . . . . . . . . . . . . . . . . . . 132

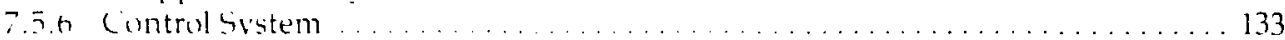

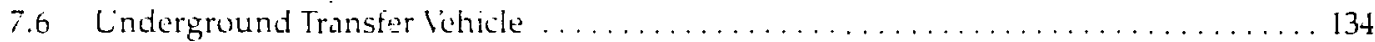

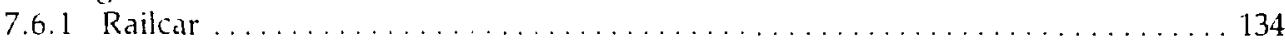

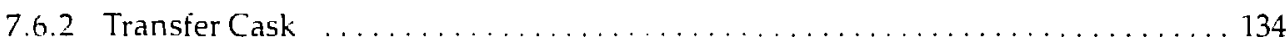

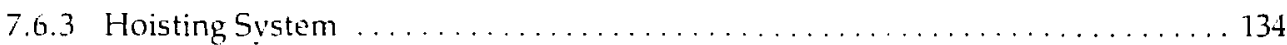

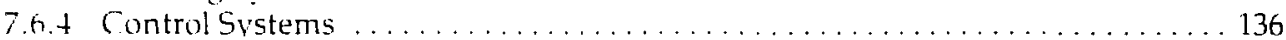

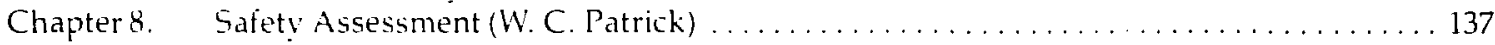

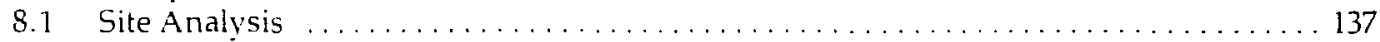

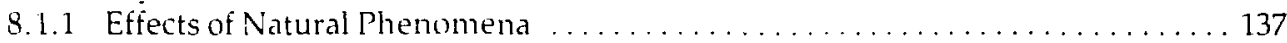

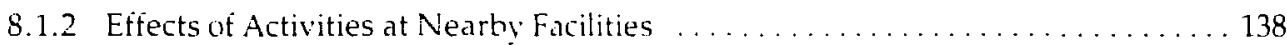

8.2 Radiological Impact of Normal Operations $\ldots \ldots \ldots \ldots \ldots \ldots \ldots \ldots \ldots \ldots \ldots \ldots$

8.3 Nonradiological Impact of Normal Operations . . . . . . . . . . . . . . . . . . 139

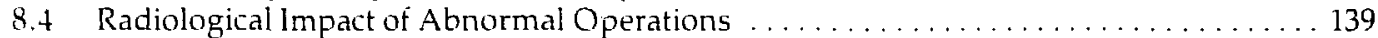

8.5 Nonradiological Impact of Abnomal Operations $\ldots \ldots \ldots \ldots \ldots \ldots \ldots \ldots \ldots \ldots \ldots$

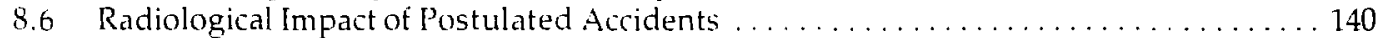

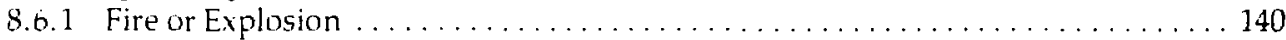

8.6.2 Inadvertent Removal of a Fuel Canister from a Shielded Cask . . . . . . . . . 140

8.6.3 Dropping a Canister Down Access Hole . . . . . . . . . . . . . . . . . . . . . . 141

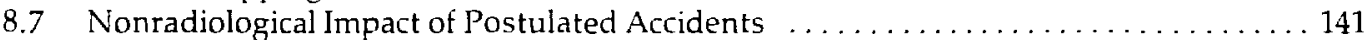

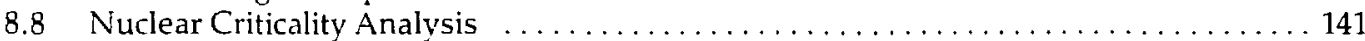

8.8.1 Flooding of One or More Canister Storage Holes Containing Canisters . . . . 142

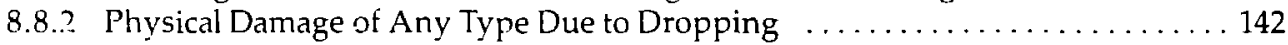

8.8.3 Physical Damage of Fuel Assembly in Canister Cornbined with Flooding . . . 142

8.8.4 Physical Damage of Fuel Assembly, Canister Geometry not Maintained,

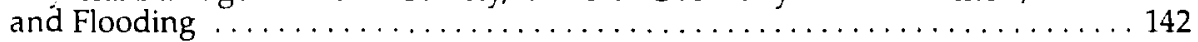

8.8.5 Fire in the Canister Drift with Flooding Associated with Fire Suppression . . . . 142

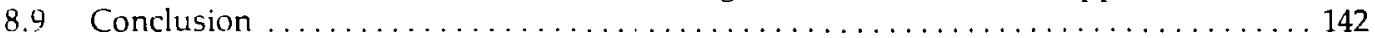

Chapter 9. Instrumentation Selection, Deployment, and Performance

(W. C. Patrick, N. L. Rector, and J. J. Scarafiotti) ......................... 143

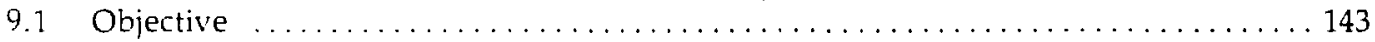

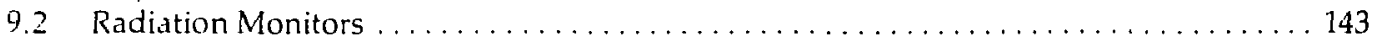

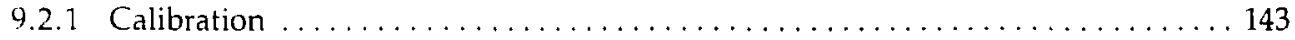

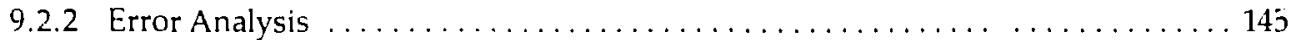

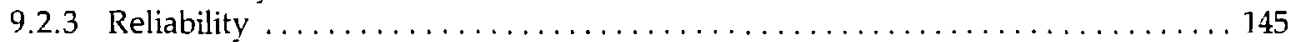

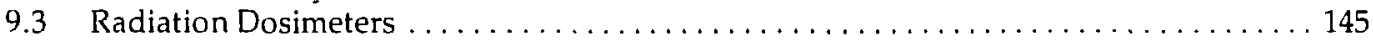

9.3.1 Performance, Reliability, and Error Analysis . . . . . . . . . . . . . . . 147

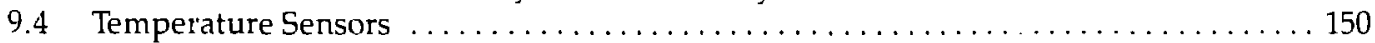

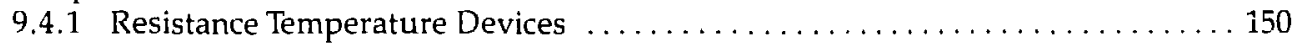

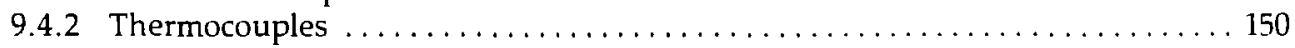

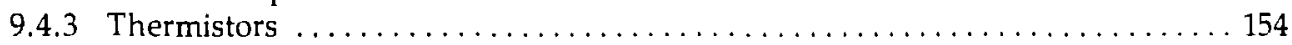

9.4 .4 Convergence $W$ ire Temperature Monitors $\ldots \ldots \ldots \ldots \ldots \ldots \ldots \ldots \ldots \ldots \ldots$

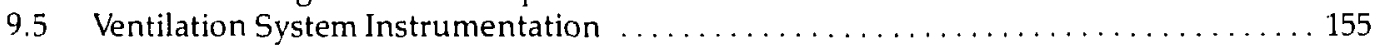

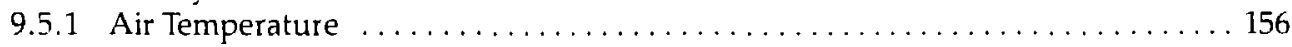

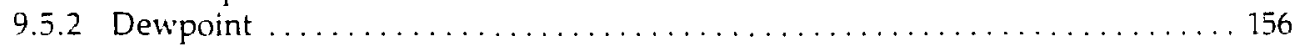

9.5 .3 Ventilation Flowrate . . . . . . . . . . . . . . . . . . . . . . . 156

9.5 .4 Energy Removal Calculation $\ldots \ldots \ldots \ldots \ldots \ldots \ldots \ldots \ldots \ldots$

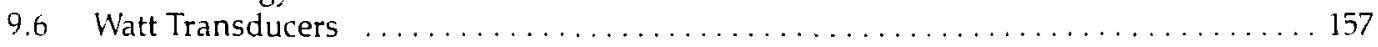

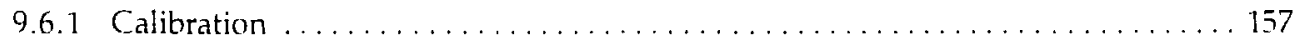

9.6 .2 Error Analysis . . . . . . . . . . . . . . . . . . . . . . . . . 158

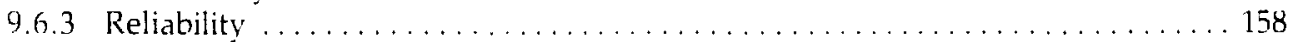

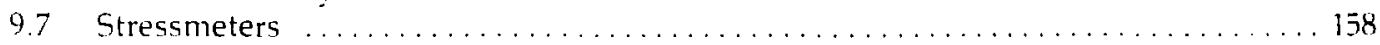

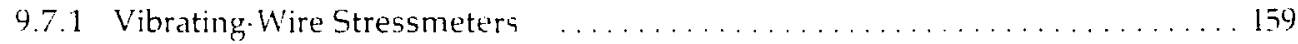

9.7 .2 USBM Borehole Deformation Gauges $\ldots \ldots \ldots \ldots \ldots \ldots \ldots \ldots \ldots \ldots \ldots \ldots$ 


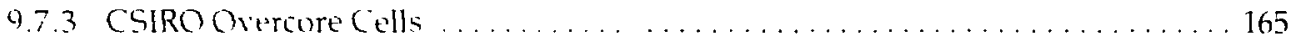

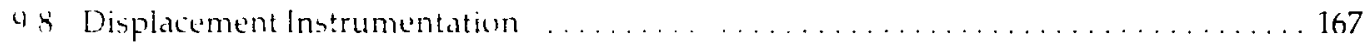

9.8.1 Borehole-Rod Extensometers . . . . . . . . . . . . . . . . . . . . 167

9.8 .2 Convergence Muniturs . . . . . . . . . . . . . . . . . . . . . . 174

9.8 .3 Fracture Moniturs . . . . . . . . . . . . . . . . . . . . . . . . . . . . . 175

9.8.4 Borehole Closure Monitor . . . . . . . . . . . . . . . . . . . . . . . . . . . 177

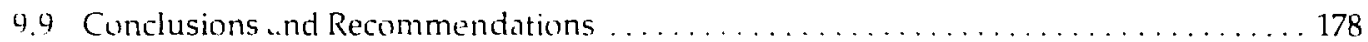

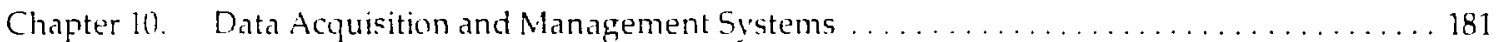

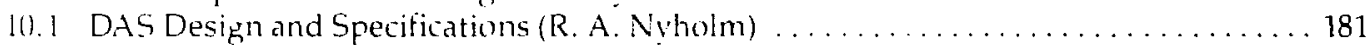

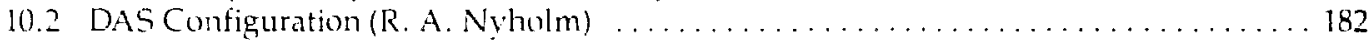

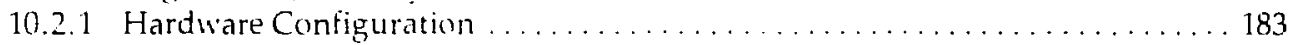

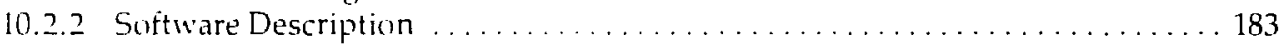

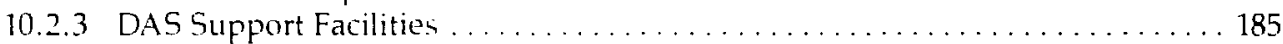

10.3 DAS Normal- and Fault-Mode Operations (R. A. Nyholm) $\ldots \ldots \ldots \ldots \ldots \ldots \ldots 187$

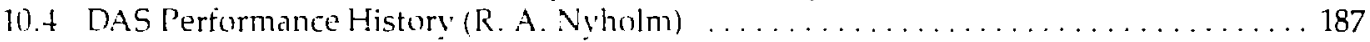

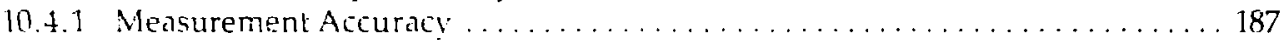

10.4 .2 System Reliability . . . . . . . . . . . . . . . . . . . . . . . . 188

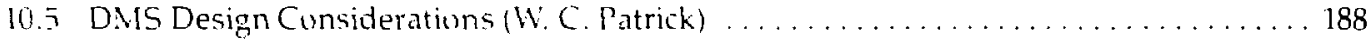

10.6 DNIS Description and Operation (R. C. Carison and W. C. Patrick) ........... 191

10.6.1 Data Receipt and Preprocessing ........................... 191

10.6.2 Data Conversion ... . . . . . . . . . . . . . . . . . . . . . . . . . . . 192

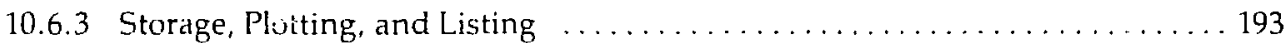

10.7 Quantity and Quality of Data Received (R. C. Carlson and W. C. Patrick) . . . . . . . . 194

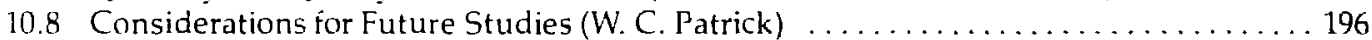

Chapter 11. Spent-Fuel Handling Experience (W. C. Patrick) . . . . . . . . . . . . . . . . . 197

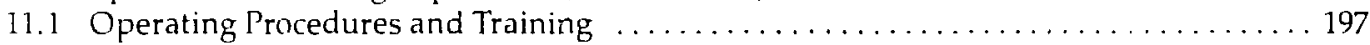

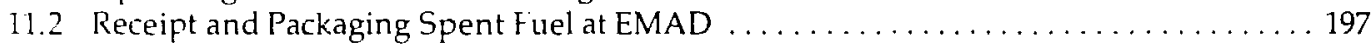

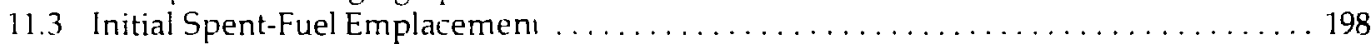

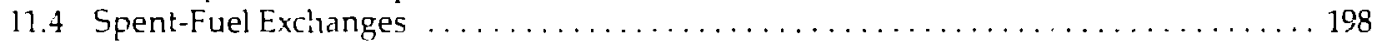

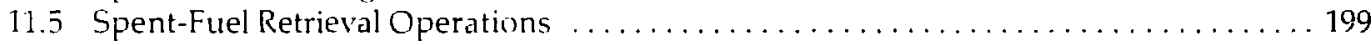

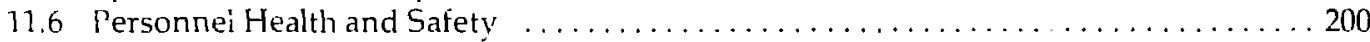

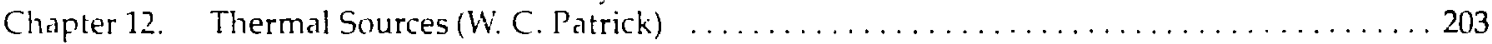

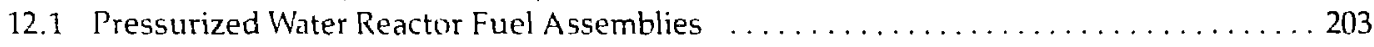

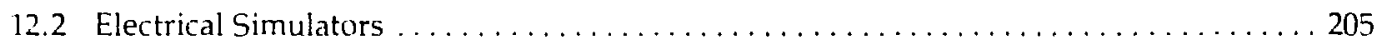

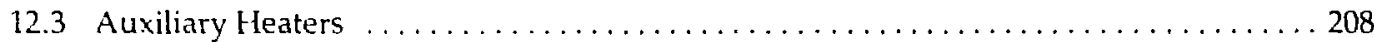

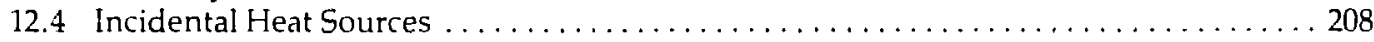

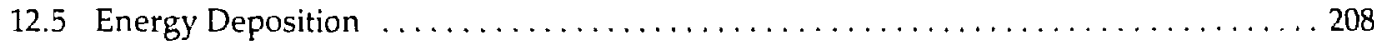

Chapter 13. Heat Transfer Analyses and Measurements (W. C. Patrick) . . .............. 211

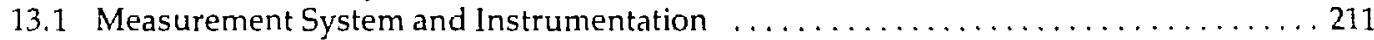

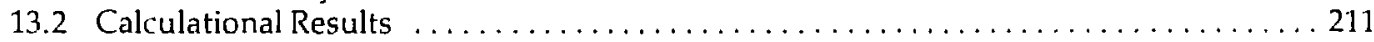

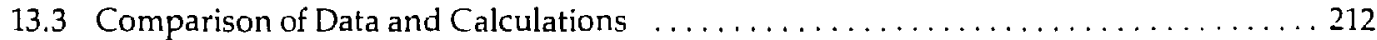

13.3.1 Near-Field Comparisons with Infinite Array Model . . . . . . . . . . . 212

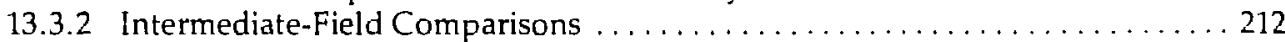

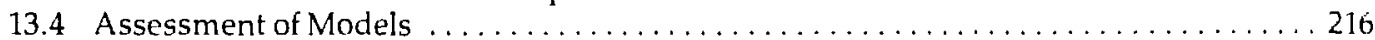

Chapter 14. Ventilation System Analyses and Measurements (W. C. Patrick) . . . . . . . . . . .. 229

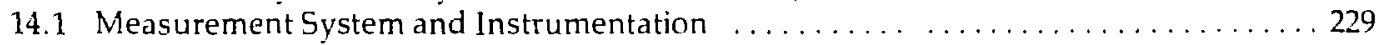

14.2 Ventilation System Measurements . . . . . . . . . . . . . . . . . . . . . 229

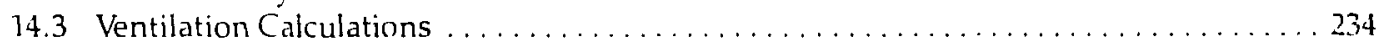

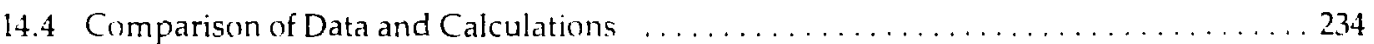

14.5 Assessment of Models ................................. 236

Chapter 15. Radiation Transport Calculations and Measurements (W. C. Patrick) ......... 237

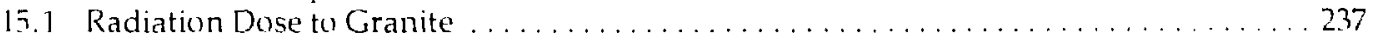

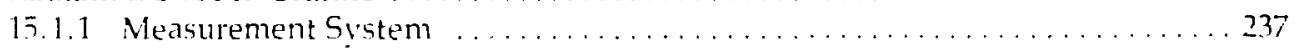

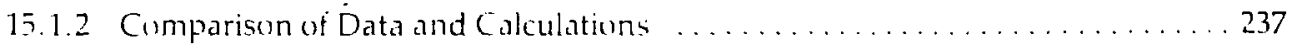

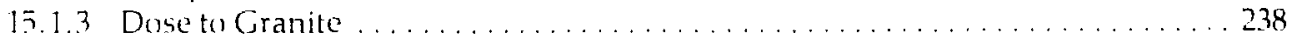




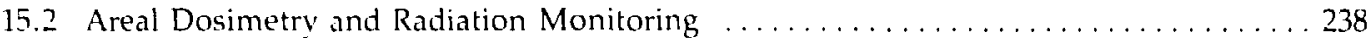

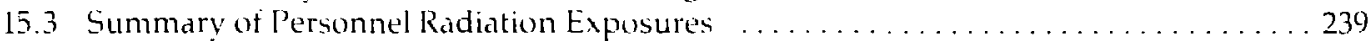

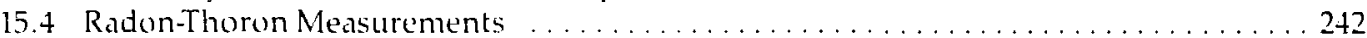

Chapter 16. Rock Mechanical Response Analyses and Measurements . . . . . . . . . . . 247

16.1 Measurement System (W. C. Patrick) . . . . . . . . . . . . . . . . . . . . . . . . . 247

16.2 Summary of Calculational Results (W. C. Patrick) . . . . . . . . . . . . . . . . . 249

16.3 Comparison of Data and Calculations (W. C. Patrick, D. G. Wilder, J. L. Yow' . . . . 250

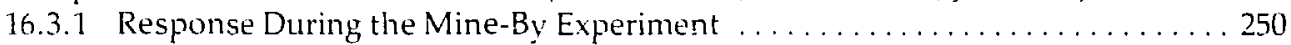

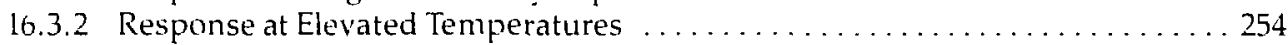

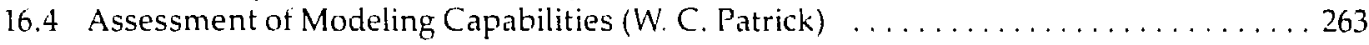

Chapter 17. Acoustic Emission and Wave Propagation Monitoring

(E. L. Majer and W. C. Patrick) . . . . . . . . . . . . . . . . . . . . . . . . . 265

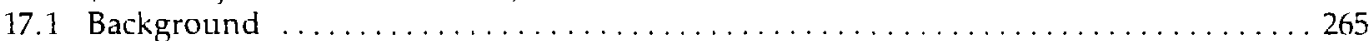

17.2 Measurement System and Instrument Locations . . . . . . . . . . . . . . . . . . . . . . 265

17.3 Summary Results of Acoustic Emission Monitoring . . . . . . . . . . . . . . . 269

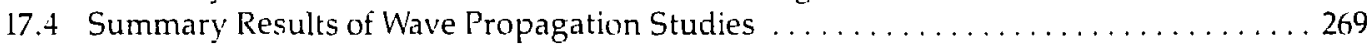

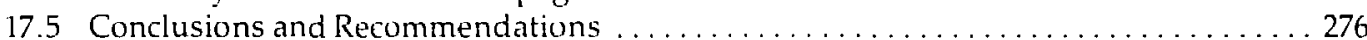

Chapter 18. Metallurgical Investigations (H. Weiss,

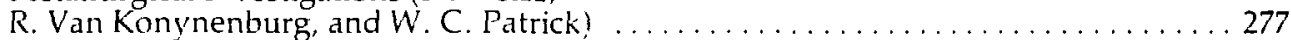

18.1 Analysis of Emplacement Borehole Liner Weld . . . . . . . . . . . . . . . . . . . . 277

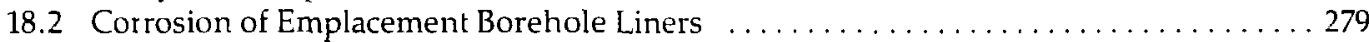

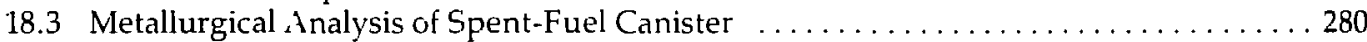

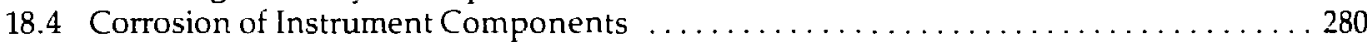

18.4.1 Analysis of Extensometer Connecting-Rod Failures $\ldots \ldots \ldots \ldots \ldots \ldots \ldots 280$

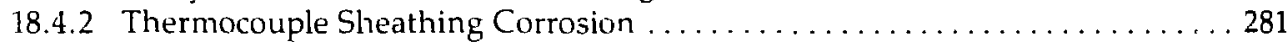

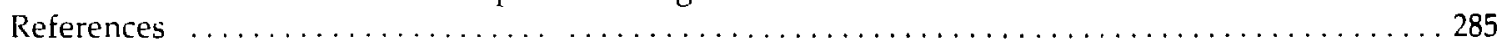

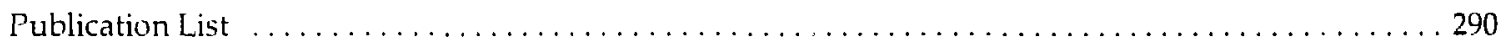




\title{
Spent Fuel Test-Climax: \\ An Evaluation \\ of the Technical Feasibility \\ of Geologic Storage \\ of Spent Nuclear Fuel in Granite
}

\author{
Final Report
}

\section{Abstract}

The Spent Fuel Test-Climax (SFT - C) was recently conducted to demonstrate the feasibility of deep geologic storage of spent nuclear fuel from commercial nuclear power reactors. Located $420 \mathrm{~m}$ below surface in the Climax stock granite on the Nevada Test Site, the test was conducted under the technical direction of the Lawrence Livermore National Laboratory (LLNL) as part of the Nevada Nuclear Waste Storage Investigations (NNWSI) Project for the U.S. Department of Energy (DOE). Eleven canisters of spent nuclear reactor fuel were emplaced, and six electrical simulators were energized in April-May 1980. When test data indicate $d$ that the test objectives were met during the 3-year storage phase, the spentfuel canisters were retrieved and the thermal sources were de-energized in March-April 1983.

The SFT - C operational objective was met by demonstrating the feasibility of packaging, transporting, storing, $i$ nd retrieving highly radioactive fuel assemblies in a safe and reliable manner. In addition to emplacement and retrieval operations, three exchanges of spent-fuel assemblies between the SFT - C and a surface storage facility, conducted during the storage phase, furthered this demonstration.

Technical objectives of the test led to development of a technical measurements program. To meet these objectives, nearly 1000 insiruments and a computer-based data acquisition system were deployed. Geotechnical, seismological, and test status data were recorded on a continuing basis for the three-year storage phase and six-month monitored cool-down of the test.

This report summarizes the engineering and scientific endeavors which led to successrul design and execution of the test. The design, fabrication, and construction of all facilities and handling systems are discussed, in the context of test ohjectives and a safety assessment. With regard to technical aspects of the test, our discussion progresses from site characterization and experiment design through data acquisition and analysis of test data in the context of design calculations.

\section{Executive Summary}

\subsection{Introduction}

The National Waste Terminal Storage (NWTS) Program was established in 1976 by the predecessur of the U.S. Department of Energy (DOE) to evaluate the feasibility of retrievable deep geolugic storage of commercial nuclear reactor wastes. In September 1983 the NWTS became the Civilian Radioactive Waste 


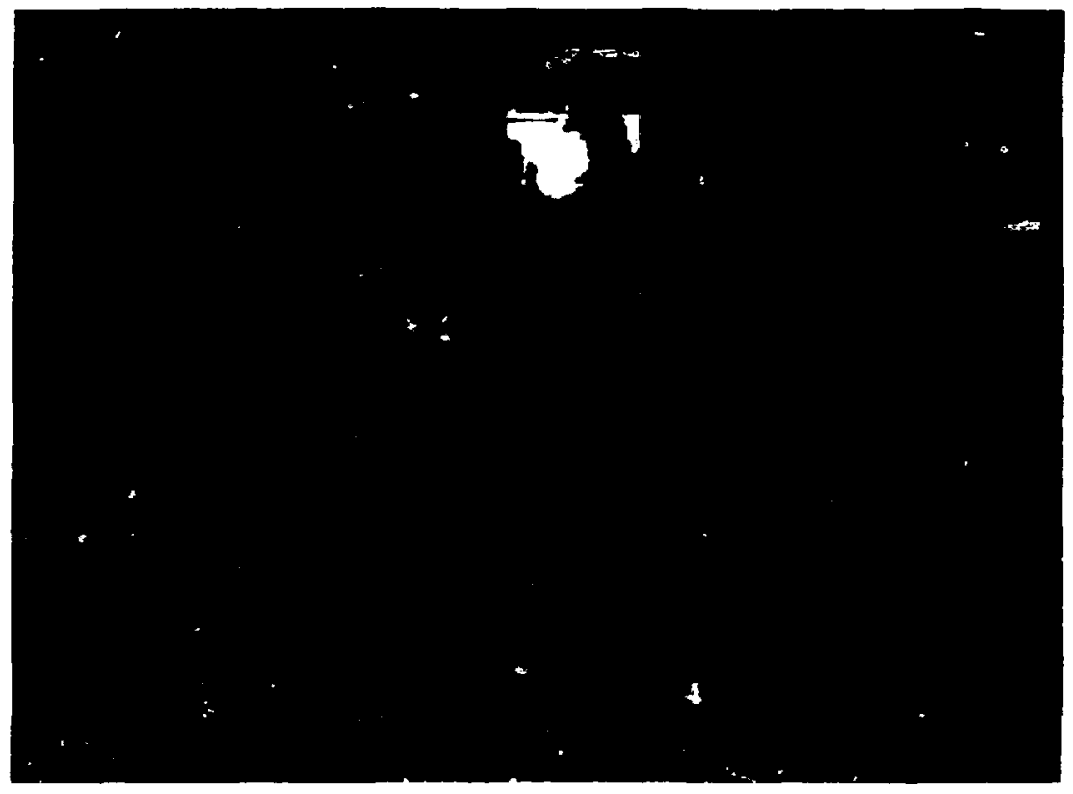

Figure 9. The eight, west-end-vessel legs after being welded to their base plates on the concrete piers. These base plates are joined to the piers by large bolts that are part of a frame deeply embedded in the reinforced concrete. The bolts and nuts provide vertical adjusiment for the end-vessel-can sections that will be placed on these legs. When final alignment is achieved, a concrete grout mixture will be pumped belween the leg base plates and the piers. Running Ieft-to-right across the vault behind the west vessel piers is the U-shaped buttess or shear wall that stabilizes the side walls of the concrete vault. In the center background of this photo is the existing east vacuum vessel that is undergoing modification.

loads at each of the bolted splice joints, three of which required 128 bolts, and four of which required 92 bolts.

The geometrical layout of these joints incorporates a pair of flanges, welded to the adjacent shell plate, that are joined with high strength. nonmagnetic bolts (SA-193 Grade B8). These bolts are located just inside the vessel shell, and they react the tensile and shear loads. The compression loads are reacted through a set of varying-thickness shim blocks located at each bolt and extended radially outward enough to be directly in line with the shell plates. Besides transmitting the compres- sion loads across the joint, these shim blocks serve two other purposes. First, because these shim bolts are custom-machined after adjacent modules are set in their final place, they allow precise positioning of the central-cell modules for magnet-solenoid alignment. Second, because they are easily removed along with the bolts, they provide a 5-to-10-cm-wide gap to facilitate assembly and disassembly of the modules (Fig. 11). After final assembly is completed, the vacuum seal is made by lap-welding a 0.5 -cm-thick stainlesssteel strip (which can be easily removed) around the outer circumference of the flauges. 
and October 1981 and August 1982. Post-test ctaracterization followed retrieval of the spent fuel and was completed diring 1985.

The operational objectives of the test were to demonstrate safe and reliabie packaging. transport, short-term storage, and retrieval of spent nuclear reactor fuel. The storage period corresponds to spentfuel ages of 2.5 to 5.5 years out of core ( $\mathrm{YOC}$ )

A technical measurements program was implemented to acquire data for the ultimate qualification of granitic rock as a repository medium, to aid in the design of such a repository, ano to predict its response in granitic rock. Numerous technical objectives were established at the beginning of the test, as presented in the technical concept report (see Ramspott et al., LCRL-52796, 1979). Our activities focused on these stated aims throughout the test.

We recorded data continuously on more than 400 computer channels during the three-year fuel storage phase and for six months following retrieval to record thermal and thermomechanical responses as the simulated repository environment cooled. Although most data were acquired through a central data acquisition system (DAS), periodic displacement measurements and radiation dosimetry data were acquired manually and processed independently of the DAS. Acoustic emissions data were also acquired independentiv:

\subsection{Chapter Summaries}

Chapters 2 through 18 are summarized below. Please refer to the full chapters for specific details.

\subsubsection{Chapter 2. Test Objectives}

Both operational and technical objectives guided the design, development, and execution of the $S F T-C$. The overall operational objective of the test was to evaluate the feasibility of safe and reliable shur -term storage of spent reactor fuipl assemblies at a plausible repository depth, and to retrieve the fuel assemblies afterward.

An underlying technical objective was to simulate the near-field thermal effects of a panel of a full-scale repository within a relatively small test volume. An additional technical objective was to evaluate the effects of heat alone and the combined effects of heat and radiation on the near-field canister environment and materials.

Although the highest priority or the SFT $-\mathrm{C}$ was a timely demonstration of spent-fuel handling, the test also addressed the ultimate qualification of granitic rocks for geologic disposal and the design of future repositories in granitic or other hard rocks. The focus of these objectives was to model and collect data on heat transfer, rock mechanical response, and radiation transport processes. Evaluating our ability to model such phenomena also became an important element of the SFT-C.

\subsubsection{Chapter 3. Test Design}

We designed the test by using a series of calculations of heat transfer, rock mechanical response, and radiation transport processes. To make the SFT - C demonstration meaningful and teclinically sound, we designed it to simulate the early, near-field history of a panel of a full-scale repository containing thousands of spent-fuel assemblies. A suite of incinasingly sophisticated heat transfer calculations was the primary basis of the SFT-C facility design.

By emplacing a central linear array of spent-fuel assemblies and simulated assemblies and flanking that array with auxiliary heaters, we matched the thermal conditions of a conceptual repository within $4.5 \%$ in a central portion of the SFT - C. Thermal calculations also estimated the temperatures of fuel cladding, handling systen hardware, and ventilation air.

We also calculated the response of the rock mass to excavating underground facilities, extensive heating, and cooling following retrieval of the sperit-fuel assemblies. Most calculations were made with the assumption that the rock was a homogeneous, isotropic, linearly clastic material; however, we also incorporated dilatant and nondilatant joints in our estimates of excavation response to mining. Calculated rock responses were used to site instrumentation and later provided a basis for comparison with field data. As field-properties data became available, the laboratory values used in initial design calculations were revised. In situ stress measurements also replaced early estimates of the stress state. 
We calculated radiation transport for two distinct purposes: to design acceptable radiation shielding and to determine the radiation dose to the granitic rock near the spent-fuel emplacement boreholes. Hand calculations of isotopic abundances, gamna eneryy' spectra, and neutron atten uation test data established the shielding necessary to limit dose rates to 100 mren h at the surface of the shielding casks and 0.5 mrem ih at the storage drift flowr. Monte Cark simulation of the complex spent-fuel storage configuration was used to estimate doses and dose rate's at various positions outward from the spent fuel assemblies. In addition, these calculations estimated the thermal contribution of gamma attenuation to be $40 \mathrm{~W}$ per canister.

\subsubsection{Chapter 4. Site Characterization and Geologic Investigations}

We studied the local structural geology and hydrology, measured the in situ state of stress, measured physical properties (in situ and in the laboratory), studied mineralogy and petrology of pre- and post-test cores obtained near the canister empiacement holes, and andyzed (by microfracture counts) potential drilling damage and radiation effects. We summarize below the more important observations.

Structural Geology. The Climax stock quartz monzonite (CSQM) in which the SFT-C was located is part of a two-component stock of Cretaceous age that intrudes Paleozoic carbonates and is partially overlain by Tertiary tuffs. We identified eight joint sets during mapping and core logging; three sets account for $80 \%$ of all joints mapped. Ar average frequency of three joints per metre produces a moderately fractured, blocky st:ucture.

Geohydrology. Relatively low annual rainfall (150 to $200 \mathrm{~mm}$ ), high evapotranspiration, and sparse overlying sedimient contribute to low infiltration of water into the stock, which is exposed at the surface above the test facility. The zone of total saturation appears to occur at about $975 \mathrm{~m}$ above mean sea level (MSL), about $145 \mathrm{~m}$ below the test horizon.

In Situ Stress. In the north and south heater drift pillars, the maximum principal stress (sigma 1) is essentially vertical, the intermediate principal stress (sigma 2) is horizontal and aligned parallel to the long axes of the pillars, and the least principal stress (sigma 3) is parallel to the pillar width. "Free field" stateof-stress measurements indicate that the maximum principal stress is oriented toward the east-northeast and is nearly horizontal, the intermediate principal stress is nearly vertical, and the least principal stress is rearly horizontal and oriented north-northwest. These results are consistent with both the conclusions of previous investigators and the motions of active faults at the Nevada Test Site (NTS). The maximum secondary principal stress levels measured in boreholes ISS-9 and ISS-10 (located at and above the facility horizon) apparently differ systematically. The observed difference does not appear to be related to any' geologic structural anomaly.

Physical Properties. Laboratory measurements indicate that Young's modulus increases with confinement, decreases with increasing temperature, and is relatively unaffected by prior treatments of heat and stress. In situ deformation modulus apparently depends on prior heating and stress conditions. The average field modulus is about half that measured in the laboratory. The coefficient of thermal expansion increases substantially with temperature and decreases somewhat as confinement increases. Thermal conductivity and diffusivity decrease with increasing temperature and with decreasing confinement. In sifu testing produced values of $3.1 \mathrm{~W} / \mathrm{m} \cdot \mathrm{K}$ and $1.2 \mathrm{~mm}^{2} / \mathrm{s}$, respectively. In situ permeability was about $l \mathrm{nD}$ at ambient temperature, decreasing to $0.2 \mathrm{nD}$ at $50^{\circ} \mathrm{C}$. No permanent change in gas permeability occurred as a result of heating and subsequent cooling.

Mineralogy and Petrology. The quartz monzonite is a porphyritic rock composed of a ground mass that is predominantly equant, subhedral grains of plagioclase, K-feldspar, quartz, and biotite; grains range from 0.5 to $2.0 \mathrm{~mm}$ in diameter. Modal percentages for the primary phases of quartz, plagioclase, and K-feidspar are $17.3 \pm 2.1 \%, 32.8 \pm 5.6 \%$, and $31.2 \pm 5.3 \%$, respectively. Igneous accessory phases make up less than 3 vol\%. The Climax record cores show significant chemical, petrographic, and modal variations. These variations result from both igneous and hydrothermal processes.

Radiation and Thermal Effects. No statistically significant changes in strength or Young's modulus were observed after intense laboratory irradiation of CSQM. Miner alogical and petrographical characteristics did not change significantly in samples obtained from nearby the spent-fuel storage boreholes or auxiliary heaters. The microfracture structure of Climax granite is highly heterogeneous on the scale of 0.1 to $10 \mathrm{~mm}$, making it difticult-if not impossible-to discern damage produced by elevated stress, temperature, gamma irradiation, or combinations of the three. No statistically significant evidence of changes in microfracturing were observed to be produced by laboratory gamma irradiation. 
Drilling Damage Effects. The damage induced by hammer-drilling the 0.61-m-diameter spent-fuel emplacement boreholes is limited to an annular ring le's than $20-\mathrm{mm}$ thick around the borehole.

\subsubsection{Chapter 5. Site Development and Facility Construction}

The PILEDRIVER shaft, headframe, and hoist system (shown in Fig. 5-2) provided access to the $420-\mathrm{m}$ test level. Developed in the 1960 s for testing nuclear weapons effects, this access was used to support a heater test known as Heater Test No. 1 before the SFT - C was authorized. After the shaft was internally refurbished, we drilled an additional 6.76-m-diameter shaft and lined it with a 0.51-m-outside-diameter steel pipe section, which was cemented in place. This canister access shaft allowed encapsulated spentfuel assemblies to be moved between the surtace and the underground. Two 3.4-m-cross section parallel drifts were driven about $70 \mathrm{~m}$ to connect drifts from the main shaft with the base of the canister access shaft. The floors of these drifts housed the auxiliary heaters during the heated phase of the SFI $-\mathrm{C}$. After the heater drifts were built, the central canister storage drift was driven in two passes: a 4.0 - $\mathrm{m}$-high $\times 4.6$ m-wide top heading and a $2.1-\mathrm{m} \times 4.6-\mathrm{m}$ bench. Controlled blasting techniques were used to excavate some portions of this drift.

Subsurface outfitting included installing ground control measures, placing a reinforced concrete fioor with embedded shielding pits and rails, drilling emplacement boreholes for spent-fuel and heater installations, and installing nearly 1000 instruments.

On the surface, construction included the ventilation and filtration system, the DAS trailer, power and water supplies, and the spent-fuel canister hoisting system.

\subsubsection{Chapter 6. Spent-Fuel Characterization}

The 13 spent-fuel assemblies used in the SFT-C came from the Florida Power and Light Co. Turkey Point Unit 3, a Westinghouse-design commercial pressurized water reactor. Hanford Engineering Development Laboratory and the Battelle Columbus Laboratory characterized the intact fuel assemblies and individual fuel rods. Their evaluation was as follows: The average length and cross-section width of the assemblies were $3.903 \mathrm{~m}$ (153.65 in.) and $211.1 \mathrm{~mm}(8.312 \mathrm{in}$.), respectively. The average weight of the assemblies was $663 \mathrm{~kg}$ ( $1459 \mathrm{lb}$ ). A combination of gas and wet sip testing indicated that no assemblies contained leaking rods. Visual inspections revealed no major anomalies (such as bulges, scars, or blisters) on the rods, although profilometry detected circumferential ridges as high as $0.076 \mathrm{~mm}(0.003 \mathrm{in}$.) at pellet interfaces.

In September 1979, a total neutron flux of $1.06 \times 10^{4} \mathrm{n} / \mathrm{cm}^{2} / \mathrm{s}$ with an average energy of $1.4 \mathrm{MeV}$ was measured and found to be distributed fairly symmetrically around the canister axial midplane. An average gamma flux of $9.11 \times 10^{4} \mathrm{R} / \mathrm{h}$ was determined. In March 1984, one year after fuel retrieval, the gamma dose rate was measured to be $2.33 \times 10^{4} \mathrm{R} / \mathrm{h}$. ORIGEN2 calculations and a series of boiling-watcr calorimetries established the decay-power-generation curve for the spent-fuel assemblies. During the test, the heatgeneration rate decreased from about 1500 to $600 \mathrm{~W}$ per canister.

\subsubsection{Chapier 7. Spent-Fuel Handling System}

Spent-fuel assemblies were shipped from the Turkey Point reactor to the engine maintenance, assembly, and disassembly (EMAD) facility in southeastern Nevada in truck-mounted, licensed, commercial shipping casks. Once the fuel assemblies were received and encapsulated, remote handling systems were used for all operations at NTS. Each assembly was encapsulated in a 356-mm- (14-in.-) outside diameter stainless steel canister that was sealed, evacuated, and backfilled with helium gas. An integral shield plug and grappling knob provided the necessary interface with the handling system.

The handling system had three major components: The surface transport vehicle (STV)-a special trailer with a rotatable shielding cask and a commercial tractor-was designed and developed to move the encapsulated spent fuel from EMAD to the SFT - C. Top and bottom gates permitted loading through the top at EMAD and unloading and loading through the bottom at the SFT - C. All functions were remotely controlled. The underground transfer vehicle (UTV)-a rail-mounted, remotely controlled shielding cask with an onboard jib crane-received the spent-fuel canisters underground and emplaced or retrieved them from the individual storage boreholes. A canister-handling system-a specially designed wire-line hoist with control and braking subs,ystems-lowered and raised the spent-fuel between the STV and the LTV. An automatically actuated brake travelled with the spent-fuel canister for protection in the event of a hoist 
or cable failure. Control systems and closed-circuit television permi ted remote operations with no risk of excess radiation exposure to personnel.

\subsubsection{Chapter 8. Safety Assessment}

The conduct of the SFT - ( required that a satety assessment decument $(S A D)$ be prepared. A similar document was also developed to cover supporting operations at the EMAD facility. The SAD showed that no unacceptable radiological or nonradiological conseyuences to site personnel, the public, nor the environment would result from normal operations, abnormal operations, or postulated accidents. Calculations showed that nuclear criticality could not wocur for any postulated fuel configuration, even with flooding.

\subsubsection{Chapter 9. Selection, Deployment, and Perfurmance of Instruments}

Nearly 1000 instruments were deployed and operated for 3.5 years to monitur the temperatures of rock, air, and metallic components of the test; displacements and stress changes in the rock mass: radiation dose to persomnel and to the ruck; thermal energy input; characteristics of the ventilation airstreani; and the "perational status of the test. Careful selection, installation, calibration, and maintenance of these instruments allowed acquisition of about $15.3 \times 10^{\text {h }}$ high-quality data points.

Odr studies show that currently arailable continusus air monitor (CAM) and remote area monitor (RAM) systems adequately monitor radiation safety in an underground environment. However, longterm gamma radiation dosimetry techniques were augmented by short-term thermoluminesence dosimetry (TLD) measurements.

Properly sheathed, commercially available RTDs, thermocouples, and thermistors provide reliable, accurate, long-term temperature data. Moisture-balance and energy-removal calculations were found to require better calibrations of flowmeters than are commonly available. In addition, systematic changes in watt transducer calibrations suggest a need for periodic calibrations if accuracies better than $5 \%$ are needed.

Available vibrating-wire stressmeters have been failure-prone in the past and do not provide data with an accuracy better than about $\pm 50 \%$. The several types of rock displacement gauges tunctioned reliably and accurately with one exception: Linear potentiometers failed early in the test, resulting in the loss of near-field rock displacement data.

\subsubsection{Chapter 10. Data Acquisition and Management Systems}

A dual HP 1000 disk-based DAS was developed to control instrument scanning, to provide preliminary data conversion, and to generate remote alarms if the data were outside of anticipated limits. The DAS performed all functions from acyuiring analog signals through digitizing and archiving the raw data records on magnetic tape for subsequent detailed conversion by the data management system (DMS).

The DAS functioned accurately and reliably throughout the 3.5-year storage and cool-dow'n phases. System statistics show that system availability averaged about $96 \%$ (functionally disabled index was $4 \%$ ), providing about $15.3 \times 10^{6}$ data points during the test. The accuracy of de voltage measurements was maintained within $\pm 4 \mu \mathrm{V}$. The accuracy of four-wire resistance measurements was occasionaliy outside the anticipated $\pm 0.0092-\Omega$ envelope because of periodic digital voltmeter failures.

In addition to several utility functions, the DMS included a binary reading and screening code, a conversion code with algorithms for incorporating individual calibrations and temperature compensation. and a set of file manipulation codes for organizing the raw and converted data files into individuai files that contain all data for each instrument. This latter feature allowed easy access to the data for plotting. DMS statistics indicate that of the $15.3 \times 10^{\mathrm{h}}$ points recorded by the DAS. $8.7 \times 10^{\mathrm{h}}$ were retained, processed, and archived for analysis. An additional $6.3 \times 10^{\mathrm{h}}$ data points from radiation monitors and test status monitors were valid but not retained. Only $2.5 \times 10^{5}$ points $(1.6 \%$ of the total) were discarded as invalid.

\subsubsection{Chapter 11. Spent-Fuel Handling Experience}

Spent-fuel handling was at the heart of the SFT-C, which had as its main goal the demonstration of the feasibility of safe and reliable transport, storage, and retrieval of spent nuclear fuel. Operating procedures, administrative controls, and persunnel training contributed to at aining this objective. 
Eleven encapsulated spent-fuel assemblies were stored at the SFT-C between April 18, 1980, and May 28,1980 , at a rate of about two per week. To mointain a state of readiness for both personnel and equipment, we exchanged single spent-fuel assemblies between the SFT-C and EMAD three times: January 12 to 14, 1981; October 26 to 28, 1981; and August 16 to 18, 1982. Between March 3 and A pril 6, 1983, all 11 assemblies were retrieved and returned to iemporary storage at the EMAD. These operations showed that spent fuel can be safely handled with available technologies.

Total radiation exposure to operating personnel was 0.4 person-rem. Although the highest exposure was 10 mrein per handling operation, the average was about $30 \%$ of this value. Neutron exposure was greater than gamma exposure. Expressed relative to the energy generated while the spent fuel was in the reactor, the nurmalized dose commitment at the SFT-C was 0.002 person-rem/MW.y (electric), a small fraction of the 1 to 4 person-ren/ $\mathrm{MW} \cdot \mathrm{y}$ (electric) received during power plant operations.

\subsubsection{Chapter 12. Thermal Sources}

Three principal sources deposited energy into the rock mass during the SFT-C: spent-fuel assemblies, electrical simulators, and auxiliary heaters. Facility lighting also contributed to the input energy.

These thermal sources were monitored during the test to ascertain their energy input for use in thermal and thermomechanical calculations of SFT - C response. Measurements show that total thermal energy input to the SFT -C was $1041 \mathrm{MW} \cdot \mathrm{h}$ during the 3-year storage phase, with $19 \mathrm{MW} \cdot \mathrm{h}$ added during post-retrieval activities. The input energy partition was $25.3 \%$ from the 11 spent fucl assemblies, $14.2 \%$ from the 6 electrical simulacors, $57.7 \%$ from the 20 auxiliary heaters, and $2.8 \%$ from the facility lights. Electrical sources of heat, associated controllers, and instrumentation were very reliable.

\subsubsection{Chapter 13. Heat Transfer Analyses and Measurements}

Measured temperatures were compared with the heat transfer calculations described briefly in Chapter 3, with the following observations and conclusions. The intended SFT-C simulation of emplacing thousands of spent-fuel assemblies in a hypothetical repository was successful. Throughout the test, measured temperatures in the vicinity of the spent-fuel storage boreholes were within $3^{\circ} \mathrm{C}$ of those calculated at the axial midplane of the heat sources. Measured temperatures were somewhat higher than calculated near the top and somewhat lower than calculated near the bottom of the heat sources. Comparison of measured and calculated temperatures throughout the approximately $10,000 \mathrm{~m}^{3}$ instrumented volume indicates very good agreement. Pairwise plots of measured and calculated temperature increases may be fit by straight lines with near-unity slopes and near-zero intercepts. Associated mean-square errors are generally about $2^{\circ} \mathrm{C}$, only slightly greater than the $1.1^{\circ} \mathrm{C}$ ISA special limits of error for the thermocouples. Analytical and finite-difference models of the finite-lengtli geometry of the SFT-C produced marked improvements in the level of agreement between data and calculations near the ends of the test array, where the infinite-length assumption of the early models is no longer valid. Temperature-measuring instruments functioned accurately and reliably during the test, as corifirmed by calibrations.

\subsubsection{Chapter 14. Ventilation System Analyses and Measurements}

We documented the energy removed from the SFT-C by the ventilation system by measuring inlet and outlet air temperatures, dewpoints, and air flowrates for the three drifts. These measurement systems functioned reliably. The ventilation system removed a total of $148 \mathrm{MW} \cdot \mathrm{h}$ during the spent-fuel storage phase or the test. Of this, $76.7 \%$ was removed as sensible heat and $23.3 \%$ as latent heat of vaporization. About 20 tonnes of water were removed from the facility each year in the ventilation airstream.

Attempts to calculate energy removed by the ventilation system were marginally successful. After trying a variety of values for the pertinent parameters, we found that good agreement between measured and calculated rock temperatures was achieved only by calculating with an energy-removal rate much higher than that measured.

\subsubsection{Chapter 15. Radiation Transport Calculations and Measurements}

The radiation dose calculations described in Chapter 3 form the basis for comparison with data measured during the test. In addition to personnel dosimetry and areal radiation monitoring, we also instrumented the rock near selected spent-fuel storage boreholes. The latter measurements used optical-grade 
LiF dosimeters at the borehole wall and at positions 200 and $360 \mathrm{~mm}$ into the rock. Neutron dosimeter foils were also incorporated with these measurement packages. The RAM and CAM areal monitors performed well but exhibited drift that required periodic adjustment. Trie fade characteristirs and temperature sensitivity of the LiF dosimeters required that they be augmented with short-term $\mathrm{MgBO}_{4}$ and $\mathrm{CaF}_{2}$ TLDs. The Monte Carlo radiation transport calculations w'ere generally more accurate than the measurements. However, generally good agreement was observed, particularly with the short-term dosimeters.

Radon-thoron concentrations in the air gradually increased from $1 \times 10^{-10}$ to about $6 \times 10^{-10} \mathrm{Ci} / \mathrm{m}^{3}$ as the rock mass was heated. The log of concentration was found to increase nearly linearly with decrease in ventilation airflow rate. As noted in Chapter 11, measurements of radiation doses to man indicate that minor whole-body doses were received during spent-fuel handling operations and that no whole-body dose above background was received during spent-fuel storage. Very low finger doses were recorded for technicians who installed thermocouples on the emplaced canisters.

\subsubsection{Chapter 16. Rock Mechanical Response Calculations and Measurements}

Calculations were made and data were obtained for each phase of the SFT-C: excavation, heating, and post-retrieval cooling. The calculations described briefly in Chapter 3 are the basis for comparisons with data. The response of rock near underground openings to the excavation process was dominated by the behavior of joints. This behavior has not been adequately modeled by either homogeneous, isotropic, elastic formulations or by two-dimensional models, which include joints with either dilatant or nondilatant behavior. The rock-mass response during extensive heating was calculated quite well by the linearly elastic formulations, provided that measured in situ stress values and proper field deformation properties were incorporated in the model. Accurate calculation of temperature changes is essential for good rockresponse results. Because commonly available codes do not incorporate all heat-flow features of interest, we found it necessary to simulate such processes as thermal radiation and ventilation by means of "effective" conductive properties.

Most displacement instrumentation performed accurately and reliably during the test. Stress-change instrumentation failed, causing loss of all early data. In addition, near-field extensometer potentiometers malfunctioned, producing loss of early data near the emplaced spent-fuel assemblies.

Rock response to post-retrieval cool-down was calculated to be very small. The heated phase instruments were augmented during cooling by instruments designed and fabricated to monitor displacements within selected canister emplacement holes after spent-fuel was retrieved.

\subsubsection{Chapter 17. Acoustic Emission and Wave Propagation Monitoring}

We studied acoustic emissions (AE) and wave propagation to improve our understanding of the rock mass response to heating and to determine whether these techniques could reliably monitor changes in a full-scale repository. Continuous AE monitoring began about three months before spent-fuel emplacement and continued through the post-retrieval cooling phase. About six months after spent-fuel emplacement, we installed wave propagation instruments. Data were acquired and processed with an automated seismic processor (ASP).

The frequency of occurrence of $\mathrm{AE}$ is directly related to changes in rate of energy deposition to the rock mass. Adjustments to heater power levels and əmplacement or retriev; al of heat sources (such as spent-fuel assemblies) produce rapid increases in AE that decrease to background levels within a few days. Analyses of $\mathrm{AE}$ data indicate small-scale shear displacement or fracturing on the order of 0.01 to $0.05 \mathrm{~mm}$ per event, with source dimensions of several centimeters. Changes in the ratio of $S$ - to $P$-wave amplitudes recorded over path lengths of several meters qualitatively agree with temperature changes in the rock mass. These changes are hypothesized to result from iracture closure. No measurable variations in P-and S-wave velocities occurred during the monitoring period.

\subsubsection{Chapter 18. Metallurgical Investigations}

We conducted metallurgical analyses to examine failures in emplacement borehole liner welds and in Superinvar connecting rods from borehole extensometers and to examine corrosion of a spent-fuel canister and thermocouple sheathing. Inadequate weld penetration caused at least one emplacement borehole liner to leak at the connection of the bottom plate and the pipe section. The stainless steel canister stored 
within the leaky liner showed no evidence of general or localized corrosion even though it withstood temperatures of about $95^{\circ} \mathrm{C}$ and radiation dose rates of $10^{4} \mathrm{rad} / \mathrm{h}$ while immersed in Climax stock ground water for at least eight months.

Superinvar connecting rods corrusion-cracked when in contact with Climax ground water at temperatures near $55^{\circ} \mathrm{C}$. Thermocouple sheathing corroded in two cases where the thermocouples were erroneously sheathed in stainless steel rather than Inconel 600, as specified. 


\section{Design Criteria and Objectives}

This chapter outlines the objectives that focused the design of the SFT-C and test equipment and facilities. The overall objective was twofold: to evaluate the feasibility of safe and reliable short-term storage of spent reactor fuel assemblies at a plausible repository depth in a typical granitic rock and to retrieve the fuel afterwards (Ramspott et al., 1979). An additional objective was to evaluate the difference-if anybetween the effects of an actual radioactive waste source and an electrically heated simulator.

\subsection{General Design Criteria}

To achieve these objectives, we specified five general design criteria for the test:

1. Create a storage drift geometry reasonably similar to that expected for a spent-fuel repository. Toward that end, deploy supplementary heat sources to simulate the thermal effects within a large repository.

2. Include enough electrical simulator canisters to evaluate the effects of heat alone and heat in comibination with ionizing radiation.

3. Develop spent-fuel handling systems compatible with test conditions to allow retrieval at any time during the test.

4. Meet appropriate industrial and radiation safety standards.

5. Allow access to the test facilities for operational, public awareness, and educational purposes.

These criteria were sufficient to define the major features of the test, including the three-drift array, the number of spent-fuel and simulator canisters, the data acquisition system with remote alarming capability, conservative radiation shielding, and remote operation of handling equipment.

\subsection{Technical and Scientific Objectives}

Although a timely engineering demonstration was the highest priority, the SFT - $C$ had technical and scientific objectives as well. Because the test involved the largest-scale heating of a hard rock medium to date for a test of this type and was the first in situ exposure of crystalline rock to spent fuel, we had the opportunity to collect technical data on the suitability of granitic rock as a medium for deep geologic disposal of high-level reactor waste. We also gathered information useful for designing future repositories in hard rocks and predicting their response to exposure to reactor waste. Our specific objectives were to:

- Analyze displacements and stress changes in the rock that forms the pillars between the central and side drifts; these displacements resulted from mechanical disturbance when the central drift was mined.

- Assess the validity of our calculational models for mechanical and thermomechanical effects.

- Measure the temperature and radiation dose in the close-in heated zone to infer both tlie total power level of the spent-fuel assemblies and the proportion of that power transported out of the canisters by nuclear radiation, as opposed to thermal processes. Similarly, measure both the heat removed by ventilation and the thermal field (both close-in and intermediate) and compare our findings with calculational models.

- Evaluate displacement and stress ir itrumentation under simulated repository conditions.

- Measure displacement and stress effects in the intermediate heated zone: these displacements were caused by the thermal disturbance of the spent fuel and heaters. Also, assess the relative effect of existing fractures on rock response by duplicating all mechanical measurements in regions that were either fractured or relatively unfractured, and by directly instrumenting selected, prominent geologic fractures. 


\section{Test Design*}

Although physical simulation is well-established in uther engineering fields, it had never been tried in nuclear waste management until the SFT-C. The associated design techniques and supporting calculations are the topics of this chapter. Heat transter, rock mechanical response, and radiation transport calculations were used in designing the experiment.

\subsection{Test Concept}

The SFT-C was planned as a generic test of deep geological storage of spent nuclear fuel from commercial power reactors (Ramspott et al., 1979). To make this test meaningful and technically sound, we designed it to simulate the near-field thermal history of a repository containing thousands of spent-fuel assemblies. As described below; we accomplished this by modeling a large panel of a full-scale repository and comparing the temperature distributions generated by this calculation with those generated by similar calculations of possible design geometries. The thermai conditions in a $15-x-15-m$ section of the array matched the conditions of the modeled repository within $4.5 \%$.

\subsection{Heat Transfer Calculations}

Heat transfer calculations were used at all stages of design, from conceptual to as-built. The purpose, general formulation, and pertinent results of each calculation that supported design, construction, operation, and subsequent evaluation of the SFT-C are described here (also see Montan and Patrick, 1981 and 1986).

\subsubsection{Preliminary Design Calculations}

The model repository that formed the basis of the SFT - C design comprised many long, parallel drifts on $15-\mathrm{m}$ centers. Spent-fuel assemblies with an initial power level of $2 \mathrm{~kW}$ were placed on 3 - $\mathrm{m}$ centers in the 5-ni-wide drifts. Using this geometry, we obtained an initial areal loading density of $190 \mathrm{~kW} / \mathrm{acre}$, which had been reported previously in preconceptual repository designs (Kibbe and Boch, 1978).

We simulated this geometry using analytical calculations and the following parameters:

$\mathrm{k}=3.0 \mathrm{~W} / \mathrm{m} \cdot \mathrm{K}$, thermal conductivity,

$\kappa=1.25 \mathrm{~mm}^{2} / \mathrm{s}$, thermal diffusivity,

$\mathrm{Q}=2 \mathrm{~kW}$, power level at 2.5 years out of core,

$\mathrm{L}=3.66 \mathrm{~m}$, length of heat sources.

Calculations were made for both a $300-\times 300-\mathrm{m}$ array containing 2000 spent-fuel assemblies and a $600-$ $\times 600-m$ array containing 8000 canisters.

The characteristics of the spent fuel were chosen to match those of the Westinghouse pressurized water reactor fuel from Turkey Point Unit \#3 (see Chapter 6). These assemblies, which were $0.21 \times 0.21 \mathrm{~m}$ in cross section by $3.66 \mathrm{~m}$ long, had an anticipated fuel loading of $448 \mathrm{~kg}$ with $2.56 \% 235 \mathrm{U}$ and a burnup of $28,000 \mathrm{MW} \cdot \mathrm{d} / \mathrm{MTU}$. The preliminary power estimates were ater shown to be somewhat higher than actual but were satisfactory for purposes of design.

Figure 3-1 shows the resulting temperature rises associated with emplacement of spent fuel at 2.5, 5, and $10 \mathrm{YOC}$. The figure clearly shows that the early-time thermal peak of $2.5 \mathrm{YOC}$ fuel is somewhat higher than the later peaks of older fuels. Thus, a test Lising spent fuel 2.5 YOC allows an assessment of maximum (or slight over-test) thermal conditions with in a few years as opposed to a few decades, as would be the case for the older fuels.

After considerable study involving not only thermal effects but rock mechanical, mining, ard operational considerations as well, a design evolved for the SFT $-C$. The heat transfer aspects of the design were developed by considering how the curve in Fig. 3-1 could be approximated in a relatively small-scale test. Figure 3-2 shows that emplacement of a single canister would produce a thermal pulse of insulficient magnitude and duration. Adding canisters to form a linear array increased the peak temperature and the duration was extended by means of auxiliary heat sources in two parallel drifts.

*Contributed by W. C. Fatruck 


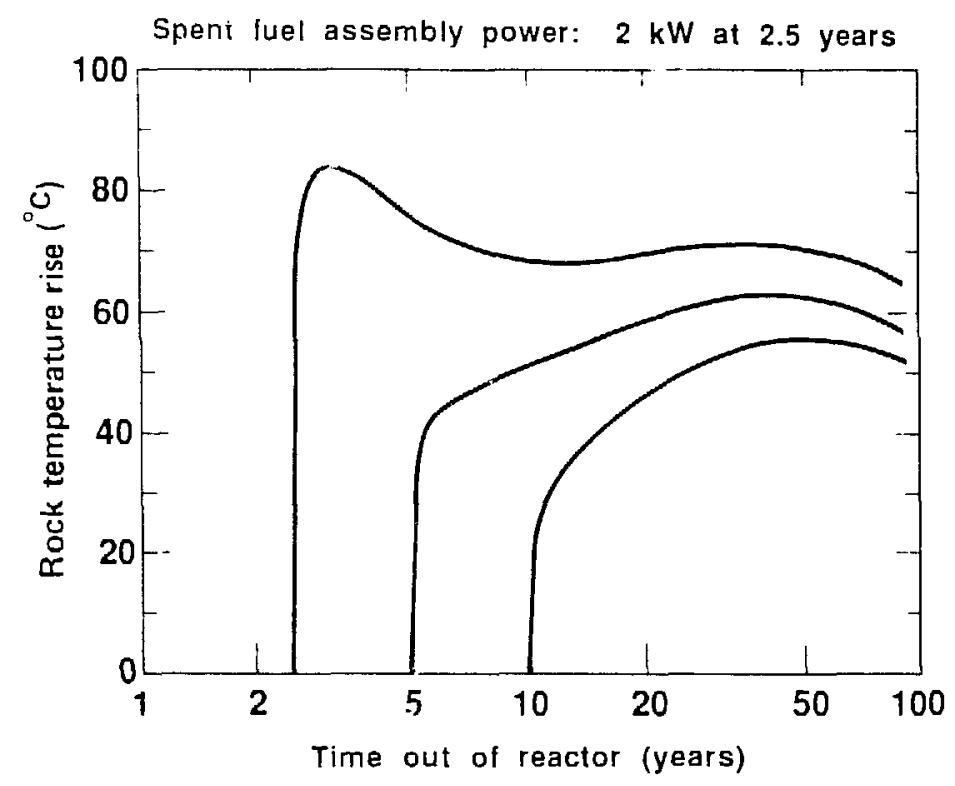

Figure 3-1. Temperature history of rock surface at fuel assembly inidpoint in center hole of hypothetical spent-fuel repository (after Montan and Patrick, 1981).

100

Spent fuel assembly power: $2 \mathrm{~kW}$ at 2.5 years

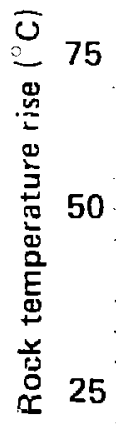

Total
Canister
array

\section{Single \\ canister}

Auxiliary heaters

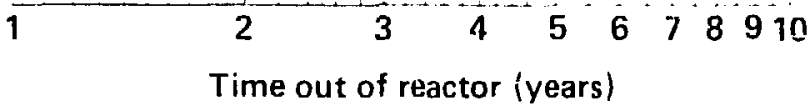

Figure 3-2. Calculated temperature on the storage-hole wall at canister midplane of 17-canister storage array (after Montan and Patrick, 1981).

The resulting SFT-C test geometry consisted of a linear array of 17 heat sources- 11 spent-fuel assemblies and 6 electrical simulators on 3-mi centers and is auxili zry heaters on 6-m centers in each of two parallel drifts positioned on 10-m centers from the cuntral drifts (Fig. 3-3). The resulting temperature histuries of the model repository and SFT-C design wore almost indistinguishable (Fig 3-4). 


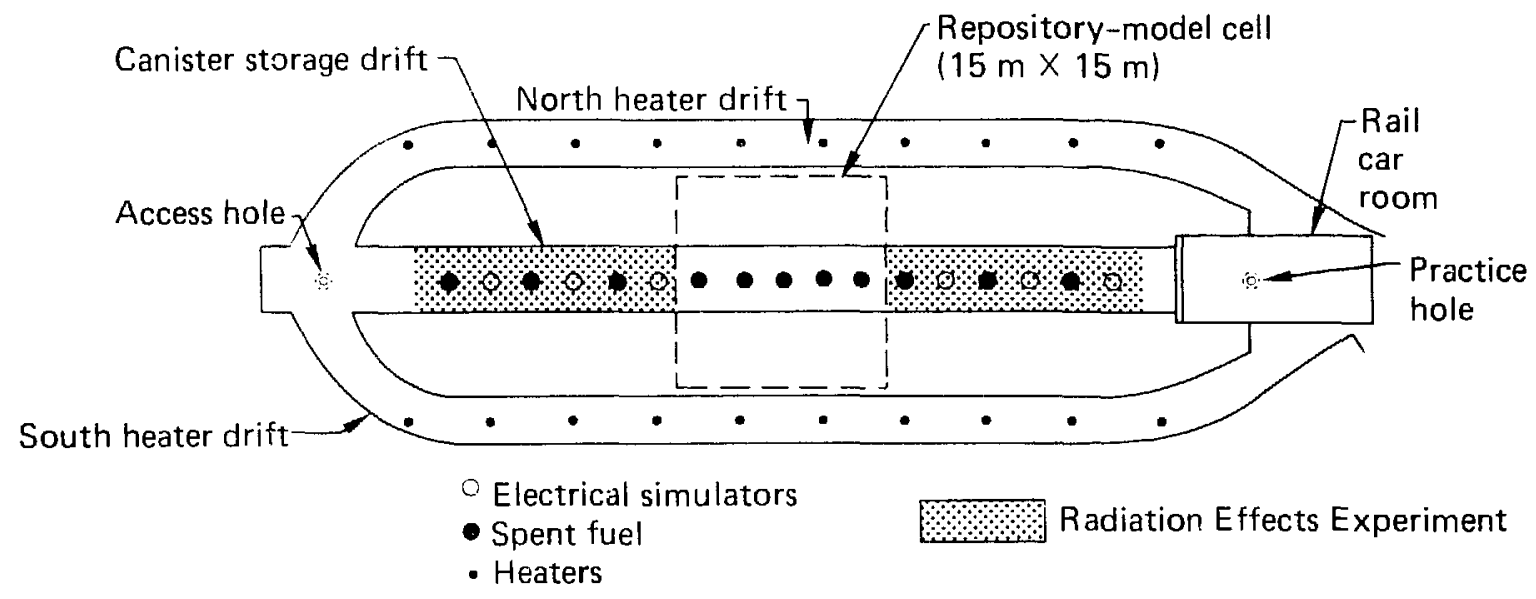

Figure 3-3. Plan view of the Spent Fuel Test-Climax.

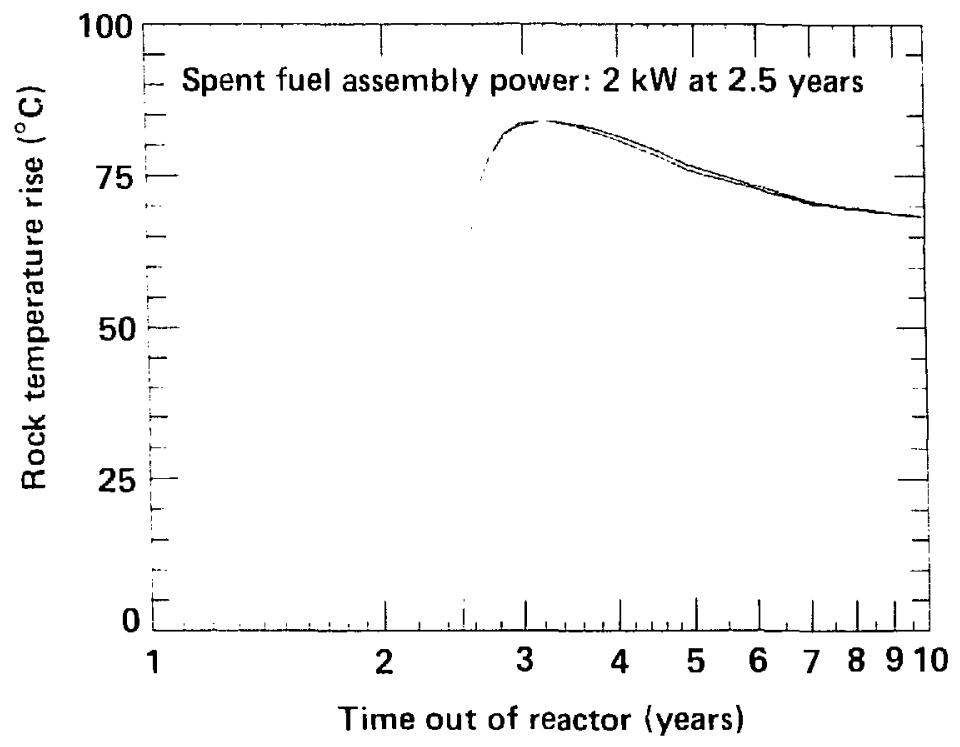

Figure 3-4. Temperature histories for model repository and SFT-C (after Montan and Patrick, 1981).

\subsubsection{Detailed Design Calculations}

The TRUMP finite difference code (Edwards, 1972) was used to address the complexities of ventilation as well as radiative, convective, and conductive heat transfer. These calculations also permitted us to assess the temperatures of operational concern, such as those of rails, air, and the shield plugs of the spentfuel canisters (Montan and Patrick, 1981).

To perform the detailed design calculations, a unit cell approach was taken. This cell contained one canister and was bounded by two parallel vertical planes perpendicular to the drifts and spaced halfway between the canisters. The four-fold axis of symmetry through the canister centerline provided two additional planes of symmetry that reduced the calculational mesh to one-fourth of the unit cell.

The mesh used in these calculations contained three basic regions (Fig. 3-5). The innermost Region IIl was $20 \mathrm{~m}$ wide $\times 40 \mathrm{~m}$ high and was divided into 1600 zones to provide the required spacial resolution. 


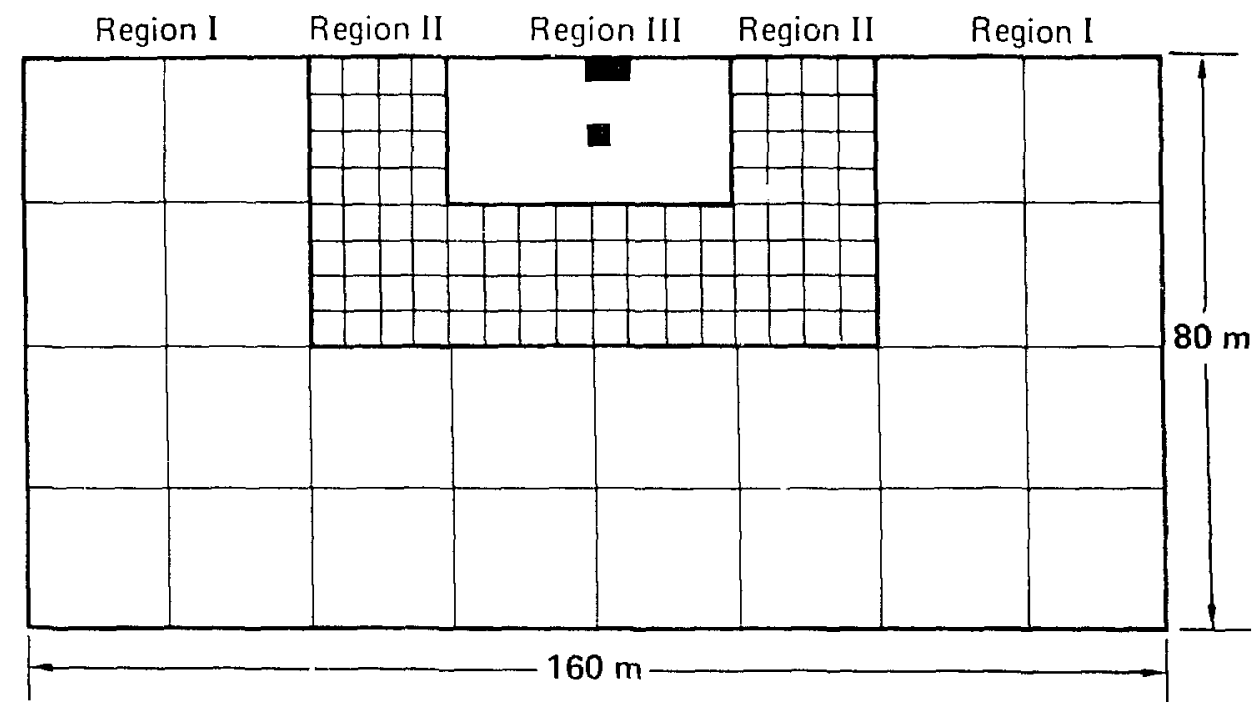

Figure 3-5. Schematic vertical section of mesh used in two-dimensional TRUMP calculations (after Montan and Patrick, 1981).

Region II, consisting of 96 zones measuring $5 \times 5 \mathrm{~m}$, and Region I, consisting of 24 zones measuring $20 \times$ $20 \mathrm{~m}$, were added to give an overall mesh size of $80 \mathrm{~m} \times 160 \mathrm{~m}$ with an associated thermal time constant of about 120 years. The thickness of the zones is $1.5 \mathrm{~m}$ : one-half the canister spacing. In the regions comprising the drifts, the regular zoning was replaced with single zones representing air. In addition, 50-mm-thick zones of rock or concrete, as appropriate, were placed in the drift surface to obtain accurate surface temperatures for radiation and convection calculations.

Accurate representation of the canister environment required that relatively large, two-dimensional blocks near the heat sources be replaced with a finer, three-dimensional mesh. To accomplish this, the 50 zones beneath the floor of the canister drift were replaced to a depth of $10 \mathrm{~m}$ with 150 zunes measuring $0.5 \times 1.0 \times 0.5 \mathrm{~m}$ each. The 54 zones comprising the $1.5-\times-6.0-\times-1.5 \mathrm{~m}$-volume whose midplane coincides with that of the canister were in turn replaced by 486 zones measuring $1 / 6 \times 1.0 \times 1 / 6 \mathrm{~m}$. Finally, the six corner zones were removed and the surrounding 18 zones were reduced in size, leaving the 305-mmradius hole in which to place the canister and steel liner. The 230 -mm-radius liner base was represented by 12 zones varying in height from 0.2 to $0.5 \mathrm{~m}$. The canister was represented by 11 zones, seven of which represented the active heat source of the spent-fuel assembly or electrical simulator.

Heat transfer from the canister to the liner and from the liner to the emplacement borehole wall was modeled as radiative and convective with emittances of 0.4 for the outer canister and inner liner surface and 0.9 for the outer liner and rock wall surfaces. Zero-volume zones were placed on the rock surfaces in the borehole to give correct temperatures for the radiative transport calculation. Additional zones were provided to model other details of the test geometry (Montan and Patrick, 1981).

The auxiliary heaters in the side drifts were removed far enough from the principal areas of interest so that they were modeled in two dimensions. In this representation, these cylindrical heat sources were "smeared out" so that they were, in effect, strip sources.

An example of the types of detailed calculational results used in the test design is given in Fig 3-6. Further discussion is provided by Montan and Patrick (1981).

A specific design concern was that the temperature of the spent-fuel cladding not exceed $380 \mathrm{C}$. To calculate the canister skin temperature that would drive the cladding-temperature calculation, we considered radiative transport across the rock/liner and liner canister air gaps. Conductive and convective proc esses were not modeled, so the resulting temperatures were conservative in the sense that they were higher than would actually occur. 


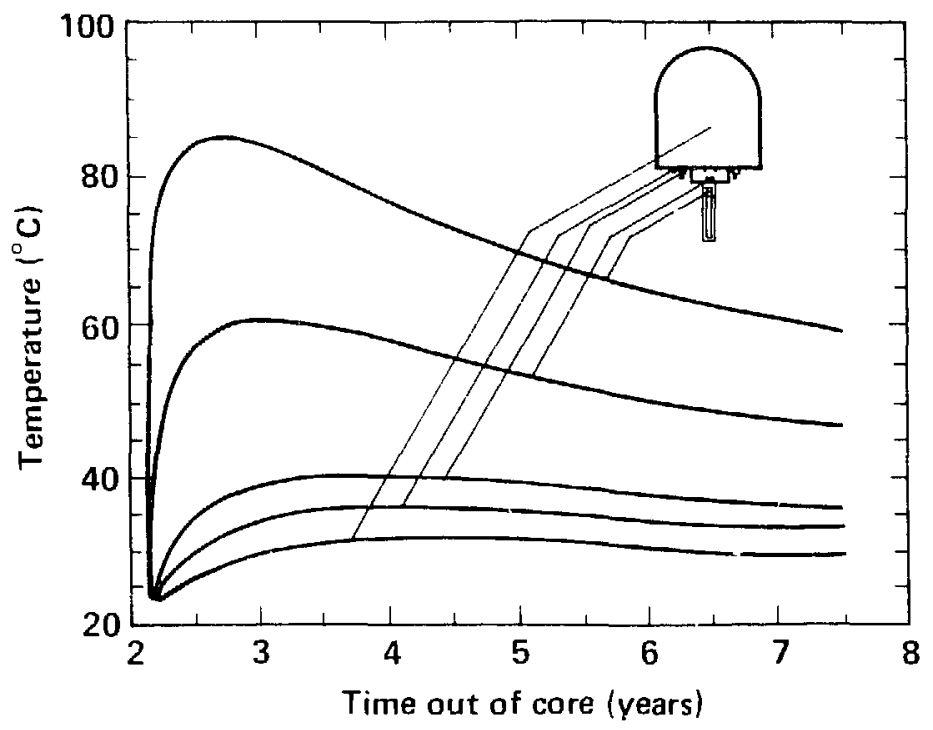

Figure 3-6. Three-dinensional TRUMP code calculations of temperature vs time at indicated locations in storage drift (ventilation effects included) (after Montan and Patrick, 1981).

Using a relaxation technique for steady-state heat transfer, we performed a sensitivity analysis for a range of all important parameters (Montan and Patrick, 1981). Only for an extreme case of canister power increased to $2.5 \mathrm{~kW}$, no conductance in the helium fill gas, and degraded thermal properties around the canister did temperatures reach $383^{\circ} \mathrm{C}$, slightly in excess of the design limit. Based on these calculations, we judged that the cladding integrity would not be jeopardized during the test.

\subsubsection{As-Built Calculations}

Using the model described above and revised thermal properties, power tables, and ventilation rates, we performed heat transfer calculations for the completed SFT $-C$ and published the results before the test commenced. As presented by Montan and Patrick (1981), the results of these calculations were the basis of the early-time comparisons of calculated and measured temperatures throughout the test array (Carlson et al., 1980, Patrick et a1., 1981, 1982, 1983).

These calculational results were post-processed in two basic formats: temperature histories at selected points and cross sections of temperature contours at selected times. Examples of the high quality of comparison are provided in Figs. 3-7 and 3-8. Calculated and measured temperatures differ at most by a few degrees Celsius.

\subsubsection{Test Completion Calculation}

When we deterrnined that a 3-year test provided enough time to achieve the goals of the SFT $-\mathrm{C}$, we began calculations to determirie the required duration of the post-retrieval cooling period. Ballou et al. (1982) documented the rationale and supporting thermal calculations that were used to establish the test completion plan and schedule.

The calculational geometry, associated mesh, material properties, and energy deposition from the spent fuel, electrical simulators, and auxiliary heaters were identical to those used in the as-built calculations discussed above. To obtain the maximum cooling rate, the ventilating capacity of the storage-phase fans (Chapter 5) was directed through the canister storage drift, and the construction-phase Sutorbilt blower capacity was partitioned between the two heater drifts. As a result, a planned $2.83 \mathrm{~m} 3 / \mathrm{s}(6000 \mathrm{cfm})$ was provided to each drift.

The calculations showed that temperatures dropped rapidly at positions near the thermal sources, bringing temperatures down to about $35^{\circ} \mathrm{C}$ after only 6 months of cooling (Fig. 3-9). Furthermore, we 


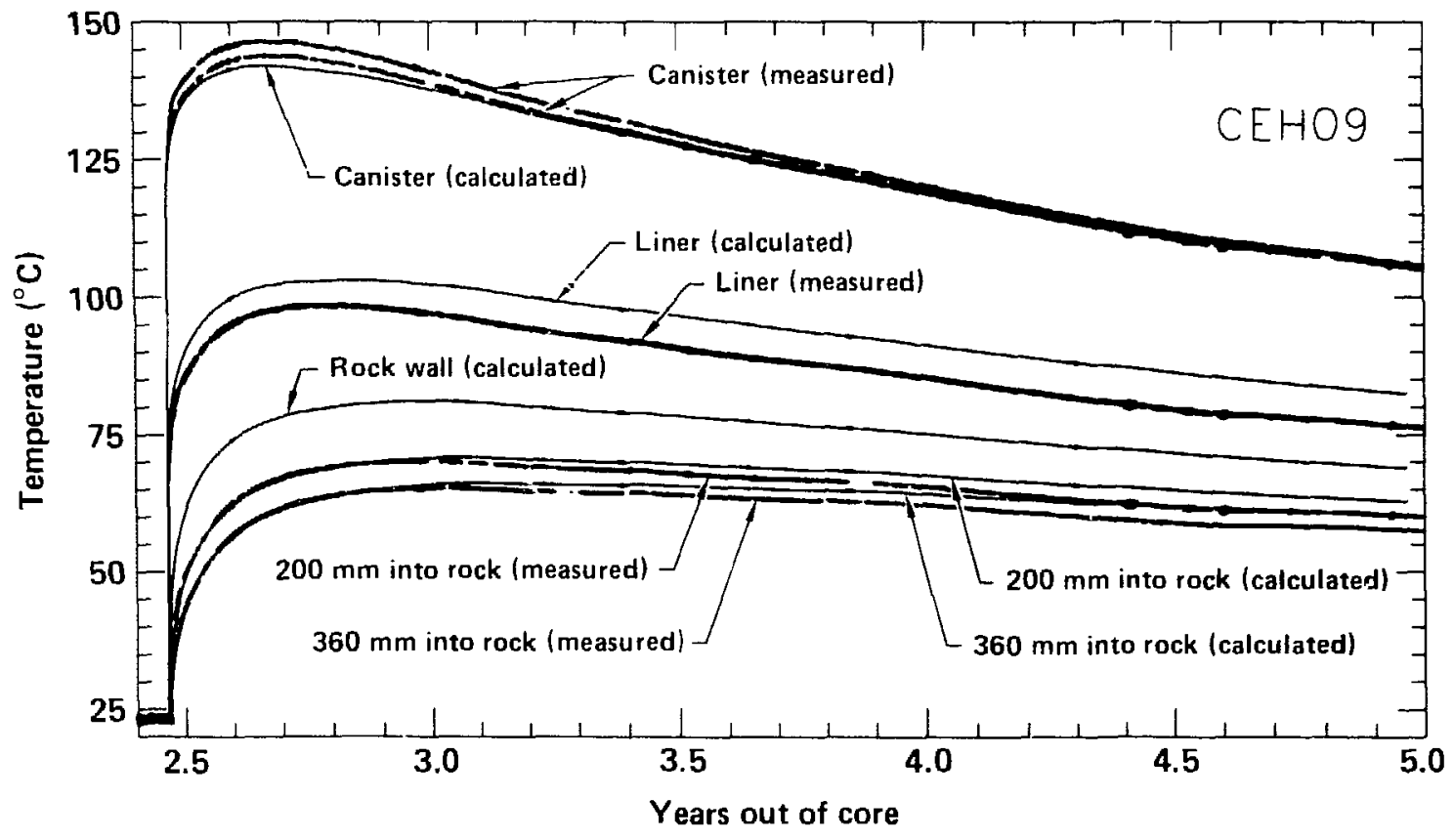

Figure 3-7. Calculated and measured temperature histories at various radial locations at axial midplane of CEH09 (as-built calculation).

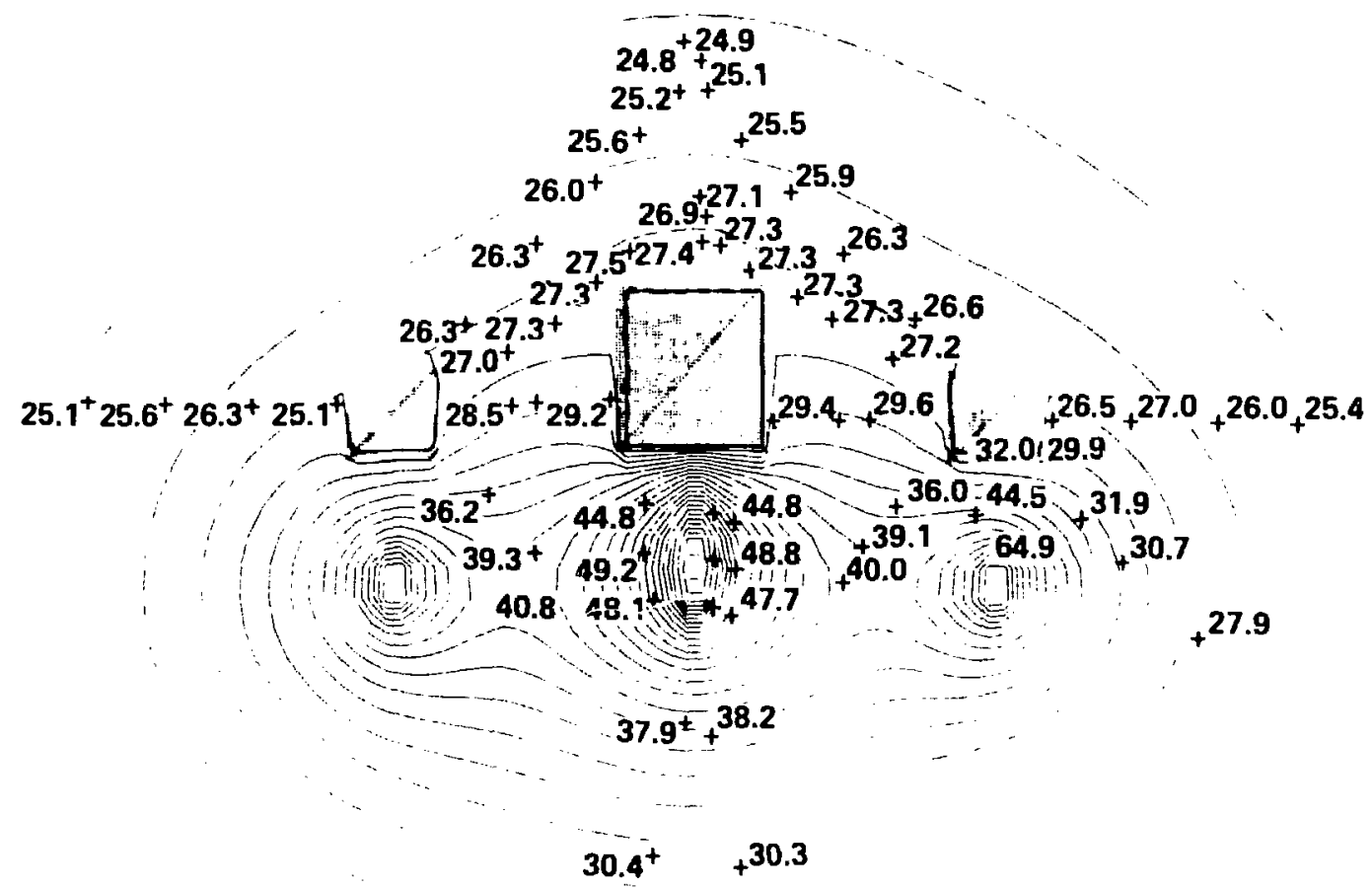

Figure 3-8. Comparison of measured temperatures with TRUMP-calculated temperature contours at 3.5 YOC at station $2+83$ (first solid contour at $24^{\circ} \mathrm{C}$, contour interval at $2{ }^{\circ} \mathrm{C}$ ). 


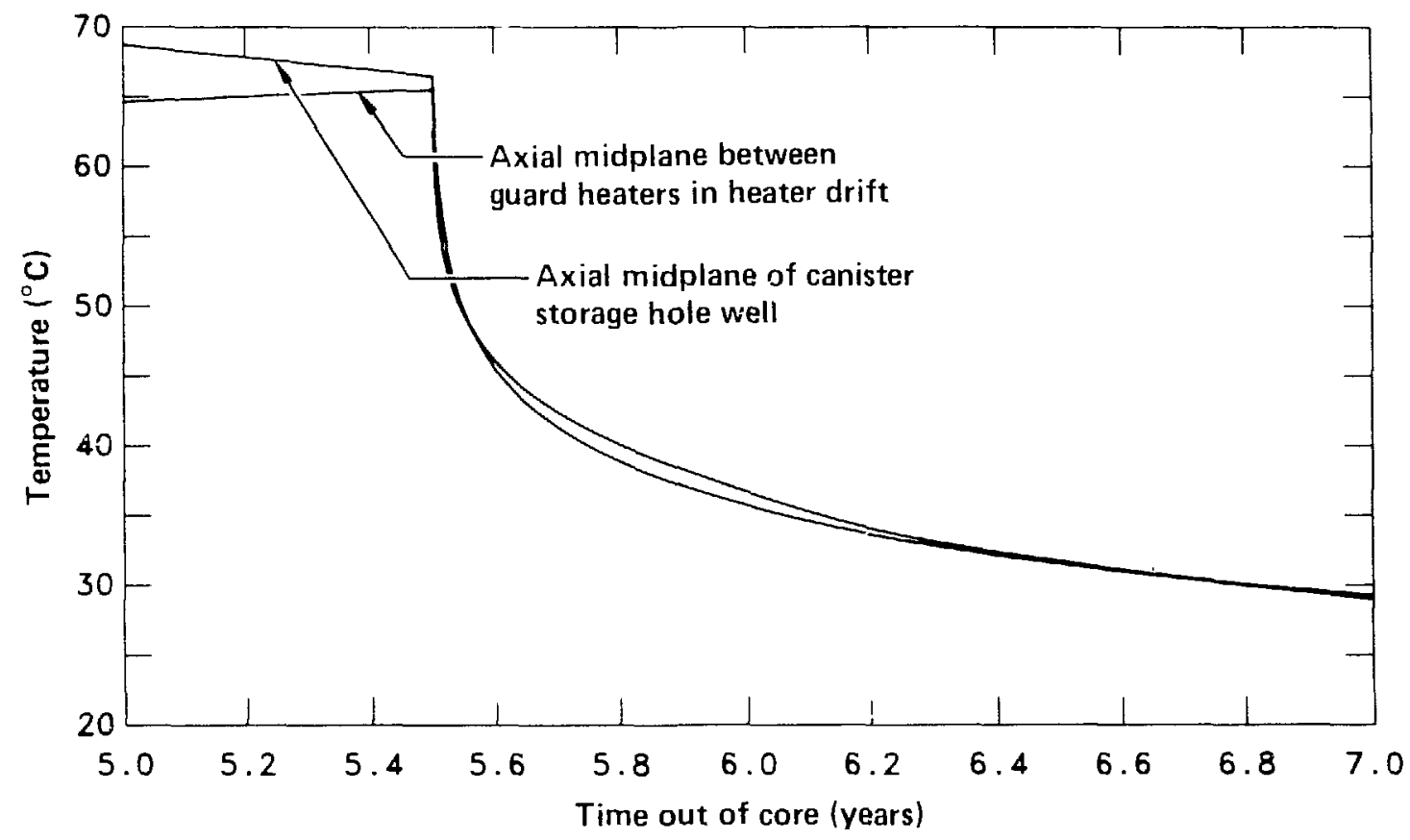

Figure 3-9. Tempe:ature histories near thermal sources resulting from fuel retrieval (after Ballou et al., 1982).

found that ais additional year of cooling would only lower the temperature another 5 to $7^{\circ} \mathrm{C}$. Expressed another way, about $70 \%$ of all the temperature change that will ever occur in returning to ambient temperature, occurs during the first 6 months.

Farther from the heat sources, the rates of cooling were much slower, as expected (Fig. 3-10). The 4 to $5^{\circ} \mathrm{C}$ temperature changes during the first 6 months represent only 20 to $40 \%$ of the temperature differential with respect to ambient.

The overall effects of cooling are seen most clearly by comparing temperature contours at a crosssection through the middle of the SFT-C. Figures 3-11 and 3-12 show the calculated temperatures after 3 years of heating and following a 6-month post-retrieval cooling period, respectively. Since additional cooling was seen to be very slow, we adopted a 6-month planned cooling phase.

\subsubsection{Post-Test Calculations}

After all test data were acquired and the SFT $-\mathrm{C}$ was completed, we performed a final series of calculations using the best-available thermal properties, power tables, and ventilation parameters. In addition, ranges of values of the more important parameters were used to complete the series of eight post-test calculations (Patrick and Montan, 1986). All these calculations used the finite-difference mesh described above. Table 3-1 summarizes the pertinent in put parameters and conditions used in these calculations.

Calculation number (CN) 1148 used the thermal properties, ventilation flowrate, ambient rock temperature, constant inlet air temperature, and convection coefficient that were selected before heated-phase testing began. This is the pretest as-built calculation reported by Montan and Patrick (1981).

For CN 1194, we used a somewhat higher ambient rock temperature and drove the ventilation model with the measured inlet air temperature history. We also included cooling of the rock mass by ventilation during construction of the SFT-C. As a result, temperatures near the drifts were cooler than the $24.7^{\circ} \mathrm{C}$ ambient, undisturbed temperature.

The next two modifications examined the effects of errors or variations in thermal conductivity on the quality of the results. CN 1195 and CN 1196 used rock mass conductivities of 3.42 and $6.22 \mathrm{~W} / \mathrm{m} \cdot \mathrm{K}$, respectively. CN 1199 treated possible decreases in thermal conductivity of the rock and concrete adjacent to the 


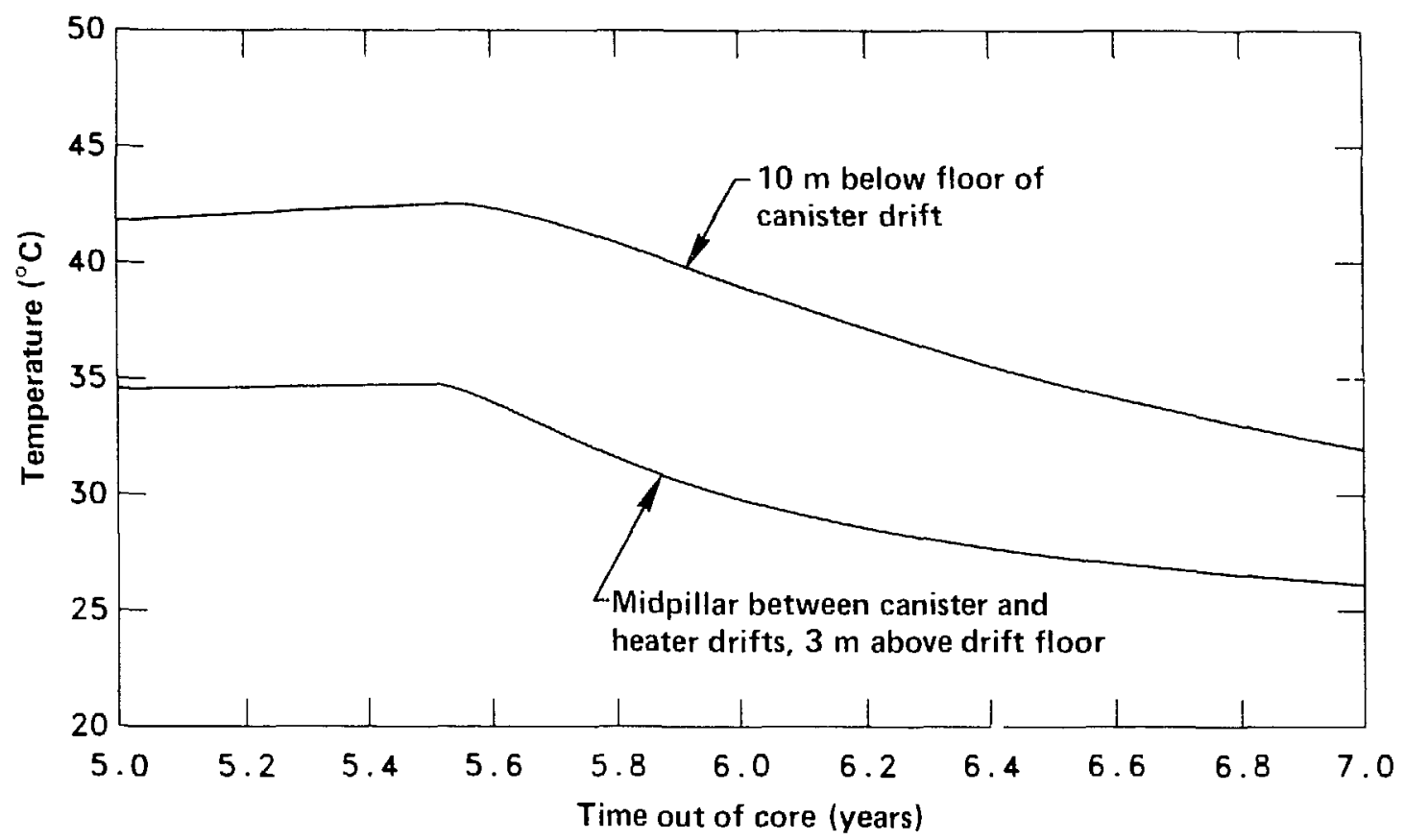

Figure 3-10. Temperature histories at intermediate locations resulting from fuel retrieval (after Ballou et al., 1982).

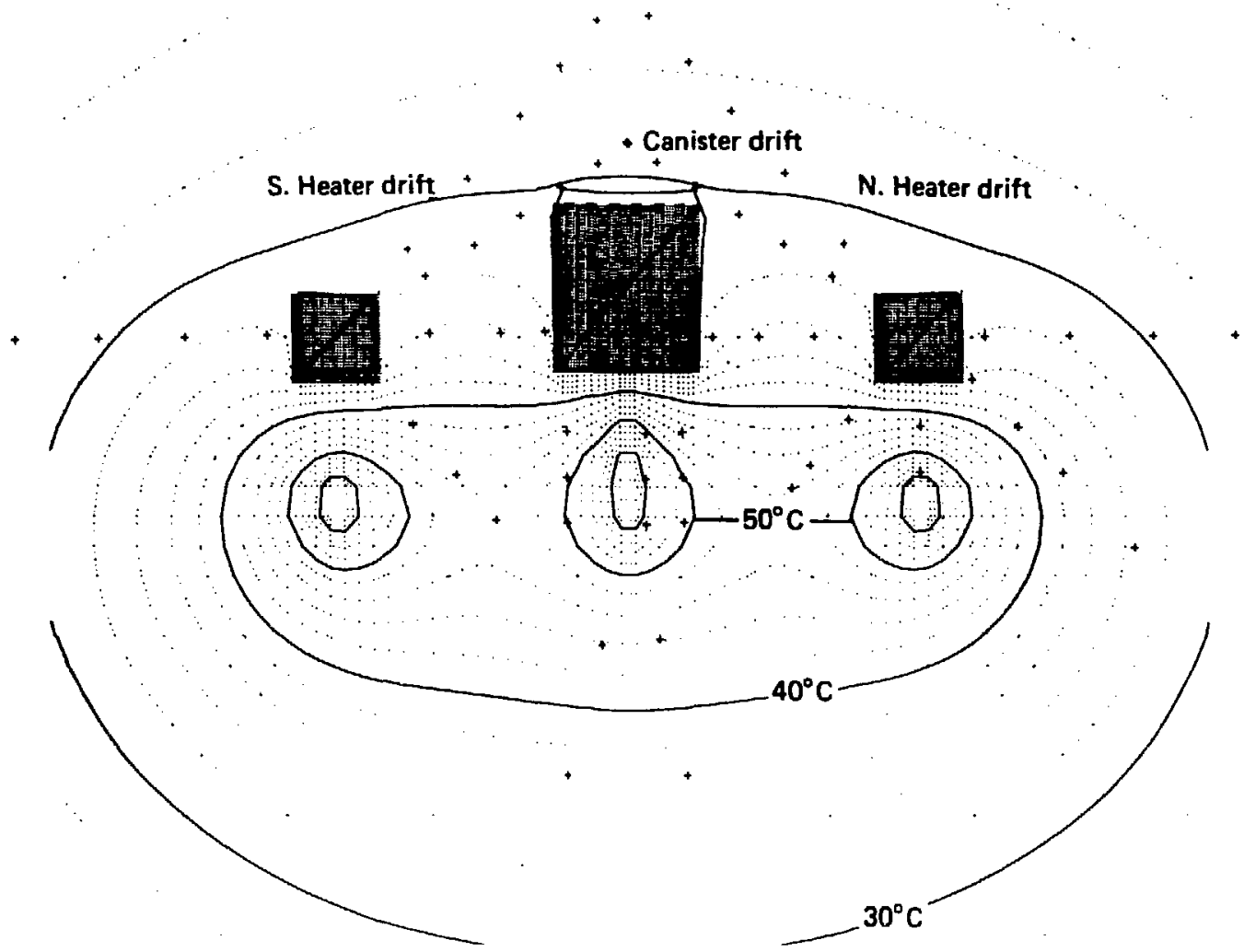

Figure 3-11. Contours of calculated temperatures at a fuel age of 5.5 years out of core, prior to spent-fuel retrieval (+ denotes thermocouple location) (after Ballou, et al., 1982). 


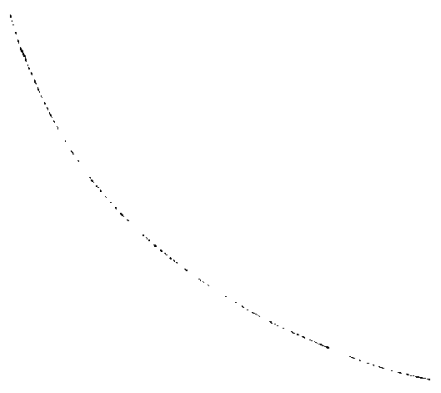

$38^{\circ} \mathrm{C}$

Figure 3-12. Contours of calculated temperatures at a fuel age of 6.0 years out of core, 0.5 years after spent-fuel retrieval (+ denotes thermocouple location) (after Ballou et al., 1982).

Table 3-1. Summary input parameters and conditions used in post-test thermal calculations (after Montan and Patrick, 1986).

\begin{tabular}{|c|c|c|c|c|c|c|}
\hline \multirow[b]{2}{*}{ Parameter } & \multicolumn{6}{|c|}{ Calculation number ${ }^{\star}$} \\
\hline & 1148 & 1194 & 1196 & 1197 & 1200 & 1201 \\
\hline$k\left(\frac{W}{m \cdot K}\right)$ & 3.11 & 3.11 & 6.22 & 3.11 & 3.11 & 3.11 \\
\hline$C\left(\frac{J}{K \mathbf{g} \cdot \mathbf{K}}\right)$ & 930 & 930 & 930 & 930 & 930 & 1860 \\
\hline Ventilation $^{\mathrm{b}}\left(\frac{\mathrm{m}^{3}}{\mathrm{~s} \cdot \mathrm{m}}\right)$ & 0.026 & 0.026 & 0.026 & 0.006 & 0.026 & 0.026 \\
\hline Amb. rock temp $\left({ }^{\circ} \mathrm{C}\right)$ & 23 & 24.7 & 24.7 & 24.7 & 24.7 & 24.7 \\
\hline Inlet air temp & $23^{\circ} \mathrm{C}$ & Meas. & Meas. & Meas. & Meas. & Meas. \\
\hline Nusselt number & $0.13 \mathrm{R},{ }^{13}$ & $0.13 R_{2}{ }^{13}$ & $0.13 R_{a}{ }^{11}$ & $0.13 R_{2}{ }^{13}$ & $0.065 R_{d}{ }^{17}$ & $0.13 R_{d}{ }^{13}$ \\
\hline
\end{tabular}

2 For $1195, k=3.42 \mathrm{~W} / \mathrm{m} \cdot \mathrm{k}$; otherwise, it is like 1194. For 1199, low $\mathrm{k}$ is used for the walls and floor; otherwise, it is like 1194.

' In the model, ventilation flowrate is normalized per unit length in the direction of flow.

'Representation of the convection coefficient. 
underground openings. (Such decreases could occur as a result of excavation-induced fracturing of the rock.) All other conditions and properties were the same as CN 1194.

The effects of changes in ventilation flowrate were examined in $\mathrm{CN}$ 1197. When preliminary calculations showed that the results were relatively insensitive to changes in flow rate, w'e introduced a four-fold reduction to examine the effect. The convective transfer of heat to the ventilation airstream was examined in $\mathrm{CN} 1200$ by reducing the convection coefficient by a factor of two. Finally, the mass heat capacity was increased by a factor of two in CN 1201 to determine the sensitivity of results to this property.

Montan and Patrick (1986) discuss the effects of each of these variations on the level of agreement between data and calculational results. In addition, they present the results of fully three-dimensional finitelength models of the SFT-C. Both finite-difference and analytical solutions to the finite-length models are presented. Calculation 1194 is the basis of most of the analyses presented in Chapters 13 and 14.

\subsection{Rock Mechanical Response Calculations}

Several finite-element calculations were made to help select instrumentation types and locations and to estimate the response of the rock mass to excavation, heating, and subsequent cooling. The purpose and general formulation of each calculation are described here.

\subsubsection{Preliminary Design Calculations}

To determine the appropriate locations, orientations, and dynamic ranges of stress and displacement instrumentation, and to estimate the response of the rock mass, we performed scoping calculations (Ramspott et al., 1979, and Butkovich, 1980). Excavation response was calculated using the ADINA finiteelement code (Bathe, 1978). For thermomechanical calculations, this code was coupled to the companion ADINAT heat transfer code (Bathe, 1977).

The unit cell modeled in the excavation response calculations was a 1-m-thick section transverse to the axis of the drifts. Because of symmetry, only half the unit cell was modeled. For these scoping calculations, the rock was assumed to be isotropic, linearly elastic, and homogeneous with an elastic modulus of 47.6 GPa and a Poisson's ratio of 0.2 . The vertical stress was taken as the weight of the overburden, and the horizontal stress was assigned a magnitude of 0.8 times the vertical stress.

Scoping calculations for thermomechanical response used the same basic mesh, with the addition of a decaying $2-\mathrm{kW}$ heat source to simulate the spent fuel and $1.6-\mathrm{kW}$ auxiliary heaters energized at 3.5 months after spent-fuel emplacement. The thermal properties were the same as for the preliminary thermal design calculations. In addition, we used a thermal expansion coefficient of $8 \times 10^{-6} /{ }^{\circ} \mathrm{C}$.

Although these calculations were quite simplistic, they were adequate for design purposes and for selecting instrumentation types and locations.

\subsubsection{As-Built Calculations}

Once the SFT - $C$ was constructed, considerably better input data were available for use in the as-built design calculations, which we used to make comparisons with the rock mechanical response data, both during mining and during the heated phase of the test. Among the input data that changed were: the spent-fuel power table, the auxiliary heater power schedule, the rock deformation modulus, and the in situ stress.

The calculational mesh (Fig. 3-13) was based on the as-built dimensions and emplacement configurations (Table 3-2). The material properties used in the calculations are shown in Table 3-3. To include the properties of the zone of rock damaged by blasting during excavation of the facility, it was necessary to redesign the mesh, allowing for a 0.5 -m-wide element group surrounding the excavations. The deformation moduli given here are markedly different from those used in the scoping calculations. Furthermore, limited in situ stress data (Ellis and Magner, 1982) led us to use a horizontal-to-vertical stress ratio of 1.2 instead of 0.8 .

To accurately simulate the thermal radiation and ventilation process that would be operative in the drifts, Butkovich and Montan (1980) developed "pseudoproperties" for the air in the drifts. Heat removal was simulated by linking the central node of each drift to an outside node, the temperature of which was constant at the anticipated inlet air temperature. Because this linkage was a temperature-dependent convection coefficient, the heat removal rate was temperature-dependent (Table 3-4). 


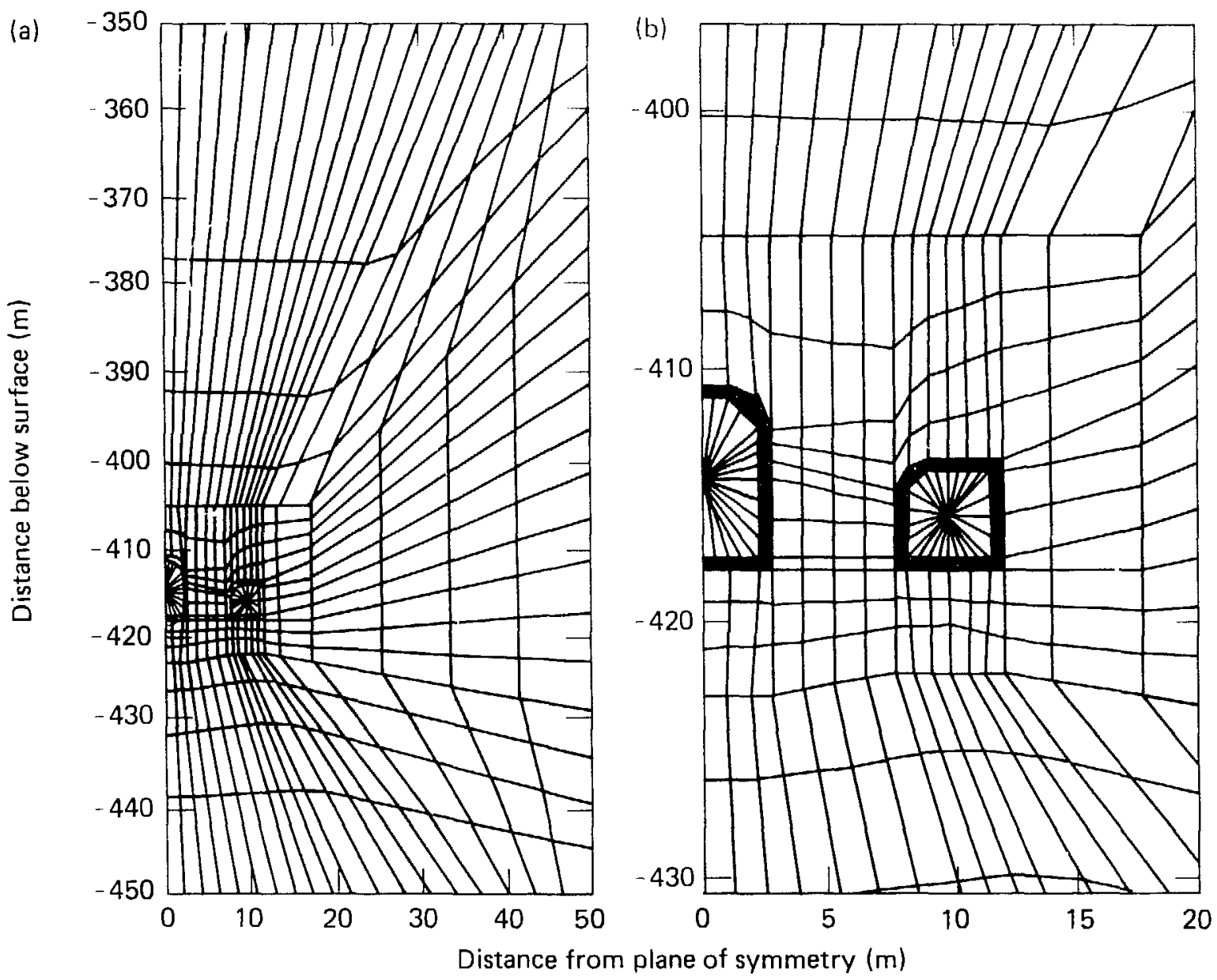

Figure 3-13. Finite-element mesh used with as-built mining and thermomechanical calculations (after Butkovich, 1981).

Table 3-2. Distances and dimensions used in ADINA and ADINAT calculations (after Butkovich, 1981a).

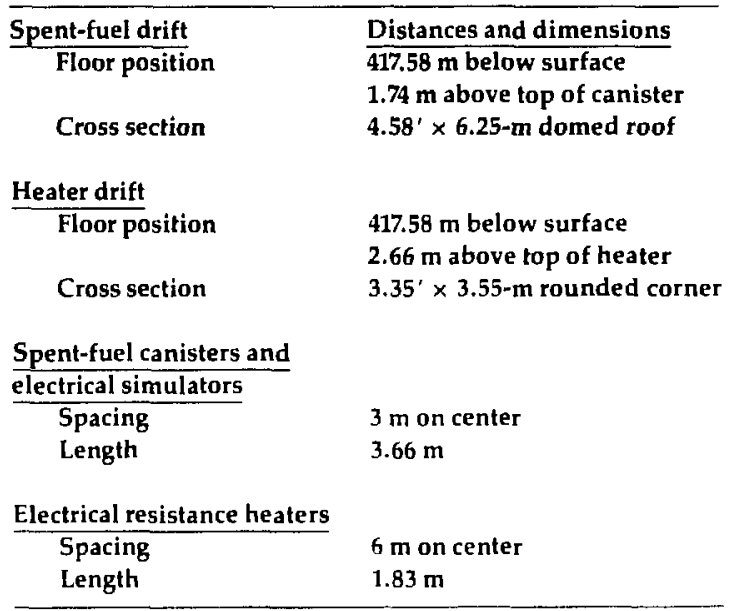


Table 3-3. Values of Climax stock granite and air properties used in calculations (after Butkovich, 1981a).

\begin{tabular}{|c|c|}
\hline Climax stock granite & Values \\
\hline Heat capacity & $930 \mathrm{~J} \mathrm{~kg} \cdot \mathrm{K}$ \\
\hline \multicolumn{2}{|l|}{ Thermal Conductivity $\left({ }^{\circ} \mathrm{C}\right)$} \\
\hline 0 & $3.1679 \mathrm{~W}^{\prime} \mathrm{m} \cdot \mathrm{K}$ \\
\hline 23 & $3.1104 \mathrm{~W}^{\prime} \mathrm{m} \cdot \mathrm{K}$ \\
\hline 477 & $2.1104 \mathrm{~W} \cdot \mathrm{m} \cdot \mathrm{K}$ \\
\hline \multicolumn{2}{|l|}{ Thermal expansion coefficient $\left({ }^{\circ} \mathrm{C}\right)$} \\
\hline 0 & $10 \times 10^{-6} \mathrm{~K}^{-1}$ \\
\hline 23 & $10 \times 10^{-b} \mathrm{~K}^{1}$ \\
\hline 40 & $8.9 \times 10^{-b} \mathrm{~K}^{-1}$ \\
\hline 80 & $7.4 \times 10^{-6} \mathrm{~K}^{-1}$ \\
\hline 125 & $8.0 \times 10^{-n} \mathrm{~K}^{-1}$ \\
\hline 175 & $9.6 \times 10^{-6} \mathrm{~K}^{-1}$ \\
\hline 225 & $12.7 \times 10^{-\mathrm{n}} \mathrm{K}^{1}$ \\
\hline \multicolumn{2}{|l|}{ Elastic modulus } \\
\hline \multicolumn{2}{|l|}{ Field } \\
\hline Explosive-damaged region & $13 \mathrm{GPa}$ \\
\hline Rock mass & $27 \mathrm{GPa}$ \\
\hline \multicolumn{2}{|l|}{ Laboratory } \\
\hline Rock samples & $48 \mathrm{GPa}$ \\
\hline \multicolumn{2}{|l|}{ Poisson's ratio: } \\
\hline \multicolumn{2}{|l|}{ Field } \\
\hline Rock mass & 0.25 \\
\hline Damaged zone & 0.35 \\
\hline \multicolumn{2}{|l|}{ Laboratory } \\
\hline Rock samples & 0.21 \\
\hline \multicolumn{2}{|l|}{ Air $^{b}$} \\
\hline Density & $1 \mathrm{~kg} / \mathbf{m}^{3}$ \\
\hline Heat capacity & $1000 \mathrm{~J} / \mathrm{kg} \cdot \mathrm{K}$ \\
\hline Thermal conductivity & $0.03 \mathrm{~W} / \mathrm{m} \cdot \mathrm{K}$ \\
\hline
\end{tabular}

Table 3-4. Values of drift material properties derived to simulate radiation and ventilation with ADINAT (after Butkovich, 1981a).

\begin{tabular}{lc}
\hline \multicolumn{1}{c}{ Proporties } & Values \\
\hline $\begin{array}{l}\text { Thermal conductivity } \\
\text { Spent-fuel drift } \\
\text { Heater drift }\end{array}$ & $70 \mathrm{~W} / \mathrm{m} \cdot \mathrm{K}$ \\
Volumetric heat capacity & $40 \mathrm{~W} / \mathrm{m} \cdot \mathrm{K}$ \\
Convection coefficient $(\mathrm{H})$ & $8 \times 10^{4} \mathrm{~J} / \mathrm{m}^{3} \cdot \mathrm{K}$ \\
IT (K) & $\mathrm{H}\left(\mathrm{W} / \mathrm{m}^{2} \cdot \mathrm{K}\right)$ \\
\hline 0 & 0 \\
0.272 & 4.5 \\
0.445 & 5.0 \\
0.903 & 5.5 \\
1.878 & 6.0 \\
4.074 & 6.5 \\
9.427 & 7.0 \\
24.042 & 7.5 \\
\hline
\end{tabular}

Table 3-5. Variation in power level in electricalresistance heaters (after Butkovich, 1981a).

\begin{tabular}{ccc}
$\begin{array}{c}\text { Time since } \\
\text { emplacement } \\
\text { (yr) }\end{array}$ & Date & $\begin{array}{c}\text { Power level } \\
(\mathrm{kW})\end{array}$ \\
\hline 0 & 6 May 1980 & 0 \\
0.14 & 27 June 1980 & 1.850 \\
0.16 & 2 July 1980 & 0.925 \\
0.60 & 17 December 1980 & 1.300 \\
1.46 & 8 March 1982 & 1.400 \\
\hline
\end{tabular}

2 Derived from diffusivity measurements.

${ }^{b}$ Used to derive input values shown in Table 3-4.

The decay curve (Fig. 3-14) and auxiliary heater power table (Table 3-5) were also notably different from those used in the scoping calculations. The peak spent-fuel power was $1,530 \mathrm{~W}$, and the auxiliary heaters were designed to operate at several different power levels during the test.

The results of the as-built calculations formed the basis for several comparisons with measured rock displacements and stress changes. In general, the as-built calculations simulated the heated-phase response quite well (Patrick et al., 1982, 1983, 1984). The response to excavation was not reproduced by the calculation because, in the pillars, the calculation and data differed in sign (Fig. 3-15), leading to a further calculational effort and analysis.

\subsubsection{Analysis of the Climax Mine-By}

Wilder and Patrick (1980) provided an initial analysis and presentation of the mine-by data in the context of calculations. They established that the major joints and faults significantly influenced rock response. The regions of the rock mass that exhibited the larger discrepancies between measured and calculated displacements coincided with regions containing major geologic discontinuities. 


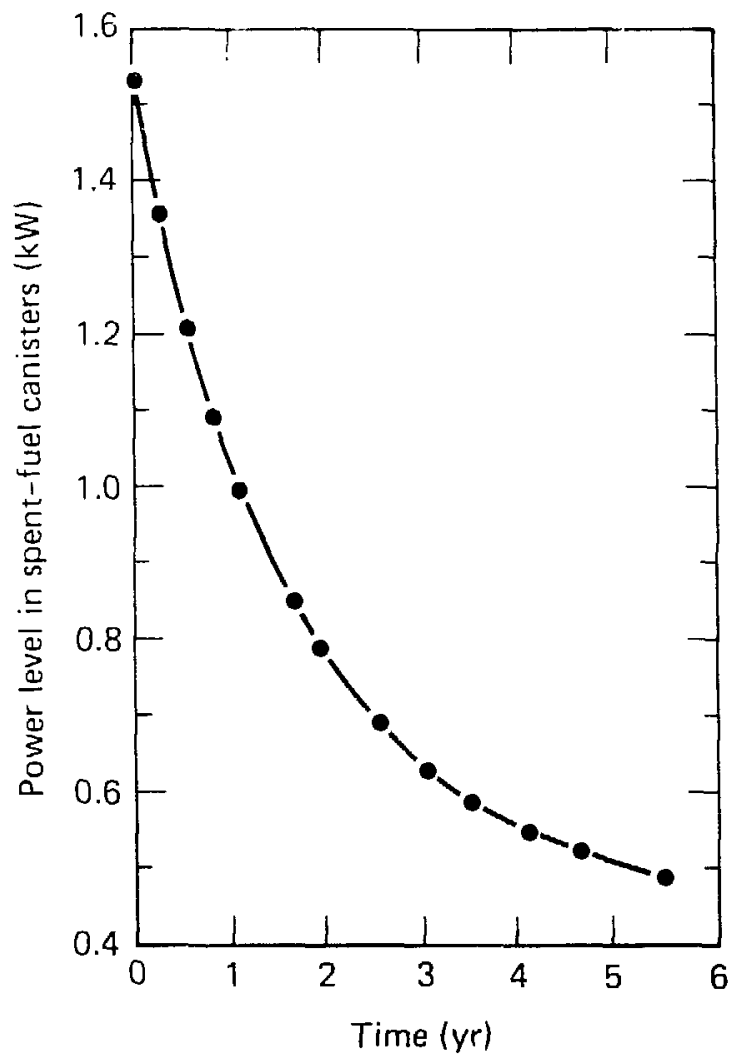

Figure 3-14. Spent-fuel decay curve used in ADINAT calculations (after Butkovich, 1981a).

Because of the poor agreement between measured and calculated rock responses to excavation, further analyses were undertaken. Calculations by Schrauf and Board (1979) using the finite-element code TWODI and the boundary element code DIG produced results that were consistent with ADINA and, hence, inconsistent with the measurements. Heuze, Butkovich, and Peterson (1981) used Heuze's JPLAXD finite-element code. Developed specifically for analysis of structures in rock, this code contains a library of solid and joint elements that can exhibit strain softening and dilatancy in the post-peak region of stress-strain response.

The JPLAXD code incorporates discrete geological discontinuities as well as strain-softening and dilatancy behaviors, which the earlier ADINA code did not. Other features were also different, including fieldmeasured rock mass modulus and in situ state of stress, field-scale Poisson's ratio derived from stress measurements (Chapter 4), and a parametric variation in the ratio of horizontal to vertical stress between 0.5 and 3.5 .

Both jointed and unjointed models were used for these calculations; the former models used dilatant and nundilatant joint behaviors. The jointed meshes for the two heavily instrumented sections of the excavation are shown in Figs. 3-16 and 3-17. Because JPLAXD is a two-dimensional formulation, it was necessary to treat featuras that were 10 to 30 degrees from parallei as though they were parallel to the axis of the drifts (Chapter 4).

The initial properties of intact rock and joints used in these calculations are given in Tables 3-6 and 3-7, respectively. As rock displacements progressed during excavation, these material properties were automatically adjusted by JPLAXD in accordance with the assigned constitutive laws for the respective materials. Because no in situ strength data were available, Heuze adopted the minimum values of the shearstrength parameters that would provide stable excavations. 


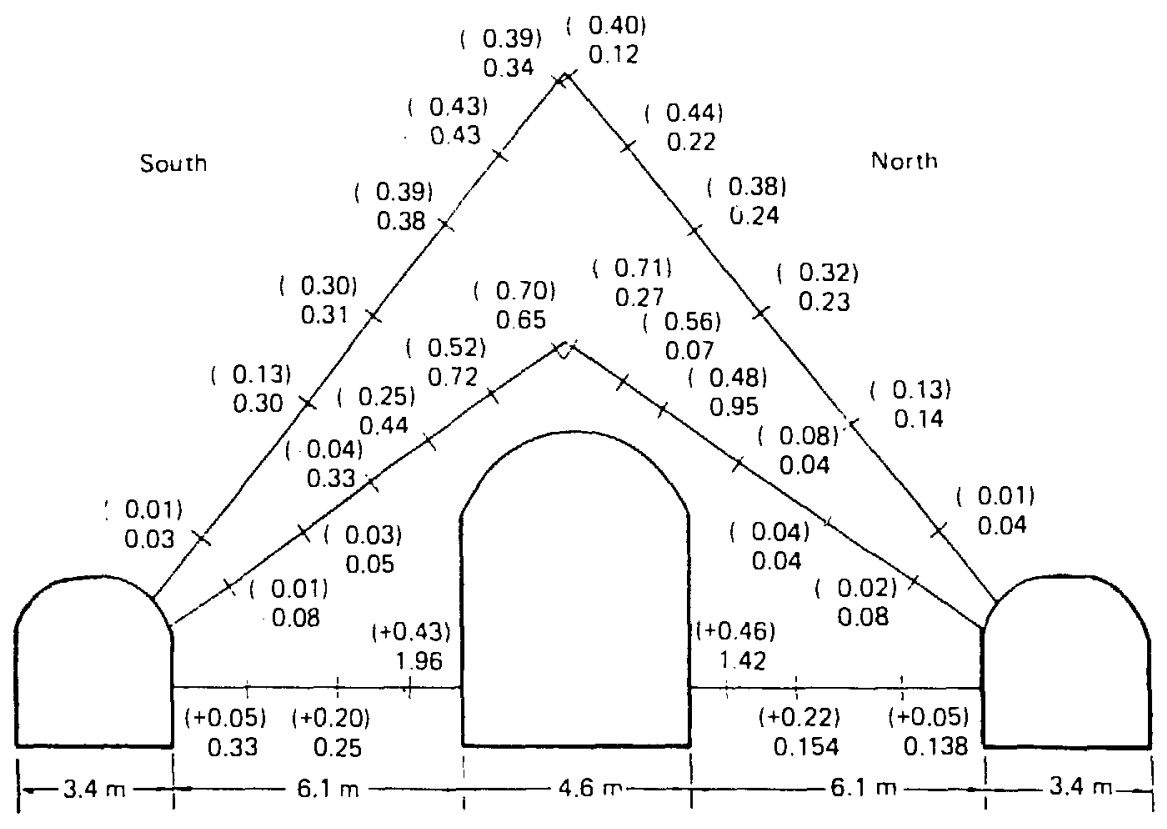

(a) Station $2+83$

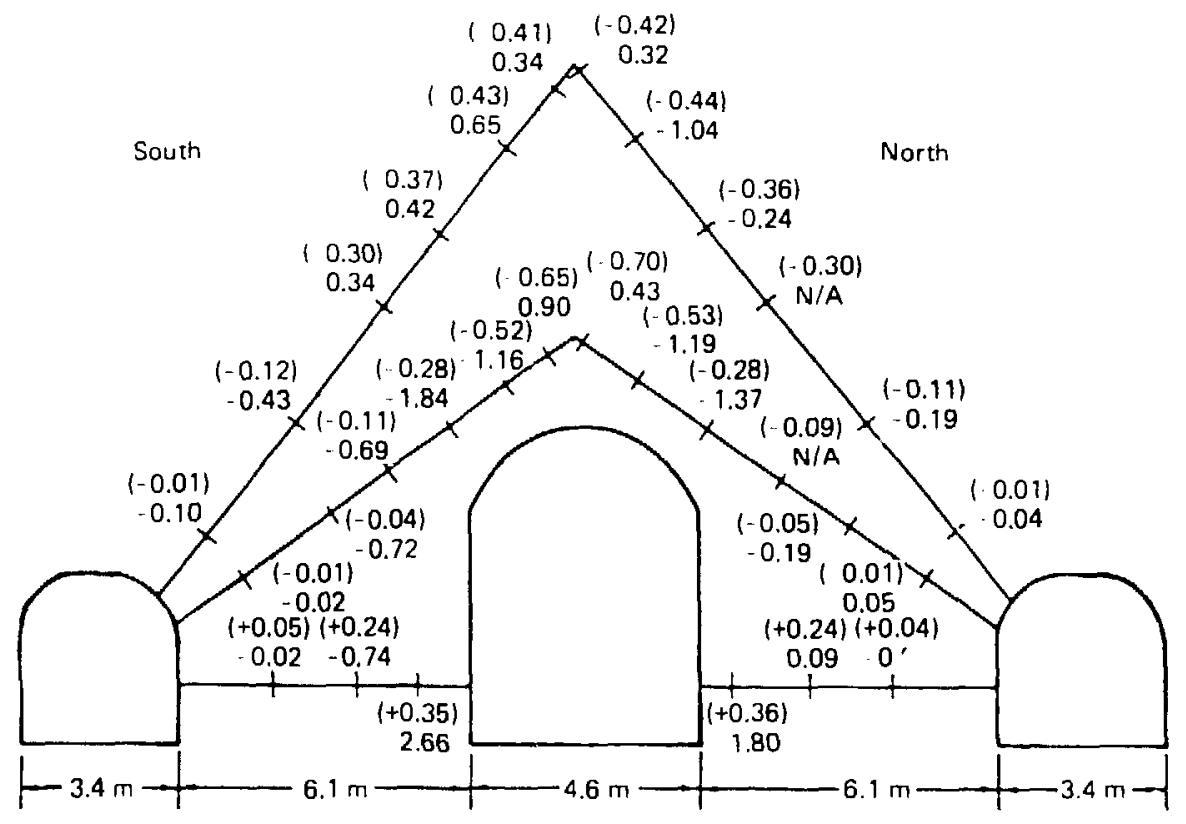

(b) Station $3+45$

Figure 3-15. Comparison of observed and (ADINA-calculated) displacements (mm) during Mineby. ${ }^{2}$ Minus sign indicates shortening; plus sign indicates lengthening (after Heuze, Butkovich, and Peterson, 1981). 


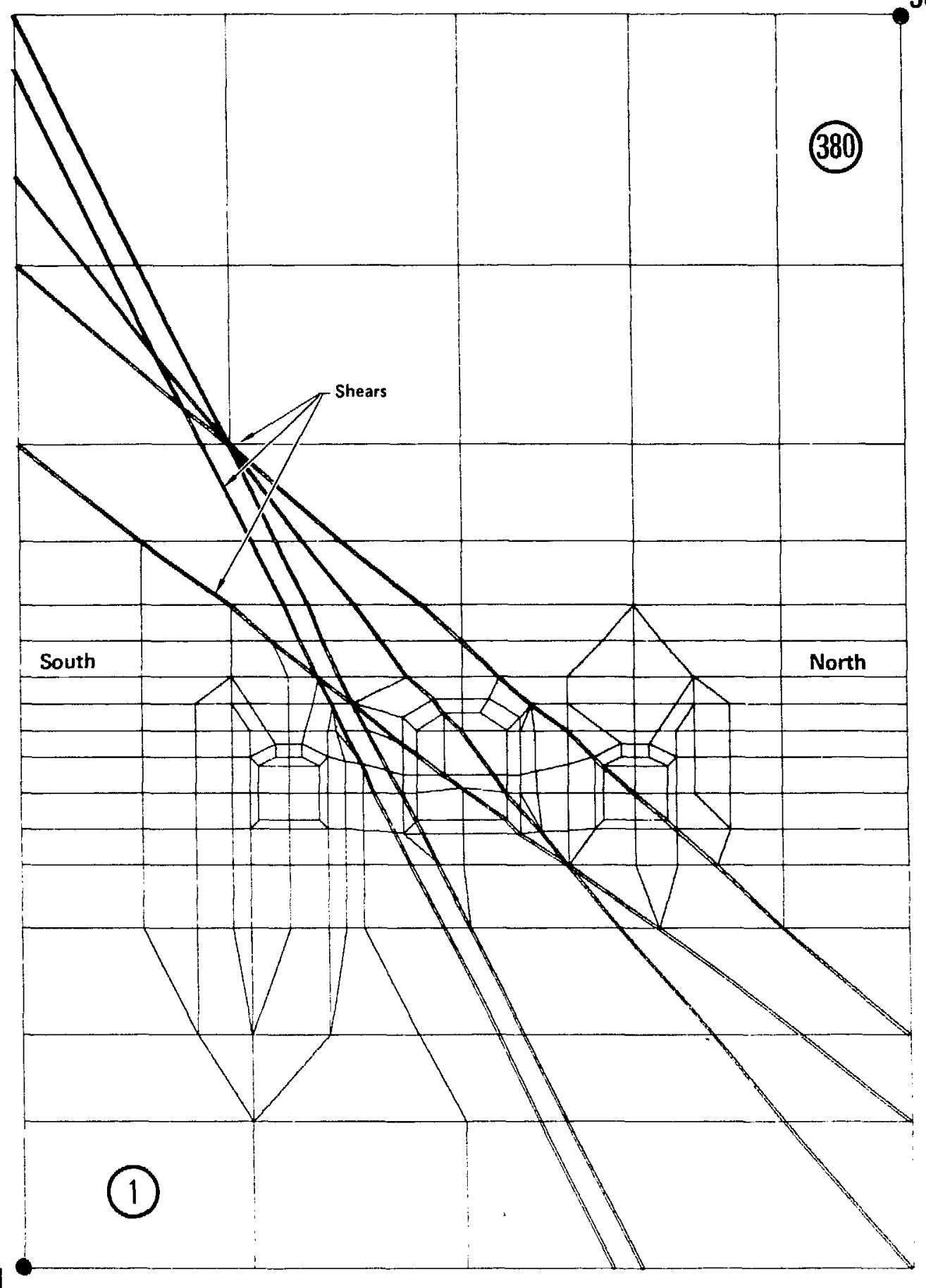

Figure 3-16. Jointed mesh of the SFT $-C$ caverns at station $2+83$ (381 nodes, 380 elements, after Heuze, Butkovich, and Peterson, 1981). 


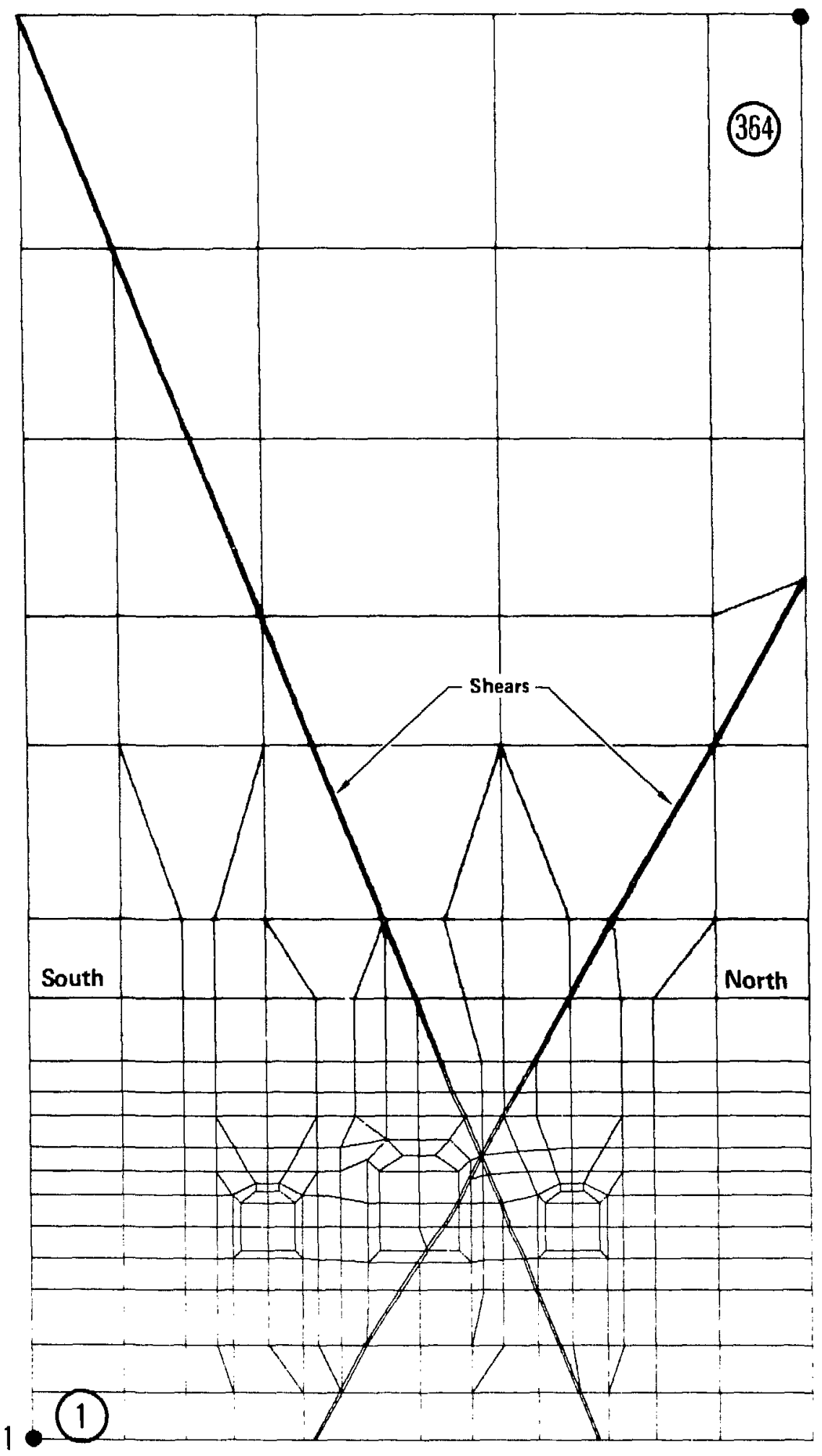

Figure 3-17. Jointed mesh of the SFT-C caverns at station $3+45$ (375 nodes, 364 elements, after Heuze, Butkovich, and Peterson, 1981). 
Table 3-6. Initial values of rock properties used for JPLAXD calculations (after Heuze, Butkovich, and Peterson, 1981).

\begin{tabular}{|c|c|c|c|}
\hline Property & $\begin{array}{l}\text { Intact } \\
\text { rock }\end{array}$ & $\begin{array}{c}\text { Damaged } \\
\text { rock }^{\lrcorner}\end{array}$ & $\begin{array}{c}\text { Excavited } \\
\text { rock }^{b}\end{array}$ \\
\hline Mass density & 2.65 & 2.65 & $10^{-2}$ \\
\hline Modulus (GPa) & 30 & 10 & $10^{-2}$ \\
\hline Poisson's ratio & 0.25 & 0.35 & 0.25 \\
\hline Peak cohesion (MPa) & 7 & 3.5 & $10^{111}$ \\
\hline Residual cohesion (MPa) & 0 & 0 & $10^{10}$ \\
\hline Peak triction (deg) & 60 & 45 & 0 \\
\hline Residual friction (deg) & 45 & 45 & 0 \\
\hline Tensile strength (MPa) & 10 & 2.7 & $10^{10}$ \\
\hline
\end{tabular}

"Damaged rock surrounds the drifts to a depth of 0.5 to $1 \mathrm{~m}$.

$r$ The excavated rock is made very light and soft, but strong to bypass the failure criterion routines.

Table 3-7. Initial values of joint properties used for JPLAXD calculations (after Heuze, Butkovich, and Peterson, 1981).

\begin{tabular}{|c|c|c|c|}
\hline Property & $\begin{array}{l}\text { Joint in } \\
\text { intact rock }\end{array}$ & $\begin{array}{c}\text { Joint in } \\
\text { damaged rock }\end{array}$ & $\begin{array}{c}\text { Excavated } \\
\text { joint }\end{array}$ \\
\hline Normal stiffness (MPa/m) & $10^{5}$ & $10^{5}$ & $10^{-3}$ \\
\hline Shear stiffness (MPa $\mathrm{m}$ ) & 2700 & 2700 & $10^{-4}$ \\
\hline Maximum closure (m) & $2.10^{-3}$ & $2.10^{-3}$ & 200 \\
\hline Peak cohesion intercept (MPa) & 5 & 5 & 0 \\
\hline Peak cohesion" & 0 & 0 & 0 \\
\hline Initial dilation angle (deg) ${ }^{2}$ & 10 & 10 & 0 \\
\hline Critical normal stress (MPa) ${ }^{\alpha}$ & 30 & 30 & $10^{10}$ \\
\hline Tensile strength (MPa) & 0 & 0 & $10^{30}$ \\
\hline Residual friction (deg) ${ }^{a}$ & 40 & 25 & 0 \\
\hline
\end{tabular}

See Heuze, Butkovich, and Peterson (1981) for derivation.

The results of Heuze, Butkovich, and Peterson (1981) are summarized for nondilatant models in Figs. 3-18 and 3-19, and in Fig. 3-20 for dilatant joint models. In general, the JPLAXD-calculated displacements are larger than those calculated by ADINA for the inclined instrument locations. At some locations, the JPLAXD results are opposite in sign from the ADINA results and the measured displacement. Although JPLAXD did calculate that vertical stresses decreased in some locations within the pillars, the average vertical stress increased. The measured narrowing across the pillar was not observed in the calculations.

Taken in total, the agreement between measured and calculated displacements was poorer for JPLAXD than for ADINA. The former differed from measured values by more than a factor of two in $87 \%$ of the cases for inclined instruments and $100 \%$ of the cases for horizontal instruments. The latter differed from measured values by more than a factor of two in $56 \%$ of the cases for inclined instruments and $100 \%$ of the cases for horizontal instruments. The JPLAXD stress-change results were clearly better than the ADINA results because they showed the measured stress decreases as excavation progressed.

Although Heuze, Butkovich, ard Peterson (1981) concluded that the instrumentation was probably in error, other researchers who have reviewed the data and calculations reached a different conclusion. Cook (1983) has shown that all the data, while highly variable, are statistically consistent, leading him to conclude that it was unlikely that instrumentation errors caused the unusual pillar narrowing. Even so, to date the observed displacements have not been successfully modeled. Scoping studies of the permanent displacements resulting from nearby detonation of high explosives indicates that this mechanism could be responsible for the observed displacements (Butkovich, 1985). Because of the limited capability of such 

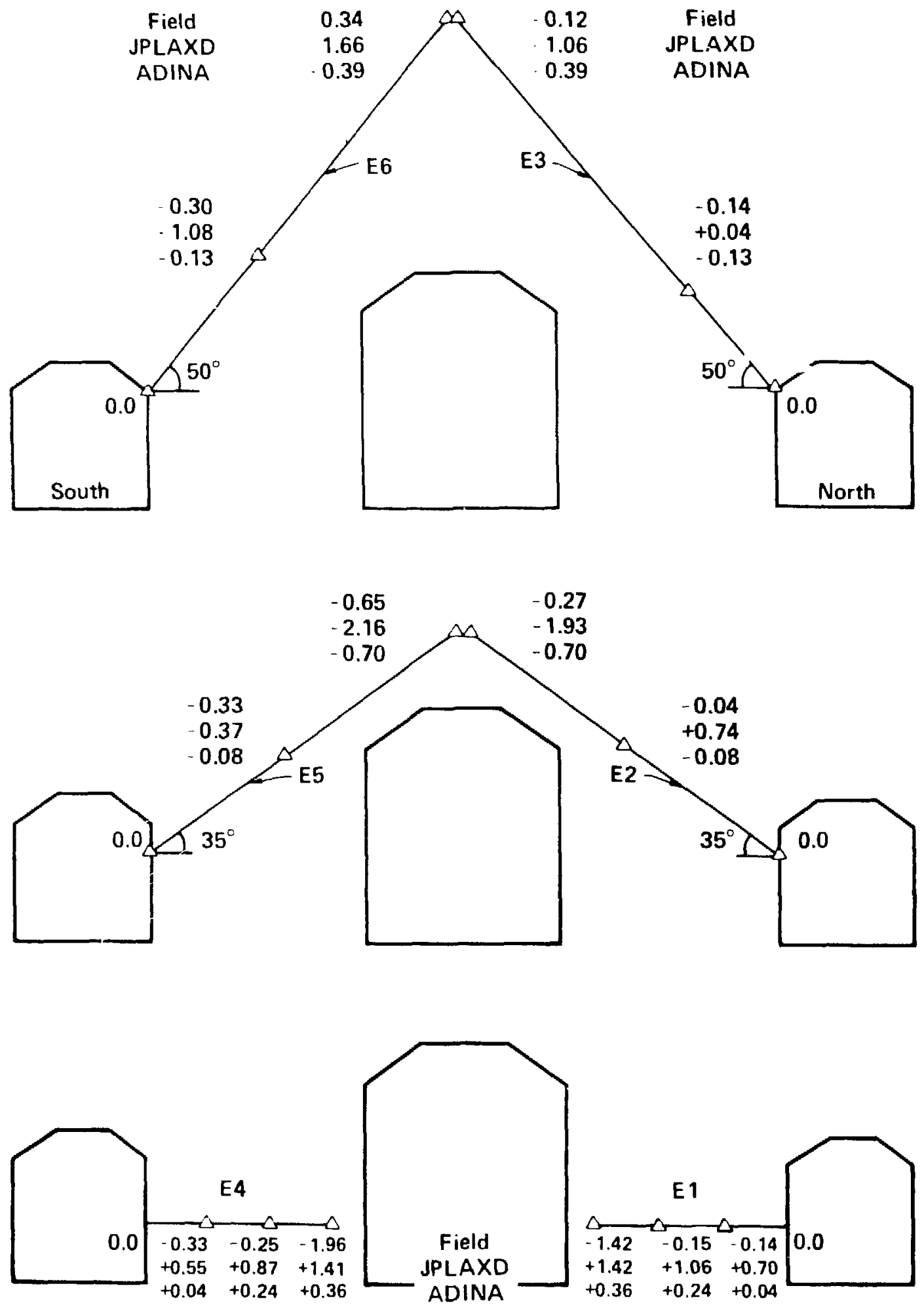

Figure 3-18. Comparison of field observations with JPLAXD and ADINA calculations, for the relative movements of MPE anchors during the mine-by $(\mathrm{mm})$. Station $2+83$, non-dilatant joints (after Heuze, Butkovich, and Peterson, 1981). 

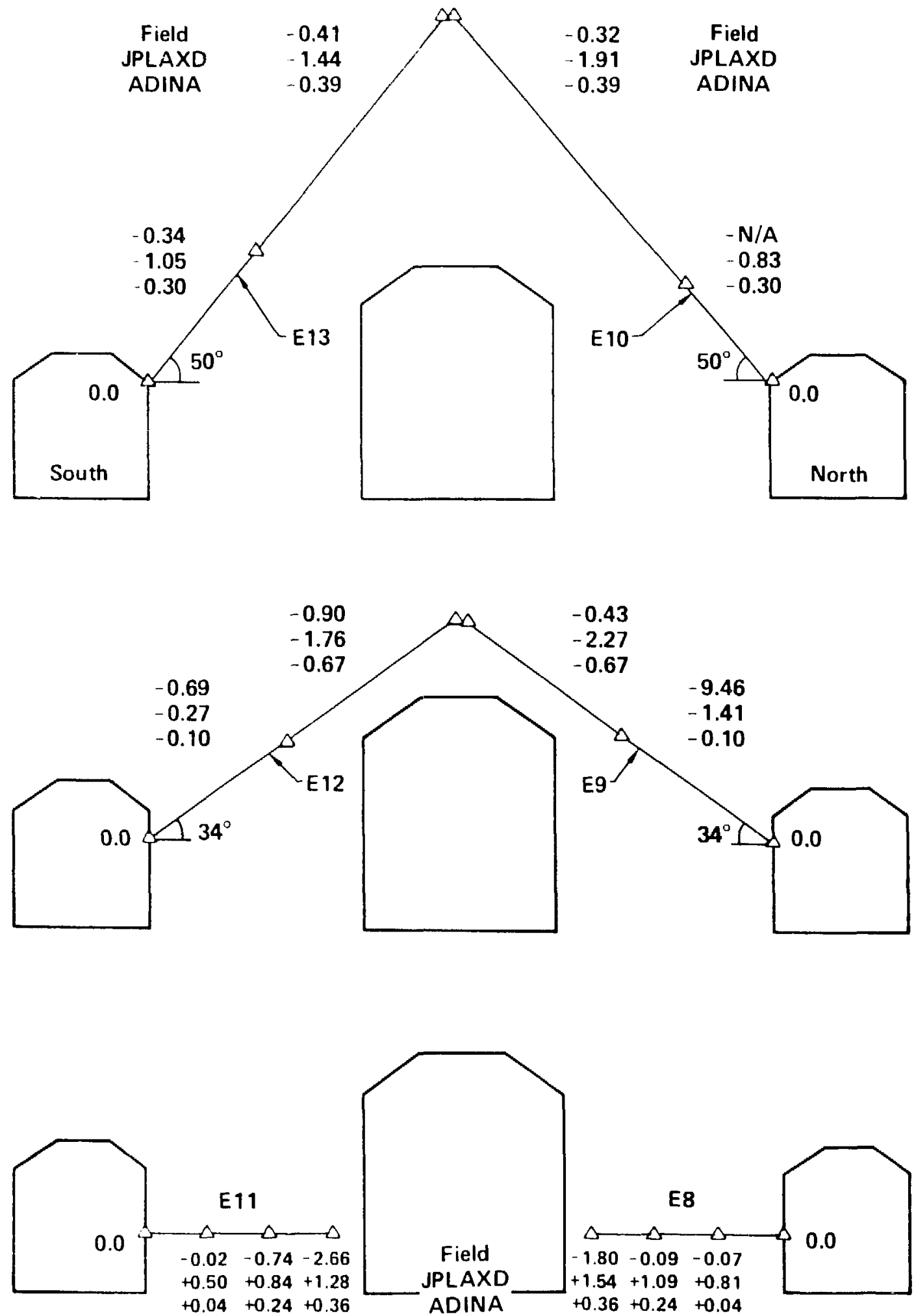

Figure 3-19. Comparison of field observations with JPLAXD and ADINA calculations for the relative movements of MPE anchors during the mine-by $(\mathrm{mm})$ (after Heuze, Butkovich, and Peterson, 1981). 

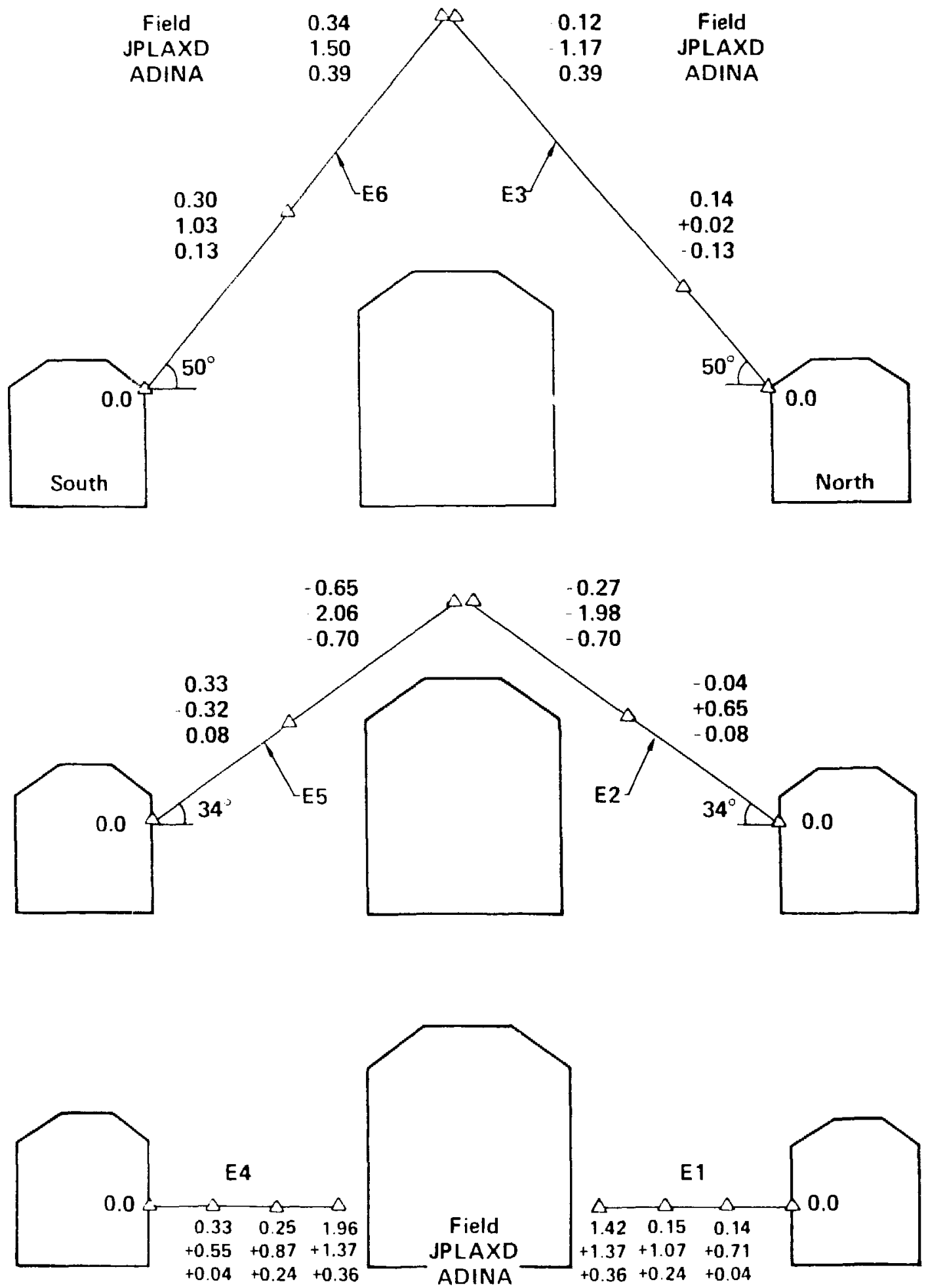

Figure 3-20. Comparison to field observations with JPLAXD and ADINA calculations for the relative movements of MPE anchors during the mine-by $(\mathrm{mm})$. Station $2+83$, dilatant joints (after Heuze, Butkovich, and Peterson, 1981). 
codes to calculate the geometry and because of the large number of explosive charges used in the excavation, definitive results have not been produced.

\subsubsection{Effects of Boundary Conditions}

To confirm the adequacy of the mesh sizes used in the ADINA as-built thermomechanical calculations and to evaluate differences between plane strain and plane stress boundary assumptions, Butkcivich (1982) performed an additional series of calculations for three cases:

- The effect of mesh loading on three progressively larger meshes.

- The difference in results from plane strain and plane stress boundary conditions.

- The effect of isothermal boundaries on a small mesh and a significantly larger mesh.

To study these effects, he developed an "onion skin" mesh consisting of a 40 - by 80 -m inner core of 274 eight-node isoparametric elements, a second laver of 52 eight-node elements that enlarged the mesh to $55 \times 110 \mathrm{~m}$, and a third layer of 56 eight-node elements that enlarged the mesh to $70 \times 140 \mathrm{~m}$ (Fig. 3-21). The effective mesh sizes were twice these dimensions because of the vertical plane of symmetry through the center of the unit cell.

The rock mass heat transfer and mechanical parameters, auxiliary heater power table, spent-fuel decay curve, and other features of the calculation were essentially the same as were used in the as-built thermomechanical analyses (Butkovich, 1981a and 1982).

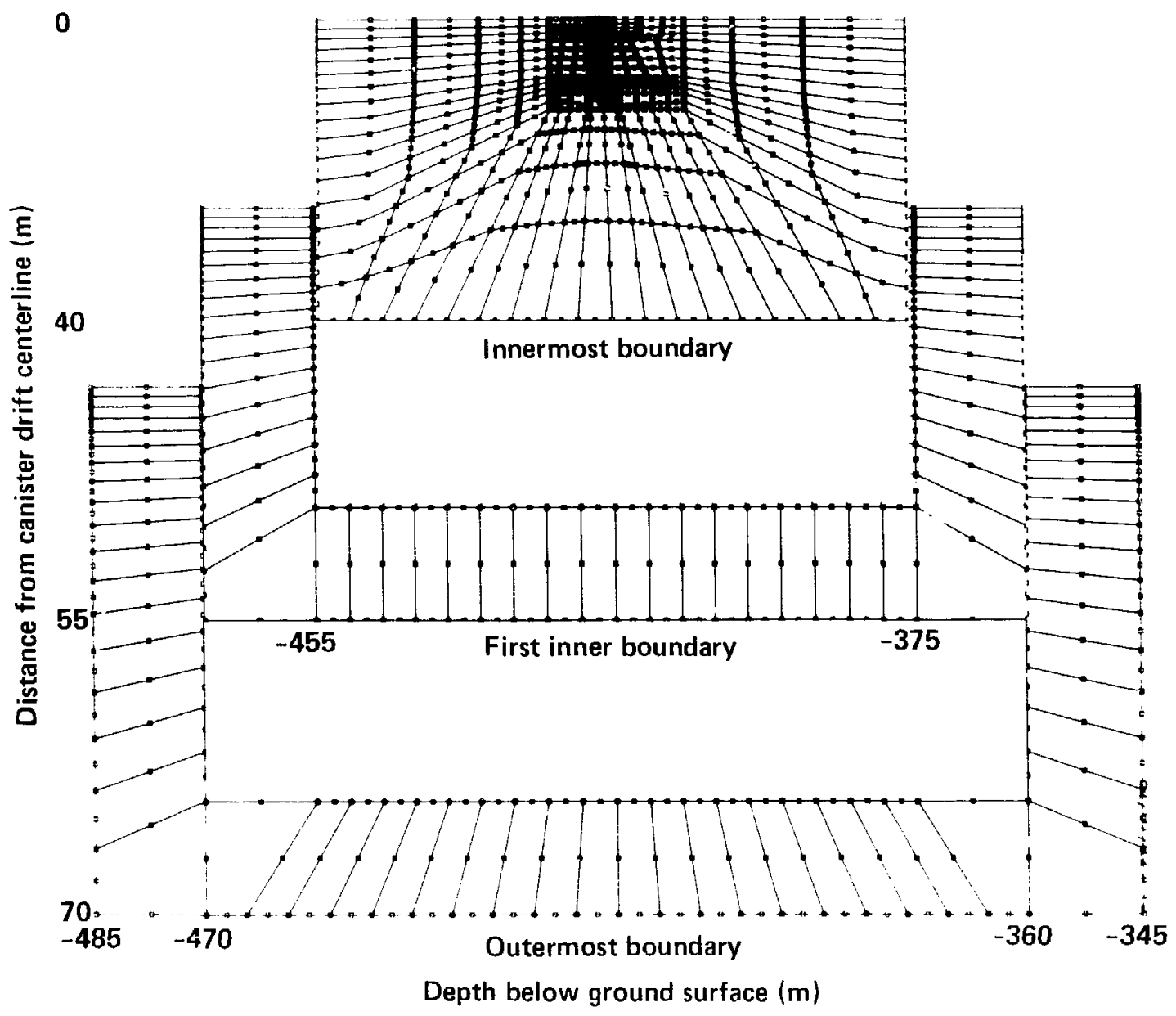

Figure 3-21. Mesh construction allows layers to be peeled off like onion skins (boundary coorainates in meters) (after Butkovich, 1982). 
The three mesh sizes produced essentially identical displacements at all times. This confirms that the smallest mesh, which was identical in sire and similarly coned to the as-built mesh, wats adeyuate for the duration of heating simulated.

The plane strain calculations commenly used do not allew out-of-plane motion. As a result, out-ofplane stressess are generated that are dependent upon the material properties and the state of stress in the other two directions. Because these out-of-plane stresse's were not the same as were measured in sith, a plane stress (zero out-of-plane stress) calculation was conducted. At the locations compared, stress changes were 5 to $10 \%$ greater for the plane stress calculation. Similar variations were seen in calculated displacements. Because the actual uut-of-plane stress value is intermediate between the plane strain and plane stress values, we judged it unlikely that the effect would significantly influence the quality of comparision between data and calculations.

The position of the isothermal boundary could affect the accuracy of the calculation because this boundary condition acts as a heat sink. This study showed that whether the isothermal boundary condition was located at the innermost or outermost boundary, differences did not exceed 1 " $\mathrm{C}$ at the end of a 5 year simulated heating phase, and did not exceed $1 / 4$ ( after 3 years of heating, the actual duration for the SFT-C. The resulting thermomechanical response's were insignificantly different.

\subsubsection{Test Completion Calculations}

When we determined that a 3 -year test duration was sufficient to achieve the gorls of the SFT-C, calculations were undertaken to determine the reyuired duration of the post-retrieval cooling period. Ballou et al. (1982) documented the rationale and supporting thermomechanical calculations, which were used in establishing the project test completion plan and associated schedule.

The geometry, associated calculational mesh, material properties, and input energy tables were the same as were used in the as-built calculations.

Because the structural response of the SFT $-\mathrm{C}$ to cooling is a direct result of temperature changes, we found that the thermomechanical response mirrored that of the thermal response discussed in Sec. 3.2.4. Stress changes and displacements occurred very rapidly near the thermal sources and relatively slowly elsewhere (Figs. 3-22 and 3-23). Using the effects after 1.5 years of cooling as a basis, we found that after 6 months:

- $50 \%$ of the stress change would have occurred at locations in the pillars.

- $70 \%$ of the stress change would have occurred at positions $1 \mathrm{~m}$ from the canister emplacement burehules.

- $75 \%$ of the horizontal and $60 \%$ of the vertical closure would have occurred in the canister drift.

- All stress changes and displacements would be very small; a few MPa and a few tenths of $\mathrm{mm}$, respectively.

Although the total stress changes and displacements were seen to be small after 6 months of cooling, the rates were also small. Because very long cooling times would be required to obtain easily measureable effects, we retained the planned 6-month cooling period that we had originally adopted on the basis of the thermal calculations.

\subsubsection{Post-Test Thermomechanical Calculations}

After all test data were acquired and the SFT $-\mathrm{C}$ was completed, a final series of thermomechanical calculations was performed using the best available material properties, test conditions, and energy deposition and removal rates (Butkovich and Patrick, 1985). The structural analysis portion of the calculation was driven with nodal point thermal histories that closely approximated the multipoint temperature measurements. The mesh used was identical to the one used for the as-built and post-test calculations discussed above.

Comparison of measured temperatures with ADINAT-calculated nodal-point temperatures revealed that they differed by as much as $5^{\circ} \mathrm{C}$ (Patrick et al., 1982). When further attempts to improve the level of agreement were unsuccessful, we used a different approach. Because the purpose of the ADINAT calculation was to produce the correct temperature change with which the thermomechanical calculation would be driven, we arbitrarily varied the convection coefficient (which controls the rate of heat remuval by the ventilation airstream) until we obtained good agreement between measured and calculated temperatures. 


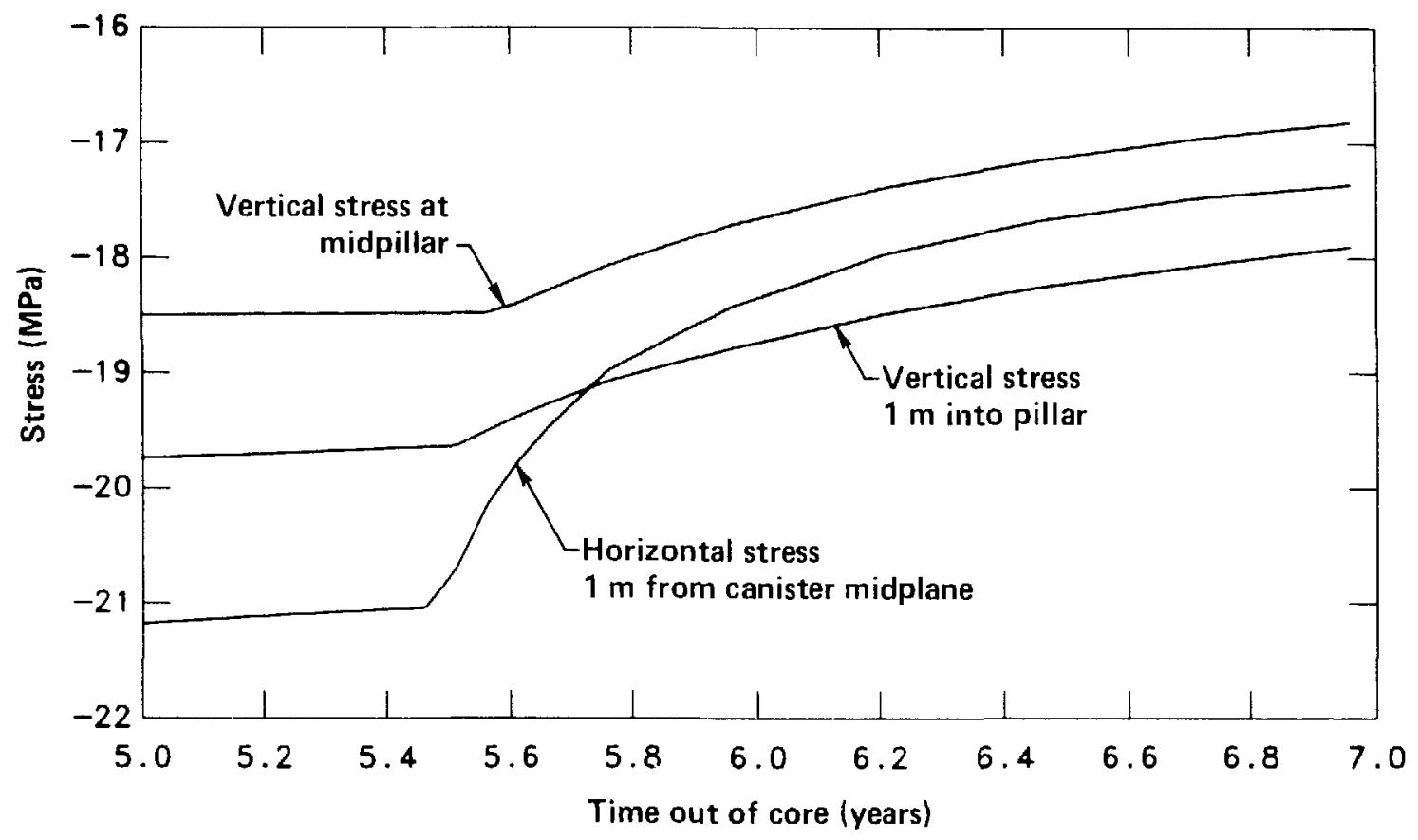

Figure 3-22. Stress changes resulting from fuel retrieval at selected locations (after Ballou et al., 1982).

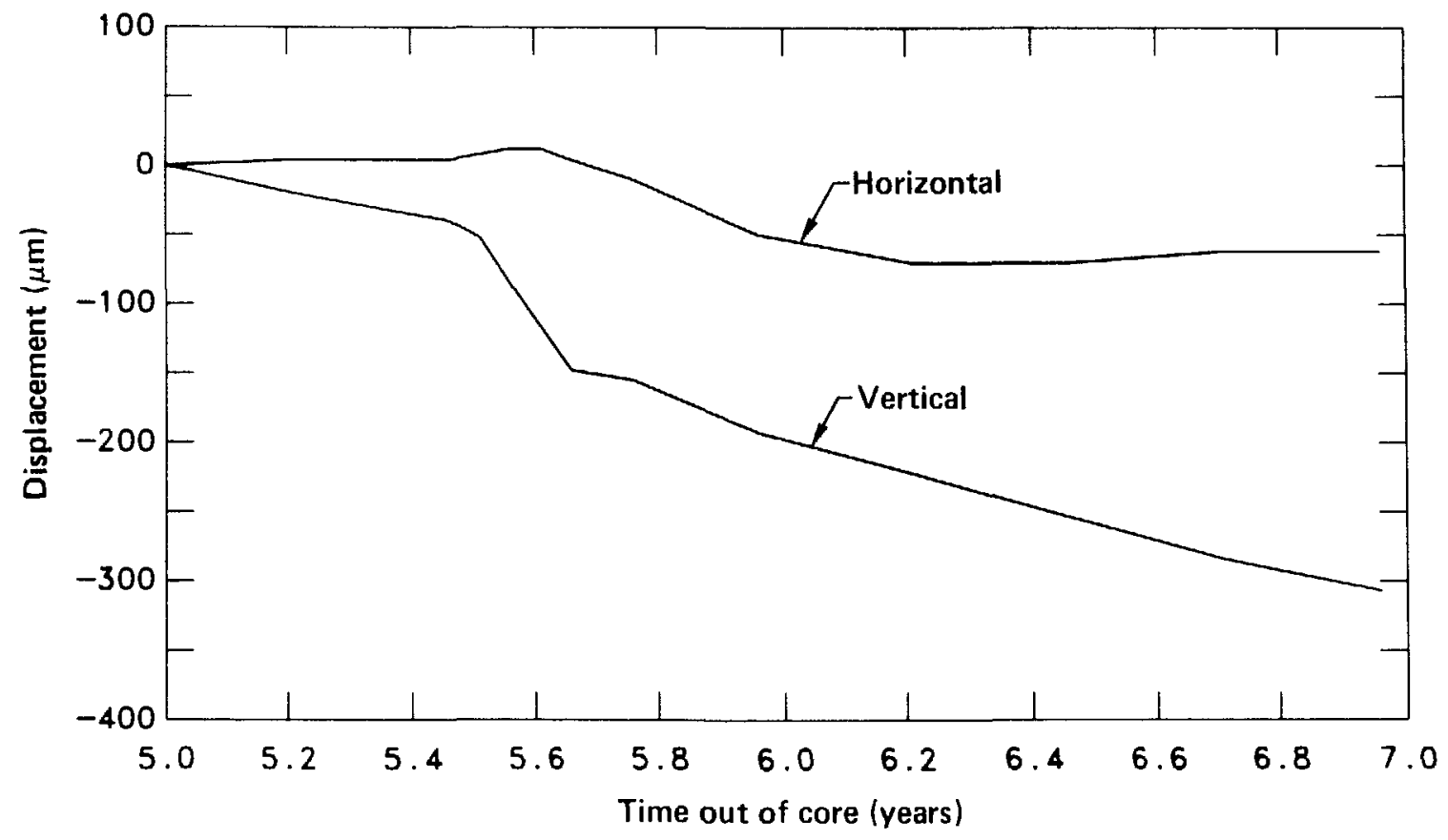

Figure 3-23. Displacements across canister drift due to fuel retrieval (plus values of displacement denote closure) (after Ballou, et al., 1982). 
As indicated in Fig. 3-24, agreement between measured and calculated temperatures was very good. After 0.5 year of heating, the least squares slope through a cross-plot of measured vs calculated temperature rises is near unity and $R^{2}=0.98$. Furthermore, the mean square error ( $R M$ ) of $0.81^{\circ} \mathrm{C}$ is less than the ISA special limits of error for the thermocouples $(1.1 \mathrm{C})$. We consider this exceptionally good agreement, considering that the positions of the thermocouples were not coincident with nodal points in the finiteelement mesh used to calculate temperatures.

Three sets of mesh loadings and deformation moduli were used in the post-test calculations (Table 3-8). These were selected from in situ stress measurements by Ellis and Magner (1982) and Creveling et al. (1984) and in situ modulus measurements by Heuze et al. (1981) and Patrick, Yow, and Axelrod (1985) to represent our best estimate of these parameters and estimates chosen to represent extreme conditions on either side of this estimate.

Several comparisons were made between measured and calculated stresses and displacements. These comparisions, which considered the accuracies of the instruments used to obtain the measurements, led to the conclusion that Calculation 2 provided the best agreement with the data. It forms the basis of the comparisions and discussions provided in Chapter 16

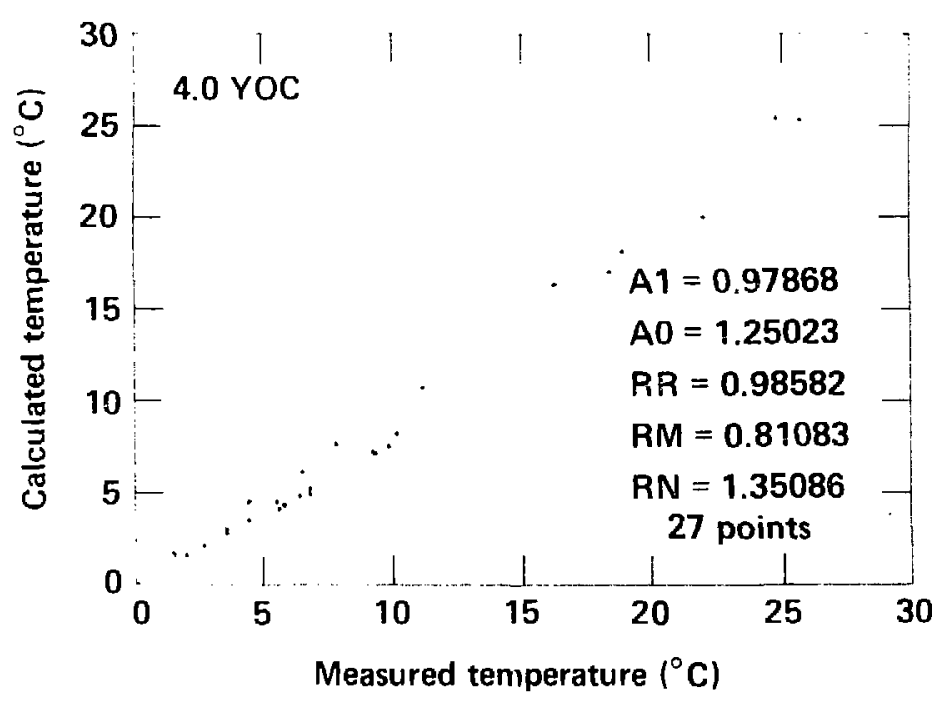

Figure 3-24. Comparison of measured and calculated temperatures (after Butkovich and Patrick, 1985).

Table 3-8. Elastic properties and mesh loadings used for three thermomechanical calculations (after Butkovich and Patrick, 1985).

\begin{tabular}{lcccc}
\hline \multicolumn{1}{c}{ Property of parameter } & & \multicolumn{2}{c}{ Calculation number } \\
\cline { 2 - 4 } \multicolumn{1}{c}{ Rock mass modulus (GPa) } & 1 & 38 & 38 \\
Rock mass Poisson's ratio & 27 & 0.25 & 3.25 \\
Damaged zone modulus (GPa) & 0.25 & 19 & 19 \\
Damaged zone Poisson's ratio & 13 & 0.35 & 0.35 \\
Vertical mesh loading' (MPa) & 0.35 & 6.21 & 12.60 \\
Horizontal-to-vertical stress ratio & 6.21 & 1.2 & 0.98 \\
\hline
\end{tabular}

a Vertical mesh loading based on in sifu stresses measurãu st mid-rib. A value of $7.89 \mathrm{MPa}$ was used in calculations 1 and 2 , and a value of $14.28 \mathrm{MPa}$ was used in Calculation 3. 


\subsection{Radiation Transport Calculations}

Radiation transport calculations were conducted to assist in the design of shielding and to determine the radiation dose to the rock in the vicinity of the canister emplacement boreholes.

\subsubsection{Shielding Calculations}

Radiation shielding calculations were used to establish design dimensions for transport casks, remote handling hardware, and the spent-fuel storage geometry (Raschke et al., 1983). The two principal design assumptions were:

- Total spent-fuel burnup of 33,000 MW•d/MTU.

- Age of spent fuel 2 years out of reactor core.

We established the design goal that dose rates be less than $100 \mathrm{mrem} / \mathrm{h}$ at contact with the transport casks and less than $0.5 \mathrm{mrem} / \mathrm{h}$ at the canister drift floor.

The required gamma ray shielding was calculated using the isotopic abundances, the gamma energy spectra, and the assumptions. Since neutron attenuation factors are less well known, shielding requirements were determined experimentally from the attenuation of ${ }^{252} \mathrm{Cf}$ fission neutrons by iron.

A $330-\mathrm{mm}$-thick (13-in.) shield was determined to satisfy the design goal of $100 \mathrm{mrem} / \mathrm{h}$ at the surface of the transport casks of both the surface transport vehicle and underground transfer vehicle (Chapter 7). A $305 \mathrm{~mm}$ (12-in.) thick shield plug was determined to provide sufficient primary shielding in the storage configuration and additional concrete shielding lowered the radiation dose rate to background levels in the canister storage drift.

Table 3-9 indicates the level of agreement between measured and calculated radiation doses reported by Raschke et al. (1983). The authors attributed the observed differences to:

1. The spent-fuel assemblies actually used were 2.45 rather than 2.0 years out of core.

2. The spent-fuel assemblies actually used had burnups of 28,000 rather than $33,000 \mathrm{MW} \cdot \mathrm{d} / \mathrm{MTU}$.

3 . The shielding calculations were based on higher than actual source dose rates.

4. Careful machining of parts reduced radiation streaming pathways.

Because each of these differences would decrease the calculated dose rates, they would also decrease the observed differences between calculated and measured values.

\subsubsection{Radiation Dose Around Emplacement Holes}

Because one of the objectives of the SFT $-C$ was to evaluate the effects of radiation on the granite, it was necessary to calculate the dose to the rock surrounding the canister emplacement boreholes. Wilcox and Van Konynenburg (1981) used the MOKSE-L Monte Carlo code to determine dose rates and cumulative doses in the materials surrounding the spent-fuel assemblies. These calculations, together with in situ measurements and spent-fuel characterization studies, were used to establish the dose rates and doses discussed in Chapter 15.

Characteristics of Spent Fuel. The Turkey Point Unit $\# 3$ spent-fuel assemblies modelled in the radiation transport calculations had the characteristics described in Chapter 6. Wilcox and Van Konynenburg (1981) cited the four most significant gamma-emitting nuclide pairs shown in Table 3-10, which were included in the calculations with gamma-ray yields from Lederer and Shirley, 1978 (Table 3-11). Using the

Table 3-9. Total (gamma and neutron) radiation dose rate calculations and measurements at selected locations (after Raschke et al., 1983).

\begin{tabular}{|c|c|c|}
\hline \multirow[b]{2}{*}{ Location } & \multicolumn{2}{|c|}{ Radiation dose rates } \\
\hline & $\begin{array}{l}\text { Calculated } \\
\text { (mrem/h) }\end{array}$ & $\begin{array}{l}\text { Measured } \\
\text { (mrem/h) }\end{array}$ \\
\hline Surface of transfer casks & 105 & 90 \\
\hline Canister shield plug & 36 & 5 \\
\hline Thermocouple tubes and shield plug interfaces & 152 & Not measured \\
\hline Canister drift floor above shield plug & 0.5 & $<0.1$ \\
\hline [ruc:: cab of surface transfer vehicle & 3 & $<1$ \\
\hline
\end{tabular}


Table 3-10. Significant gamma emitters in the spent-fuel assemblies (after Wilcox and Van Konynenburg, 1981).

\begin{tabular}{lccc}
\hline Nuclide & $\begin{array}{c}\text { Concentration } \\
\text { at } 740 \text { days (gram-atoms) }\end{array}$ & Half-life & $\begin{array}{c}\text { Activity } \\
\text { at 2.45 yoc (Ci) }\end{array}$ \\
\hline${ }^{106} \mathrm{Ru}-{ }^{10 n} \mathrm{Rh}$ & 0.1575 & $366.5 \mathrm{~d}$ & $4.18 \times 10^{4}$ \\
${ }^{134} \mathrm{Cs}$ & 0.1595 & $2.062 \mathrm{y}$ & $2.40 \times 10^{4}$ \\
${ }^{137} \mathrm{Cs}-{ }^{13} \mathrm{Ba}$ & 3.202 & $30.17 \mathrm{y}$ & $3.76 \times 10^{4}$ \\
${ }^{1+4} \mathrm{Ce}-{ }^{154} \mathrm{Pr}$ & 0.1516 & $284.5 \mathrm{~d}$ & $4.77 \times 10^{+}$ \\
\hline
\end{tabular}

Table 3-11. Gamma ray yields of the significant gamma emitters in the spent-fuel assemblies (after Wilcox and Van Konynenburg, 1981).

\begin{tabular}{|c|c|c|}
\hline Nuclide & Energy $(\mathrm{meV})$ & Gammas disintegration \\
\hline \multirow[t]{7}{*}{ 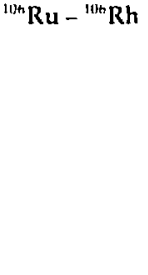 } & 0.5118 & 0.19 \\
\hline & 0.6163 & 0.0082 \\
\hline & 0.6221 & 0.098 \\
\hline & 0.8738 & 0.0045 \\
\hline & 1.0507 & 0.016 \\
\hline & 1.128 & 0.0042 \\
\hline & 1.562 & 0.0017 \\
\hline \multirow[t]{10}{*}{${ }^{1.94} \mathrm{Cs}$} & 0.4753 & 0.01465 \\
\hline & 0.5632 & 0.0838 \\
\hline & 0.5693 & 0.1543 \\
\hline & 0.6047 & 0.9756 \\
\hline & 0.7958 & 0.8544 \\
\hline & 0.8019 & 0.0873 \\
\hline & 1.0386 & 0.0100 \\
\hline & 1.1679 & 0.01805 \\
\hline & 1.3651 & 0.0304 \\
\hline & 1.4005 & 0.0008 \\
\hline${ }^{137} \mathrm{C} s-{ }^{137} \mathrm{Ba}$ & 0.6616 & 0.850 \\
\hline \multirow[t]{5}{*}{${ }^{14+4} \mathrm{Ce}-{ }^{14+} \mathrm{Pr}$} & 0.0801 & 0.0113 \\
\hline & 0.1335 & 0.111 \\
\hline & 0.6965 & 0.0133 \\
\hline & 1.4891 & 0.0029 \\
\hline & 2.1856 & 0.0075 \\
\hline
\end{tabular}

results of ${ }^{137} \mathrm{Cs}$ gamma scans performed by Davis (1980), the axial source strength distribution was estimated (Fig. 3-25). Since the neutron dose contribution was known to be small relative to the gamma dose, no attempt was made to accurately estimate the neutron source strength.

Calculational Geometry. The actual spent-fuel emplacement geometry was approximated for purposes of the calculation (Fig. 3-26). The exact geometry of the upper shield plug was simplified, the hemispherical bottom of the canister was treated as flat, and the helium fill gas was considered a vacuum. Because water could possibly enter the liner borehole annulus, calculations were made for each material. Clay, a potential backfill material, was also treated as a liner borehole annular fill. 


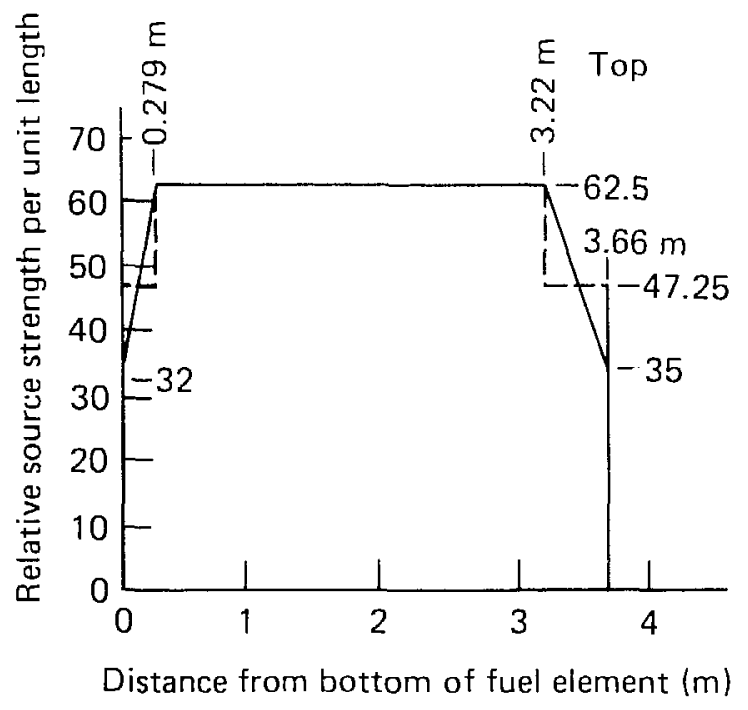

Figure 3-25. Axial gamma source distribution (dotted lines show the configuration used in the computer simulation, after Wilcox and Van Konynenburg, 1981).

Wilcox and Van Konynenburg (1981) used the Monte Carlo code because of the folluwing complicating factors:

- The uranium content of the spent fuel results in self-absorption with several scattering collisions before the average gamma ray reaches the borehole wall.

- Gamma ray transport out of the fuel is complicated by the nonuniform geometry, which causes variations in flux with angular position.

- The nonuniform geometry causes streaming out the top and botton ends of the fuel assembly.

- The transmission properties of the media vary greatly over the energy ranges of emitted gamma rays and neutrons.

- Many of the fluxes of interest are at interfaces between materials where simpler hand calculations give inaccurate results.

The MORSE-L Monte Carlo Code (Wilcox, 1972) used LLNL's L-Division gamma library (Wilcox, 1973) to track the scattering history of photons until their energies fell below $150 \mathrm{keV}$, at which energy they were assumed to be totally absorbed.

A series of gamma calculations was made for each of the four dominant nuclide pairs. The neutron component and coupled neutron-gamma problems were also solved to determine neutron dose rates and secondary gamma dose rates.

Results. The results of the MORSE-L calculations showed that the neutron dose was negligible in comparison to the gamma dose, as anticipated. Within the central $2.44 \mathrm{~m}$ of the $3.66-\mathrm{m}$-long assemblies, the dose to granite was found to be uniform within the uncertainty of the calculations.

Radiation-absorbed dose rates and total doses for the four liner/borehole/backfill options are shown in Figs. 3-27 and 3-28, respectively. These results are largely as expected: the decrease in dose rate with distance into the rock is essentially linear on a semilog plot, and the decrease in dose rate within the liner/ borehole gap is dependent on the density of the fill material.

These calculations were also used to estimate the thermal contribution of the gamma ray attenuation. Fitting the dose rate by a function of the form $\mathrm{Ae}^{-\mu \mathrm{r}} / \mathrm{r}$ and integrating over the volume of granite from the borehole outward to infinity, Wilcox and Van Konynenburg (1981) calculated a contribution of $40 \mathrm{~W}$, less than $3 \%$ of the total heat output.

In Chapter 15 the results of these calculations are compared with the actual radiation dose and dose rates measured in the field. 


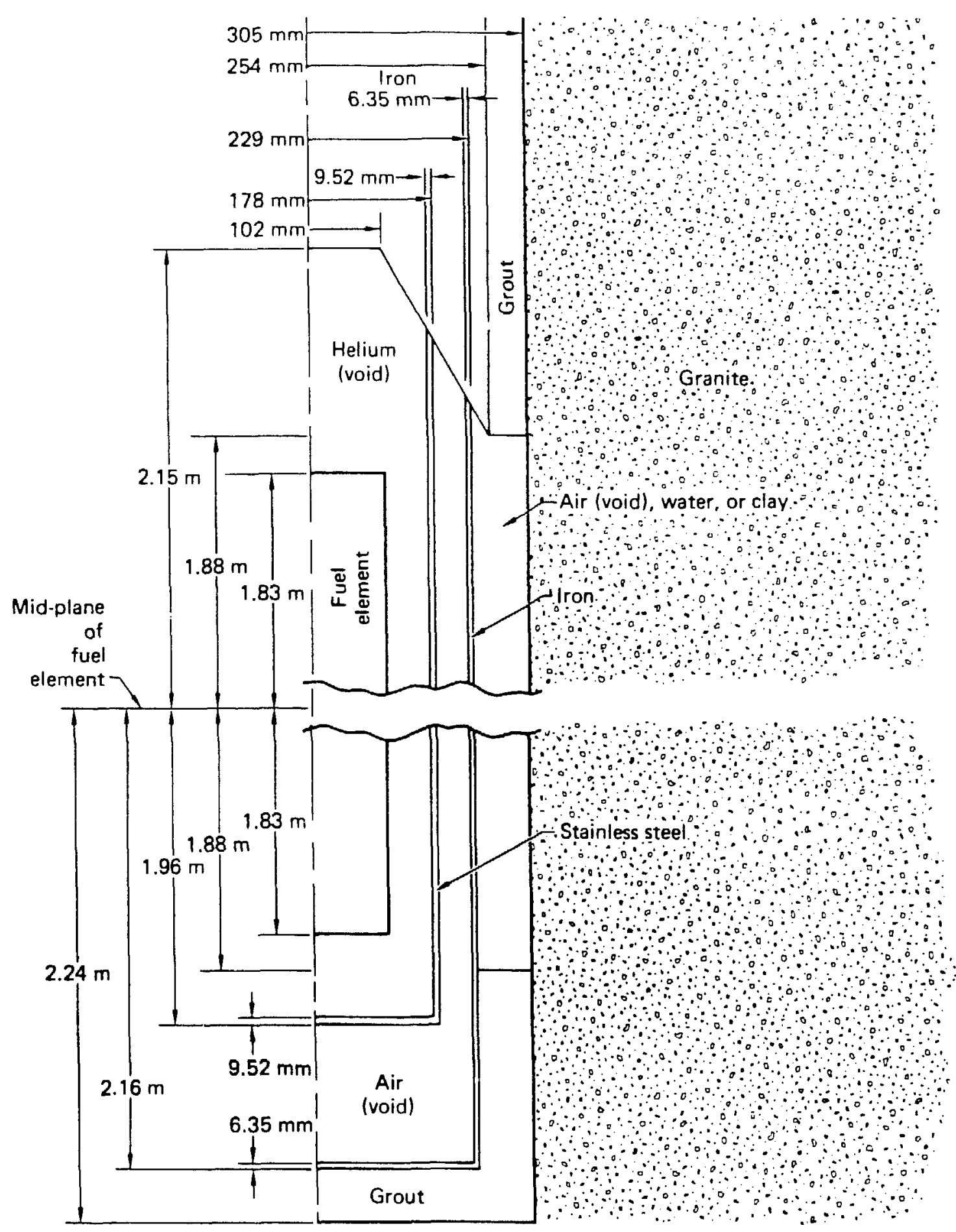

Figure 3-26. Approximate geometry of spent-fuel emplacement. Calculations assumed voids rather than air or helium in the actual case; this substitution is indicated by the "void" in parentheses in the figure (after Wilcox and Van Konynenburg, 1981). Treated as flat, and the helium fill gas was considered a vacuum. Because there was a possibility of water entering the liner borehole annulus, calculations were made for each material. Clay, a potential backfill material, was also treated as a liner/borehole annular fill. 


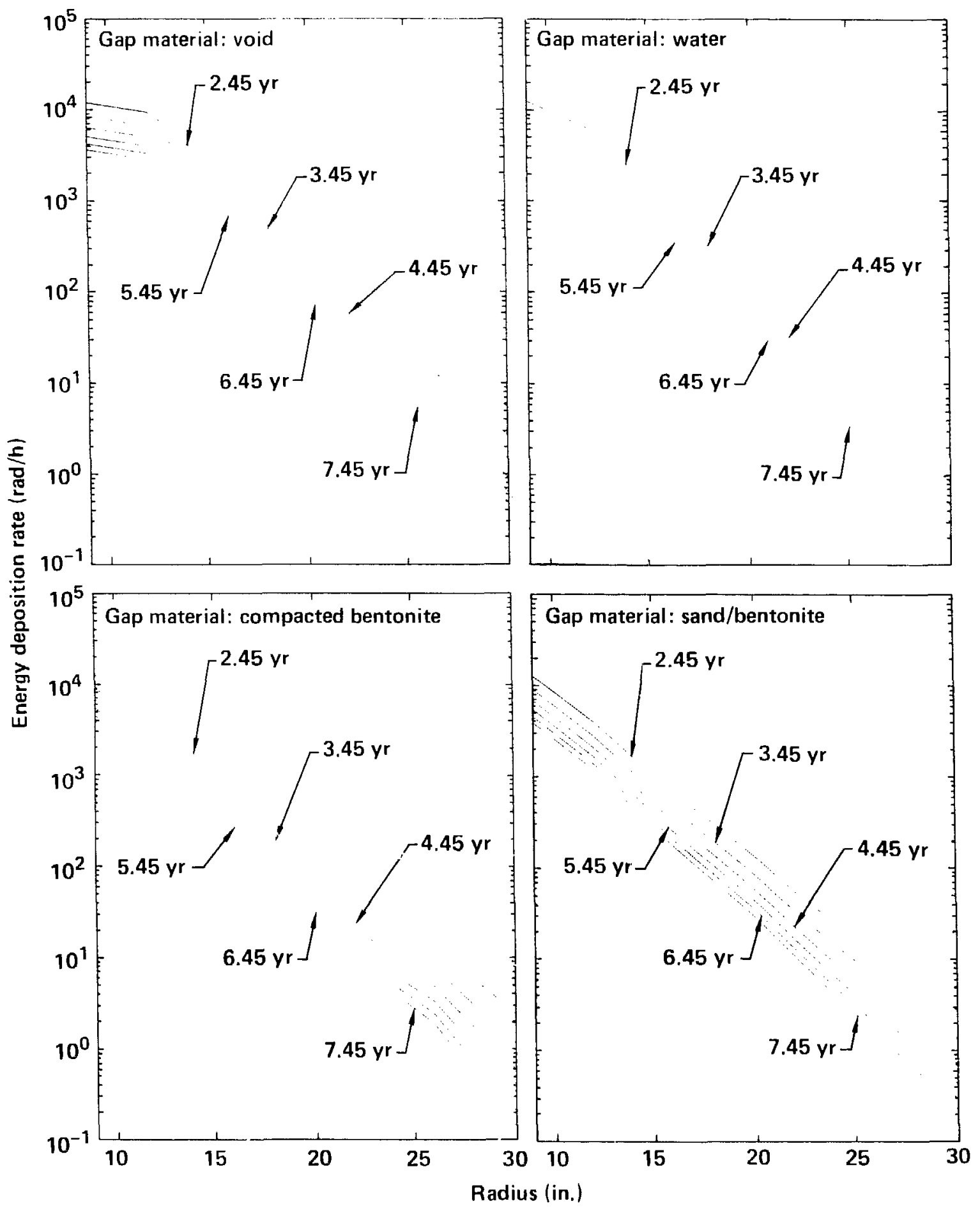

Figure 3-27. The absorbed dose rate ( $\mathrm{rad} / \mathrm{h}$ to granite) outside the iron liner as a function of radius from the center !ine of the fuel assembly. The values plotted are averages over the central $2.44 \mathrm{~m}(8 \mathrm{ft})$ of the fuel asseinbly. The gap between the liner and the granite was assumed to be VOID, or filled with WATER or COM?ACTED BENTONITE or a SAND/BENTONITE mixture, as shown in the legends of the plots. The parameter is time elapsed since discharge of fuel from reactor (after Wilcox and Van Konynenburg, 1981). 


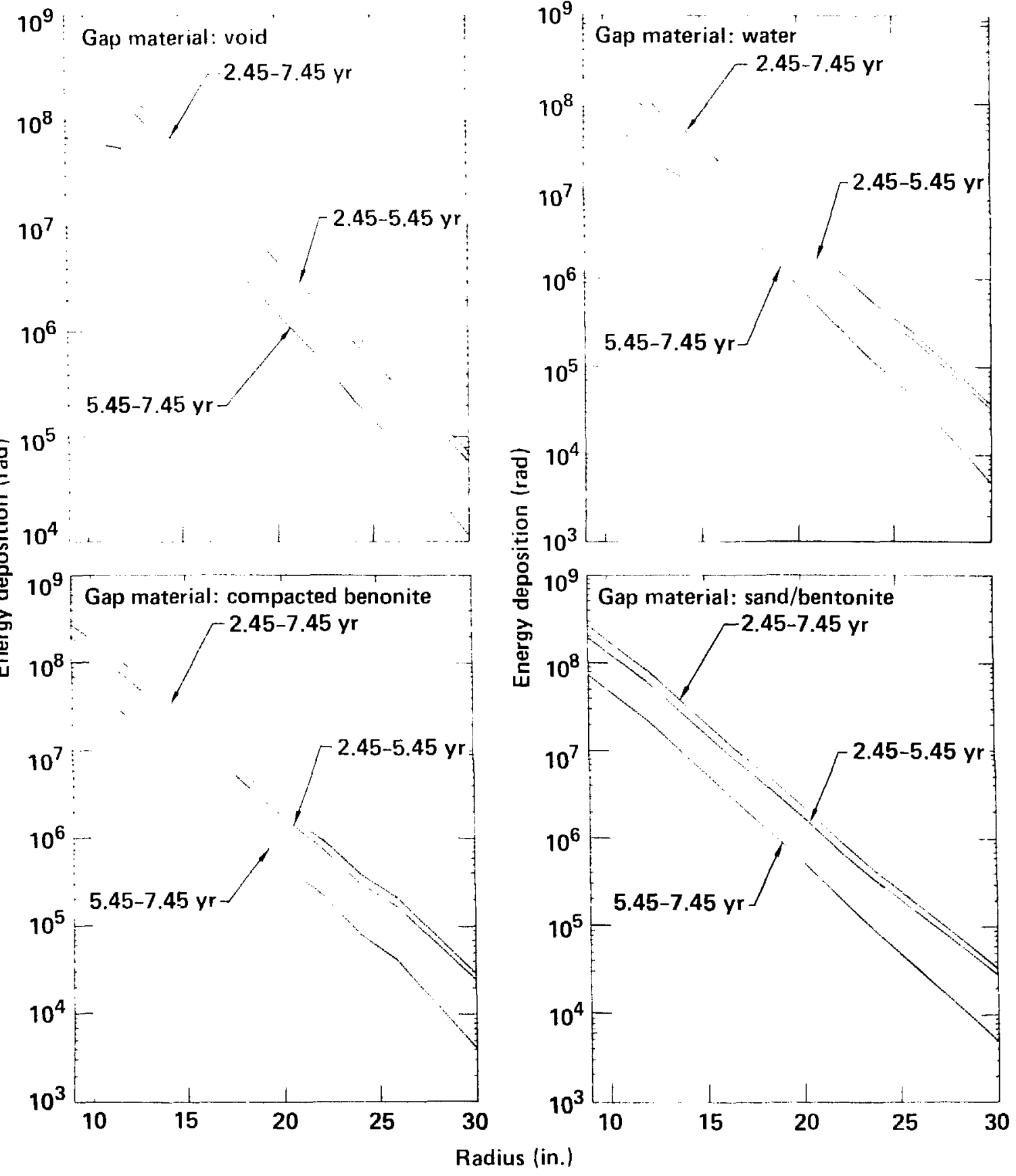

Figure 3-28. The absorbed dose rate ( $\mathrm{rad} / \mathrm{h}$ to granite) outside the iron liner as a function of radius from the center line of the fuel assembly. The values plotted are averages over the central $2.44 \mathrm{~m}(8 \mathrm{ft})$ of the fuel assembly. The gap between the liner and the granite was assumed to be VOID, or filled with WATER or COMPACTED BENTONITE or a SAND/BENTONITE mixture, as shown in the legends of the plots. The parameter is time period after discharge of fuel from reactor (after Wilcox and Van Konynenburg, 1981). 


\section{Site Characterization and Geologic Investigations}

Several different investigations were undertaken to determine the pertinent mechanical, thermal, thermomechanical, and hydrologicai properties of the Climax Stock Quartz Monzonite (CSQM) in which the SFT $-C$ was conducted. We also measured in situ stresses and studied the thermal and radiological effects on selected material properiies and on the mineralogy and petrology of the CSQM.

\subsection{Structural Geology*}

Many reports have been written on the structural geology of the Climax stock. Although studies by Maldonado (1977), Allingham and Zietz (1962), Barnes and Poole (1968), and Houser and Poole (1960) predate the SFY -C, the works of Connolly (1982), Thorpe (1984), Wilder and Yow (1981), Wilder, Yow, and Thorpe (1982), and Yow and Wilder (1983) were done in direct support of the test. Most of these investigations have been synthesized and analyzed by Wilder and Yow (1984), whose work is the basis of the summary given here.

There were three main reasons for studying the structural geology at the SFT $-\mathrm{C}$ :

- To provide data on geologic structure relevant to facility design and safety considerations.

- To help select the types and lccations of rock-response instrumentation.

- To identify and characterize geological features for incorporation in rock-response models.

\subsubsection{Characterization Techniques}

The previously cited literature gave us an initial understanding of the structural geology of the CSQM. Exploratory drilling conducted before underground excavation provided a means to assess the rock mass for large geological features that could adversely affect the stability of the facility (Fig. 4-1).

As excavation progressed, we conducted reconnaissance mapping of the ribs and roof, followed by more detailed mapping that included the drift floor. Wilder and Yow (1982) reported the details of the mapping techniques and data. Joint alteration studies were also conducted to assess the chronology of the dominant fracture sets (Connolly, 1981).

We conducted reconnaissance mapping on the strface to determine the continuity of geological structure with depth, and to attempt to identify surface expressions of faults observed underground. These studies relied upon surface outcroppings, six trenches across the Boundary fault, and a nearby borrow pit as data sources.

\subsubsection{Regional Geology}

The NTS is located in the Basin and Range Province of southern Nevada, within the miogeosynclinal belt of the Cordilleran geosyncline. More than $11,300 \mathrm{~m}(37,000 \mathrm{ft})$ of marine sediments accumulated in this area during the Precambrian and Paleozoic eras (Ekren et al., 1968). The regional geology is expressed as complexly folded and faulted Paleozoic sedimentary rocks overlain by Tertiary tuffs and lavas. Valleys are typically filled with Tertiary and Quaternary alluviums.

These rocks and related tault structures identified by Barnes and Poole (1968) are shown in Fig. 4-2. Also shown is the Climax stock, one of three plutons formed during the Mesozoic era. Malcionado (1981) considers the Climax and Twin K. Jge stocks to be diapiric extensions of the same deep-seated crystalline body.

Following an episode of post-intrusion erosion, Tertiary volcanic activity deposited several hund -eds of meters of rhyolitic ash-flow and ash-fall tuffs as well as some rhyolite lavas and basalts on the NTS area. These have since eroded, exposing the Climax stock at the surface.

\subsubsection{Local Geology}

Located in the northeastern corner of the NTS, the Climax stock outcrops over an area of about $4 \mathrm{~km}^{2}$ (Fig. 4-3). Geophysical evidence indicates that the stork expands conically downward to an area of $100 \mathrm{~km}^{2}$ at several kilometers depth (Allingham and Zietz, 1962). Recent geophysical studies by Orkild (1983) have revised the details of this model but support the concept of conical expansion with depth.

\footnotetext{
*Contributed by W. C. Patrick
} 


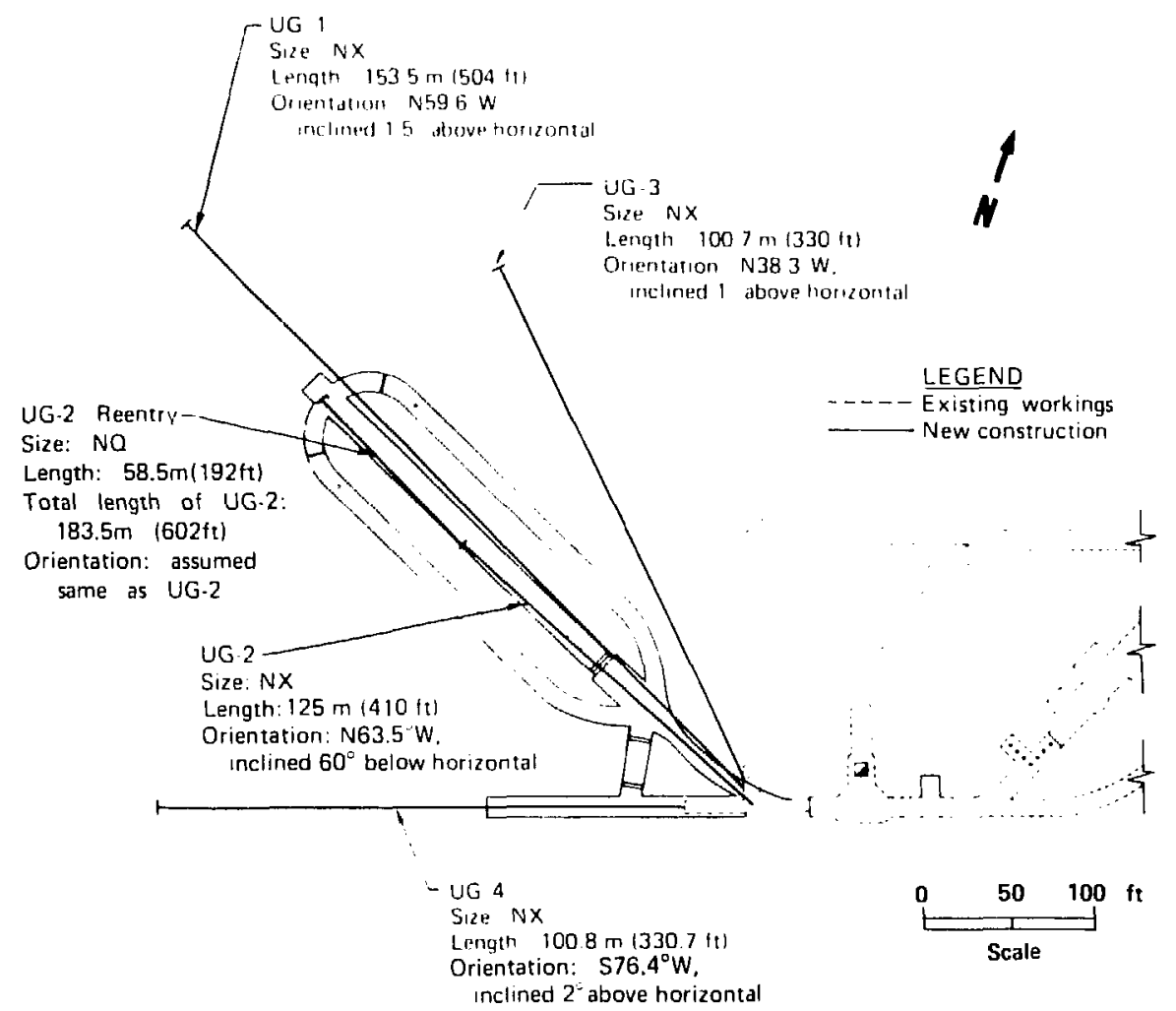

Figure 4-1. Exploratory boreholes.

The stock consists of a granodiorite unit to the north and a slightly younger quartz monzonite unit to the south and east. Houser and Poole (1961) indicate that the contact between the units is very steep or vertical. The SFT $-C$ is located completely within the quartz monzonite unit, at least $65 \mathrm{~m}$ from the contact at its nearest approach (Connolly, 1981).

The average modal analysis of the intrusives is provided in Table 4-1. Pink alkali feldspar phenocrysts up to $150 \mathrm{~mm}$ long are scattered throughout the light- to medium-gray holocrystalline porphyritic groundmass. The major mineral constituents occur as follows:

- Quartz as anhedral grains from 0.25 to $5 \mathrm{~mm}$.

- Plagioclase as euhedral to subhedral grains from 0.25 to $3.5 \mathrm{~mm}$.

- Orthoclase as anhedral grains from 0.15 to $3 \mathrm{~mm}$ and as pink euhedral phenocrysts from 10 to 150 $\mathrm{mm}$ in length.

- Biotite as subhedral grains averaging $1.5 \mathrm{~mm}$.

\subsubsection{Area Faults}

The high-angle Tippinip Fault, located just west of the stock (Fig. 4-3), has been cited by Orkild (1983) as a possible magma path during intrusion.

As its name implies, the Boundary Fault forms the contact between the stock and the valley fill alluvium to the southeast. At its northeast end it merges with the Butte Fault, and its southwest end may intersect the Tippinip Fault. The Boundary and Yucca Faults may also merge near the southeastern boundary of the stock.

Maldonado (1977), Orkild (1983), and Knauss (1981) have investigated the complex interrelationships among these faults. The reader is referred to these sources or to Wilder and Yow (1984) for a summary of their findings. 


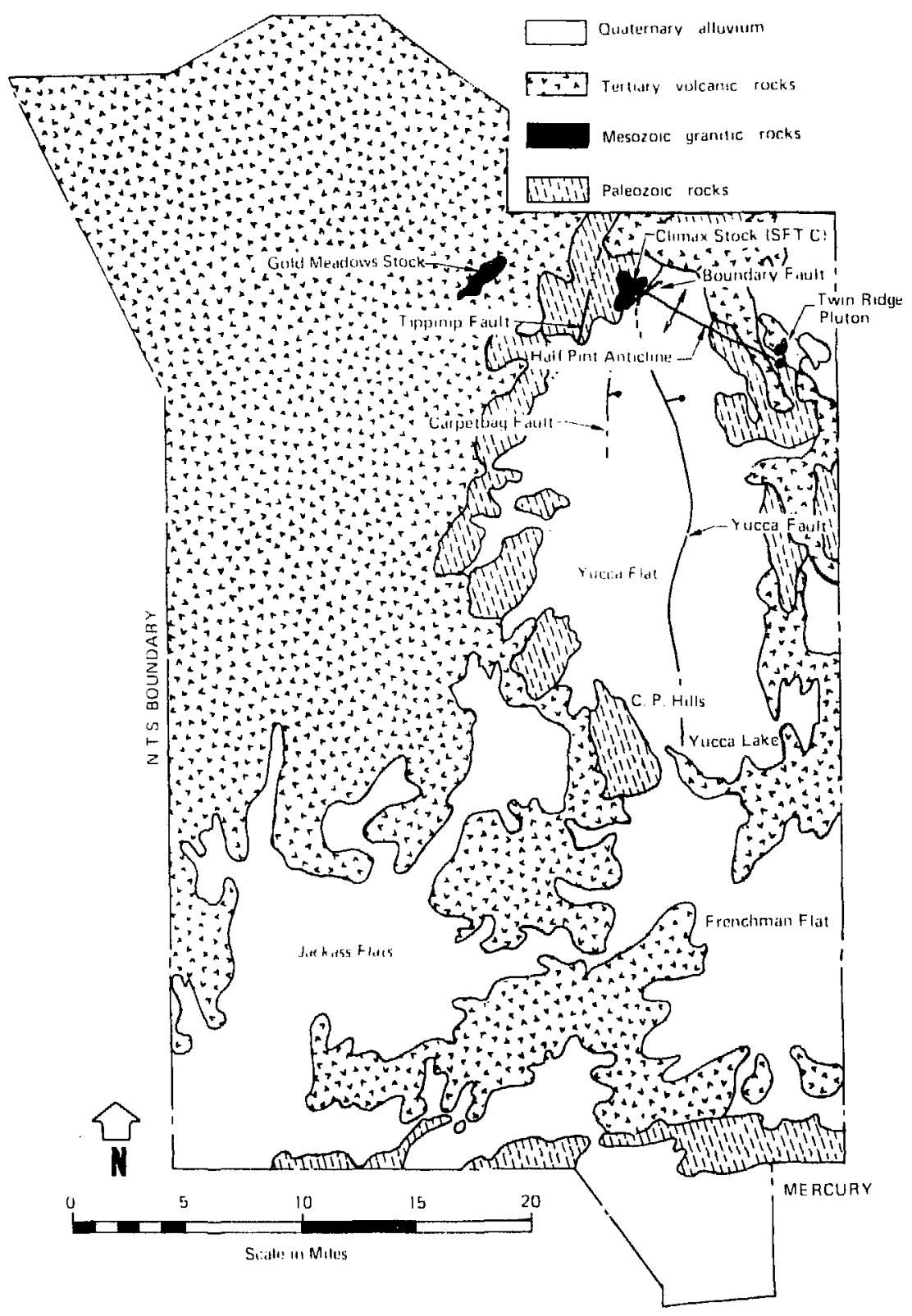

Figure 4-2. NTS geology.

\subsubsection{Subsurface Geological Features}

During underground fracture mapping for the SFT-C, eight joint sets were identified. Wilder and Yow (1984) numbered these joint sets in chronological urder of formation rather than in abundance, as is often done. Even so, they are discussed here in order of prominence because this aspect is more important to our understanding of the structural ability and response of the SFT - C. Orientation and frequency data are provided for each set in Table 4-2. An equal area lower hemisphere pole plot of the fracture data is provided in Fig. 4-4.

The mineralization and alteration characteristics of these joints are provided in Table 4-3. Pervasive wall-rock alteration and joint infilling contributed to easy identification of joint set 2 . The clay and calcite 

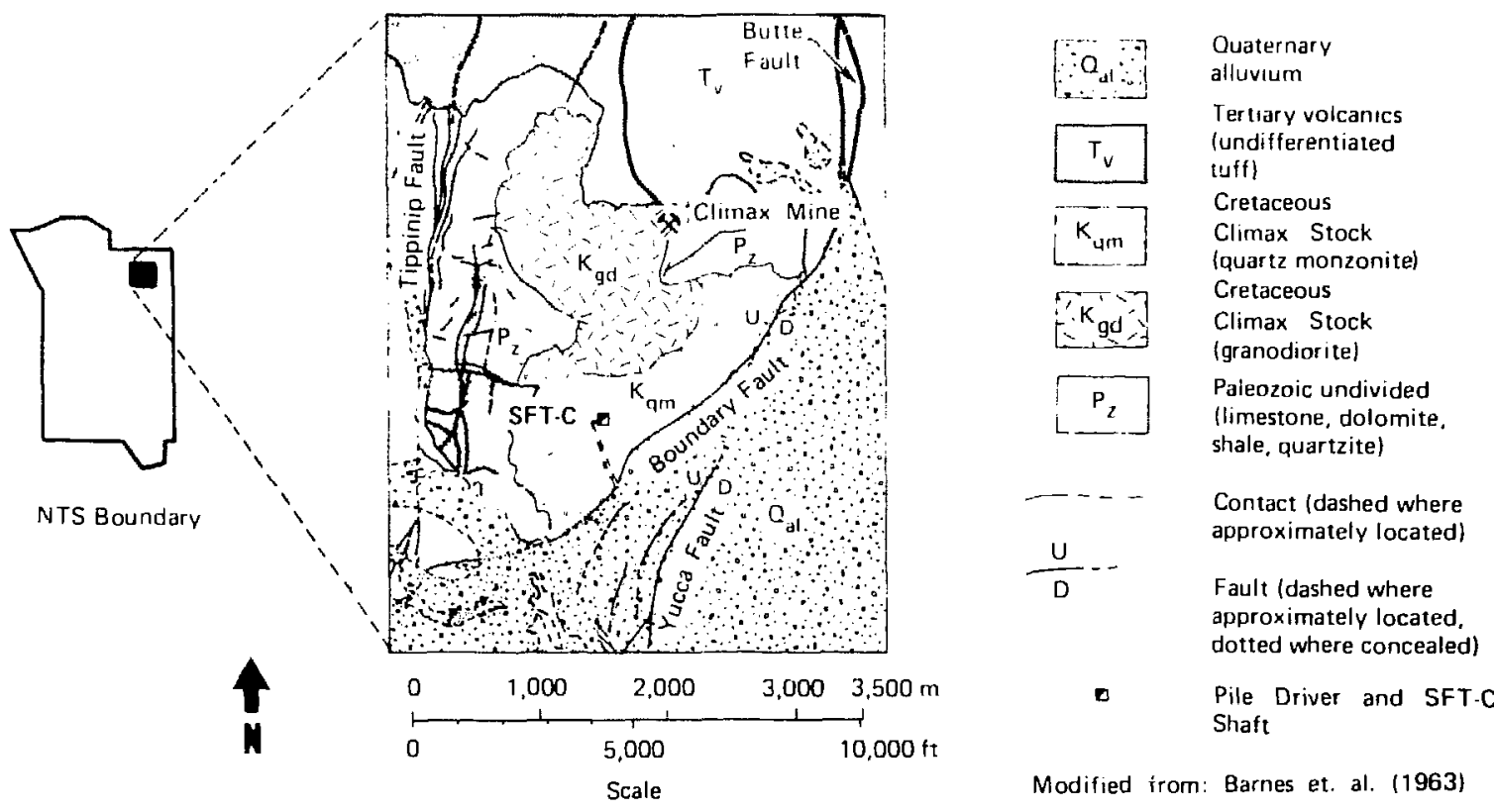

Figure 4-3. Climax geology map.

Table 4-1. Average modal analyses for rock of the Climax stock (after Houser and Poole, 1961).

\begin{tabular}{lcc}
\hline \multicolumn{1}{c}{$\begin{array}{l}\text { Essential } \\
\text { minerals }\end{array}$} & \multicolumn{2}{c}{ Volume (\%) of minerals } \\
\cline { 2 - 3 } $\begin{array}{l}\text { Quartz } \\
\begin{array}{l}\text { Potassium and/or } \\
\text { sodium feldspar }\end{array}\end{array}$ & $\begin{array}{c}\text { Quartz } \\
\text { monzonite }\end{array}$ \\
$\begin{array}{l}\text { Plagioclase } \\
\text { Biotite }\end{array}$ & 16 & 28 \\
\hline \multicolumn{2}{c}{ Accessory minerals (mainly apatite, sphene, opaque iron } \\
oxides, and zircon), which together constitute 1 to $2 \%$ of the \\
rock, are not reported here.
\end{tabular}

Table 4-2. Joint sets identified during mapping of the SFT-C (after Wilder and Yow, 1984).

\begin{tabular}{ccc}
\hline $\begin{array}{c}\text { Joint set } \\
\text { (in chronological } \\
\text { order of formation) }\end{array}$ & Orientation & $\begin{array}{c}\text { Frequency of occurrence } \\
\text { (as percent of total } \\
\text { number of joints) }\end{array}$ \\
\hline 1 & N59 ${ }^{\circ} \mathrm{E}-39^{\circ} \mathrm{NW}$ & 0.4 \\
2 & $\mathrm{~N} 44^{\circ} \mathrm{W}-20^{\circ} \mathrm{NE}$ & 23 \\
3 & $\mathrm{~N} 2^{\circ} \mathrm{W}$-vertical & 2 \\
4 & $\mathrm{~N} 24^{\circ} \mathrm{W}$-vertical & 23 \\
5 & $\mathrm{~N} 59^{\circ} \mathrm{W}$-vertical & 35 \\
6 & $\mathrm{~N} 82^{\circ} \mathrm{W}$-vertical & 5 \\
7 & $\mathrm{~N}^{\circ} \mathrm{E}-80^{\circ} \mathrm{SE}$ & 8 \\
8 & $\mathrm{~N}^{\circ} 3^{\circ} \mathrm{E}-78^{\circ} \mathrm{SE}$ & 4 \\
\hline
\end{tabular}

infillings were treated by Wilder and Yow (1984) as indicators that the joints were open to groundwater flow, at least in the geologic past.

In addition to these joints, three sets of shears were identified, oriented $\mathrm{N} 40^{\circ} \mathrm{W}-85^{\circ} \mathrm{NE}, \mathrm{N} 55^{\circ} \mathrm{E}-80^{\circ} \mathrm{SE}$, and $\mathrm{N} 53^{\circ} \mathrm{W}-85^{\circ} \mathrm{NE}$ (Fig. 4-5). A fault zone extending from the receiving room nearly $20 \mathrm{~m}$ down the drifts is also noted in Fig. 4-5. Initially identified as a single feature in the north heater drift where it is a 2- to 3-mthick (6- to 10-ft) fracture zone with a 0.3- to 0.4-m-thick (12- to 16-in.) clay-gouge-filled zone, it was later related to other fault traces. Although these latter traces appear to be minor where exposed, the variable character of the Receiving Room fault suggests that this appearance may be deceptive. This conclusion is based on exploratory borehole UG-1 (Fig. 4-1), which perforated the Receiving Room fault but did not detect the significance of the feature as expressed in the north heater drift.

Core Logging Data Analysis. Wilder and Yow (1984) used several methods of presenting and analyzing the fracture data obtained from core logs. One of the more informative presentations is a histogram of fracture spacings. Figure 4-6 displays histograms for the four exploratory boreholes and a "composite" 
Table 4-3. Mineralization and alteration characteristics of the eight joint sets identified during the SFT-C (after Wilder and Yow, 1984)."

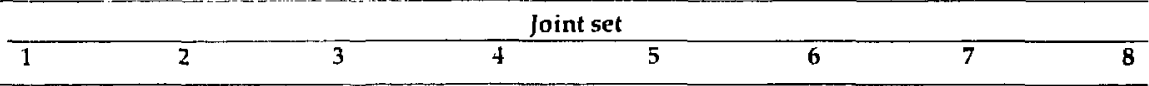

\begin{tabular}{|c|c|c|c|c|c|c|c|c|}
\hline \multicolumn{9}{|l|}{ Mineralization } \\
\hline Quartz & A & A & $\mathbf{P}$ & - & - & A & NB & NB \\
\hline Calcite & $\mathrm{P}$ & A & $P$ & $\mathbf{A}$ & A & A & $\mathbf{P}$ & - \\
\hline Chlorite & $\mathbf{P}$ & $\mathbf{P}$ & - & - & - & - & - & - \\
\hline Clay & - & $P$ & $\mathbf{P}$ & - & - & $\mathbf{P}$ & $\mathbf{A}$ & $\mathbf{P}$ \\
\hline Pyrite & A & $\mathbf{A}$ & $P$ & NB & NB & - & $P$ & $\mathbf{m}$ \\
\hline Iron staining & $P$ & $\mathbf{P}$ & $\mathbf{P}$ & - & NB & $\mathbf{p}$ & $\mathbf{P}$ & $\mathbf{P}$ \\
\hline \multicolumn{9}{|l|}{ Alteration } \\
\hline$\overline{\text { Albitization }}$ & $\mathbf{P}$ & $\mathbf{A}$ & - & - & - & $\mathbf{P}$ & $\mathbf{m}$ & - \\
\hline Bleaching & $\mathbf{A}$ & $\mathbf{A}$ & $\mathbf{P}$ & - & NB & - & $\mathbf{P}$ & 一 \\
\hline Altered feldspar & $\mathbf{A}$ & $\mathbf{A}$ & - & - & - & - & NB & NB \\
\hline Healed/filled & $\mathbf{A}$ & $\mathbf{A}$ & $\mathbf{p}$ & NB & - & - & - & NB \\
\hline Saussuritization & $\mathbf{A}$ & $\mathbf{A}$ & - & - & - & - & - & - \\
\hline Sericite & - & A & NB & - & - & - & $\mathbf{P}$ & - \\
\hline Shearing & - & $m(N B)$ & - & NB & A(NB) & $\mathbf{m}$ & NB & - \\
\hline
\end{tabular}

${ }^{2} \mathrm{~A}=$ abundant, $\mathrm{P}=$ present, $\mathrm{m}=$ minor, $\mathrm{NB}=$ in nearby fractures that are not specifically part of the set, and $-=$ not present.

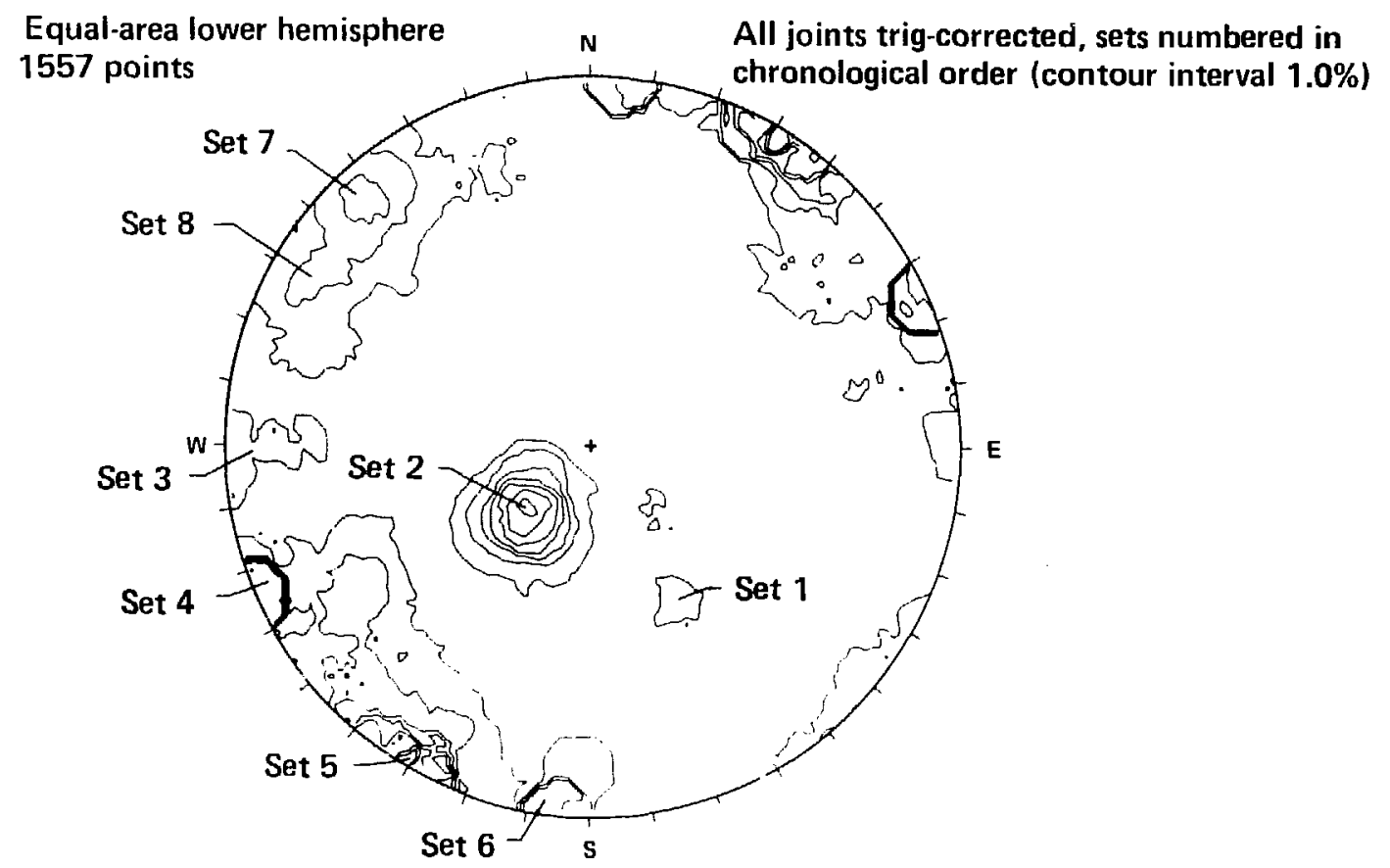

Figure 4-4. Joint sets identified during mapping of the SFT $-\mathrm{C}$ (after Wilder and Yow, 1984).

comprising four boreholes oriented vertically downward. Data for each segment of these borcholes are displayed in Table 4-4. The composite was prepared to provide a similar length of hole (and number of fractures) as was available for the exploratory boreholes. 


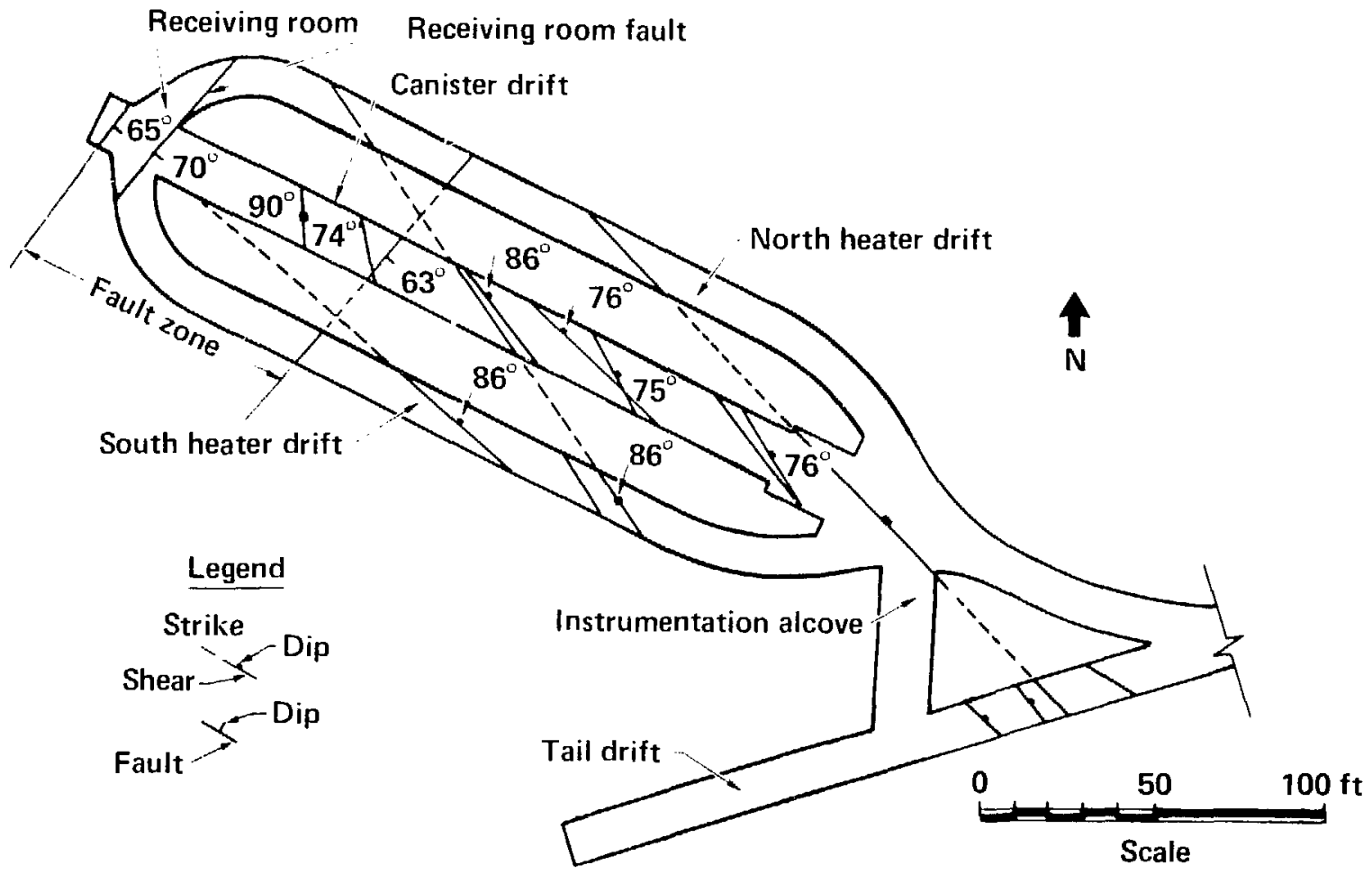

Figure 4-5. Shears and faults in the SFT-C drifts (after Wilder and Yow, 1984).

Table 4-4. Tallies of natural fractures in SFT-C exploratory holes (after Wilder and Yow, 1984).

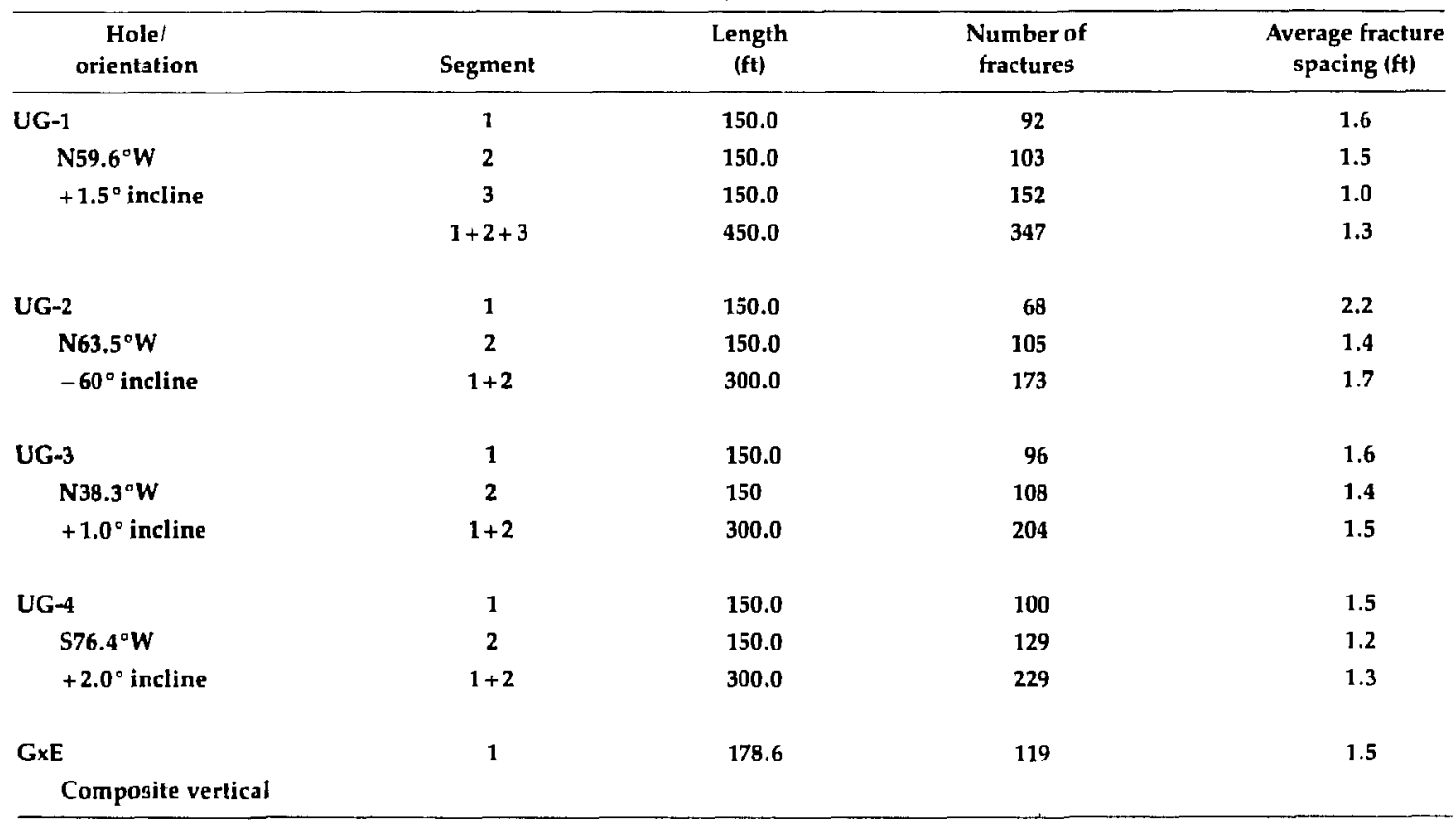


50

40 -

Borehole Ug-1

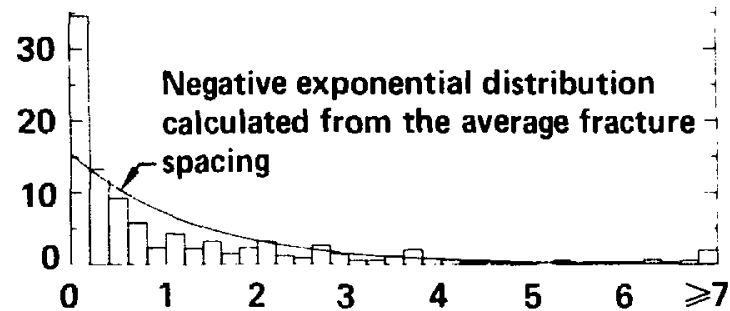

Fracture spacing (ft)

畓

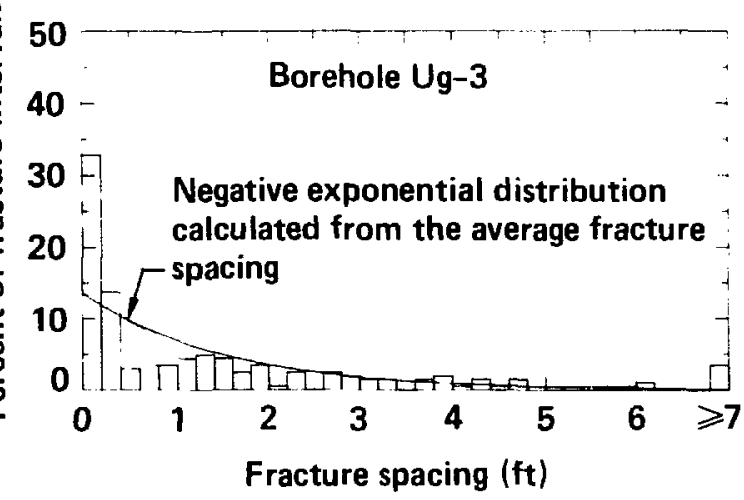

\section{Borehole Ug-4}

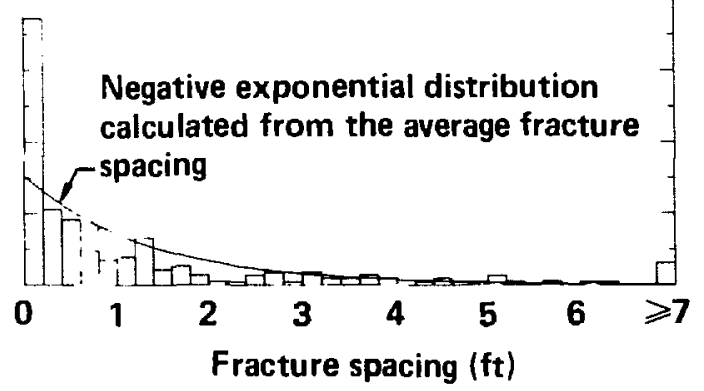

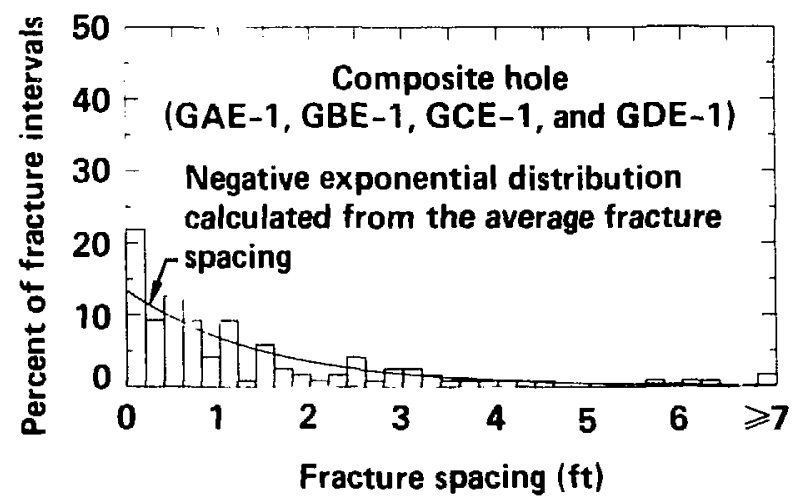

Figure 4-6. Spacing distribution of open fractures in selected boreholes (after Wilder and Yow, 1984).

Although a casual inspection of these curves indicates a reasonable fit to the data, detailed analysis revealed that this was not the case. The prominent spike at very small spacings and the absence of a monotonic decline in frequency with increasing spacing suggests that these histograms represent composites of two or more joint populations. This is consistent with our understanding of the numbers of joint sets identified in mapping. Further analyses are provided by Wilder and Yow (1984).

Mapping Data Analysis. Wilder and Yow (1984) recognized that both "blind zones" and trace length biases exist as a result of using scanline techniques to map excavation surfaces. Bias introduced by differences in fracture trace lengths has been discussed by LaPointe and Hudson (1981) but could not be treated in this study because fracture length data were typically not collected. 
Two methods were considered for treating the effects of blind zones, which, according to Goodman (1976), occur when the orientation of a geological feature is within $20^{\circ}$ of that of the mapped surface. The first method intruduces a trigonometric correction to the number of mapped fractures $N$ by dividing this number by the sine of the angle $A$ between the normal to the feature and the normal to the mapped surface. That is, $N_{k C}=N / \sin (A)$. To be correctly applied, the joint must be a member of a set; otherwise the apparent frequency of occurrence of truly random joints will increase.

A second approach is to compensate for one blind zone by adding in the results of mapping on another surface with a different blind zone. Because such mapping surfaces are typically not the same length, the respective data-set frequencies must be normalized to a common length. For such additive adjustments to be legitimate, all data sets must come from the same population.

Wilder and Yow (1984) used both techniques, with a further subdividing of all data and only data mapped on surfaces oriented $\mathrm{N} 61^{\circ} \mathrm{W}$. Because complete orientation data were not available for all of the 2578 discontinuities mapped, at most 1820 could be treated in these analyses. The frequency of occurrence of certain mineralogical characteristics of these features is provided in Table 4-5, and the numbers and spacings of joints mapped on the drift ribs are provided in Table 4-6. Detailed analyses of these data are presented by Wilder and Yow (1984). In addition, the data base was published by Yow (1984) and is available to the technical community for further analysis.

\subsubsection{Chronology of Fractures}

By studying the structural interrelationships and the petrology of alteration products, Wilder and Yow (1984) were able to postulate the history and genesis of the observed fracture sets. These studies rely heavily on the work of Connolly (1982). Based on these studies and an assumption that fracture orientations at the time of formation were normal to the least principal stress, they postulated the stress-path history depicted in Fig. 4-7.

Table 4-5. Results of different analytical approaches, showing the percentage of discontinuities with certain characteristics recorded during the SFT-C (after Wilder and Yow, 1984).

\begin{tabular}{|c|c|c|c|c|}
\hline \multirow[b]{2}{*}{$\begin{array}{l}\text { Discontinuity } \\
\text { characteristics }\end{array}$} & \multicolumn{4}{|c|}{ Discontinuities (\%) based on } \\
\hline & $\begin{array}{l}\text { All mapping } \\
\text { data }\end{array}$ & $\underset{\text { data }}{\mathrm{N} 61^{\circ} \mathrm{W} \text { mapping }}$ & $\begin{array}{c}\text { Additive } \\
\text { correction } \\
\text { of } \mathrm{N} 61^{\circ} \mathrm{W} \text { and } \\
\mathrm{N} 7^{\circ} \mathrm{E} \text { data }\end{array}$ & $\begin{array}{c}\text { Trigonomeiric } \\
\text { correction } \\
\text { of } N 61^{\circ} \mathrm{W} \\
\text { data }\end{array}$ \\
\hline \multicolumn{5}{|l|}{ Mineralogy } \\
\hline Albite alteration & 8 & 8 & 7 & 7 \\
\hline Bleaching & 5 & 4 & 3 & 3 \\
\hline Calcite & 34 & 31 & 27 & 33 \\
\hline Chlorite & 3 & 2 & 3 & 1 \\
\hline Clay & 4 & 4 & 11 & 4 \\
\hline $\begin{array}{l}\text { Feldspar (misc.) } \\
\text { alteration }\end{array}$ & 1 & 1 & 1 & 1 \\
\hline lron oxide stains & 4 & 4 & 4 & 4 \\
\hline Pyrite & 32 & 29 & 25 & 23 \\
\hline Saussuritization & 2 & 1 & 1 & 1 \\
\hline Sericite & 9 & 10 & 9 & 7 \\
\hline Quartz & 29 & 28 & 21 & 23 \\
\hline \multicolumn{5}{|l|}{ Joint characteristics } \\
\hline Healed & 5 & 3 & 3 & 3 \\
\hline Truncated & 22 & 2.4 & 19 & 22 \\
\hline Master (truncating) & 6 & 7 & 5 & 6 \\
\hline \multicolumn{5}{|l|}{ Total number of fractures } \\
\hline All joints & 1820 & 1120 & 1648 & 1557 \\
\hline Shears & 97 & 40 & 124 & 80 \\
\hline
\end{tabular}


Table 4-6. Number of joints mapped on ribs trending $\mathrm{N} 61^{\circ} \mathrm{W}$ (after Wilder and Yow, 1984). ${ }^{a}$

\begin{tabular}{cccc}
\hline Drift & Stations & $\begin{array}{c}\text { Number of } \\
\text { joints }\end{array}$ & $\begin{array}{c}\text { Joint spacing } \\
\text { (ft) }\end{array}$ \\
\hline North heater & $2+30$ to $2+81$ & 176 & 0.58 \\
& $2+81$ to $3+32$ & 111 & 0.92 \\
& $3+32$ to $3+83$ & 160 & 0.64 \\
Canister & $2+00$ to $2+50$ & 127 & 0.79 \\
& $2+50$ to $3+00$ & 61 & 1.64 \\
& $3+00$ to $3+50$ & 68 & 1.47 \\
& $3+50$ to $4+00$ & 110 & 0.91 \\
& & & \\
South heater & $2+30$ to $2+81$ & 133 & 0.77 \\
& $2+81$ to $3+32$ & 115 & 0.88 \\
& $3+32$ to $3+83$ & 121 & 0.84 \\
\hline
\end{tabular}

- Tallies were taken from both ribs in a given drift between stations listed. Therefore, mapped lengths were twice the differences between the station designators. The canister drift floor was excluded. Both healed and open joints were tallied.

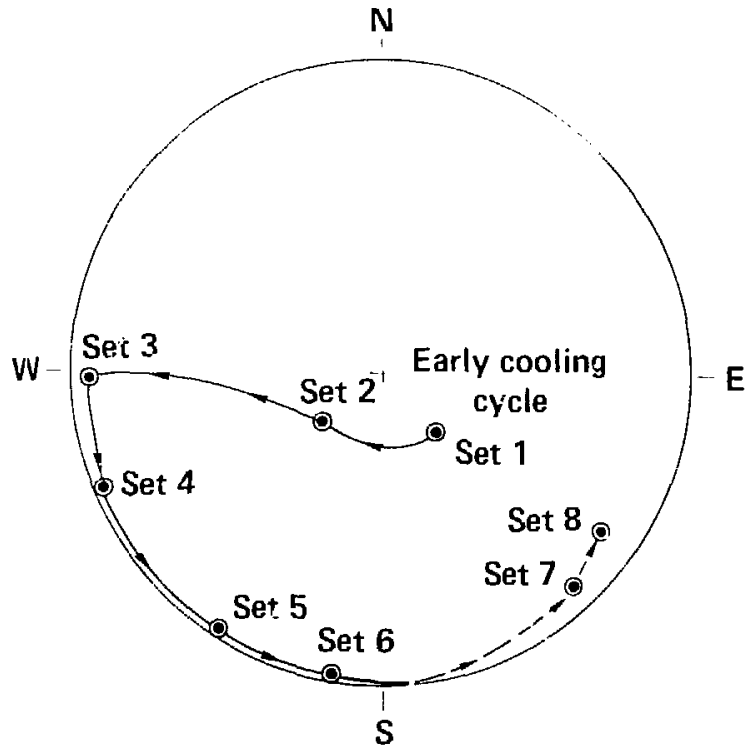

Stress path in lower hemisphere _-_- Stress path in upper hemisphere

Figure 4-7. Orientation with time of the least principal stress in the Climax stock (after Wilder and Yow, 1984).

\subsection{Geohydrology*}

Because the SFT-C was conducted above the regional water table and was planned to be of short duration, relatively few hydrological investigations were conducted. Studies were undertaken to summarize anticipated hydrological conditions and to determine the depth of the zone of total saturation beneath the test facility.

\subsubsection{Physiography}

The ground-surface elevation above the Climax stock varies from about $1500 \mathrm{~m}$ near the southern edge to about $1800 \mathrm{~m}$ to the north. Located between Yucca Flat and the Pahute and Ranier Mesas, elevations drop steeply to the southeast and rise to the north and west to over $2100 \mathrm{nl}$ (Fig. 4-2).

With an average annual rainfall of $150-200 \mathrm{~mm}$, the local climate produces vegetation common to desert environments. While rainfall in the valleys range from 80 to $150 \mathrm{~mm}$, the mesas and ridges experience up to $250 \mathrm{~mm}$ (Winograd and Thordarson, 1975).

Borg et al. (1976) concluded that precipitation may exceed evapotranspiration in the uplands during the winter periods. It is doubtful that precipitation exceeds evapotranspiration in the valleys. The typically thin overlying unconsolidated materials immediately above the stock are believed to provide opportunity for infiltration (Murray, 1981).

\subsubsection{Regional Hydrology}

Both Winograd and Thordarson (1975) and Borg et al. (1976) describe the geohydrology of the NTS where test drilling has shown at least five intermontane basins connected by groundwater movement in the deep Paleozoic carbonate strata.

Three of the 10 main geohydrolic units have major influence on the hydrology of the Climax stock. These are the lower carbonate aquifer, the lower clastic aquitard, and the upper clastic aquitard (Murray,

${ }^{\star}$ Contributed by W. C. Patrick. 
1981). Although transmissivities of the Paleozoic carbonates range from 12 to $12,090 \mathrm{~m}^{2} /$ day, the clastic rocks have transmissivities of less than $12 \mathrm{~m}^{2} /$ day.

The general directions of groundwater movement are noted in Fig. 4-8. As suggested by Borg et al. (1976), there appears to be a groundwater divide running approximately north-south between the stock and Pahute Mesa to the west.

\subsubsection{Geohydrology of the SFT-C Site}

Previous investigators had identified many zones of perched water in and around the stock, but the zone of total saturation had not been identified when site characterization began (Fig. 4-9 and Table 4-7). Although local seeps occur where water-bearing fractures intersect the underground openings, the stock is unsaturated at the $1120-\mathrm{m}$ elevation above mean sea level (MSL) of the SFT $-\mathrm{C}$ (Fig. 4-10). Previously published data and recent water level measurements in an exploratory borehole indicate that the top of the zone of saturation exists at an elevation of about $975 \mathrm{~m}$, or about $145 \mathrm{~m}$ below the test level (Murray, 1981).

To the southeast, the stock is in fault contact with Paleozoic carbonates where water levels vary from 1100 to $1200 \mathrm{~m}$ above MSL in the northeast to 800 to $900 \mathrm{~m}$ above MSL in the southwest (Fig. 4-11). Since the stock is of low permeability (except where faults and shear zones are present), the water level was inferred to be somewhat higher in the stock than in the higher permeability carbonates.

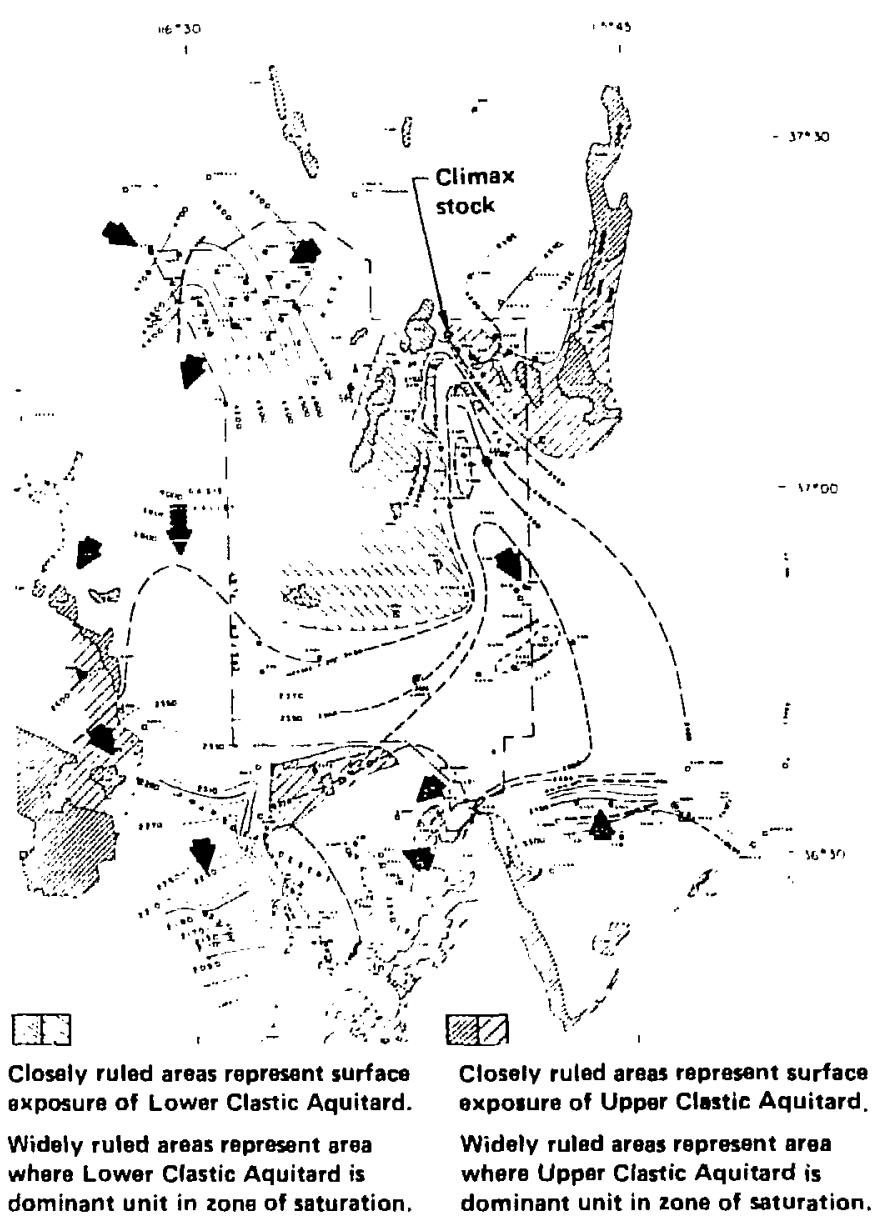

Figure 4-8. Potentiometric contours (Nevada Test Site and vicinity) are dashed where inferred and given in feet above MSL (from Winograd and Thordarson, 1975). 


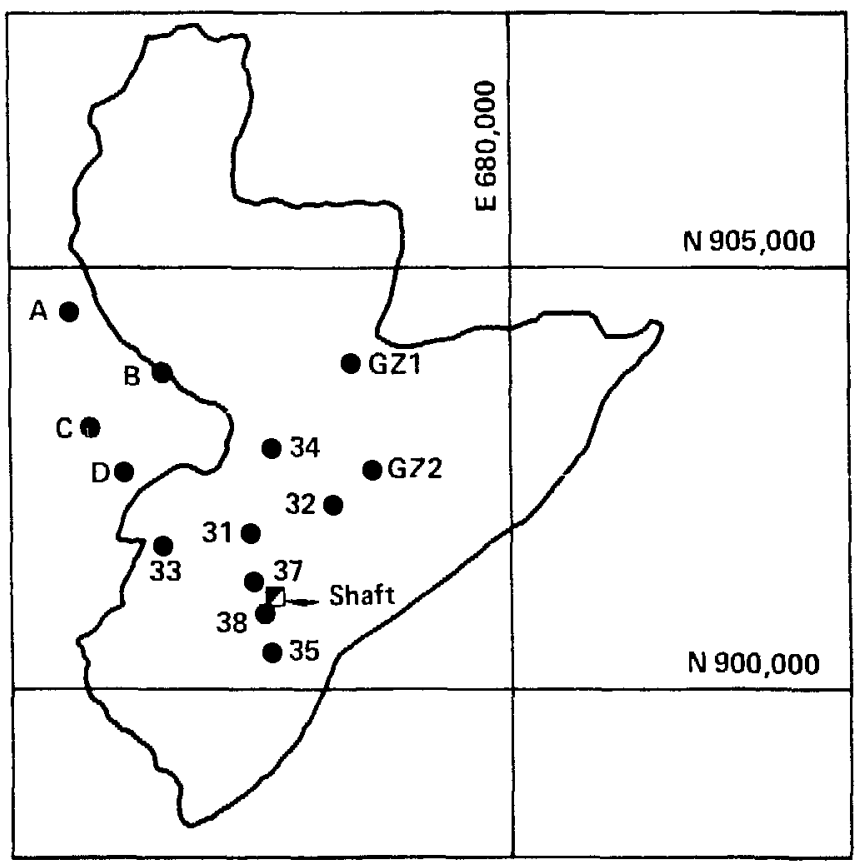

Figure 4-9. Vertical borehole locations in the Climax stock (after Murray, 1981).

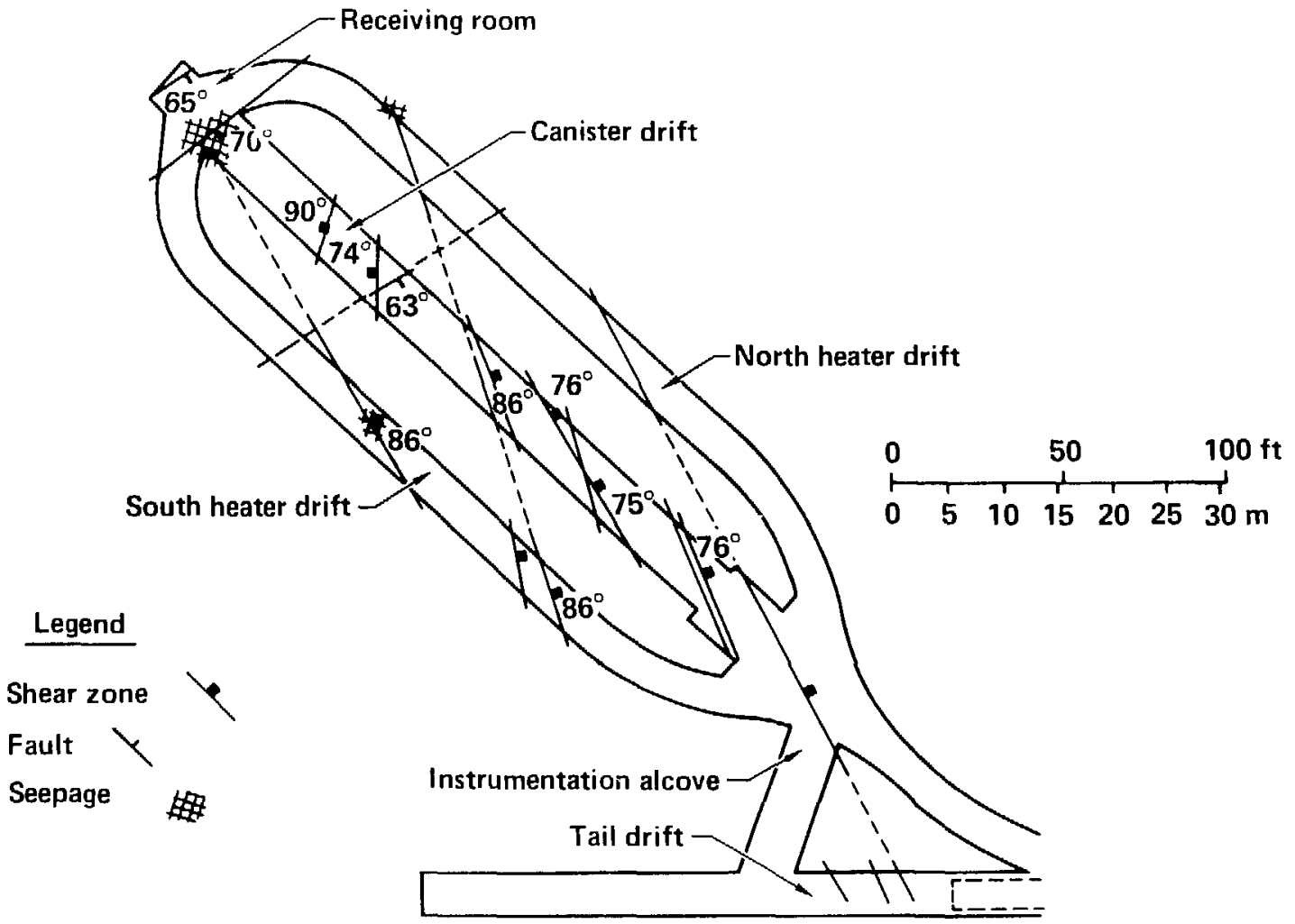

Figure 4-10. Location of seepage zones in the SFT-C (after Wilder and Patrick, 1980). 


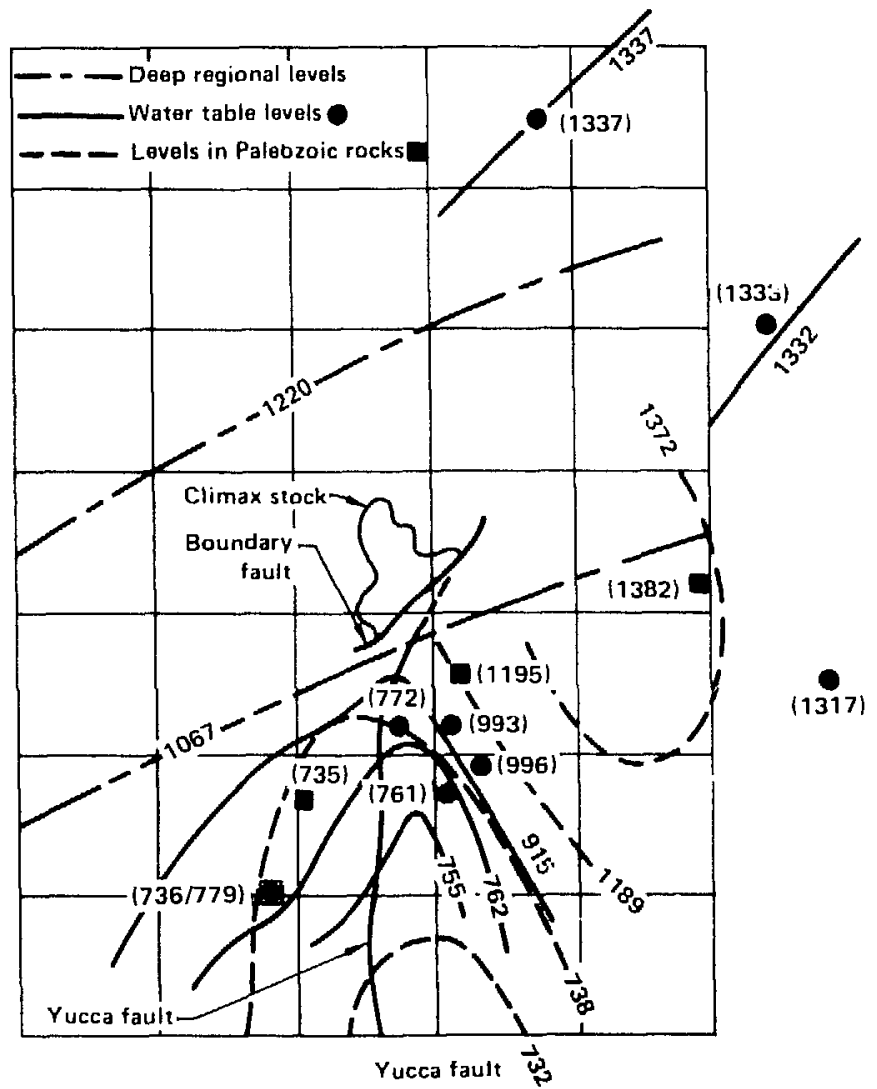

Figure 4-11. Potentiometric levels surrounding the Climax stock in metres above MSL. Numbers in parentheses indicate measured water levels. Where two numbers are separated by a slash, the first refers to the Paleozoic rocks; the second is the water table in the Cenozoic rocks (after Murray, 1981).

Table 4-7. Vertical boreholes in the Climax stock and vicinity (after Murray, 1981).

\begin{tabular}{ccccc}
\hline Borehole $^{2}$ & Ground surface elevation $^{b}(\mathrm{~m})$ & Hole depth $(\mathbf{m})$ & Water level ${ }^{\mathrm{b}}(\mathrm{m})$ & Comments \\
\hline A & 1674 & 362 & 1387 & Perched water \\
B & 1599 & 60 & 1549 & Perched water \\
C & 1621 & 298 & 1475 & Perched water \\
D & 1588 & 115 & 1486 & Perched water \\
31 & 1559 & 366 & 1502 & Perched water \\
32 & 1548 & 277 & 1418 & Perched water \\
33 & 1571 & 301 & - & Dry \\
34 & 1571 & 301 & 1363 & Perched water \\
35 & 1519 & 246 & 1494 & Perched water \\
37 & 1543 & 508 & - & Dry \\
38 & 1536 & 610 & - & May be dry \\
GZ-1 & 1590 & 549 & 549 & Unknown \\
G.Z-2 & 1550 & & & Unknown \\
\hline
\end{tabular}

'See Fig. 4-9.

beferenced to MSL. 
An existing exploratory borehule (UG-(12) was deepened to probe for the water level inferred from measurements in the carbomates. After extendin; the borehole to $960 \mathrm{~m}$ above MSL, a series of water level measurements was made (Fig. 4-12. Table 4-8).

Once the water level in UG-02 stabilized, bailing tests were performed to determine the recovery characteristics of the water levels. Analysis of the bailer test data indicated a permeability of about $10^{-5} \mathrm{D}$. The rising trend of the hydrograph $(-0.25 \mathrm{~m} / \mathrm{mo})$ was apparently caused by recharge of the well through a pervasive fracture system. These data (together with the inferred water level of 800 to $1200 \mathrm{~m}$ above MSL)

Table 4-8. Water levels in exploratory borehole UG-02 (after Murray, 1981).

\begin{tabular}{|c|c|c|c|}
\hline Date & Time & $\begin{array}{c}\text { Water level } \\
\text { (m above MSL) }\end{array}$ & Comments \\
\hline $09: 12: 80$ & - & - & Drilling ended \\
\hline $10 \cdot 14.80$ & 1200 & 977.7 & - \\
\hline 110680 & 1200 & 974.5 & - \\
\hline $11: 19: 81$ & 1200 & 974.0 & - \\
\hline $02 / 18 / 81$ & 1017 & 974.6 & - \\
\hline $02 / 18 / 81$ & 1528 & 973.2 & Bailer Test 1 \\
\hline $03 / 04 / 81$ & 1000 & 974.9 & - \\
\hline $03 / 25 / 81$ & 1035 & 974.9 & - \\
\hline $03 / 25 / 81$ & 1520 & 973.8 & Bailer Test 2 \\
\hline $03 / 27 / 81$ & 1000 & 974.6 & - \\
\hline $03 i 27 / 81$ & 1137 & 973.1 & Bailer Test 3 \\
\hline $03 / 30 / 81$ & 0900 & 974.3 & - \\
\hline $04 / 01 / 81$ & 1300 & 974.7 & - \\
\hline $04 / 09 / 81$ & 1300 & 975.1 & - \\
\hline $05 / 07 / 81$ & 1200 & 975.4 & $\begin{array}{l}\text { New probe on water } \\
\text { level indicator }\end{array}$ \\
\hline
\end{tabular}

- UG-02 is a 76-mm-diam (3-in.) cored borehole.

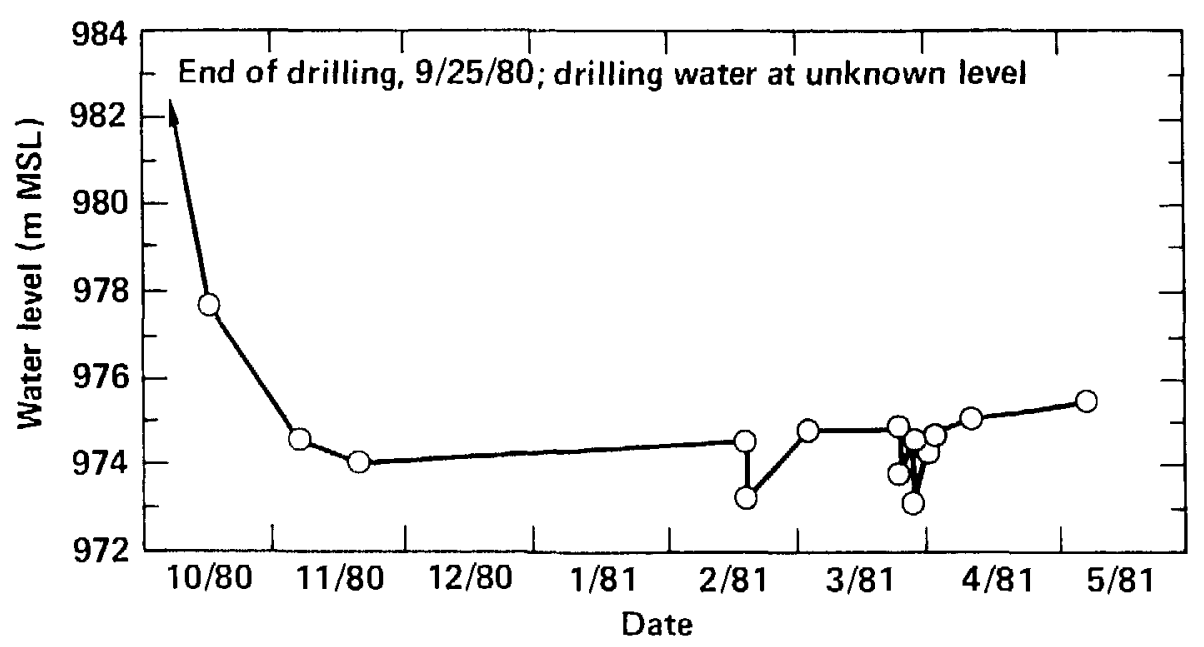

Figure 4-12. Water-level hydrograph for exploratory borehole UG-02 (after Murray, 1981). 
indicate that the local zone of saturation is about $975 \mathrm{~m}$ above MSL. Further discussion of the data and the geohydrology of the stock and surrounding formations is provided by Murray (1981).

\subsection{Summary of In Situ Stress Measurements*}

The in situ state of stress is one of the most important parameters in determining the response of a rock mass to excavation and heating. As discussed in Chapter 3, we found substantial differences in calculational results when the ratio of horizontal-to-vertical stress was changed from 0.8 to 1.2 . To obtain information on the in situ state of stress and its spacial variations, we undertook three series of measurements at the SFT $-\mathrm{C}$. Each is discussed in turn here.

\subsubsection{Pretest Measurements}

Following excavation of the heater drifts, Ellis and Magner (1982) conducted in situ stress measurements under contract to LLNL. These measurements were obtained in three boreholes drilled outward and downward from the south heater drift of the SFT-C (Table 4-9). A U.S. Bureau of Mines (USBM) borehole deformation gauge was used for these overcoring measurements. One borehole (ISS-2) provided a stress profile outward from the drifts, and two additional boreholes completed the strain-relief rosette.

The magnitudes and orientations of the three principal stresses determined from measurements in these boreholes are shown in Table 4-10. It is interesting to note that the vertical stress component calculated from these values is $7.92 \mathrm{MPa}$, about $73 \%$ of the $10.9-\mathrm{MPa}$ value calculated from the weight of overburden.

Since these boreholes were only 5.5 to $7.5 \mathrm{~m}$ long ( 4.8 to $6.5 \mathrm{~m}$ from the rib) and the drift had a 3.4 cross section, it is possible that the measurements were not within the "free field." Ellis and Magner (1982) report that the last three secondary stress measurements in ISS-2 appear to be in a different block of rock than the previous measurements.

Despite these cautions, we proceeded to use these data in the as-built thermomechanical calculations (Chapter 3 ) because at the time we felt they were superior to values one might calculate from depth of overburden and Poisson's effect. This judgment was vindicated by an extensive series of post-test measurements.

\subsubsection{Undercoring Measurements}

As part of a general investigation of the in situ geomechanics of the SFT-C, Heuze et al. (1981) obtained undercoring measurements on the surfaces of the north and south heater drifts. These values were obtained by measuring the response of a rosette of six metal reference pins when a central section of core was removed.

Two sets of measurements, one in $\mathrm{ti}_{\mathrm{i}}$ ? roof of each heater drift, provided the drift-surface stresses shown in Table 4-11. These were judged to be reasonably consistent with the horizontal "free-field" stresses of 9.2 and 4.2 MPa calculated by Huze et al. (1981).

Table 4-9. Location and configuration of the in situ stress borehole used by Ellis and Magner (1982).

\begin{tabular}{lccc}
\hline Designator & Bearing $^{2}$ & Inclination $^{\mathrm{b}}$ & Total depth $(\mathrm{m})^{\circ}$ \\
\hline ISS-1A & $\mathrm{N} 29^{\circ} \mathrm{E}$ & $-76.5^{\circ}$ & 6.1 \\
ISS-2 & $559^{\circ} \mathrm{W}$ & $+3.0^{\circ}$ & 5.5 \\
ISS-3 & S01 $\mathrm{E}$ & $+3.0^{\circ}$ & 7.5 \\
\hline
\end{tabular}

" South heater drift bearing was $N 61$ W.

'Negative is below horizontal.
Table 4-10. Pretest in situ stress determinations (after Ellis and Magner, 1982).

\begin{tabular}{lccc}
\hline Component & Magnitude (MPa) & Bearing $^{2}$ & Inclination $^{\dagger}$ \\
\hline$\sigma_{1}(\max )$ & 11.56 & $\mathrm{~N} 56^{\circ} \mathrm{E}$ & $-29^{\circ}$ \\
$\sigma_{2}$ & 7.13 & $\mathrm{~N} 26^{\circ} \mathrm{E}$ & $+57^{\circ}$ \\
$\sigma_{1}(\mathrm{~min})$ & 2.75 & $\mathrm{~N} 43^{\circ} \mathrm{W}$ & $-14^{\circ}$ \\
\hline
\end{tabular}

- South heater drift bearing was N61 $\mathrm{W}$.

'Negative is below horizontal.

- Contrituted by H. C. Cianow and W. C. Patrick. 
Table 4-11. Undercore measurements of driftsurface stresses.

\begin{tabular}{llrl} 
Measurement & Component & Magnitude (MPa) & Bearing \\
\hline Undercore 2 & Min. & 1.3 & N56 W \\
& Max. & 11.0 & N34 E \\
Undercore b & Min. & 3.8 & N79 W \\
& Max. & 7.1 & N11 ${ }^{\prime 2} \mathrm{C}$ \\
\hline
\end{tabular}

Positive is compression.

\subsubsection{Post-Test Measurements}

After spent fuel was retrieved from the SFT-C, we conducted many in situ stress measurements to determine the in situ stress states within two distinct regions of the facility. The first of these areas includes the two fairly long pillars located between the central canister drift and the north and south heater drifts (Fig. 4-13). In these pillars, four fairly short test borings designated ISS-4 through ISS-7 were drilled to measure stress profiles. The second measurement area was located in relatively virgin rock that was reache:- by drilling test boreholes outward from the south heater drift (ISS-8) and from the tail drift extension (15-9. ISS-10, and ISS-11), as shown in Fig. 4-13. Tests in these boreholes were intended to measure the $f .1 \mathrm{~d}$ state of stress that existed before the rock mass was excavated and heated. In addition, borehole IS 8 o was used to obtain a profile of stresses outward from the SFT-C facility.

Two different types of stress relief or "overcoring" measurement instruments were used during this study: the U.S. Bureau of Mines (USBM) gauge and the Commonwealth Scientific and Indusirial Research Organization (CSIRO) gauge. Both were modified to include a thermistor heat-sensing element through which we were able to directly measure ambient rock temperature at the actual test location. Standard test procedures were also extensively modified to maintain, to the extent possible, a constant temperature during each overcoring measurement.

Foundation Sciences, Inc. (FSI), supplied the USBM and CSIRO gauges, calibration and readout apparatus, and various support equipment for these measurements, along with three staff members, who assisted LLNL personnel in conducting these tests. The data presented here are summarized from Creveling et al. (1984), which contains details of the measurements.

Test Methods. Both the USBM and CSIRO gauges use strain relief by overcoring to measure the magnitude and orientation of the stress regime. During the test, one of the gauges is inserted in a nominally EX size (38-mm-diameter) borehole and is coaxial!y overcored with a nominally $150-\mathrm{mm}$-diametcr $\mathrm{r}$ (6-in.) core barrel. These gauges measure changes in the size and shape of the central borehole. After the overcoring is complete, the recovered core is tested in a hydraulic "biaxial" test cell to obtain data used to calculate a Young's modulus. This modulus value is in turn used to calculate the rock stresses at the test location.

The USBM and CSIRO gauges are fundamentally different in the manner in which they measure borehole deformation. The USBM gauge uses six strain-gauged beriflium-copper cantilevers mounted so that they measure three equally spaced borehole diameters in a single transverse plane (Fig. 4-14). This reusable instrument cannot measure borehole axial deformation and therefore cannot measure all the strain components necessary to determine the complete state of stress. The information obtained is sufficient to derive two secondary principal stresses ( $P$ and $Q$ ) that exist perpendicular to the horehole axis. These values are combined with measurements obtained in at least two other nonparallel boreholes to obtain directions and magnitudes for the true principal stresses.

The CSIRO gauge consists of nine variously oriented electrical-resistance-type strain gauges encased in a thin plastic cylinder (Fig. 4-15). This unit is then irretrievably bonded to the borehole wall using a special epoxy-based adhesive. The nine strain gauges are arraryst: such that the'y measure all three princifal strain components, which allow's, using the modulus valis nd thin-walled cylinder thesry, a direct calculation of the principal atresses. Clearly, a rery high yualiog gauge -to-borehole bond is required if one is to measure correct strain relief values with this gauge.

Fur tests within the induced thermal field at the Climax stork, the USBM gauge probes were modified to indude thermicturs for direct temperature measurenent, and all CSIRO gauges were modified dering 
Spent fuel canister shaft

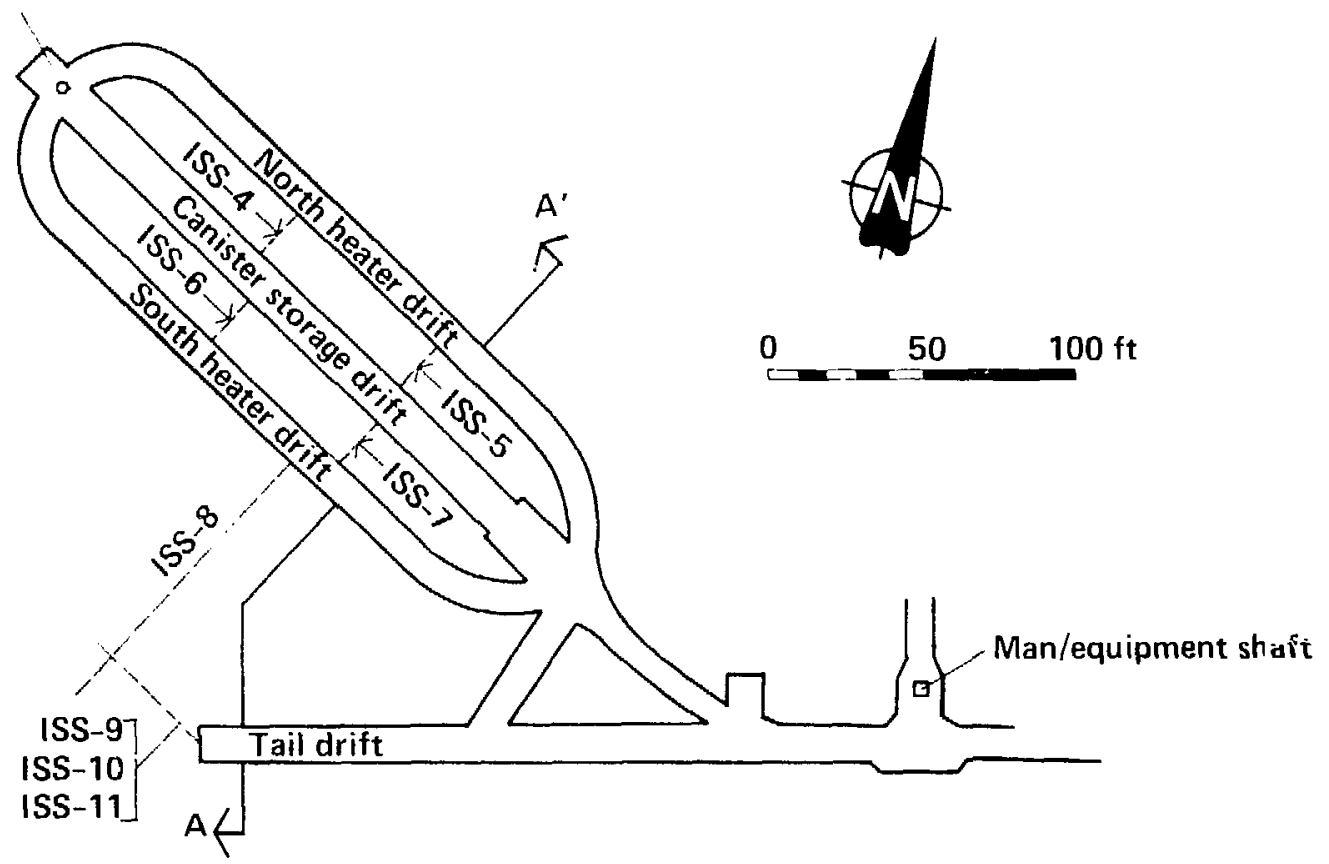

Plan view

Note: ISS-10 is inclined upward about $45^{\circ}$.

ISS-11 is ir.clined downward about $45^{\circ}$.

Both are on the same bearing as ISS-9.

'Other boreholes horizontal.
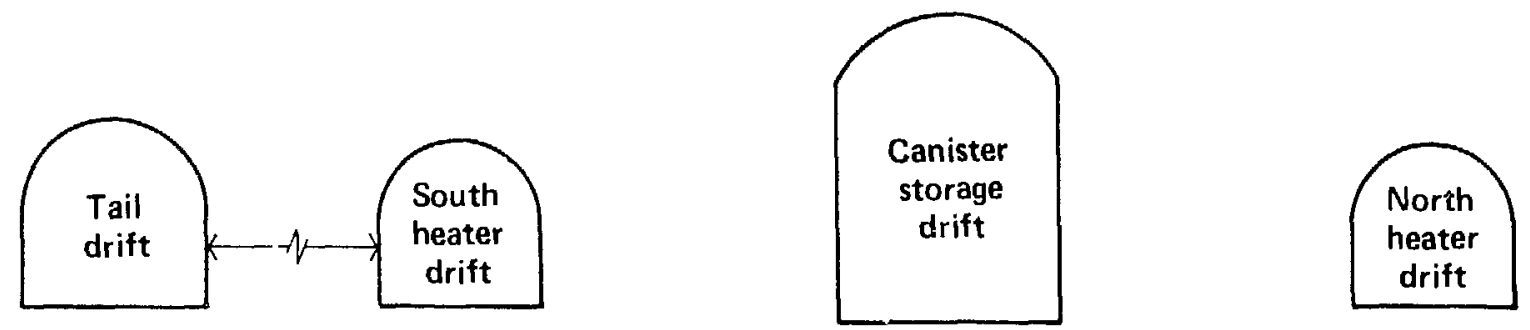

Section A-A'

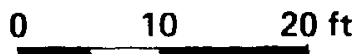

Figure 4-13. Map and section views of the Spent Fuel Test site showing the locations of the in situ state of stress measurement boreholes ISS-4 through ISS-11 (after Creveling et al., 1984).

manufacture to include a similar thermistor within the unit's plastic shell. Both types of devices required electrical cables with additional conductors for the thermistor signal. Following gauge insertion and thermal equilibration, the temperature value measured was used as a reference for adjusting the initial drilling water temperature. During actual overcoring, cold run-of-mine water was added to the circulating water to cumpensate for the thermal energy deposited in the rocl by the drilling process. Following the test, the circulating water was warmed by electrical heaters to reestablish the same initial temperature. The total strain relief values obtained after thermal equilibration were the ones used to calculate the secondary or true principal state of stress values, as appropriate. 

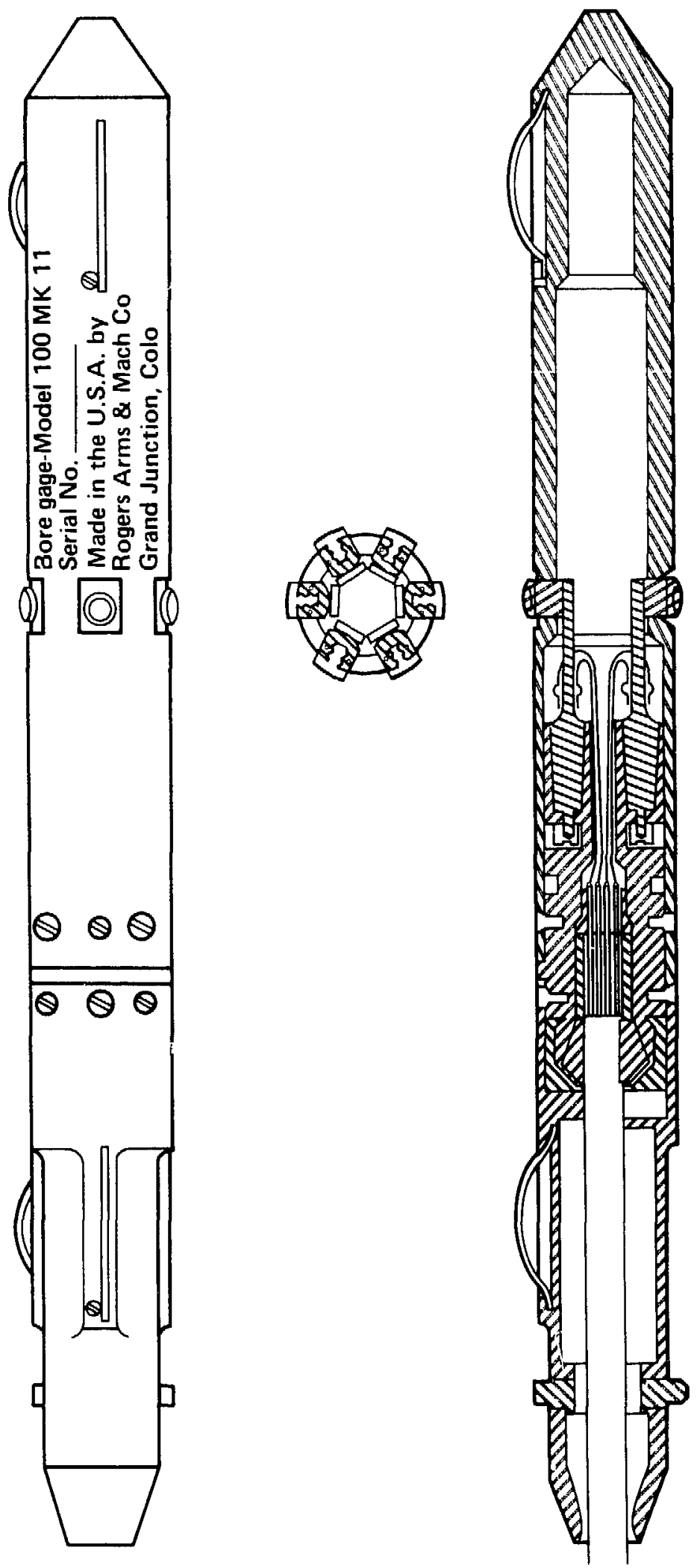

Figure 4-14. Three views of the modern reverse case U.S. Bureau of Mines Borehole Deformation Gauge (modified after drawing by Rogers Arms and Machine Co.). 

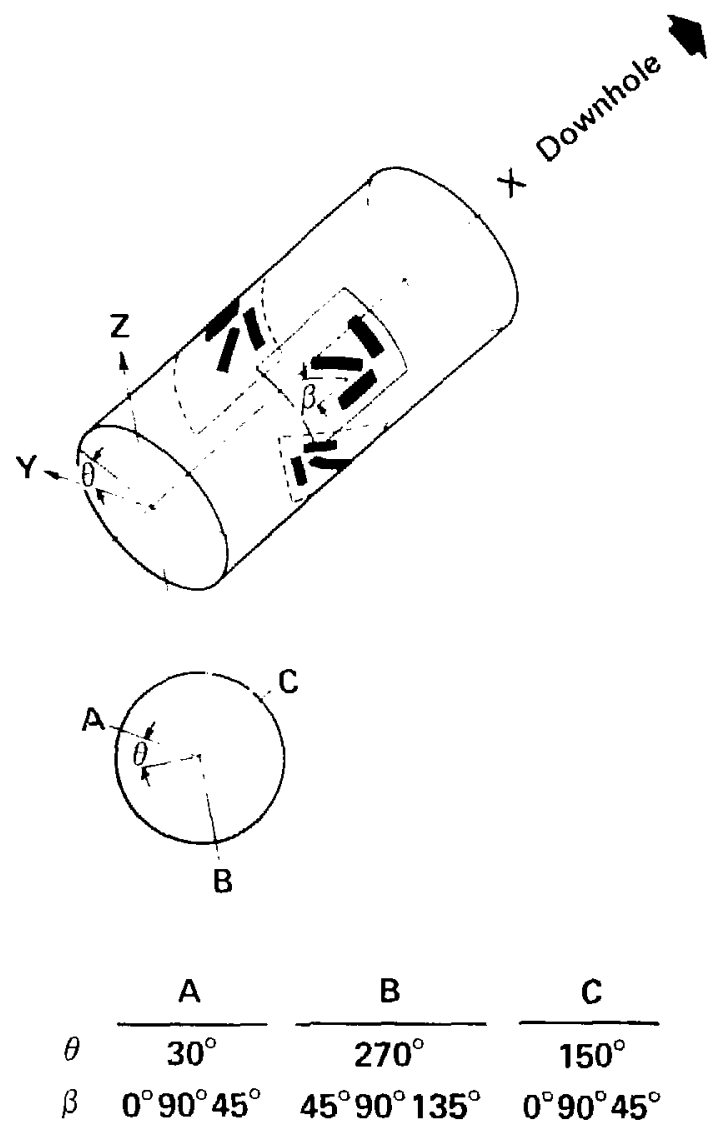

Figure 4-15. Oblique view showing the orientations of the nine electrical strain gauge elements of the CSIRO thin walled borehole deformation gauge (after Worotnicki and Walton, 1979).

Pillar Stress Measurements. Four test boreholes, designated ISS-4 through IS5-7, were drilled through and perpendicular to the two long, slender, rock pillars that separate the central canister drift from the north and south heater drifts (Fig. 4-13). Fifteen USBM and three CSIRO gauge tests were successfully conducted in these boreholes. The purpose of these tests was to:

- Determine the magnitudes and orientations of the secondary principal stresses (USBM gauge) and total principal stresses (CSIRO gauge). drift ribs.

- Determine whether the USBM and CSIRO gauges yield similar values for these stresses.

The results of these tests are shown in Figs. 4-16, 4-17, and 4-18 which are taken from the report by Creveling et al. (1984). Figure 4-16 shows the magnitude of the major " $\mathrm{P}$ " and minor " $Q$ " secondary principal stresses (those stresses that exist in a plane perpendicular to the borehole axis) from USBM gauge tests. These values are calculated assuming that no axial deformation occurred during overcoring. Synthetic (back-calculated) secondary principal stresses are also shown for the three CSIRO gauge tests. These data generaliy indicate that the P-value ranges from about 1900 to $500 \mathrm{psi}$, and that maximum values are located near the inner heater drift ribs and decrease to a minimum at the canister drift ribs. The Q-value ranges from about 700 to $-200 \mathrm{psi}$ (tension) and shows a similar, although weaker, trend.

Figure 4-17 shows these same data plotted in a graphical form along the borehole such that both their orientations and relative magnitudes can be studied. Recall that the $P$ and $Q$ stresses actually exist in a plane transverse to the borehole and are portrayed as though one were looking into the borehole collar. 


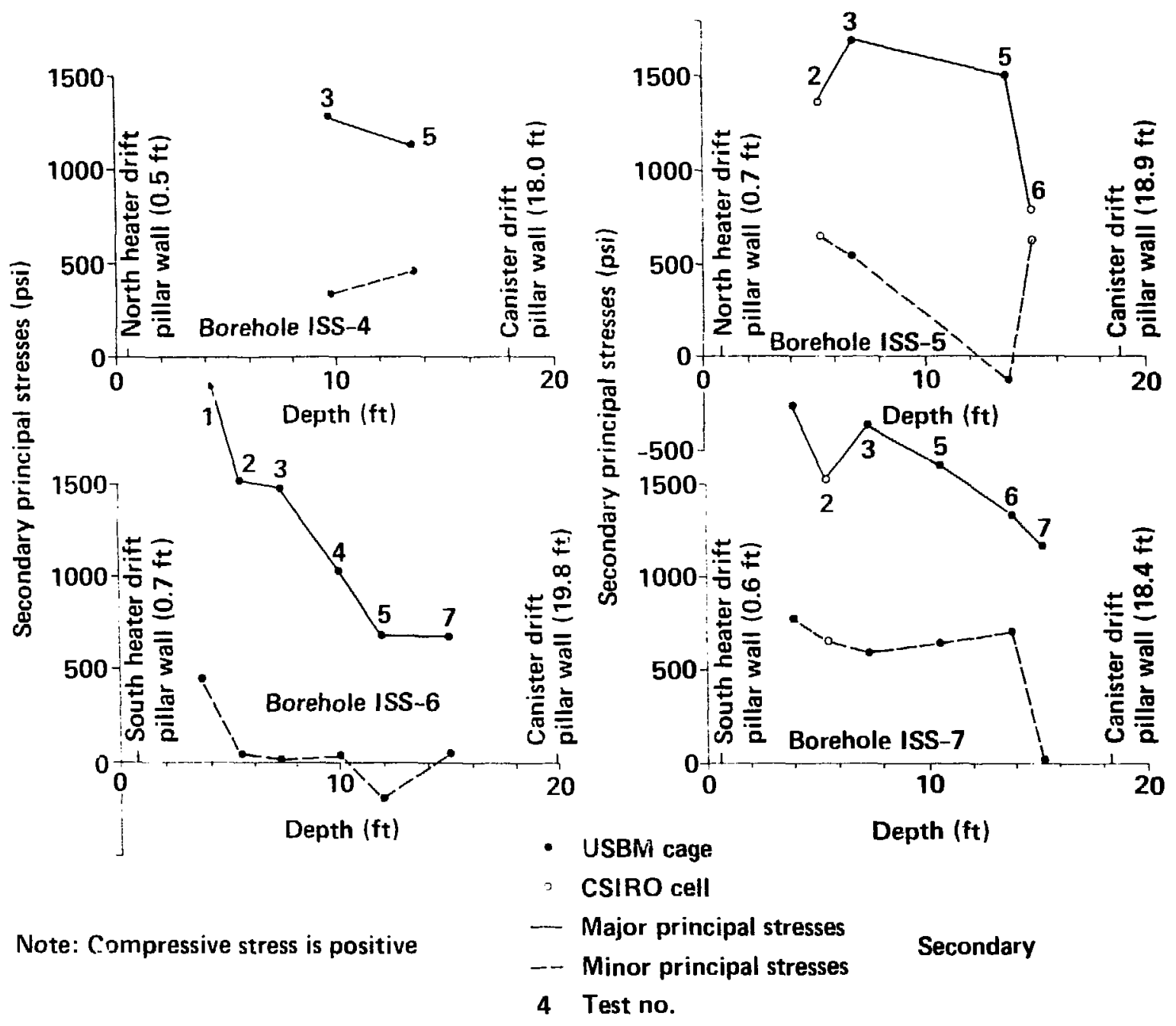

Figure 4-16. Secondary principal stress values of $P$ and $Q$ vs borehole depth for both USBM gauge and CSIRO gauge pillar stress measurements in boreholes ISS-4, ISS-5, ISS-6, and ISS-7 (after Creveling et al., 1984).

From these diagrams, it is clear that the maximum secondary stress is nominally within 20 to 30 degrees of vertical; therefore, $Q$ is nearly horizontal. In general, the data between the borehcles are quite similar in form, with the possible exception of tests 1, 2, and 3 in ISS-6. These measurements are quite consistently inclined to the northwest, which, in itself, suggests they are correct. This orientation change may reflect the influence of nearby prominent joints and shears (Wilder and Yow, 1981).

The orientations of the principal stresses obtained from the CSIRO tests in pillar boreholes are shown in the upper-hemisphere polar steronet plot in Fig. 4-18. These data generally confirm the previous statements and, along with the tabulated stress magnitudes, provide additional information. The maximum principal stress (sigma 1) is systematically inclined toward the north-northeast. The intermediate principal stress (sigma 2) is nearly horizontal and aligned parallel to the pillar axis, and the least principal stress (sigma 3) is also essentially horizontal and oriented parallel to the minimum pillar width. These findings are quite consistent with the long, thin geometry of the pillars.

Free-Field Stress Measurements. Four boreholes, designed 1SS-8 through 1SS-11, were drilled into a relatively undisturbed portion of the stock from the tail drift extension and south heater drift (Fig. 4-13) 


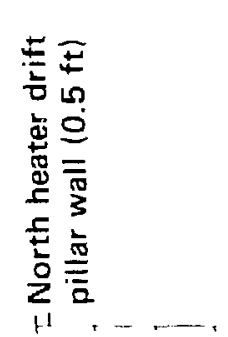

0

(Borehole collar)

Depth ( $\mathrm{ft}$ )
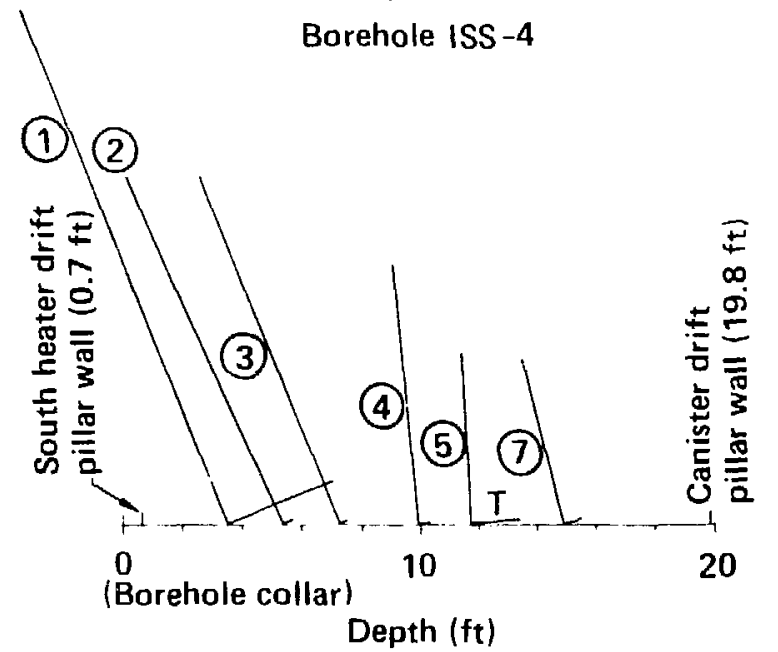

Borehole ISS-6

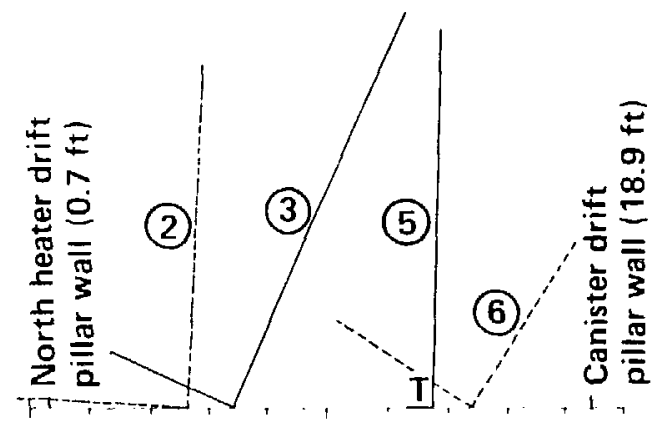

0

(Borehole collar)

10

Depth ( $f t$ )

Borehole ISS-5

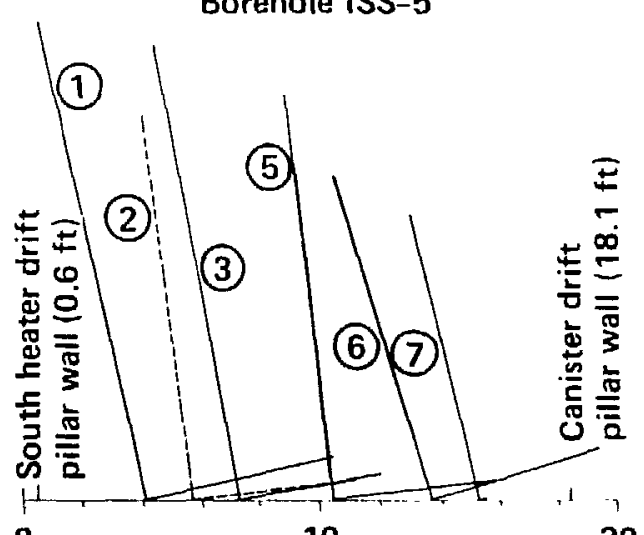

(Borehole collar)

Depth ( $\mathrm{ft}$ )

Borehole ISS-7

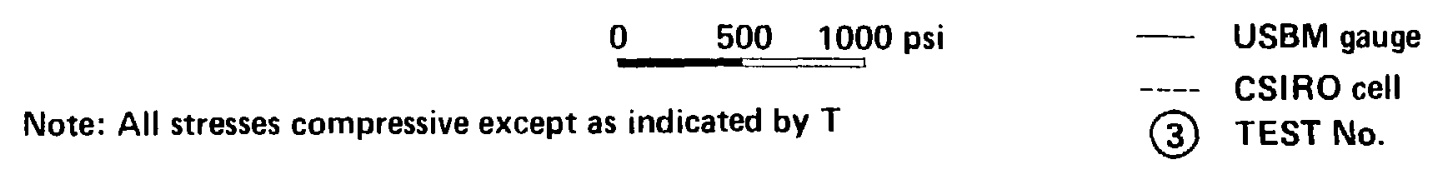

Figure 4-17. Secondary principal stress orientations of $P$ and $Q$ vs borehole depth for both USBM gauge and CSIRO gauge pillar stress measurements in boreholes ISS-4, ISS-5, ISS-6, and ISS-7 (after Creveling et al., 1984).

with the intent of measuring the existing free-field state of stress before excavation began. Many of the experimental objectives were the same as for the pillar study, but we also need to (1) measure the stress distribution in an outer heater drift rib for a significant distance into the virgin rock; and (2) perform an independent check on the CSIRO gauge results, using USBM gauge data from various combinations of boreholes ISS-8, 1SS-9, ISS-10, and ISS-11.

Twenty-eight USBM gauge tests and 22 CSIRO gauge tests were successfully conducted in these four boreholes. Figure 4-19 shows the major $P$ and minor $Q$ secondary principal stresses for borehole ISS-8. It appears that the magnitudes of stresses measured by USBM and CSIRO methods agree reasonably well. The major secondary stress $(P)$ ranges from about 800 to $1700 \mathrm{psi}$, and increases gradually away from the rib (0- to 30 -ft region). Both $P$ and $Q$ values fall to a very low 700 and $500 \mathrm{psi}$, respectively, in the 40 - to 45 -ft depth range, and there is no obvious explanation for this change. The $P$ value then increases from 900 to 


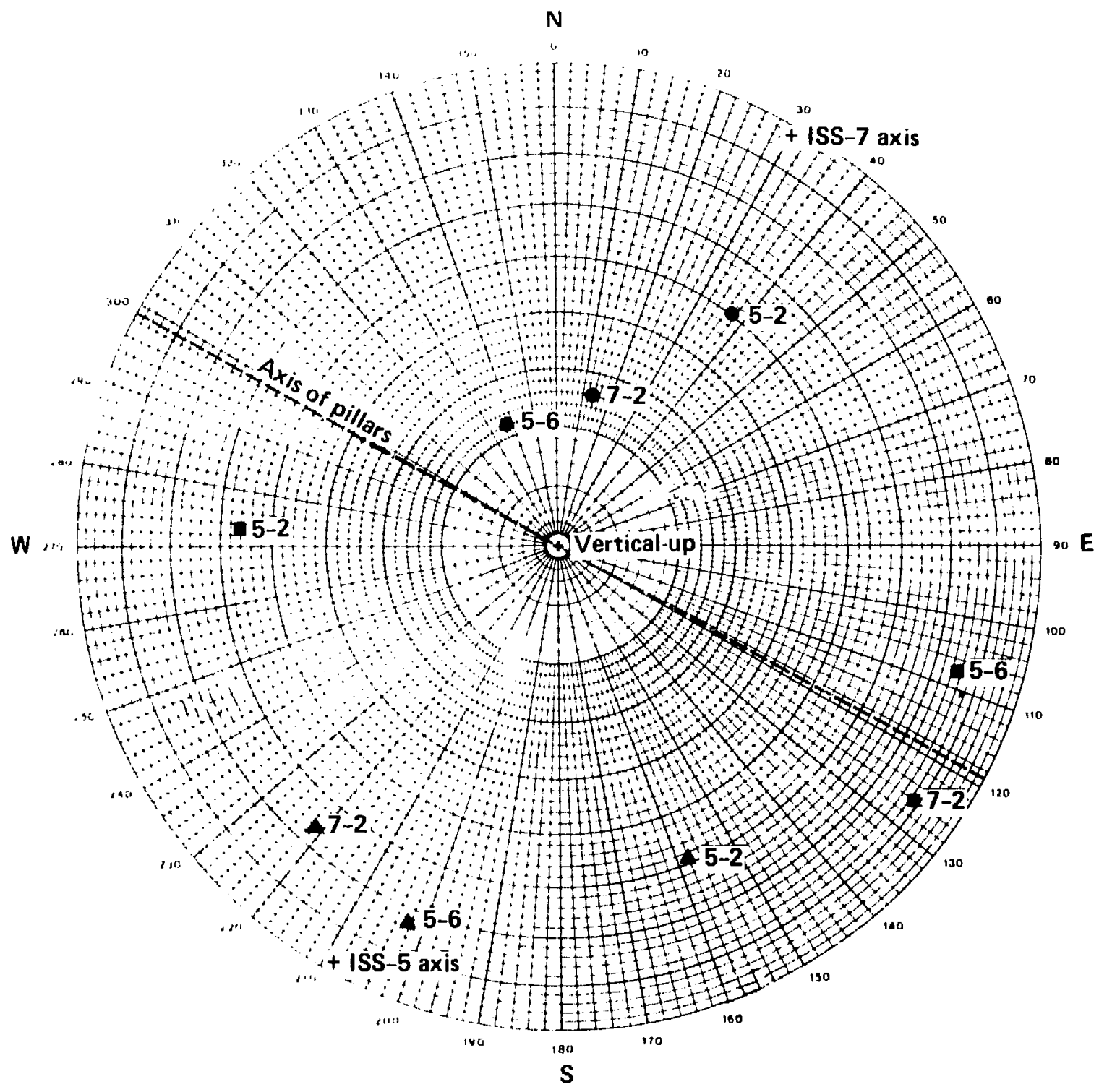

Principal stresses (psi)

\begin{tabular}{|c|c|c|c|c|}
\hline Test No. & $\begin{array}{c}\text { Depth } \\
\text { (ft) }\end{array}$ & $\sigma_{1}$ & $\sigma_{2}$ & $\underset{\sigma_{3}}{\Delta}$ \\
\hline $\begin{array}{l}\text { ISS-5-2 } \\
\text { ISS-5-6 }\end{array}$ & $\begin{array}{r}5.3 \\
14.8\end{array}$ & $\begin{array}{r}2,290 \\
822\end{array}$ & $\begin{array}{l}836 \\
674\end{array}$ & $\begin{array}{r}433 \\
-294\end{array}$ \\
\hline
\end{tabular}

\section{Note: Compressive stress positive}

Figure 4-18. Polar stereonet plot showing the principal stress orientations obtained from three CSIRO gauge measurements made in boreholes ISS-5 and ISS-7 (after Creveling et al., 1984). 


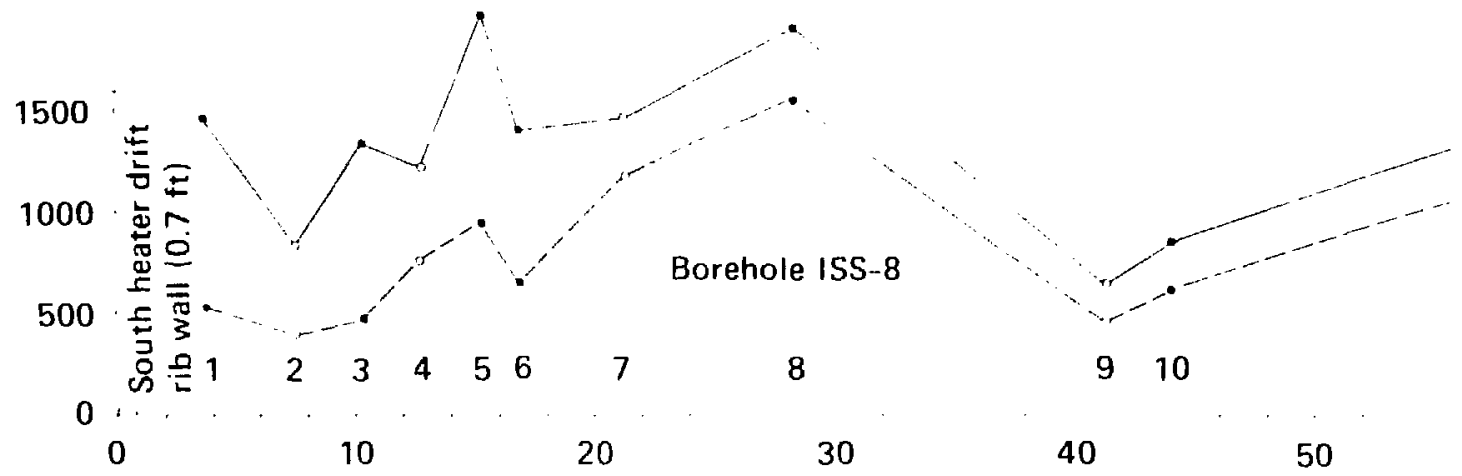

Depth $(\mathrm{ft})$

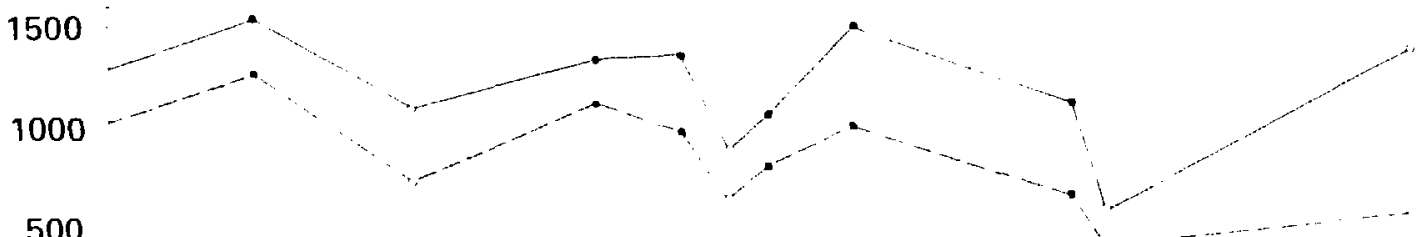

500

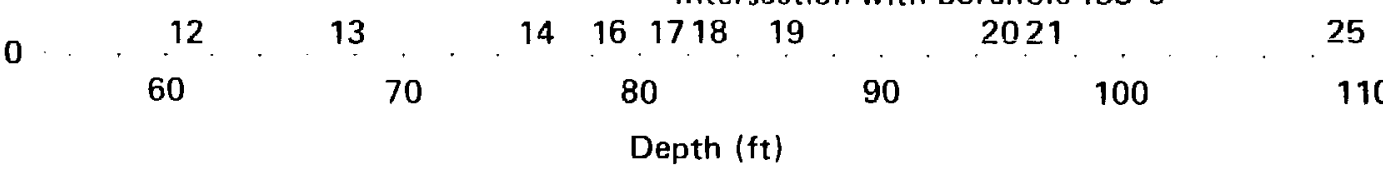

Note: compressive stress is positive

Borehole ISS-8 (cont.)

- USBM gauge

CSIRO cell

-.. Major principal stresses

- Minor principal stresses

19 Test No.

Figure 4-19. Secondary principal stress values of $P$ and $Q$ vs borehole depth for both USBM gauge and CSIRO gauge measurements in boreholes ISS-8 (after Creveling et al., 1984).

1600 psi for the remainder of the borehole. The stress differential is maximum for those tests in the 0 - to 30 $\mathrm{ft}$ region, as well as at CSIRO Test No. 25, located at the very end of the borehole. The latter may be an anomaly, however.

Figure 4-20 shows the $P$ and $Q$ stress orientations. The maximum secondary stress tends to be oriented nearly vertical in the 0 - to $30-\mathrm{ft}$ portion of $155-8$, which is probably a result of its relatively clnse proximity to the drifts. Beyond this region, $P$ tends to be highly inclined, reflecting the influence of the true free-field state of stress.

As shown in Fig. 4-13, boreholes ISS-9 and ISS-10 were drilled along the same bearing and inclined upward 4 and 46 degrees, respectively, and borehole ISS-11 was on the same bearing but inclined downward about 45 degrees. Secondary principal stress magnitude data and orientation data are shown in Fig. 4-21 and Figs. 4-22 and 4-23, respectively. In 15S-9, the stress values appear relatively constant along the borehole length except for test pair numbers 7 and 8 . Nominally, the $\Gamma$ and $Q$ stress values are 700 to 1100 psi and 400 to 700 psi, respectively. However, in IS5-10, the P value is consistently higher at 1300 to 2100 psi, and the $\Gamma$-to-Q stress differential is larger. Although the presence of a shear zone has heen suggested as the cause of this disparity, careful examination of the core from hoth ISS-4 and ISS-lll does not support 


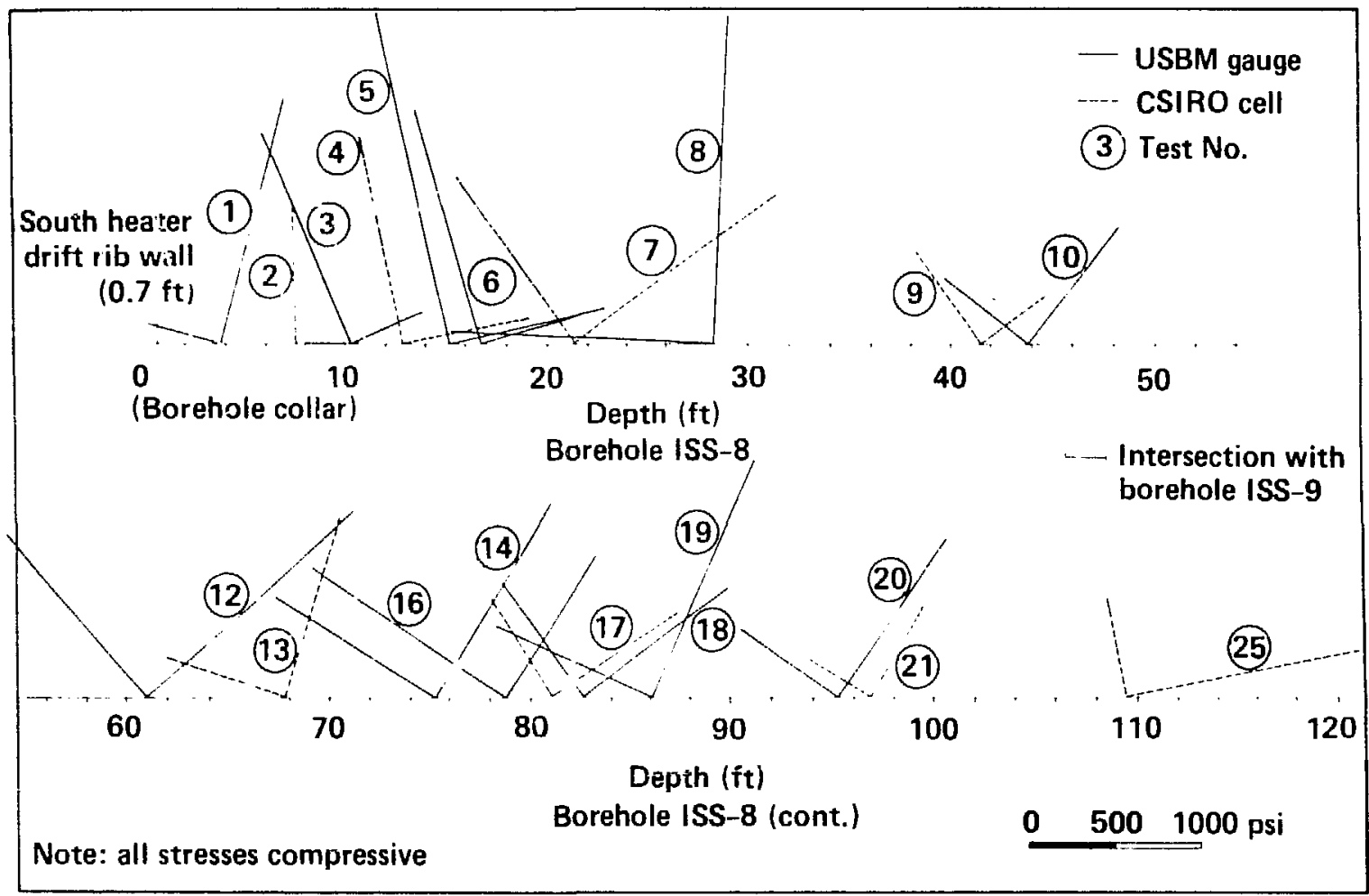

Figure 4-20. Secondary principal stress orientations of $P$ and $Q$ vs borehole depth for both USBM gauge and CSIRO gauge measurements in borehole ISS-8 (after Creveling et al., 1984).

this interpretation. In IS5-11, we see a fairly consistent increase in the major secondary stress with depth. Although this trend is also evident to a depth of $85 \mathrm{ft}$ for the minor stress, a rapid decrease is noted at greater depths.

Figures 4-24 and 4-25 are upper-hemisphere polar steronet plots of the average principal stress orientations from CSIRO gauge tests in ISS-8 through ISS-11 and the principal stress orientations calculated from USBM gauge tests in various combinations of these four boreholes. Note that these combinations give considerably different results-a natural consequence of obtaining the data from three separate, usually diverging boreholes in a spacially varying stress field. The combination of ISS 8, 9, and 10 is considered to most represent conditions at the depth of the SFT-C. The maximum principal stress (sigma 1) values tend to cluster at about $N 70^{\circ} \mathrm{E}$, with a plunge of 20 to 30 degrees to the northeast. The intermediate and least principal stress (sigmas 2 and 3 ) values alternate from nearly horizontal and trending to the northwest to nearly vertical. This is because they tend to be more nearly equal in magnitude. It is interesting to note that the maximum stress orientation of $\mathrm{N} 70^{\circ} \mathrm{E}$ is reasonably consistent with Carr's (1974) estimate of $\mathrm{N} 40^{\circ} \mathrm{E}$. Also, Wilder and Yow (1984) and Zoback and Zoback (1980) estimate that the least principal horizontal stress is oriented about $N 45^{\circ} \mathrm{W}$, which compares with the $\mathrm{N} 30^{\circ} \mathrm{W}$ calculated from these data.

\subsubsection{Conclusions}

The following conclusions are offered with regard to this study.

1. Acceptable results were obtained from both the USBM and CSIRO gauges, and the experimental objectives were achieved. The CSIRO gauge results appear to be consistently about $30 \%$ lower than values obtained with the USBM gauge.

2. In the north and south heater drift pillars, the maximum principal stress (sigma 1) is essentially vertical, the intermediate principal stress (sigma 2) is horizontal and aligned parallel to the long axes of the 
1500

1000

500

0 .

30

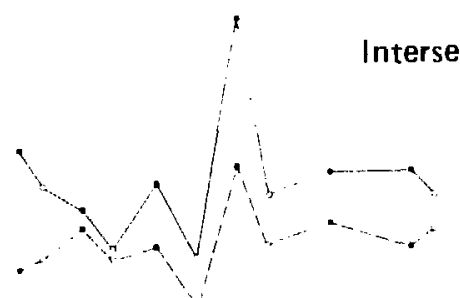

$\begin{array}{lllllll}2345 & 6 & 7 & 89 & 10 & 1213\end{array}$

50

40

Depth from borehole collar ( $\mathrm{ft}$ )

1500

1000

500

0 . 60 Borehole ISS-9

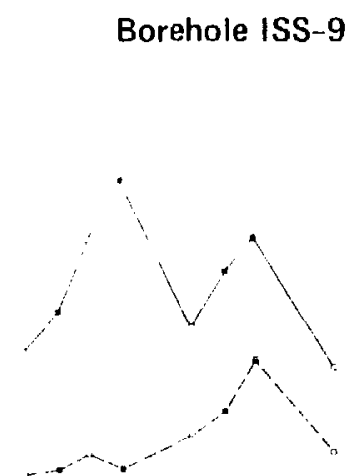

$23456678 \quad 9$
60

3000

Zone $\sim 55 \mathrm{ft}$ above
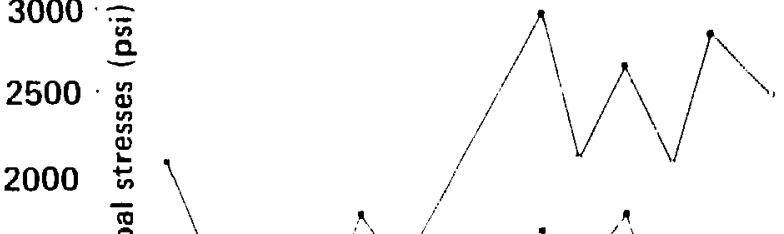

1500

1000

500

0 边

$\begin{array}{lllll}2 & 3 & 4 & 5 & 6\end{array}$

70

80

90

11

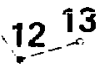

8910111213

Depth from borehole collar $(\mathrm{ft})$

Borehole ISS-11

Depth from borehole collar $(\mathrm{ft})$

Borehole ISS-10

Figure 4-21. Secondary principal stress values of $P$ and $Q$ vs borehole depth for both USBM gauge and CSIRO gauge measurements in boreholes ISS-9, ISS-10, ISS-11 (after Creveling et al., 1984).

pillars, and the least principal stress (sigma 3 ) is parallel to the pillar width. These results are consistent with the long, thin geometry of the pillars.

3. The "free-field" state of stress measurements indicate that the maximum principal stress is oriented toward the east-northeast and is nearly horizontal, the intermediate principal stress is nearly vertical, and the nearly horizontal least principal stress is oriented north-northwest. These results are consistent with the conclusions of previous investigators and motions of active faults at the NTS.

\subsection{Physical Properties Measurements*}

Both laboratory and in situ measurements were undertaken to determine mechanical, thermal, and thermomechanical properties for use in calculations that formed the basis for design (Chapter 3 ) and subseipuent comparisons with data obtained during the test (Chapters 13,14, and 16). The effects of heat and ionizing radiation on selected properties are discussed in Section 4.6. The transport of heat and the resulting thermomechanical response of a rock mass are controlled in large part by the physical properties of the rock mass. Among the properties important to heat transport are the thermal conductivity, diffusivity, and

* Cuntributed by W. C I'strich 
To tail drift $\leftarrow$ 20

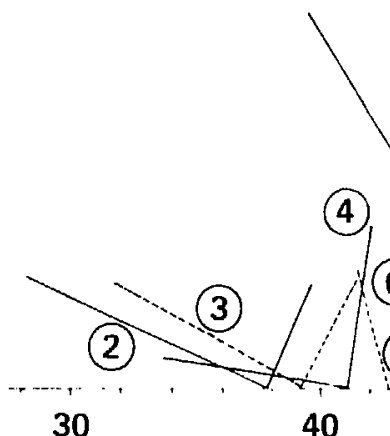

40 Intersection with borehole ISS-8

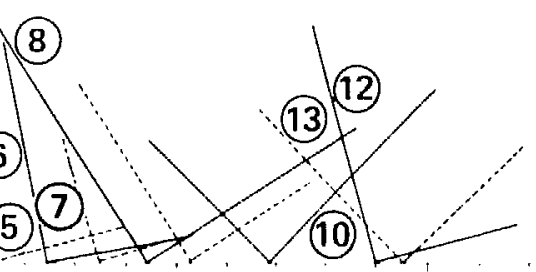

50
60 70

- USBM gage

Depth ( $\mathrm{ft}$ )

Borehole ISS-9

-.-- CSIRO cell

(3) Test no.

To tail drift $\&$<smiles>[194Os]</smiles>

Note: All stresses compressive

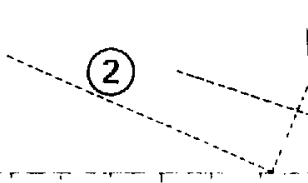

60

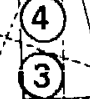

(6)

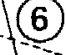

70

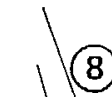

(8)

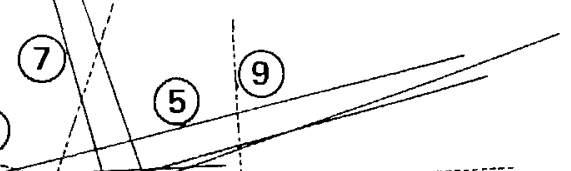

Depth ( $\mathrm{ft}$ )

Borehole ISS-10

80

90

$0 \quad 500 \quad 1000$ psi

Figure 4-22. Secondary principal stress orientations of $P$ and $Q$ vs borehole depth for both USBM gauge and CSIRO gauge measurements in borehole ISS-9 and ISS-10 (after Creveling et al., 1984).

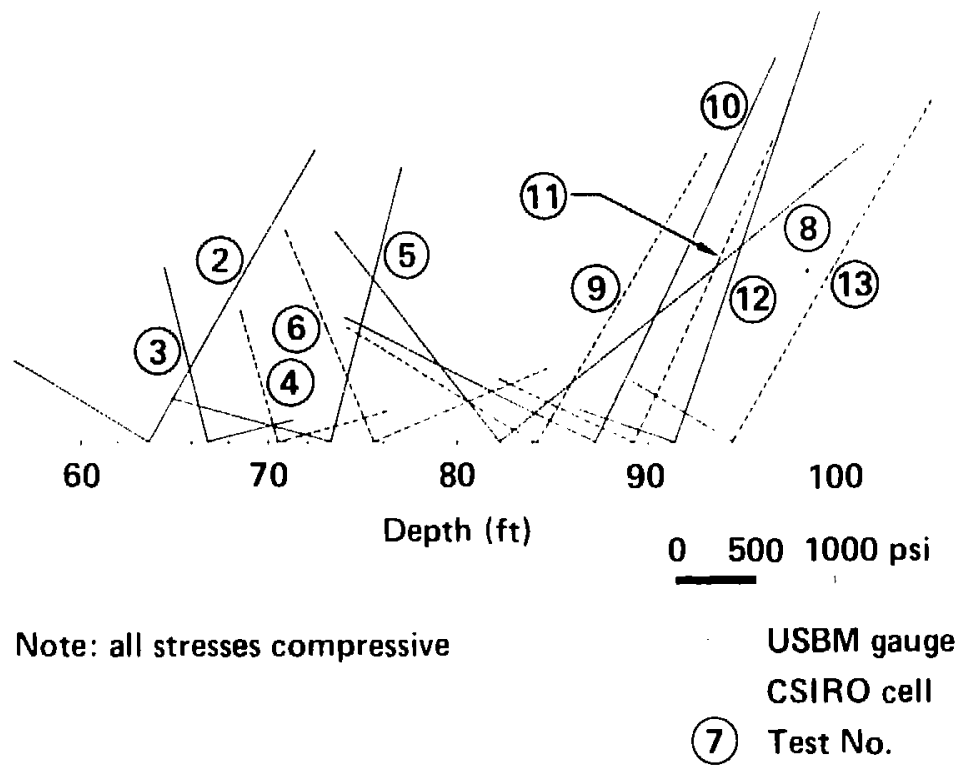

Figure 4-23. Secondary principal stress orientations of $P$ and $Q$ vs borehole depth for both USBM gauge and CSIRO gauge measurements in borehole ISS-9, ISS-10, and ISS-11 (after Creveling et al., 1984). 


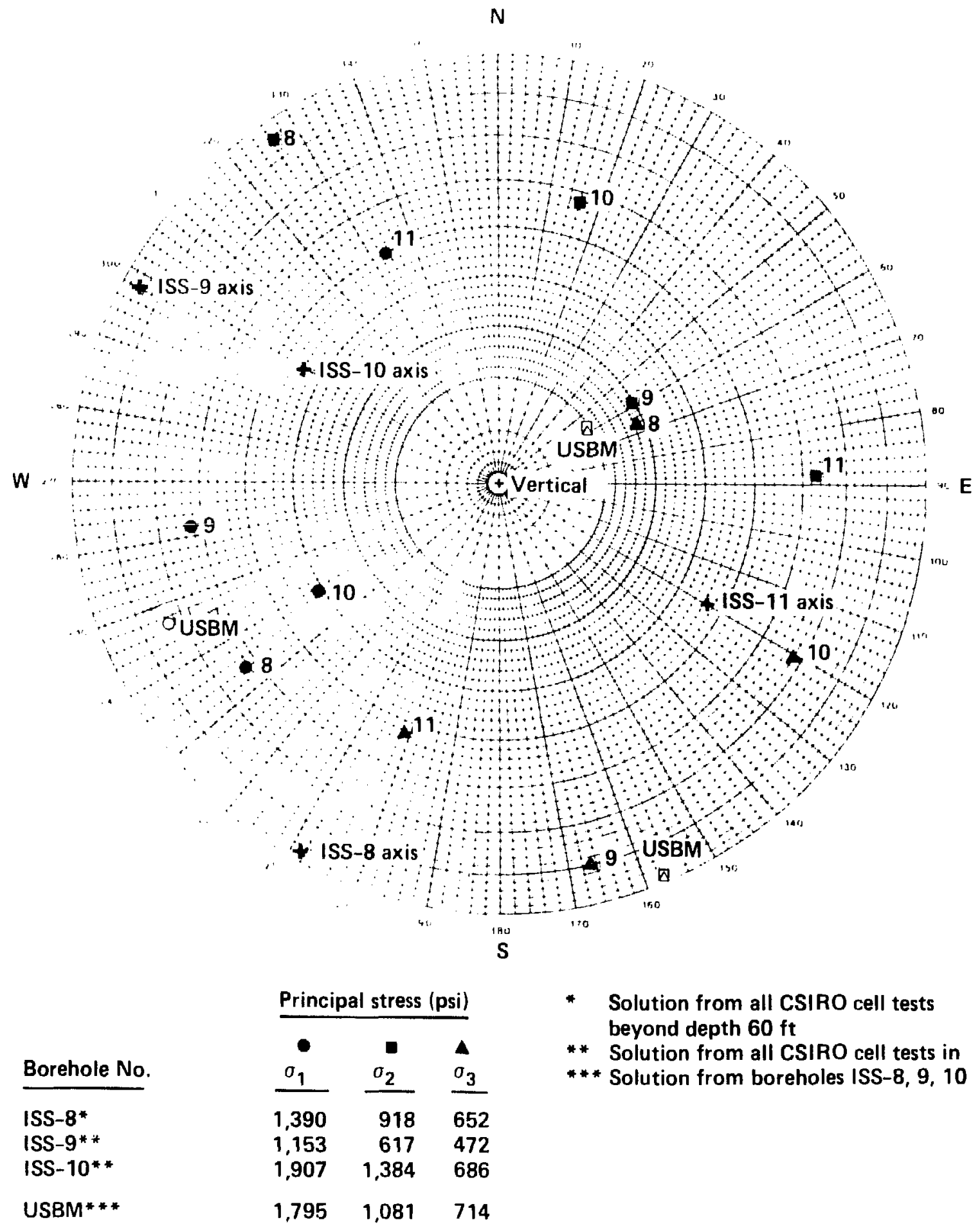

Figure 4-24. Polar stereonet plot showing principal stress orientations obtained from CSIRO gauge measurements; and principal stresses calculated from USBM gauge measurements in boreholes ISS-8, ISS- 9, and ISS-10 (after Creveling et al., 1984). 


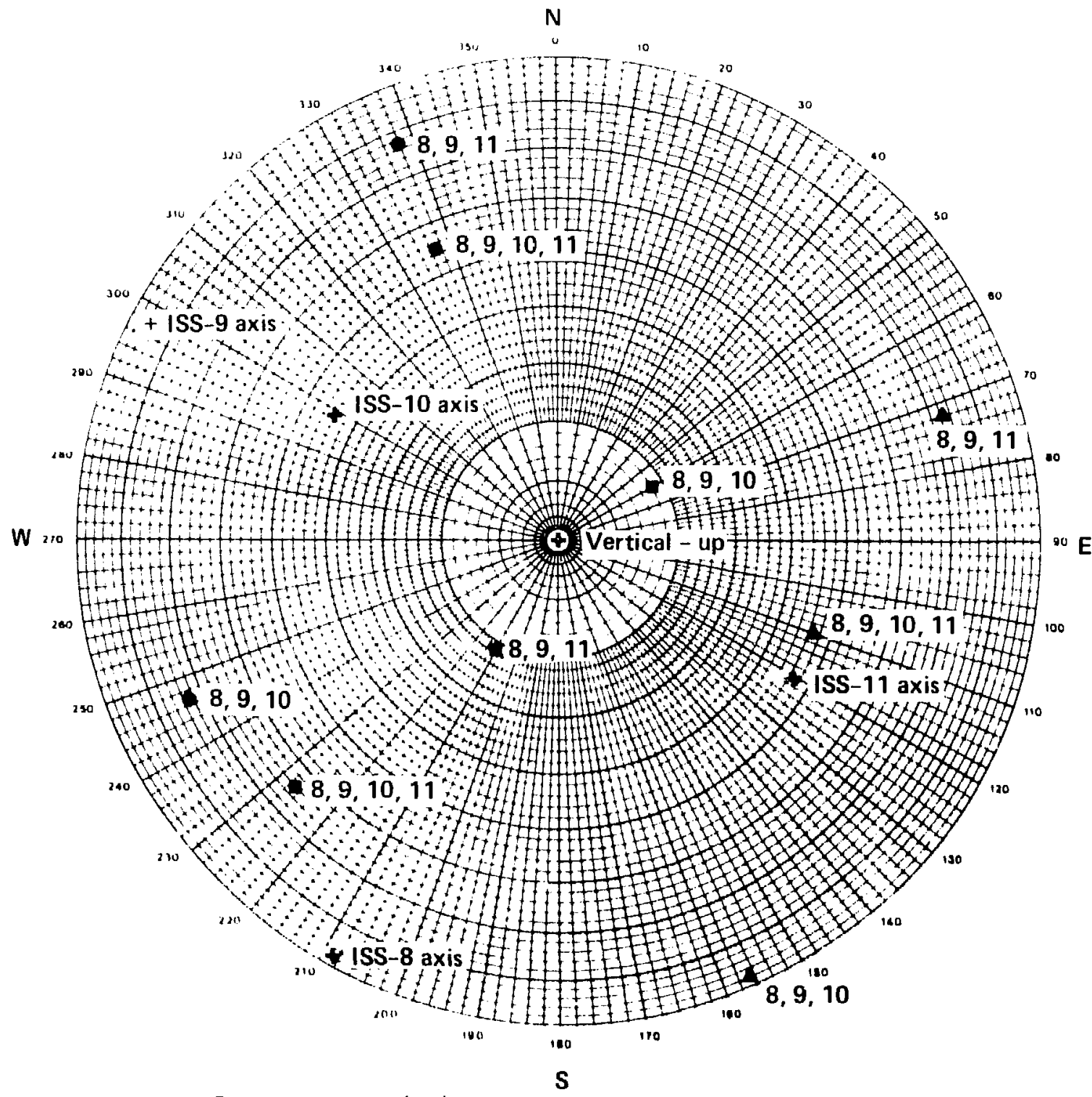

Principal stresses (psi)

\begin{tabular}{|c|c|c|c|}
\hline $\begin{array}{l}\text { Borohole } \\
\text { combinations }\end{array}$ & $\sigma_{1}$ & $v_{2}$ & $\stackrel{\Delta}{\sigma_{3}}$ \\
\hline $\begin{array}{l}\text { ISS-8, 9, } 10 \\
\text { ISS-8, 9, } 11 \\
\text { ISS-8, 9, 10, } 11\end{array}$ & $\begin{array}{l}1,795 \\
1,844 \\
1,654\end{array}$ & $\begin{array}{l}1,081 \\
1,287 \\
1,195\end{array}$ & $\begin{array}{l}714 \\
557 \\
992\end{array}$ \\
\hline
\end{tabular}

Borehole ISS-8 includes all USMB gauge tests beyond 60-ft depth.

Note: All stresses compressive

Borehole ISS-8 includes all USMB gage tests beyond $60-\mathrm{ft}$ depth.

Figure 4-25. USBM Gage Principal stressses, boreholes ISS-8, ISS-4, ISS-10, and ISS-11 (after Creveling et al., 1984). 
density. For thermomechanical response, the "stiffness" of the rock (usually expressed in terms of its response to loading and reported as Young's modulus, shear modulus, and Poisson's ratio), themal expansivity, and measures of strength (induding a failure envelope) are important. If the rock mass is jointed or fractured, the pertinent shear and normal stiffnesses and related strength parameters must also be known.

Complicating factors in expressing these properties are:

- Temperature and pressure dependence.

- Effects of sampling disturbances.

- "Scale effects" resulting from sample inhomogeneities.

- Sampling biases that tend to eliminate weaker, softer materials, ofter during the drilling process. As a result, we elected to cunduct both laboratory and in situ tests to determin the pertinent rock properties. The former were effectively used to examine pressure and temperatur dependences whereas the latter were used to determine the field-scale values of selected properties.

\subsubsection{Laboratory Studies of Thermomechanical Properties}

Some of the earliest physical properties data for the SFT $-C$ were obtained by Pratt, Lingle, and Schrauf (1979). The resulting data are summarized in Table 4-12. While the 76-mm-dianeter cores " $\mathrm{G}-1$ " and " $\mathrm{G}-2$ " were obtained from exploratory borings in the region where the SFT $-C$ was later constructed (Chapter 3), the "large core" (143-mm) was obtained from the floor of an alcove in which an earlier in situ heater test was performed (Sec. 4.4.4).

These data display several interesting trends: First, there seems to be relatively minor variability in properties at a given set of conditions, typically no more than $10 \%$. Second, strength increases with confinement, which is fairly conmon. Third, there appears to be little effect (at least no monotonic change) of confining pressure on Young's modulus. Fourth, the effect of confining pressure on Poisson's ratio is unclear-it appears to increase for the smaller cores and decrease for the large core.

Page and Heard (1981) later studied in detail the effects of temperature and pressure on selected properties. Young's modulus was seen to increase fairly consistently with increases in confining pressure and decrease with increasing temperature (Fig. 4-26). Similar effects were observed in the bulk modulus (Fig. 4-27).

The same study, which also summarized the earlier work of Heard (1980), indicated that porosity and permeability decrease with increasing confining pressure and increase with increasing temperature (Fig. 4-28).

Preliminary studies by Heard (198()) indicated that the coetficient of expansion of the CSQM was not a simple function of pressure or temperature. Page and Heard (1981) extended these studies to provide the

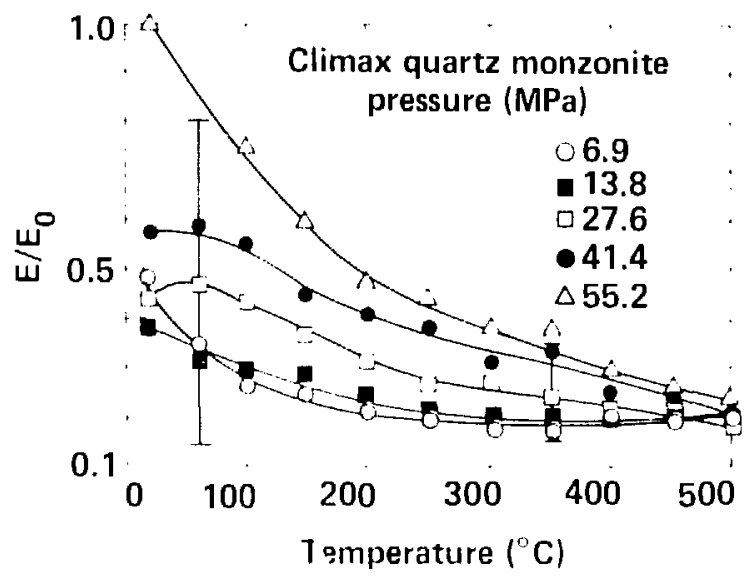

Figure 4-26. Normalized Young's modulus $\left(E / E_{0}\right)$ vs temperature for Climax quartz monzonite. The error bars represent 1 std dev of the 9-sample population, which averages $\pm 7 \%$ at $10^{\circ} \mathrm{C}$, ranging to $\pm 40 \%$ at $350^{\circ} \mathrm{C}$. Estimated std dev for $\mathrm{E} / \mathrm{E}_{\mathrm{o}}$ of a uniform population is $\pm 10^{\circ} \%$ at $19^{\circ} \mathrm{C}$, and $\pm 6^{\circ} \%$ at $350^{\circ} \mathrm{C}$ (after Page and Heard, 1981). 
Table 4-12. Summary of laboratory thermomechanicai properties of Climax stock quartz monzonite (after Pratt et al., 1979).

\begin{tabular}{|c|c|c|c|}
\hline \multirow{2}{*}{ Thermomechanical properties } & \multicolumn{3}{|c|}{ Sample source } \\
\hline & G-l core & G-2 core & Large core \\
\hline \multicolumn{4}{|l|}{ Physical Properties } \\
\hline 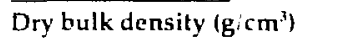 & & $2.635 \pm 0.036$ & \\
\hline Grain density $\left(\mathrm{g} / \mathrm{cm}^{3}\right)$ & & $2.723 \pm 0.027$ & \\
\hline Total porosity $\left({ }^{(0 / o}\right)$ & & $3.2 \pm 0.7$ & \\
\hline Permeability $(\mu \mathrm{D})$ & 0.12 & 0.10 & \\
\hline
\end{tabular}

Mechanical properties

\section{Compressive strength (GPa)}

$$
\begin{aligned}
& \text { (i) } \sigma_{3}=0 \mathrm{MPa} \\
& \text { al } \sigma_{3}=3.4 \mathrm{MPa} \\
& \text { (it } \sigma_{1}=6.9 \mathrm{MPa} \\
& \text { (ac } \sigma_{3}=10.3 \mathrm{MPa} \\
& \text { (a) } \sigma_{3}=20.7 \mathrm{MPa} \\
& \text { a) } \sigma_{3}=41.4 \mathrm{MPa}
\end{aligned}
$$$$
0.20 \pm 0.03
$$$$
0.20 \pm 0.03
$$

\section{Young's Modulus (GPa)}

$$
\begin{aligned}
& \text { (4) } \sigma_{3}=0 \mathrm{MPa} \\
& \text { (a) } \sigma_{3}=3.4 \mathrm{MPa} \\
& \text { (a) } \sigma_{\mathfrak{i}}=6.9 \mathrm{MPa} \\
& \text { (1i) } \sigma_{3}=10.3 \mathrm{MPa} \\
& \text { (c) } \sigma_{1}=20.7 \mathrm{MPa} \\
& \text { (G) } \sigma_{1}=41.4 \mathrm{MPa}
\end{aligned}
$$

Dynamic

$48 \pm 5$

82.8

$14 \pm 2$

3.541

$16 \pm 2$
$0.275 \pm 0.007$

$0.282 \pm 0.044$

$0.337 \pm 0.027$

$0.452 \pm 0.016$

$0.569 \pm 0.032$

73.3

$66.7 \pm 5.9$

$54.4 \pm 5.1$

$61.8 \pm 7.0$

$63.7 \pm 6.4$

$66.8 \pm 1.9$

$67.2 \pm 3.9$

\section{P-wave}

"Brazilian test.

data shown in Fig. 4-29. Although there are no exceptions, the increase in $\alpha$ with increasing temperature and the decrease with increasing pressure are quite consistent. The curve labelled "calculated" indicates the theoretical coefficient based on the expansivity of the individual mineral constituents and their relative proportions of the cores tested. Note that the measured values are consistently substantially higher than those of the crack-free mudel. 


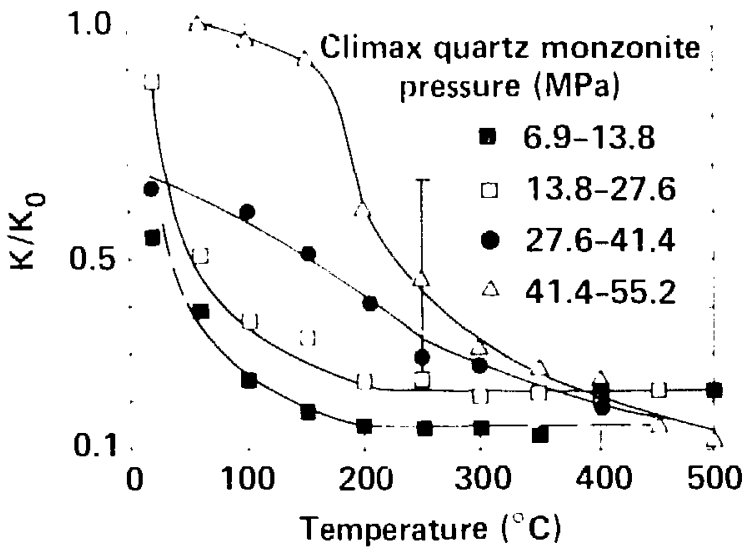

Figure 4-27. Normalized bulk modulus $\left(K / K_{0}\right)$ vs temperature for Climax quartz monzonite. The error bar represents 1 std dev of the 9-sample population, which averages $\pm 50 \%$. Estimated std dev for $K / K_{0} r . f$ a uniform population is $\pm 10 \%$ at $19^{\circ} \mathrm{C}$, ranging down to $\pm 6 \%$ at $250^{\circ} \mathrm{C}$ (after Page and Heard, 1981).

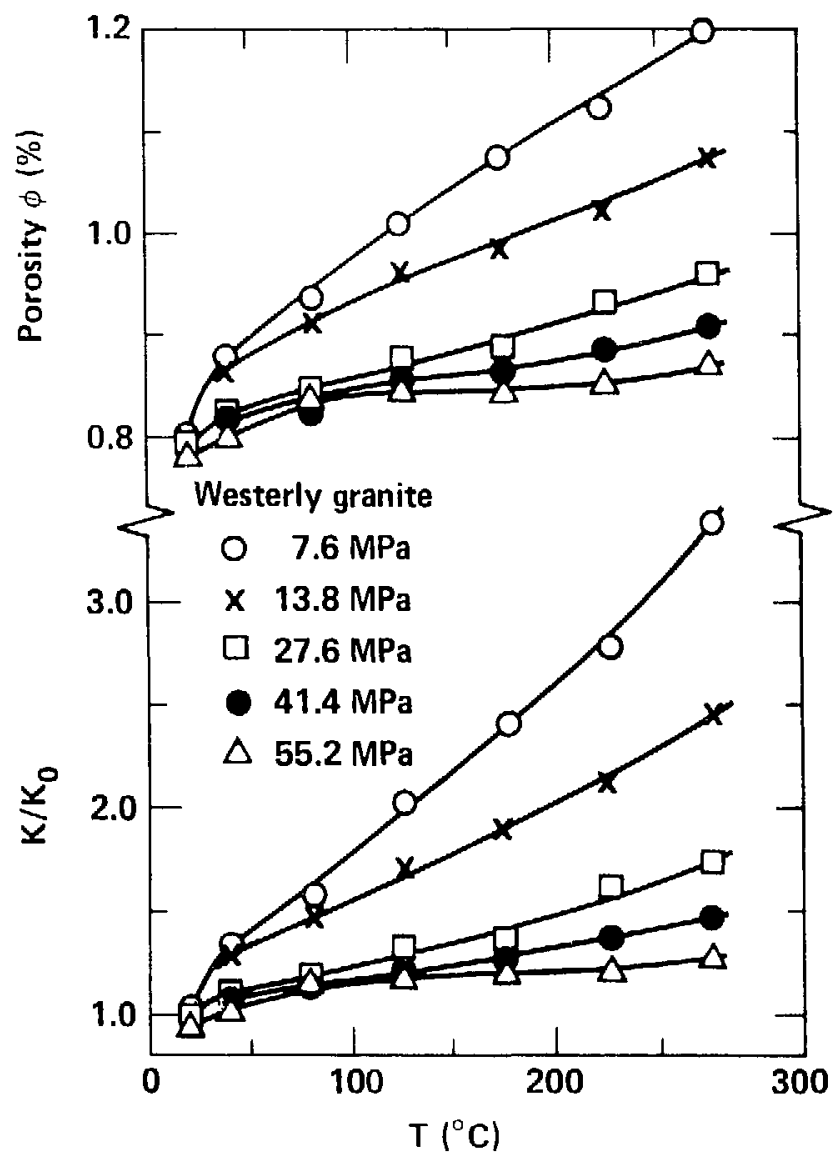

Figure 4-28. Calculated porosity (A) and normalized permeability (calculated) $K / K_{0}$, (B) at 5 pressures vs temperature for Climax quartz monzonite (after Page and Heard, 1981). 


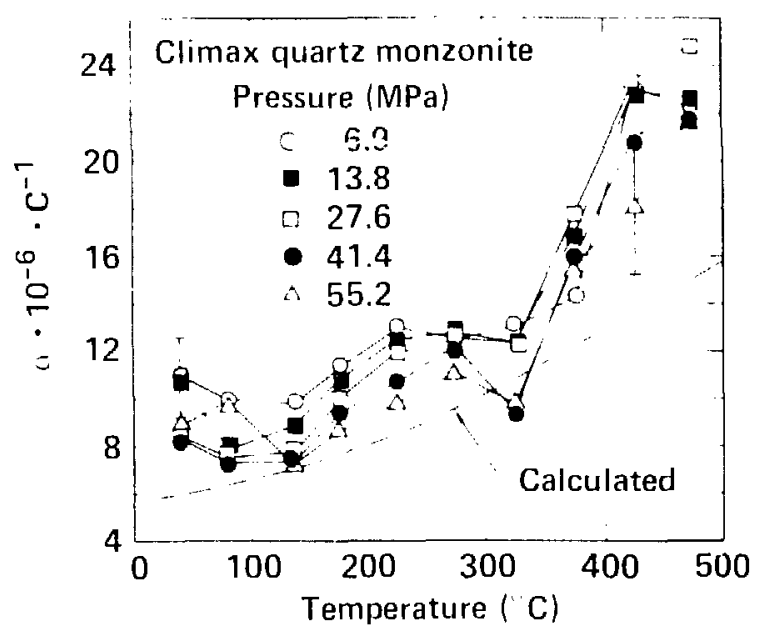

Figure 4-29. Coefficient of thermal linear expansion at five pressures vs temperature for the Climax quartz monzonite. The error bars represent 1 std dev of the 9-sample population which averages $\pm 15 \%$. Estimated std dev of a uniform population is $\pm 2 \%$ (after Page and Heard, 1981).

The observed relationships are consistent with the generally accepted model for the material: a solid containing microfractures whose behavior is altered by the generation of new microfractures with increasing temperature. Because microfractures neither open and extend as much nor form as easily at higher pressures, increasing pressure tends to resu t in properties that are nearer their intrinsic values.

\subsubsection{Laboratory Studies of Thermal Properties}

The previously cited studies of Pratt, Lingle, and Schrauf also provided thermal properties for use in early calculations (Table 4-13). These studies were extended by Durham and Abey (1981) and Durham (1982) to establish the temperature and pressure dependence of thermal conductivity and diffusivity.

The latter study also examines the effect of precondition:' $\mathrm{g}$ the samples at selected combinations of temperature and pressure.

Durham and Abey's data (1981) show the expected increase with pressure (Fig. 4-30) and decrease with temperature (Fig. 4-31) of the thermal conductivity. These effects are essentially monotonic but nonlinear. Durham (1982) subsequently showed a similar temperature effect on diffusivity (Fig. 4-32) and confirmed the previously observed effects on conductivity, even after preconditioning (Fig, 4-33). His study concluded that:

- Thermal conductivity of CSQM is $2.75 \pm 0.25 \mathrm{~W} / \mathrm{m} \cdot \mathrm{K}$ at $313 \mathrm{~K}$ and $3 \mathrm{MPa}$ confining pressure, and increases nearly linearly with pressure.

- Thermal conductivity decreases in the temperature range of 373 to $523 \mathrm{~K}$ (at all pressures) approximately as $1 / \mathrm{T}$. A slower rate of decrease is observed at lower temperatures.

- Conditioning at temperatures as high as $473 \mathrm{~K}$ has no discernable effect on room-temperature properties.

- Thermal diffusivity is $1.25 \pm 0.4 \times 10^{-\mathrm{t}} \mathrm{m}^{2} / \mathrm{s}$ at $300 \mathrm{~K}$ and $50 \mathrm{MPa}$. Variations with temperaiure and pressure are proportiona! to those observed in conductivity.

\subsubsection{Field Studies of Mechanical Properties}

Six different techniques were used to estimate in sifw deformability (Heuze et al., 1981). The means and ranges of moduli, together with selected laboratory values, are displayed in Fig. 4-34. As indicated, four of the technicyes provided sinilar estimates; the mean was $26 \mathrm{GPa}$. An estimate of the laboratory deformability was $70 \mathrm{GPa}$, yielding a ratio of field-to-laboratory deformability of 0.37 , which is about average for jointed hard rocks such as the Climax stock (Heuze, 1980). Heuze estimated the rock mass Poisson's ratio) 
Table 4-13. Summary of laboratory thermal properties of Climax stock quartz monzonite (after Pratt et al., 1979).

\begin{tabular}{lccc}
\multicolumn{1}{c}{ Properties } & $\bar{G}-1$ core & Sample source & Large core \\
\hline $\begin{array}{l}\text { Conductivity }\left(W / \mathrm{m}^{\circ}{ }^{\circ} \mathrm{C}\right) \\
\begin{array}{l}\text { vs pressure } \\
\text { vs temperature }\end{array}\end{array}$ & 3.6 & 3.7 & \\
& & & $2.92(\bar{g}) 25^{\circ} \mathrm{C}$ \\
& & $2.76 \omega 100^{\circ} \mathrm{C}$ \\
& & $1.95 @ 200^{\circ} \mathrm{C}$ \\
\hline
\end{tabular}

Not pressure-dependent in the range from 0 to $34.5 \mathrm{MPa}$.

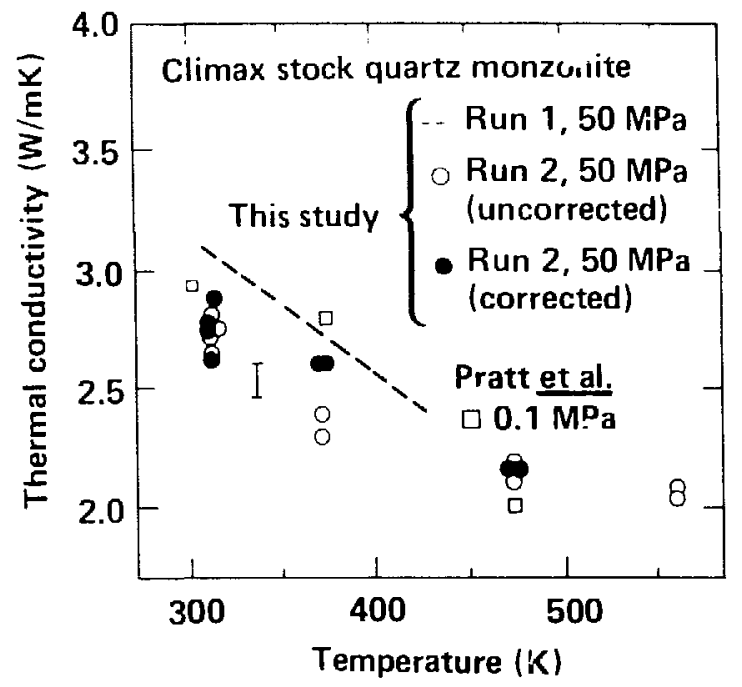

Figure 4-30. Thermal conductivity vs pressure at $313 \mathrm{~K}$ for CSQM Run 2, corrected (solid symbols). Also shown are the uncorrected data, open symbols (after Durham and Abey, 1981).

at 0.246 on the basis of stress undercore measurements and an assumption of plane strain conditions (Sec. 4.3). This study also detected an effect of excavation that caused the modulus within $0.5 \mathrm{~m}$ of the drifts to be about one-half the value elsr where.

Two of the field techniques gave estimates close to those observed in the laboratory. As explained by Heuze et al. (1981), the "modified NX jack" of de la Cruz gave high estimates because of the presence of fractures. These fractures were located such that the friction strain gauges employed in the jack experienced anomalously low strain, causing the calculated modulus to increase. In addition, petite sismique modulus estimate agreed quite well with laboratory values. It was not until several years later that Zucca (1984) was ab! to repeat the petite sismique measurements and determine that there are fundamental problems with the technique and, further, that transducer (receiver) and source problems occurred during the previous study.

With source and receiver problems resolved or mitigated, Zucca produced a dominant shear-wave frequency of $480 \mathrm{~Hz}$, substantially below the $1100-\mathrm{Hz}$ value reported by Heuze et al. (1981). As a result, the estimate of deformability decreased by more than a factor of 3 to about $15 \mathrm{GPa}$. More importantly, he concluded that since the recorded signals were source- and distance-dependent (and, hence, not solely a result of intrinsic rock properties), the petite sismique technique cannot be used with any confidence until further research resolves these dependencies. 


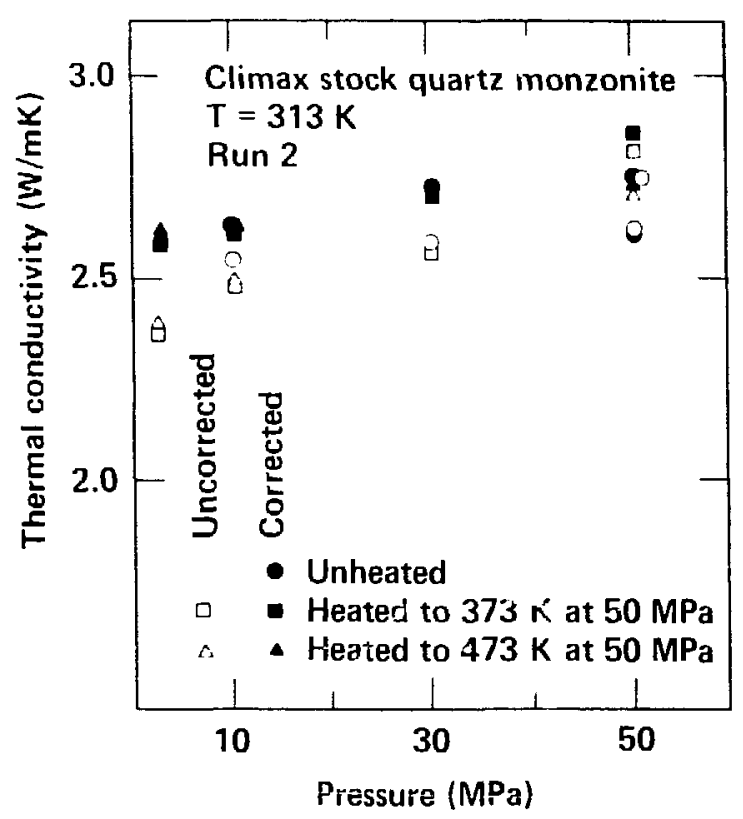

Figure 4-31. Thermal conductivity vs temperature at $50 \mathrm{MPa}$ for CSQM Run 2, corrected and uncorrected. Dashed line is uncorrected data from F.un 1. Error bar indicates precision of data from this study (after Durham and Abey, 1981).

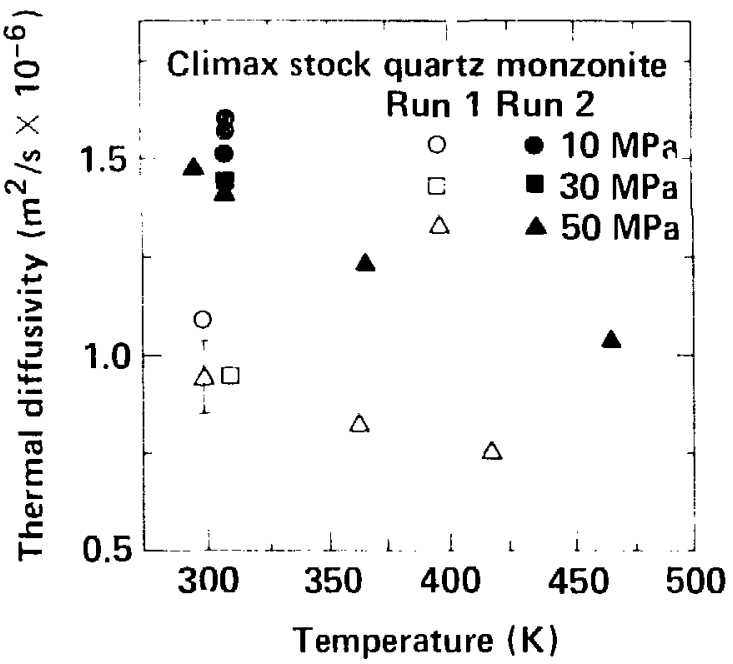

Figure 4-32. Thermal diffusivity vs temperature for various pressures for Runs 1 and 2 (after Durham, 1982).

Zucca (1984) also determined the dynamic moduli of the rock in the vicinity of the SFT-C by means of in situ compression- and shear-wave velocity measurements. He used distributions of these velocities to estimate the deformation modulus and Poisson's ratio ( \pm 1 std dev) as $61 \pm 16 \mathrm{GPa}$ and $0.28 \pm 0.08$, respectively.

After spent fuel was retrieved from the SFT-C, in $\mathrm{k}, \mathrm{Yrw}$, and Axelrod (1985) conducted extensive in situ deformability measurements using an NX bresivie jack to determine the effects of heating on the 


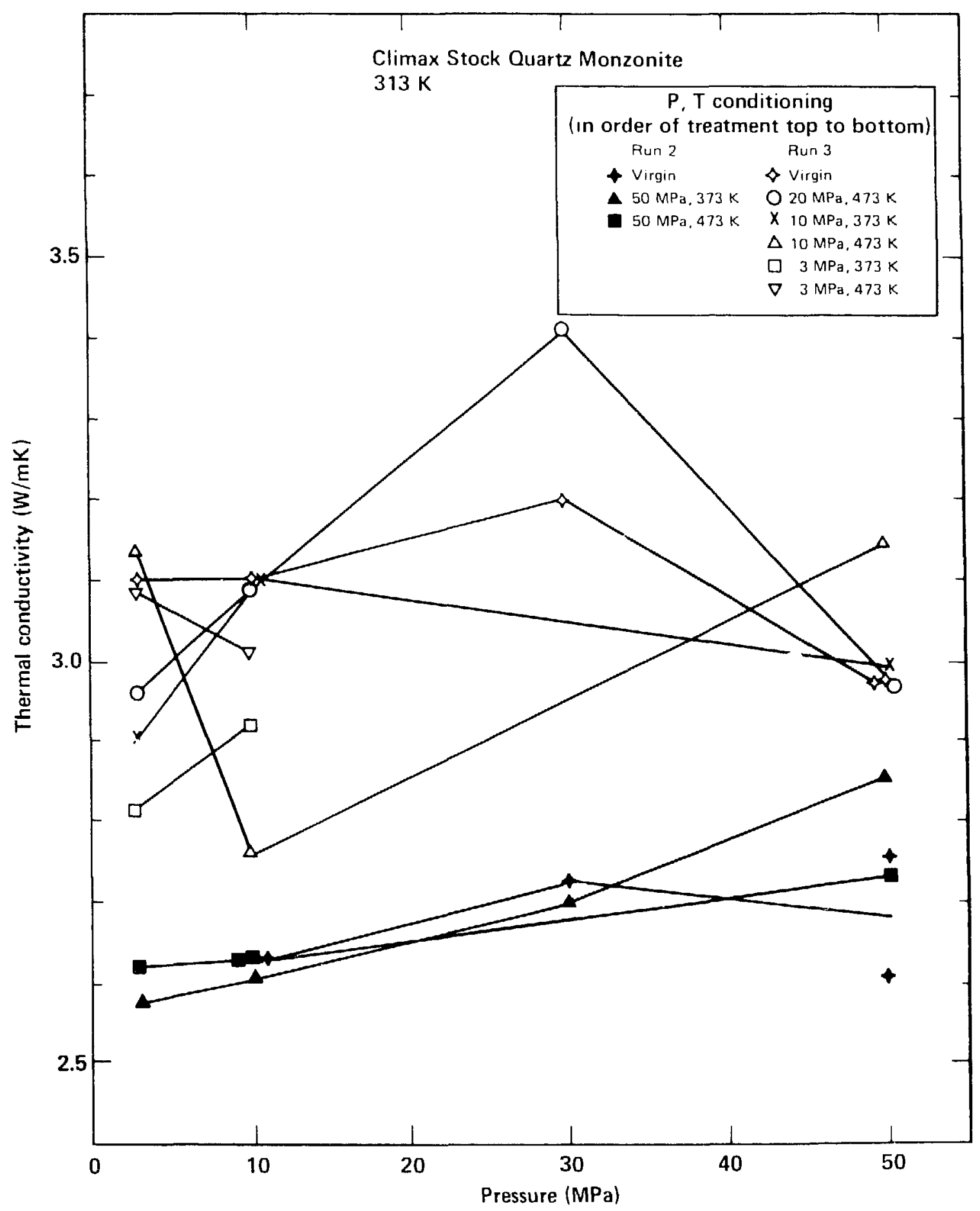

Fig. $\quad-33$. Thermal conductivity vs pressure at $313 \mathrm{~K}$ for Runs 2 and 3 showing a lack of effect due to thermus cycling (after Durham, 1982). 


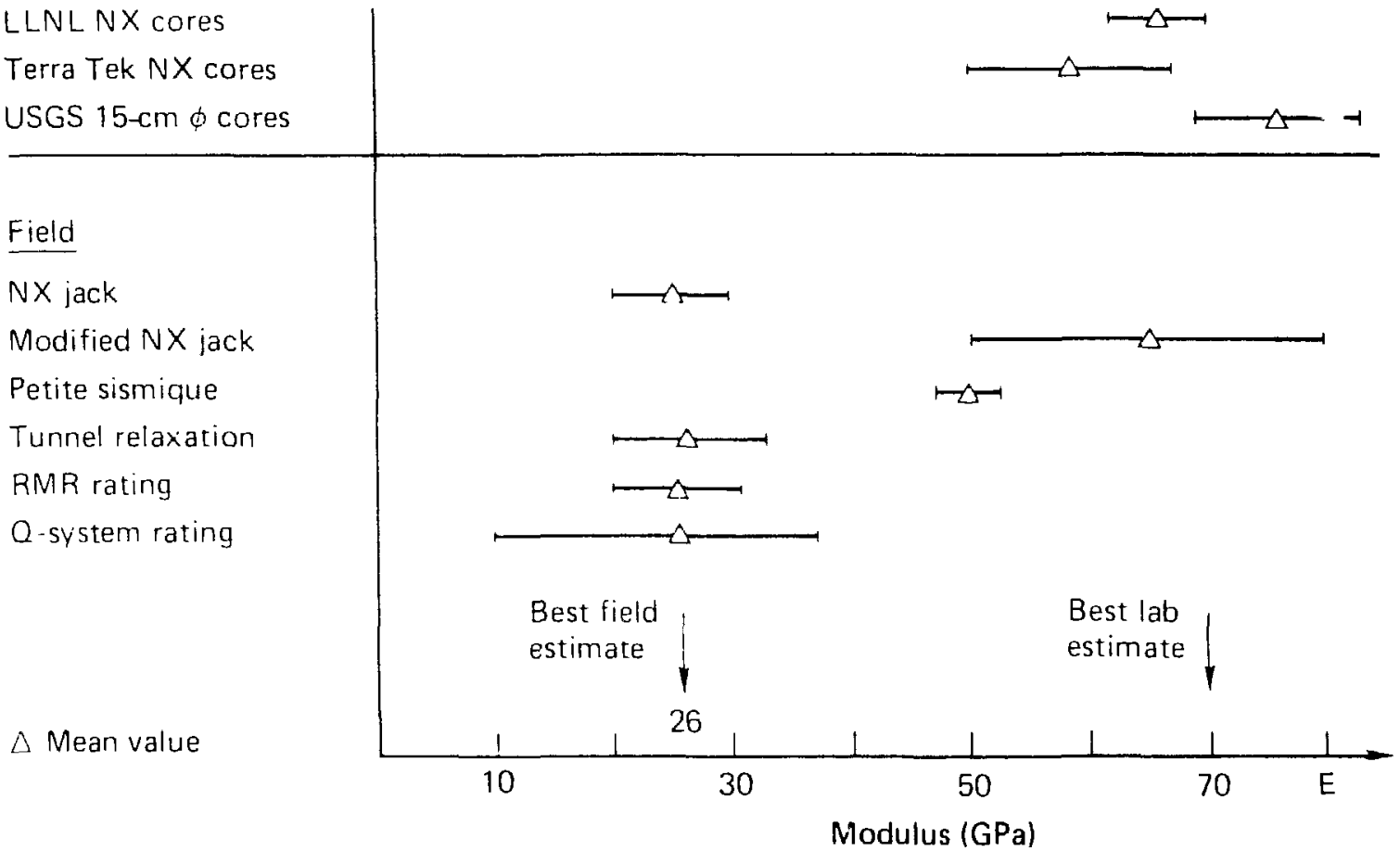

Figure 4-34. Multiple estimates of laboratory and field modulus for Climax granite (after Heuze et al., 1981).

rock mass modulus. To examine this effect, 41 preheat and 63 post-heat modulus values were compared. All these measurements were obtained from four NX $(76-\mathrm{mm}$ diameter) boreholes located in the pillars between the drifts of the SFT-C facility (Fig. 4-35). The preheat values were obtained by reanalyzing data from Heuze et al. (1981) to include the new scaling factor developed by Heuze and Amadei (1984). Postheat measurements were made in the same boreholes.

In addition to heat, the following factors were found to influence the value of modulus: position within the borehole, location within the facility (borehole location), and loading direction. Linear statistical models were used to analyze the data for these effects. Table 4-14 lists the "intercept" terms associated with the statistical models developed for data from boreholes MBI07N, MBI07S, and MBI14S. Figure 4-36 provides an example of how these general equations represent the data subsets.

These intercepts represent the mean moduli observed at the pillar center. Because modulus decreases in both directions toward the ribs, the data were pooled and the locations of measurements were referenced with respect to "distance from centerline." A pooled slope of $-7.00 \mathrm{GPa} / \mathrm{m}$ expresses this decrease in modulus from pillar center.

From Table 4-14, we conclude the following:

- Preheat modulus is strongly anisotropic with the vertical about $10.7 \mathrm{GPa}$ less than horizontal.

- Post-heat modulus is also anisotropic, but vertical values now exceed horizontal by about $9.8 \mathrm{GPa}$.

- Heating produced substantial increases in modulus values obtained under vertical loading, probably as a result of heat-induced stress increases.

- Heating effects on the modulus under horizontal loading are equivocal.

Similar statistical models for deformation modulus were developed using data from other individual boreholes or groups of boreholes (Patrick, Axelrod, and Yow, 1985). The reader is referred to their work for further discussion of spacial and thermal effects on the nearly 250 measurements obtained at the SFT-C. 


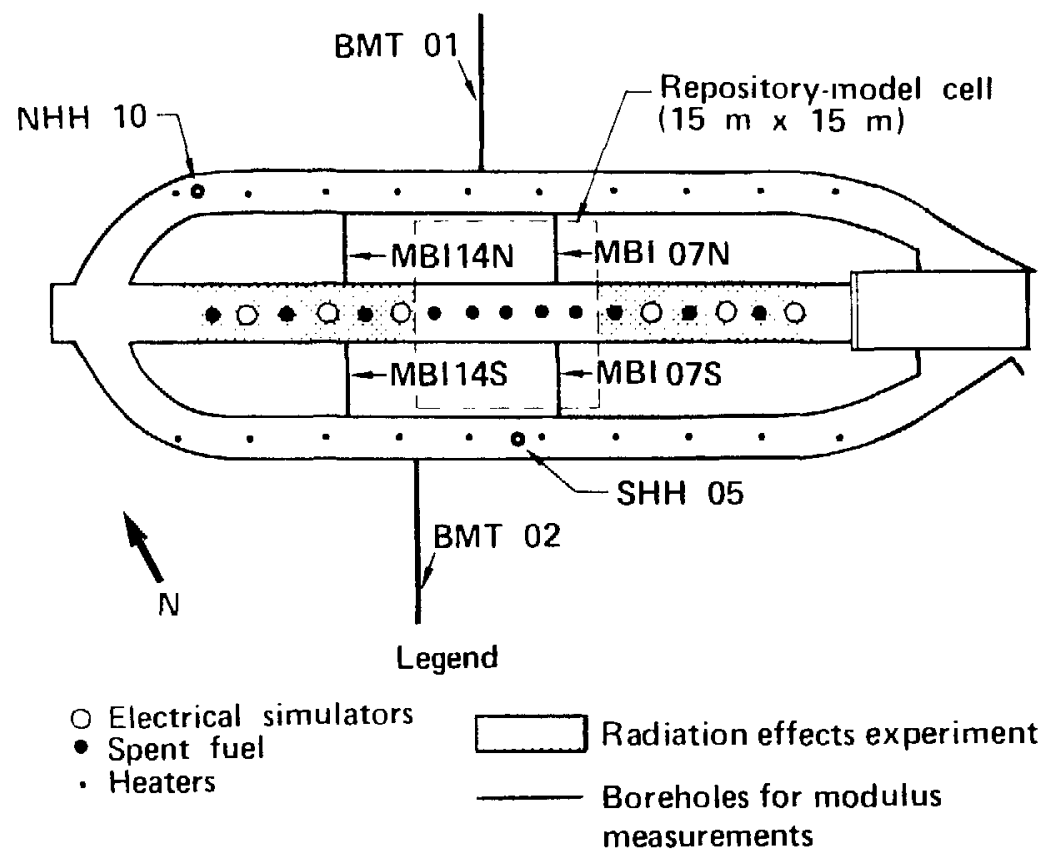

Figure 4-35. Plan view of Spent Fuel Test-Climax facility showing location of thermal sources, principal experiments, and boreholes (after Patrick, Yow, and Axelrod, 1985).

Table 4-14. Intercept coefficients calculated using a 12-term general linear model for deformation modulus, in GPa (after Patrick, Yow, and Axelrod, 1985).

\begin{tabular}{lccccc}
\hline Time of & \multicolumn{2}{c}{ North pillar } & \multicolumn{2}{c}{ South pillar } \\
\cline { 5 - 6 } medsurement & $\begin{array}{c}\text { Vertical } \\
\text { loading }\end{array}$ & $\begin{array}{c}\text { Horizontal } \\
\text { loading }\end{array}$ & $\begin{array}{c}\text { Vertical } \\
\text { loading }\end{array}$ & $\begin{array}{c}\text { Horizontal } \\
\text { loading }\end{array}$ \\
\hline Preheating & 46.5 & 57.2 & 26.3 & 37.0 \\
Post-heating & 62.7 & 52.9 & 54.6 & 44.8 \\
\hline
\end{tabular}

\subsubsection{Field Studies of Thermal Properties}

Before the SFT - C. was authorized, a relatively large-scale heater tesi was conducted at the Climax stock to determine the in situ thermal properties and gas permeability of ihe rock mass (Montan and Bradkin), 1984). The geometry of Heater Test No. 1 and its location relative to the shaft used to access the SFT $-C$ are shown in Figs. 4-37 and 4-38. The alignment of the two heaters and instrument arrays was selected to facilitate determination of anisotropy with respect to heat transfer and permeability.

Montan and Bradkin (1984) analyzed the test thermal data by varying the thermal conductivity and diffusivity values in a model for conductive heat transfer, which treated the heaters as a set of point sources with appropriate source strengths. Based on a sensitivity study in which conductivity, diffusivity, and thermocouple location were varied, they estimate the conductivity and diffusivity values to be about 3.1 $\mathrm{W} / \mathrm{m} \cdot \mathrm{K}$ and $1.2 \mathrm{~mm}^{2} / \mathrm{s}$, respectively (Fig. 4-39). Durham's (1982) comparable laboratory values of these properties are $2.75 \pm 0.25 \mathrm{~W} / \mathrm{m} \cdot \mathrm{K}$ and $1.25 \pm 0.4 \mathrm{~mm}^{2} / \mathrm{s}$, respectively. Although Durham's mean conductivity appears to be substantially lower than the field value, Fig, 4-33 reveals that his data cluster near 2.6 $\mathrm{W} / \mathrm{m} \cdot \mathrm{K}$ for one sample and $3.0 \mathrm{~W} / \mathrm{m} \cdot \mathrm{K}$ for the other. Given the known heterogeneity of the CSQM and the 


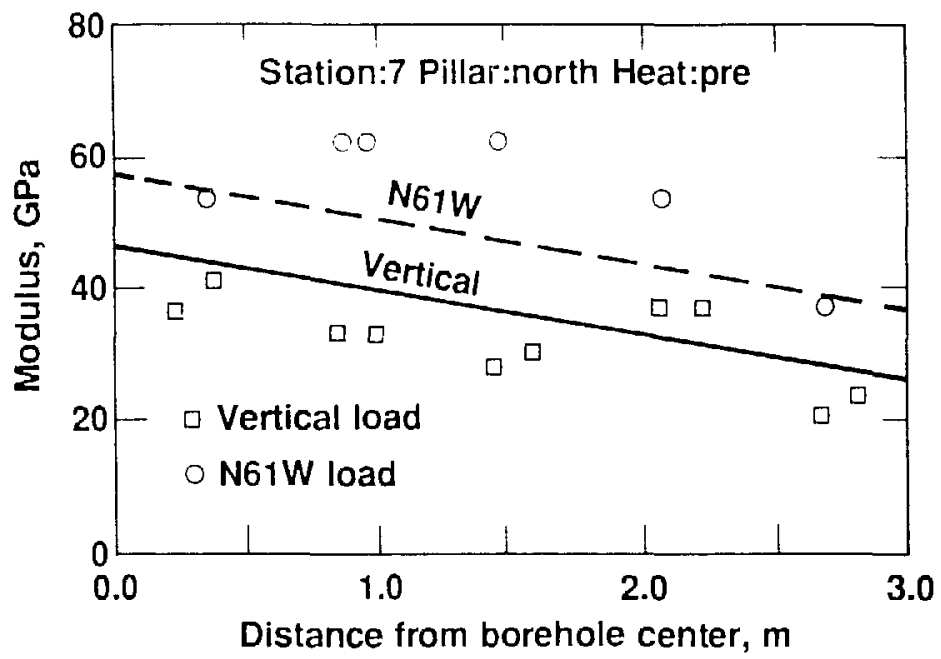

Figure 4-36. Typical example of relationship between borehole modulus value and distance from pillar center. The slope and intercepts of the lines were developed from a 12-term general linear model (after Patrick, Yow, and Axelrod, 1985).

laboratory sample size, Montan and Bradkin (1984) concluded that their in situ measurements are a more accurate reflection of the average rock properties.

\subsubsection{Field Studies of Permeability}

Gas permeability measurements were also made as an integral part of Heater Test No. 1. Permeability tests were conducted during periods of relatively stable borehole temperatures (Fig. 4-40).

Data analysis was based on Jaeger's (1956) solution for cooling a heated infinite cylinder and used Morrison's (1972) technique for "linearizing" this inherently nonlinear problem of porous flow of a compressible gas. Details of this analysis and related data reduction techniques are provided by Montan and Bradkin (1984).

Table 4-15 summarizes the average permeabilities measured during Heater Test No. 1. Included are the porosities, temperatures, and root-mean-square residuals resulting from the curve fitting. Ambienttemperature permeability was about $1 \mathrm{nD}$, decreasing to $0.2 \mathrm{nD}$ at $50^{\circ} \mathrm{C}$ above amoient. At higher temperatures, they reported that the permeability was too small to measure with the techniques used. Upon cooling, the permeability returned to near its initial value, implying that no permanent change occurred in this property.

\subsection{Mineralogical and Petrological Studies of c nax Pretest Cores*}

This section presents mineralogical and petrological data from the characterization of samples from the 17 canister core holes (CCH 1-17) by Ryerson and Qualheim (1983). These cores were obtained from just inside the perimeter of emplacement holes that were subsequently hammer-drilled to $0.61 \mathrm{~m}$ in diameter and loaded with either spent-fuel assemblies (hole numbers $1,3,5,7-12,14,16$ ) $c$ electrical simulators (hole numbers 2, 4, 6, 13, 15, 17) (Chapter 12 and Ramspott et al., 1981). The purpose of this investigation was to provide a data base of mineralogical compositions, assemblages, and modal proportions from pretest samples to compare with a similar data base obtained from post-test samples. The post-test core samples were ubtained from just outside the perimeter of the canister emplacement holes directly adjacent (along a radius) to the pretest core. This allowed us to determine whether any mineralogical changes occurred during the course of the test. The close proximity of the pre- and post-test cores also allowed us to

*Contributed by F I Ryersion 
(a)
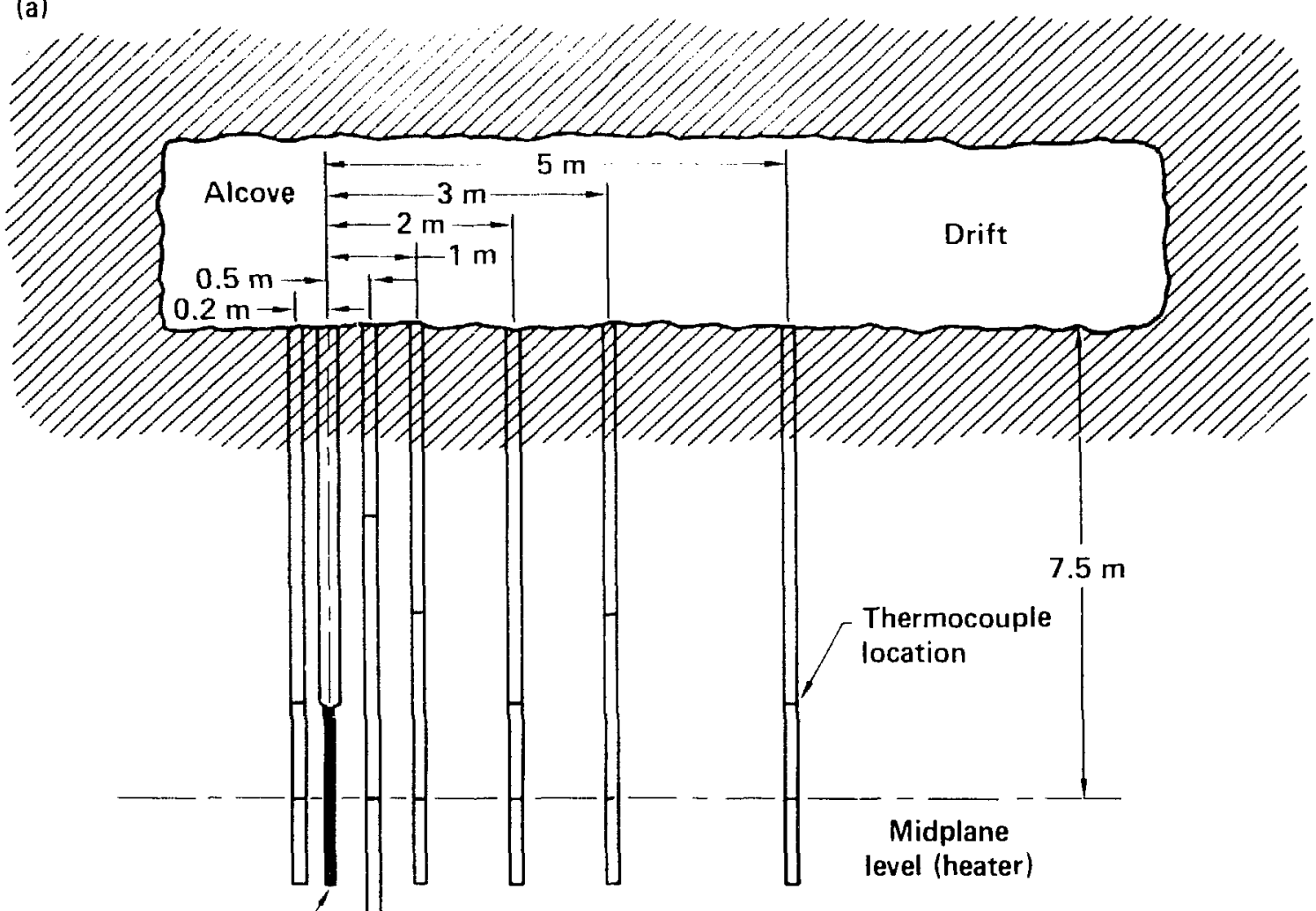

(b)

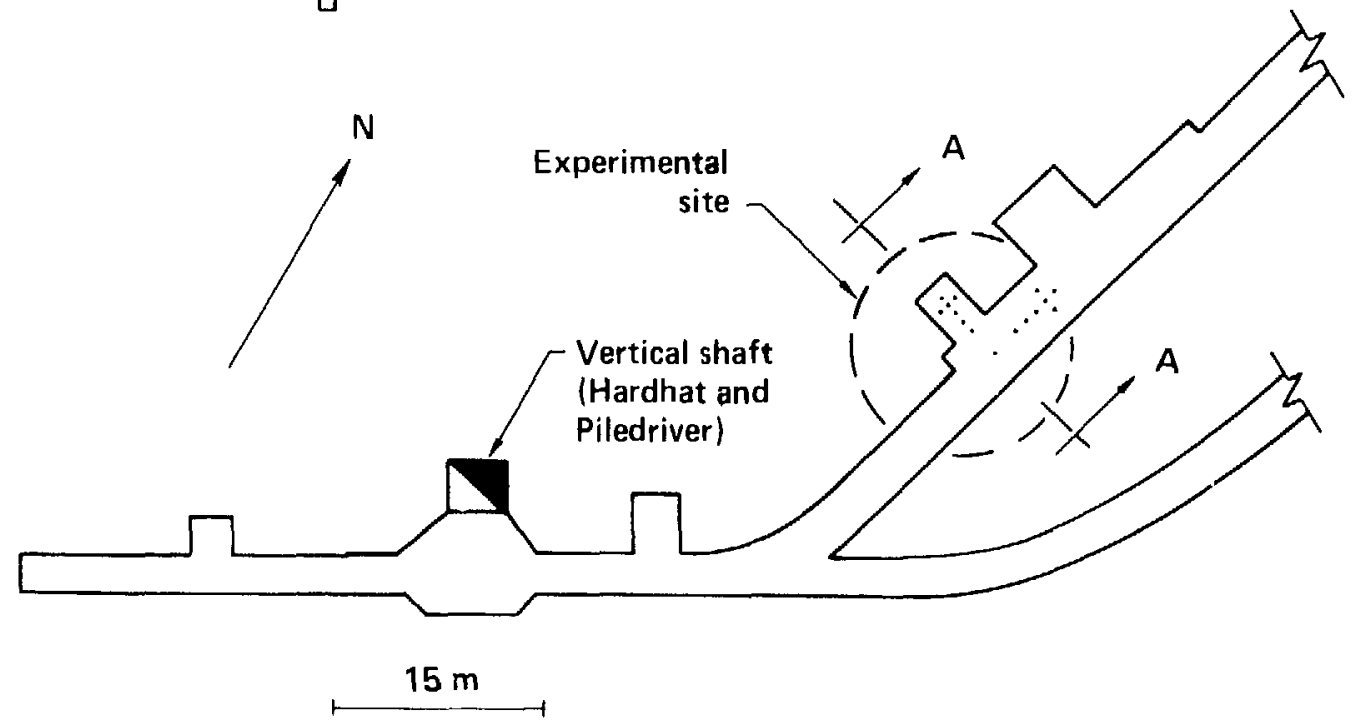

Figure 4-37. (a) Vertical cross section and (b) plot plan of Heater Test No. 1 (after Montan and Bradkin, 1984). 


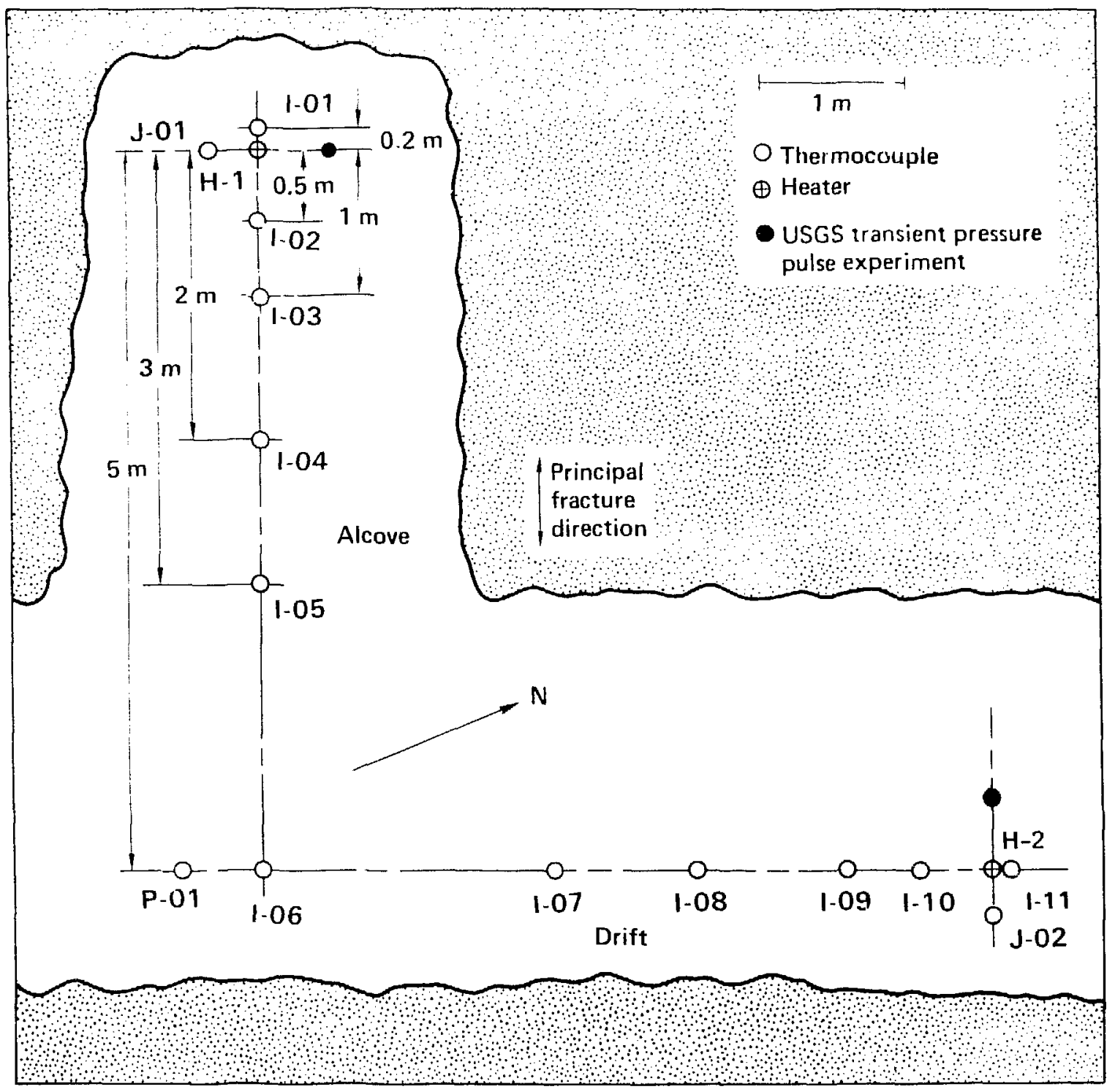

Figure 4-38. Heater test layout (after Montan and Bradkin, 1984).

assess the possible migration of materials produced as a result of the stored spent-fuel assemblies, electrical simulators, and/or the presence of alteration-generated materials along the various types of fractures in the quartz monzonite. The effects of spent-fuel assemblies vs electrical simulators were also investigated (Sec. 4.6).

\subsubsection{Sample Selection}

A reference line was drawn longitudinally along the recovered core to measure distances along the core and to determine the relative orientations of tractures for logging and sample selection. The location and orientation of all fractures and alteration zones in the 17 core samples were recorded at NTS. Using these core logs, $0.3-$ to $0.6-\mathrm{m}$ sections of core were selected using the following criteria:

1. Top of core.

2. Bottom of core. 

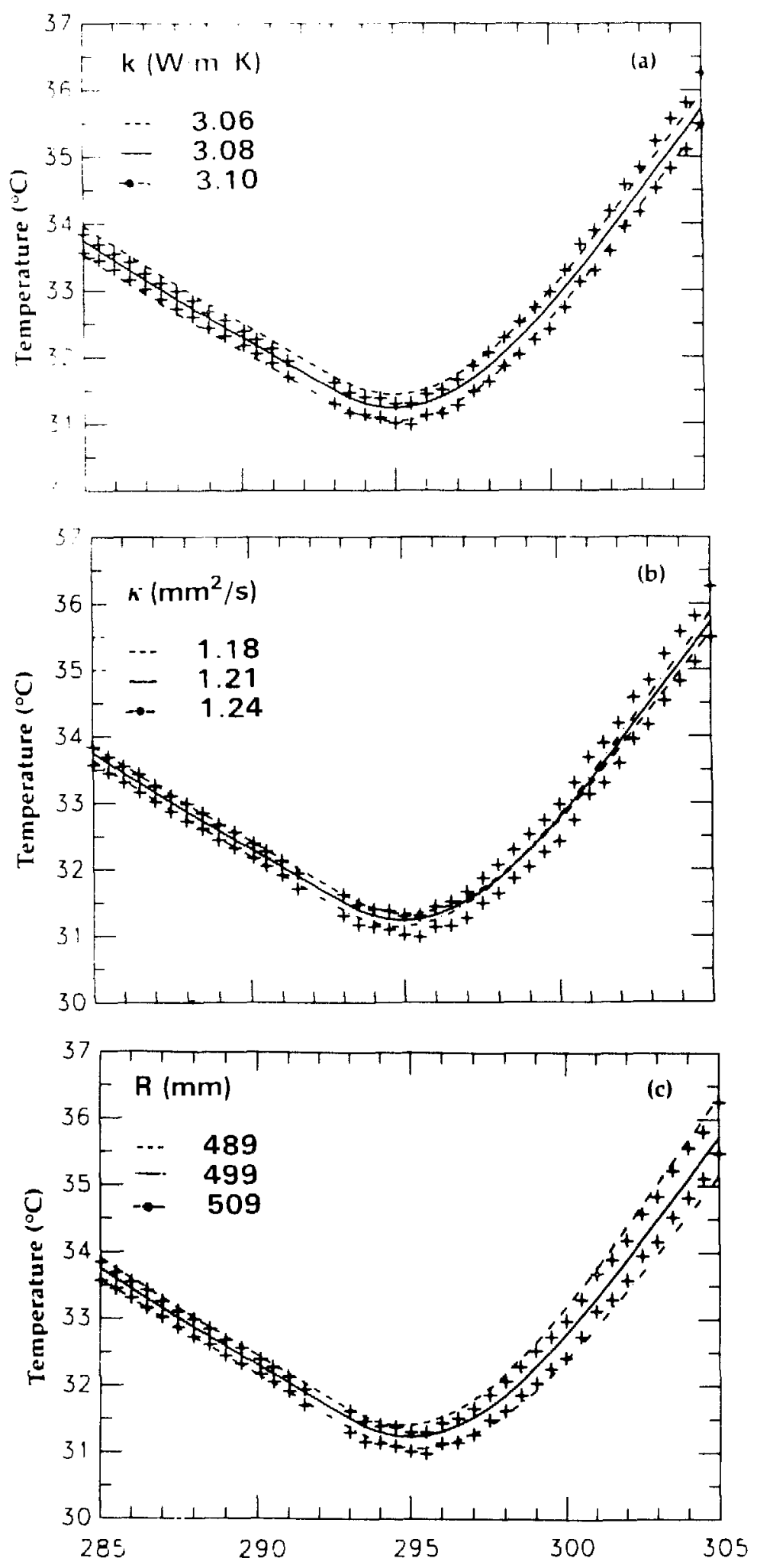

Time (hours)
Figure 4-39a. Measured and calculated data for 20-h time span from two midplane thermocouples in hole I-02, showing sensizivity with respect to conductivity. Here $k=$ $1.21 \mathrm{~mm}^{2} / \mathrm{s}$ ?ind $\mathrm{R}=499 \mathrm{~mm}$ (after Montan and Bradkin, 1984).

Figure 4-39b. Measured and calculated data for 20-h time span from two midplane thermocouples in hole $1-02$, showing sensitivity with respect to diffusivity. Here $k=3.08$ $\mathrm{W} / \mathrm{m} \cdot \mathrm{K}$ and $\mathrm{R}=\mathbf{4 9 9} \mathrm{mm}$ (after Montan and Bradkin, 1984).

Figure 4-39c. Measured and calculated data for 20-h time span from two midplane thermocouples in hole U-02 showing sensitivity with respect to distance. Here $k=3.08$ $W / \mathrm{m} \cdot \mathrm{K}$ and $\kappa=1.21 \mathrm{~mm}^{2} / \mathrm{s}$ (after Montan and Bradkin, 1984). 


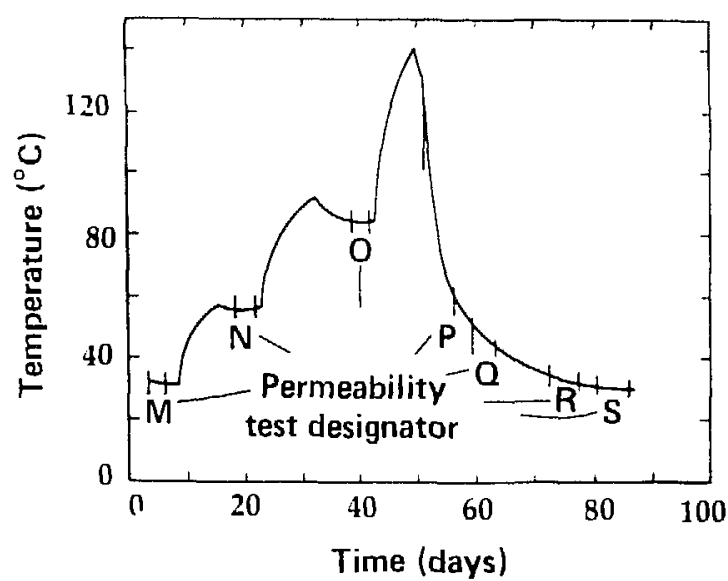

Figure 4-40. Temperature history of permeability test at $0.4 \mathrm{~m}$ from heater (after Montan and Bradkin, 1984).

Table 4-15. Permeability test results (see Fig. 4-40 for test sequence designator) (after Montan and Bradkin, 1984).

\begin{tabular}{|c|c|c|c|c|c|c|c|c|c|c|c|c|c|c|c|c|}
\hline \multirow{3}{*}{$\begin{array}{c}\begin{array}{c}\text { Borehole } \\
\text { designator }\end{array} \\
\mathrm{H}-2\end{array}$} & \multirow{3}{*}{$\begin{array}{c}\begin{array}{c}\text { Distance } \\
\left(\mathrm{w}^{\prime}\right.\end{array} \\
0.0\end{array}$} & \multicolumn{2}{|r|}{$\mathbf{M}$} & \multicolumn{2}{|c|}{$\mathbf{N}$} & \multicolumn{2}{|c|}{0} & \multicolumn{2}{|c|}{$P$} & \multicolumn{2}{|c|}{$Q$} & \multicolumn{2}{|r|}{$\mathbf{R}$} & \multicolumn{3}{|c|}{ S } \\
\hline & & b & b & $\mathbf{b}$ & b & 1.09 & 0.0071 & $\mathrm{~b}$ & $\mathbf{b}$ & PF & & PF & & $\mathrm{Pr}$ & Perm., & Porosity, \\
\hline & & 32.4 & 0.016 & 290.9 & 0.049 & 419.3 & 0.082 & 85.0 & 0.261 & & & & & & $k, \mathrm{nD}$ & $\phi$ \\
\hline \multirow[t]{2}{*}{$\mathrm{J}-02$} & 0.4 & 0.40 & 00.0028 & 0.15 & 50.0010 & $b$ & b & PF & & PF & & PF & & PF & Temp., & Residual \\
\hline & & 32.3 & 0.007 & 51.2 & 0.009 & 74.3 & 0.015 & & & & & & & & $1,{ }^{\prime \prime C}$ & error, psi \\
\hline \multirow[t]{2}{*}{1.09} & 0.73 & 0.62 & 20.0047 & 0.13 & 30.0103 & $b$ & b & 0.070 & 00.0029 & 0.93 & 30.0011 & 1.08 & 00018 & NI & & \\
\hline & & 32.4 & 0.007 & 43.6 & 0.007 & 59.4 & 0.014 & 70.9 & 0.060 & 46.8 & 0.009 & 36.4 & 0.008 & & & \\
\hline \multirow[t]{2}{*}{$1-10$} & 0.37 & 1.19 & 90.0031 & 0.24 & 40.0053 & b & b & b & b & 0.78 & 80.0013 & 1.16 & 0.0009 & NI & & \\
\hline & & 32.4 & 0.007 & 53.4 & 0.017 & 78.4 & 0.062 & 80.8 & 0.043 & 47.7 & 0.008 & 36.6 & 0.009 & & & \\
\hline \multirow[t]{2}{*}[-1]{} & 0.4 & 0.65 & 90.0001 & 0.13 & 30.0012 & b & b & $\mathrm{b}$ & b & 1.03 & 30.0025 & 1.27 & 70.0013 & 1.310 .0010 & & \\
\hline & & 32.3 & 0.009 & 51.3 & 0.018 & 74.1 & 0.067 & 78.8 & 0.077 & 47.5 & 0.008 & 36.5 & 0.007 & $33.7 \quad 0.009$ & & \\
\hline \multirow[t]{2}{*}{ I-06 } & 4.92 & NI & & NI & & NI & & NI & & NI & & NI & & 0.880 .0013 & & \\
\hline & & & & & & & & & & & & & & $28.7 \quad 0.010$ & & \\
\hline \multirow[t]{2}{*}{$P-01$} & 5.23 & NI & & NI & & NI & & NI & & NI & & NI & & 1.670 .0001 & & \\
\hline & & & & & & & & & & & & & & $28.2 \quad 0.015$ & & \\
\hline
\end{tabular}

- Distance to test borehole measured from centerline of heater borehole.

"No meaningful result. Negative permeability and porosity calculated.

NI = not instrumented.

$\mathrm{PF}=$ packer failure.

3. Sample representing (as closely as possible) "fresh" unaltered rock free of fractures, i.e., "bulk sample."

4. Samples encompassing all the different types of alteration that could be described in hand specimen (it turns out that much of the sampling was redundant). 


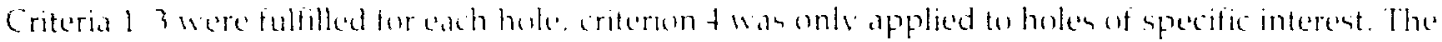

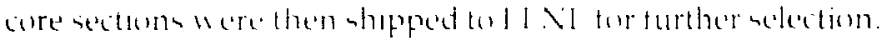

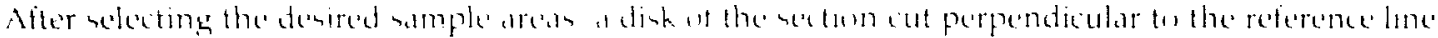
was removed irom the core. Thes disk was then cut in half parallel to the reference line, anc piece was retained at LLNL while the other was unet to propare potiahed thin sections.

\subsubsection{Petrography}

Petrography and Modal Analysis. All thin sections were obererved in plane and coms polarized, transmitted light to determme mineral assemblegres and textures. Several samples were then puintcounted $200(0)$ point modes) in tranamitted light to determine modal ahundances. The samples selerted for modal analysis were:

1. All samples frum CCH-1.

2 The "bulk sample" from each hole

Samples from group (1) were uned to demonatrate the vartation in modal abundances in a epecific hole ar a result of alteration and rein injection. The group (2) hamples were thosen as "fresh" rock. Modal variatoons among these numples should. therefore, demonstrate the range of nostal abundances in unattored rock as a function of pusition along the canister dritt.

Unaltered Rock. The quarte monzonite in a porphritic rock componed of a groundmass comprining

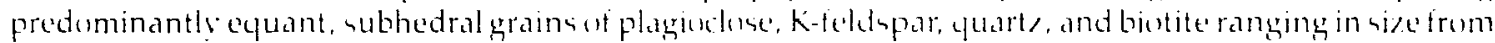
0.5 to $2.0 \mathrm{~mm}$ in diameter. Ignewus accessury phases (titanite, allanite, ziroun, and apatite) are below $3 \mathrm{vol} \%$.

Vein Mineralogy. Two distinctly different types of mineral assemblages are found in the veins within the canister drift region. The first vein, henceforth referred to as "barren," is composed of cuart/ with or without pyrite. Alteration zones adjacent to the barren veins are typically thin $(<5 \mathrm{~mm}$ ) and lack intense secondary mineralization. In particular, calcite is never found in these alteration zones.

The secund rein assemblage is composed of yuartz, calcite, pyrite, and apatite. It may alsucontain grains of muscovite. K-feldspar, and intensely altered plagioclase. The alteration zones adjacent to these "fertile" reins can he as large as $2 \mathrm{~cm}$ in width, and often show intense alteration.

Alteration of Plagioclase. Plagioclase from the Climax stock is almost always altered to some combination of muscovite, epidote, and calcite (Table 4-16). The most common assemblages are plagioclase and musco:ite (B) and plagioclase, muscovite and calcite (C), which are found in $43 \%$ and $35 \%$ of the sample areas, respectively. The alteration phases generally have irregular outlines, although muscovite is often present as fan-shaped aggregates. The percentage of plagioclase converted in a single grain can range from 0 to $75 \mathrm{vol} \%$, and the distribution of converted and unconverted plagioclase is sporadic, although greater conversion is noted near veins.

It should also be noted that the plagioclase alteration assemblages can be correlated with the vein mineral assemblage about which they are localized. Assemblages B and D (from Table 4-16) are usually found adjacent to "barren" veins, whereas assemblages $C$ and $E$ are found adjacent to "fertile" veins.

Alteration of Biotite. The alteration of biotite in these samples is extremely complex and makes any classification scheme quite difficult. The secondary phases found on biotite include chlorite, muscovite, epidote, titanite, rutile, calcite, and pyrite. In any particular sample, the number of phases found on biotite

Table 4-16. Mineral assemblages formed during the alteration of plagioclase (after Ryerson and Qualheim, 1983).

$\begin{array}{ccc}\begin{array}{c}\text { Assemblage } \\ \text { designator }\end{array} & \begin{array}{c}\text { Principle assemblage } \\ \text { components }\end{array} & \text { No, of regions } \\ \text { A } & \text { Pc } & 10 \\ \text { B } & \text { Pc. Mu } & 55 \\ \text { C } & \text { Pc, Mu, C } & 45 \\ \text { D } & \text { Pc, Mu, Ep } & 8 \\ \text { E } & \text { Pc, Mu, Ep, Cc } & 11\end{array}$


may vary: For instamce, une biotite grain may include only chlorite, whereas an adjacent grain contains chlorite and epidente. ()urclassitication schene is based on the maximum number of phases found on hiotite rather than on the must treyuent asemblage. lis: variability and, in some cases, large number of phases may be related to variability in the pore flude conposition during alteration and or the variability in cation transport paths within the rocks.

A large variety of alteration assemblages is found on biotite (Table $4-17$ ). The most common of these are (a) biotite and chlorite; (b) biotite, chlorite and epidote, and (c) chlorite, muscovite, epidote, and titanite, which are found in $23 \%$, $20 \%$, and $13 \%$ of the somples classified, respectively.

The alteration assemblages in Table 4-17 record a progressive loss of iron and magnesium from the biotite sites. This is first seen by the replacenent of biotite by chlorite. Further depletion of iron and magnesium results in the complete disappearance of biotite, which often produces symplectic intergrow ths of muscovite and chlorite that include scattered anhedral grains of epidete or titanite and or rutile needles. Eventually, even chlorite may disappear, leaving assemblayes that are prodominantly muscovite. An additional feature of the biotite-free samples is the presence of alcite after biotite. The calcite commonly appears along cleavage traces in chlorite or muscovite, but may also be found as anhed ral grains with these phasises.

Modal Analyses. Results of modal analyses for CCH-1 samples and "bulk amples" from each of the $17 \mathrm{CCHs}$ are presented in volume percent and were obtained from 2000 point modes. Percentages of key phases have been plotted against sample position in Figs. 4-41 and 4-42. Table 4-17. Mineral assemblages formed during
the alteration of biotite (after Ryerson and
Qualheim, 1983).

\begin{tabular}{|c|c|c|}
\hline $\begin{array}{l}\text { Assemblage } \\
\text { designator }\end{array}$ & $\begin{array}{c}\text { Principle assemblage } \\
\text { components }\end{array}$ & No. of regions \\
\hline 1 & Bt & 0 \\
\hline$:$ & Bt, Chl & 30 \\
\hline 3 & Bt, Chl, Mu & 1 \\
\hline 4 & $B t, C h l, E_{p}$ & 26 \\
\hline 5 & Bt, Chl, Tn & 2 \\
\hline b & Bt, Chl, Mu, Ep & 1 \\
\hline 7 & Bt, Chl, Ep, Tn & 5 \\
\hline 8 & Bt, Chl, $\mathrm{Mu}_{\mathbf{u}}, \mathrm{Tn}, \mathrm{Ru}$ & 1 \\
\hline 9 & $\mathrm{Bt}, \mathrm{Chl}, \mathrm{Mu}, \mathrm{Ep}, \mathrm{Tn}$ & 2 \\
\hline 10 & Bt, Chl, Ep, Tn, Ru & 1 \\
\hline 11 & $\begin{array}{l}\text { Bt, Chl, Mu, Ep, Tn, } \\
\text { Ru }\end{array}$ & 2 \\
\hline 12 & $\mathrm{Chl}, \mathrm{Mu}, \mathrm{Tn}$ & 6 \\
\hline 13 & Chl, Ep, Tn & 4 \\
\hline 14 & Chl, Mu, Ep, Tn & 17 \\
\hline 15 & Chl, Mu, Tn, Cc & 2 \\
\hline 16 & $\mathrm{Chl}, \mathrm{Mu}, \mathrm{Tn}, \mathrm{Ru}$ & 3 \\
\hline 17 & $\mathrm{Chl}, \mathrm{Mu}, \mathrm{Ru}, \mathrm{Cc}$ & 4 \\
\hline 18 & $C h i, \mathrm{p}_{\mathrm{p}}, \mathrm{T}_{\mathrm{n}}, \mathrm{Ru}$ & 1 \\
\hline 19 & Chl, Mu, Ep, Tn, Cr & 3 \\
\hline 20 & Chl, Mu, Ep, Tn, Ru & 4 \\
\hline 21 & Chl, Mu, Ep, Ru, Cc & 3 \\
\hline 22 & $\mathrm{Chl}, \mathrm{Mu}, \mathrm{Tn}, \mathrm{Ru}, \mathrm{Cc}$ & 4 \\
\hline 23 & $\begin{array}{l}\text { Chl, Mu, Ep, Tn, Ru, } \\
\text { Cc }\end{array}$ & 1 \\
\hline 24 & $\mathrm{Mu}, \mathrm{Tn}_{\mathrm{n}}$ & 4 \\
\hline 25 & $\mathrm{Mu}, \mathrm{E}_{\mathrm{p}}, \mathrm{Tn}, \mathrm{Cc}$ & 2 \\
\hline
\end{tabular}




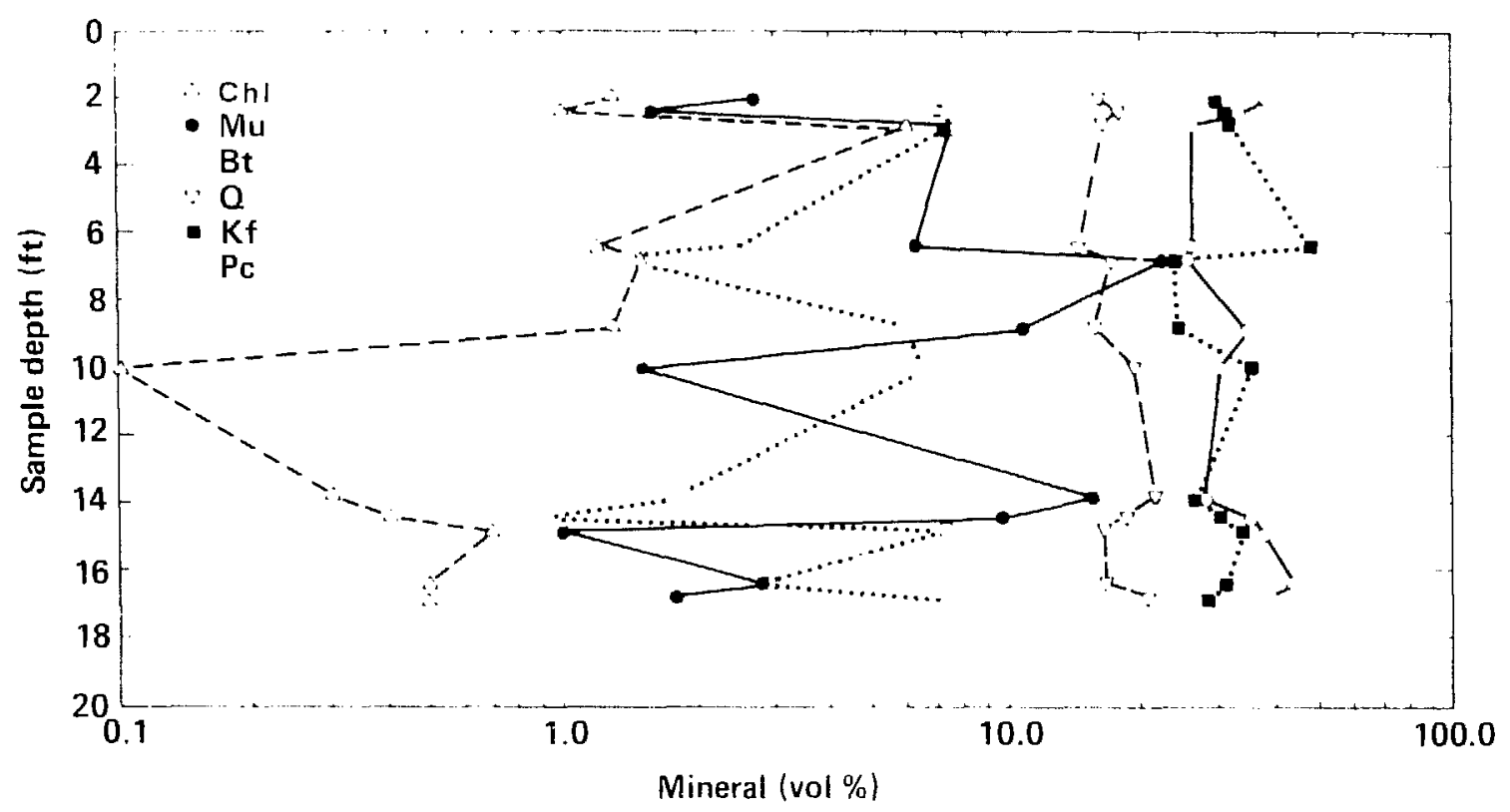

Figure 4-41. Modal abundances of major minerals from $\mathrm{CCH} 1$ samples plotted vs depth in sample core (after Ryerson and Qualheim, 1983).

Modal analyses for the $\mathrm{CCH}-1$ were obtained from the entire thin section regardless of any sample heterogeneity. Material from veins, alteration zones, and unaltered regions was all weighted equally so that we could document sample variability on this scale. Modal percentages for the primary phasesquartz, plagioclase, and K-feldspar-are fairly constant, with average modal volumes of $17.3 \% \pm 2.1 \%$, $32.8 \% \pm 5.6 \%$ and $31.2 \% \pm 5.3 \%$, respectively. The variation of 1 std dev for plagioclase and K-feldspar is similar in spite of the much more pronounced alteration of plagiodase. Biotite is also a primary phase, but displays a much larger percent variation than do the felsic phases. The average biotite volume is $4.9 \% \pm$ $2.7 \%$. The higher variability in biotite abundance is consistent with textural variability demonstrated earlier for biotite alteration.

Muscovite, chlorite, epidote, clinozoisite, titanite, and pyrite are present as secondary minerals. Their secondary origin is reflected in much larger variations in their modal abundance (Fig. 4-41), and results from both variabilty in alteration down $\mathrm{CCH}-1$ and the presence or absence of veins that carried the hydrothermal solutions.

The modal abundances for the bulk samples are shown in Fig. 4-42. Of the primary phases, only plagioclase appears to be significantly higher in the fresh bulk samples than in the variably altered samples from $\mathrm{CCH}-1: 42.8 \%$ vs $32.8 \%$, respectively. This is consistent with the observation that plagioclase is the only felsic phase that undergces significant alteration.

The modal volumes of the secondary phases are as variable in the "bulk samples" as in those from $\mathrm{CCH}-1$ (Fig. 4-42). However, the variation in average volumes of secondary phases in the bulk samples is less.

\subsubsection{Mineral Chemistry}

Microprobe Analysis. Ryerson and Qualheim (1983) obtained micruprobe analyses in buth automated and interactive modes by using a $2-\mu \mathrm{m} \times 2-\mu \mathrm{m}$ rastered beam at 15 na sample current (measured in a Faraday cup), with an accelerating voltage of $15 \mathrm{kV}$. The totally automated analyses were undertaken to objectively determine the frequency of $K$-feldspar and plagioclase compositions within selected samples. In this mode, 300 analyses were obtained along a grid covering the sample surface. The interactive analysis required the operator to select specific analysis points to determine the compositions of alteration phases that are normally low in the mode. 


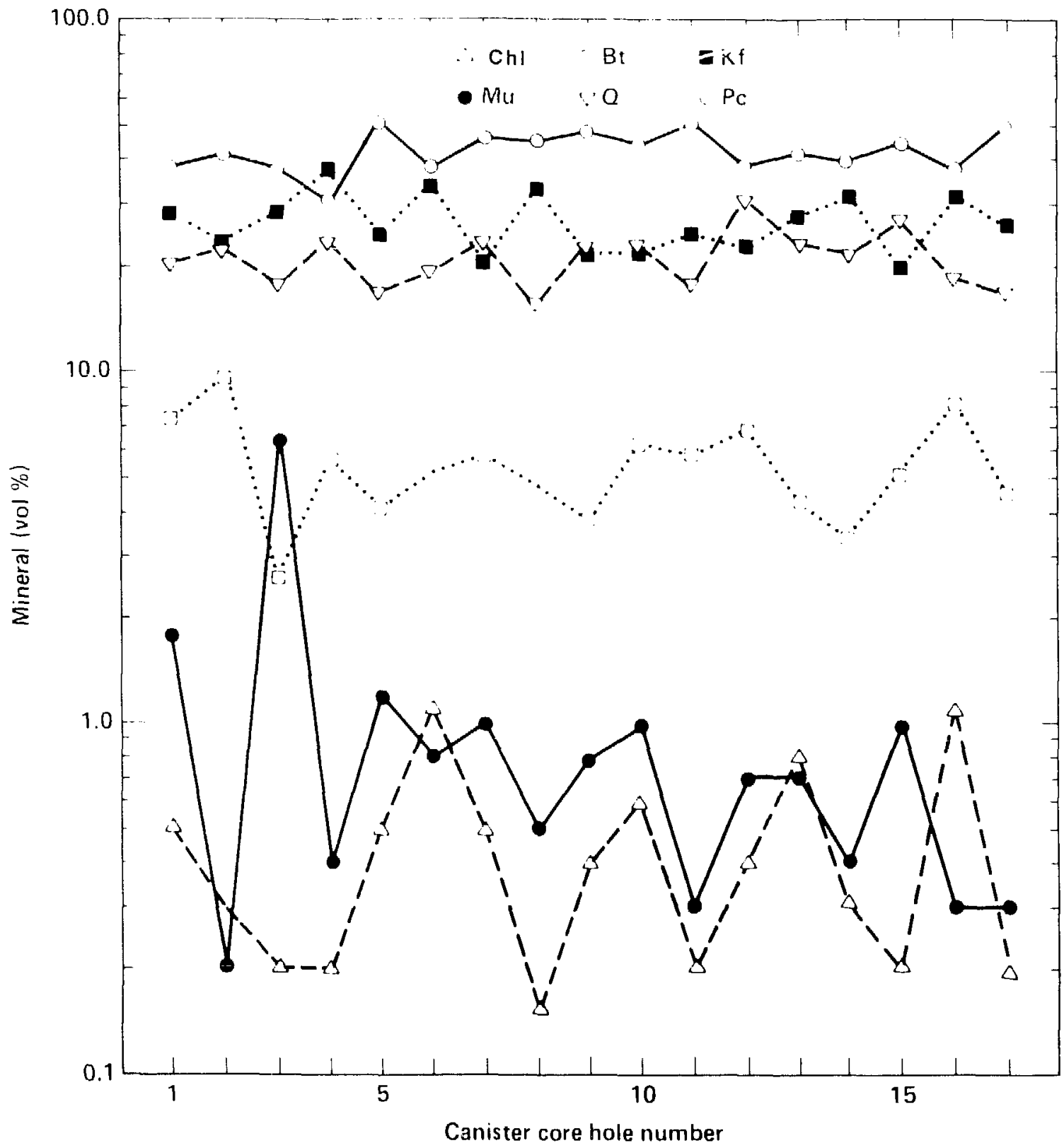

Figure 4-42. Modal abundance of major minerals from "bulk samples" plotted versus canister core hole number (after Ryerson and Qualheim, 1983).

Primary Phases. The major igneous phases are quartz, plagioclase, K-feldspar, and biotite. Analyses obtained in the interactive mode are presented in Ryerson and Qualheim (1983). In addition to interactive analysis, feldspar analyses were alsu obtained by automated step-scan iraverses to objectively determine the extent of zoning and average feldspar compusitions.

Histograms of feldspar analyses obtained from step-scan traverses indicate that the K-feldspar analyses vary between $\mathrm{Or}_{40}$ and $\mathrm{Or}_{48}$ with only occasional analyses falling at lower Or concentrations (Fig. 4-43). The average analysis is $\mathrm{Or}_{44}$, and show's very little variation from sample to sample. These valuo arrs: quite well with those obtained during the interactive analyses. The K-feldspars show very little alteration, 


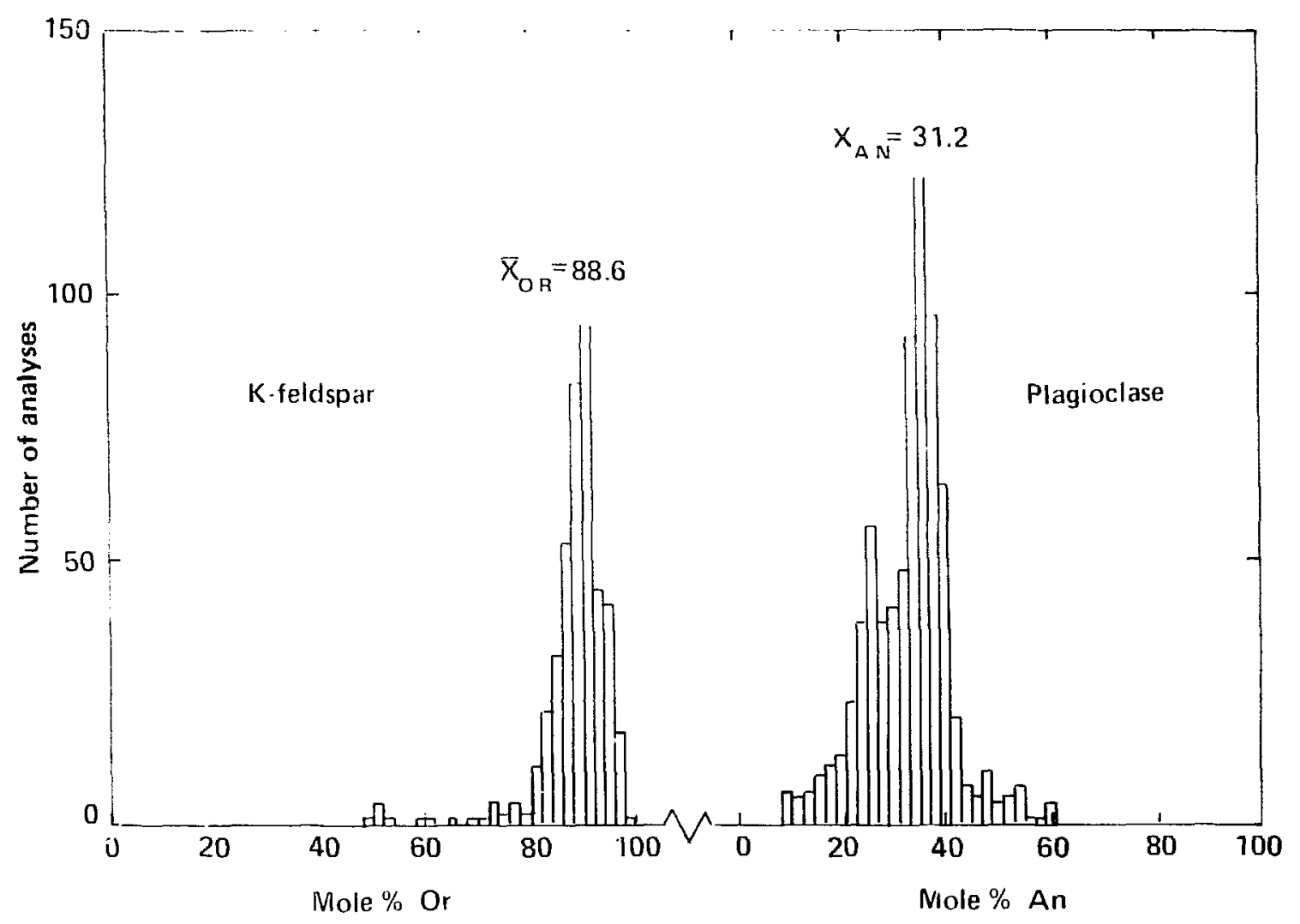

Figure 4-43. Number of feldspar analyses from "bulk" samples plotted vs feldspar composition. Analyses were obtained in step-scan mode (after Ryerson and Qualheim, 1983).

so that the variation must be due to a combination of primary igneous zoning coupled with subsolidus reequilibration.

The majority of the plagioclase compositions fall between $A n_{20}$ and $A n_{50}$, with the average at $A n_{31}$ (Fig. 4-43). In contrast to the K-feldspar analyses, comparisons of the plagioclase analyses collected in automated and interactive analyses show an important difference. The interactive analyses focused upon plagioclase grains containing significant amounis of secondary phases. This group of analyses contains significantly more analyses in the range from $\mathrm{An}_{20}$ to $\mathrm{An}_{0}$ than do those obtained in the automated step-scan traverses, indicating incongruent plagioclase alteration. The albite end member is conserved during hydrothermal alteration, while the anorthite component is preferentially dissolved and transported from the plagioclase site.

The bintite analyses can be represented by the formula

$\mathrm{K}\left[\mathrm{Ti}_{0.2}(\mathrm{Fe}, \mathrm{Mg})_{2}{ }_{4} \mathrm{~A} 1_{112.2} \mid\left[A 1_{1.2} \mathrm{Si}_{2.4}\right] \mathrm{O}_{10}(\mathrm{OH})_{2}\right.$

The $\mathrm{Mg} /(\mathrm{Mg}+\mathrm{Fe})$ ratio in these biotites lies between 0.50 and 0.68 .

Secondary Phases. All data for secondary minerals were collected in an interactive mode. The muscovite compositions fall in the range approximated by the formula

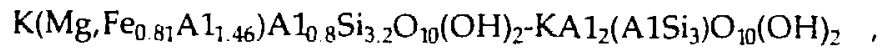

with a range in $\mathrm{ing}(\mathrm{Mg}+\mathrm{Fe})($ atom) between 0 and 1.0 . The muscovites found as pseudomorphs of biotites are generally enriched in $\mathrm{MgO}$ and $\mathrm{FeO}$ relative to those found on plagioclase. This most likely indicates 
increased activitres of the components on the biotite sites and also indicates that cation exchange equilibrium between plagiolase and bistite sites was not attained un even a thin-section scale during t.ydrothermal alteration.

Chlorite is found exclusively un biotite sites, and its compusition is given by the formula $(\mathrm{Fe}, \mathrm{Mg})_{4}{ }_{4} \mathrm{Mn}_{0.10 .2} \mathrm{Al}_{2}{ }_{6} \mathrm{Si}_{2.7} \mathrm{O} \mathrm{O}_{10}(\mathrm{OH})_{2}$. The range in $\mathrm{Mg}(\mathrm{Mg}+\mathrm{Fe})$ is between 0.42 and 0.74 and is slightly larger than the range for the primary biotite.

Mineral compositions and zoning patterns in the clinozoisite-epidote series are complex. The compositions are generally expressed by the formul $2 \mathrm{Ca}_{2}\left(\mathrm{Al}_{1} \mathrm{Fe}^{3+}\right)_{3} \mathrm{Si}_{3} \mathrm{O}_{12}(\mathrm{OH})$. Generally, the "epidotes" found on biotite are more iron-rich than the "clinuzoisites" found on plagioclase. The $\mathrm{Al} /(\mathrm{Al}+\mathrm{Fe})$ in the epidotes ranges from 0.86-0.68, whereas that in the clinozuisites varies between 0.99 and 0.79 .

For all practical purposes, the composition of pyrite can be assumed as $\mathrm{FeS}_{2}$ and the composition of titanite as $\mathrm{CaTiSiO}_{5}$. The calcite composition is given by the formula $\mathrm{Ca}_{10}$ yg $_{4} \mathrm{Mig}_{0.01} \mathrm{Fe}_{0.01} \mathrm{CO}_{3}$.

\subsubsection{Summary}

The data presented here summarize documentation of the chemical, petrographic, and modal variatiuns in core samples from the canister drift of the SFT-C and will serve as a data base for comparison with post-test samples (Ryerson and Qualheim, 1983). On a thin-section scale ( $3 \times 5 \mathrm{~mm}$ ), all of these properties vary significantly as a result of both igneous processes and hydrothermal alteration localized along fractures.

Variations due to primary igneous processes include zonation in plagioclase and K-feldspar within a particular section. The range and freyuency of feldspar compositions have been documented through the use of an automated step-scanning procedure on an electron microprobe. Modal variations are primarily caused by either the presence or absence of quartz and K-feldspar phenocrysts.

Features due to hydrothermal alteration are highly variable both within a particular section as well as between samples. Alteration zones up to $2 \mathrm{~cm}$ wide are localized along veins. The actual assemblages of secondary phases can be quite variable from sample to sample and from grain to grain of primary mineral phases. The compositions of some secondary phases (muscovite and epidote) can vary between different primary-phase reaction sites, documenting gradients in chemical potentials of these components during hydrothermal alteration. The altaration assemblies also demonstrate that $\mathrm{CO}_{2}, \mathrm{~S}$, and $\mathrm{H}_{2} \mathrm{O}$ were added to the rock during hydrothermal alteration. The source of $\mathrm{CO}_{2}$ is presumably the decarbonation of the carbonate country rock during the emplacement of the stock.

\subsection{Rad: :tion and Thermal Effects*}

O If the principal objectives of the SFT - C $C$ was to evaluate the relative effects upon the rock of heat alone and in combination with ionizing radiation. To determine these effects, we studied changes in mechanical properties, microfracture development, and alteration of the mineralogy and petrology of the rock.

\subsubsection{Effects on Mechanical Properties}

Following Durham's (2982) discovery of an apparent degrading effect of gamma irradiation upon the mechanical strength and deformability of CSQM, additional laboratory w.rk was undertaken to determine the validity of the effect and some of its details. The latter study used a statistical design and highly accurate and precise measuring techriques to provide a more definitive, less questionable result. Specific changes included:

- Rebuilding the test apparatus.

- Increasing the number of samples tested.

- Including samples of Westerly granite in the test matrix to provide a continuous calibration of the apparatus

Experiment Design. For this experiment, a newly fabricated testing system consisted of a 100-ton reacti in frame, a 50 -ton hydraulic ram, redundant load cells above and below the sample, upper and lower r'a.ens between the load cells and the sampie, and hardened steel caps between the load cells and the

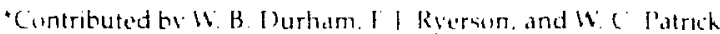


frame (above) and ram (below). The lower platen included a hemispherical seal to improve column alignment. Shims of $0.01-\mathrm{mm}$-thick aluminum foil were used between the sample ends and the platens.

Sample material was ubtained from borchole 155 -9 (5ec. 4.3). Of the 66 CSQM samples tested, 60 came from the 8.75- to 10.18-m interval and to came from the 16.71- to 16.89-m interval. The Westerly granite samples came from a single slab. Test cylinders $25.4 \mathrm{~mm}$ in diameter by $130 \mathrm{~mm}$ long were cored from the source rock and were cut to provide two matched $65-\mathrm{mm}$-long samples. With two exceptions, finished lengths were $63.50 \pm 0.03 \mathrm{~mm}$, and ends were parallel within $0.02 \mathrm{~mm}$.

Statistical design techniques were used to establish the required sample size to detect a $10 \%$ change in strength and to establish the need for a "matched pair" analysis as used here. Both the selection of which member of a pair would be irradiated and the order of testing following treatment used a randomization technique (Durham et al., 1985).

Experimental Procedure. Gamma irradiation was accomplished in the ${ }^{\text {hl }} \mathrm{Co}$ irradiation pool of the LLNL Standards and Calibration Laboratory: Calibration of the cell immediately following treatment of the samples showed the dose rate to be about $9.7 \mathrm{~Gy} / \mathrm{s}(970 \mathrm{rad} / \mathrm{s})$. Over the 11-day exposure, the samples received total doses of $9 \pm 1 \mathrm{MGy}\left(0.9 \times 10^{4} \mathrm{rad}\right)$.

Based on a randomization procedure, the operator tested each specimen by loading it rapidly to 100 MPa and then loading it at a controlled strain rate of 1.5 to $4.0 \times 10^{-1 /} / \mathrm{s}$ until the rock failed. Data aquired by the HP3497A data aquisition system allowed us to calculate maximum stress, Young's modulus at strains above $0.1 \%$, and Poisson's ratio at $0.1 \%$ longitudinal strain. Various diagnostic plots were alsu prepared.

Results. For the CSQM, Durham et al. (i265) found nu significant change in the unconfined compressive strength. The calculated Student's $t$ value of -0.864 indicates that differences between the unirradiated and irradiated values were not significantly different from zero. The experiment had a $90 \%$ chance of detecting a difference of $14 \mathrm{MPa}$ at the $5 \%$ confidence level. In addition, no effect was found on the Young's modulus or Poisson's ratio. A Student's $t$ value of -0.572 was calculated for the Westerly granite control samples. Here, too, there was no significant gamma irradiation effect.

\section{4.ó.2 Microfracture Analysis of Laboratory-Irradiated Climax Core}

In addition, we examined the possible causes of the previously observed weakening effect in CSQM following heavy dosages of gamma irradiation. As noted above, Durham (1982) first detected this weakening effect, which has not been verified by additional testing (Durham et. al., 1985) nor, to our knowledge, has a similar phenomenon been observed in other silicate rocks. Our study was based on scanning electron microscope (SEM) examination of polished sections of Climax core. For the study, 10 identical test cores $63 \mathrm{~mm}$ long by $25 \mathrm{~mm}$ in diameter were prepared for unconfined compressive loading. Before testing, five of the cores were given a gamma ray dosage of about $10 \mathrm{MGy}$ from a ${ }^{60} \mathrm{Co}$ source over a 9-day period, approximately the same irradiation treatment given in the study by Durham (1982). All 10 samples were then compressively loaded to $150 \mathrm{MPa}$ (approximately $90 \%$ of the expected strength of irradiated samples), held at that stress level for 60 seconds, then unloaded and prepared for SEM examination (Beiriger and Durham, 1984).

Microfractures in rocks stand out rather clearly in an SEM image, and what Beiriger and Durham (1984) were hoping to observe was a difference in the crack structure between the two groups of test specimens. To be as quantitative and unbiased as reasonably possible, they used a crack measurement technique developed recently for measuring borehole wall damage induced by hammer-driliing at the SFT $-C$ (Weed and Durham, 1983). The results are shown broken down by sample in Table 4-18 and by irradiation treatment in Table 4-19.

The most notable characteristic of the crack data in Tables 4-18 and 4-19 is the scatter. There is no detectable correlation between the measured crack parameters (areal density and average length) and irradiation treatment in stressed rock. In fact, based on a series of measurements on a single section of unirradiated, unstressed rock (Table 4-19), we have only weakly detected an effect on crack structure induced by the loading treatment itself.

These results are presented and discussed in greater detail by Beiriger and Durham (1984). Their principal conclusions were as follows:

1. The crack structure of Climax granite is highly heterogeneous on the scale of laboratory sections $(0.1$ to $10 \mathrm{~mm})$. The underlying cause may be that grain sizes in the rock are heterogeneous, ranging in scale from 0.1 to $100 \mathrm{~mm}$. 
Table 4-18. Crack statistics by sample (after Beiriger and Durham, 1984).

\begin{tabular}{|c|c|c|c|c|}
\hline Samplet & $\begin{array}{l}\text { Sumber of } \\
\text { crachs } \\
\text { counted }\end{array}$ & $\begin{array}{l}\text { Areal number } \\
\text { density } \\
\text { (mm - }\end{array}$ & $\begin{array}{l}\text { Average } \\
\text { length } \\
\text { tytmt }\end{array}$ & $\begin{array}{l}\text { Areal length } \\
\text { densily } \\
\text { (mm mm') }\end{array}$ \\
\hline \multirow{3}{*}{$2 \operatorname{lno} 1)$} & is & 85 & 52 & $4 .+1$ \\
\hline & 31 & 177 & 14 & $2.4 \%$ \\
\hline & 38 & $1 \geq 0$ & $3(1$ & 3.34 \\
\hline \multirow{3}{*}{$3(7)$} & 45 & 15 & 30 & 4.70 \\
\hline & 66 & 2016 & 14 & 2.74 \\
\hline & 20 & $\$ 1$ & 32 & 2.61 \\
\hline \multirow{3}{*}{$f(n 0) y)$} & 23 & 104 & 36 & 3.48 \\
\hline & 48 & 171 & 1.5 & 2.54 \\
\hline & 51 & 182 & $2 \mathrm{~h}$ & 4.67 \\
\hline \multirow{3}{*}{$5(\%)$} & 22 & 40 & +1 & 3.66 \\
\hline & 49 & 124 & 14 & 1.74 \\
\hline & 22 & 75 & 33 & 2.46 \\
\hline \multirow{3}{*}{$6($ no $y)$} & 12 & 57 & 35 & 1.99 \\
\hline & 64 & 214 & 12 & 2.47 \\
\hline & 15 & 71 & 44 & 3.12 \\
\hline \multirow{3}{*}{$7(7)$} & 25 & 119 & 36 & 4.27 \\
\hline & 62 & 158 & 13 & 2.07 \\
\hline & 30 & 107 & 38 & 4.01 \\
\hline \multirow{3}{*}{$8($ no $\%)$} & 49 & 175 & 28 & 4.89 \\
\hline & 45 & 117 & 15 & 1.78 \\
\hline & 14 & 67 & 29 & 1.95 \\
\hline \multirow{3}{*}{$9(y)$} & 24 & 114 & 34 & 3.88 \\
\hline & 46 & 131 & 16 & 2.15 \\
\hline & 47 & 167 & 23 & 3.78 \\
\hline \multirow{3}{*}{$10($ no $\gamma)$} & 18 & 86 & 30 & 2.53 \\
\hline & 71 & 285 & 16 & 4.44 \\
\hline & 35 & 125 & 33 & 4.06 \\
\hline
\end{tabular}

' Results are given for three indepenuent traces across each sample, a middle scan, and two outer scans. The second number of each group gives the statistics for the middle scan. A subtle difference in SEM operating conditions existed for the middle scan.

2. Our microstructural measurements reveal no evidence that gamma irradiation lowers the compressive strength of the ruck, although the resolution of the measurements is pour.

3. Improvements in the signal-to-noise ratio of the crack measurements in future experiments are not practical. Signal (i.e., damage) does not seem to be very sensitive to unconfined stress, except within a few percent of the failure stress, making a target stress difficult to attain in a rock with such a large variance in its fracture strengih. Noise can be decreased only by increasing the quantity of measured values. 
Table 4-19. Crack statistics by irradiation treatnent after Beiriger and Durham, 1984).

\begin{tabular}{|c|c|c|c|c|c|c|c|c|}
\hline \multirow[b]{2}{*}{$\begin{array}{l}\text { Sample } \\
\text { treatment }\end{array}$} & \multicolumn{3}{|c|}{ Maddle trace } & & \multicolumn{4}{|c|}{ Outertracen } \\
\hline & $\begin{array}{l}\text { Number } \\
\text { counted }\end{array}$ & $\begin{array}{l}\text { Ireal } \\
\text { density } \\
\text { Imm it }\end{array}$ & $\begin{array}{l}\text { dietrage } \\
\text { length. } 1 \\
\text { loml }\end{array}$ & $\begin{array}{c}\text { 1 } 1 \mathrm{red} \\
\mathrm{mmm} \mathrm{mm}\end{array}$ & $\begin{array}{l}\text { Number } \\
\text { counted }\end{array}$ & $\begin{array}{c}\text { - treal } \\
\text { denuity } \\
\text { | }\end{array}$ & $\begin{array}{c}\text { l. } \\
(\mu \mathrm{m})\end{array}$ & $\begin{array}{l}\text { 1. Ared } \\
\left(\mathrm{mm} \mathrm{mm} \mathrm{mm}^{2}\right)\end{array}$ \\
\hline No\% & 223 & $14^{9} \pm 153^{\prime}$ & $14 \pm 12$ & $2.11 \pm 2.31$ & 235 & $115 \pm 105$ & $32 \pm .30$ & $3.64=3.42$ \\
\hline$y$ & 2.34 & $140=178$ & $1+ \pm 13$ & $2.71 \pm 2.64$ & 273 & $113 \pm 100$ & $32 \pm 33$ & $3.61 \pm 3.17$ \\
\hline $\begin{array}{l}\text { Untreat :d, } \\
\text { unstressed }\end{array}$ & & & & & 54 & $91 \pm 91$ & $3 b \pm 47$ & $3.24 \pm 3.16$ \\
\hline
\end{tabular}

\subsubsection{Effects on Mineralogy and Petrology}

Mineralogical and petrological studies of post-test cores were conducted to determine and evaluate changes in these characteristics that may have resulted from the three-year episude of heating and irradiation (Rverson and Beiriger. 1985). Data wbtained trum adjacent pretest samples provided the baseline for these comparisuns (Sec. 4.5).

Sample Selection and Preparation. Post-test investigations focused on samples ubtained frum canister emplacement holes (CEH) 1, 3, 4, and 9. Although CEH01, 03, and 09 contained spent-fuel assemblies, CEH04 had housed an electrical simulator during the SFT-C. Furthermore, CEHO1 contained water (Chapter 18); therefore, it provided the greatest opportunity for both hydrothermal and radiolytic effects to occur.

Samples were prepared from 140-mm-diameter post-test corcs obtained by drilling longitudinally along the CEHs at such a radial distance that the wall of the hole was included in the sample. The azimuthal position was chosen to provide a sample adjacent to the pretest sample. The steps in the sampling are displayed in Fig. 4-44.

Analytical Techniques. Based on the results of pretest investigations, the post-test petrographic analyses were revised to eliminate counting of any phases greater than $4 \mathrm{~mm}$ in diameter. This was done to reduce the variability that results from the presence of phenocrysts, and was justified by the observation that natural hydrothermal alteration was concentrated in the groundmass rather than in phenocrysts. To permit a direct comparison between pre- and post-test petrology, Ryerson and Beiriger (1985) reanalyzed $13 \mathrm{CCH}$ samples using this revised technique (Table 4-20). Microprobe analyses were conducted in the same manner as for pretest samples (Sec. 4.5).

Post-Test Results. The appearance of new phases in the post-test samples was the principal basis for detecting hydration and dehydration reactions and precipitation of new phases from solution. Most cation exchange processes were anticipated to be very slow at SFT-C conditions but could be detected as changes in mineral chemistry.

The post-test petrology detected no new phases in the samples studied. Furthermore, the identified alteration textures present in the post-test samples were identical to those identified in the pretest studies.

Although no fenetrating chemical alteration was observed, we examined a film of fine-grained material that was apparently deposited on the surface of post-test core from CEH01. Since the phases identified by $x$-ray diffraction are the principai mineral constituents of the CSQM, Ryerson and Beiriger (1985) concluded that the film was simply rock flour from drilling. However, based on an earlier study of Climax groundwater chemistry (Isher wood et al., 1982), the possibility remains that some of the calcite identified was a chemical precipitate.

Modal analyses of the post-test samples are displayed in Table 4-21. L'sing Student's test, they found no statistically significant diffe: ence between the pre- and post-test samples. Significant modal variations wer? found to exist between samples taken at a particular depth, but these variations did not display any particular trend $\cdot$ ith radial distance (Fig. 4-45).

Tables 4-22 and 4-23 display the mineral chemistry data of primary feldspar phases for pre- and pust$u^{-+}$samples, respectively. There are no intra- or interhole variations in the feldspars, and no statistically significant chenges in composition wercubserved. Biotite analyses show similar results, with the port-test compositions lying entirely within the range of the pretest analysen. 


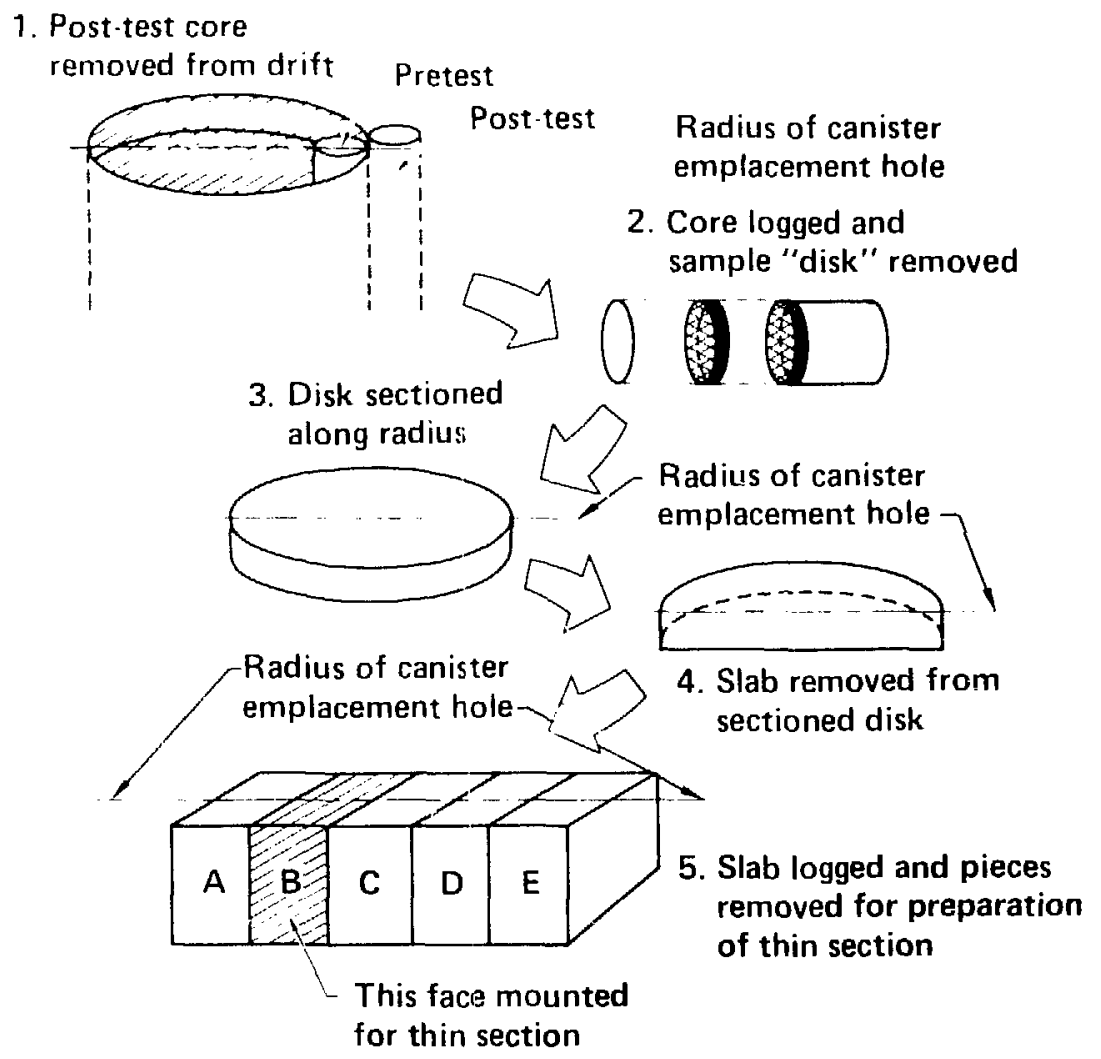

Figure 4-44. Location of post-test core samples with respect to the canister emplacement hole. Sample A is closest to the canister, and all samples are taken along a radius of the canister emplacement hole (after Ryerson and Beiriger, 1985).

Table 4-20. Modal distribution (vol \%) of pretest samples (after Ryerson and Beiriger, 1985). ${ }^{\mathrm{b}}$

\begin{tabular}{ccccccccccccc}
\hline CCH & & & & & & & & & & \\
Sample & Plag & Ksp & Q & Bt & Mu & Ch1 & Czo+Ep & Ti & Ru & Mt & Py & ACC \\
\hline 1 & 49.2 & 21.1 & 18.9 & 8.3 & 0.4 & 0.9 & 0.1 & 0.2 & 0 & 0.5 & 0.4 & 0 \\
2 & 49.6 & 18.0 & 17.6 & 12.3 & 0.2 & 0.7 & 0.2 & 0 & 0 & 0.7 & 0.6 & 0.1 \\
3 & 44.9 & 24.7 & 21.9 & 4.5 & 0.3 & 1.0 & 0.7 & 0.4 & 0 & 0.1 & 1.3 & 0.2 \\
5 & 47.1 & 20.6 & 23.9 & 3.9 & 0.3 & 1.1 & 0.3 & 0.3 & 0 & 0 & 2.5 & 0 \\
6 & 50.5 & 20.5 & 20.7 & 5.2 & 0.1 & 1.2 & 0.1 & 0.4 & 0 & 0.2 & 1.1 & 0 \\
7 & 44.1 & 21.2 & 23.7 & 4.7 & 0.6 & 1.8 & 0.6 & 0.7 & 0 & 0.6 & 1.8 & 0.2 \\
8 & 40.9 & 27.4 & 23.4 & 5.0 & 0 & 1.4 & 0.1 & 0.4 & 0 & 0 & 1.4 & 0 \\
10 & 52.7 & 18.7 & 22.1 & 3.8 & 0 & 1.0 & 0.5 & 0 & 0 & 0 & 1.2 & 0 \\
11 & 52.0 & 23.2 & 17.9 & 4.1 & 0.4 & 0.9 & 0.2 & 0.7 & 0 & 0 & 0.5 & 0.1 \\
13 & 50.5 & 21.6 & 19.2 & 5.3 & 0 & 1.9 & 0 & 0.6 & 0 & 0.7 & 0.2 & 0 \\
14 & 49.5 & 28.4 & 14.7 & 2.7 & 0.1 & 0.9 & 0.1 & 0.3 & 0 & 0 & 3.3 & 0 \\
16 & 42.3 & 22.1 & 22.5 & 7.4 & 0.1 & 1.8 & 0.5 & 1.3 & 0 & 0.5 & 1.5 & 0 \\
17 & 52.8 & 15.3 & 17.3 & 9.7 & 0.4 & 1.8 & 0 & 1.2 & 0 & 1.0 & 0.3 & 0 \\
Avg & 48.2 & 21.8 & 20.3 & 5.9 & 0.2 & 1.3 & 0.3 & 0.9 & 0 & 0.3 & 1.2 & 0.2 \\
S.D. & 4.0 & 3.6 & 2.9 & 2.7 & 0.2 & 0.4 & 0.2 & 1.6 & 0 & 0.3 & 0.9 & 0.5 \\
\hline
\end{tabular}

"Phenncrysts greater than $4 \mathrm{~mm}$ in diameter were not counted.

"Samples represent "fresh" material without littear features, i.e., verns, alteration, etc.

'Allanite, apatite and zircon. 
Table 4-21. Modal distribution (vol "1)" of post-test samples (after Ryerson and Beirger, 1985).

\begin{tabular}{|c|c|c|c|c|c|c|c|c|c|c|c|c|}
\hline $\begin{array}{l}\mathrm{CCH} \\
\text { sample }\end{array}$ & Plag & $k s p$ & $Q$ & $B t$ & Mu & Chl & $(\angle 0)-E_{p}$ & $\mathrm{Ti}$ & $\mathbf{R u}$ & $\mathrm{Mt}$ & $P y$ & $A C C^{\prime \prime}$ \\
\hline $1-2.6 \mathrm{~A}$ & +8.2 & 17.8 & 21.0 & 3.2 & 1.4 & 1.3 & 1.6 & 0.8 & 0.1 & 0.1 & 1.0 & 0 \\
\hline $1-2.68$ & 49.2 & 17.5 & 21.5 & 5.3 & 1.4 & 1.2 & 2.8 & 0.8 & 0 & 0 & 0.3 & 0 \\
\hline $1-2.6 \mathrm{C}$ & 52.2 & 19.4 & 18.4 & 2.4 & 1.2 & 2.4 & 2.6 & 0.2 & 0 & 0.6 & 0.1 & 0 \\
\hline $1-2.6 \mathrm{D}$ & 56.4 & 19.1 & 16.0 & 4.1 & 0.4 & 1.0 & 1.0 & 0.2 & 0.1 & 0.5 & 0.7 & 0 \\
\hline $1-2.6 \mathrm{E}$ & 55.2 & 17.3 & 16.0 & 4.3 & $\mathrm{I} .2$ & 1.6 & 2.5 & 0.7 & 0.1 & 0.7 & 0.1 & 0.1 \\
\hline Avg. & 52.2 & 18.3 & 18.6 & 4.0 & 1.4 & 1.5 & 2.1 & 0.5 & 0.1 & 0.4 & 0.4 & 0 \\
\hline S.D. & 3.6 & 0.9 & 2.6 & 1.0 & 1.7 & 0.5 & 0.8 & 0.3 & 0.1 & 0.3 & 0.4 & 0 \\
\hline $1-15.0 \mathrm{~A}$ & 48.7 & 19.8 & 19.3 & 8.3 & 0.2 & 0.4 & 1.2 & 0.6 & 0 & 0.2 & 0.7 & 0.1 \\
\hline $1-15.0 B$ & 54.4 & 17.4 & 15.3 & 9.2 & 0.3 & 1.5 & 0.6 & 0.3 & 0 & 0 & 0.9 & 0.1 \\
\hline $1-15.0 \mathrm{C}$ & 55.9 & 18.0 & 17.4 & 3.9 & 0.3 & 1.1 & 0.9 & 1.0 & 0 & 0 & 1.0 & 0 \\
\hline $1-15.00$ & 55.5 & 18.0 & 15.5 & 6.8 & 0.7 & 1.6 & 0.7 & 0.5 & 0.2 & 0 & 0.4 & 0.1 \\
\hline $1-15.0 \mathrm{E}$ & 58.1 & 19.4 & 16.6 & 2.7 & 0.1 & 1.3 & 0.5 & 0.5 & 0 & 0.1 & 0.6 & 0.1 \\
\hline Avg. & 54.5 & 18.5 & 16.9 & 6.2 & 0.3 & 1.3 & 0.8 & 0.6 & 0 & 0.1 & 0.7 & 0.1 \\
\hline S.D. & 3.5 & 1.0 & 1.7 & 2.8 & 0.2 & 0.3 & 0.3 & 0.3 & 0 & 0.1 & 0.2 & 0.0 \\
\hline 9-9.9A & 48.3 & 18.2 & 21.9 & 0.7 & 0 & 1,2 & 0.7 & 0.4 & 0 & 0.4 & 0.1 & 0.1 \\
\hline $9-9.9 B$ & 47.1 & 19.2 & 19.9 & 7.2 & 0.4 & 2.5 & 2.1 & 0.5 & 0.1 & 0.3 & 0.7 & 0 \\
\hline $9-9.9 \mathrm{C}$ & 50.4 & 17.1 & 22.9 & 3.2 & 0.6 & 1.4 & 1.8 & 0.8 & 0.5 & 0 & 1.3 & 0 \\
\hline $9-9.9 \mathrm{D}$ & 45.5 & 23.0 & 21.6 & 1.9 & 1.1 & 1.4 & 2.1 & 0.9 & 0 & 2.0 & 0.5 & 0 \\
\hline $9-9.9 \mathrm{E}$ & 53.4 & 18.3 & 17.7 & 3.9 & 0.3 & 1.7 & 2.5 & 0.6 & 0 & 1.3 & 0.3 & 0 \\
\hline Avg. & 49.9 & 19.2 & 20.8 & 5.0 & 0.5 & 1.6 & 1.8 & 0.6 & 0.1 & 0.8 & 0.6 & 0 \\
\hline S.D. & 3.1 & 2.3 & 2.0 & 2.9 & 0.4 & 0.5 & 0.7 & 0.2 & 0.2 & 0.8 & 0.5 & 0 \\
\hline Avg. & 51.6 & 18.5 & 18.5 & 4.3 & 0.4 & 1.4 & 1.1 & 0.6 & 0 & 0.1 & 0.6 & 0 \\
\hline S.D. & 2.8 & 0.5 & 2.0 & 1.4 & 1.1 & 0.2 & 0.9 & 0.1 & 0.1 & 0.5 & 0.2 & 0.1 \\
\hline
\end{tabular}

"Phenocryst greaier than $+\mathrm{mm}$ in diameter were not counted.

- Allanite, apatite and zircon.

'All post-test data.

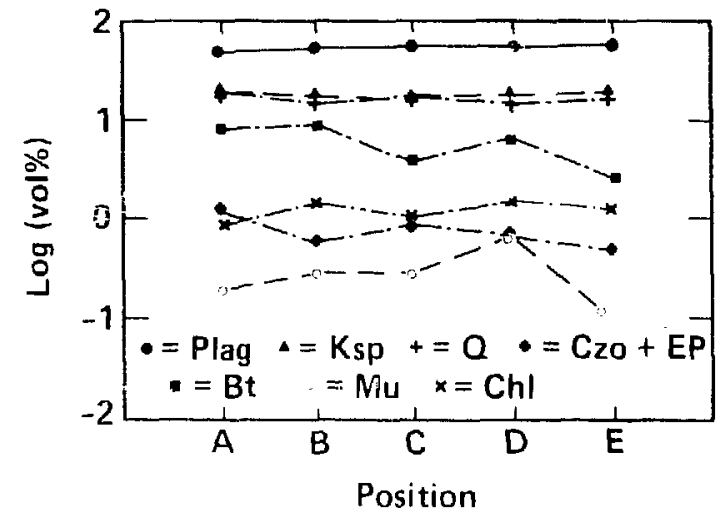

Figure 4-45. Modal data for CCH1-15.0 PT, showing vol\% of mineral vs position wiin respect $t$ to the CEH (after Ryerson and Beiriger, 1985). 
Table 4-22. Microprobe analyses of pretest feldspars. Numbers in parentheses are sample population sizes (after Ryerson and Beiriger, 1985).

\begin{tabular}{|c|c|c|c|c|c|c|c|c|c|c|c|c|c|}
\hline $\begin{array}{l}\text { Hole' } \\
\text { Depth }\end{array}$ & $\begin{array}{c}1 \\
16.75\end{array}$ & $\begin{array}{c}5 \\
10.05\end{array}$ & $\begin{array}{l}b \\
8.3\end{array}$ & $\frac{7}{10.3}$ & $\begin{array}{l}8 \\
4.8\end{array}$ & $\begin{array}{c}6 \\
13.3\end{array}$ & $\bar{i}_{4.15}$ & $\begin{array}{l}3 \\
4.4\end{array}$ & $\begin{array}{l}4 \\
3.1\end{array}$ & $\begin{array}{l}2 \\
7.6\end{array}$ & $\begin{array}{c}1 \\
14.8\end{array}$ & $\begin{array}{l}3 \\
4.1\end{array}$ & $\begin{array}{l}8 \\
9.3\end{array}$ \\
\hline 'lag ${ }^{2}$ & 33.03 & 31.63 & 31.19 & 31.94 & 31.79 & 33.19 & 33.17 & 32.45 & 30.17 & 38.53 & 31.24 & 34.04 & 34.40 \\
\hline S.D. & $\begin{array}{l}8.63 \\
(95)\end{array}$ & $\begin{array}{r}6.40 \\
(108)\end{array}$ & $\begin{array}{l}6.27 \\
(24)\end{array}$ & $\begin{array}{l}6.97 \\
(95)\end{array}$ & $\begin{array}{l}6.07 \\
(55)\end{array}$ & $\begin{array}{l}6.04 \\
(93)\end{array}$ & $\begin{array}{l}7.97 \\
(95)\end{array}$ & $\begin{array}{l}7.91 \\
(26)\end{array}$ & $\begin{array}{l}9.21 \\
(17)\end{array}$ & $\begin{array}{r}9.17 \\
(108)\end{array}$ & $\begin{array}{l}8.15 \\
(56)\end{array}$ & $\begin{array}{r}6.81 \\
(119)\end{array}$ & $\begin{array}{l}11.35 \\
(103)\end{array}$ \\
\hline$K$-feld ${ }^{b}$ & 90.71 & 85.65 & 87.97 & 89.02 & 50.42 & 38.74 & 88.88 & 88.62 & 86.22 & 87.73 & 88.93 & 89.15 & 86.70 \\
\hline S.D. & 2.85 & 14.35 & 8.56 & 7.74 & 18.67 & 5.77 & 11.48 & 4.45 & 7.33 & 9.17 & 6.16 & 6.81 & 13.77 \\
\hline
\end{tabular}

Aternge of all pretest analyses

Plagioclased $32.61 \pm 2.11$

K-feldspar' $89.05 \pm 2.85$

${ }^{4} \mathrm{Mol} \%$ anorthite.

Moloin K-feldspar

Table 4-23. Microprobe analyses of post-test feldspars. Numbers in parentheses are sample population sizes (after Ryerson and Beiriger, 1985).

\begin{tabular}{|c|c|c|c|c|c|c|c|c|c|c|c|c|c|c|c|}
\hline $\begin{array}{l}\text { Hole No. } \\
\text { Depth(m) } \\
\text { Position }\end{array}$ & $\begin{array}{c}1 \\
7.25 \\
\mathrm{~A}\end{array}$ & $\begin{array}{c}1 \\
7.25 \\
\text { B }\end{array}$ & $\begin{array}{c}1 \\
7.25 \\
C\end{array}$ & $\begin{array}{c}1 \\
7.25 \\
D\end{array}$ & $\begin{array}{c}1 \\
7.25 \\
E\end{array}$ & $\begin{array}{c}1 \\
17.0 \\
\text { A }\end{array}$ & $\begin{array}{c}1 \\
17.0 \\
B\end{array}$ & $\begin{array}{c}1 \\
17.0 \\
C\end{array}$ & $\begin{array}{c}1 \\
17.0 \\
D\end{array}$ & $\begin{array}{c}1 \\
17.0 \\
E\end{array}$ & $\begin{array}{l}9 \\
9.9 \\
\text { A }\end{array}$ & $\begin{array}{l}9 \\
9.9 \\
\text { B }\end{array}$ & $\begin{array}{l}9 \\
9.9 \\
C\end{array}$ & $\begin{array}{l}9 \\
9.9 \\
0\end{array}$ & $\begin{array}{l}9 \\
9.9 \\
\text { E }\end{array}$ \\
\hline $\operatorname{lag}^{2}$ & $3 J .11$ & 30.59 & 30.64 & 32.13 & 33.09 & 30.83 & 32.45 & 31.93 & 32.14 & 32.29 & 34.92 & 33.74 & 30.93 & 29.62 & 32.74 \\
\hline D. & $\begin{array}{l}5.76 \\
(93)\end{array}$ & $\begin{array}{l}6.68 \\
(62)\end{array}$ & $\begin{array}{l}7.07 \\
(64)\end{array}$ & $\begin{array}{r}9.50 \\
(107)\end{array}$ & $\begin{array}{r}7.58 \\
(106)\end{array}$ & $\begin{array}{l}7.06 \\
(63)\end{array}$ & $\begin{array}{c}5.12 \\
(102)\end{array}$ & $\begin{array}{l}8.52 \\
(68)\end{array}$ & $\begin{array}{l}6.58 \\
(93)\end{array}$ & $\begin{array}{l}6.45 \\
(97)\end{array}$ & $\begin{array}{c}10.95 \\
(84)\end{array}$ & $\begin{array}{l}9.13 \\
(95)\end{array}$ & $\begin{array}{l}7.84 \\
(63)\end{array}$ & $\begin{array}{l}7.97 \\
(64)\end{array}$ & $\begin{array}{r}8.38 \\
(106)\end{array}$ \\
\hline K-feld ${ }^{b}$ & 86.85 & 87.12 & 90.39 & 84.52 & 88.67 & 89.91 & 89.61 & 91.63 & 86.40 & 87.45 & 86.55 & 89.28 & 88.08 & 89.82 & 89.32 \\
\hline S.D & 18.29 & 17.58 & 11.46 & 21.41 & 10.21 & 11.70 & 10.08 & 4.112 & 9.74 & 13.96 & 13.72 & 9.17 & 12.28 & 6.67 & 4.3 \\
\hline
\end{tabular}

Average of .zll post-test samples

Plagioclase $31.87 \pm 1.44$

K-feldspar ${ }^{b} 89.8 \pm 2.2$

${ }^{a}$ Mol\% anorthite.

${ }^{b}$ Mol\% K-feldspar.

Analyses of the alteration phases confirm the lack of heating and irradiation effects on the CSQM. As displayed in Fig. 4-46(a)-(c), the post-test compositions of the alteration phases fall within the ranges of compositions observed in the pretest samples.

Conclusions. Since no mineralogical or petrological changes were observed for any samples, it follows that there was no significant difference between the effects of heat alone or heat in combination with ionizing radiation. Although this is an encouraging resuli for considering crystalline rocks for a full-scale repository, the limited time and range of conditions studied here must be recognized.

\subsubsection{Physical and Chemical Changes Due to Heating}

Beiriger et al. (1985) studied cores obtained from nearby auxiliary heaters at the SFT-C to evaluate possible changes in the microfracture characteristics and mineralogy of the CSQM.

Sample Selection and Preparation. To conduct this study, they obtained samples from nearby heaters designated $\mathrm{NHH} 10$ and $\mathrm{SHH} 05$. Pretest samples w'ere obtained from the core retrieved to produce the heater boreholes. Post-test samples were obtained by drilling a $150-\mathrm{mm}$-diameter borehole tangent to each heater borehole and a parallel 76- $\mathrm{mm}$-diameter borehole $0.76 \mathrm{~m}$ from each heater borehole. Maximum 


\section{$\mathrm{Al}_{2} \mathrm{O}_{3}-\mathrm{K}_{2} \mathrm{O}$}

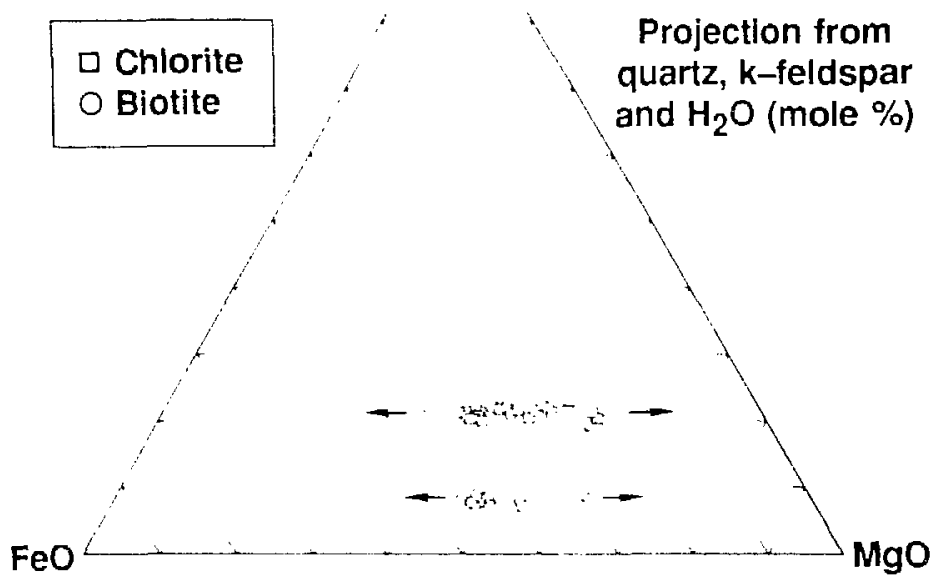

Figure 4-46a. Compositions of post-test chlorites and biotites projected from quartz, muscovite, and water. The symbols give post-test data; the range of pre-test data is shown by the arrows (after Ryerson and Beiriger, 1985).

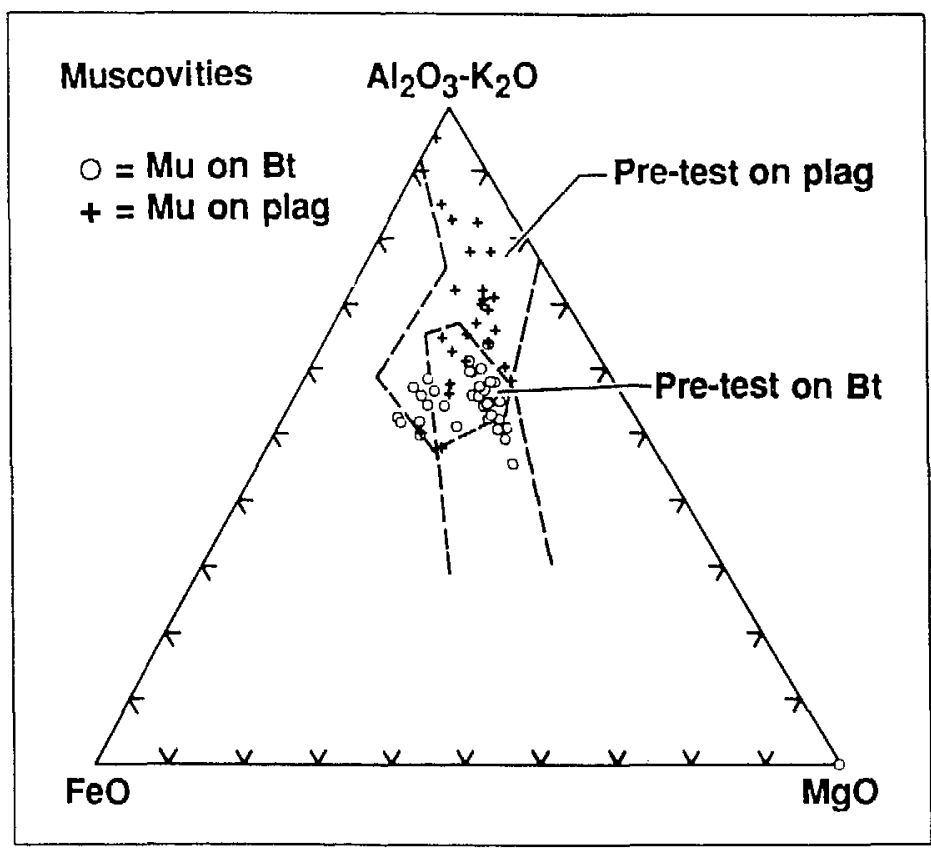

Figure 4-46b. Compositions of post-test muscovites projected from quartz and water. The open circle (o) represents muscovite found on biotite, and the plus $(+)$ is muscovite found on plagioclase. The symbols give post-test data; the range of pre-test data is shown by the two outlined fields (after Ryerson and Beiriger, 1985). 


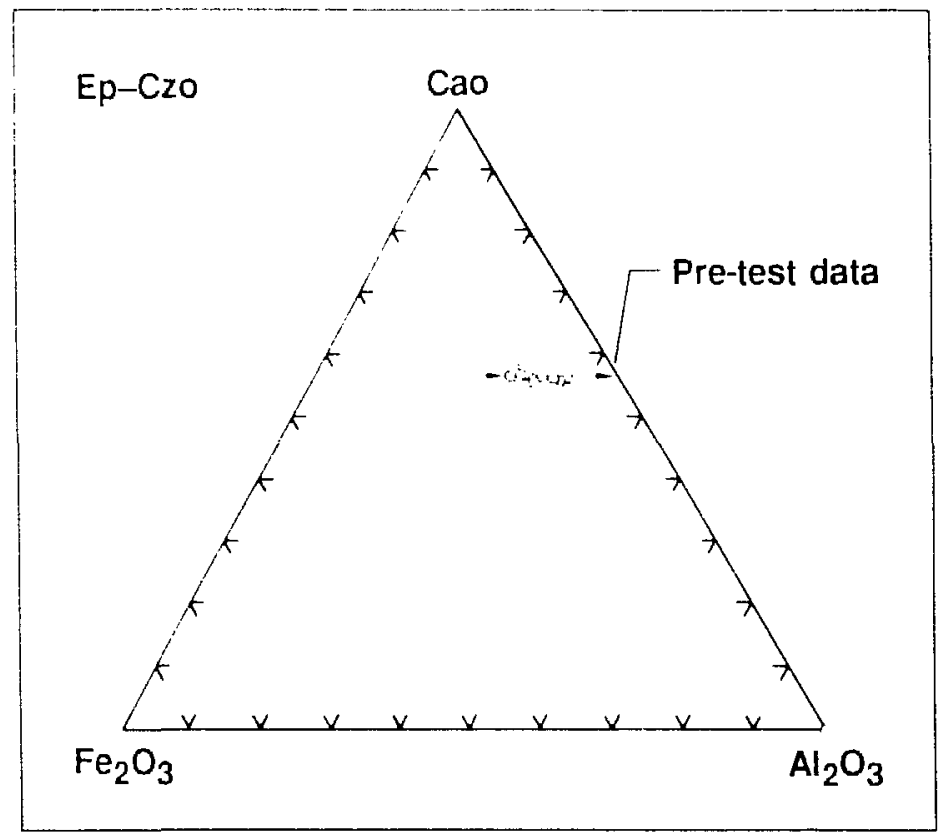

Figure 4-46c. Compositions of post-test epidotes and clinozoisites projected from quartz and water. The symbols give post-test data; the range of pre-test data is shown by the arrows (after Ryerson and Beiriger, 1985).

temperatures in these two positions were estimated to be near 350 and $80^{\circ} \mathrm{C}$, respectively. The sampling depth was at the midheight of the heater.

Samples were prepared using a strict regimen similar to that described in Sec. 4.6.3. Facing pairs of sections were prepared for the SEM and optical microscopy studies. Crack counting techniques were as described by Durham et al. (1984), and included preselection of areas to be scanned to avoid operator biases associated with studying the more interesting areas. Microanalytical techniques were as described in Sec. 4.5

Results. Three crack parameiers were studied to detect a possible heating effect: areal number density, average crack length, and areal total length density. Although a significant difference in crack statistics was found between the NHH10 and SHH05 boreholes, there were no signficant differences between preand post-test cores. Furthermore, no change in fracture characteristics with radial distance was detected. The rock near NHH10 displayed about $25 \%$ more cracks per unit area with about $10 \%$ greater length than the rock near $\mathrm{SHH} 05$. This is believed to be related to the proximity of $\mathrm{NHH} 10$ to a major geological feature (Sec. 4.1).

Petrological studies showed no differences between the NHH10 and SHH05 cores. No new phases were found to have resulted from this episode of heating at temperatures near $350^{\circ} \mathrm{C}$. The pre- and posttest samples were essentially identical, indicating that hydration, dehydratio 1 , and cation exchange mechanisms are too slow for a test of the intensity and duration of the SFT-C to produce measurable changes.

\subsection{Drilling Damage Assessment*}

To discriminate physical changes to ruck induced by the waste storage canisters from damage induced by drilling the canister emplacement boreholes, Weed and Durham (1982) undertook an observational study of rock from the wall of an emplacement hole. Since the emplacement holes $(610 \mathrm{~mm}$ in diameter) were hammer-dralled a hapter 7 ) a technique that requires that rock be broken up before it is remored-a 
possibility exists that fractures generated by hammer-drilling extend into the wall rock around the hole. The importance of identifying drillmg-induced damage was raised by the fact that the wall rock receives the most intense radiation and thermal energy from the canisters and was, therefore, the focus of attention when the canisters were removed (Sec, 4.h).

Weed and Durham examined rock trum a section of $150-\mathrm{mm}$-diameter core that intersected, along its length, the edge of the practice canister emplacement hole CEH 18 . This core was obtained before thermal and radiation sources weie introduced to the test area and thus served as a "control" for the studies of thermal and radiation effects. Sev'eral 25-mm-diameter sections were cut from the 150 -mm core parallel to the hole axis at varving distances trom the wall of the canister hole. These sections were polished and their surtaces examined for fractures and microfractures in the SEM. Several hundred fractures were photographically documented and quantified with the help of image analyzing hardware. Plots were then made of crack density and average fracture length as a tunction of distance from the wall of the emplacement hole. An example of the results is shown in Fig. 4-47.

As a general statement, the rock in the 15() -mm-diameter core turned out nut to contain a high density of fractures, so the noise level in the crack counting statistics was quite high. At most points in the core, the densities and length distributions of fractures could not be distinguished from background levels observed in rock far from the canister wall The only 25 -mm-diameter sections observed to contain abnormal fracture statistics were those that intersected the canister emplacement hole.

Therefore, the study concluded that the hammer-drilling of the canister emplacement holes changed the physical nature of the rock only within a thin annulus less than $20 \mathrm{~mm}$ thick around the emplacement hole, and that the physical change involved only a subtle increase in fracture density and length.

\subsection{Radon Content*}

Samples of CSQM were analyzed to determine the potential for radon exposures to underground workers. Concentrations of ${ }^{227} R$ n were determined to be about $2 \mathrm{pCi} / \mathrm{g}$ of CSQM.

The background racton concentrations in air averaged about $1.1 \times 10^{-11} \mathrm{Ci} / \mathrm{m}^{3}$ in the drifts and alcoves assuciated with the test (Ramspott et al., 1979). For practical purposes, the one "working level" limit impused by 1OCFR20 and 30CFR57 is equivalent to $1 \times 10^{-7} \mathrm{Ci} / \mathrm{m}^{3}$ of air. Thus, the background radon levels were a small percentage of the permissable limit. The effects of prolonged extensive heating and changes in ventilation on the radon concentration in air are discussed further in Chapter 15.

Cuntributed hy W\& Pitrik 


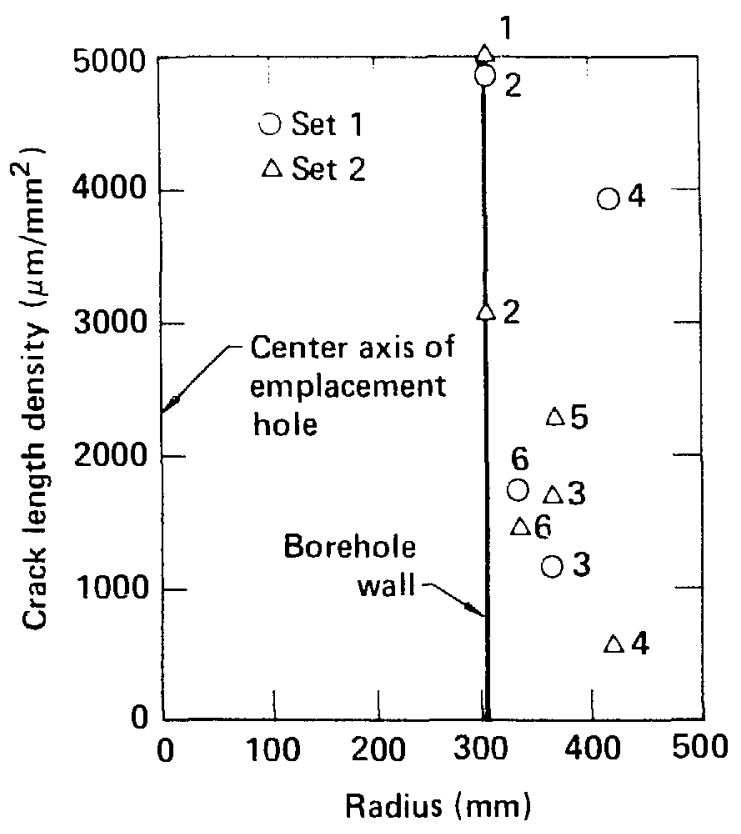

Figure 4-47. Example plot of crack length density vs radial distance from borehole wall; two independent sets of measurements were made (sets 1 and 2) on six specimens (numerals adjacent to data points indicate specimen numbers) (after Weed and Durham, 1982). 


\section{Site Development and Construction of the Facility*}

Although an existing personrel and material shatt and associated surface plant were already in place at the SFT-C site, these facilities needed to be refurbished and the test areaconstructed. Necessary design, construction, and rehabilitation were initiated shortly after the SFT-C was authorized on June 2 , 1978. Eleven spent-fuel assemblies were emplaced between April 18 and May 28, 1980, marking the completion of site development and construction activities.

\subsection{Existing Facilities}

Access to the $420-\mathrm{m}(1400-\mathrm{ft})$ te, level was provided by the PILEDRIVER underground nuclear test shaft and its associated healtrame and hoist systen (Figs. 5-1 and 5-2). Having these facilities already available shortened the developr "ent and construction time at the site and substantially reduced the cost of the test.

Beginning in the early 1960s, the Climax stock was host to nuclear weapons effects tests. To support these activities, a shaft was sunk $244 \mathrm{~m}$ for the HARD HAT underground nuclear test and was later deeperied to the present level where the PILEDRIVER test was conducted. The shaft internals and surrounding rock were damaged during both of these tests.

In 1977 th. shaft $w$ as again brought into service to provide access for Heater Test No. 1 (Montan and Bradkin, 1984), :vhich was also conducted under the technical direction of LLNL. Repairs were limited to replacing damaged guides, installing a telephone messenger cable, and emplacing instrumentation cables in a 150 -mm-diameter conduit.

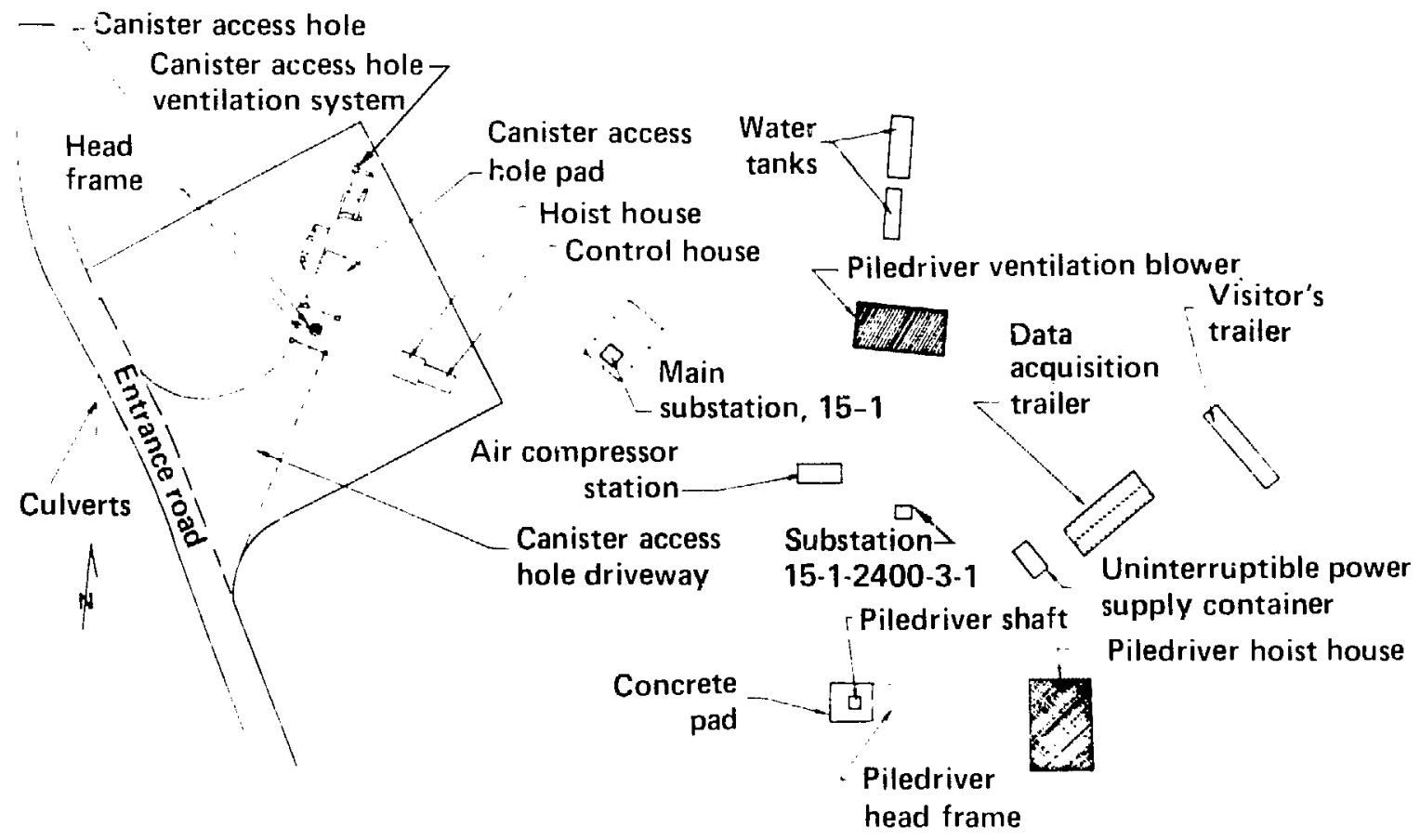

Figure 5-1. Surface area layout of the Climax site.

- Cintributed by W P Patrak 


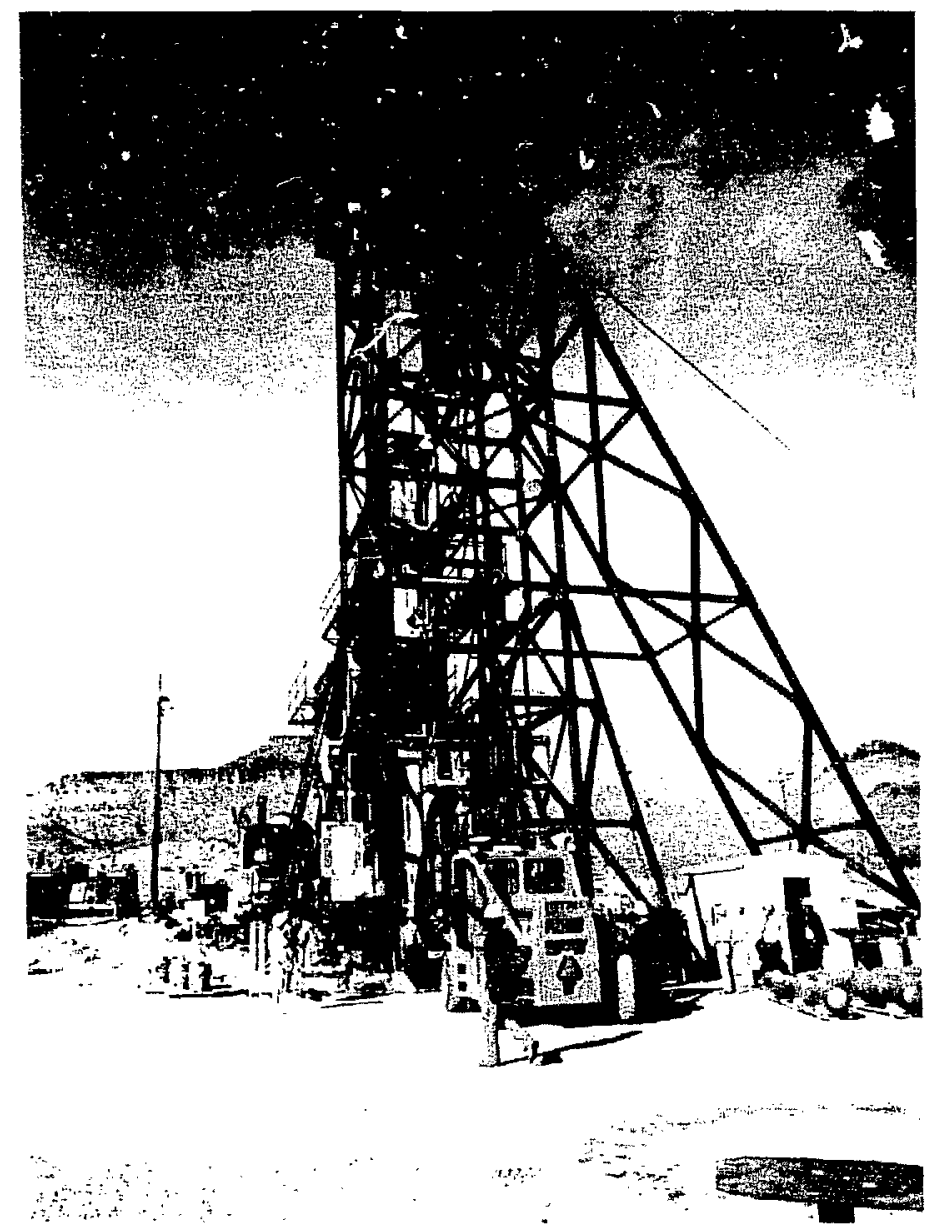

Figure 5-2. Piledriver head frame.

Divided in to three compartments, the overall shaft dimensions are nominaily $1.8 \times 3.7 \mathrm{~m}(6 \times 12 \mathrm{ft})$ (Fig. 5-3). A hoisting compartment $1.8 \times 2.6 \mathrm{~m}(6 \times 8.5 \mathrm{ft})$ accommodates materials, muck, personnel, and power and instrumentation cabling, and a ladderway $1.1 \times 1.2 \mathrm{~m}(3.5 \times 4-\mathrm{ft})$ is provided for emergency use in the event of power tailure. The third compartment, which measures $0.6 \times 1.1 \mathrm{~m}(2 \times 3.5 \mathrm{ft})$, is the passageway for ventilation ducts and compressed air and water piping.

Once the SFT-C was authorized and tunding was approved, major rebuilding of the shaft commenced, including:

- Replacement of elevator guides to accommodate heavy usage and high-speed mucking operations.

- Installation of new ladders and landings.

- Complete replacement of the twin $406-\mathrm{mm}$-diameter ventilation exhaust ducrs, which were severely corroded.

- Inspection and replacement, as necessary, of wooden lagging between steel sets.

- Installation of a new $2400-V$ power and phonc cobles.

After refurbishment was completed, the shaft was ready to support the necessary underground construction activities.

The second majur facility existing at the time the SFT-C was authorized was EMAD (Fig. 7-4). This large, shielcied, highbay structure had been constructed to support a deep-space nuclear propulsion program and had since been idle. Relatively minor refurbishments and modificatisms brought EMAD to a 


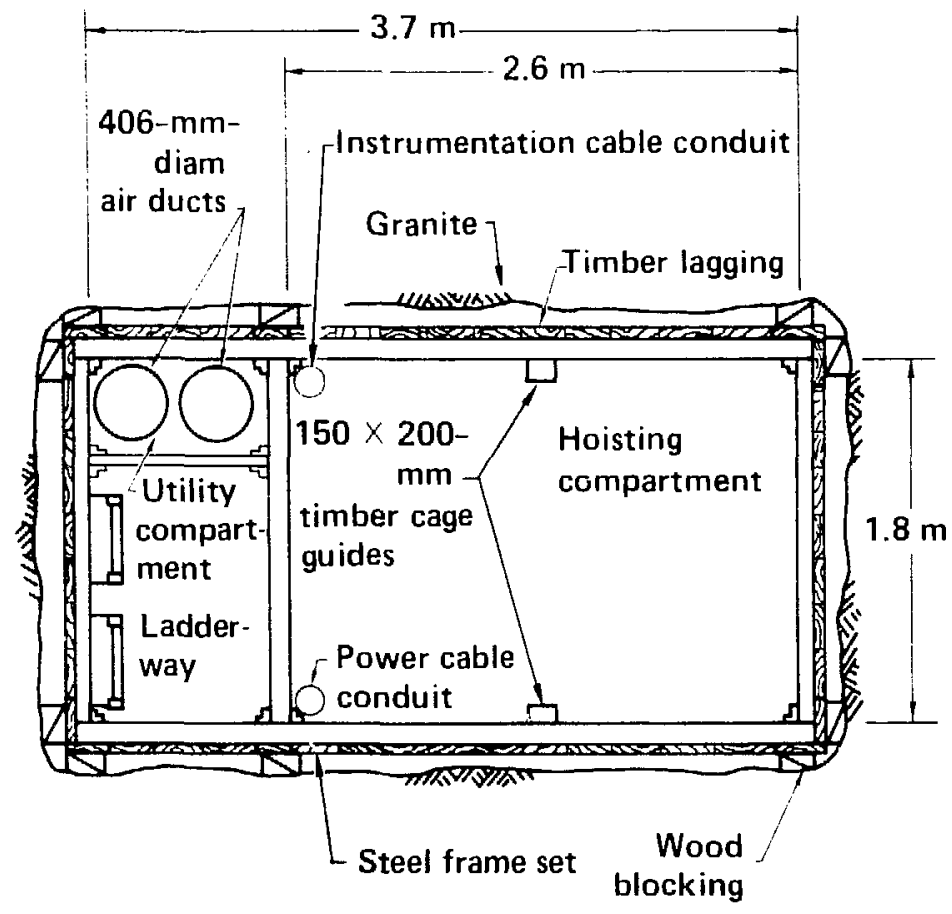

Figure 5-3. Plan view of Piledriver shaft.

state of readiness to receive, evaluate, and encapsulate intact spent-fuel assemblies for use in the SFT-C studies. These preparations are discussed further in NVO-198 and in Chapter 7 of this report.

\subsection{Design and Construction Constraints}

Several factors influenced the design and cor struction of the SFT $-\mathrm{C}$ facilities. As noted above, the availability of the PILEDRIVER and EMAD facilities produced significant cost and scheduling advantages. Likewise, they constrained the design and construction activities in the sense that they were unspecified subsystems within the larger system that was designed and constructed for the express purpose of executing the SFT $-\mathrm{C}$.

The subsurface geology, in situ state of stress, and surface topography were used to establish the positions of the canister access shaft and underground workings. The three-drift complex was oriented N61 ${ }^{\circ} \mathrm{W}$ to be roughly parallel and perpendicular to frequently encountered joint sets (Chapter 4). As a result, the drifts were also approximately aligned with the minimum principal stress. Although this alignment with respect to the fracture system produced somewhat irregular surfaces on the excavations because of overbreak, it resulted in a favorable position for the collar of the canister access shaft (Patrick and Mayr, 1981). Alternative orientations would have positioned the canister access shaft and headframe on steep hillsides or in a ravine.

The dimensions of the canister drift, as well as those of the railcar and receiving rooms, were selected as the minimum necessary for operation of the Underground Transfer Vehicle (UTV). The dimensions of the two heater drifts were the minimum necessary to permit mining and installation of heaters and instrumentation. The spacing between drifts was established by comparing thermal calculations of a full-scale repository with those of the proposed test geometry (Chapter 3 ).

The remaining constraints governed the sequence and method of excavation. Because alignment of the canister drift with respect to the canister access shaft was critical, the shaft was drilled before drift construction. After the location of the access shaft was determined by wireline surveying methods, the 


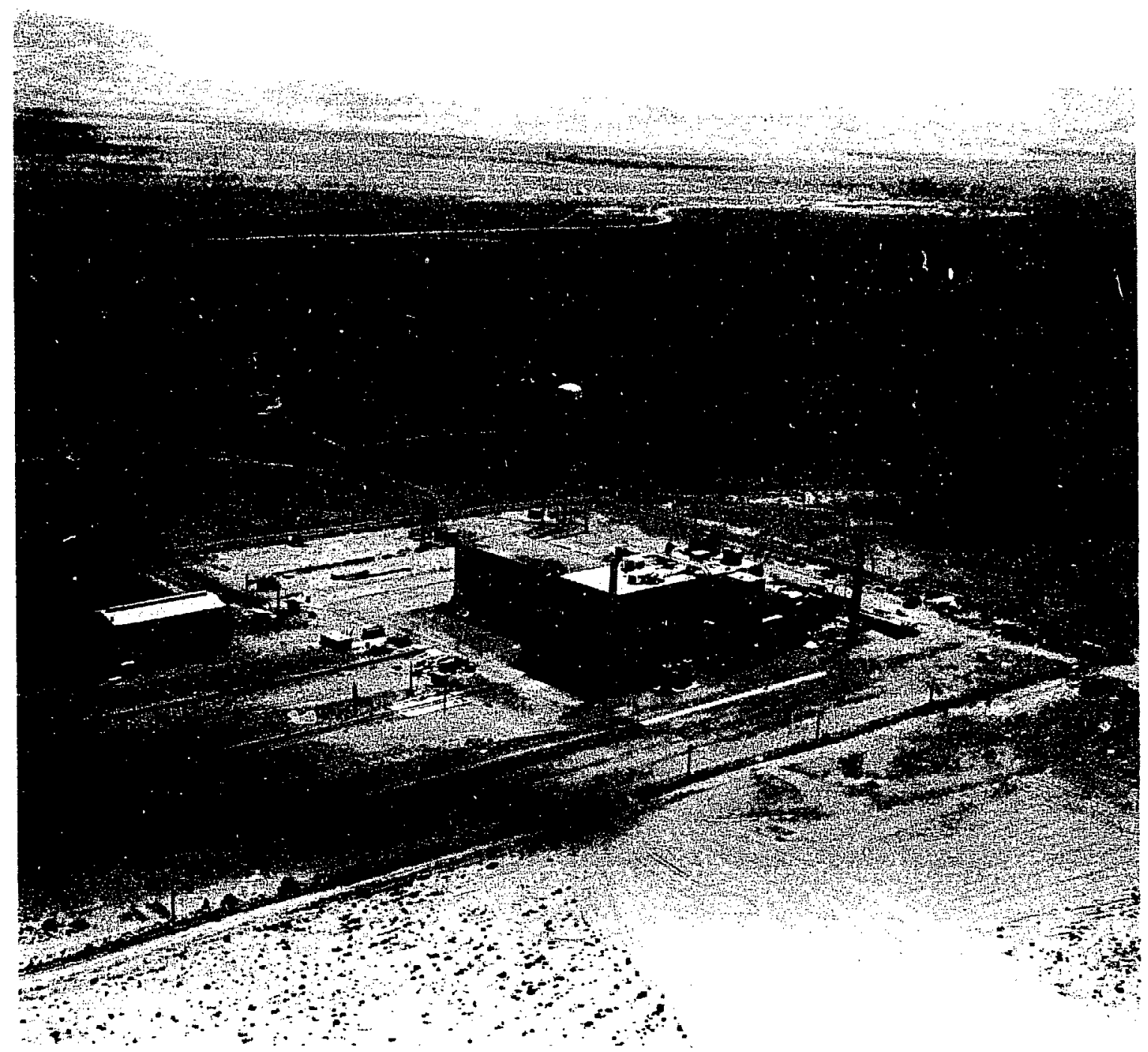

Figure 5-4. Aerial view of EMAD.

two heater drifts were driven to connect with it, thus confirming the location of the shaft. The canister drift alignment was then adjusted slightly and excavated. Conventional drill-and-blast excavation techniques were used in all but two short, instrumented sections where smooth-wall blasting techniques were specified.

\subsection{Facility Description}

The design and construction constraints described above and the construction activities described in Sec. 5.4 produced the underground structures shown in Figs. 5-5 and 5-6.

A $3.7-x-3.7-\mathrm{m}$ access drift extends from the existing PILEDRIVER complex to the railcar room, which is $14.6 \times 6 \times 7.6 \mathrm{~m}$ high. Beyond this room, the 6.1-m-high $\times 4.6-\mathrm{m}-v$ ide canister sturage drift extends $64 \mathrm{~m}$ 


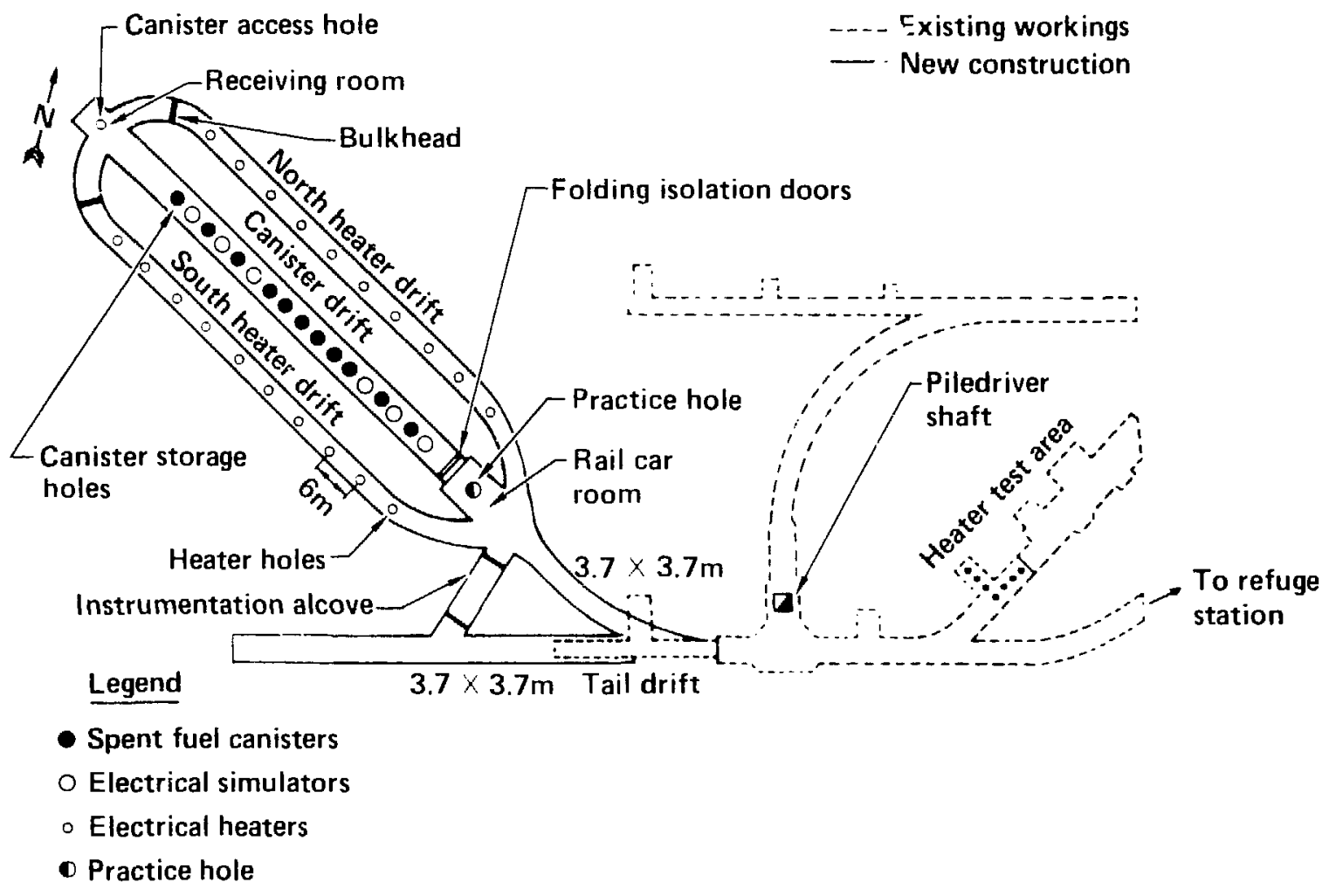

Figure 5-5. Climax site subsurface structures and facilities.

to the receiving room, which is located at the base of the $485-\mathrm{mm}$-inside diameter steel-lined canister access shaft.

A linear array of 17 storage holes is located on 3-m centers in the floor of the canister drift. Of these, 11 housed spent-fuel assemblies and 6 housed electrically heated simulators during the test. To accommodate personnel training and equipment evaluations, an additional hole with a dummy canister was provided in the railcar room. These 18 storage holes are identical: $610 \mathrm{~mm}$ in diameter by $5.2 \mathrm{~m}$ deep, with a $457-\mathrm{mm}$ steel liner grouted in position at the top and bottom.

The north and south heater drifts on either side of the canister drift measure $3.4 \times 3.4 \mathrm{~m}$. As we indicated above, their 9.8- and 10.2-m spacings from center line of the canister drift resulted from adjustment of the planned drift alignment. Ten auxiliary electrical heaters were emplaced in small-diameter boreholes on 6-m centers in the floor of each of these drifts.

\subsection{Facility Construction}

Following refurbishment of the PILEDRIVER personnel and materials shaft, preparation and construction began on the hoist, headframe, and site.

\subsubsection{Canister Access Shaft}

The collar location of the canister access shaft, through which the encapsulated spent-fuel assemblies were lowered and raised, was selected based on surface topography and subsurface geological conditions.

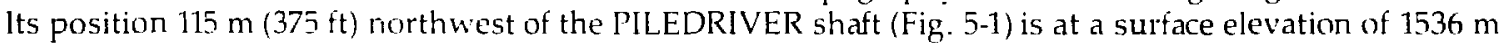
(5040 ft) above MSL. 


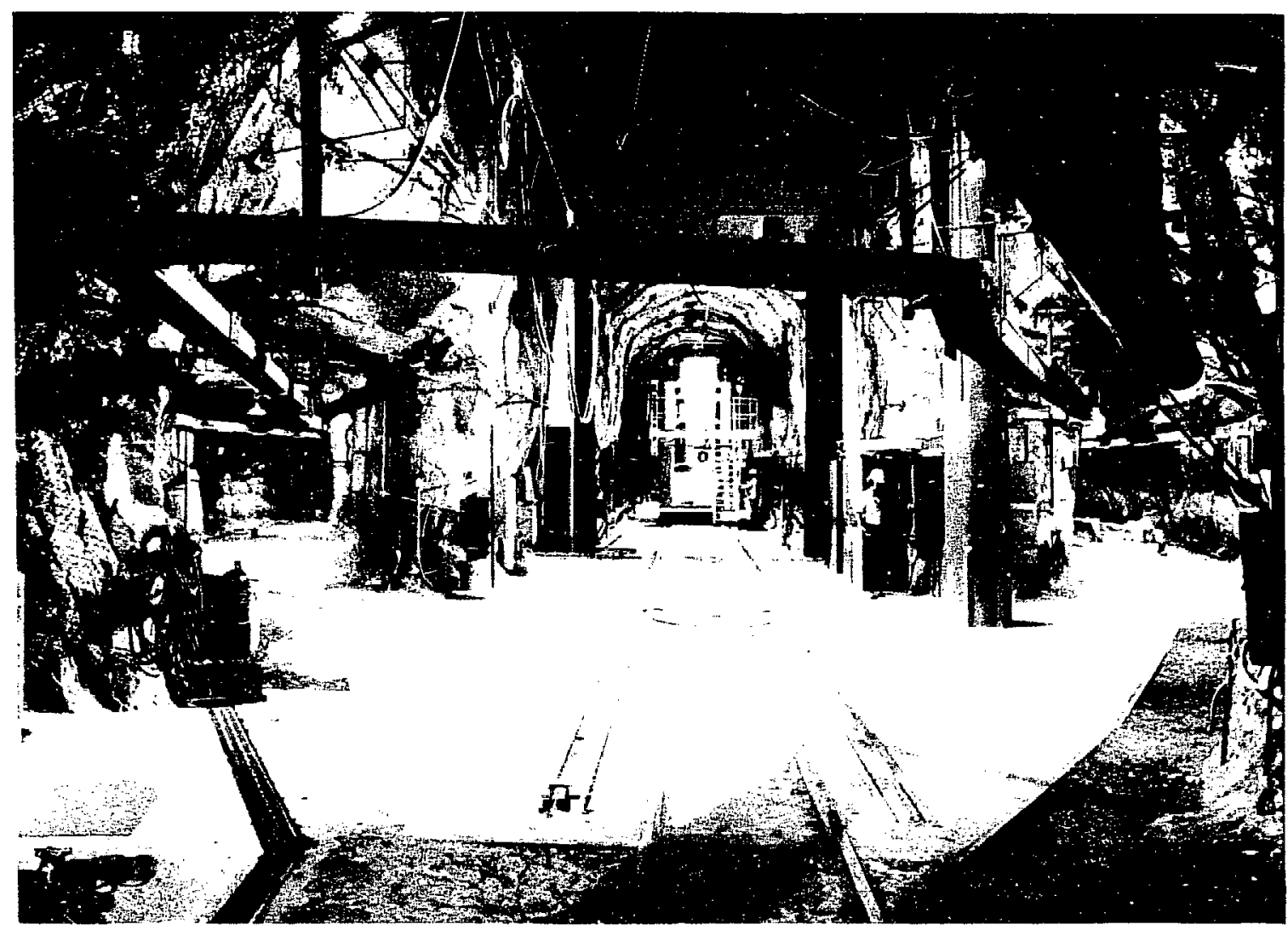

Figure 5-6. Panorama of Spent Fuel Test-Climax drifts.

Drilling of the 762 -mm-diameter shaft was initiated in October 1978 using a tricone rotary bit with carbide button inserts. Although a number of collar weights and rotation speeds were tested, penetration was excessively slow (Table 5-1). After using this technique for $90 \mathrm{~m}$, we rented an Ingersoll-Rand downhole hammer drill with an on-the-drill weight of about $7,000 \mathrm{~kg}$ and a rotation speed of about $2 \mathrm{rpm}$. As the table shows, substantial improvements were seen in the mean drilling rate (based on drilling time) and the effective drilling rate (based on total rig time). This method was used for all but the lower $14 \mathrm{~m}$ of the shaft, where the tricone bit was used because additional hammer-drill bits were unavailable.

Two directional surveys were conducted during the drilling operations: one when the shaft was at a depth of $90.5 \mathrm{~m}$ and one at a depth of $315 \mathrm{~m}$. After total depth was reached, three directional logs were made with logging on both the up and down trips. The effective shot spacing was $1.5 \mathrm{~m}$. Using a computer code previously developed at LLNL for post-shot drilling for underground nuclear testing, a total depth coordinate was calculated with a possible error circle of $150 \mathrm{~mm}$. The shaft was line-of-sight to a depth of $305 \mathrm{~m}$, and total shaft deviation was $4.92 \mathrm{~m}(1.2 \%)$.

After directional surveying was completed, the shaft was washed, bailed, and photographed, and density logs were taken. The 508-mm-outside diameter, $485-\mathrm{mm}$-inside diametor, $140-\mathrm{kg} / \mathrm{m}$ casing was then lowered and cemented into position. The Type A cement with $2 \%$ calcium chloride additive was pumped through two $50-\mathrm{mm}$ diameter cementing lines.

Near the top of the shaft, the liner is slotted to provide a takeoff for ventilation air exhausted from the underground workings (Fig. 5-7). A pit was constructed to ensure that the Surface Transport Vehicle (STV) cask was aligned with the access shaft and to provide radiation shielding during transfer aperations. The pit also incorporated hydraulic cylinders for emergency closing of the STV bottom gate (NVO-210. 1980). A similar shielding collar was alsoriconstructed at the base of the shaft. 
Table 5-1. Drilling statistics for the carister-access shaft (after Patrick and Mayr, 1981).

\begin{tabular}{|c|c|c|c|c|}
\hline \multirow[b]{2}{*}{ Drilling parameter } & \multicolumn{2}{|c|}{ Rotarytricune } & \multirow[b]{2}{*}{$\begin{array}{l}\text { Hammerdrill } \\
\text { (redrilling) }\end{array}$} & \multirow[b]{2}{*}{$\begin{array}{l}\text { Hammerdrill } \\
\text { (new drilling) }\end{array}$} \\
\hline & $\begin{array}{l}\text { Lpper } \\
\text { section }\end{array}$ & $\begin{array}{l}\text { Luwer } \\
\text { section }\end{array}$ & & \\
\hline Distance drilled (m) & 90.5 & 13.7 & 90.5 & 305 \\
\hline Rotating time (h) & 381 & 68.0 & 37.5 & 201 \\
\hline Mean drill: o rate $(\mathrm{m} h)$ & 0.24 & 0.20 & 2.4 & 1.5 \\
\hline Rig time (h) & 364 & 88.0 & 73.5 & 616 \\
\hline Mean effective drilling rate $(\mathrm{m} . \mathrm{h}$ ! & 0.16 & 0.16 & 1.2 & 0.5 \\
\hline
\end{tabular}

'Rig time is total time on the hole excluding approved work stop pages and logging time.

\subsubsection{Underground Exploration}

To confirm that the selected location was adequate for the purposes of the SFT-C and that no unexpected geolugical conditions would be encoun ered, four 76 -mm-diameter (NX) exploratory borings were obtained with a Longyear 14 rig. All borings were collared near the end of the existing workings northwest of the PILFDRIVER shaft. Threc boreholes were nearly horizontal and explored the regions north of, south of, and alung the cel aral axis of the canister drift, while the fourth probed the region below the proposed SFT-C (Chapter 4). A total of $480 \mathrm{~m}$ of drilling was done at an average rate of about $1 \mathrm{~m} / \mathrm{h}$, with about $99 \%$ core recovery. Cores were logged, photographed and archived. Selected intervals were retained for subsequent testing.

\subsubsection{Underground Excavation}

Excavation was accomplished using drill-and-blast techniques to fragment the rock and a load-hauldump (LHD) unit to move the rock to the PILEDRIVER hoisting station. The taildrift, alcove, access to the railcar room, and the two heater drifts were excavated using two Atlas-Copco 205 "Miniboomers" supported by an EIMCO 913 LHD.

After the heater drifts intersected the access shaft, thereby confirming its location, the canister storage drift was excavated. This was done in two passes. The top $4.0 \quad 1.6-\mathrm{m}$-wide heading was excavated using a shop-built drill jumbo with four Gardier-Denver 123 rotary percussion machines, again supported by the EIMCO 913 LHD. A Leroi airtrack was ther used to drill the bench, enlarging the drift to $6.1 \times 4.6 \mathrm{~m}$ wide. The Miniboomers and jacklegs were used to extend the taildrift, construct the alcove, trim the excavations, and enlarge the railicar and receiving rooms.

Several problems were encountered during underground development (Patrick and Mayr, 1981). A significant fraction of oversized material was produced, requiring secondary breakage. Primarily, this resulted from the geological fractures, which produced a blocky structure.

Many blast rounds failed to break to the full drilling deptt. These "bootlegs" were attributed to the fact that the mining work force was more experienced in the weaker tuffs that are present in other tunnels at the NTS. Smooth-wall blasting results were not as good as anticipated for three reasons: drills were unable to be accurately positioned, stemming materials were not used, and delays were not properly patterned. And finally, overbreak in the floor of the caniste1 drift was excessive because of the short vertical height of the benches. This problem was accentuated by the presence of a low-angle joint set that produced a saw tooth profile on the floor.

Excavation rates averaged about $2 \mathrm{~m}^{3} / \mathrm{h}$ and ranged from a high of $3.6 \mathrm{~m}^{3} / \mathrm{h}$ in the canister drift heading to $1.5 \mathrm{~m}^{3} / \mathrm{h}$ in the canister drift bench. In comparison, low productivity mining methods typically average less than $2 \mathrm{~m}^{3} / \mathrm{h}$, whereas recent European tunneling rates in granite have been reported at 3.6 and $4.5 \mathrm{~m}^{3} / \mathrm{h}$ for tunnel boring machine and for drill-and-blast methods, respectively.

Hercules "Unigel $65 \%$ " or DuPont "Tovex" were used in the main rounds, whereas Hercules "Hercosplit" or DuPont "Trimtex" were used in the perimeter holes. Explosive consumption varied widely. depending on drift dimensions, ranging from about $6 \mathrm{~kg} / \mathrm{m}^{3}$ for the heater drifts to $1.8 \mathrm{~kg} / \mathrm{m}^{3}$ for the canister drift bench, with an average of $5 \mathrm{~kg} / \mathrm{m}^{3}$.

Based on core !ogs and inspection of existing underground workings, it appeared that the excavations would remain upen for extended periods with minimal ground control measures. Because there was little 


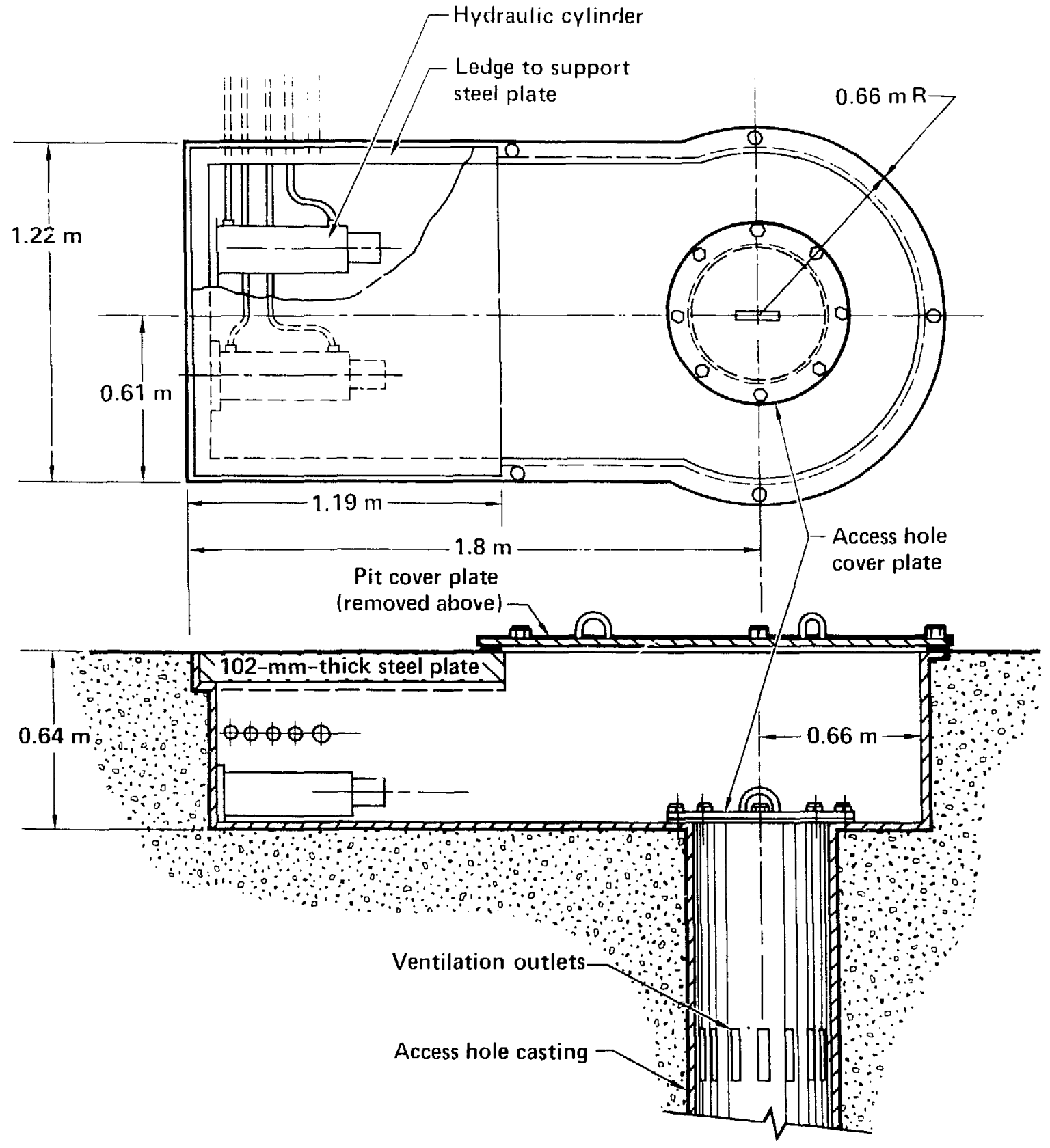

Figure 5-7. Canister access hole pit.

experience with stabilization of heated rooms, and because even minor rock falls could cause injury to workers, visitors, and instrumentation, more support was used than would be required for typical civil works in granitic rocks. Factors influencing the type and quantity of rock support included opening dimensions, local geology, and consideration of whethror the support would carry external loads (such as a lifting fixture).

In the heater drifts, tail drift, and canister drift access, point-anchored resin bolts $1.8 \mathrm{~m}$ long by $19 \mathrm{~mm}$ in diameter or $2.4 \mathrm{~m}$ long by $22 \mathrm{~mm}$ in diameter with wire mesh was the principal ground support system. 
A nominal 1.5-m spacing was used (Fig 5-8). It the canister drift and receiving room, 3.6-m-long by $22-$ mm-diameter bolts were used partway down the ribs. Once again, wire mesh was used to secure loose rock fragments. The railiar room was cupported with 4. :-m by 28 -mm-diameter full-column grouted bolts with mesh in the crown as well as 2.4-m-long point-anchured bolts with mesh along the brow and ribs.

\subsubsection{Subsurface Outfitting}

After excavations were completed, the underground chambers were prepared for the test. The canister drift floor was completely cleaned, storage hole pits were formed from steel tubs, reinforcing steel was emplaced, rails for the UTV were positioned, and the concrete floor was constructed in two placements (Fig. 5-9).

Using a 610-mm-diameter downhole hammer drill mounted on a shop-built crawler unit, an outside. contractor, New Jersey Drilling Company, drilled the 17 storage holes and the practice hole. Maximum penetration rates reached $2.3 \mathrm{~m} / \mathrm{h}$, with an average rate of $1.4 \mathrm{~m} / \mathrm{h}$ including set-up time. Before the emplacement boreholes were drilled, a $76-\mathrm{mm}$-diameter $(\mathrm{NX})$ core was obtained by drilling just inside the perimeter of each emplacement borehole. These cores provided baseline information for subsequent thermal and radiation effects studies (Chapter 4 ).

The 610-mm-diameter boreholes were cased with $508-\mathrm{mm}$ outside diameter carbon steel pipe sections. Grouting at the upper and lower sections provided radiation shielding and held the liners in position.

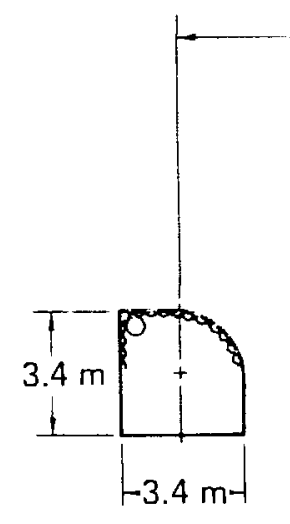

South heater

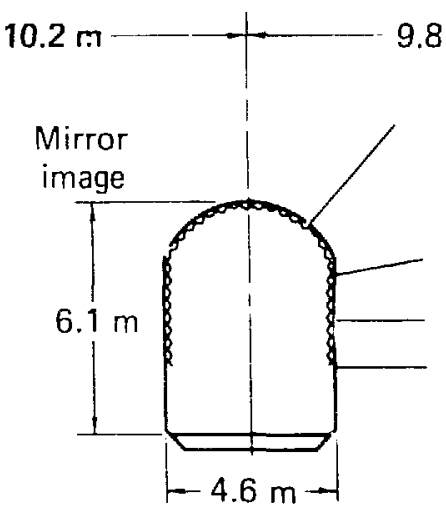

Canister storage

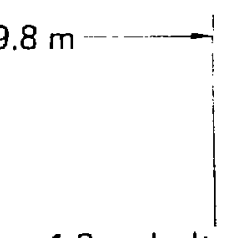

$1.8-\mathrm{m}$ bolts on $1.5-\mathrm{m}$ centers in heater drifts

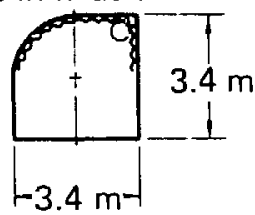

North heater

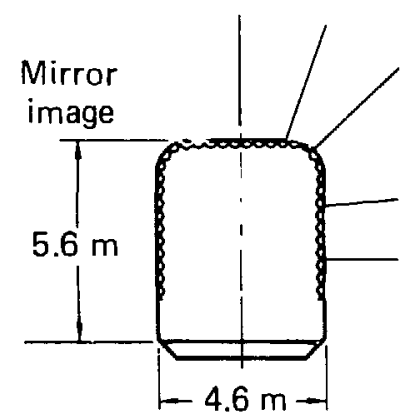

Receiving room

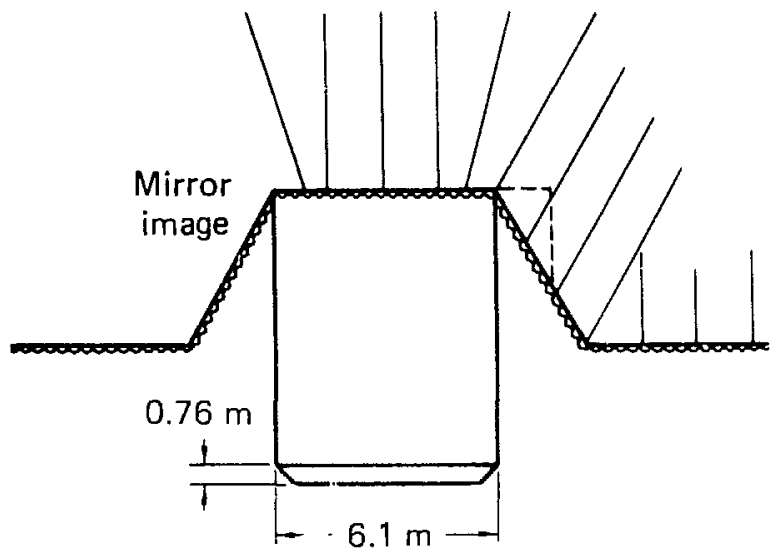

Railcar room

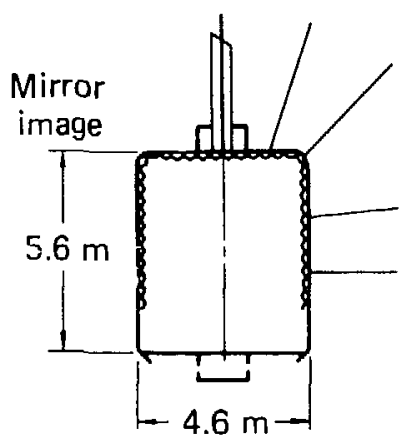

At access hole

Figure 5-8. Ground support deployed in the SFT $-C$ drifts and rooms (after Patrick and Mayr, 1981 ). 

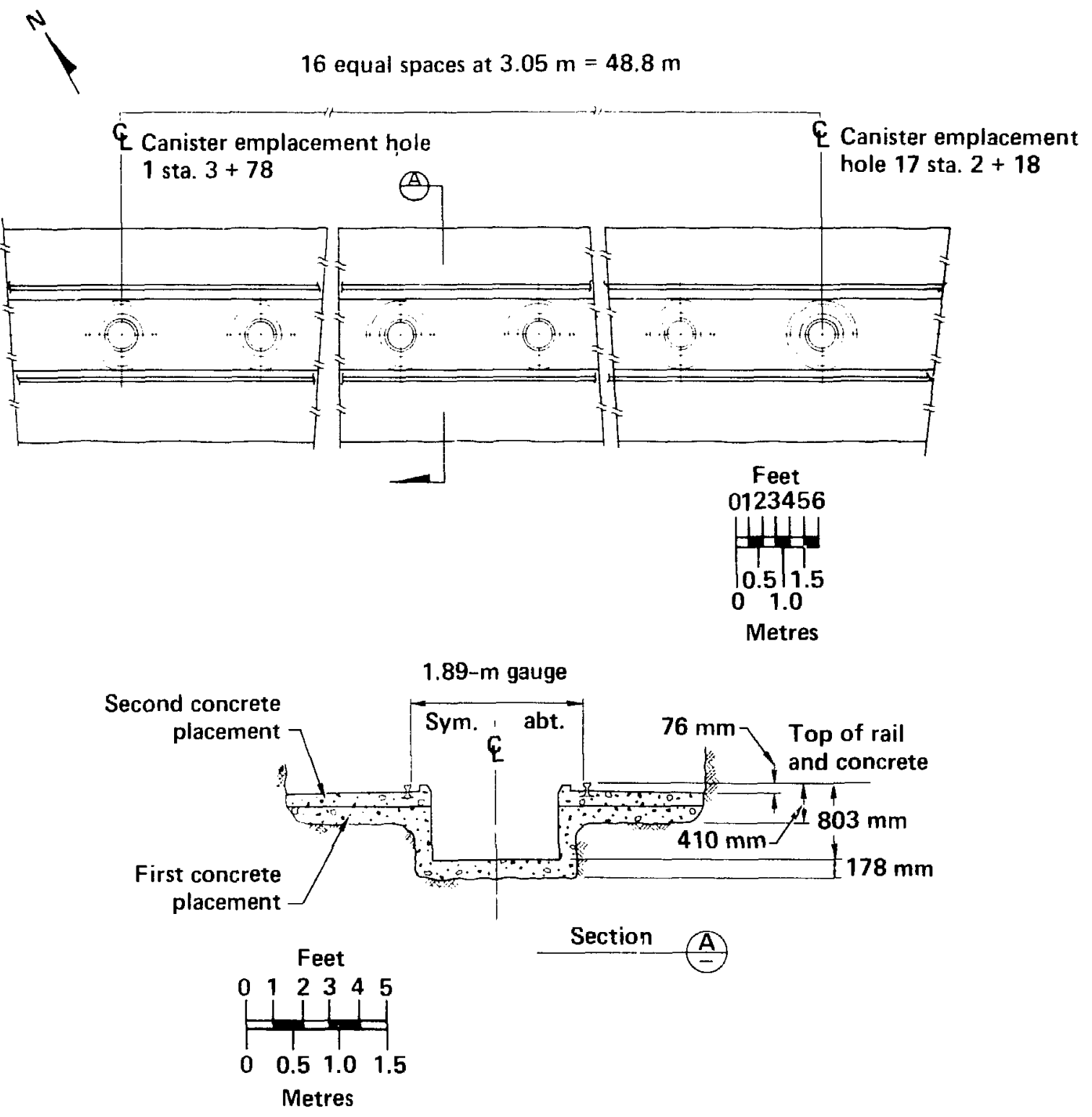

Figure 5-9. Canister storage drift configuration before drilling canister emplacement holes (after Patrick and Mayr, 1981).

The auxiliary heater boreholes consisted of a $1.2-\mathrm{m}$ by $76-\mathrm{mm}$-diameter upper section and a 3.9-m by 51-mm-diameter lower section, both core-drilled. Ten of these boreholes were located in the floor of each heater drift on 6-m centers. A post-mounted CP-65 drill was used to core these holes.

Numerous boreholes were drilled for installing instrumentation, for geological sampling, and for in situ stress measurements. In general, Longyear 38 s and 445 , a CP-65, and a Joy 22 were used, depending on the drilling requirements. Descriptions of these boreholes are noted in Chapters 4 and 9.

\subsubsection{Data Acquisition System Facilities}

Both underground and surface facilities were required to house the data acquisition system (DAS). The former consisted of a cross-cut $4.6 \times 9.1 \times 3.0 \mathrm{~m}$ high enclosed by gypsumboard construction (Fig. 5-5). 
The alcove was air-conditioned and was provided with a Halon fire-suppression system and batteryoperated uninterruptible power supply (L'PS). At the surface, a double-wide trailer $6.1 \times 15.2 \mathrm{~m}$ housed the uphole portion of the DAS (Fig. 5-1). This specially built trailer included redundant air conditioning systems, smoke alarms, and a Halon fire-supiression sy'stem. A UPS was located nearby.

\subsubsection{Electrical Power}

Power was provided to the site substation by a $34.5-\mathrm{kV}$ highline with a capacity of $1500 \mathrm{kVA}$. After conversion to $480 \mathrm{~V}$ by stepdown transformers, power was distributed to the canister access pad, headframe, ventilation blowers, personnel and materials hoist house, and DAS trailers (Fig. 5-1). Underground power was distributed from a 150-kVA, 2400!480-V underground substation.

\subsubsection{Ventilation}

During construction, ventilation was provided by a single 400-hp, Buffalo "squirrel-cage"-type blower that exhausted through two 406-mm-diameter ducts. To control potential releases of radionuclides during spent-tuel handling operations, a separate ventilation system was installed. Two squirrel-cage blowers were connected and valved so that they could be operated separately, in parallel, or in series. Provision was made to draw all air through high-efficiency particulate air (HEPA) filters during handling operations. In the subsurface, flow's through the three drifts were controlled by means of bulkheads and louvers (Fig. 5-10). Airtlow, temperature, dewpoint, and radioactive materials were monitored at selected positions within the airstream (Chapter 9).

\subsection{Cost and Schedule Considerations}

The total project cost through emplacement of 11 spent-fuel assemblies was $\$ 18.4$ million, including all construction, equipment fabrication, technical, and scientific activities. These activities were completed between June 1978 and May 1980. Underground excavation and related activities accounted for about $\$ 2.5$ million of this cost. Through completion of the project in September 1985, total project costs were about $\$ 34$ million. 
(B)
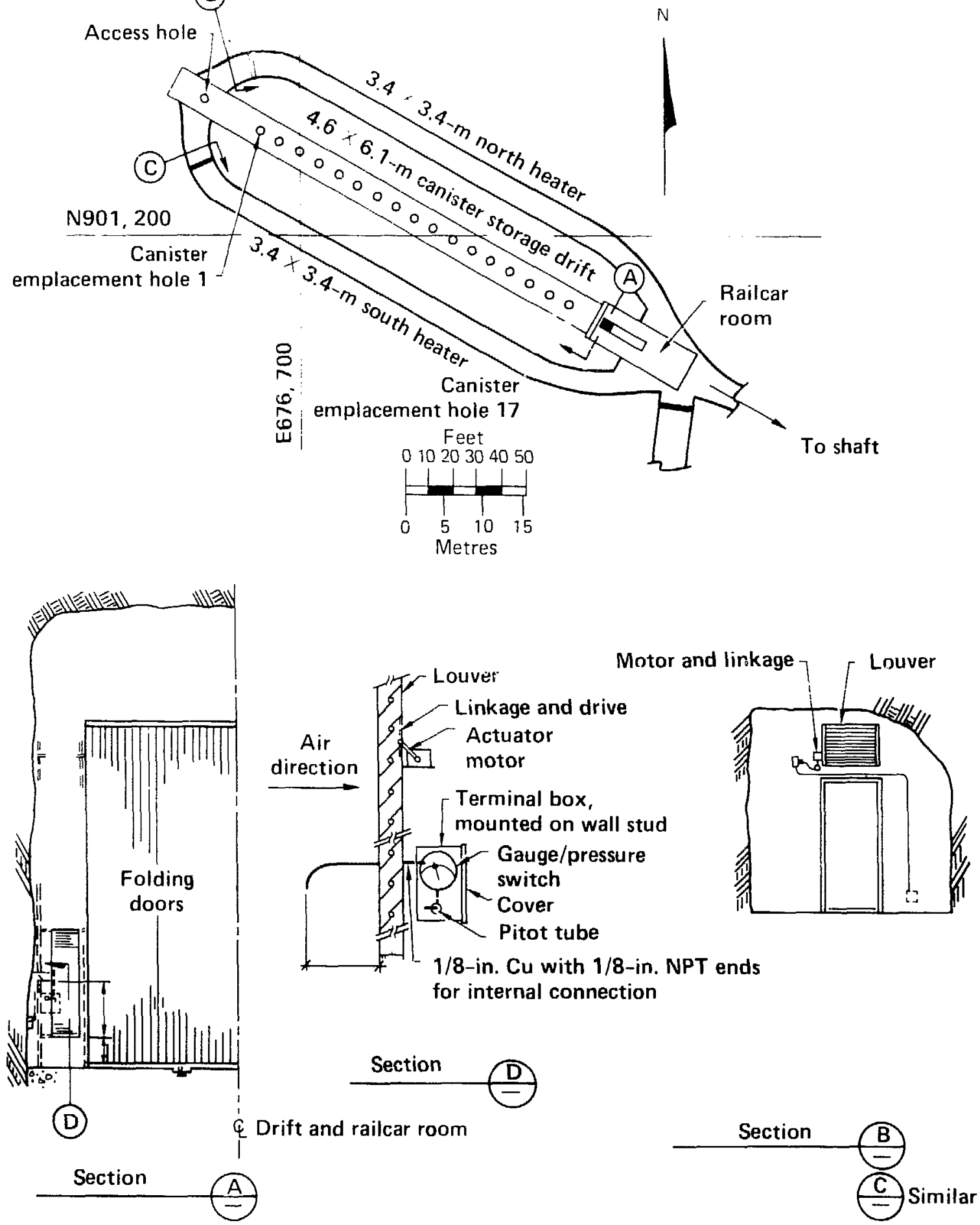

Figure 5-10. Flow regulator system for SFT-C subsurface facilities (after Patrick and Mayr, 1981). 


\section{Spent-Fuel Characterization *}

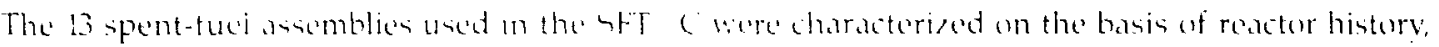
nondestructive testing, calorimetry and doimetry In addition. the isotope inventory and decay history

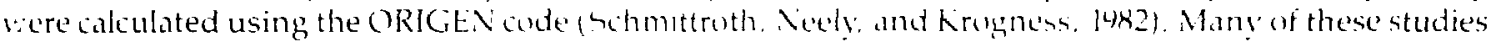
were conducted under separate funding for the (rfice of Nuclear Waste Isolation (ONWI) by the Hanford Engineering Development Laboratory (HEDLL.). The results of these studies are summarized here.

\subsection{Source and History of Spent Fuel}

Thirteen spent-fuel assemblies were selected for use in the SFT-C based on their estimated burnup and age since discharge from reactor core at the anticipated emplacement date at the SFT-C (Chapter 12). This set of assemblies was discharged from Turkey Point Lnit 3 following cycles 2, 3, and 4 in the reactor. Operated by Florida Power and Light Company, Turkey Point Unit 3 is a Westinghouse-designed pressurized water reactor (PWR) with a rated capacity of ofo MWe.

Pertinent dimensions and materials of these PWR assemblies are given in Table 6-1. As noted in Table 6-2, the relative power of assembly serial number $(S, N)$ D22 is somewhat lower than that of the other 12 assemblies in the set. This information was the basis for excluding this assembly from the test array until the final exchange (Chapter 11). Even then, it was placed near the end of the emplacement array to minimize the effect of its lower power level on the simulation.

\subsection{Nondestructive Testing}

To gain a better understanding of the characteristics of spent-fuel assemblies before and after geologic storage, the ONWI funded the HEDL to perform certain nondestructive evaluations of three of the PWR spent-fuel assemblies before their encapsulation for use in the SFT-C. Fifteen rods were selected for nondestructive evaluations and an additional five for destructive evaluations aimed at characterizing the internal conditions of the fuel rods before storage at the SFT-C. These studies were performed at the Battelle Columbus Lahoratories under the direction of HEDL (Davis, 1980).

Although the original plan was to select five rods each from S/N D01, D04, and D06, complications related to Nuclear Regulatory Commission (NRC) shipping regutations and rigid test schedules required that testing proceed with 15 rods from D01. Once shipments were on schedule, five of the characterized D01 rods were exchanged with five rods each from S/N D04 and D06. The five (total) rods for destructive testing were removed from D01 and D04 and were replaced with stainless steel rods. As described by Davis (1980), a total of 38 rods were removed from the three assemblies. The reader is referred to this publication for details concernirg the positions of the rods selected, the replacement scheme of spent fuel and stainless steel rods, and the techniques for extracting the rods.

\subsubsection{Sip Testing}

Before shipment to EMAD, eight of the spent-fuel assemblies were wet sip-tested at Turkey Point. They were also gas sip-tested upon arrival at EMAD. The five assemblies shipped through Batelle Columbus Laboratories (BCL) were not tested at Turkey Point, but were wet sip-tested upon arrival and before departure from BCL. They were later gas sip-tested at EMAD.

Wet sip testing was based on analyses for ${ }^{137} \mathrm{Cs},{ }^{1.34} \mathrm{Cs}$, and ${ }^{6 x)} \mathrm{Co}$ using gamma ray spectrometric techniques (Davis, 1980). After filling and flushing the cask cavity with deionized water, samples were drawn immediately and after 2 - and 16 -h soaking times.

Dry sip testing was performed by drawing a sample of cask cover gas into an evacuated gas-collection cylinder.

Sip testing detected no leaking fuel rods among the 13 assemblies. In general, the concontrations of cesium isotopes were very low. An exeeption was S N DOM, which showed relatively high concentrations of ${ }^{17.4}\left(s\right.$ and $C_{s}$. Davis (1980) reports that this sheservation may be the result of contamination from the

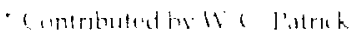


Table 6-1. Characteristics for Turkey Point spent-fuel assemblies used in the SFT-C lafter Davis, 1980).

\begin{tabular}{|c|c|}
\hline Characteristic & Value \\
\hline Vendor & Westinghouse Elec ric Corp. \\
\hline Type (rod array) & $15 \times 15$ \\
\hline \multicolumn{2}{|l|}{ Assembly parameters } \\
\hline Transverse dimension & 8.426 in. \\
\hline Assembly weight & $1420 \mathrm{lb}$ \\
\hline Assembly length & 161.3 in. \\
\hline \multicolumn{2}{|l|}{ Guide tubes } \\
\hline Number & 20 \\
\hline Upper O.D. & $0.544 \mathrm{in}$. \\
\hline Wall thickness & $0.017 \mathrm{in.}$ \\
\hline Material & $2 r-4$ \\
\hline \multicolumn{2}{|l|}{ Instrument tubes } \\
\hline Number & 1 \\
\hline O.D. & 0.544 in. \\
\hline Wall thickness & 0.017 in. \\
\hline Material & $\mathrm{Zr}-4$ \\
\hline \multicolumn{2}{|l|}{ Spacer grids } \\
\hline Number & 7 \\
\hline Material & Inconel 718 \\
\hline Spring material & Inconel 718 \\
\hline \multicolumn{2}{|l|}{ Fuel rods $s^{\lrcorner}$} \\
\hline Numiber & 204 \\
\hline Length & 152.0 in. \\
\hline O.D. & 0.422 in. \\
\hline Wall thickness & $0.0243 \mathrm{in.}$ \\
\hline Material & $\mathrm{Zr}-4$ \\
\hline Fuel length & $144.0 \mathrm{in}$. \\
\hline Orifice, plate material & 304 SS \\
\hline \multicolumn{2}{|l|}{ Plenum springs } \\
\hline Working length & $6.80 \mathrm{in.}$ \\
\hline Material & 302 SS \\
\hline \multicolumn{2}{|l|}{ Fuel pellet } \\
\hline Material & $\mathrm{UO}_{2}$ \\
\hline Enrichment & 2.559 wt $\%{ }^{235} \mathrm{U}$ \\
\hline Weight/assembly & 0.448 t/uranium \\
\hline \multicolumn{2}{|l|}{ Planar Smear density } \\
\hline Dish not smeared in & $90.81 \%$ theoretical \\
\hline Dish smeared in & $89.72 \%$ theoretical \\
\hline
\end{tabular}

- Helium prepressurization le vel is 465 psig.
Table 6-2. Reactor operation data for SFT-C spent-fuel assemblies (after Davis, 1980).

\begin{tabular}{|c|c|}
\hline $\begin{array}{l}\text { Beginning of first cycle of } \\
\text { irradiation }\end{array}$ & December 12, 1974 \\
\hline Discharge date & November 19, 1977 \\
\hline Cycles of operation & 2,3, and 4 \\
\hline $\begin{array}{l}\text { Total irradiation time in } \\
\text { EFPD of core residence }\end{array}$ & 851 EFPD \\
\hline Specific power & $31.203 \mathrm{MW}(\mathrm{th}) / \mathrm{MTU}$ \\
\hline \multicolumn{2}{|l|}{$\begin{array}{c}\text { Assembly average relative power } \\
\text { averaged over all } 3 \text { cycles }\end{array}$} \\
\hline Assemblies D09, $\overline{\mathrm{i}}:$;, D18, D34 & 1.061 \\
\hline Assemblies D01, D15, D35, D47 & 1.082 \\
\hline Assemblies D04, D06, D40, D46 & 1.082 \\
\hline Assembly D22 & 1.008 \\
\hline $\begin{array}{l}\text { Accumulated neutron fast fluence } \\
\text { per assembly at discharge } \\
\text { (nvt }>\mathrm{MeV} \text { ) }\end{array}$ & $5.6 \times 10^{21} \mathrm{n} / \mathrm{cm}^{2}$ \\
\hline
\end{tabular}


$0.127 \mathrm{~mm}(0.005 \mathrm{in}$.$) for S \mathrm{~N} D 04$ and Doh. The weragt assembly length was reported as $3.403 \mathrm{~m}$ (153.65 in .).

Individual rod-length measurements were nbtained by resting the rod in a set of $V$-blocks positioned at 0.61-m (24-in.) intervals on an I-beam. A micrometer was used to make comparative length measurements with reference to a standard. Thermal expansive co rections were employed. Rod lengths varied beween 3.878 and $3.872 \mathrm{~m}$ ( 152.663 and $152.426 \mathrm{in}$.). with an average of $3.875 \mathrm{~m}$ (152.561 in.).

Width of the fuel assemblies, measured from flat-to-flat, ranged from 210.1 to $212.1 \mathrm{~mm}(8.272$ to 8.349 in.), with an average of $211.1 \pm 0.43 \mathrm{~mm}(8.312 \pm 0.017 \mathrm{in}$.$) .$

Profilometry studies indicated that minimum rod diameters averaged $10.7 \mathrm{~mm}(0.420 \mathrm{in}$.) and ranged from $10.65 \mathrm{to} 10.77 \mathrm{~mm}(0.4194$ to $0.4242 \mathrm{in}$.). The largest variations reported were in the range of 0.127 to $0.254 \mathrm{~mm}(0.005$ to $0.010 \mathrm{in}$.). Although no major anomalies such as bulges, scars, or blisters were detected, ridges measuring as high as $0.076 \mathrm{~mm}(0.003 \mathrm{in}$.) were seen. They appear to occur at the pellet interfaces, as inferred from eddy current and gamma scans 'Davis, 1980).

A load cell accurate to $\pm 1.4 \mathrm{~kg}( \pm 3.0 \mathrm{lb})$ was used to weigh the three assemblies. The average weight was $663 \mathrm{~kg}(1459 \mathrm{lb})$ with only $2.3 \mathrm{~kg}(5 \mathrm{lb})$ of variation between the high and low values. A load cell accurate to $0.023 \mathrm{~kg}(0.05 \mathrm{lb})$ was used to weigh individual rods. Rod weights ranged from 3.10 to $3.09 \mathrm{~kg}(6.83$ to 6.74 lb) with an average of $3.1 \mathrm{~kg}(6.82 \mathrm{lb})$.

\subsubsection{Flux Measurements}

Both neutron and ganma flux measurements were made on the intact D04 assembly before it was disassembled and the rods removed. Individual rods wert also gamma scanned.

The neutron field of assembly D04 was characterized using six packages of solid-state track recorders (SSTR) comprising thin mica sheets in contact with fissile isotopes (Davis, 1980). The neutron energy spectrum was determined using ${ }^{235} U(n, f),{ }^{235} U(n, f)$ cadmium covered, ${ }^{232} \operatorname{Th}(n, f),{ }^{238} U(n, f)$, and ${ }^{237} N p(n, f)$. Measured neutron fluxes at the asseribly midplane are tabulated in Table 6-3. Variations in flux in the axia! direction and as a function of distance from the source are displayed in Figs. 6-1 and 6-2, respectively. The average neutron flux and energy at the mid plane are $1.06 \times 10^{4} \mathrm{n} / \mathrm{cm}^{2} / \mathrm{s}$ and $1.4 \mathrm{MeV}$, respectively. With the exception of the slight upturn in the epithernal neutrons, the axial distribution displays a nearly symmetric pattern about the midplane with a somewhat lower flux near the top of the assembly. Davis (1980) attributed the noted upturn in epithermal neutrons near the top to reflection of higher energy neutrons from the shielded cell walls and the lack of absorption of neutions in this sampling position, which was $0.3 \mathrm{~m}$ (12 in.) from the high-mass fuel assembly. An approximately $1 / \mathrm{r}$ attenuation with distance was observed in the higher-energy neutrons.

Thirty-six aluminum-wrapped capsules, each containing five thermoluminescent dosimeters (TLD), were used to determine gamma flux of assembly D04 on September 12, 1979. After 10-min exposure times, the TLDs were counted. Variations in gamma flux along the assembly and as a function of distance from the assembly are shown in Tables 6-4 and 6-5, respectively. Fairly constant gamma flux averaging about $9.11 \times$ $10^{4} \mathrm{R} / \mathrm{h}$ was observed along most of the length of the assembly. At the $0.91-\mathrm{m}(3-\mathrm{ft})$ position, the flux is low coinciding with the presence of a support strap. In addition, there is a notable decrease in flux in the upper $0.61 \mathrm{~m}$ ( $2 \mathrm{ft}$; positions 10, 11, and 12) of the fuel assembly; paralleling a similar decrease in neutron flux.

Table 6-3. Neutron fluxes measured at fuel assembly D04 midplane (after Davis, 1980).

\begin{tabular}{lcc}
\hline \multicolumn{1}{c}{ Energy range } & $\begin{array}{c}\text { Flux } \\
\left(\mathrm{n} / \mathrm{cm}^{2} / \mathrm{s}\right)\end{array}$ & $\begin{array}{c}\text { Estimated } \\
\text { uncertainty } \\
(\%)\end{array}$ \\
\hline Thermal E $<0.5 \mathrm{eV}$ & 30 & 20 \\
Epithermal $(0.5 \mathrm{eV}-0.1 \mathrm{Mit} !)$ & 390 & 20 \\
Fast $(0.1 \mathrm{MeV}-2 \mathrm{MeV})$ & $1.02 \times 10^{!}$ & 15 \\
High energy $(>2 \mathrm{MeV})$ & $49 \times 10^{3}$ & 15 \\
Total flux & $1.06 \times 10^{4}$ & 15 \\
\hline
\end{tabular}

'Average energy $=1.4 \mathrm{MeV}$. 


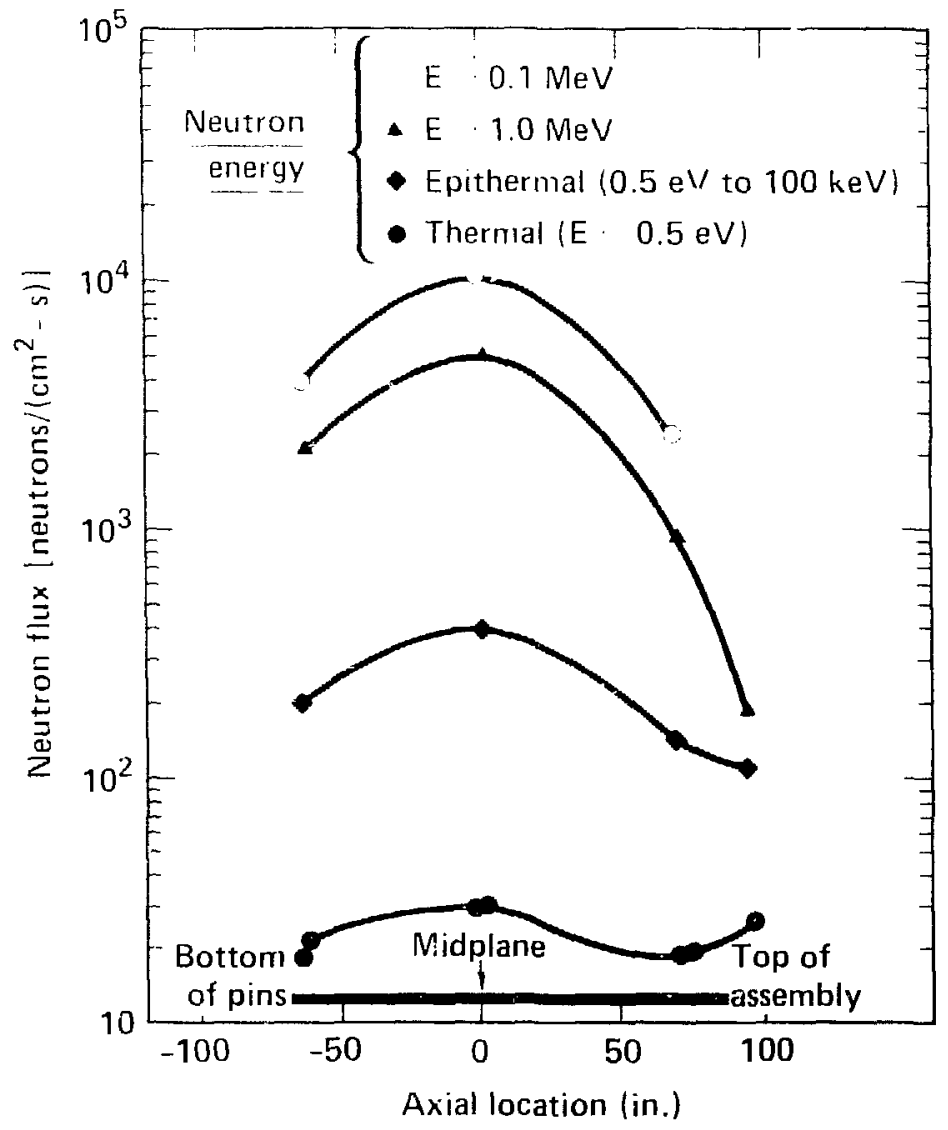

Figure 6-1. Neutron flux as a function of axial location (after Davis, 1980).

Individual rods were gamma-scanned using a motor-driven scanning system consisting of a variablesiit lead collimator [set with a width of $0.635 \mathrm{~mm}(0.025-\mathrm{in}$.)] and a germanium-lithium counting crystal spectrometer. Total activity and ${ }^{137} \mathrm{Cs}$ gamma activity were scanned. As reported by Davis (1980), both the total activity and ${ }^{137} \mathrm{Cs}$ activity displayed the typical flat, chopped cosine profiles (Figs. 6-3 and 6-4). Except for about $0.41 \mathrm{~m}$ ( $16 \mathrm{in}$.) near each end of the rods, the profiles were fairly constant. Gamma depressions of about $10 \%$ were seen at the pellet-to-pellet interfaces and at each spacer grid location. The cesium profiles closely tracked those of total gamma, indicating no cesium migration.

Following retrieval of spent fuel from the SF $[-C$, Van Konynenburg (1984) obtained additional dosimetry measurements. Three Harshaw TLD-700 LiF chips were mounted in each of 24 plastic dosimeter packets to obtain measurements on assembly D34. Six packets that were beta-shielded with 1.6-mm-thick aluminum and six unshielded packets were placed in contact with one of the faces of the fuel assembly for 10 min. each. The positions of the dosimeters were as noted in Fig. 6-5. Two other packets were instrumented with thermocouples. Since the maximum packet temperature was only $30^{\circ} \mathrm{C}$, no thermal corrections were required. The remaining packets were shipped and stored with the exposed packets to detect possible unplanned exposures.

Van Konynenburg (1984) reported a contact dose rate of $2.33 \times 10^{4} \mathrm{R} / \mathrm{h}$ on March 28, 1984. This value includes correction for the small dose received during handling and positioning of the TLDs but does not include correction for gamma attenuation by the beta shield.

\subsubsection{Visual Examinations}

In-pool examinations of D01, D04, and D06 were conducted at the Turkey Point reactor to provide videotape recurds o. their external appearances. The three assemblies were similar in appearance with all 


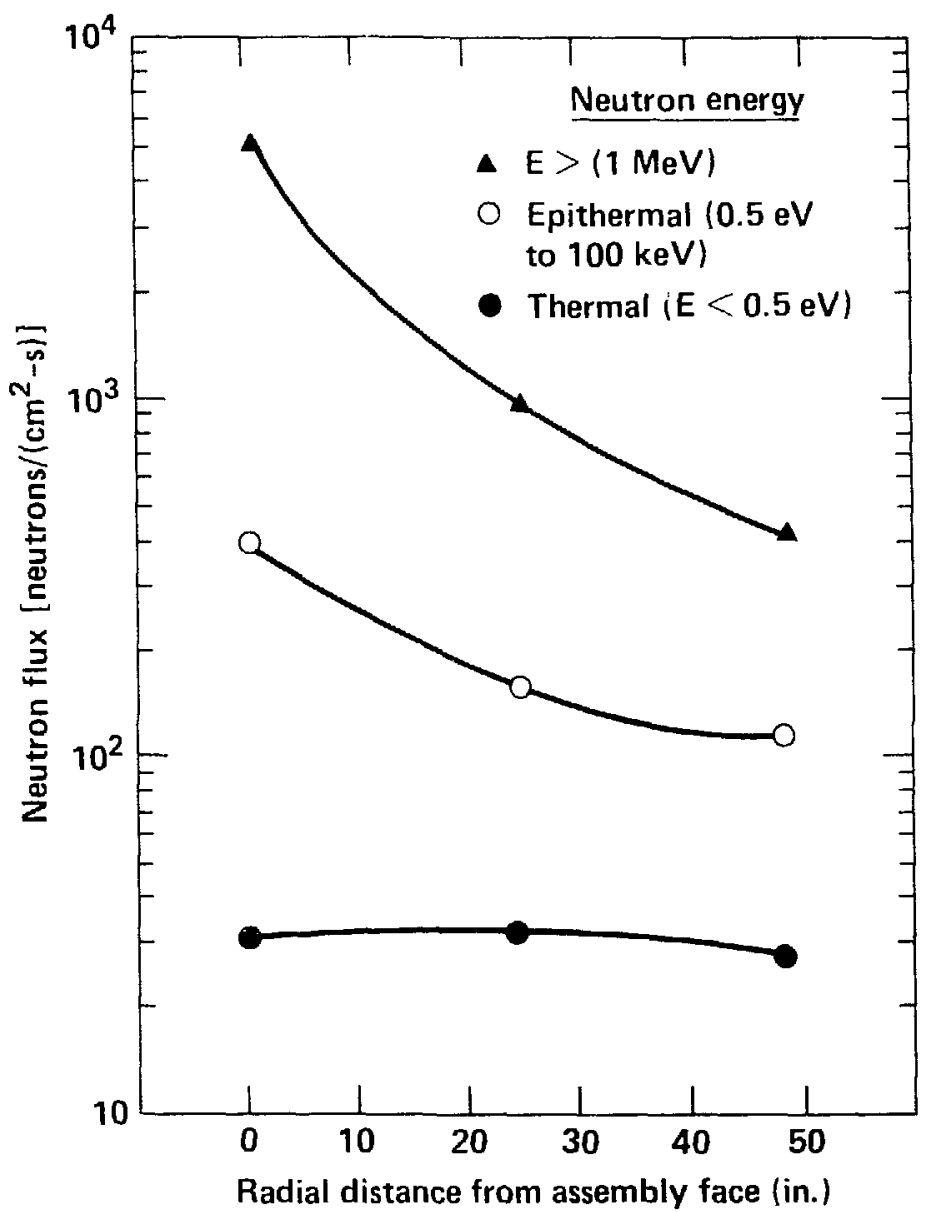

Figure 6-2. Neutron flux as a function of radial distance from the fuel midplane (after Davis, 1980).

Table 6-4. Axial gamma exposure rate from fuel assembly D04 (after Davis, 1980).

\begin{tabular}{|c|c|c|c|c|}
\hline \multirow[b]{2}{*}{$\begin{array}{l}\text { Distance from } \\
\text { bottom of fuel } \\
\text { assembly (ft) }\end{array}$} & \multicolumn{2}{|c|}{$\begin{array}{l}\text { Contact with fuel } \\
\text { assembly surface }\end{array}$} & \multicolumn{2}{|c|}{$\begin{array}{l}12 \text { in. from fuel } \\
\text { assembly surface }\end{array}$} \\
\hline & $\begin{array}{l}\text { Exposure } \\
\text { rate }(R / h)\end{array}$ & $\begin{array}{c}\text { lo } \\
\text { uncertainty } \\
(\%)\end{array}$ & $\begin{array}{l}\text { Exposure } \\
\text { rate }(R / h)\end{array}$ & $\begin{array}{c}\sigma \\
\text { uncertainty } \\
(\%)\end{array}$ \\
\hline 0 & $8.81 \times 10^{4}$ & 3.4 & $7.42 \times 10^{3}$ & 2.4 \\
\hline 1 & $8.91 \times 10^{4}$ & 3.6 & $1.21 \times 10^{4}$ & 0.8 \\
\hline 2 & $9.30 \times 10^{4}$ & 3.3 & $1.49 \times 10^{4}$ & 4.8 \\
\hline 3 & $6.57 \times 10^{4}$ & 2.6 & $1.62 \times 10^{4}$ & 4.1 \\
\hline 4 & $9.25 \times 10^{4}$ & 1.6 & $1.62 \times 10^{3}$ & 4.0 \\
\hline 5 & $9.00 \times 10^{4}$ & 1.8 & $1.71 \times 10^{4}$ & 1.1 \\
\hline 6 & $9.52 \times 10^{4}$ & 3.5 & $1.63 \times 10^{4}$ & 4.1 \\
\hline 7 & $9.37 \times 10^{4}$ & 1.9 & $1.58 \times 10^{4}$ & 2.5 \\
\hline 8 & $9.27 \times 10^{4}$ & 2.9 & $1.61 \times 10^{4}$ & 1.6 \\
\hline 9 & $8.25 \times 10^{4}$ & 2.3 & $7.54 \times 10^{-1}$ & 6.2 \\
\hline 10 & $5.48 \times 10^{4}$ & 4.2 & $1.42 \times 10^{4}$ & 4.3 \\
\hline 11 & $1.29 \times 10^{4}$ & 7.4 & $1.10 \times 10^{4}$ & 3.3 \\
\hline 12 & $2.75 \times 10^{3}$ & 4.4 & $7.29 \times 10^{3}$ & 3.8 \\
\hline
\end{tabular}


Table 6.5. Gamma dose rate as a function of distance from assembly D04 midplane (after Davis, 1980).

\begin{tabular}{ccc}
$\begin{array}{c}\text { Distance from } \\
\text { assembly midplane } \\
(\mathrm{ft})\end{array}$ & $\begin{array}{c}\text { Exposure rate } \\
(\mathrm{R} / \mathrm{h})\end{array}$ & $\begin{array}{c}\text { lo } \\
\text { uncertainty }(\%)\end{array}$ \\
\hline 0 & $6.30 \times 10^{4}$ & 3.8 \\
1 & $1.86 \times 10^{4}$ & 2.7 \\
2 & $9.88 \times 10^{3}$ & 3.3 \\
3 & $6.81 \times 10^{3}$ & 4.9 \\
4 & $4.91 \times 10^{3}$ & 4.2 \\
5 & $3.92 \times 10^{3}$ & 4.1 \\
6 & $3.34 \times 10^{3}$ & 2.6 \\
7 & $2.85 \times 10^{3}$ & 1.7 \\
8 & $2.24 \times 10^{3}$ & 4.2
\end{tabular}

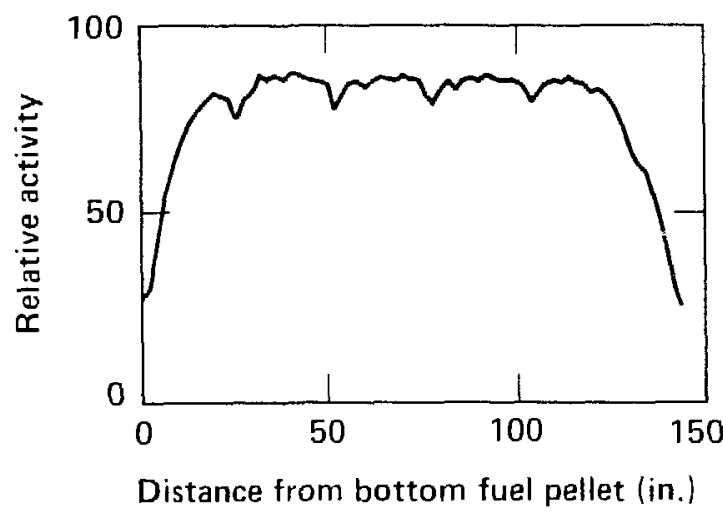

Figure 6-3. Gross gamma scan trace for D01-F7 (after Davis, 1980).

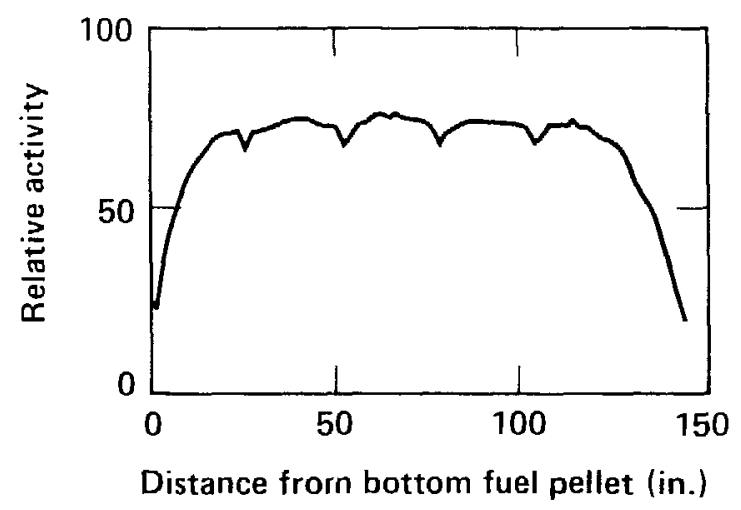

Figure 6-4. Cesium 137 gamma scan for D04-39 (after Davis, 1980).

structural members showing a uniform flat black oxide layer. Minor scratches on grid straps and tiebacks were attributed to handling. About half the rods around the periphery were seated in the bottom tie plate, very few were distorted, and none were in rod-to-rod contact.

Inspection of 20 rods from assemblies D0I and D04 showed them to have generally the same appearance. No gross distortions were reported. The oxidation varied from a flat dark black near the bottom to a uniform light gray near the top. In the range of 1.52 to $2.54 \mathrm{~m} \mathrm{(60} \mathrm{to} 100 \mathrm{in}$.) from the bottom of the rod was the transition in coloration. In this region, the coloration was spotied with a blotchy combination of black and light gray. Scratches attributable to rod insertion and removal were also noted, in some cases along the entire rod length. Lighter colored circumferential rings were frequently observed, coinciding with the ridges observed during profilometry and occurring at pellet-to-pellet interfaces.

\subsection{Thermal Characteristics}

The decay heat of the spent-fuel assemblies was calculated and measured (Schmittroth, Neely, and Krogness, 1982) to establish the power-generation curve for use in SFT-C thermal and thermomechanical calculations (Chapter 3). Calculations were performed witi ORICiEN2 and calorimetry was performed at EMAD using a boiling-water calorimeter. 


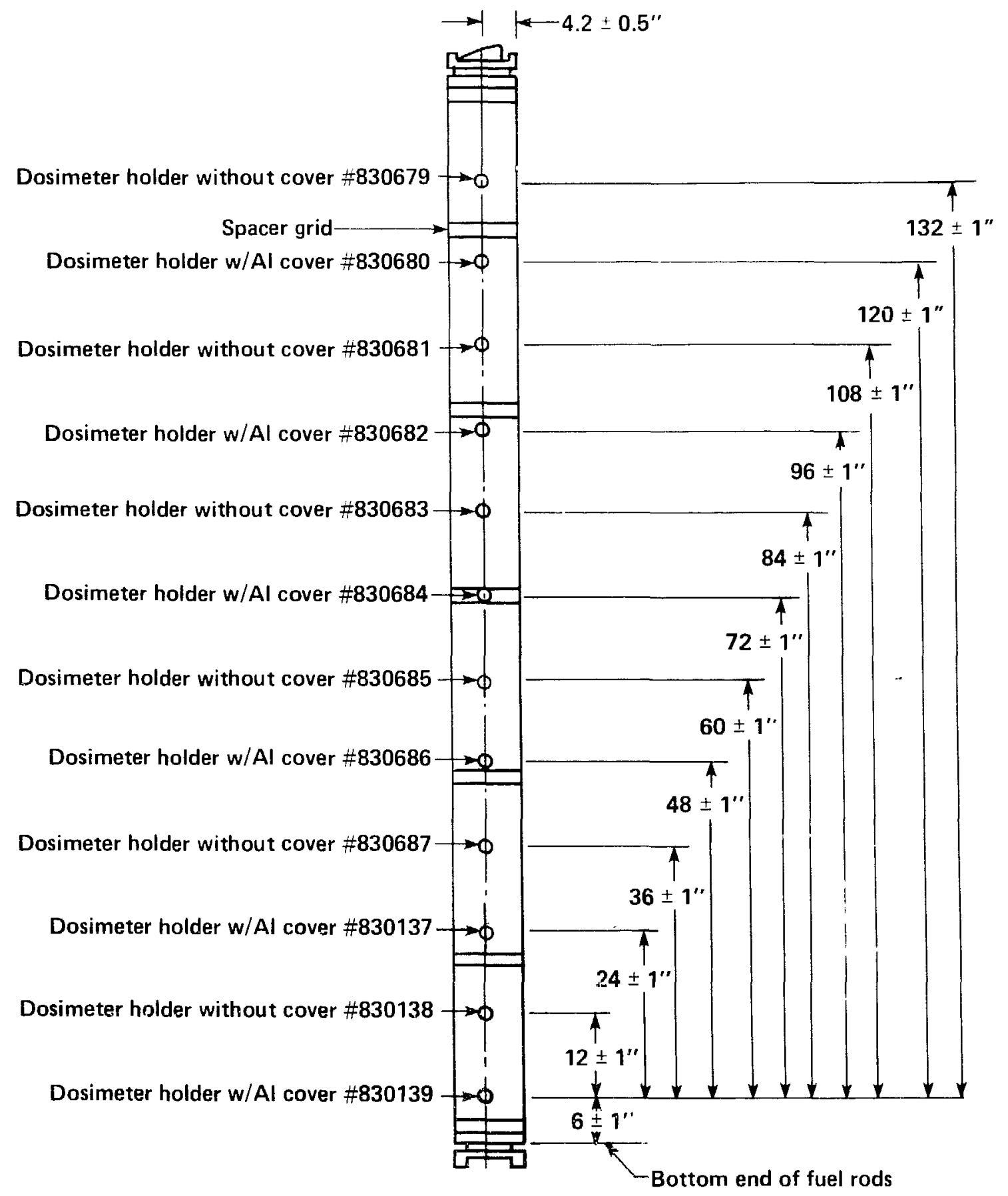

Figure 6-5. Locations of dosimeter holders (after Van Konynenburg, 1984).

Although the concepts of ciecay heat calculation are well established and commoniy employed, there was little validation of the codes in use. This was particularly true for the short decay times of interest in the SFT-C. Factors affecting uncertainty in the calculations include the complexity of the early-time isotope inventory, uncertainties in reactor operating history and spectrum, and uncertainties in the basic nuclear cross-section and decay data. 
The OPIGEN2 calculations of Schmittroth, Nexly; and Krogness (1982) used the fuel characteristics and reactor history discussed earlicr in this chapter. They report a total calculational uncertainty of about $8.6 \%$.

The calorimeter configuration shown in Fig. 6-6 was used to obtain decay heat measurements on assemblies D34, D04, D15, and D22. By evaluating differential steam condensation collection rates, the power contribution of each fuel assembly was determined. Anticipated accuracies were $\pm 5 \%$ for powers greater than $1.0 \mathrm{~kW}$, decreasing to $\pm 10 \%$ for powers of $0.1 \mathrm{~kW}$.

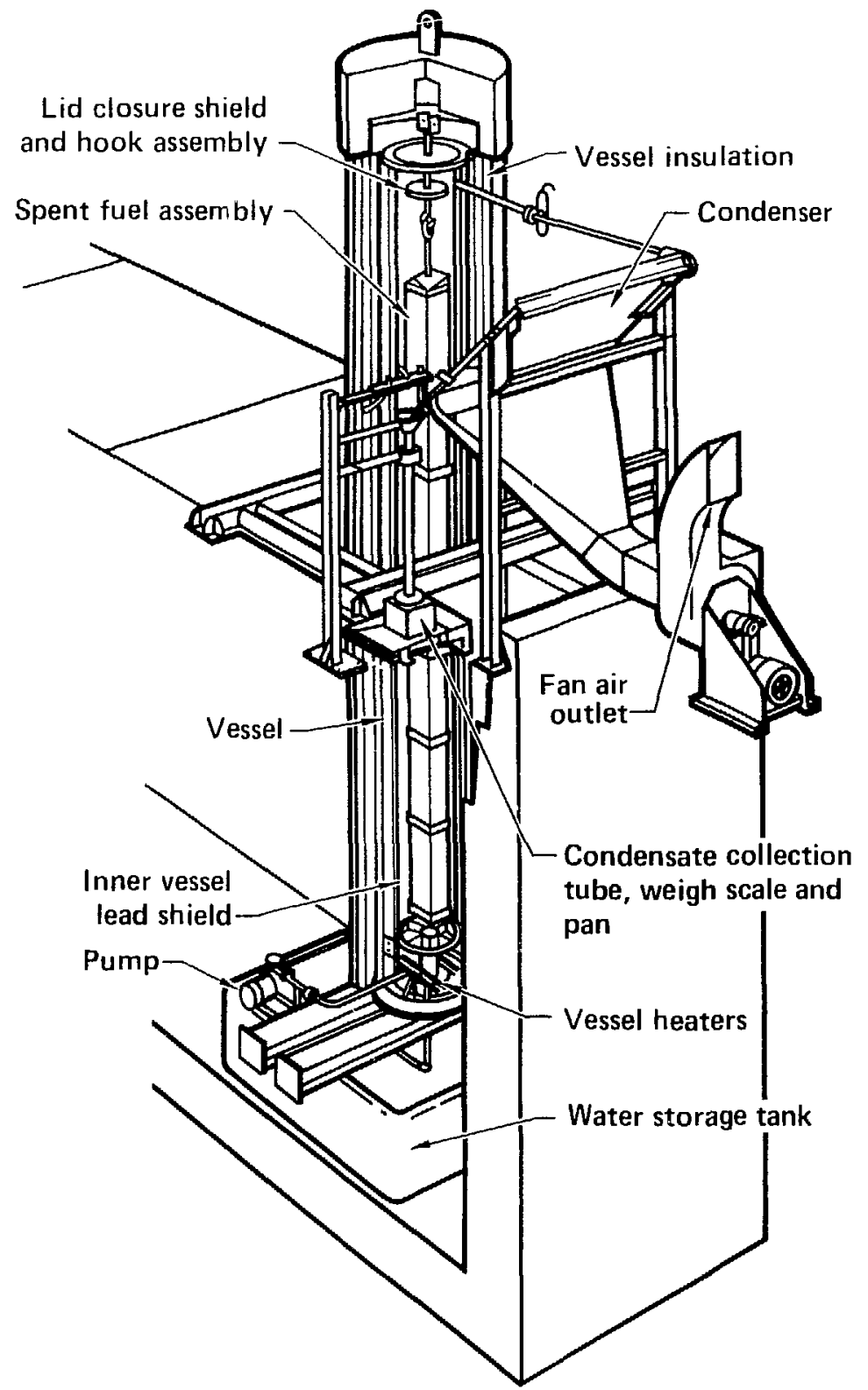

Figure 6-6. Spent-fuel calorimeter (after Schmittroth, Neely, and Krogness, 1982). 
Table 6-6 indicates the good level of agreement between the measured and calculated decay heats for these assemblies at early times. With the exception of D04, all agree within $6 \%$. Low confidence is expressed in the D04 measurement because reanalysis of the data indicated that thermal equilibrium was not obtained during calorimetry of this assembly.

Additional calorimetry was conducted throughout the testing period (Table 6-6). Of particular interest is fuel assembly D15, which was calorimetered at EMAD on July 28, 1983, following spent-fuel retrieval. Using essentially the same apparatus as the earlier measurements, a decay heat generation rate of $625 \mathrm{~W}$ was measured (Patrick et al., 1984). This is within 3\% of the calculated rate of decay heat generation of $609 \mathrm{~W}$.

Table 6-6. Summary results of calorimetry of spent-fuel assemblies used in the SFT-C.

\begin{tabular}{|c|c|c|c|c|c|c|}
\hline \multirow{2}{*}{$\begin{array}{c}\text { Fuel assembly } \\
\text { number }\end{array}$} & \multirow{2}{*}{$\begin{array}{c}\text { Calculated } \\
\text { burnup } \\
\text { (MW'd/MTU) }\end{array}$} & \multirow{2}{*}{$\begin{array}{c}\text { Calorimetry } \\
\text { date }\end{array}$} & \multirow{2}{*}{$\begin{array}{c}\text { Fuel age, } \\
\text { (YOC) }\end{array}$} & \multicolumn{2}{|c|}{ Decay heat (W) } & \multirow{2}{*}{$\begin{array}{c}\text { Error }^{\mathrm{r}} \\
(\%)\end{array}$} \\
\hline & & & & Meas." & Calc. ${ }^{b, c}$ & \\
\hline \multirow[t]{2}{*}{$\mathrm{D} 04^{\mathrm{d}}$} & 28,430 & $05 / 20 / 80$ & 2.500 & $1385^{e}$ & 1555 & $+12.3 \%$ \\
\hline & 28,430 & $08 / 28 / 85$ & 7.773 & 487 & $\mathbf{N} / \mathbf{A}$ & $\mathbf{N} / \mathbf{A}$ \\
\hline \multirow[t]{4}{*}{ D15 } & 28,430 & $07 / 08 / 80$ & 2.634 & 1423 & 1491 & $+4.8 \%$ \\
\hline & 28,430 & $01 / 06 / 81$ & 3.132 & 1126 & $\mathbf{N} / \mathbf{A}$ & $\mathbf{N} / \mathbf{A}$ \\
\hline & 28,430 & $07 / 28 / 83$ & 5.687 & 625 & $\mathbf{N} / \mathbf{A}$ & $\mathbf{N} / \mathbf{A}$ \\
\hline & 28,430 & $08 / 22 / 85$ & 7.756 & 506 & $\mathbf{N} / \mathbf{A}$ & $\mathbf{N} / \mathbf{A}$ \\
\hline $\mathrm{D} 22$ & 26,485 & $07 / 09 / 80$ & 2.637 & 1284 & 1357 & $+5.7 \%$ \\
\hline $\mathrm{D} 22$ & 26,485 & $08 / 29 / 85$ & 7.775 & 451 & $\mathbf{N} / \mathbf{A}$ & $\mathbf{N} / \mathbf{A}$ \\
\hline D34 & 27,863 & $04 / 01 / 80$ & 2.366 & 1550 & 1640 & $+5.8 \%$ \\
\hline D34 & 27,863 & $03 / 29 / 84$ & 6.357 & $467^{\prime}$ & $\mathbf{N} / \mathbf{A}$ & $\mathbf{N} / \mathbf{A}$ \\
\hline D34 & 27,863 & $08 / 21 / 85$ & 7.754 & 479 & $\mathbf{N} / \mathbf{A}$ & $\mathbf{N} / \mathbf{A}$ \\
\hline
\end{tabular}

Measurement uncertainty is $5 \%$.

${ }^{b}$ Calculational uncertainty is $8.6 \%$.

'After Schmittroth, Neely, and Krogness (1982).

$\checkmark$ Calculated value is reduced by $213 / 217$ to account for the removal of four fuel pins.

'Possible calorimetry error.

'Invalid calorimetry result. 


\section{Spent-Fuel Handling System *}

A spent-fuel handling system comprising a surface transpurt vehicle (STV), canister hoisting system (CHS), and underground transfer vehicle (LTV) was designed, fabricated, and deployed to demonstrate the feasibility of handling and storing spent nuclear fuel. In addition to describing this system, we also discuss the spent-fuel canister design and storage configuration and the encapsulation of the spent-fuel assemblies for test storage.

Although the handling system was not intended to be prototypical of what might be used in a future full-scale repository, it incorporated several concepts that should be considered in developing such systems for future repositories, including (Ballou, 1983):

- An integral shielding plug that minimized radiation streaming.

- Transfer cask jacking and shielding gates that reduced excavation height requirements.

- A small-diameter shaft for the sole purpose of transferring spent fuel to and from the underground storage area.

- A wire-lire hoisting system with a positive emergency braking system that travelled with the spent-fuel canister.

- A rail-:mounted underground transfer vehicle that obviated the need for personnel to be underground during transfer operations.

- Remotely actuated grapples that were insensitive to load orientation.

Note that the entire spent-fuel handling process (after the spent-fuel assemblies were received at EMAD) took place at the DOE-controlled NTS. Thus, the Nuclear Regulatory Commission's and Department of Transportation's regulations governing transport of radioactive materials over public roads did not apply. Consistent with assuring safety and attaining test objectives, cost and development time were strong constraints.

\subsection{Preparation and Use of EMAD}

One of the attractions of conducting the SFT-C at the NTS was the availability of the EMAD facility. Originally constructed in the 1960s to support the nuclear rocket propulsion program, the facility had recently fallen into disuse. When the DOE began evaluating handling and encapsulation aspects of nuclear waste disposal, the role of EMAD developed to include not only support to the SFT $-\mathrm{C}$ but broader aspects of a Spent-Fuel Handling and Demonstration Program (NVO-198). This facility is operated for the DOE by Westinghouse Electric Corporation.

The principal features of EMAD that were important to the SFT-C were its large shielded highbay, adjacent shielded transfer ports and smaller shielded cells, and a variety of remote manipulators for assembling and loading spent-fuel canisters in a shielded environment. Facilities for spent-fuel dosimetry and calorimetry were also developed and used to support the SFT $-\mathrm{C}$. The reader is referred to the EMAD Safety Assessment Document (NVO-198) for a detailed description of the facility and its operations.

\subsection{Transport from the Reactor}

Thirteen spent-fuel assemblies having the characteristics discussed in Chapter 6 were received at EMAD for use in the SFT-C. These were shipped from the Florida Power and Light Company Turkey Point Unit No. 3 to EMAD in NRC-licensed shipping casks in accordance with Department of Transportation (DOT) regulations (Fig. 7-1).

After arrival at EMAD, the tractor-trailer rig was parked in the highbay and the cask was removed and readied for removal of the spent-fuel assembly. Under remote operating conditions, the shielding head was removed and the spent-fuel assembly was withdrawn from the cask, inspected, and placed in lag storage awaiting encapsulation. Details of these operations are provided by Bensky et al. (1979).

* Cuntributed by. W. C Patrick 


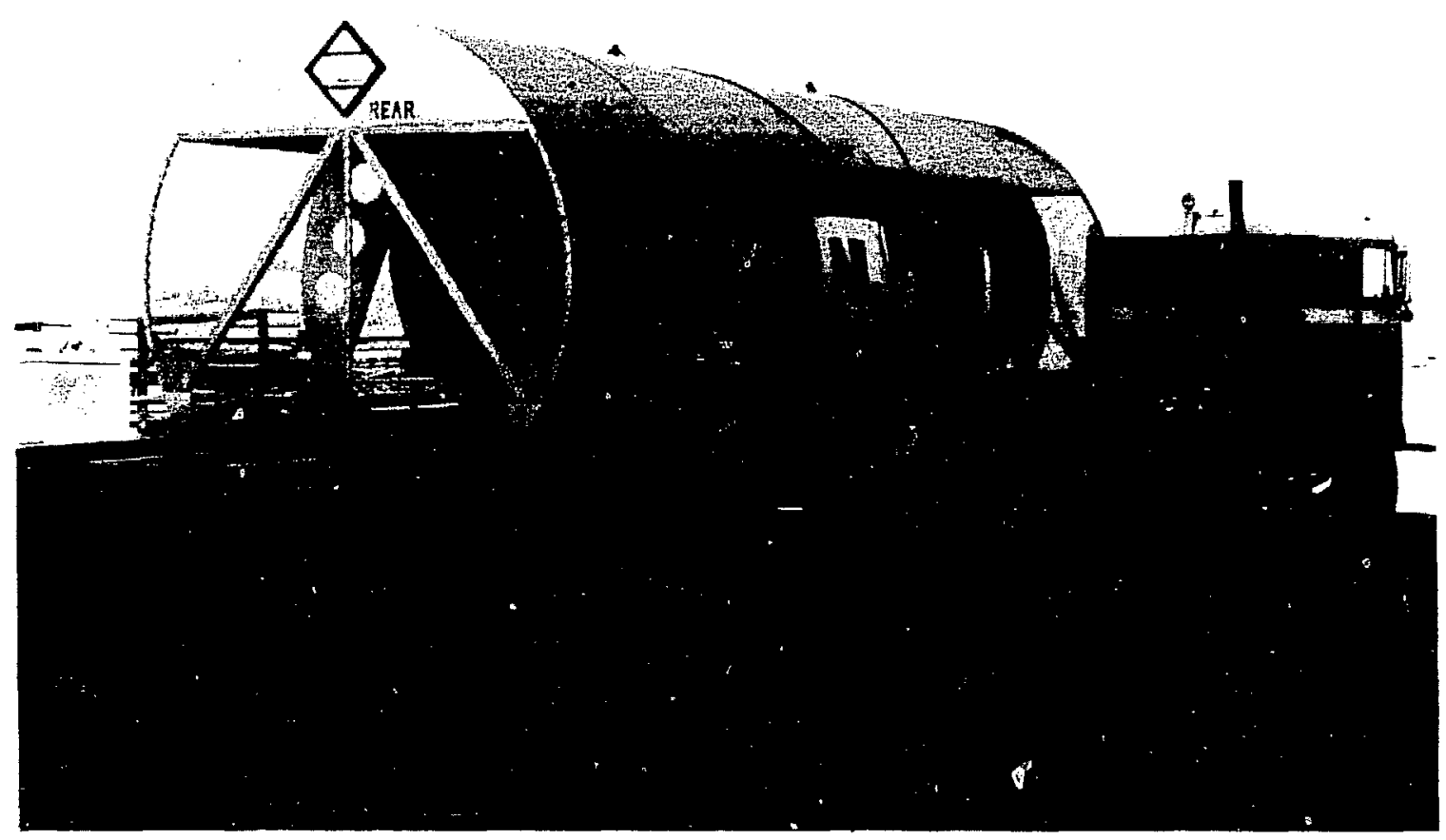

Figure 7-1. NLI 1/2 cask/trailer/tractor as received at EMAD.

\subsection{Canister Design and Storage Configuration}

The spent-fuel assemblies described in Chapter 6 were encapsulated in gas-tight stainless steel canisters in preparation for transport and storage activities associated with the SFT $-\mathrm{C}$. The total fuel assembly cross section $[0.214 \times 0.214 \mathrm{~m}(8.43 \times 8.43 \mathrm{in}$.) $]$ and length $[4.097 \mathrm{~m}(161.3 \mathrm{in}$.)] were the principal dimensional controls on canister design.

As presented in the SAD (NVO-210), the design basis for the spent-fuel canisters was to provide a corrosion-resistant, leak-tight container with provisions for:

- Containing one fuel assembly (Chapter 6).

- Remote closure and sealing by welding.

- Remote evacuation, gas backfilling, and leak testing.

- Maintaining leak tightness at an internal gas pressure of $200 \mathrm{psig}$ at $200^{\circ} \mathrm{F}$ and when subjected to $0.7 \mathrm{~g}$ of horizontal acceleration.

- Interfacing with EMAD and SFT - C storage wells and shield plugs.

The shield-plug design basis was to provide:

- Radiation attenuation and streaming protection to limit the surface dose rate to $50 \mathrm{mrem} / \mathrm{h}$.

- Mechanical support to maintain the integrity of the canister shield-plug system at horizontal ground accelerations of $0.7 \mathrm{~g}$.

- Means for thermocouple installation.

- An interface with the handling system grapple.

The resulting spent-fuel canister comprised a main body, an upper body, a closure lid, and an ellipsoidal end cap (Fig. 7-2). A standard 356-mm-outside diameter (14-in.), 9.52-mm wall thickness (0.375-in.) Type 304L stainless steel pipe section $3.91 \mathrm{~m}$ (154 in.) long formed the main body, and a $9.52-\mathrm{mm}$ wall thickness $(0.375$-in.) standard ellipsoidal end cap with an internal cruciform fixture of $19.1-\mathrm{mm}(0.75-\mathrm{in}$.) stainless stock formed the bottom closure. On the top of the main body was welded a 356-mm-outside diameter (14-in.) $23.8-\mathrm{mm}\left(0 .{ }^{13} 37\right.$-in.) wall $304 \mathrm{~L}$ pipe section that was machined to include the provisions 


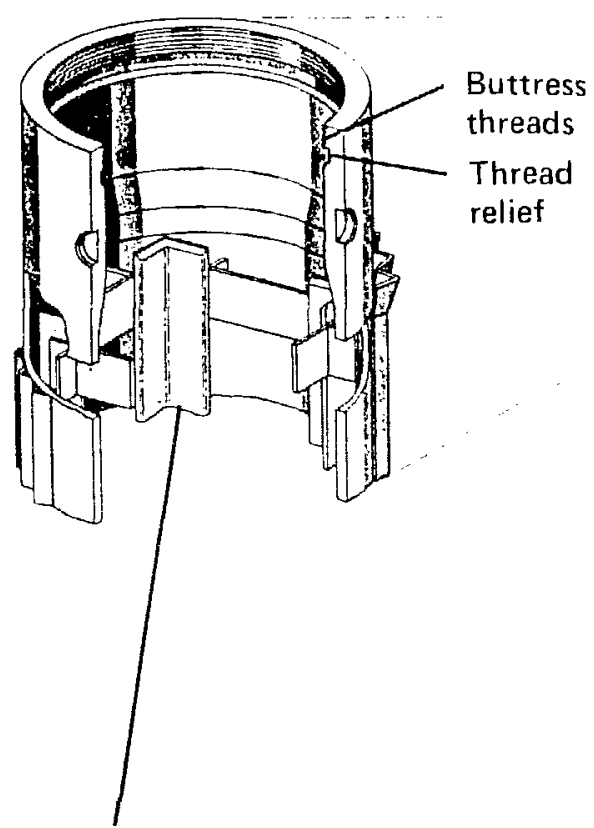

Fuel assembly support cage

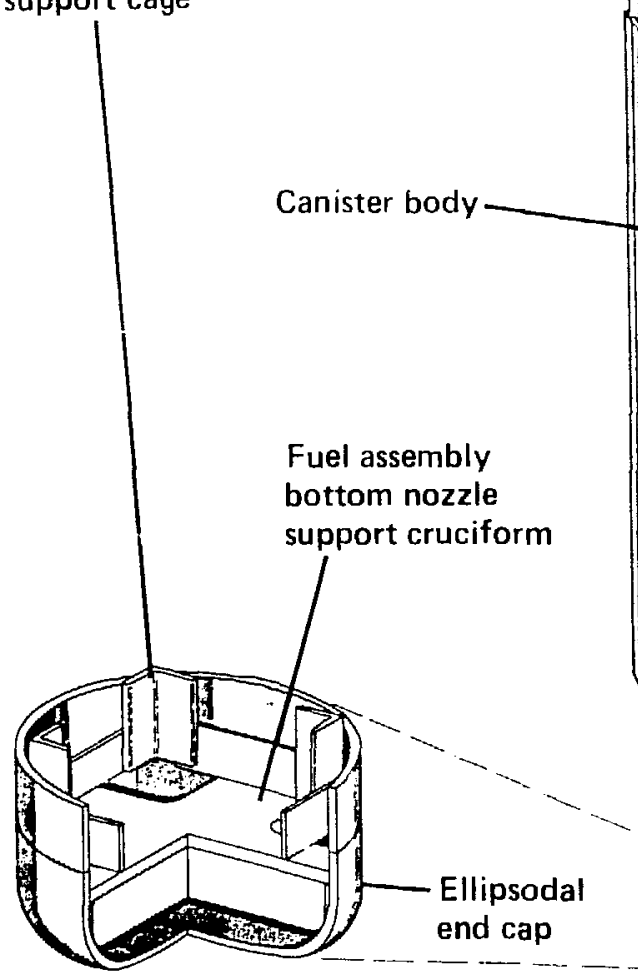

Evacuation/ backfill fitting with mechanical seal cap of seal lip weldi. . Canister machine

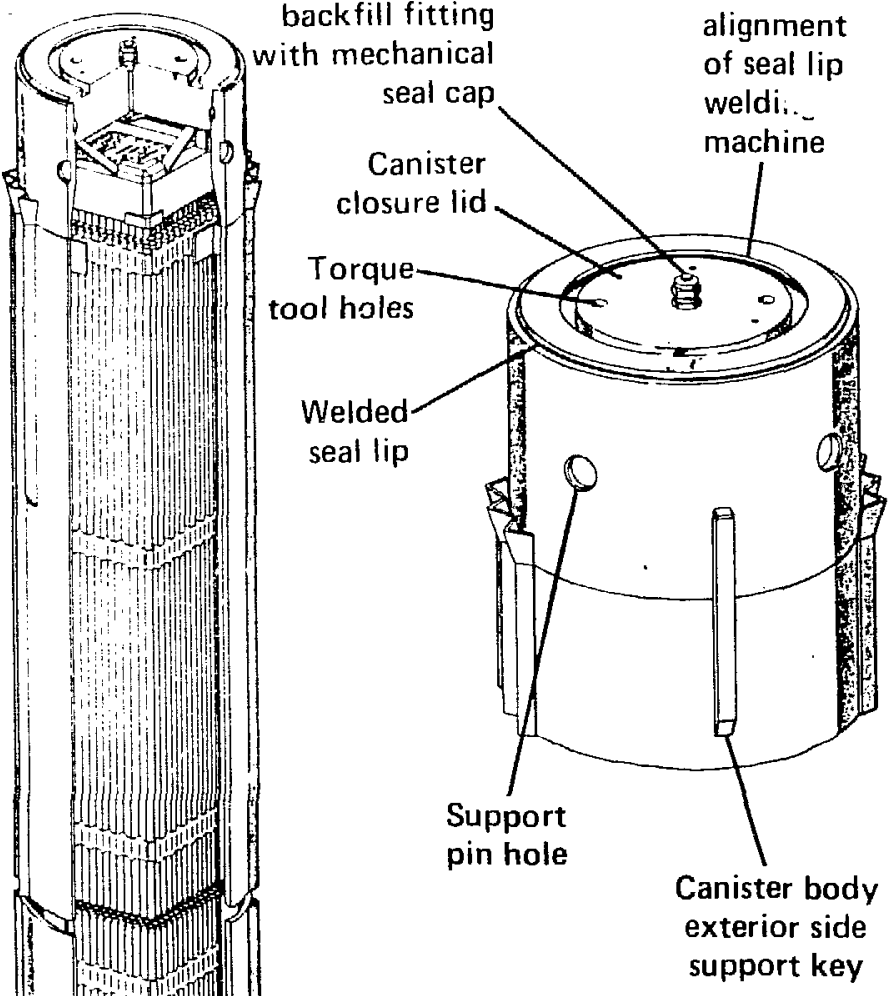

Canister body external thermocouple tubes

Figure 7-2. Spent-fuel canister assembly (after NVO-210, 1980). 
indicated in Fig. 7-2. In addition, an internal support cage was provided to stabilize the spent-fuel assembly during transport and potential ground shahing, limiting its lateral movement to approximately $7.6 \mathrm{~mm}$ (0.3 in. . All welds were made using 308 . Weld wire in decordance with hection IX of the ASME code, and all were dye-penetrant tested.

The canister top closure consisted of a 8.9 -cm-thick (3.5-in.) by $318 \mathrm{~mm}$-diameter (12.5-in.) 304L disc with buttress threads machined near the top. A machined lip and capped fitting accommodated seal welding, backfilling, and leak-testing operations, respectively. To enhance conductive heat transfer, the canisters were backfilled with helium. Each canister was leak-tested against a criteria of $1 \times 10^{-} \mathrm{s}$ std $\mathrm{cos}$. Other details of this design are discussed in NVO-210 (1980).

On each side of the canister body, three $304 \mathrm{~L}$ stainless steel angles were welded to provide for thermocouple installation and positioning. These channels were of three lengths to position the thermocouples $0.3 \mathrm{~m}(1 \mathrm{ft}$ ) below the top, at the mid-height, and $0.3 \mathrm{~m}(1 \mathrm{ft}$ ) above the bottom of the spent-fuel rods.

To provide for radiation shielding, a mild steel block was machined for attachment to the spent-fuel canister (Fig. 7-3). Features of this shield plug included a tapered shoulder to minimize streaming radiation, guide tubes for thermocouple sensors, and a grapple lifting knob. The emplacement configuration at the SFT $-C$ is shown in Fig. 7-4.

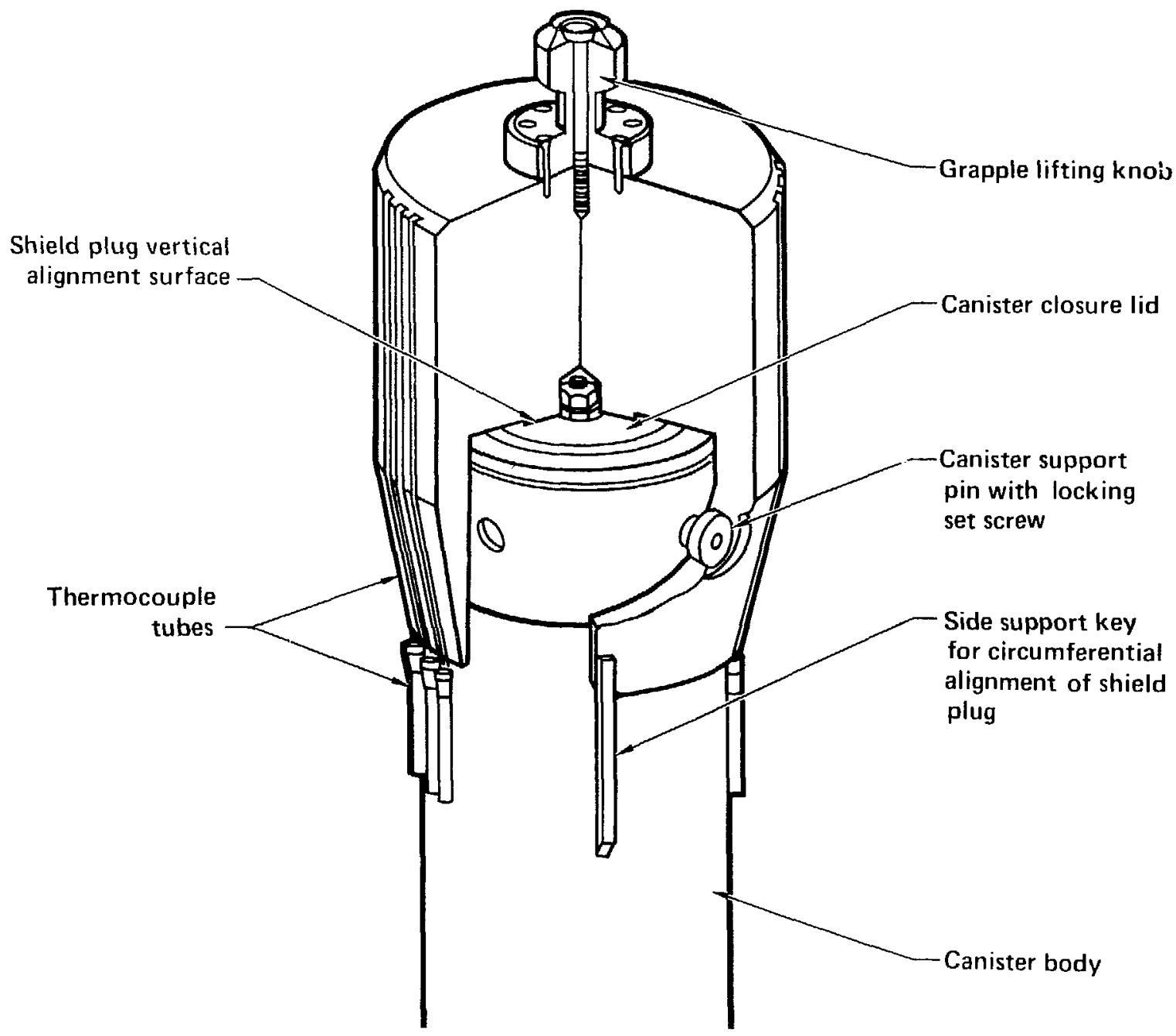

Figure 7-3. Canisterishield-plug mating arrangement (after NVO-210, 1980). 


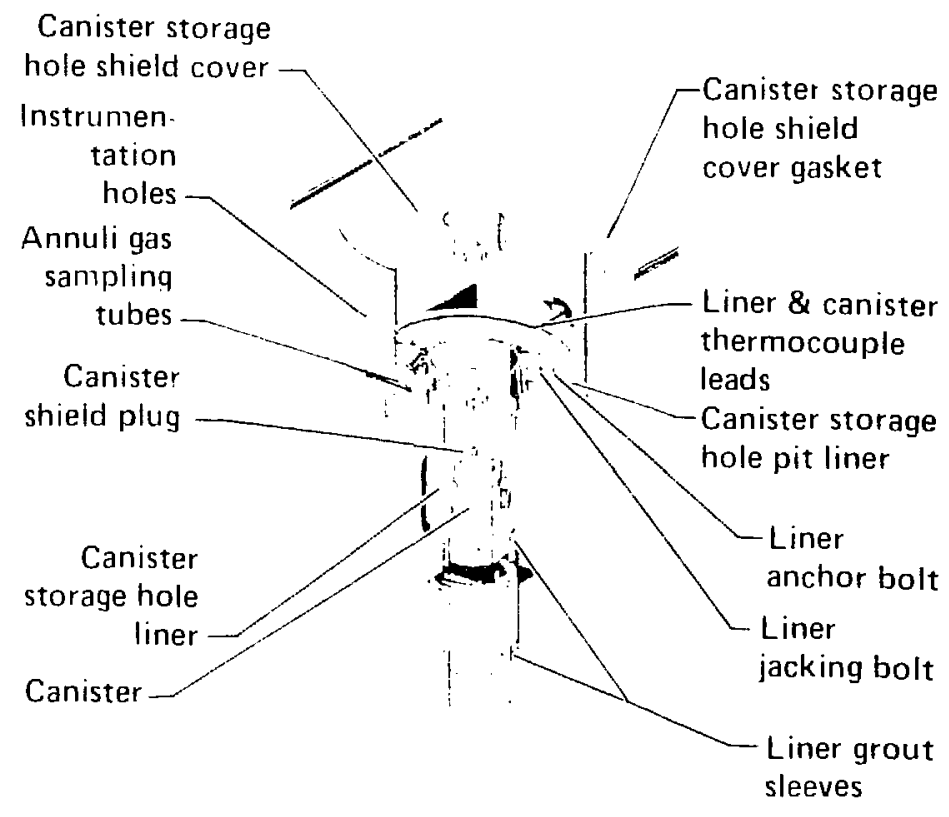

Figure 7-4. Canister storage configuration (after NVO-210, 1980).

We selected 304L stainless steel because of its generally good corrosion resistance. Because potential sensitization could lead to accelerated intergranular corrosion in the presence of chloride ion in the groundwater, we selected a low-carbon type (less than $0.03 \%$ ). An emplacement borehole liner further limited the likelihood of corrosion by preventing the inflow of water (Chapter 5).

As part of a separate program, a similar canister design was tested on a shaker table to $0.7 \mathrm{~g}$ using a dummy fuel assembly (WAES-TME-2906). Negligible wear and impact damage were observed in this study. Additional testing showed successful performance at a pressure of $300 \mathrm{psig}$ at $700^{\circ} \mathrm{F}$. These tesis confirmed the adequacy of the design.

\subsection{Surface Transport Vehicle}

The first component of the handling system was the STV, which was designed and fabricated to transport canistered spent-fuel assemblies between the EMAD and SFT-C facilities. The design basis for the STV was to provide:

- Safe and reliable transport of canistered spent fuel between EMAD and the SFT-C.

- Radiation shielding to meet DOE requirements for the transport of radioactive materials under test cr.sditions.

- Heat dissipation to limit fuel cladding temperature to less than $380^{\circ} \mathrm{C}\left(715^{\circ} \mathrm{F}\right)$.

- Interfacing with EMAD and SFT-C site handling systems.

- Remotely controlled movements of a shielding cask and associated shielding gates with appropriate interlocks to minimize radiation exposure.

Based on these considerations, an STV comprising a heavy-duty 16-wheel semitrailer with a remotely operated shielding cask was designed and fabricated. This unit was transported by a standard 10 -wheel tractor (Figs. 7-5 and 7-6) and was designed to conform to 49CFR and the State of California Vehicle Code (with the exception of allowable gross weight). Although the basic semitrailer weighed $9000 \mathrm{~kg}(19,80(0) / \mathrm{b})$, the addition of the 1.14-m-outside diameter, 33-cm wall thickness sted cask, closures, and related equipment increased the total weight to $48,000 \mathrm{Kg}(105,600 \mathrm{lb})$. 


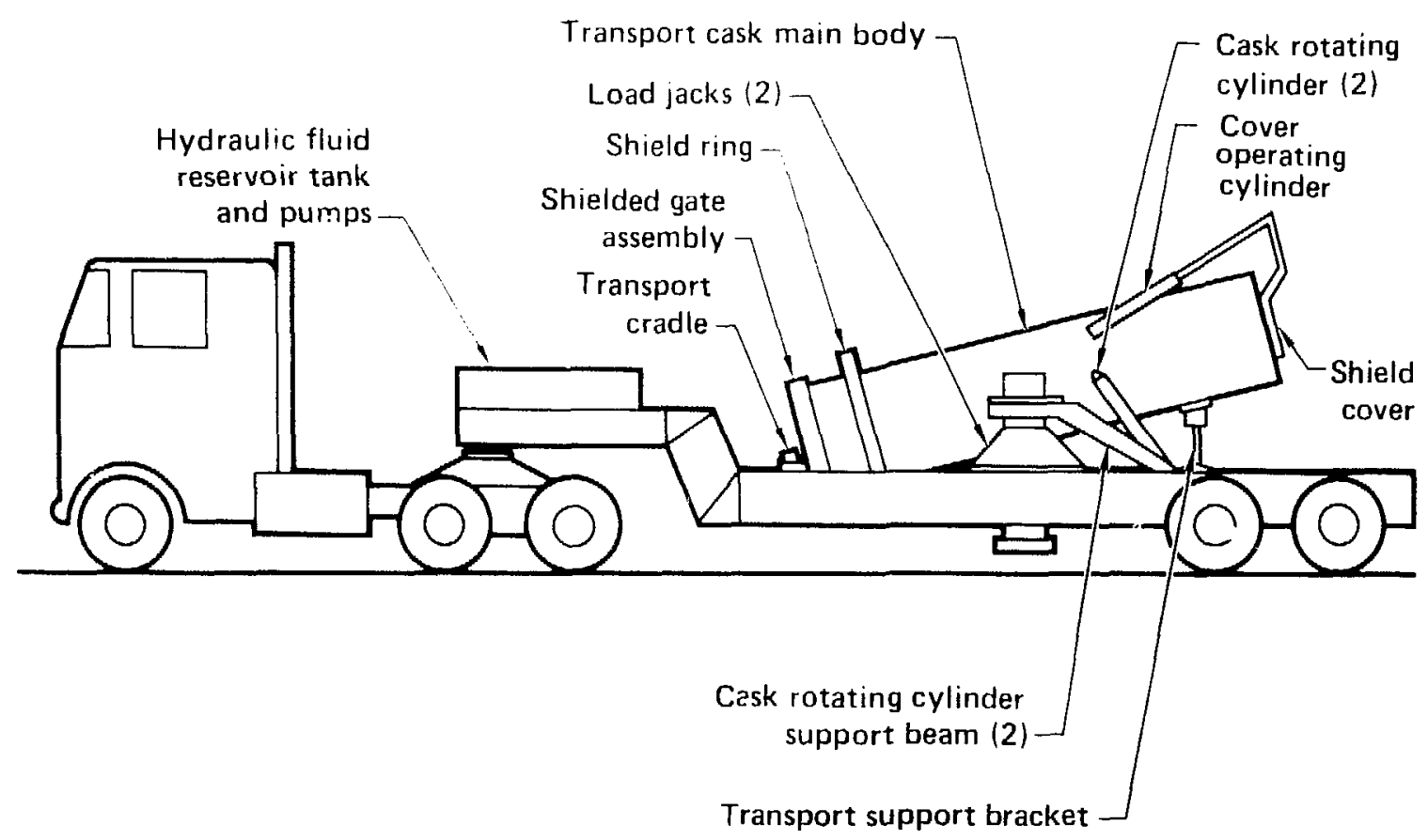

Figure 7-5. Surface Transport Vehicle schematic (after NVO-210, 1980).

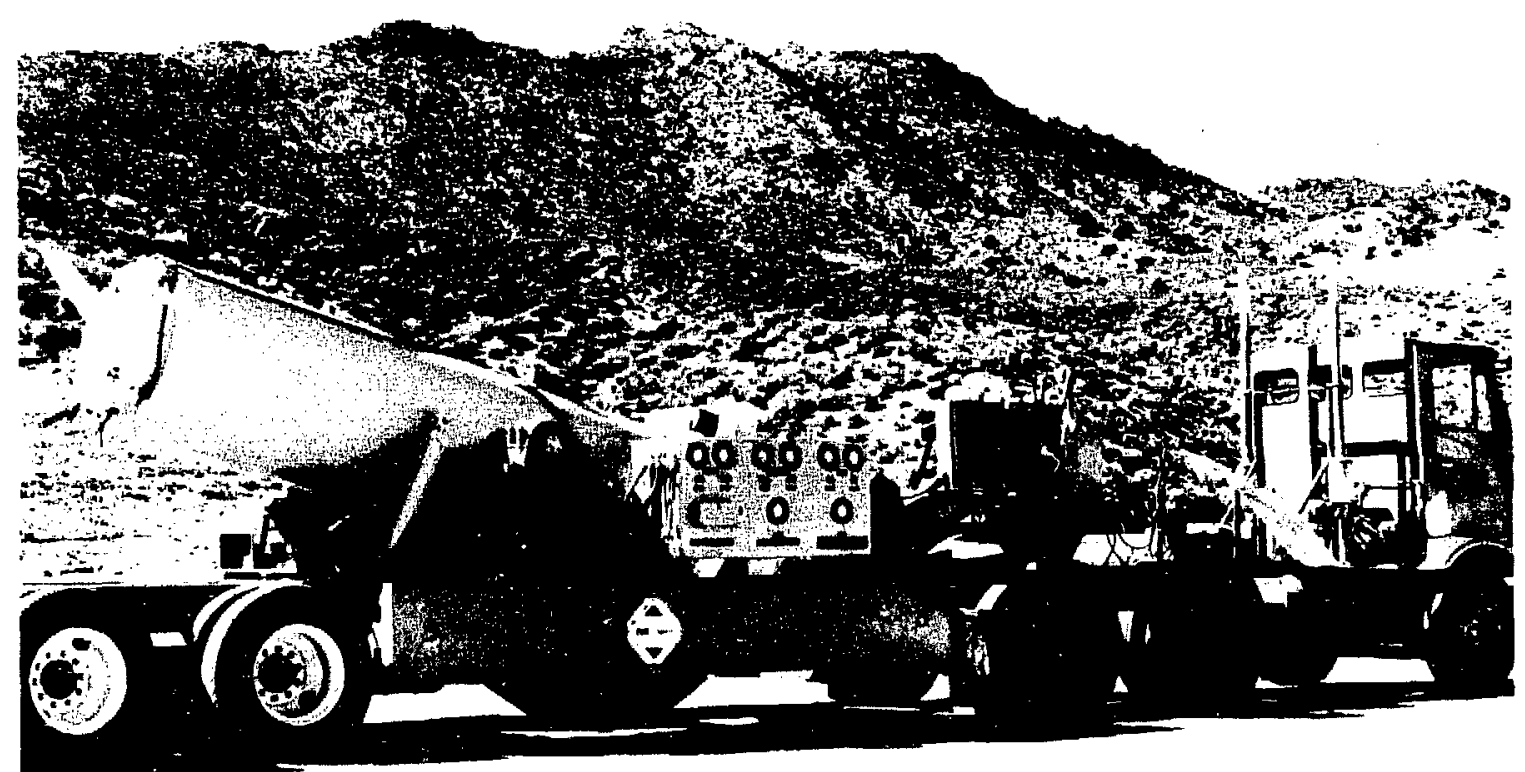

Figure 7-6. Surface Transport Vehicle. 
Several inspections and evaluations were cor fucted to ensure the structural adeyuacy of the STV trailer. These included review of drawings, independent stress analyses, and magnetic-partide and dyepenetrant testing of critical welds. In additum, a static load test to $159 \%$ of the static design load was conducted. No measurable plastic strains were sbserved (NVO-210, 1980). Finally, dry runs were conducted, using a simulated spent-fuel assembly at dynamic loads up to the $1.5-\mathrm{g}$ design criterion.

The cask consisted of a 1.14-m-outside diameter (45-in.) 4.67-m-long (184-in.) cylinder of low carbon manganese steel with a wall thickness of $330 \mathrm{~mm}$ (13 in.). At the top end of the cask, its inside diameter was reduced to about $457 \mathrm{~mm}$ (18 in.) to provide lateral support against the canister shield plug. A $241-\mathrm{mm}$ diameter (9.5-in.) diameter hole was bored in each side of the cask and fitted with trunnions to facilitate cask rutation.

To accommodate loading through the top at EMAD and unloading through the bottom at the SFT-C, both top and bottom closures were provided. Although the upper closure included a lid rotated by a hydraulic cylinder, the bottom closure was a gear-driven sliding gate. The top shield cover was about $184 \mathrm{~mm}$ ( $7.25 \mathrm{in.}$ ) thick and weighed about $523 \mathrm{~kg}(1150 \mathrm{lb}$ ). The bottum gate comprised a 432 -mm-thick (17-in.), $1545-\mathrm{kg}$ (3400-lb) block supported on slide bars. An elliptical contour on the inside of the gate provided lateral support for the canister during transport and eftectively locked the gate closed, precluding accidental opening of the gate. Machined steps in the gate top surface and gate assembly mated with steps in the bottom of the cask to minimize radiation streaming. Pins were incorporated in the design to fix these gates and the entire shielding cask in position for transport.

The cask was oriented vertically during loading and unloading operations. It was rotated through $75^{\circ}$ and lowered onto a cradle for stable transport. Transport speeds were linited to about $55 \mathrm{~km} / \mathrm{h}$.

The 330-mm (13-in.) steel shielding of the cask kept surface dose rates to about $15 \mathrm{mrem} / \mathrm{h}$ gamma and from 70 to $90 \mathrm{mrem} / \mathrm{h}$ neutron. Dose rates in the STV tractor cab were about $0.05 \mathrm{mrem} / \mathrm{h}$ ganma and 0.5 nirem/h neutron.

The cask rotation and jacking system is shown schematically in Fig. 7-5. See NVO-210 (1980) for a more detailed discussion of the STV, including the hydraulics and interlock systems.

\subsection{Canister Hoisting System}

The second component of the handling system was the CHS. The principal function of the CHS was to lower or raise the canistered spent-fuel assembly between the STV ( which was positioned over the canister access shaft) and the UTV (which was positioned at the base of the canister access shaft $420 \mathrm{~m}$ below).

The design basis of the CHS was to provide: and UTV.

- Handling and shielding interfaces with the STV and UTV.

- Support of the design loads with adequate safety factors.

- Capability for remote and emergency manual grappling and ungrappling of the canister.

- Means for controlling speed, detecting the canister's position, and sensing the load.

- Redundant means for stopping the hoist with or without electrical power.

- Means for preventing canister free-fall in the event of cable or hoist failure.

- Protection of the hoisting and internal electrical cable.

- Control system to ensure proper sequencing of operation, minimize personnel radiation exposure, and protect equipment.

The principal components of the resulting CHS are the headframe, hoist, hoist cable, emergency brake, grapple, and control system. Each component is discussed briefly here. See NVO-210 (1980) for further information.

\subsubsection{Headframe}

Located directly over the canister access shatt, the headframe structure comprised four vertical ASTM A-36 steel beams that were anchored to four 1.52 -m-square ( 5 -ft) reinforced cuncrete pads and cross beams that supported the sheave, provided positive stops to the vertical travel of the spent-fuel canister, and provided resistance to the transverse component of cable load (Fig. 7-7). The anchor pads were $0.76 \mathrm{~m}$ thick 


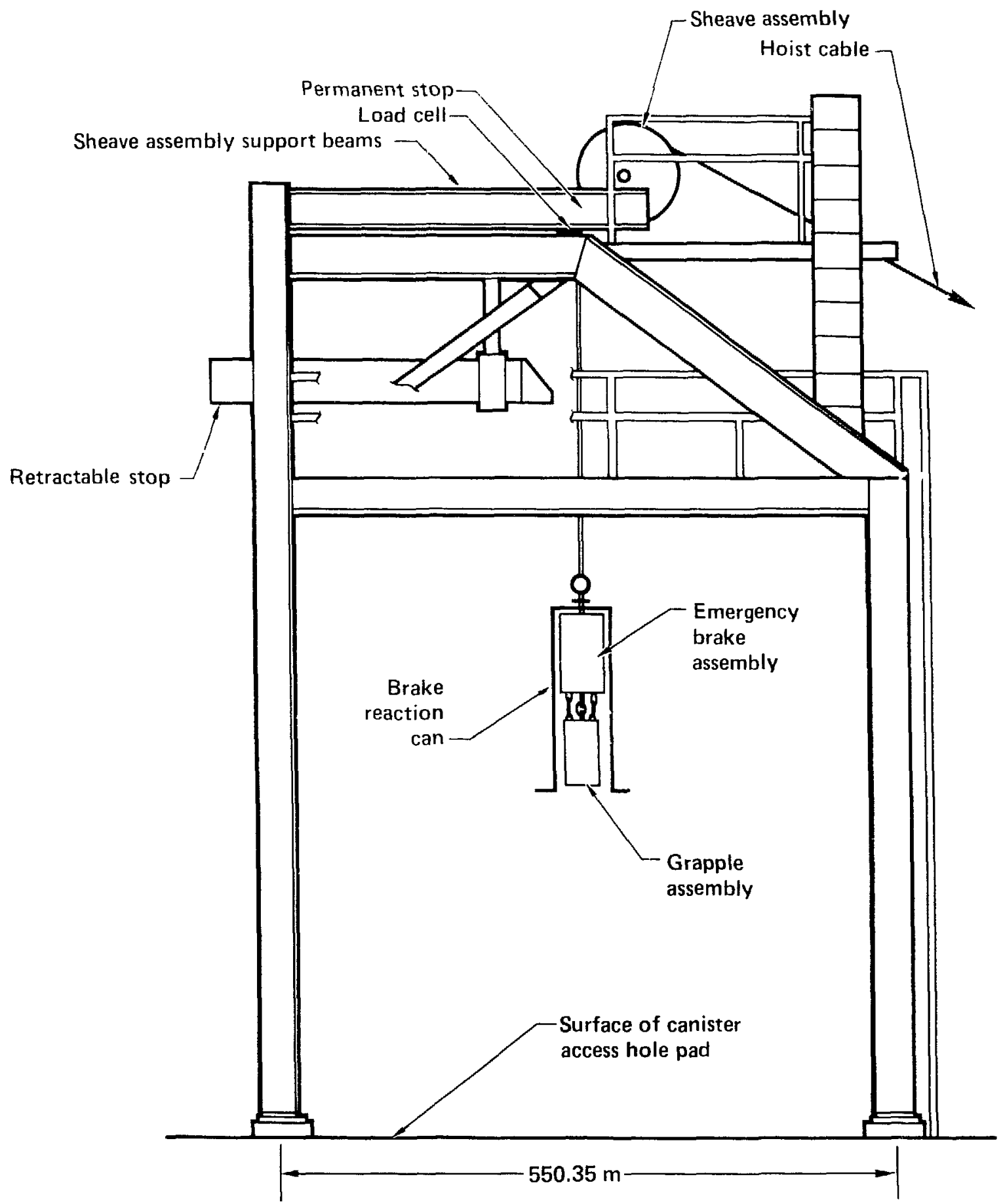

Figure 7-7. Canister access hole head frame (after NVO-210, 1980). 
(2.5 ft) opposite the cable and $1.37 \mathrm{~m}$ thick $(4.5 \mathrm{ft}$ ) on the cable side. The headframe was fabricated and erected :n accordance with appropriate standards (1) $10(0)-210,1980)$.

The 797-mm-diameter (31-3 8-1n.) cint steel hhewe was mounted tutwo horizontal beams by means of its 88.9-mm-diameter (3.5-in.) sted shaft and two pillow blocks. Load cell- and a tachometer were provided to sense cable load and velucity.

A permanent mechanical stop (Fig. 77) was provided tu prevent the brake and grapple assembly from being raised to where they could damage the shewe. Immediately below this stop were electrical limit switches that were set to stop the hoist when the grapple brake assembly was within $25 \mathrm{~mm}$ ( 1 in.) of the stop.

To preclude raising a spent-fuel assembly partially out of the shielding cask, a retractable stop was also provided (Fig. 7-7). Once again, limit switches were used to stop the hoist when the grapple, brake was within $25 \mathrm{~mm}(\mathrm{l} \mathrm{in}$.) of the retractable stop.

\subsubsection{Hoist}

The cable drum, drive sy stem, and braking system that made up the hoist were located in a hoist house adjacent to the headframe (Chapter 5 ) and were bolted to a concrete foundation. The cable dium was a 0.8()-m-diameter (31.5-in.) by 1.02-m-wide (40-in.) reinforced steel cylinder with 1.24-m-diameter (49-in.) flanges in each end. A 127-mm-diameter (5-in.) steel shaft riding in two bearing assemblies supported the drum in a steel plate frame.

Because of the close proximity of the headirame and hoist, maximum fleet angles of 1.7 were encountered. To ensure that the five layers of cable could be properly laid on the drum, an air-driven level-winder was provided.

A variable-speed, 20-hp dc motor mounted behind the drum powered it through a worm-gear ana chain-drive system. The worm-gear 50-to-1 reducer and drive mechanism were self-braking: the drum could not turn without power even if the brakes were not set.

The hoist braking system comprised spring-set calipertype brakes on each of the drum flanges. In this design, the brakes were set until they were retracted by an air-activated hydraulic pump. Thus, the CHS "failed safe" by applying the brake when pow'er or hydraulic pressure were lost. If cable speeds exceeded certain limits, these brakes automatically set.

\subsubsection{Hoist Cable}

To provide for signal and sensing communications hetween the control system and grapple/brake assembly, the 20.7 -mm-diameter $(0.815$-in.) hoist cable was provided with an inner core of 18 No. 20 AWG insulated shielded pairs. These were wrapped around a polypropylene rod. Two contrahelical layers of high-strength galvanized steel wires formed the outer tension member of the cable, which had a tensile strength exceeding $18,180 \mathrm{~kg}(40,000 \mathrm{lb})$.

\subsubsection{Emergency Brake Assembly}

Mounted on the lower end of the hoist cable was an emergency brake assembly capable of preventing the canister from free falling in event of a hoist or cable failure. The $457-\mathrm{mm}$-diameter (18-in.) by 889-mmlong (35-in.) cylindrical main body of the brake was fabricated from 6061-T6 aluminum allow. The principal components of the brake are depicted in Fig. 7-8.

During normal operations, the canister payload compressed the activation springs, thus retracting the serrated wedge brake shoes. If loss of load occurred, these wedges were driven out against the canister access shaft casing, stopping the descent of the canister. A brake reaction can (Fig. 77) was provided on the headframe to make the brake operable when the canister was in the shielding cask with the bottom gate open.

A motor-driven locking cam was provided to deactivate the brake during those sequences of the handling operation when the canister load was not acting on the brake assembly. In addition, an emergency lifting capability was provided to tacilitate recovery of a spent-fuel canister in the event of a cable failure. An upward lifting force on this knob would release the wedge brakes, allowing the canister to be retrieved. 


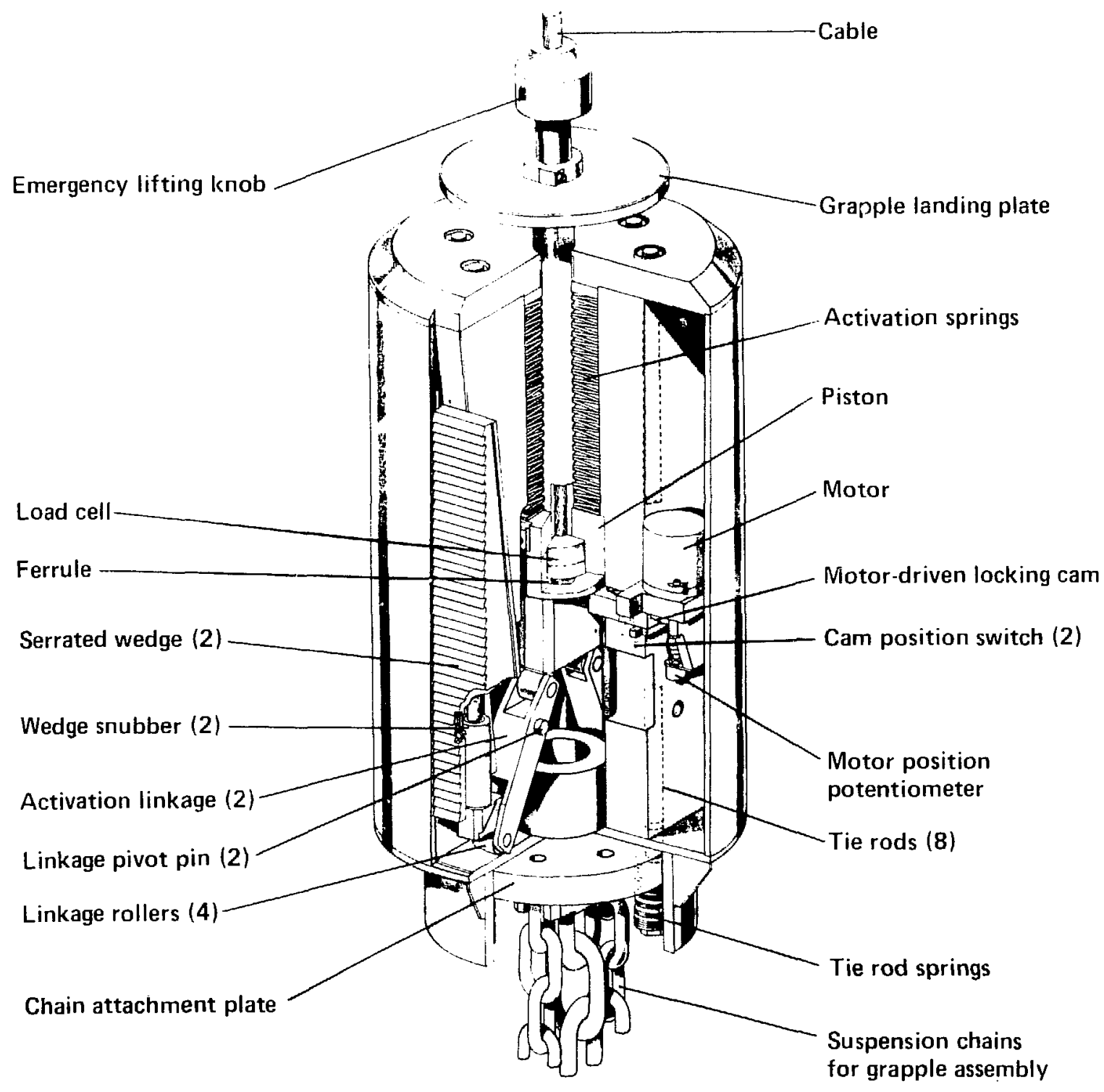

Figure 7-8. Emergency brake assembly (after NVO-210, 1980).

\subsubsection{Grapple Assembly}

Grapple assemblies were required at each handling interface. A common design was used at EMAD (where it was suspended from the uverhead crane), on the CHS (where it was suspended by chain links from the braking system), and on the UTV (where it was suspended from an un-board jib crane).

The 266.7-mm-diameter (10.5-in.) by 558.8-mm-long (22-in.) grapple body housed a motur-driven worm-gear assembly that rotated a spherical locking ball (Fig. 7-9). In addition to electronic cont rol through limit switches, the locking ball was designed to self-lock when carrying a load. This was done by enlarging the internal radius at the load-carrying (closed) position to $73.02 \mathrm{~mm}(2.875 \mathrm{in}$.). The $71.76-\mathrm{mm}(2.825-\mathrm{in}$.) radius of the canister lifting knob (Sec. 7.3 ) rested in this low spot, preventing rotation of the locking ball. 


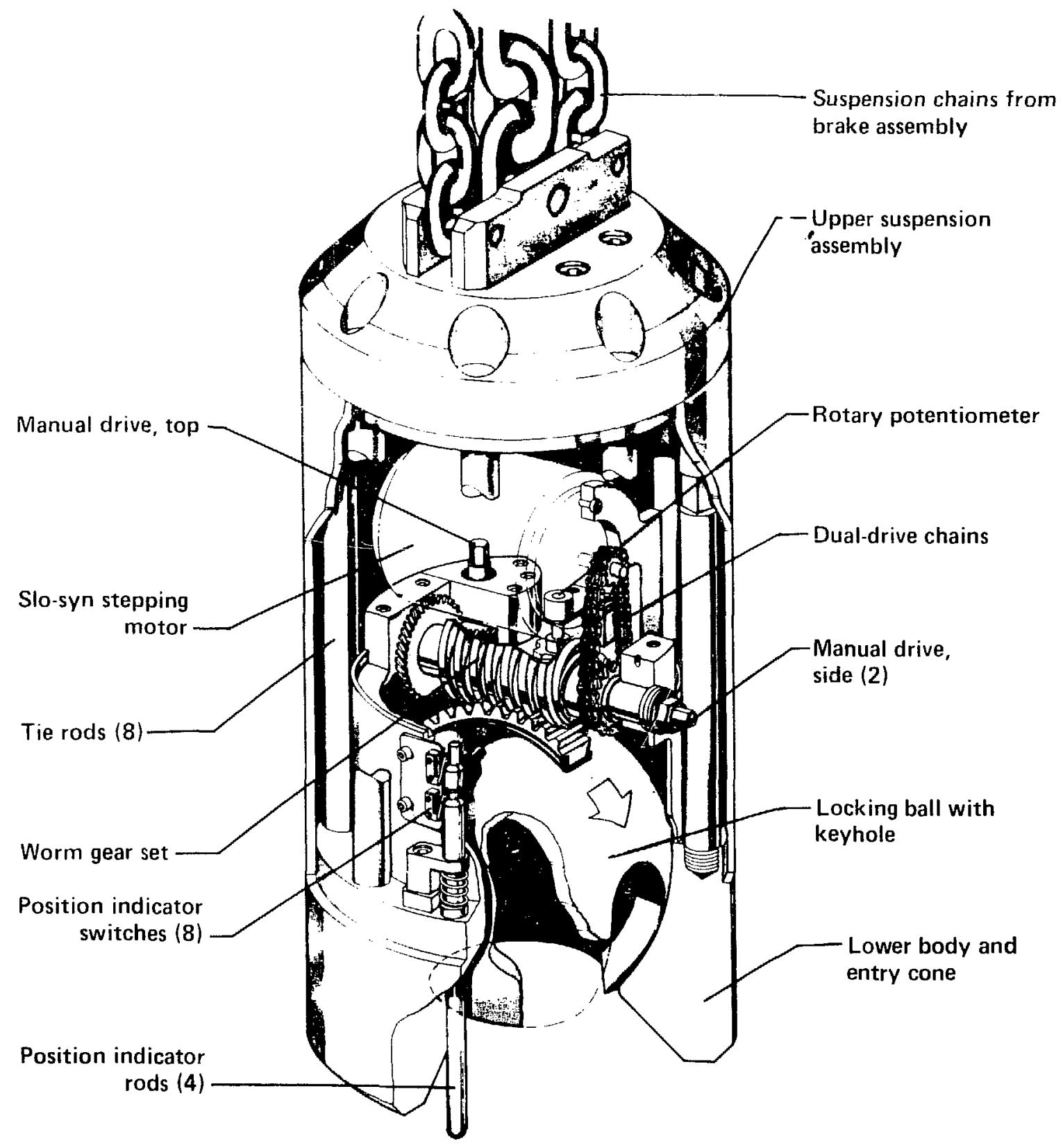

Figure 7-9. Grapple assembly (after NVO-210, 1980).

\subsubsection{Control System}

A control system locoted adjacent to the hoist house provided controls for the STV, UTV, and CHS. Pertinent portions of this system relevant to STV operations were duplicated in a control console at EMAD.

The heart of the control system was a solid-state sequential logic controller designed with interlocks and automatic operational controls to prevent unsafe handling configurations. Nearly all positioning operations were automatically controlled by this system. In addition to the logic and electronic interlocks, administrative controls and operating procedures were integral parts of the control system. Cameras were 
provided on the headtrame and the LTV to provide visual confirmation of critical sequences in the operations.

The principal tunctions of the STV. CHS, and L'TV provided by the control sytem were:

- STV and L'TV cask pusitiming and gate upening and closing.

- Spent-fuel canister grappling and ungrappling by the CHS and UTV.

- Spent-fuel canister lowering and raising by the CHS and LTV an-board hoist.

\subsection{Underground Transfer Vehicle}

The third major component of the handling system was the UTV. The principal function of the UTV was to receive a spent-fuel canister at the base of the canister access shaft, to transter it to and lower it into a canister emplacement hole, and to reverse the process for retrieval operations. The design basis for the UTV was to provide:

- Safe and reliable receipt and transfer of spent-fuel assemblies between the access shaft and emplacement holes.

- Heat dissipation to limit the fuel cladding temperature to less than $380 \cdot C\left(715^{\circ} \mathrm{F}\right)$.

- Means for electrical controls and interlocks.

- Support of design loads with adequate facturs of satety.

- Means for remote grappling and ungrappling ot spent-fuel canisters.

- Means for load monitoring.

- Redundant means of stopping hoist travel with or without electrical power.

The principal components of the UTV are the railcar, transfer cask, hoisting system, and cuntrol system. Each component is described briefly here. See NVO-210 (1980) for further information.

\subsubsection{Railcar}

The raiicar chassis was $2.36 \mathrm{~m}$ wide (93 in.) and $5.18 \mathrm{~m}$ long (204 in.). Its four double-flanged wheels distributed the $59,000-\mathrm{kg}$ (130,000-lb) load on rails located $1.96 \mathrm{~m}$ (77 in.) apart (Chapter 5). The two drive wheels were powered by a variable-speed do motor through a worm-gear box and spur-gear drive.

Power, signal, and television cables were suspended in loops from an overhead support cable that spanned the distance from the railcar room to the receiving room. The three on-board TV cameras monitored all UTV operations, which were controlled from the surface.

\subsubsection{Transfer Cask}

The transfer cask was constructed from six cylindrical modules that were tied together by 12 external tie rods (Fig. 7-10). Precision-machined stepped interfaces limited the extemal dose rate to about $105 \mathrm{mrem} / \mathrm{h}$. Because the capacity of the personnel and materials hoist that lowered these sections to the subsurface area were limited, the cask was fabricated in modules. Shields and gate assemblies were located at each end of the 1.14-m-outside diameter (45-in.) 0.483-m-inside diameter (19-in.) main cask body. Both of these gates were made up of opposing V-shaped blocks that were driven on rectangular ways through a pair of travelling nuts on lead screws. Stepping motors and limit switches controlled the movement and position of these gates. The top gate was provided with a 279 -mm-diameter (11-in.) port through which the grapple could be attached to the canister with the top gate closed.

Because there was no requirement for rapid movement of the UTV over uneven surfaces, the shielding cask could be maintained in the vertical, upright position. Screw jacks were provided to raise the cask into a shielding collar at the base of the canister access shaft during transfer operations. These jacks also low'ered the cask into the pits above each canister emplacement hole to provide a shielded interface during emplacement and retrieval operations.

\subsubsection{Hoisting System}

A 5-ton-capacity self-supported jib crane with a 3.75-ton double-reaved drum hoist was provided to transfer a spent-fuel canister between the cask and a canister emplacement hole. To remove the storage hole pit plug (Sec. 7.3), the jit was rotated outboard of the cask. Interlocks prevented the grapple from lowering far enough to engage a spent-fuel assembly outboard of the shielding cask. When rotated to the inboard position, the jib crane supported the grappling of a spent-fuel canister. 


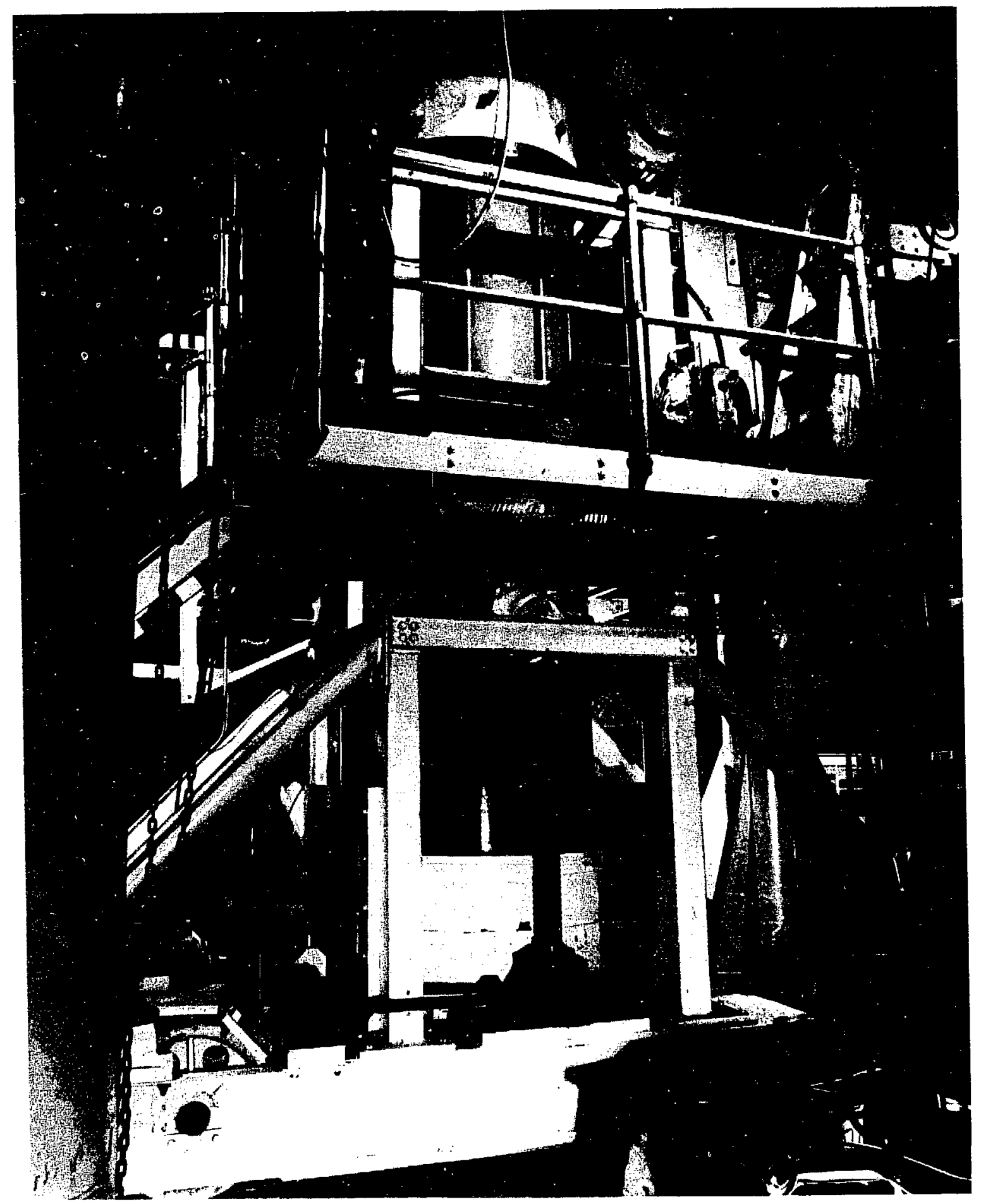

Figure 7-10. Underground Transfer Vehicle undergoing assembly and checkout in the railcar room. 
A Weston-type mechanical brake and an electrical brake were provided for controlled lowering and raising of the canisters. In addition, the regenerative do motor drive controlled lowering of the canister.

Two 12.7 -mm-diameter (0.5-in.) stainless steel cables minimized rotation of the canister pit plug. Signals to the grapple were provided through a separate cable rather than through the load-carrying members.

\subsubsection{Control Systems}

The UTV was controlled at the surface, as discussed in Sec. 7.5. The principal controls were for railcar position and drive actuation, cask jack drive, jib rotation, gate position and drive actuation, jib crane position and actuation, and grapple activation. 


\section{Safety Assessment*}

A Safety Assessment Document (SAD) was prepared and issued in compliance with the environmental, safety, and health (ES\&H) program requirements stipulated by the U.S. Department of Energy (NVO210, 1980). This SAD document.d the identification and control of risks associated with the SFT-C. The three main elements of the SAD are the descriptions of:

- The SFT-C site including surface and subsurface structures.

- The equipment and operations used to perform the test.

- An overall assessment of the potential environmental, safety, and health risks, as well as the consequences associated with postulated abnormal conditions, accidents, and natural phenomena.

In addition, the organizational structure and responsibilities of SFT-C project participants were delineated. The reader is referred to the SAD for details on the state of knowledge that existed at the time of its writing. Currently available information on the site and facilities is provided in Chapters 4 and 5 of this report, respectively, and Chapter 7 provides a description of the handling equipment and related facilities. We focus here on a summary of the safety assessment.

\subsection{Site Analysis}

In analyzing potential ES\&H impacts related to the site, we considered both natural phenomena and the influence of activities at nearby facilities.

\subsubsection{Effects of Natural Phenomena}

As established in a separate SAD for the EMAD facility, spent-fuel assemblies in storage at that location are protected from all credible adverse meteorological conditions (NVO-198, 1978). The direct effects of such events are likewise nonexistent for spent fuel stored $420 \mathrm{~m}(1400 \mathrm{ft})$ underground at the SFT $-\mathrm{C}$.

During transport between the EMAD and the SFT $-C$, the spent fuel was exposed to potentially adverse meteorological events. Several preventive and mitigating factors were identified that minimized the likelihood of occurrence and the potential impacts of an occurrence. First, operational procedures prevented initiation of movement of spent fuel when severe weather was occurring or was forecast. The effects of flash flooding or snowstorms during transport would stop the convoy until conditions improved or were corrected by onsite road-service crews. Second, the SAD for the EMAD showed that tornado-driven missiles could not penetrate the 330-mm-thick ( 13 -in.) transport cask. Furthermore, locking pins and cask closures that required positive mechanical actions to be opened made it highly unlikely that a canistered spent-fuel assembly would come out of the transport cask even if the cask became detached from the STV. Third, the electrical conductance of the thick-walled cask would prevent damage to the canister due to lightning strike. Fourth, although tornado conditions could damage the hoist used to lower the spent-fuel canister underground, the brake (which travels with the canister) would arrest the fall if the hoisting system were disabled. Fifth, loss of electrical power, the most likely meteorological-related event, would have no impact during transfer; the canister would remain in the access shaft until power was restored. Similarly, meteorological events causing loss of site power or damage to surface structures or control systems would not affect the underground transfer or storage operations. Sixth, surface runoff associated with local flash flooding would be prevented from entering the access shaft by means of diversion ditches and a gasketed cover on the access shaft.

The potential effects of earthquakes were also considered. Since the spent-fuel assemblies were contained in gas-tight canisters, the canister would have to be breached to release radioactive contaminants. Snaker-table testing showed that the canisters sustained negligible damage at maximum horizontal ground accelerations of $0.7 \mathrm{~g}$. During the planned 5-year test period, the probability that an event of this magnitude or larger would occur was estimated to be $3.9 \times 10^{-4}$ (Campbell, 1980). Furthermore, the probability that a stored canister would rupture was estimated to be less than $10^{-3}$ for the planned 5 -year test period. These unlikely seismic effects could also be expected to damage the personnel shaft, canister access shaft, and possibly the underground workings.

* Cuntributed by W. C. l'atrkh 
If any of these improbable eanth did acur after all 11 spent-fuel assemblies were emplaced and if all 11 were somehow breached reled.ing the fission-product gises, the radention dose at the site boundary would be no more than $\mathrm{h}$ mrem; an in ignificant anount compared to the Nuclear Regulatury Commission's reterence values of $25 \mathrm{rem}$ whole budy and $300 \mathrm{rem}$ thyroid (in 10 CFR $10(1)$.

\subsubsection{Effects of Activities at Nearby Facilities}

Because the EMAD and SFT-C are in remote locations on a controlled-access site, the only activities that could have atfected the test were well known. The two most likely of these were seismic disturbances and the release of airburne radiuativity from nuclear-weapons testing.

The SAD concluded that the Climax site was unlikely to sustain seismic damage from testing, since then-current testing restrictions precluded the detonation of large events. In addition, any tests in the general area of the test could be and were courdinated and evaluated un a case-by-case basis with the nuclearweapons test program.

Venting of underground nuclear events is a credible erent. All SFT-Cactivities were coordinated with the NTS Operations Curdination Center, and in no case were personnel permitted to be at the Climax site during nuclear weapons tests.

\subsection{Radiological Impact of Normal Operations}

Four normal operations were identified as presenting a potential for radiation exposure to site personnel. No operations were found to constitute a radiological hazard to site personnel, the public, or the environment. These activities-emplacement, post-emplacement operations, and retrieval-span the time frame beginning with SFT - C personnel taking custody of a shielded spent-fuel assembly at the EMAD gates for transport to the SFT-C.

Precautions taken to reduce radiation exposures to as low as practicable included:

- Shielding by means of STV and UTV casks and special interfaces between the STV and access shaft collar at the surface, the UTV and the access collar underground, and the UTV and the storage hole.

- Control-system interlocks that prevented personnel from being accidentally exposed to the spentfuel canister.

- Leak-tight containment of all radioactive materials in canisters.

- Control systems to prevent dropping or breaking (shearing) a canister.

- Operational access control of surface and underground facilities.

- Radiation monitoring and alarming system.

- Personnel dosimetry, special radiation monitoring, and bioassays.

- Marking and controlling access to all radiation areas where dose rates were greater than $5.0 \mathrm{mrem} / \mathrm{h}$.

During transport from the EMAD to the SFT-C (and the reverse process for retrieval operations), the estimated radiation dose at the STV cab was $3 \mathrm{mrem} / \mathrm{h}$. The two personnel in the cab would receive a maximum 13.5 mrem exposure for each $4.5 \mathrm{~h}$ of transporting spent fuel.

Preparing the STV at the canister access shaft was estimated to take 16 to $18 \mathrm{~min}$ in a maximum 50 mrem $/ \mathrm{h}$ field, producing maximum exposures of $15 \mathrm{mrem}$. Preparing the UTV at the shielding pit ( $w$ here thermocouples were installed) was estimated to produce maximum doses of 8 mrem to the hands and 5 mrem whole tody. In addition to the usual film badges and pocket dosimeters worn by all personnel, workers installing thermocouples were monitored to confirm low doses to hands and eyes.

During post-emplacement operations, the spent-fuel assemblies were heavily shielded by a steel shield plug and concrete-filled storage-hole cover. These were calculated to reduce the radiation level to about 0.5 mirem/h on contact.

Retrieval from the SFT-C and transport of the canistered spent-fuel assemblies back to EMAD were calculated to result in similar radiation exposures as were encountered during the analogous emplacement operations. Exposures were anticipated to be somewhat less due to radioactive decay of the fuel during storage at $S \mathrm{FT}-\mathrm{C}$. 


\subsection{Nonradiological Impact of Normal Operations}

No normal operation was determined to impose an unacceptable impact on the nonradiological safety of either operating personnel or the gene'ral public. I'otential hazards were those associated with handling heavy equipment at the surface and in confined underground spaces. Typical mining-related hazards were not present because all construction was completed, including reinforcement of the underground openings. A postulated hazard was radiolytic generation of hydrogen to explosive mixtures, but this was calculated to be impossible for time periods of less than a century.

Precautions taken to minimize the likelihood of nonradiological hazards included:

- Use of personal safety equipment such as hardhats, safety goggles, and safety shoes.

- Use of approved safety and operational procedures and training.

- Availability of fire extinguishers and autumatic Halon fire-suppression systems in critical areas.

- Availability of first-aid supplies and a fully equipped mine refuge station.

\subsection{Radiological Impact of Abnormal Operations}

Abnormal operations that were considered included equipment malfunctions, operator error, or similar problems that were believed to have a putential for serious consequences. Precautions identified to minimize the likelihood of such events included.

- Inspections, testing, and periodic maintenance of all equipment.

- Training and certification of personnel to include dry run operations with nonradioactive canisters.

- Utilization of verified and approved operating procedures.

- Incorporation of conservative designs and fail-safe control systems and interlocks.

For each major fuel-handling operation, potential abnormal conditions were identified. Since radiation exposure of all SFT -C personnel was to be monitored and limited in accordance with applicable DOE requirements, no undue risk to the health and safety of operating personnel or to the public was determined to result from postulated abnormal operations.

In transporting a spent-fuel canister to or from the SFT - C C, abnormal conditions such as traffic delays, failure of STV electrical or mechanical systems, collision, or inclement weather could delay the movement. The convoy leader was authorized to correct such situations or to move personnel a safe distance from the vehicle, if necessary: Minor increases in exposure could occur under these conditions.

Any of several abnormal conditions during preparation to lower the canister or receive it from the test level could result in moderate increases in exposures to personnel who took corrective actions. Among the conditions considered were difficulty positioning the loaded STV, trouble disengaging or removing locking pins, and loss of function of hydraulics or electronics systems.

Once the canister was in the access shaft, the likelihood of exposure of personnel decreased to zero. Thus, no radiological impact would occur during corrective actions if the canister remained in the access shaft. A grapple failure after the canister was in the UTV would require personnel to manually operate it, producing some increase in dose.

Certain failures of the UTV drive jacks, grapple, crane, and gates would require personnel to work in a radiation field of up to $100 \mathrm{mrem} / \mathrm{h}$. In some cases, the canister could be returned to the surface while repairs were made. If the estimated time to complete the repair would result in an unacceptable exposure, provisions were made to incorporate additional personnel shielding.

Corrective actions necessary in the event that a thermocouple was broken or improperly installed were postulated to take a short time, and exposure rates would not exceed $25 \mathrm{mrem} / \mathrm{h}$ whole body and 75 mrem/h to the hands.

Potential abnormal operations and their consequences were the same for retrieval operations as for emplacenent.

Loss of site power would halt all canister handling operations, ventilation, and personnel hoisting. An uninterruptible power supply (UTS) would maintain all data acquisition and radiation monitoring functions. Such a power luss would cause a canister at any point in the transfer process to remain where it wa: indetinitely. No impact was anticipated to result. Likewise, loss of power when the fucl ascemblies were in 
storage would produce no hasard. Fen with hoson ventilation for extended periods, the spent-fuel chadding temperatures would remain lar behw the man imum permissible temperature.

\subsection{Nonradiological Impact of Abnormal Operations}

Except for underground operations, the numbdiological hazards of abnormal operations at the SFT-C were deemed nogreater than most other occupational endearors. Therefore, only potental abnormal occurrences associated with underground operations were considered, including tire and loss of power while personnel were underground.

To limit the potential for underground fires, the quantities of flammable liquids and gases permitted underground were limited, adequate breakers were provided to prevent heating associated with circuit overioads, and the accumulation of wood and related combustibles was controlled. Fire control equipment such as fire extinguishers and Halon fire suppression systems were avilable at selected iocations, and a refuge station $w$ as provided.

Short power outages were anticipated to have little or no adverse impacts. Strategically located batiery-powered emergency lights allowed sate egress trom the storage rooms where temperatures were as high as +0 . Natural ventilation was shwn to be effective in limiting the increase in air temperature that would otherwise accompany loss of forcet ventilation. A ladderway in the personnel and materials shaft was available for emergency egress from the underground.

\subsection{Radiological Impact of Postulated Accidents}

Three postulatnd accidents had potential radiological impact:

- Fire ur explosion.

- Inadvertent removal of a fuel canister from a shielded cask.

- Dropping a canister down the access shaft.

Each of these postulated accidents, associated consequences, and preventive and mitigating factors are discussed briefly below.

\subsubsection{Fire or Explosion}

As noted in Sec. 8.5 , only a limited amount of combustible material was permitted underground at the SFT-C. Therefore, only a fire during transport by the STV was considered credible. The worst-case hypothetical fire was a collision between the STV and another vehicle with the associated ignition of about $400 \mathrm{~L}$ (100 gal) of diesel fuel and about $80 \mathrm{~L}$ ( $20 \mathrm{gal}$ ) of gasoline.

Preventive and mitigating factors included: siow [48 kph (30 mph)] movement of STV, use of convoy procedures, prohibition of movement under severe weather conditions, back-up emergency braking systems, availability of fire extinguishers, presence of two trained operators in the cab with certain redundant controls, and the low ignition potential of diesel fuel. Furthermore, the thick shielding of the transport cask would limit the effects on the canister. No radiological hazard was determined to result from the postulated fire or explosion.

\subsubsection{Inadvertent Removal of a Fuel Canister from a Shielded Cask}

In this accident scenario we only considered a single procedural error or equipment failure because the probability of multiple equipment failures or a simultaneous equipment failure and procedural error was considered negligibly low.

Preventive and mitigating factors for surface operations included: use of top-and bottom-gatte locking pins, cautious convoy movement of the STV, assured shielding by mechanical interfaces at the upper access-shaft transfer point, mechanical and electrical stops to limit upward travel of the brake assembly: grapple above the canister, electrical (logicai) interlocks, and local radiation monitors that would provide immediate warning. For underground operations, preventive and mitigating factors included: remote handling concept (personnel were not underground during transfer operations), shielding by mechanical interfaces at the lower access-shaft transfer point, and electrical (logical) interlocks on the LTV.

Since the preventive and mitigating factors made it highly unlikely that the pustulated accident would occur, we concluded that exposure of personnel to exessive radiation was even morc improbable. 


\subsubsection{Dropping a Canister Down Access Hole}

Dropping a canister dow $n$ the acess hole couming the canister to break and rupture all the fuel cladding could release fission-product gases to the envomment. In this acident analysis we used the calculated fission-product inventury of the gap, and assumed that the entire inventory was released in an instantaneous puff at ground level, and that atmompheric dilution occurred as estimated using Regulatory Guide 1.25. Details of the methodologry and results are provided in the SAD (NVO-210, 1980).

P'reventive and mitigating facturs included: conservative design of handling equipment, positive grappling of canisters, a brake assembly grapple subsystem that travelled with the canister and would prevent free-fall in the event of hoisting equipment failure, and the remote location of the test facility.

Maximum radiation exposure at the define'd site boundary was estimated to be less than $0.5 \mathrm{mrem}$. No thyroid dose from radionctive iodine was calculated to wccur offsite. Likewise, the effect on site personnel would be minimal because surfice radiation monitors would alert the personnel and they would evacuate the area around the access shaft. Release of particulates were expected to be largely contained in the underground structure, but a bank of HEPA filters was installed to further limit dispersal at the surface (Chapter 5).

\subsection{Nonradiological Impact of Postulated Accidents}

In general, we judged that the potential for nonradiological accidents was less for the SFT-C than for other industrial and mining uperations. Two hazards associated with the underground structures were identified. First, it was always possible to fall into the access shaft or the personnel and material shaft. The former was provided with two bolted covers and the latter had a heavy steel cover. These covers were in place with security seals attached when unattended. Personnel working near either shaft were required to use safety belts and lines.

Second, the underground structures could partially collapse. Conservative design and construction, including calculation of the thermal effects of canister and heater emplacement in structurally sound rock, made such an event highly improbable. Only a very severe earthquake (a low probability event, as discussed in Sec. 8.1) could lead to a significant collapse of the roof.

\subsection{Nuclear Criticality Analysis}

The basic nuclear safety criterion used in this analysis was that: "All spent-fuel canister handling operations, storage facilities, and associated equipment shall be designed to preclude achievement of a critical configuration due to the occurrence of any single credible accident including the effects of natural phenomena. Further, the simultaneous occurrence of two likely or related accidents shall not result in criticality. This double accident requirement need not be met in the case of two simultaneous, unlikely, and unrelated accidents, provided that the probability of occurrence of either of the two accidents is judged adequately low."

Assumptions and considerations and the methodology used in the criticality calculations are detailed in the SAD (NVO-210, 1980).

The following preventive and mitigating factors were included:

- The handling system could only move one fuel assembly at a time so two could not be accidently brought into close proximity.

- Only one PWR assembly would fit in a canister.

- Only one canister wuuld fit in the STV, UTV, or storage hole.

- Grapples were designed to prevent dropping a canister.

- An emergency brake and other measures were provided to prevent a canister from dropping down the access shaft.

- Measures were provided to linit the entry of water into the storage locations.

- Canisters were protected by the STV cask from physical damage by tornado winds and missiles.

- Water could not leak into a canister unless it was dropped down the access shaft or after an extremely luw probability seismic event.

- Stured canisters were neutronically isolated by at least $2.45 \mathrm{~m}(8 \mathrm{ft})$ of intervening granite. 


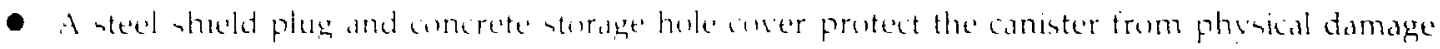
whilem intrage

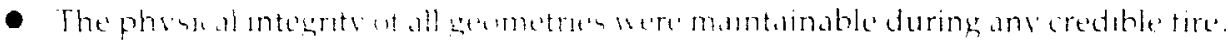

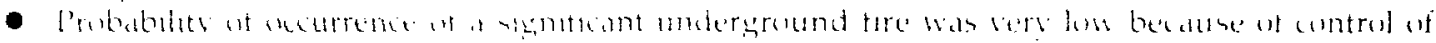
flummablen.

\subsubsection{Flooding : One or More Canister Storage Holes Containing Canisters}

The $k_{\text {int }}$ (ot a man moderated and reflected unirradiated fuel assembly was reported to be about 1).k9.

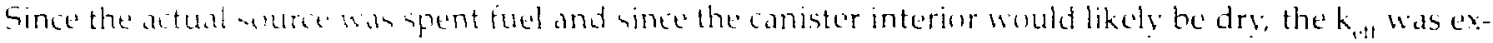

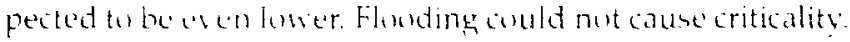

\subsubsection{Physical Damage of Any Type Due to Dropping}

Calculations showed that nucontigurationut dry upent fuel could produce criticalit:

\subsubsection{Physical Damage of Fucl Assembly in Canister Combined with Flooding}

If water did not enter the conister, nu fuet anfiguration could produce criticalit: In nocase for irradi-

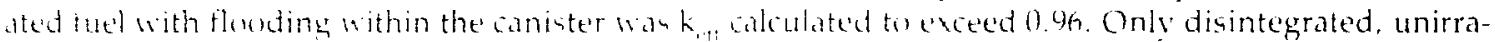
drated pullets suppended in an optimal uran um-to-hydrogen ratio and fully reflected approdhed a nearcritual contiguration.

\section{8.t Physical Damage of Fuel Assembly, Canister Geometry Not Maintained, and Flooding}

A severe earthquake or dropping a canister down the access shaft could rupture the canister and severely damage the fuel assembly. No attempt was made to calculate the $k_{\text {aff }}$ for this case because the probability of the dropping accident and subsequent flouding was very low, and the consequence of criticality wais also very low (beause personnel would not be underground)

\subsubsection{Fire in the Canister Drift with Flooding Associated with Fire Suppression}

A significant fire was highly improbable, and breach of a canister in the STV, UTV, or storage hole as a result of such a fire was not considered credible. As a result, the postulated flooding would produce a nuncritical configuration similar to that dercribed in Sec. 8.8.1.

\subsection{Conclusion}

It is noteworthy, though not surprising, that few of the postulated abnormal occurrences and no accidents touk place during the test. Noradverse impact resulted to the health and safety of the general public or operating personnel or to the environment. 


\section{Instrumentation Selection, Deployment, and Performance*}

Nearly 1000 instruments were deployed and operated for a period of 3-1:2 years to monitur the temperature of the rock, air, and metallic components of the test: displacements and stress changes in the rock mass: radiation dosage to personnel and to the rock; thermal energy input; characteristics of the ventilation airstream; and the operational status of the SFT-C. Because of the careful selection, installation, cali-

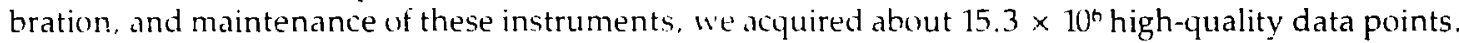

Frough and Patrick ( 1982 ) describe in detail how the instrumentation was selected and deployed, and a second instrumenration report describes certain instrumentation malfunctions and associated corrective actions (Patrick, Carlson, and Rector, 1981). Finally, a complete analysis of the performance and reliability of all SFT-C instrumentation is given by Patrick, Rector, and Scarafiotti (1984). The reader is referred to these reports for further details concerning the information presented here.

\subsection{Objective}

The SFT-C instrumentation program hat three main objectives. First, the instrumentation had to provide data to meet the technical objectives of the test. Second, it had to ensure radiation safety. Third, it was required to monitor the status of the test, including measurements of the ventilation airstrenm, the power distribution system, and the data acquisition system. The instrumentation plan led to the successful specification, design, calibration, and installation of the instrumentation required to meet these three objectives (Brough and Patrick, 1982).

The data acquisition system (DAS) had a profound, direct effect on the quality and quantity of data produced by the instrumentation. Likewise, the data management system (DMS), which provided data conversions and archiving, was a key element in ensuring that high-quality data were available for analysis and reporting. The characteristics and performance of the DAS and DMS are described in Chapter 10.

\subsection{Radiation Monitors}

Radiation moniturs were deployed to measure ionizing radiation as well as airborne gaseous and particulate radioactive materials. Monitoring was provided continuously during the 3-year spent-fuel storage period. Results and discussion of these measurements are provided by Rasclike et al. (1983) and in Chapter 11 of this report.

Remote area monitors (RAMs) were used to measure gamma radia ion levels in the SFT-C underground complex and at the surface where the spent-fuel assemblies were received and lowered to the storage level (Figs. 9-1 and 9-2). The RAMs were in place at the surface locations only during handling operations. Eleven Nuclear Measurements Corp. Model GA-3M RAMs were procured for this purpose (Brough and Patrick, 1982); the manufacturer's specifications indicate a precision of $\pm 15 \%$.

Continuous air monitors (CAMs) were located to sample fer motential release of ${ }^{3} \mathrm{H}$ and ${ }^{85} \mathrm{Kr}$. These are gaseous products that would be released if the spent-fuel assembly canisters and Zircalloy cladding were breached by corrosion or an accident. Two Overhoff and Associates, Inc., Betatec Model 210 CAMs were procured for this purpose (Brough and Patrick, 1982). The use of two CAM chambers permitted redundant sampling from each port. These units have a specified sensitivity of $0.6 \mu \mathrm{Ci} / \mathrm{m}^{3}$. In addition to the continuously monitored locations, ports were also provided to permit sampling from the canister/liner and lineri rock annuli of each canister emplacement borehole.

\subsubsection{Calibration}

The RAMs were provided with a pulsed light-emitting diode (LED) as an internal calibration source that could be turned on and off at the control module. More meaningful and accurate calibrations were performed in siftu before each spent-fuel handling operation by using a ${ }^{22 h} \mathrm{Ra}$ source up to $100 \mathrm{~m} R / \mathrm{h}$ and a m'Co source up to $1000 \mathrm{mR}$ hr. In addition, laboratory calibration of the high-level RAMs was performed

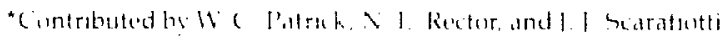




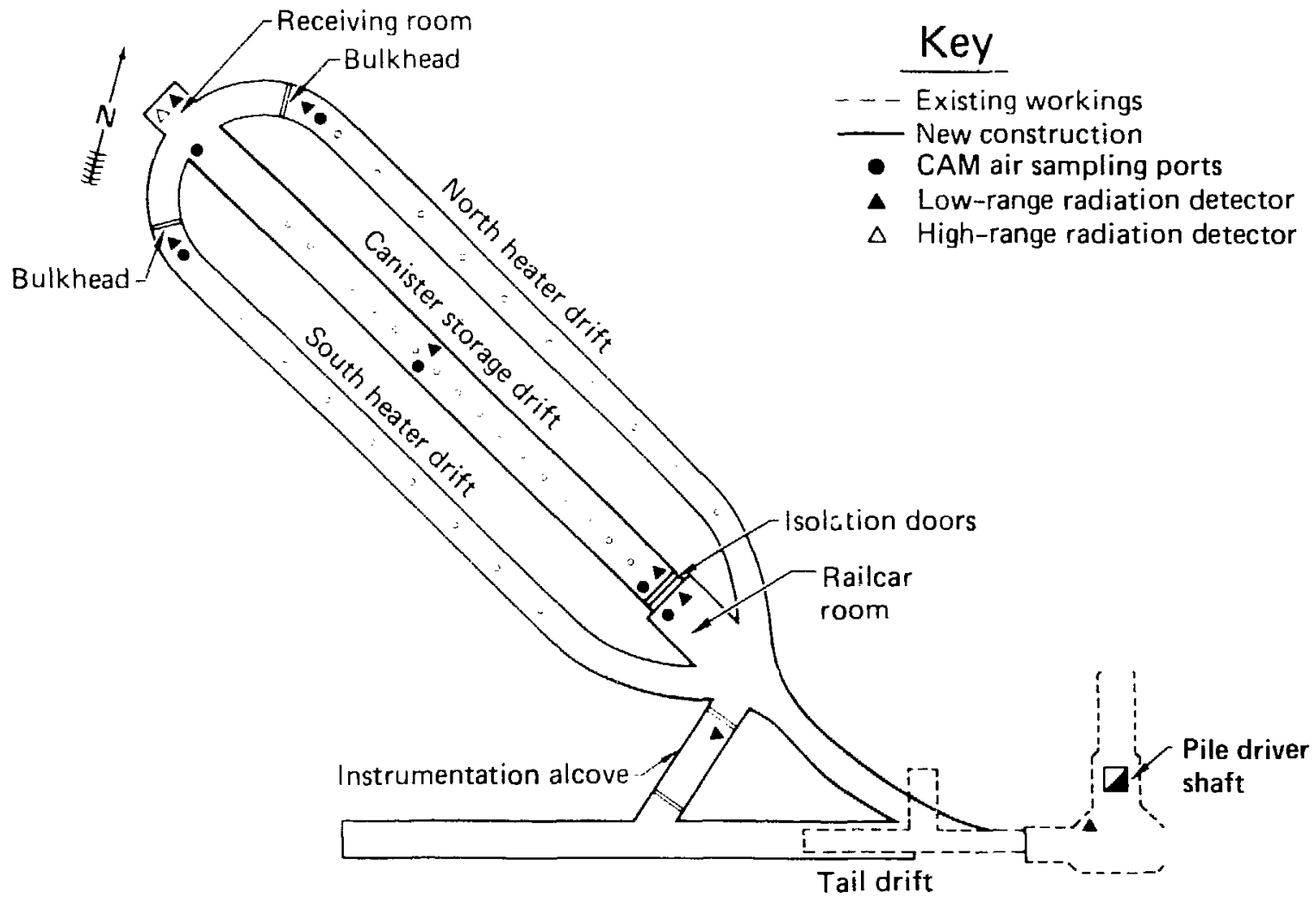

Figure 9-1. Underground radiation monitor locations (after Patrick, Rector, and Scarafiotti, 1984).

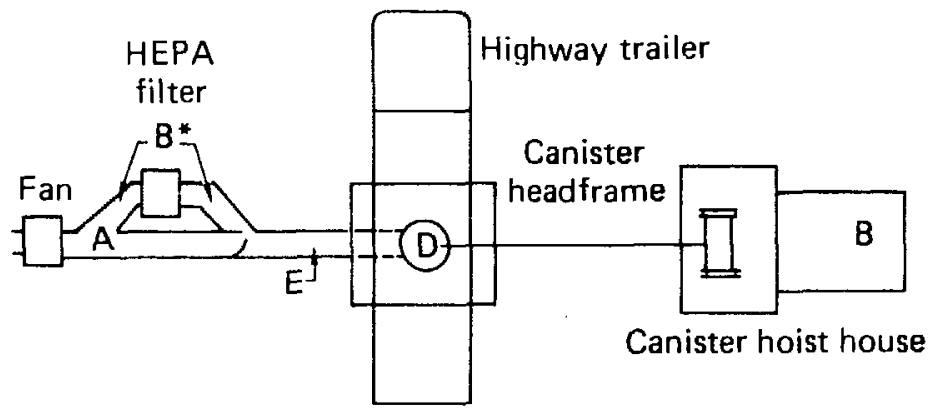
$A=$ Fixed CAM sampling ports.
$B=$ Low-level RAM detectors $\left(B^{*}=\right.$ normal mode $)$.
$D=$ High-level RAM detectors.
$E=$ Particulate sampling port.

Figure 9-2. Surface radiation monitor locations (after Patrick, Rector, and Scarafiotti, 1984). 


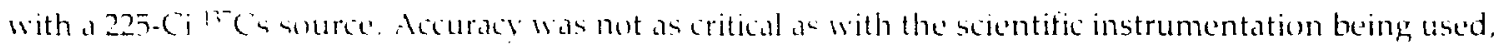
the main concern being adequate s'meitivity.

The purpese af the in situ calibrations was to determine that the units were functioning properly and that they were pertorming at the same !esel at acurac as when they were procured from the manutaturer The hig. sensitivity of these units, which was required to measure low levels of radionativity, made it very difficult to achieve accuracy better than the specified $\pm 15 \%$ of reading. The RAMs were adjusted when the K facturs exeeded by 0.50 the numinal 2.010 value used in the data conversion algorithms.

Calibration of the CAM units employed an internal radiation source. The chambers for the Betatec 210 CAM units were modified to include a "Sr calibration source for this purpose. When placed in the calibrate mode, a $0.4-\mu \mathrm{Ci}$ source was exposed at the chamber, producing a reading equivalent to $180 \mu \mathrm{Ci} / \mathrm{m}^{3}$. The NMC ${ }^{\text {sin }} \mathrm{Kr}$ CAM and the portable (AM units were calibrated at LLNL using radioactive sources. Minor adjustments were made to compensate for instrumicnt drift.

\subsubsection{Error Analysis}

Because the role of the radiation instrumentation was fo detect and monitur for the presence of radiatiun and radioactive materials rather than to provide high-acuracy medsurements for analysis, detailed error analyses were not performed for the RAMs and CAMs.

\subsubsection{Reliability}

With a few minor exceptions, the RAM and CAM units performed satisfactorily throughuut the spentfuel storage period. Aging of the RAM photomultipliers and CAM circuitry caused the DAS to generate spurious alarms (on the low side of the alarm linit). Because of the high single-unit reliability of the RAMs and the application of redundancy in the CAMs, radiation monitoring was provided continuously without a significant period of downtime.

\subsection{Radiation Dosimeters}

Radiation dose-to-granite measurenients were made to document the exposure of the granite to ionizing radiation and for comparison with radiation transport calculations (Wilcox and Van Konynenburg, 1981). These measurements were obtained under subcontract to LLNL by EG\&G-Santa Barbara Operations. Comparisuns of calculational results with data obtained using these instruments are provided in Chapter 15.

Four types of passive dosimeters were deployed at the SFT - C to obtain the required data. Long-term gamma dosimetry used optical grade ${ }^{7} \mathrm{LiF}$ detectors that operate on the principal that optical absorbance of the crystals increases as they are irradiated. Individual ${ }^{7} \mathrm{LiF}$ chips were enclosed in stainless steel holders that were in turn joined together with sections of braided stainless steel cable to make seven dosimeter assemblies (Fig. 9-3). These assemblies were installed in 6.35-mm-diameter stainless steel tubes. Four tubes were attached to emplacement borehole walls where spent nuclear fuel was stored (Table 9-1). The fifth and sixth tubes were grouted into boreholes located 508 and $660 \mathrm{~mm}$ radially outward from the centerline of one of the emplacement boreholes, and the seventh was attached to the emplacement borehole wall where an electrical simulator was stored. The latter installation allowed us to examine thermal annealing of pre-irradiated dosimeters (Quam and DeVore, 1981). These dosimeters were depluyed during three time intervals: April 18, 1980, to January 12, 1981; January 12, 1981, to October 23, 1981; and October 23, 1981, to March 8, 1983.

Long-term neutron dosimetry was performed in conjunction with the long-term gamma dosimetry outlined above. The primary purpose of these measurements was to document the neutron dose for ase in corrections if the gamma dosimeters were found to be neutron sensitive. The five dosimeter assemblies on the emplacement borehole walls provided for $\mathrm{Co}$ and $\mathrm{Ag}$ foils. In addition, the $\mathrm{Ni}$ and $\mathrm{Mn}$ present in the 303-series stainless steel dosimeter holders were also used to help establish the neutron dose (Quam and DeVore, 1981). The measurement periods were the same as for long-term gamma dosimetry.

Buth $\mathrm{MgB}_{4} \mathrm{O}_{7}$ and $\mathrm{CaF}_{2}$ short-term thermoluminescent dosimeters were deployed to provide information on the long-term fade characteristics of the ${ }^{7} \mathrm{LiF}$ dosimeters. Short-term (1-h) measurements we: obtained on August 13, 1982, and March 8, 1983. These measurements were votained at the borehole wall and at positions 508 and $660 \mathrm{~mm}$ radially vulward from the spent-fuel assembly in canister emplacement borehole (CEH) number CEII03 

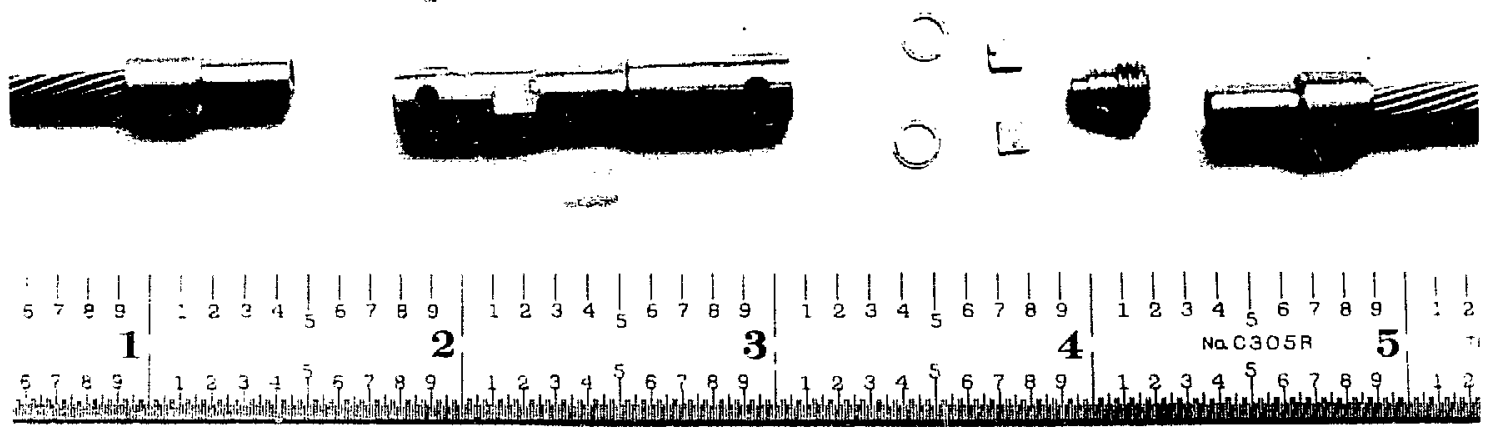

Figure 9-3a. Exploded view of dosimeter subassembly (after Patrick, Rector, and Scarafiotti, 1984).

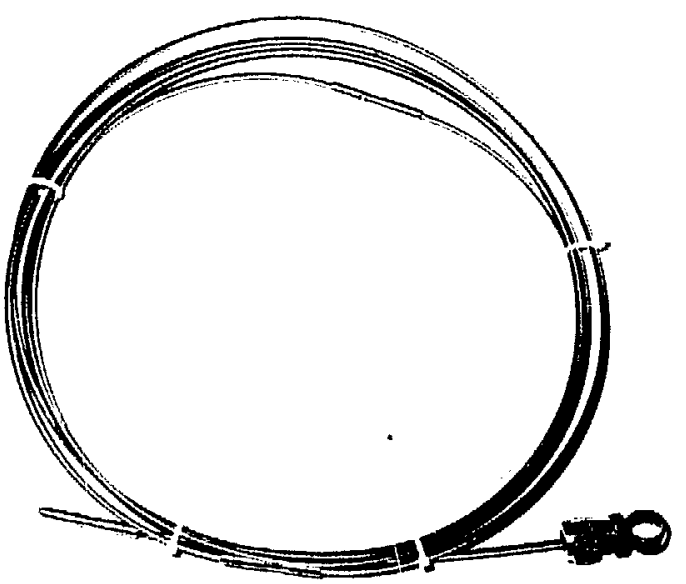

Figure 9-3b. Complete dosimeter assembly ready for installation (after Patrick, Rector, and Scarafiotti, 1984).

146 
Table 9-1. Dosimeter locations in the field installation (after Patrick, Rector, and Scarafiotti, 1984).

\begin{tabular}{|c|c|c|c|}
\hline CEH No. ${ }^{\perp}$ & $\begin{array}{l}\text { Vertical distance } \\
\text { of dosimeters } \\
\text { from centerline }(\mathrm{m})^{\mathbf{b}}\end{array}$ & $\begin{array}{l}\text { Lithium } \\
\text { fluoride } \\
\text { No. }\end{array}$ & $\begin{array}{c}\text { Cobalt foil } \\
\text { No. }\end{array}$ \\
\hline \multirow[t]{3}{*}{1 (wall) } & +1.22 & 14 & - \\
\hline & 0 & 15 & 5,6 \\
\hline & -1.22 & 16 & - \\
\hline \multirow[t]{7}{*}{3 (wall) } & +1.83 & 7 & - \\
\hline & +1.22 & 8 & - \\
\hline & +0.61 & 9 & - \\
\hline & 0 & 10 & 3,4 \\
\hline & -0.61 & 11 & - \\
\hline & -1.22 & 12 & - \\
\hline & -1.83 & 13 & - \\
\hline \multirow[t]{3}{*}{$3(20 \mathrm{~cm})$} & +1.22 & 84 & - \\
\hline & 0 & 5 & 1,2 \\
\hline & -1.22 & 6 & - \\
\hline \multirow[t]{3}{*}{$3(36 \mathrm{~cm})$} & +1.22 & 20 & - \\
\hline & 0 & 21 & 7.8 \\
\hline & -1.22 & 22 & - \\
\hline \multirow[t]{3}{*}{$4{\text { (wall, heater })^{\mathrm{c}}}$} & +1.22 & 1 & 一 \\
\hline & 0 & 2 & 9,10 \\
\hline & -1.22 & 3 & - \\
\hline \multirow[t]{3}{*}{7 (wall) } & +1.22 & 17 & - \\
\hline & 0 & 18 & - \\
\hline & -1.22 & 19 & - \\
\hline \multirow[t]{3}{*}{11 (wall) } & +1.22 & 23 & - \\
\hline & 0 & 24 & - \\
\hline & -1.22 & 25 & - \\
\hline
\end{tabular}

- CEH denotes canister emplacement hole number. Data in parentheses are used to denote radial locations of dosimeters relative to the borehole wall.

"The midheight of the spent-fuel assembly is taken as zero, positive numbers are above and negative numbers are below this center position.

' CEH 4 is an electrical simulator used as a nonradiative control.

\subsubsection{Performance, Reliability, and Error Analysis}

Long-Term Gamma Dosimeters. One set of long-term gamma dosimeters was deployed for a 9month period, read in the laboratory, and redeployed for a subsequent 17 -month period. The other set was deployed for a single 9-month period while the first set was out of service to be read. Temperatures at the dosimeters ranged from about 60 to $80^{\circ} \mathrm{C}$, depending upon the time interval and exact location of the dosimeter. The mechanical design and fundamental approach proved to work reliably for the duration of the SFT-C.

Calibrations of the ${ }^{7} \mathrm{LiF}$ chips were performed at the EG\&G-Santa Barbara Operations ${ }^{\text {(n) }} \mathrm{Co}$ source range at various controlled temperatures up to $60^{\circ} \mathrm{C}$ at exposures up to $10^{7}$ rads- $\mathrm{LiF}$ and at the Sandia Gamma Irradiation Facility at an uncontrolled temperature near $60 \mathrm{C}$ at exposures up to $10^{\mathrm{k}} \mathrm{rads}$-LiF. The 247-nm peak in the absorption spectrum was used in the range of $2 \times 10^{3}$ to $9 \times 10^{6}$ rads-LiF and the 374-nm peak was used in the range of $2 \times 10^{h}$ to $10^{\mathrm{R}} \mathrm{rads}-\mathrm{LiF}$. 
A Beckman 5270) ipectrophotometerwas used for all the 374-nm data and for the 247-nm data produced by exposures up to ahouly $\times$ (1) rad-Lil-about 1.5 AL. An IL 50), modified with a high-pressure mercury vapor light, was used to whtain the 247-nm data for esposures ranging from about $10^{+}$to $10^{7}$ rads-LiF (about 0.1 to $4.5 \mathrm{AU}$ ) because the optical density was sogreat at these exposures. The data from these two instruments agree very well in the overlapping portion of their ranges.

The high quality of the calibration data is evident in Figs. 9-4 and 9-5 for the 374- and 247-nm peaks, respectively. These calibration curves relate known exposures in rads-LiF to observed AU readings, where the AU is the common logarithm of the reciprocal of uptical transmission.

Temperature effects on dosimeter sensitivity were found to be a serious problem with the ${ }^{7}$ LiF dosimeters. Two types of sensitivity were observed. First, irradiated chips were found to fade when held at elevated temperatures following irradiation. Although fade at the 374-nm peak was generally less than $5 \%$ for temperatures of interest here (up to $85 \mathrm{C}$ ), fade at the $247 \mathrm{~nm}$ peak was nearly $30 \%$, so fade corrections were applied to the 247-nm data (Quam and DeVore, 1981). Second, the chips also exhibited a change in sensitivity when simultaneously heated and irradiated. Changes in sensitivity of about $1 \% /{ }^{\circ} \mathrm{C}$ were documented for the $374-\mathrm{nm}$ peak. Changes in sensitivity of the $247 \mathrm{~nm}$ peak appears to be about $5 \%$ at exposures up to $10^{5}$ ads-LiF over a temperature range of $25 \mathrm{to} 60 \mathrm{C}$. Rather than document sensitivity as a function of temperature and exposure for the 247-nm peak, Quam and DeVore (1984a) developed a calibration curve at the proper temperature to eliminate the need for such corrections. Quam and DeVore (1984a) report the overall accuracy of the 'LiF dosimeters as $\pm 11 \%$.

Neutron Dosimeters. The neutron dosimeters were operated at the lower limit of their usable range of exposures. Quam and DeVore (1982) report that the foil counting rates were very low. Exposure rates were measured to be less than $1.09 \times 10^{-4} \mathrm{rem} / \mathrm{s}$, with overall errors of at least $\pm 30 \%$. Since the gamma dosimeters were confirmed to be insensitive to neutrons [as was indicated in the literature (McLaughlin et al., 1978) ], accurate knowledge of neutron dose was relatively unimportant. No further efforts were made to reduce the observed errors or to deploy a more accurate neutron dosimetry technique.

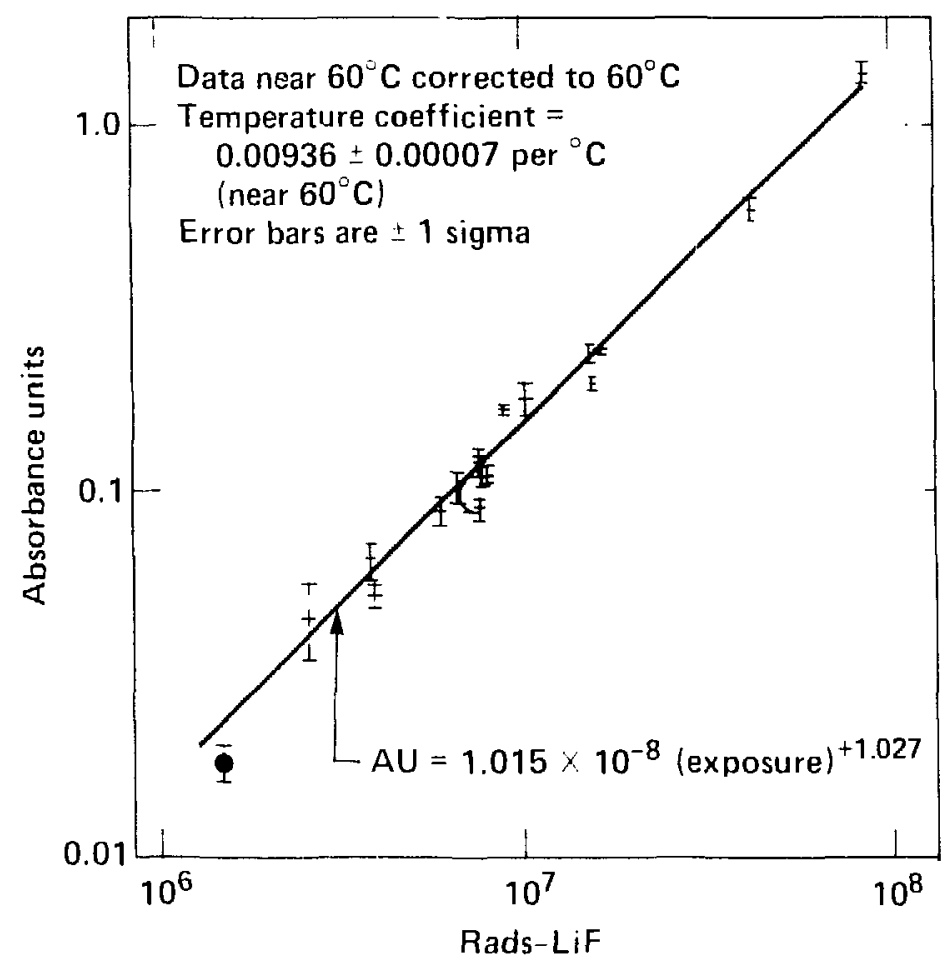

Figure 9-4. Calibration data for the 374-nm peak, polished LiF, 2-mm thickness (after Quam and DeVore, 1984b). 


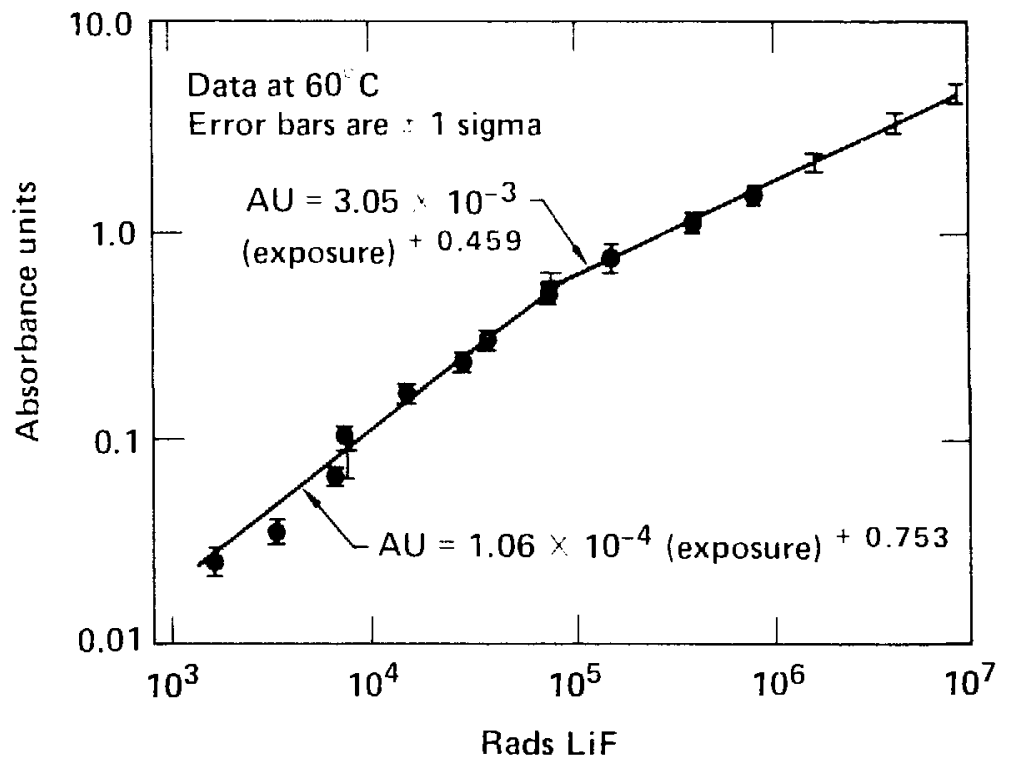

Figure 9-5. Calibration data for the 247-nm peak, polished LiF, 2-mm thickness (after Quam and DeVore, 1984b) $247-\mathrm{nm}$ peak appears to be about $5 \%$ at exposures up to 105 rads-LiF over a temperature range of 25 to $60^{\circ} \mathrm{C}$. Rather than document sensitivity as a function of temperature and exposure for the 247-nm peak, Quam and DeVore (1984a) developed a calibration curve at the proper temperature to eliminate the need for such corrections. Quam and DeVore (1984a) report the overall accuracy of the $7 \mathrm{LiF}$ dosimeters as $\pm 11 \%$.

Short-Term Gamma Dosimeters. An initial 1-h exposure of both $\mathrm{CaF}_{2}$ and $\mathrm{MgB}_{4} \mathrm{O}_{7}$ thermoluminescent dosimeters (TLDs) was conducted August 13, 1982. Calibrations were made at 60 and $25^{\circ} \mathrm{C}$ for both types of TLDs. The ratios of these calibration values were $1.01 \pm 0.085$ for the $\mathrm{CaF}_{2}$ TLDs and $1.03 \pm 0.103$ tor the $\mathrm{MgB}_{4} \mathrm{O}_{7}$. Theretore no temperature corrections to the data were required.

The magnesium borate TLD material was selected because of its low-Z, which should produce little trouble in terms of low energy response, in contrast to the high- $Z$ calcium fluoride TLD, and because it had a relatively high-temperature trap at $200^{\circ} \mathrm{C}$ that should make it more stable at the $60^{\circ} \mathrm{C}$ iriadiation temperature. However, the $\mathrm{MgB}_{4} \mathrm{O}_{7}$ dosimetry provided data that steadily decreased in quality during this phase of calibrating and initial field measurements. Therefore, only $\mathrm{CaF}_{2}$ dosimeters were deployed for the second set of short-term measurements. The calibration data and initial field data showed that the stainless steel holders used to encapsulate the dosimeters trimmed the low-energy photons enough so that the response of the two types of TLDs were essentially the same.

The second 1-h exposure used only $\mathrm{CaF}_{2}$ dosimeters in the same design stainless steel holders as were used for long-term dosimetry. A post-exposure calibration of each individual TLD chip was pertormed so that we did not have to rely on average sensitivity values. In addition, this eliminated the need to make corrections for nonlinearity that occurred at high exposures. This calibration was performed in a thick aluminum holder, the temperature of which was controlled to the field irradiation temperature of $60^{\circ} \mathrm{C}$. Exposure rates were controiled to be the same as those calculated to occur in the field. Both ${ }^{137} \mathrm{Cs}$ and ${ }^{41} \mathrm{Co}$ sources were used in the calibrations to confirm that TLD response was not energy dependent. Calibration dose rates were measured with a Keithley Model 616 electrometer and related precision resistors and voltage source. This set of instruments has been shown to be within $1 \%$ of the NBS values at 1 std dev. The standards themselves are $\pm 1-1 / 2 \%$, and Quam and DeVore (1984b) estimated the total system error (including positioning relative to the source) as $\pm 5 \%$.

The short-term gamma dosimeters proved to be an important adjunct to the originally planned longterm dosimeters. The calcium fluoride TLDs exhibited better accuracy and, because exposure times were short, could be calibrated after exposure in a manner that eliminated the uncertainties associated with the long-term dosimeters. 


\subsection{Temperature Sensors}

\subsubsection{Resistance Temperature Devices}

Resistance temperature devices (RTD) were selected to measure the temperature of thermocouple reference-junction isothermal hlocks and to use as system standards to verify the quality of four-wire resistance measurements made by digital multimeters (DMMs). The reference block RTDs experienced temperatures in the range of 18 to $40 \mathrm{C}$ at relative humidities of 50 to $70 \%$. One RTD was immersed in a Kaye icebath to provide a system standard as noted in the "Data Acquisition System" section of Chapter 10. Standard, industrial-grade platinum Degussa Model 2101 RTDs were procured from C.S. Gordon, Co. for these applications (Brough and Patrick, 1982).

Calibration. Pre- and post-test laboratory calibrations of the RTDs were performed using HP3455A digital multimeters, a Kaye Instruments Model 374 temperature probe, a Rosemount Co. Model 911A1 calibration bath, a Kaye lnstruments Model UTR-AS isothermal reference block, and a Delta Design Model $6400 \mathrm{C}$ environmental chamber. Values of $R_{1}$, were established at $0^{\circ} \mathrm{C}$, and calibrations were obtained at temperatures of approximately 23 and $38^{\circ} \mathrm{C}$. Results of these calibrations are provided in Table 9-2.

Error Analysis. As reported by Patrick, Rector, and Scarafiotti (1984), the maximum root-sum-square (RSS) uncertainty in temperature ranges from $0.038^{\circ} \mathrm{C}$ at $0^{\circ} \mathrm{C}$ to $0.041^{\circ} \mathrm{C}$ at $40^{\circ} \mathrm{C}$.

Reliability. All 20 RTDs functioned reliably throughout the period of deployment.

\subsubsection{Thermocouples}

Type K Chromel-Alumel thermocouples (TCs) were selected as the principal temperature-measuring device for the SFT-C and were procured from C.S. Gordon, Co. These devices wert sheathed in Inconel 600 with $\mathrm{Mg0}$ insulation, and each TC junction was grounded to its sheath. Data obtained using these instruments are compared with calculational results in Chapter 13.

As described by Brough and Patrick (1982), thermocouples were deployed under a variety of operating conditions for periods of up to 3-1/2 years. Temperature environments ranged from an ambient $23^{\circ} \mathrm{C}$ in farfield applications (Fig. 9-6) to about $450^{\circ} \mathrm{C}$ on the electric heaters (Fig. 9-7). A combination of temperatures up to $145^{\circ} \mathrm{C}$ and intense ionizing radiation up to $50,000 \mathrm{rad} / \mathrm{h}$ were present near the spent-fuel assemblies (Fig. 9-8). Depending on location within the test facility, relative humidity ranged from about 50 to $100 \%$. Many TCs were in contact with the chloride- and sulphate-rich groundwater (Isherwood et al., 1982).

Most TCs were installed in guide tubes so that they could be removed for field calibration using the central data acquisition system. Pre- and post-test calibrations of all these units were conducted. A total of 56 TCs were permanently located in borehole extensometers. Therefore, only pretest laboratory calibrations were conducted for these units.

Calibration. Field calibrations were conducted at temperatures appropriate to the application of the individual TC. A Rosemount Model 911A1 ice bath was used for $0^{\circ} \mathrm{C}$, a Kaye Model HTR150 temperature reference for 50 and $100^{\circ} \mathrm{C}$, ind a Procedyne Model TH050 dry bath for the $150^{\circ} \mathrm{C}$ measurements. Actual temperatures of the baths wel: measured with laboratory-calibrated RTDs that were scanned in sequence with the TCs.

The results of the pre- and post-test calibrations showed that only three thermocouples were outside the $\pm 1.1^{\circ} \mathrm{C}$ ISA special limits of error. At temperatures in the range of 20 to $60^{\circ} \mathrm{C}$, where most thermocouples were deployed, errors were generilly limited to $\pm 0.25^{\circ} \mathrm{C}$ and were symmetrically distributed around

Table 9-2. Results of pre- and post-test laboratory calibrations of RTDs (after Patrick, Rector, and Scarafiotti, 1984).

\begin{tabular}{|c|c|c|c|c|}
\hline \multirow[b]{2}{*}{ Calibration } & \multirow{3}{*}{$\frac{\begin{array}{c}\text { Number } \\
\text { calibrated }\end{array}}{19}$} & \multirow{3}{*}{$\begin{array}{c}\text { Mean } \\
0.032\end{array}$} & \multicolumn{2}{|c|}{ Calibration errors ( $\mathrm{C}$ ) } \\
\hline & & & Std dev. & Range \\
\hline Pretest, $23^{\circ} \mathrm{C}$ & & & 0.048 & $-0.014 \operatorname{lo} 0.225$ \\
\hline Pretest, $38^{\circ} \mathrm{C}$ & 20 & 0.039 & 0.037 & -0.016100 .172 \\
\hline Post-test, $23 \mathrm{C}$ & 20 & 0.090 & 0.011 & 0.063100 .108 \\
\hline Post-test, $38 \mathrm{C}$ & 20 & 0.112 & 0.045 & -0.008100 .191 \\
\hline
\end{tabular}



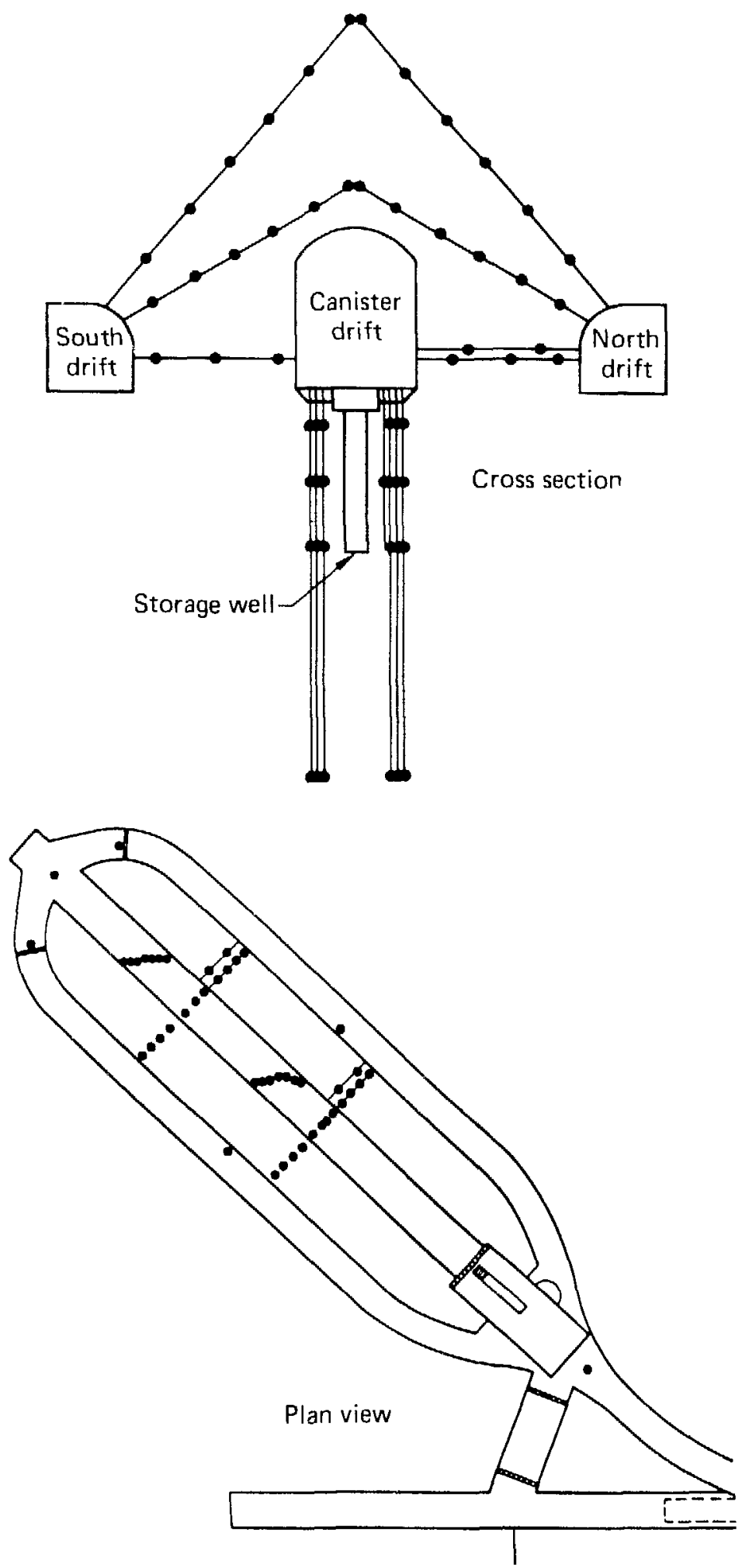

Figure 9-6. Intermediate- and far-field thermocouples. Locations in the storage facility are indicated by dots (after Patrick, Rector, and Scarafiotti, 1984). 

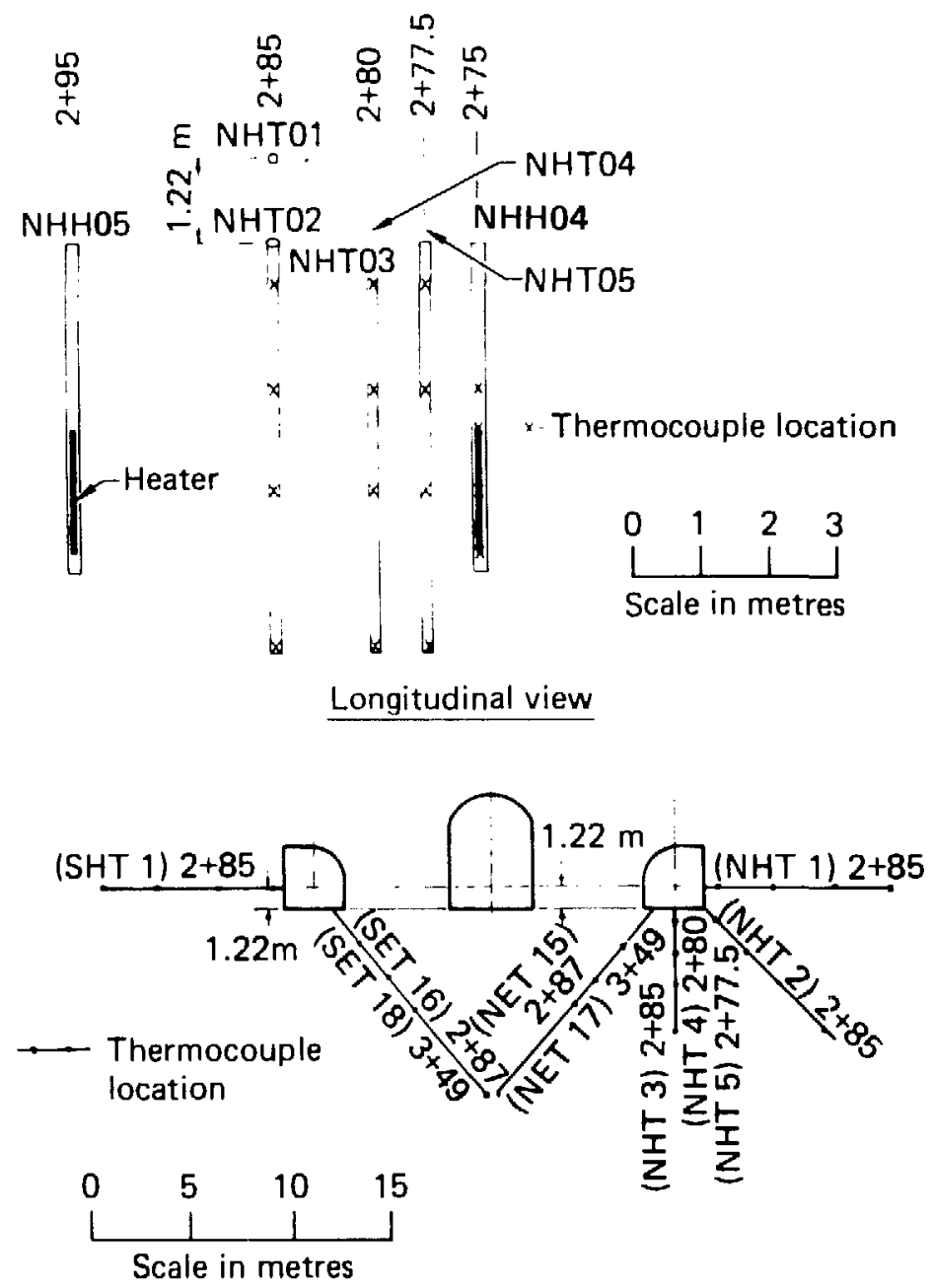

\begin{abstract}
Axial view
Figure 9-7. Additional intermediate-field thermocouple locations associated with auxiliary heaters (after Patrick, Rector, and Scarafiotti, 1984).
\end{abstract}

$0^{\circ} \mathrm{C}$. However, at higher temperatures, such as those observed on canisters, liners, and heaters, the errors become somewhat larger and were skewed toward positive values.

Error Analysis. The maximum uncertainty in temperature was calculated to be $\pm 0.12^{\circ} \mathrm{C}$. Residual errors in the temperature vs voltage equation were minimized by fitting quartics to four segments of the temperature range of interest. Initial break points were selected at $100,200,400$, and $1000^{\circ} \mathrm{C}$. Best-fit quartics were then obtained for National Bureau of Standards (NBS) tabulated paired values of temperature and voltage (Powell et al., 1974). The break points were then adjusted to coincide with the intersections of adjoining quartics, thus providing a smooth transition in the errors. The adjusted break points were 96.49 , $200.39,407.21$, and $1000^{\circ} \mathrm{C}$. Residual errors for the four segments were calculated to be $0.0004,0.0023$, 0.0102 , and $0.02{ }^{\circ} \mathrm{C}$, respectively. These are minor contributions to the RSS error calculated above.

Reliability. The TCs performed reliably throughout the measurement period. Performance was evaluated on a continuing basis during the SFT-C by means of loop-resistance checks and through the DAS alarm system. The resistance checks were conducted on all TCs at about 6-month intervals. In addition, the DAS alarm system (Chapter 10) provided for prompt recognition and correction of such problems. Since 


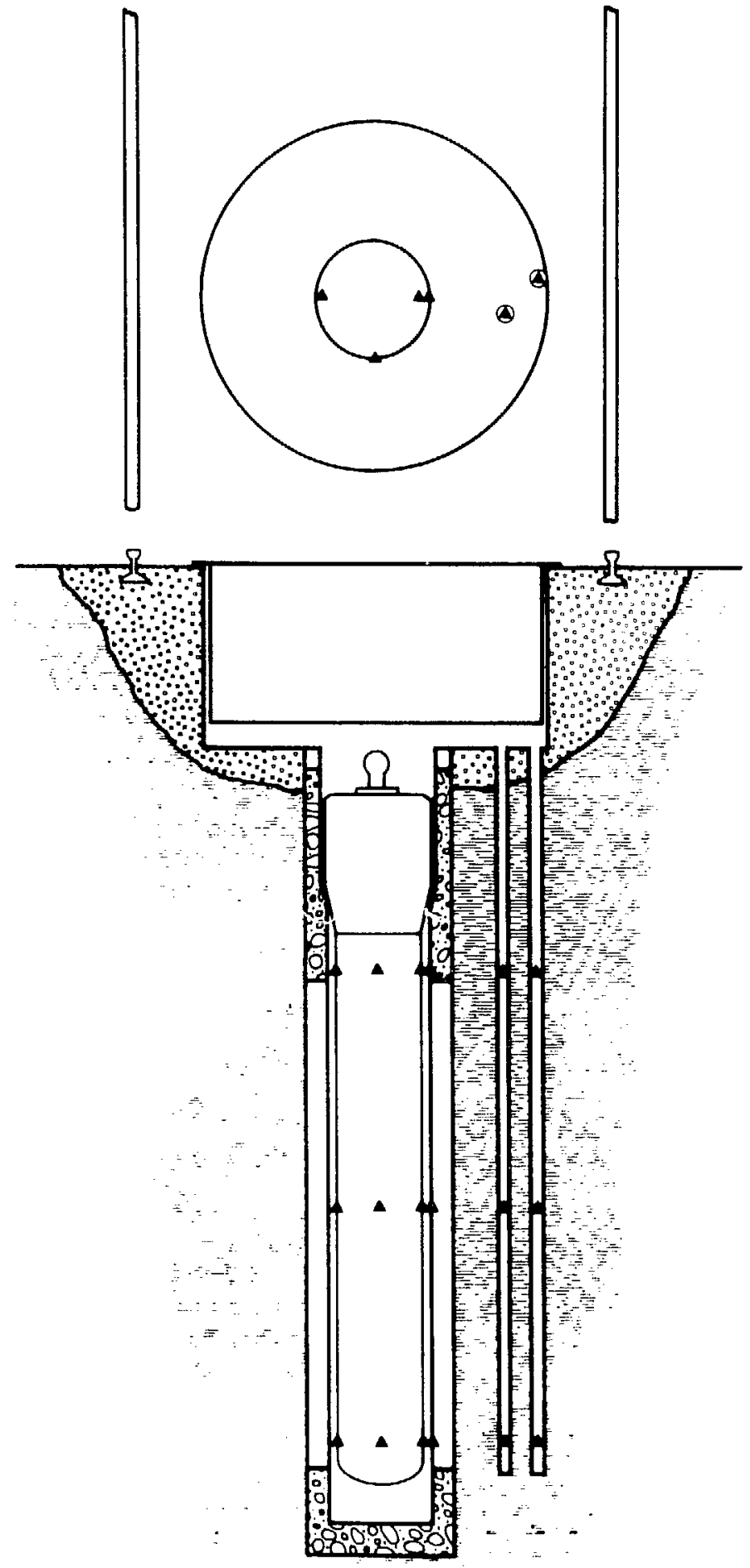

Figure 9-8. Near-field thermocouples. Locations are designated with triangles (after Patrick, Rector, and Scarafiotti, 1984). 
anticipated temperatures were well known based on thermal calculations, alarm limits were set quite narrow: As a result, problems (which were expressed as temperatures that were out of expected limits) were quickly observed and corrected.

Four thermocouple sheaths were found to be corroded when they were recovered for post-test calibrations. However, none of these units exhibited abnormal behavior in service. All four were located in spentfuel storage boreholes. Metallurgical analyses of the corroded TC sheaths revealed that two were Inconel 600 , as specified, but the other two were 304-series stainless steel (Chapter 18).

\subsubsection{Thermistors}

Two arrays of thermistors were deployed within the canister storage drift to document nonuniformities in the air temperature distribution. Nominal 340-k $\Omega$ YSI Model 44014 thermistors were attached to two large crosses constructed from sections of 19 - $\mathrm{mm}$-diameter polyvinylchloride (PVC) pipe. The crosses were positioned so that five temperature measurements could be obtained along both the vertical and transversely horizontal axes of the drift cross section. Nine thermistors were used at each of two locations in the drift (the center thermistor was common to the vertical and horizontal profiles). In addition, another thermistor was located on the outer surtace of a National Electrical Manutacturers' Association (NEMA) enclosure containing TC reference blocks to provide a comparison between temperatures recorded by the thermistor and the RTDs. Temperatures in the ventilation airstream varied from about 18 to $40^{\circ} \mathrm{C}$ during the SFT $-C$, with temperatures near $30^{\circ} \mathrm{C}$ most of the time.

Calibration. Pretest calibrations were performed at a nominal $23^{\circ} \mathrm{C}$ ambient temperature, and posttest calibrations were performed at nominal temperatures of 19,23 , and $30^{\circ} \mathrm{C}$. All calibrations were performed in the laboratory using an Instrulab Model 841-12 temperature sensor, an Instrulab Model 4202-131506 temperature monitor, and a Fluke Model 8860A digital multimeter (DMM). Accuracy of the temperature sensor was $\pm 0.02{ }^{\circ} \mathrm{C}$, and accuracy of the DMM was $\pm 0.014 \%$ of reading plus three counts. All calibrations were performed with lead wires and cabling attached to the thermistors.

The thermistor calibrations (Table 9-3) show that both the mean errors and the standard deviations of those errors increased substantially between the time of pretest calibrations in May 1981 and post-test calibrations in December 1983. However, examination of individual calibration records shows that only one thermistor had an error outside the desired $+0.1^{\circ} \mathrm{C}$ window at $30^{\circ} \mathrm{C}$ and that none had an error this large at $23^{\circ} \mathrm{C}$.

Error Analysis. Error analysis indir: ted a maximum uncertainty in temperature of $0.022^{\circ} \mathrm{C}$.

Reliability. Nineteen thermistors wis deployed in the two arrays. All functioned without failure during the measurement period. One lead wire was broken at the thermistor bead during handling and could not be repaired for post-test calibration (Table 9-3).

\subsubsection{Convergence Wire Temperature Monitors}

Convergence wire extensometers (CWLs) are long-gauge-length, removable instruments capable of accurately measuring relative displacements across mined underground openings. Because the 0.635mm-diam connecting wire used on this in:sr ument changes length with changes in temperature, it was necessary to develop a technique capable of mecisuring the average temperature of stainless steel wires 2.9 to $8.0 \mathrm{~m}$ long.

The convergence wire temperature monitors (CWTs) operated on the same principal as RTDs. Two small metal clamps attached near the end points of the stainless steel wire were in turn attached to two

Table 9-3. Results of pre- and post-test laboratory calibrations of YSI Model 44014 thermistors (after Patrick, Rector, and Scarafiotti, 1984).

\begin{tabular}{|c|c|c|c|c|}
\hline \multirow[b]{2}{*}{ Calibration } & \multirow{2}{*}{$\begin{array}{l}\text { Number } \\
\text { calibrated }\end{array}$} & \multicolumn{3}{|c|}{ Calibration errors ( $\mathrm{C}$ ) } \\
\hline & & Mean & Std. dev. & Range \\
\hline Pretest, mean temp. $=22.55 \mathrm{C}$ & 19 & 0.006 & 0.005 & -0.0087 to 0.0205 \\
\hline Post-test, mean temp. $=19.13 \mathrm{C}$ & 18 & 0.091 & 0.036 & 0.048 to 0.138 \\
\hline Post-test, mean temp. $=22.73 \mathrm{C}$ & 18 & 0.015 & 0.032 & -0.046 to 0.078 \\
\hline Post-test, mean temp $=29.58 \mathrm{C}$ & 18 & -0.019 & 0.114 & -0.437 to 0.086 \\
\hline
\end{tabular}


pairs of lead wires, one of which provided a known pulsed current while the other measured the voltage drop across the wire. Thus, a four-wire resistance measurement was made. Knowing the temperature coefficient of resistance and an initial wire resistance at a known temperature, it was possible to calculate an average wire temperature. Sequential CWT measurements were used to calculate changes in temperature, which in turn were used to calculate the thermal expansion of the wire.

Calibration. The individual wires were calibrated in isothermal containers constructed from two overlapping cardboard boxes lined with low-density styrofoam blocks about $70 \mathrm{~mm}$ thick. The wires coiled naturally into circles about $0.2 \mathrm{~m}$ in diameter when removed from the CWE, and the individual loops of each coil were insulated, using either plastic sheets or tubing, to prevent shorting during the calibration process. Two Yellow Springs Instruments (YSI) Model 44014 thermistors were placed at diametrically opposite positions on the coil, and the insulated box was closed and sealed for about 12 hours. Once the temperature withia the box became uniform and stable, the thermistors and CWT resistance were recorded. An equiiibrium value of $R_{1}$ was thus obtained at a single known temperature $T_{0}$.

Table 9-4 provides the measured changes in offset constant that occurred between the pre-installation February 1982 calibration and the post-test February 1984 calibration. Because errors are a function of wire length, the CWTs are treated in three groups. Note that while the average errors were acceptably small, individual errors in some cases approached or exceeded $0.5^{\circ} \mathrm{C}$.

Error Analysis. The RSS errors tor these instruments were directly dependent upon wire length. The calcidit d total RSS errors for wires 2.9 to $3.5 \mathrm{~m}, 4.6$ to $5.9 \mathrm{~m}$, and $8.0 \mathrm{~m}$ were $0.848,0.544$, and $0.407^{\circ} \mathrm{C}$, respoitioly.

Fon ility. The $32 \mathrm{CWT}$ units deployed at the SFT-C tunctioned relicbly throughout the monitoring PE: . . 4 with one exception. CWT011 was located across a tault zone where the rock and clay gouge were very moist and pyrite was plentiful. These conditions produced a small battery that caused current to pass through the wire. As a result, variations in the apparent resistance of the wire made this CWT unusable.

\subsection{Ventilation System Instrumentation}

To maintain a safe, habitable working environment while not extracting so much thermal energy that the rock would not attain realistic temperatures, it was necessary to control the ventilation of the underground space. Pretest calculations (Montan and Patrick, 1981) indicated that without ventilation, air temperatures would reach about $60^{\circ} \mathrm{C}$ during the test. These calculations also showed that a modest air flow would limit air temperatures to about $40^{\circ} \mathrm{C}$ and remove about a third of the total energy deposited during the test.

It was necessary to monitor the energy removal in order to evaluate the ventilation model and to modify the general heat transfer model as necessary to account for the loss of energ, itom the test environment. Instrumentation was deployed to measure air temperature, dewpoint, and ventilation flowrate. Data from those instruments are presented and compared with calculational results in Chapter 14.

During the spent-fuel storage phase of the test, all air flow occurred through a single exhaust port-the canister access shaft. Flow was regulated in the three drifts by means of bulkheads and louvers (Chapter 5 and Patrick and Mayr, 1981). Following spent-fuel retrieval, an additional exhaust port was added to each heater drift to expedite cooling of the rock mass surrounding the facility. Ventilation system instrumentation was deployed for each of these phases of the test.

Table 9-4. Measured errors resulting from changes in offset constant during the two-year period of deployment of convergence wire temperature monitors (after Patrick, Rector, and Scarafiotti, 1984).

\begin{tabular}{|c|c|c|c|c|}
\hline Wire length & Number & & Error & \\
\hline (m) & calibrated & Mean & Std. dev. & Range \\
\hline 2.9 to 3.5 & 18 & -0.101 & 0.354 & -0.814 to 0.429 \\
\hline 4.6 to 5.9 & 11 & -0.090 & 0.219 & -0.426 to 0.384 \\
\hline 8.0 & 1 & -0.248 & $\mathrm{NMF}^{\Delta}$ & $\mathrm{NMF}^{a}$ \\
\hline
\end{tabular}

No meaningful figure. 


\subsubsection{Air Temperature}

Type $\mathrm{K}$ thermocouples sheathed in Inconel 600 were positioned at the trifurcation of the heater drifts and canister drift, at the ventilation-contrul bulkheads at the far ends of the two heater drifts, at the heater drift midpoints, and at the far end of the canister drift where the canister access shaft intersects the roof line. This last location is where the ventilation air exited the facility. In addition, a thermocouple was located at the inlet of each of two exhaust tubes that were used to expedite cooling of the facility following spent-fuel retrieval.

Thermocouples measured the so-called dry bulb temperature of the airstream. Changes in temperature between the ventilation inlet and outlet points at a constant water content were thus used to calculate the sensible heat removed from the SFT-C. Since these thermocouples were from the batch described in Sec. 9.4.2, they are not described further here. The RSS uncertainty in temperatures in the 20 to $40^{\circ} \mathrm{C}$ range was previously established to be $\pm 0.12^{\circ} \mathrm{C}$ for the batch of thermocouples, but by using individual calibrations, maximum errors were limited to $\pm 0.005^{\circ} \mathrm{C}$.

\subsubsection{Dewpoint}

Dewpoint sensors were located at the ventilation inlet and outlet points to determine changes in the water content of the ventilation airstream. These measurements were used to calculate the energy removed as a result of adding water to the airstream through vaporization. This component due to the latent heat of vaporization and the sensible heat component noted above constituted the total energy removed in the ventilation airstream.

Two YSI Model 9400 lithium chloride dewpoint cells were mated with Weather Measure Corp. Model H361-DPYA dewpoint sensor assemblies to provide the necessary dewpoint measurements during the spent-fuel storage phase of the test. Two additional cells were added to obtain measurements at the two exhaust points added during the cooling phase.

Calibration. Dewpoints ranged from 10 to $22^{\circ} \mathrm{C}$ during the test with differences between inlet and outlet dewpoints of about 1 to $2^{\circ} \mathrm{C}$ (relative humidity was about $50 \%$ during the test).

The dewpoint cells were calibrated before and after the test to confirm their adherence to YSI-tabulated values. Calibrations were performed at 21 and $49^{\circ} \mathrm{C}$ pretest and at $21^{\circ} \mathrm{C}$ post-test. These calibrations were performed under contract at the Sandia Standards Laboratory, Albuquerque, New Mexico. We found excellent agreement between calibration results and YSI-tabulated relationships between dewpoint cell resistance and dewpoint temperature.

Error Analysis. Comparisons between YSI and calibration resistance readings at dewpoint temperatures between 10 and $22^{\circ} \mathrm{C}$ showed that typical errors in RTD resistance were 0.1 to $0.2 \%$ with two extreme errors of 0.4 and $0.9 \%$. Since RTD readings were a linear function of cell temperature in this range, the RTD errors could be expressed as dewpoint errors of about $2.2^{\circ} \mathrm{C} / 1 \%$ error in RTD reading.

In the er: ${ }^{n}$ gy balance calculations, vapor pressure (rather than dewpoint temperature) was used directly. Maximum uncertainty in vapor pressur: due to errors in resistance readings was calculated to be \pm 0.0187 Torr, based on an error in resistance of $0.011 \Omega$ (Patrick, Rector, and Scarafiotti, 1984). Since the energy calculations were based on differences in vapor pressures, any systematic errors that may have existed were cancelled.

Reliability. All four dewpoint cells functioned reliably throughout their deployment periods. Two of the cells were in use for about three years, while the other two were in service only for the 6-month cooling period that followed spent-fuel retrieval.

\subsubsection{Ventilation Flowrate}

An Engineering Measurements Company Model TMP turbine flowmeter was located in the surface duct-work of the ventilation system to measure air flow. In addition, a Model FTP-812S3700-GJS-12 "MiniProbe" flow meter was installed in the duct-work of each heater drift following spent-fuel retrieval to monitor the augmented airflow. These units are referred to as "airflow monitors" and car: $y$ designations of the form AFMxxx.

Calibration. Calibrations were performed by REECo Ir Justrial Hygiene Section personnel using a hand-held pitot tube inserted through a port in the duct-work. Simultaneous readings of the pitot tube and flowmeter were obtained at 10 positions across both the horizontal and vertical diameters of the duct. Measurements were obtained at three flowrates. The pitot tube measurements used a Magnehelic panel consisting of a barometer and Dwyer magnehelics with ranges of 0 to 2 in. $\mathrm{H}_{2} \mathrm{O}, 0$ to 5 in. $\mathrm{H}_{2} \mathrm{O}$, and 0 to 60 in. 
$\mathrm{H}_{2} \mathrm{O}$. The REECo Standards and Calibration Facility certified an accuracy $\pm 0.1 \%$ of reading for the magnehelics. However, the rather poor resolution of the magnehelics limited the actual accuracy to $\pm 3 \%$ for the main ventilation system (AFM201) and $\pm 5 \%$ for the augmented ventilation system (AFM002 and AFM003).

A comparison of the pre- and post-test calibrations indicated that sub-tantial shifts occurred. The resulting errors were $0.20 \mathrm{~m}^{3} / \mathrm{s}(17 \%)$ fur AFM002 (north drift), $0.22 \mathrm{~m}^{3} / \mathrm{s}(18 \%$ ) for AFM003 (south drift), and $0.50 \mathrm{~m}^{3} / \mathrm{s}(18 \%)$ for AFM201 (main exhaust). In all cases, the post-test measured flowrates were lower for a given voltage output. Conversely, the voltage output was higher for a given measured flowrate, which is the opposite of what occurs when a turbine fails because of increased friction in the bearings or because of dust accumulations on the turbine blades. Examination of the flowrate data recorded during the SFT-C indicated no systematic increase in apparent flow with time. We suspect that this very consistent $(18 \%)$ error was introduced in calibration, and it was not present in the data acquired during the test (Chapter 14).

Reliability. The three turbine flowmeters appear to have functioned reliably throughout the test period. The only question concerning reliability relates to the apparent $18 \%$ shift in readings discussed above. AFM201, which was in service for 3.5 years, experienced one turbine failure at about 4.5 YOC (two years into the test) and was replaced at that time. It also malfunctioned at about 4.72 YOC in August 1982 during the third exchange of spent-fuel assemblies. The turbine was cleaned, reinstalled, and functioned reliably through termination of the test.

\subsubsection{Energy Removal Calcula'tion}

The sources of error described above propagate to the calculation of energy removal from the SFT-C. We calculated a total uncertainty in energy removal rate of $\pm 0.19 \mathrm{~kW}$, or about $\pm 3.4 \%$ during the spent-fuel storage phase of the test. This uncertainty increased to $\pm 0.21 \mathrm{~kW}$, or about $\pm 3.7 \%$ during the cooling phase of the test when the auxiliary ventilation system was operating.

\subsection{Watt Transducers}

Watt transducers were selected and deployed to measure the quantity of electrical energy introduced to the rock mass and ventilation airstream during the SFT-C. Three primary sources of electrical heat ivere present: electrical simulators, auxiliary heaters, and areal lighting. An overall accuracy requirement of $2 \mathrm{~kW}$ for the system-1.5 $\mathrm{kW}$ with lighting off-was determined to be adequate for the purposes of the SFT-C (Brough and Patrick, 1982). Data obtained using these transducers are presented in Chapter 12.

The thermal output of the six electrical simulators was individually monitored and controlled. During the three-year test, outputs ranged from about 1.6 to $0.6 \mathrm{~kW}$ per simulator. Loyola Industries BPAC-series controllers (SCR-type) delivered power to the simulators. American Aerospace Controls, Inc., Model 41325-230 watt transducers measured the power output of the controllers.

The power output of the 10 auxiliary heaters located in each of the side drifts ranged from 1.85 to 0.625 $\mathrm{kW}$ per heater. Since the heaters were grouped in two sets of three and one set of four in each drift, measured powers ranged from 7.40 to $1.88 \mathrm{~kW}$. Loyola SCRs and American Aerospace Controls, Inc., Model 413-100-115 watt transducers were used.

The power output of the areal lights was monitored with two ranges of transducers. Canister drift lighting was monitored with three American Aerospace Controls, Inc., Model 413-100-115 watt transducers, whereas the heater drift lighting was monitored with a total of four Model 413-25-115 watt transducers. Electrical lights were connected directly to utility power with no intervening SCRs.

\subsubsection{Calibration}

Calibrations were performed to examine the accuracy and behavior of the transducers under realistic conditions. The relative complexity and need for precision precluded the use of field calibrations, so laboratory calibrations were performed. We developed a calibration system that used incandescent lights as electrical loads. Both pre- and post-test calibrations were conducted. Details of the calibration configuration are presented by Brough and Patrick (1982).

Means and standard deviations of errors for each set of transducers are given in Table 9-5. Both watt and percentage-of-reading errors are provided. In all cases, a systematic change in transducer response 
Table 9-5. Errors measured during pre- and post-test calibration of watt transducers (after Patrick, Rector, and Scarafiotti, 1984).

\begin{tabular}{lcccr}
\hline \multicolumn{1}{c}{ Type } & \multicolumn{2}{c}{$\begin{array}{c}\text { Pretest calibration mean } \\
\text { (std dev) error }\end{array}$} & \multicolumn{2}{c}{$\begin{array}{c}\text { Post-test calibration mean } \\
\text { (std dev) error }\end{array}$} \\
\cline { 2 - 5 } \multicolumn{1}{c}{ Watts } & o Reading & Watts & $105.6(63.5)$ & $2.5(1.2)$ \\
Auxiliary heaters & $-63.7(86.6)$ & $-1.3(1.4)$ & $19.4(8.6)$ & $3.2(1.3)$ \\
Electrical simulators & $-76.2(38.9)$ & $-3.5(1.1)$ & $7.7(12.8)$ & $0.5(0.9)$ \\
Heater-drift lights & $-36.5(10.5)$ & $-2.7(0.4)$ & $-66.1(31.9)$ & $-1.8(0.9)$ \\
Canister-drift lights & $-151.5(109.0)$ & $-3.7(2.4)$ & & \\
\hline
\end{tabular}

was noted. Pretest errors were negative (measured power less than power calculated using the manufacturer's sensitivity and offset values) for all but one individual instrument. On the other hand, post-test errors were positive for all but two instruments and even here the errors became more positive (Patrick, Rector, and Scarafiotti, 1984).

The observed systematic changes in transducer response are attributed nonspecifically to component aging. The same measurement system, calibration standards, and procedures were used in both calibrations, so there was little likelihood that a different error source was introduced at this point. Furthermore, it is clear that the offset, while systematic in design, varied quite widely in terms of both absolute power and percentage of reading. We are confident that these differences in pre- and post-test errors represent actual changes in transducer responses.

\subsubsection{Error Analysis}

Analysis of the calibration data indicates that at the start of the SFT-C, 1.3\% less energy than planned was teing deposited by the auxiliary heaters and 3.5\% less energy than planned was being deposited by the electrical simulators. By the end of the test, these two heat sources were depositing 2.5 and $3.2 \%$ more energy than plarned, respectively. Because there was a period when the average error was negative and then positive, it follows that the cumulative error was less than either of these extremes.

\subsubsection{Reliability}

With the exception of an SCR failure that affected CEH17 for 12 days, the watt transducers deployed on the six electrical simulators functioned reliably throughout the 2.8-y heating ?hase of the SFT-C. Examination of the individual plots of power output showed no other periods of erratic behavior. When the sensitivity of the partial duty cycle controllers to variations in line voltage became excessive as the power level was reduced below about $1 \mathrm{~kW}$, a set of process controllers with pover-sensing feedback was installed to reduce the variability in output power. A markedly more stable power output resulted (Chapter 12).

Several component malfunctions were observed in the auxiliary heater control system. The failure mode for the heater controller made the power level fluctuate, fairly repeatedly, between the setpoint and some higher power level that was less than the full power of the controller.

Individual data records indicate that the canister-drift and heater-drift-lighting watt transducers functioned reliably throughout the measurement period.

\subsection{Stressmeters}

Three types of stress-measuring devices were used at the SFT-C. During the tesi, vibrating-wire stressmeters recorded stress changes that occurred as a result of excavating, heating, and subsequently cooling the rock mass. In addition, United States Bureau of Mines (USBM) borehole deformation gauges and Commonwealth Scientific and Industrial Research Organization (CSIRO) overcore cells were used to obtain absolute stress measurements by means of the stress-relief overcoring technique. The use, evaluation, and performance of each type are summarized here 


\subsubsection{Vibrating-Wire Stressmeters}

Vibrating-wire stressmeters were deploved at the SFT - C to measure stress changes that occurred as a result of heating the rock mass. Three IRAD Gage Co. Model VBS-1HR (hard rock) stressmeters were used in the pillars during the Mine-by experiment (Wilder and Patrick, 1980). During the heated phase of testing, 18 Model VBS-1HT (high-temperature hard rock) stressmeters were used in the pillars and at pcitions $1.2 \mathrm{~m}$ radially outward from the spent-fuel assemblies (Brough and Patrick, 1982; Figs. 9-9 and 9-10). The principal differences in the latter units were the use of Teflon-sheathed electrical wire and higher temperature potting and $\mathrm{O}$-ring seals. Data obtained using these stressmeters are presented and discussed in the context of calculational results in Chapter 16.

Three steps were taken to reduce the likelihood of corrosion of the stressmeters during the heated phase. These actions were taken based on observed corrosion of the three stressmeters deployed for the Mine-by experiment (Carlson et al., 1980). First, the stressmeter bodies and platens were plated before assembly with a $0.127-\mathrm{mm}$-thick electroless nickel containing 7 to $10 \%$ phosphorus. Second, the stressmeters were coated with a $0.167-\mathrm{mm}$-thick film of Pyrolene- $\mathrm{N}$. Third, following installation, the borehole void was filled with inert high-density foam.

Twelve stressmeters were deployed in two sets of three in each of two 38-mm-diam horizontal boreholes in the north pillar of the SFT-C. Vertical, 60-degree clockwise and 60-degree counterclockwise orientations were used in each set of three to form a rosette with $150-\mathrm{mm}$ spacings between gauges (Carlson et al., 1980). Two sets were positioned near the center of the pillar and two setr were located within $1 \mathrm{~m}$ of the canister drift rib. In addition, six stressmeters were deployed in two rosettes in vertical boreholes adjacent to canister emplacement boreholes $\mathrm{CEH03}$ and $\mathrm{CEH} 09$. Details concerning the positioning and installation of all stressmeters are reported by Abey and Washington (1980). A single Type K thermocouple was positioned with each set of three stressmeters to provide temperature data to compensate for the effects of thermal expansion.

The initial set of 18 stressmeters failed in service and were replaced with units featuring a new seal design (Patrick et al., 1981). Stainless steel end-caps were electron-beam welded in place to hermetically seal the center cavity of the stressmeters, which houses the vibrating wire. Details concerning the positioning and installation of the replacement units are provided in Patrick et al. (1982 and 1983) and Patrick et al. (1981).

Calibration. Three special investigations were conducted on the calibration characteristics of the IRAD vibrating-wire stressmeters. An in-house study by Abey and Washingtori (1980) focused on techniques to reliably install a stressmeter in such a way that its calibration coefficient was known. Depending on borehole conditions, the initial preload decreased varying amounts when the installation tool was released. This study found that the calibration coefficient was directly related to the preload on the stressmeter.

IRAD Gage, Inc. was contracted to perform a second, broader series of laboratory calibration studies that focused on the behavior of vibrating-wire stressmeter in Climax granite at elevated temperatures (Dutta, Hatfield, and Runstadler, 1981). A test program was developed to study nine important factors that influence stressmeter response: test block size, stressmeter stiffness, gauge reproducibility and hysteresis, gauge preload, initial stress field, platen geometry, platen orientation, elevated temperature, and rock anisotropy. Many of these tests were conducted under uniaxial, biaxial, and triaxial loading conditions. In addition to improving our basic understanding of the stressmeter response to a variety of test conditions, the results of these studies were used to develop the algorithm for data reduction and interpretation. These results are summarized below.

1. Blocks of aluminum, Barre granite, and lucite were used in this study to examine the effect of sample size. Although sample width was constant at $250 \mathrm{~mm}$, the height-to-width ratio varied from 1.0 to 1.5 or 2.0. For the three materials tested, the influence of sample size on stressmeter sensitivity was $7.3,3.1$, and $1.1 \%$, respectively.

2. Stressmeter stiffness studies revealed that the LLNL gauge, plated with electroless nickel, had a stiffness of $1.29 \times 10^{7} \pm 1 \% \mathrm{~N} / \mathrm{cm}$, whereas the standard VBS-1HT had a slightly lower stiffness of $1.24 \times 10^{7} \pm 3 \% \mathrm{~N} / \mathrm{cm}$.

3. Gauge reproducibility was investigater under two conditions: a single setting with multiple-load cucles and a multiple setting with a single-load cycle. For all materials tested, a zero shift was noted between the first and second cycles. This zero shift (expressed as a percentage of the maximum stress change 


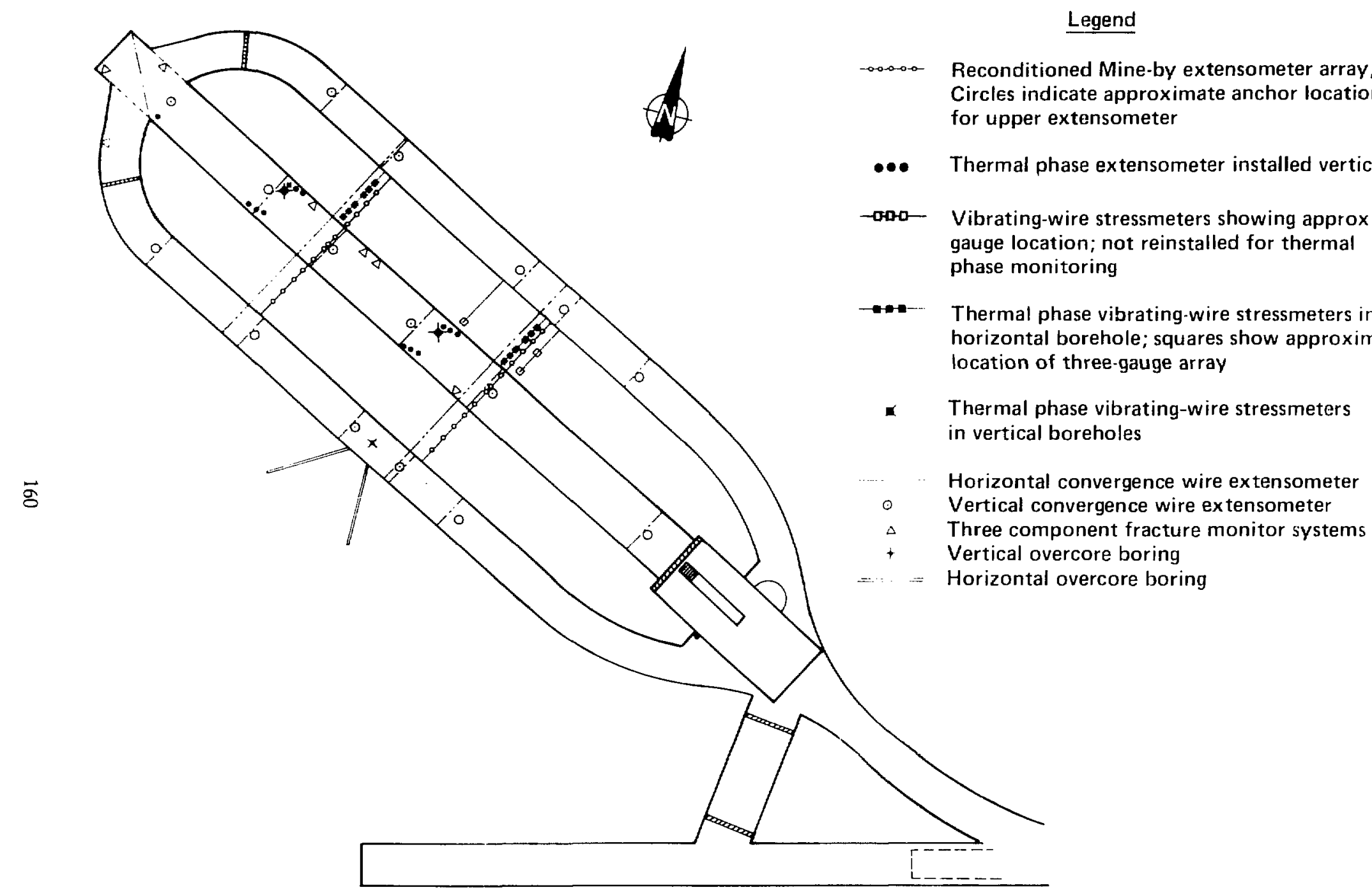

Figure 9-9. Location of thermal phase instrumentation (after Patrick, Rector, and Scarafiotti, 1984). 


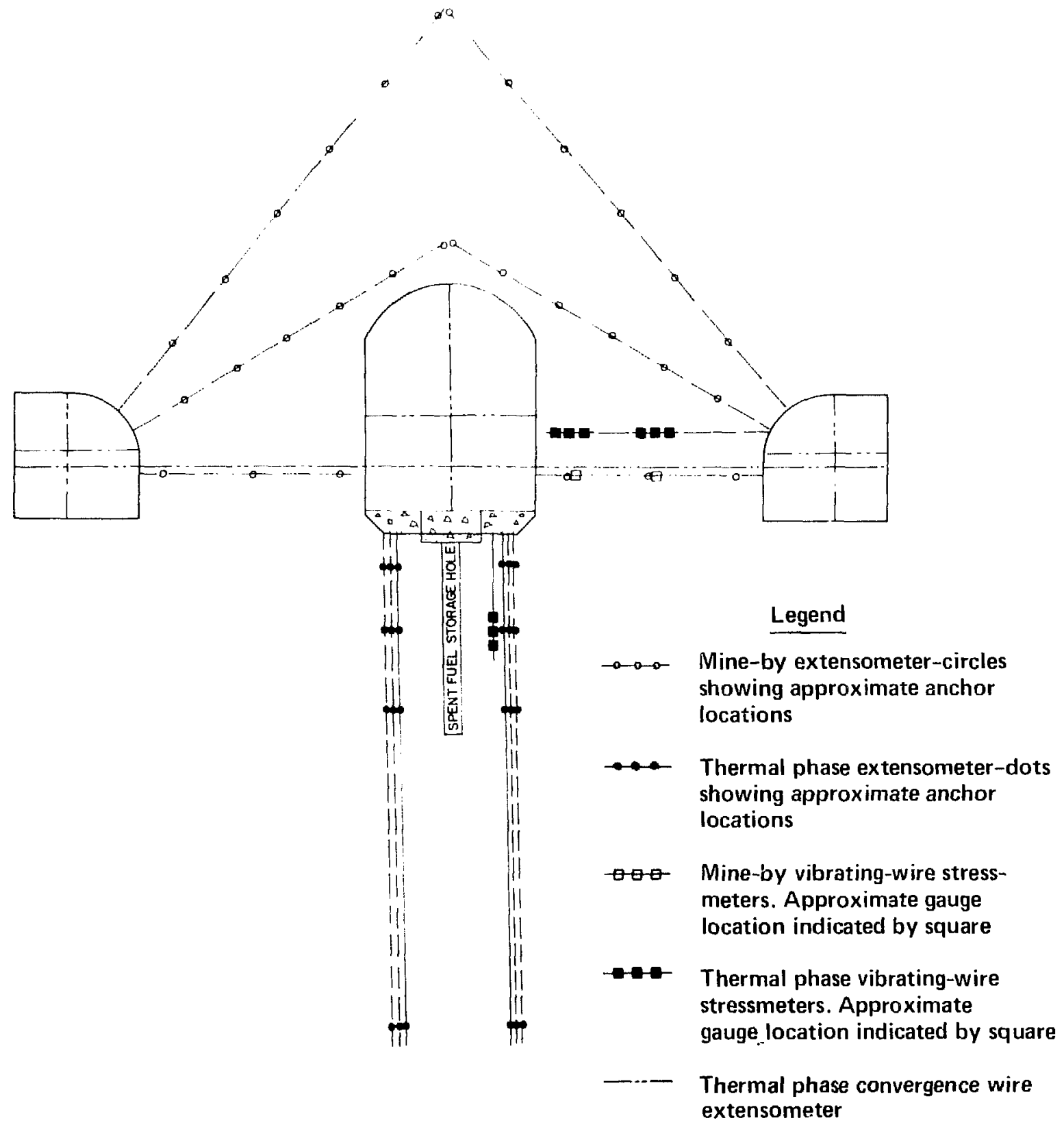

Note: lines dashed when borehole is out of the plane of the cross section

Figure 9-10. Cross section showing thermal-phase and Mine-by instrumentation arrays (after Patrick, Rector, and Scarafiotti, 1984).

in the wire) was $18.3,17.5$, and $7.06 \%$ for Climax granite, Barre granite, and alumirum, respectively. It appears that this zero shift was a result of the stressmeter "bedding in" on the first cycle because, for later cycles, the shift was almost nonexistent.

4. Gauge preload effects were observed at low preload values, but the sensitivity of the gauge was nearly constant for preloads of 175 units or more. 
5. The influence of initial stress field on gauge response was determined to be negligible.

6. Tests in lucite and alu minum indicated that the hard rock (HR) platen resulted in markedly smaller (in fact, negligible) variations in the sensitivity factor as a function of stress than whien soft rock and modified soft rock (SR and MSR) platens were used.

7. Theory shows that the ratio of gauge sensitivity to loading parallel to the wire compared to loading perpendicular to the wire should be -3.00 . However, test results indicated that the actual ratio varied from -2.84 to -3.28 , depending on stress level.

8. The influence of temperature is probably the most critical aspect of gauge response as it relates to the SFT $-C$. Changes in temperature were found to simply cause an offset in stressmeter reading by a tactor $1.55 \Delta \mathrm{t}$. For the range of temperatures experienced at the SFT $-\mathrm{C}$, changes in stressmeter sensitivity with increasing temperature were negligible.

9. Tests in three slabs of Climax granite revealed a fairly significant anisotropy ( 11 to $27 \%$ ) for different stressmeter orientations. This may be the result of preferential orientation of healed geologic fractures and feldspar phenocrysts in the rock slabs.

The first two calibration studies made it clear that the response of a stressmeter was a unique function of the local rock conditions and installation process. Since the stressmeters have no provision for in situ calibration, we developed an experimental approach to retrieve the gauges while they were still encased in a core of rock for subsequent laboratory calibration (Mao, 1984).

Each rosette of three stressmeters was retrieved by overcoring with a nominal 0.25 -m-diameter diamond-impregnated bit. Only 6 of the 18 stressmeters were successfully retrieved because of problems associated with the geological structure and the drilling technique. Once the large-diameter core was received at the laboratory, it was overcored with a nominal 0.15 -m-diameter bit to obtain concentricity with the 38-mm-diameter borehole containing the stressmeters.

The retrieved stressmeters, still encased in the section of rock in which they were installed, were calibrated under uniform biaxial compression. Mao (1984) showed that the sensitivity factor fur a particular stressmeter installation may vary widely from the nominal value obtained during conventional laboratory calibration. The importance of accurately knowing the sensitivity factor is discussed below.

Error Analysis. The study by Mao (1984) indicated that variations in the gauge constant A, which are caused by unique gauge-rock interactions, were the most significant source of error in the stressmeters. Gauge-to-gauge variations were small (when the gauge was tested independent of the rock) and gauge sensitivity and stability were excellent -0.1 to $1.0 \%$ (Patrick et al. 1982). Likewise, errors in temperature readings of $0.14^{\circ} \mathrm{C}$, as developed in Sec. 9.4.2. produced stressmeter errors of $0.019 \mathrm{MPa}$, a trivial quantity compared with anticipated magnitudes of stress changes on the order of several MPa. On the other hand, differences between the assumed A values and those reported by Mao (1984) produced large errors in calculated stress changes (Table 9-6).

This analysis highlights the need to obtain reliable post-test calibrations of the stressmeters while they are still encased in the same volume of rock as in the field.

Table 9-6. Errors introduced by differences between assumed and measured calibration constants for six vibrating-wire stressmeters (after Patrick, Rector, and Scarafiotti, 1984).

\begin{tabular}{cccc}
\hline $\begin{array}{c}\text { Instrument } \\
\text { license plate }\end{array}$ & $\begin{array}{c}\text { Assumed } \\
\text { "A" value }\end{array}$ & $\begin{array}{c}\text { Measured } \\
\text { "A"rvalue }\end{array}$ & $\begin{array}{c}\text { Percentage } \\
\text { error }\end{array}$ \\
\hline NSG231 & 1.6 & 0.99 & +38 \\
232 & 1.6 & 1.30 & +19 \\
233 & 1.8 & 2.85 & -58 \\
N5G244 & 1.6 & 2.42 & -51 \\
245 & 1.6 & 2.34 & -46 \\
246 & 1.8 & 2.51 & -39 \\
.- Based on data from Patrick, Cartson, and Rector (1981). \\
"Based on data from Mao (1984).
\end{tabular}


Reliability. The original set of vibrating-wire stressmeters began failing a tew months after they were installed in March 1980, with the onset of failure marked by an erratic output signal. The earliest failures were noted in the CSG-series instruments, which experienced the thermal pulse that accompanied spentfuel emplacement much sooner than the NSC;-series instruments. Thermal time constants for these positions were 12.5 and 240 days and the mean times to failure were 114 and 352 days, respectively.

Although we have defined failure here in terms of erratic gauge behavior, it is quite possible that the stressmeter data were incorrect by some amount for an unknown time period before the onset of erratic behavior. Direct inspection of the wires determined the failures to be caused by rusting of the vibrating wires (Patrick et al., 1981). The erratic output signal was apparently generated when rust particles on the wire critically damped the vibrations. Before the critical damping, however, the wire was increasing in mass as a result of rust (Patrick et al., 1981). This mass loading would tend to decrease the vibrational frequency of the wire, which would be interpreted as an increase in rock stress. Since an actual increase in stress was anticipated based on rock response calculations, it is impossible to discern what portion of the observed gauge response w'as due to actual stress changes in the rock and what was due to mass loading of the wire.

Under independent funding, IRAD subsequently designed and tested a new version of the gauge, hermetically sealed by thin, stainless-steel cups welded to the gauge body around the perimeter of the hole at the ends of the gauge. Because welding is done by electron beam, the interior of the gauge is a hard vacilum, thereby preventing any moisture irom entering during assembly.

Nine of these new gauges were installed at the SFT-C on June 16 and 17, 1981, and the remaining nine were installed on October 15-27, 1982. With the assistance of a borescope, the location and orientation of each gauge was precisely selected to avoid rough spots, fractures, and residual foam on the wall contact areas. Locations and initial readings of the replacement gauges are provided by Patrick et al. (1981) and Patrick et al. (1983).

With two exceptions, the 18 replacement stressmeters functioned reliably. Stressmeter number NSG242 occasionally returned erratic output signals for about 3.5 months following its installation in October 1982, and NSG243 exhibited sinilar behavior throughout its 1-year deployment period. Most readings were reliable for both gauges. The cause of the erratic readings was not determined.

\subsubsection{USBM Borehole Deformation Gauges}

U.S. Bureau of Mines (USBM) borehole deformation gauges were used at the SFT-C to obtain measurements of the in situ state of stress (Chapter 4). These are relatively short-term measurements that do not require that the gauges be subjected to harsh environments for extended periods of time, such as occurs for stress-change monitoring.

When a "negative hysteresis" behavior was observed during a major campaign of in situ stress measurements at the SFT-C (Creveling et al., 1984), Ganow (1985) undertook a study to determine the nature, magnitude, and possible causes of the phenomena. To accomplish this, he developed a "microindenter" apparatus that could be used to calibrate the deformation gauge by depressing individual cantilevers either directly or through the compound button, which in field use contacts the borehole wall.

Originally detected while using the standard calibration fixture, the negative hysteresis was large compared with the strains typically recorded during stress measurements (Fig. 9-11). Ganow (1985) suggested three possible causes of the hysteresis (described in detail in the referenced report):

- Energy stored in the sensor piston and O-ring seal system that was released primarily during the first increment of unloading.

- Interaction between the calibration micrometer and the piston/button that would tip and rotate the piston on the USBM gauge cantilever.

- Differential shearing motion between the piston and cantilever as the indentation-relaxation cycle takes place.

The microindenter test apparatus (Fig. 9-12) was designed to hold the USBM gauge and to provide an accurate means of depressing the gauge cantilevers in a nearly unidirectional manner. Although a micrometer was provided to establish the approximate displacement of the gauge cantilever, the actual displacement measurement was made by a modified GCA Corporation Model VLM 200 Laserruler. All measurements were made in the LLNL's environmentally controlled precision machining shop.

Microindenter measurements over the full range of the USBM gauge produced a mean hysteresis loop with peak values on the order of $125 \mu \mathrm{in}$. In ., considerably smaller than were cobserved in the ficld using the 


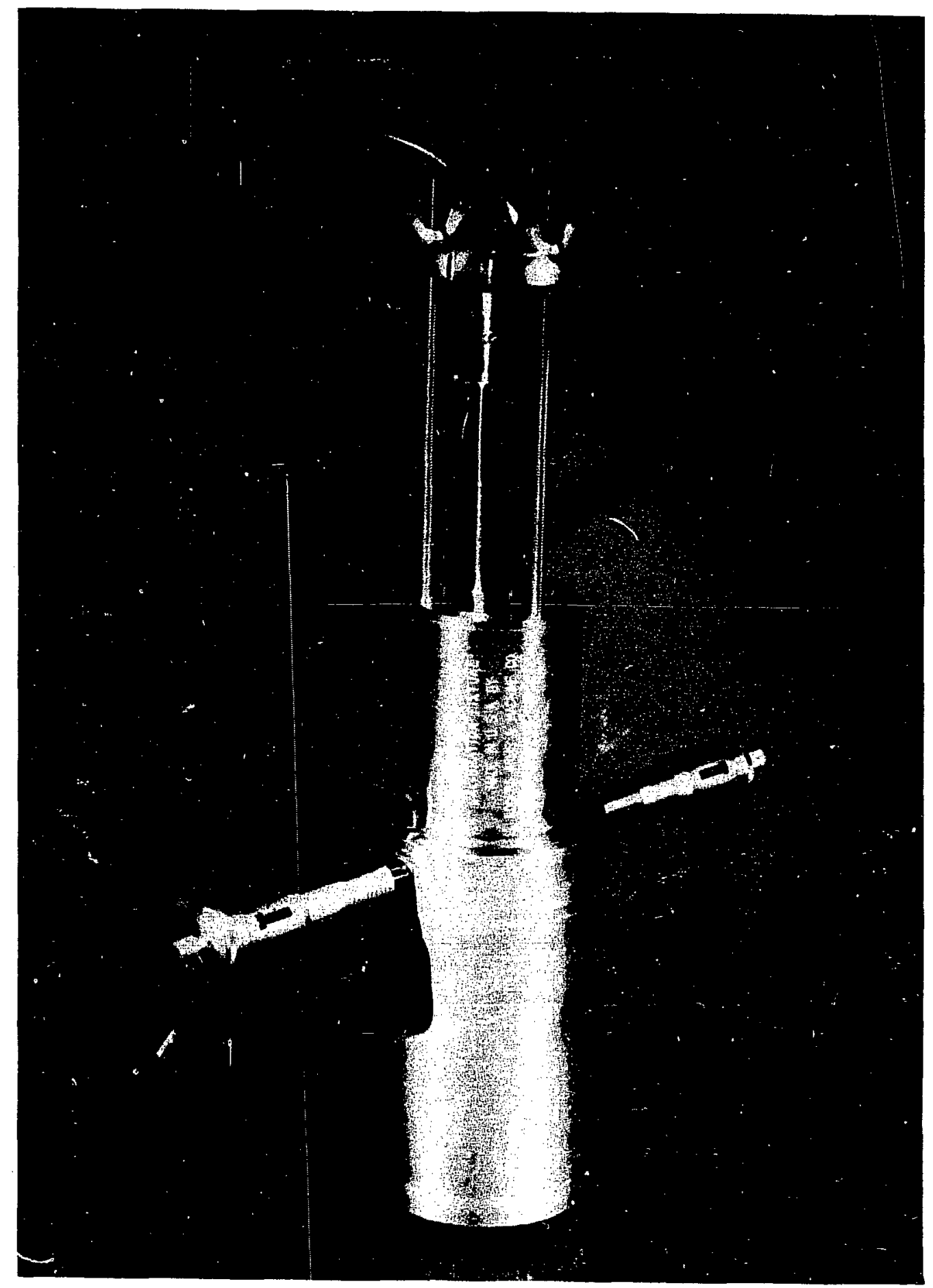

Figure 9-11. The standard U.S.B.M. borehole deformation gauge calibration fixture with the horizontally opposed end bearing micrometers (after Ganow, 1985). 


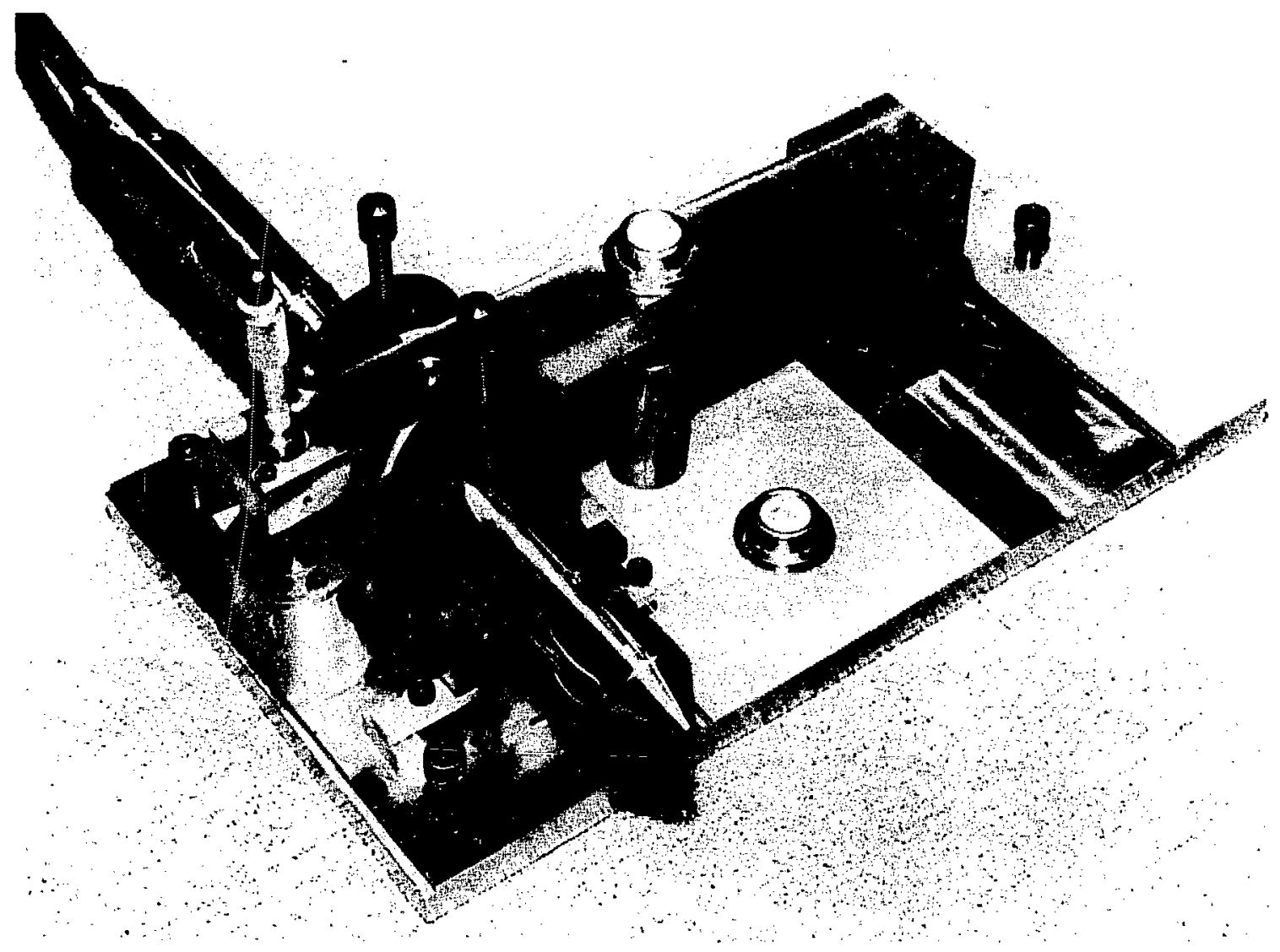

Figure 9-12. Photograph of "microindenter" apparatus showing position of a USBM gauge for calibration (after Ganow, 1985).

standard calibration fixture (Fig. 9-13). Measurements restricted to 1000- $\mu$ in./in. ranges centered on the upper, middle, and lower quarter points of the full ranges showed markedly better results. As indicated in Fig. 9-14, hysteresis is less than $3 \%$ of the range.

Ganow concluded that the effect of hysteresis on in situ stress measurements may range from about $7 \%$ where total strain relief is small, to as little as $1.3 \%$ where larger strains associated with the maximum stress are recorded. His data also suggest that the mechanism for hysteresis is differential motion between the button/piston and the cantilever. These motions are caused by a combination of the piston tipping and its tip progressively slipping outward on the cantilever from its initial point of contact.

\subsubsection{CSIRO Overcore Cells}

The in situ state-of-stress determinations at the SFT-C also used CSIRO inclusion-type overcore cells (Chapter 4). Because these cells contain a total of nine strain gauges and only six are used to determine the complete stress tensor, it is possible to calculate a "best fit" stress tensor.

Creveling et al. (1984) ieported significant discrepancies between the CSIRO and USBM results, with the former being consistently about $30 \%$ lower than the latter. Because no subsequent use of the overcore cell was planned and the SFT $-\mathrm{C}$ was coming to a close, no specific studies of the behavior of CSIRO overcore cells were undertaken. 


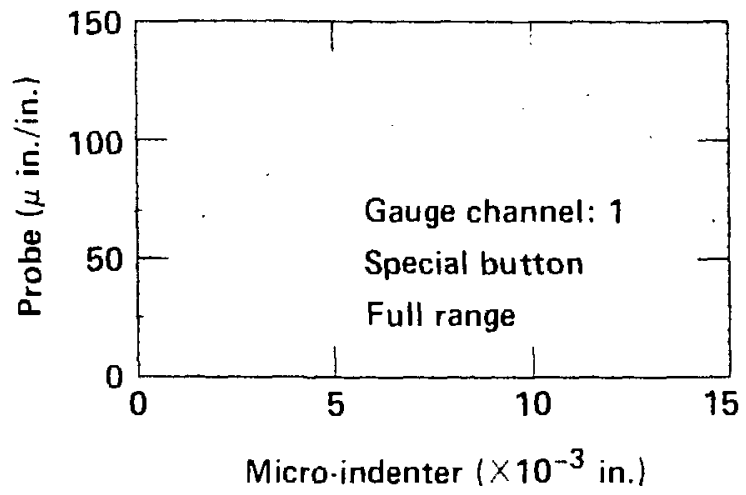

Figure 9-13. Mean hysteresis loop with \pm standard deviation values (shown as dashes) for BMG channel 1 for the special "fitted" button used in place of the standard O-ring supported button. Other test conditions are as shown (after Ganow, 1985).
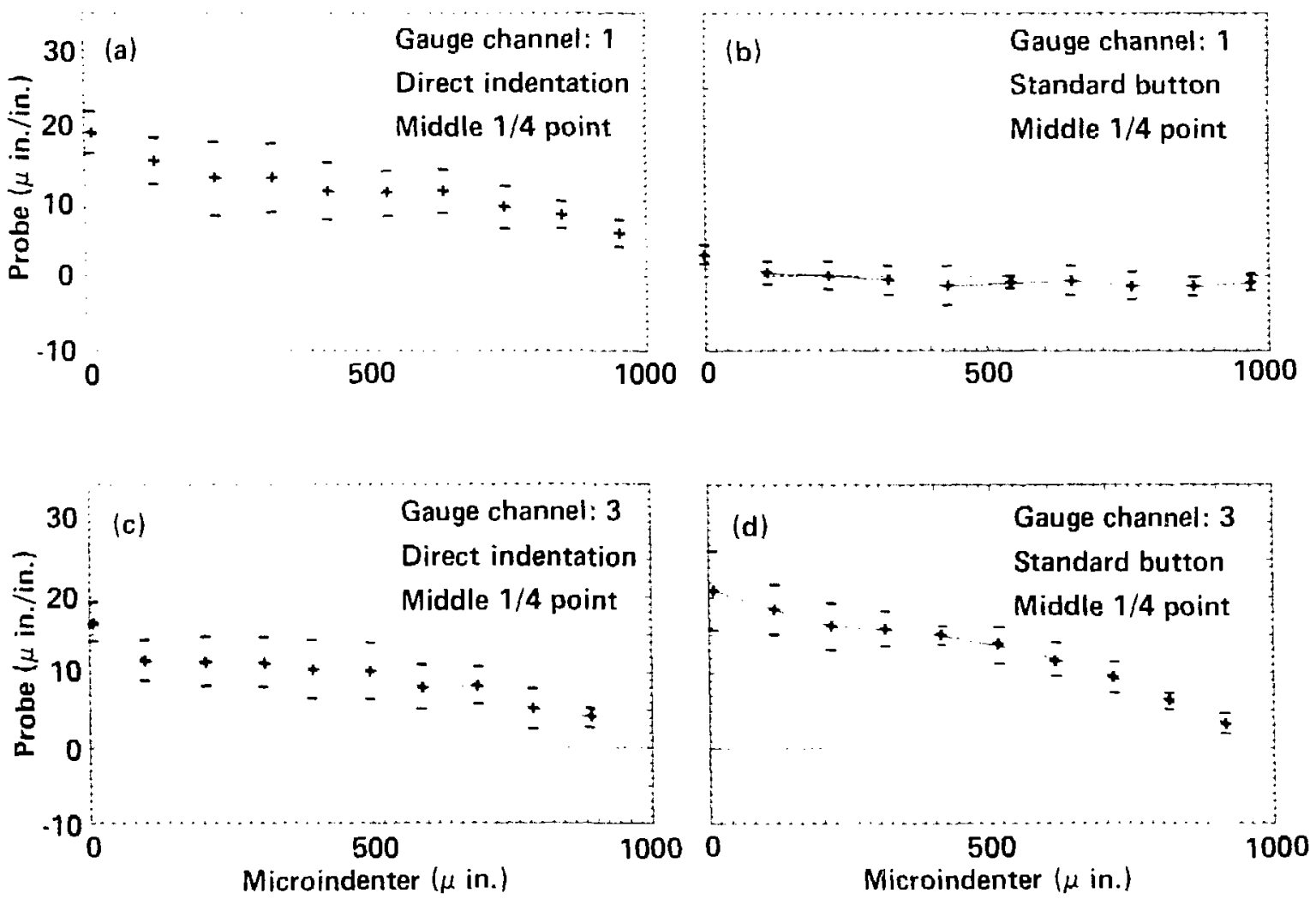

Figure 9-14. Mean hysteresis loop with \pm standard deviation values for standard button on cantilever: (a) and (b) = No. 1 (C-1) BMG channel 1; (c) and (d) = No. 3 (C-3) BMG channel 3. Data are \pm 500 MS about the middle one quarter point of the BMG dynamic range (after Ganow, 1985). 


\subsection{Displacement Instrumentation}

To measure the renponse of the rock mass. four types of displacement-measuring devices were deployed. Borehole rod extensometers and convergence-wire t'xtensoneters were used to measure displacements over relatively long distances within the rock mass and across underground openings, respectively. Fracture monitors recorded the responses of discrete geological features. Following spent-fuel retrieval, borehole closure monitors were used to measure displacements within the spent-fuel storage boreholes. Data from each of these types of instrumentation are presented and discussed in the context of calculational results in Chapter in.

\subsubsection{Borehole-Rod Extensometers}

Commercially available multiple-point borehole extensometers (MPBX) were used as the principal instruments for measuring relative displacements within the rock mass at the SFT-C. Two series of extensometers were deploved, both of which were manufactured by Terrametrics Co., Golden, Colorado.

The Mint-by instrument (MBI) series consisted of four sets of three- and six-anchor units installed trom the north and south heater dritts of the SFT-C (Figs. 9-9 and 9-10) and were originally used to measure the relative displacements that took place as the canister drift was excavated (Wilder and Patrick, 1980, and Heuze et al., 1981). The MBI-series extensometers were hydraulically anchored in 76-mmdiameter (NX) boreholes using a standard burst tube and check-valve inflation system. Only the collar stabiizer tube was grouted; the rest of the borehole remained open. The connecting rods were carbon steel and were enclosed as a group in a silicone-rubber-sheathed flexible metal conduit. Following the Mine-by experiment, the head assemblies were refurbished, the associated linear potentiometers were recalibrated, and the MBI-series extensometers were returned to service for the heated phase of the SFT $-C$

During the heated phase, the MBI-series extensometers were augmented by a second series grouped in four sets to measure near-field thermal effects in the canister storage drift. These units were called the GiE-serie's where the " $\checkmark$ " is A, B, C, ur D, depending on which set is being described (Figs. 9-9 and 9-10). The GAE and GDE units each comprised one four-anchor MPBX, whereas the GBE and GCE units each comprised two subsets of three four-anchor MP'BXs located on either side of the drift centerline. The GxEseries extensometers were also hydraulically anchored but used a nitrogen-over-hydraulic-oil-pressure maintenance svstem $t(1)$ ensure adeyuate initial inflation and subsequent pressures during the heated phase of the test (Brough and Patrick, 1982). These units were grouted along their entire length using a grout formulated to expand slightly as it cured. Th allow for differential expansion and shear between extensiometer components, grout, and rock, a ring of closed-cell foam was attached about $0.3 \mathrm{~m}$ above and below each hydraulic anchur. Because temperatures would reach 60 to $65^{\circ} \mathrm{C}$. Superinvar connecting rods were used on the GxE-series extensometers. The connecting rods were enclosed as a group in a siliconerubber-sheathed thexible metal conduit.

For their initial deployments, both the MBI- and GxE-series extensometer transducers were Bourns Model 5184 rectilinear potentiometers. The refurbished MBI units also used these transducers. The potentiometer shafts were attached to the extensometer connecting rods with threaded fittings and lock nuts.

The GxE-series extensometers experienced severe transducer failures shortly after deployment for the heated phase (Patrick et al., 1981). As a result, four types of transducers were installed to evaluate how each type performed. Three extensometers were equipped with each type for a total of 12 of each transducer type. The transducers used in this evaluation were the Bourns Model 5184 rectilinear potentioneter, Vernitron Model 113 rectilinear potentiometer, Schaevitz Model 250 HCD LVDT, and Kaman Sciences Model KD-2310-6U electrumagnetic proximeter. With the exception of the proximeter, which is a noncontacting device, the tranducers were coupled to the connecting rods through a spring-londed ball resting un a machined flat surface. Fach set of four transducers of each type was subjected to one of thres environments: sealed head assembly connected to sealed burehole, head assembly continuously flushed with a small flow of dry nitrngen, and head assembly ventilated of potentially harmful vipors with a slight vacuum.

Laboratory Calibrations. All tranducers were laberatorv-calibrated before installation to estahlish that the individual transducer was operating within specifications. Post-lest laburaterv calibrations were used to medsure changes in transducer sensitivits, linearits, and hesteresis characteristics. Because there was no means ost reliably establishing a "mechanical aro" for the transducer trom which one could deter-

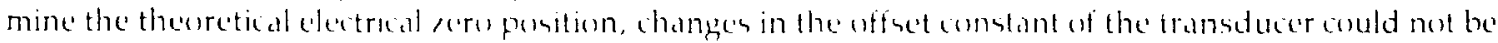


determined. Significant changes weurred in the semsitivity of each type of transducer with the performance of the electromagnetic proximetern clearly being pourer than that of the potentiometers and the linear, variable differential transformers (LVDTS).

The distribution of errors resulting from changes in transducer sensitivity is shown in histugram form in Fig. 9-15. Note that the distribution is fairly symmetric around zero, and that about $80 \%$ of all errors fall within a $\pm 50-\mu \mathrm{m}$ range. Errors of this magnitude are a relatively small contribution to the total system errors for the extensometers, as discussed below in "Error Analysis."

In Situ Calibrations. Because MPBXs are relatively complex mechanical systems, we also performed field calibrations. The manufacturer's recommended procedure was followe for all pretest field calibrations of MBI- and GXE-series units. These calibrations were performed in 1- $\mathrm{m} \mathrm{m}$.teps over a range of $5 \mathrm{~mm}$ for the potentiometers and in $0.5-\mathrm{mm}$ steps over a range of $4 \mathrm{~mm}$ for the elecir.magnetic proximeters and the LVDTs (Brough and Patrick, 1982, and Patrick et al., 1981).

A new device was develuped to facilitate field calibration of borehole rod extensometers. Based on a concept developed by researchers at the Lawrence Berkeley National Laboratory for studies at the Stripa Mine in Sweden (DuBuis et al., 1981), our calibrator incorporated several improvements, including a motor drive, microprocessor control, and independent transducers that provided reference data for the calibratiuns. The calibrator buth automated the calibration process and circumvented the need for lowering the head assembly onto step blocks. Hysteresis and stick-slip behavior were mure readily studied with the system's truly bidirectional calibration capability.

Two types of error analyses were performed using the field calibration data. First, an end-point (or terminal-point) analysis was used to determine the range of errors that occurred during the pre-and posttest calibrations. Second, pre- and pust-test calibration results were examined to detect changes in transducer sensitivity that would introduce errors in displacement readings.

The end-point analysis was a convenient technique for examining the extreme errors that occurred over the range of the field calibration. Note that this calibration range corresponded to the range of actual displacements recorded in the field rather than the full range of the transducer. While all transducers performed quite well in the calibrations, the LVDTs exhibited less variability than the potentiometers during both the pre- and pust-test calibratiuns. On the other hand, the electromagnetic proximeters were mare variable from unit to unit and also had a larger mean error. The distributions of the pre- and post-test

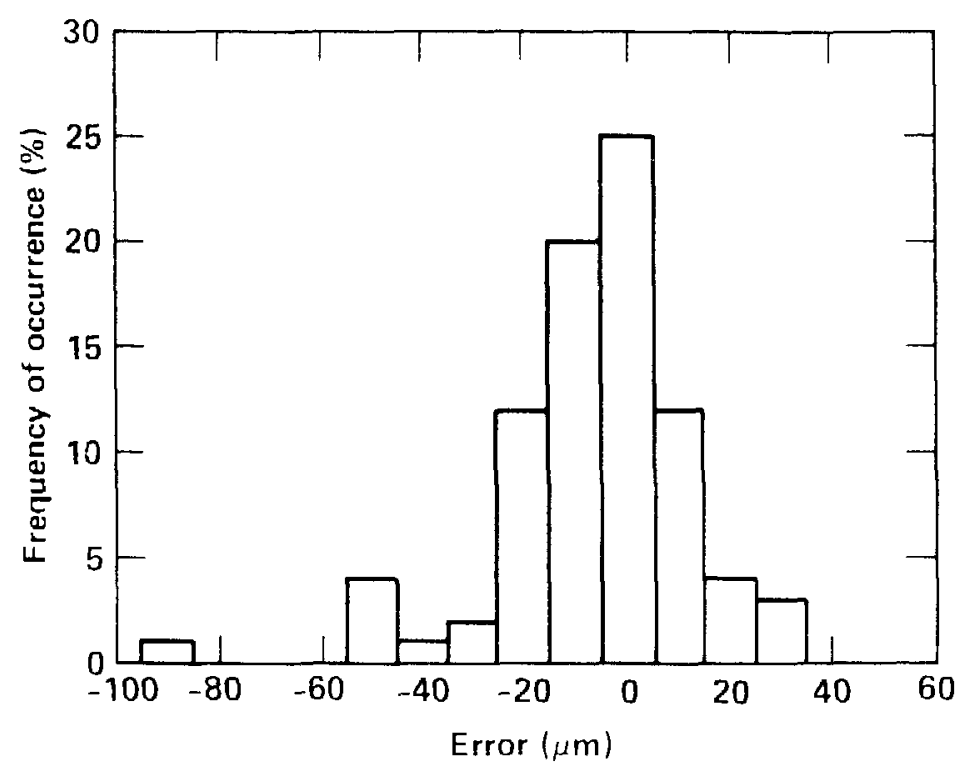

Cigure 9-15. Distribution of errors measured in laboratory calibration of GxE- and MBI-series extensometer transducers. Errors result from changes in transd ucer sensitivity between pre-and post-test calibrations (after Patrick, Rector, and Scarafiotti, 1984). 
calibration errors showed a tight grouping near the zero point, and were rather flat but symmetric beyond $\pm 5 \mu \mathrm{rn}$ (Fig. 9-16). Only subtle changes were evident between the pre- and post-test distributions of errors. About $74 \%$ of the pretest errors and $75 \%$ of the post-test errors fell within a $\pm 50-\mu \mathrm{m}$ window.

As was the case for laboratory calibrations, it was not possible to determine changes in the offset constant because there was no way to establish a zero value for the transducers. However, we could determine the errors in displacement readings generated by changes in transducer sensitivity. Once again, these errors were evaluated from changes in slope over a range of $5 \mathrm{~mm}$. The measured changes in extensometer sensitivities and the errors associated with those changes were quite large, as indicated in the distribution of field calibration errors shown in Fig. 9-17. These errors were larger and had a different-shaped distribution than those observed in laboratory calibrations (Fig. 9-15).

It appears, then, that the errors associated with changes in extensometer sensitivity observed in the field calibrations were not solely the result of changes in transducer sensitivity. Nor were they the result of

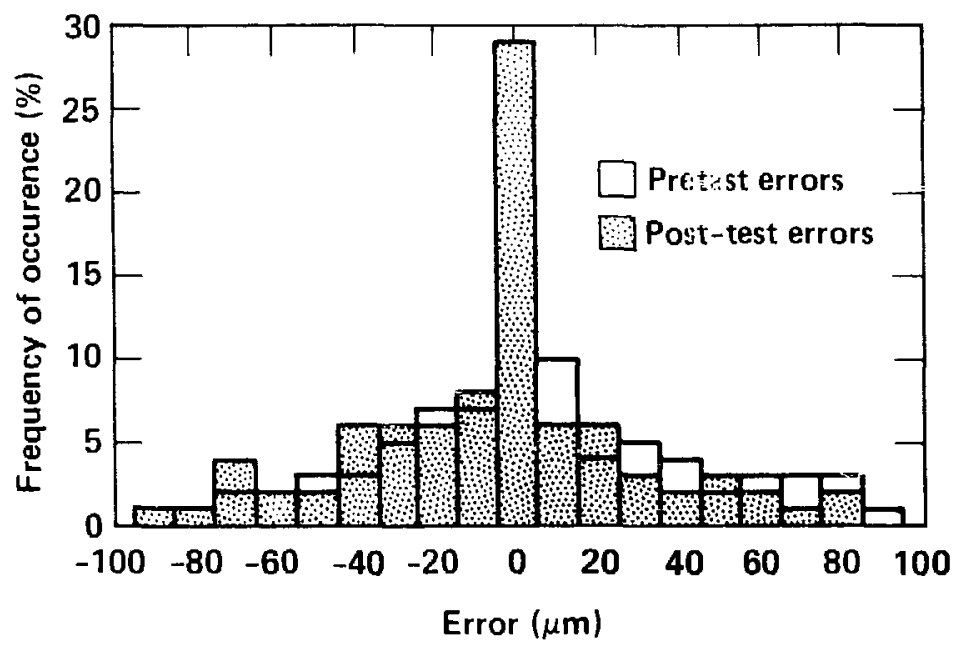

Figure 9-16. Distribution of errors measured in pre- and post-test field calibrations of borehole extensometer transducers. Data represent extreme errors calculated from an end point error analysis (after Patrick, Rector, and Scarafiotti, 1984).

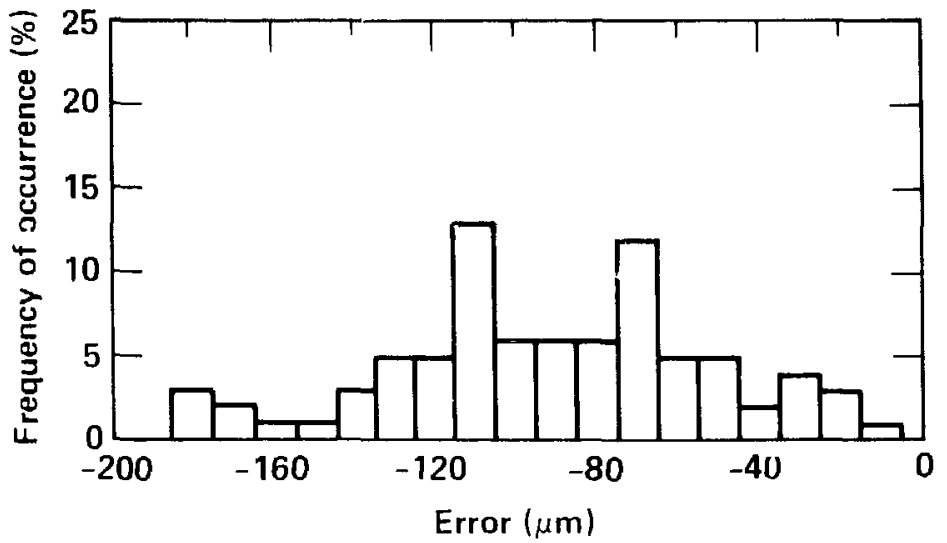

Figure 9-17. Distribution of errors measured in field calibrations of GxE- and MBI-series borehole extensometers. Errors result from changes in transducer sensitivity between pre- and post-test calibrations (after Patrick, Rector, and Scarafiotti, 1984). 
a difference in the errors generated during the pre- and post-test calibrations, since these error distributions are nearly identical (Fig. ". Ih). We hy pothe'size tw' plausible sumes of the observed changes in sensitivity. First, rust on the extensometer comnecting rods may have prevented then from moving freely through the collar stabilizer tube and head assembly during the post-test calibration. The net result would he a smaller transducer output for a given (apparent) displacement. The transducer would appear to decrease in sensitivity, as was ubserved. The potential for this problem was recognized and all extensometers were exercised over the range of the calibration before any data were acquired. How'ever, minor problems may still have occurred. Second, the differences in extensometer sensitivity may have been an accurate reflection of the differences between the two calibration procedures. No explicit cause of such differences has been identified to date, however.

Error Analysis. As described above, three types of transducers, each with different operating characteristics, were deployed un borehole rod extensometers: potentioneters. LVDTs, and electromagnetic proximeters. Connecting rods were fabricated from Superinvar for near-field GxE-series units, or carbon steel, for MBl-series units. These variations were present in four combinations, requiring an error analysis for each type.

Table 9-7 displays maximum calculated errors tor each of the four combinations of transducers and rod materials, and for three typical rod lengths for cach of these four combinations. The effects of time-varying temperatures directly and indirectly introduced the most significant errors. Our relatively pour knowlecige of and the high variability in the coefficient of thermal expansion of the rod materials introduced errors for all four combinations. Where carbon steel rods were used, significant errors were also generated as a result of the scheme used to approximate rod temperatures. In addition, the thermal sensitivity of LVDTs and proximeters was a major contributor to the total error. Note that the "calibration coefficient" errors shown in this table do not include the errors associated with changes in transducer sensitivity that were recorded during field calibrations, but rather are the calculated values (Patrick, Rector, and Scarafiotti, 1984).

Reliability. Three classes of problems were identified with the borehole rod extensometers: (1) transducers on the GxE series units deployed in the canister storage drift failed during use; (2) the GxE Superinvar connecting rods experienced stress-corrosion tracturing; (3) the stability of some of the MBl-series extensometer anchors were determined to be inadequate or marginally adequate. These latter units were inflated with the burst-line technique. In addition, a variety of minor miscellaneous problems occurred during the test period. These problems are summarized below.

Table 9-7. Calculated maximum trors for borehole rod extensometers (after Patrick, Rector, and Scarafiotti, 1984).

\begin{tabular}{|c|c|c|c|c|c|c|c|c|}
\hline \multirow{2}{*}{\multicolumn{2}{|c|}{$\begin{array}{l}\text { Extensometer series, } \\
\text { transducer type, and } \\
\text { rod length }(\mathrm{m})\end{array}$}} & \multicolumn{7}{|c|}{ Error source and magnitude $(\mu \mathrm{m})$} \\
\hline & & $\begin{array}{l}\text { Calib. } \\
\text { coef. }\end{array}$ & $\begin{array}{l}\text { Excit. and } \\
\text { signal }\end{array}$ & $\begin{array}{l}\text { Component } \\
\text { temp. }\end{array}$ & $\begin{array}{l}\text { Coeff. of } \\
\text { expansion }\end{array}$ & $\begin{array}{l}\text { Temp. coeff. } \\
\text { of transducer }\end{array}$ & $\begin{array}{l}\text { Component } \\
\text { length }\end{array}$ & RSS \\
\hline \multirow[t]{3}{*}{ GxE, potentiometer } & 2 & 1.3 & 0.02 & 1.9 & 13.2 & 0 & 0.03 & 13.4 \\
\hline & 5 & 1.3 & 0.02 & 1.9 & 33.0 & 0 & 0.03 & 33.1 \\
\hline & 13.5 & 1.3 & 0.02 & 1.9 & 89.1 & 0 & 0.03 & 89.1 \\
\hline \multirow[t]{3}{*}{ GxE, LVDT } & 2 & 2.5 & 0.01 & 1,9 & 13.2 & 106 & 0.03 & 107.3 \\
\hline & 5 & 2.5 & 0.01 & 1.9 & 33.0 & 106 & 0.03 & 111.5 \\
\hline & 13.5 & 2.5 & 0.01 & 1.9 & 89.1 & 106 & 0.03 & 138.8 \\
\hline \multirow[t]{3}{*}{ GxE, proximeter } & 2 & 2.6 & 0.02 & 1.9 & 13.2 & 53 & 0.03 & 54.7 \\
\hline & 5 & 2.6 & 0.02 & 1.9 & 3.0 & 53 & 0.03 & 62.5 \\
\hline & 13.5 & 2.6 & 0.02 & 1.9 & 89.1 & 53 & 0.0 .3 & 103.7 \\
\hline \multirow[t]{3}{*}{ MBI, polentiometer } & 1 & 1.7 & 0.02 & 24.8 & 9.9 & 0 & 0.78 & 26.8 \\
\hline & 5 & 1.3 & 0.02 & 24.8 & 49.7 & 0 & 0.78 & 55.6 \\
\hline & 15 & 1.3 & 0.112 & 24.8 & 149.2 & 0 & 0.78 & 151.3 \\
\hline$\cdot$ & $\cdots$ & & $\cdots$ & & & $\cdots$ & & $\cdots \cdots$ \\
\hline
\end{tabular}


Transducer Failures. Several episodes of failures of GxE-series extensometer transducers occurred. The onset of the first failures began about four months after the spent fuel was emplaced. lnitially, these tailures went undetected because the electrical signals were not erratic and the apparent displacements were reasonable in form and magnitude.

Two principal means were used to detect maltunctions of the linear potentiometers: measurement of total resistance and examination of output voltage time-series plots for breaks in trend (Patrick, Carlson, and Rector, 1981). Total resistance was outside manufacturer's specifications of $5 \mathrm{k} \Omega \pm 10 \%$ for 23 of the 56 transducers. The mean and standard deviation of time-to-tailure were 223 and 259 days, respectively.

We considered seven failure hypotheses in evaluating the failures. As documented by Patrick et al. (1981), the evaluation techniques included field resistance measurements, gas sampling, hygroscopy studies at low pressure and elevated temperature, microscopic textural inspections, and chemical interaction tests. Although these investigations led us to eliminate several possible causes of failure, we have not tound a totally satisfactory answer to the problem to date. The most plausible remaining hypothesis is that higher downhole temperatures caused the sealing agents to cure, producing chemical vapors that damaged the resistive elements. We found that venting the potentiometers by removi.g the head assembly cover appeared to curtail and possibly reverse the observed degradation.

Following these initial failures and evaluations, we bought replacement Bourns potentiometers and had them calibrated at the EG\&G-Atlas facility. About two weeks later, before fielding, a sample of the replacement units was checked for total resistance and found to be out of specification. In all, 21 of the 64 replacement units $(33 \%)$ tailed. Testing showed that these transducers remained linear, contrary to the nonlinear mode of failure observed in the units deployed in the field. Since none of these transducers was fielded, their tailures resulted in no direct loss of data.

At this time, we decided to revise our original decision to install only "off-the-shelf" instrumentation (Brough and Patrick, 1982) to correct the problem of the failed potentiometers. A period of instrument evaluation was planned for the remaining life of the SFT-C.

Four types of transducers were selected to replace the $48 \mathrm{GBE}$ - and GCE-series units, where all failures had occurred to that date. Schaevitz Model 25YHCD linear, LVDT were installed in GBE21x, GBE22x, and GBE23x; Bourns Model 5184 rectilinear potentiometers were reinstalled in GBE24x, GBE25x, and GBE26; Kamarı Model KD-2310-6U electromagnetic proximeters were installed in GCE21x, GCE22x, and GCE23x; and Vernitron Model 113 rectilinear potentiometers were installed in GCE24x, GCE25x, and GCE26x. The characteristics of the selected transducers are summarized by Patrick et al. (1981). Although each of the three alternates compares favorably in several ways with the original Bourns potentiometers, both the LVDTs and proximeters are temperature-sensitive.

During replacement operations all screw' couplings of potentiometer and LVDT shalts to rods were replaced by spring-loading the shaft against a flat, smooth, stainless-steel fitting attached to the rod to eliminate eccentric loading of the shafts. A stainless-steel sphere screwed onto the shaft provided a point contact against the stainless-steel, machined flat surface attached to the rod. The proximeter was a noncontacting device that used a 19-mm-diameter $\times 6.4$-mm-thick aluminum target attached to the rod

Another modification was to subject each of the head assemblies associated with the Bourns, Vernitron, Schaevitz, and Kaman transducers to three different environments. To produce the three test environments, the head assemblies were either (1) sealed with an O-ring on the cover of the head assembly; (2) sealed and flushed with dry nitrogen; or (3) sealed and ventilated of potentially harmful vapors with a small vacuum.

As an added precaution, all Vishay precision bridge completion resistors associated with linear potentiometers were replaced with hermetically sealed units. This change was implemented in response to two observed resistor failures (Patrick et al., 1981).

A few months after the second deployment, the Vernitron linear potentiometers began to fail. Two failure modes were exhibited. Whereas most units showed a slight rise in signal as a function of time followed by a precipitous fall, the others showed an abrupt rise, typically to full scale positive voltage, followed by a precipito us fall to a voltage of -2 to $-4 \mathrm{~V}$. For the latter cases, the signal was generally erratic. The mean and standari cieviations of time to failure were 210 days and 141 days, respectively. As with the original failures, we rannot be certain that data were reliable before the break in trend, which was used as the failure criterian.

Failure analysis for these units revealed that the resistive clements were severely fractured. In general, these fractures wert transverse to the length of the resistive element and appeared tooriginate on the outer 
edge of the element and propagate inward. Fracturing was most intense opposite the shaft end of the potentiometer and decreased to none near the center (wiper) location.

After the Vernitron potentiometers failed, they were replaced with Bourns potentiometers. The leading digit of the numeric code was changed to 4 to denote this series of transducers.

Anchorage Stability. Both the MBI- and GxE-series horehole extensometers used hydraulic bladder anchors that comprised sections of flattened copper tube welded along the ends and formed around a cylindrical mandrel. To ensure that the anchors were properly fabricater leak tests were performed before installation. A connecting rod was attached to the mandrel to provide a reference for displacement measurements. In the case of the MBI units, the anchors had an integral check valve that was used in conjunction with a hydraulic burst-line to inflate the anchors and, presumably, maintain anchor pressure after the inflation line burst. These units were not grouted in place. The initial inflation pressure was provided to the GxE anchors through high-pressure Bundiweld tubing, and the pressure was maintained with a nitrogen-over-hydraulic system (Brough and Patrick, 1982). As previously noted, these units were fullcolumn grouted.

Schrauf and Board (1979) reported problems associated with inflating the MBI anchors. Many of the hydraulic lines burst prematurely at about $1000 \mathrm{psi}(6.9 \mathrm{MPa})$, and the lin? associated with MBI 136 burst at about 500 psi (3.4 MPa).

As iloted above, the near-field (GxE-series) rod extensometers used a nitrogen-over-hydraulic fluid system in an effort to maintain stable anchor pressure. At approximately 1-month intervals, the pressure of each anchor was checked for conformance to a 1750- \pm 50-psi (12.1- $\pm 0.3-\mathrm{MPa})$ criterion. Nitrogen was added or vented to adjust the observed pressure to the acceptable range. Both pressure decreases and increases were observed. Pressure decreases may have been due to system leaks, continued deformation of the anchor in the borehole, or differential expansion of the borehole relative to the anchor. Pressure increases were generally thought to be due to thermal expansion of the hydraulic fluid and differential contraction of the borehole relative to the anchor.

Although all GxE unit anchors were successfully inflated to the 1750-psi (12.1-MPa) anchoring pressure, 27 of the $56(48 \%)$ exhibited pressure losses as the test progressed. Nearly $80 \%$ of the leaks occurred durine the first yea: of the test when significant heating of the rock mass was in progress (Fig. 9-18). There is $r$ idence that these pressure losses adversely affected data quality. This is attributed to the fact that all ancnors were subjected to proper inflation pressures for a minimum of two months before leaks occurred.

A positive-displacement hydraulic system was designed, fabricated, and deployed to pull-test each individual rod of the MBI- and GxE-series extensometers after the post-test calibrations were completed. These puil-test results were used to confirm that the anchors were stable during the SFT-C. To provide an average displacement value at each load increment, three linear potentiometers were positioned at 120-degree azimuthal orientations at a common radial distance from the rod axis. The reference for the potentiometers was attached directly to the individual rod, so slip of the coupling, which was being pulied by the hydraulic ram, would not be measured. Load was measured by a calibrated load cell located between the hollow hydraulic ram and the reaction plate of the test fixture. Each rod and anchor assembly was subjected to four cycles of loading and unloading. The test plan required a minimum load of $300 \mathrm{lb}$ ( 1.3 $\mathrm{kN})$ [6100 psi (42.1 MPa) rod stress], bu't mosi tests on GxE-series extensometers were conducted to $900 \mathrm{lb}$ $(4.0 \mathrm{kN})$ to examine anchor and rod integrity at higher loads.

Anchor slip was interpreted by comparing the measured stiffness of the system $\mathrm{K}_{\mathrm{a}}$ with the calculated rod stiffness $K$. The value of $K_{a}$ was obtained graphically as the slope of the load vs displacement plot at the nominal rod tension of $100 \mathrm{lb}(0.4 \mathrm{kN})$ for the first loading of the rod and anchor system. The value of $\mathrm{K}$ was calculated as $K=E A / L$, whrere $E$ is the Young's modulus of the rod, $A$ is tile rod cross-sectional area, and $L$ is the rod length. Nominal values of $E$ and $A$ and measured values of $L$ were used in these calculations.

The ratio of $\mathrm{K}_{\mathrm{a}} / \mathrm{K}$ was near unity for most anchors of the MBI-series extensometers, and load-vsdisplacement curves were linear, indicating that the anchors were stable under the nominal force exerted on the rods during the active phases of testing at the SFT-C. Furthermore, the load at which the anchors slipped (as noted by a change in slope of the load-vs-displacement curve) was typically several times the nominal force. In only five cases was nonlinear behavior observed at loads less than $100 \mathrm{lb}(0.4 \mathrm{kN})$. In addition, units MBI-022, $-036,-131$, and -132 showed anchor slip at loads less than $200 \mathrm{lb}(0.9 \mathrm{kN})$, twice the nominal load. We judge that these nine anchors were stable during the heated phase of the SFT $-\mathrm{C}$, but may have slipped during the excavation phase (Mine-by) when they weie subjected to high-explosive shocks. 


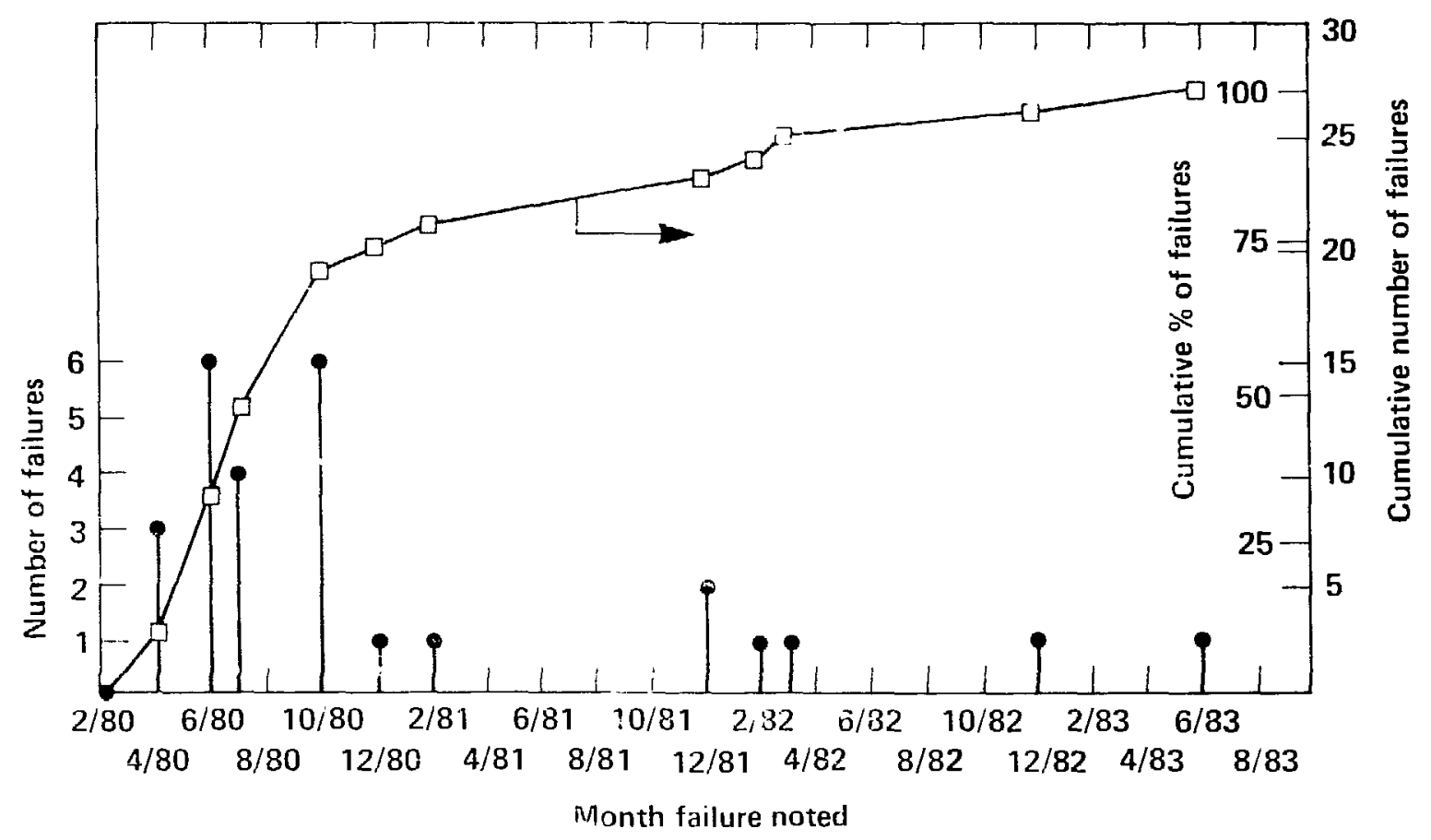

Figure 9-18. History of pressure loss for GxE-series rod extensometers that had pressure maintenance systems (after Patrick, Rector, and Scarafiotti, 1984).

For the $\mathrm{G}$. displacement curves were linear. The longest rod of each set exhibited nonlinear behavior, which resulted in a lower valuc of $\mathrm{K}_{\mathrm{a}}$. We believe that nonlinear behavior at low loads was caused by the rods being stri:ghtened trom their relaxed position. In the relaxed position, the $13.2 \mathrm{-m}$-long rods, which were orienteò vertically downward, flexed (buckled) elastically under their own weight of about $3.5 \mathrm{~kg}$. In additiun, during assembly of the extensometers, the rods were noted to have a permanent curvature that was introduced in manufacturing and shipping the rods. This curvature was straightened as the load on the rods increased, producing a linear curve at higher loads. Since the nominal $100-\mathrm{lb}$ rod tension was essentially constant with time, this behavior did not adversely affect data quality.

In Situ Test of Rod Integrity. The Superinvar connecting rods of the GxE-series borehole extensometers began failing about three years into the test, shortly before the heated phase of the test concluded. Seven rods failed in service as noted in Table 9-8. The rod and anchorage integrity tester was used to determine which rods were approaching failure by subjecting them to load. Three additional rods failed during testing, bringing the total to 10 of the $56(18 \%)$ Superinvar rods deployed on the test. The failure loads indicate that the rod cross sections at failure were about $15 \%$ of the nominal value.

Metaliographic sections of the rod failure surfaces revealed that classic stress-corrosion cracking was the failure mechanism. The presence of a small amount of calcium carbonate at the root of the corrosion cracks leads us to believe that the extensometer seals leaked at some point during the test. This allowed ground water to contact the rods, and possibly caused galvanic coupling with the copper hydraulic anchors and zinc-plated hardware that was also present in the borehole. Analysis of these failures is discussed in Chapter 18.

Miscellaneous Problems. A variety of relatively minor problems also arose and were corrected during the SFT - C. Although each of these adversely affected the data for several days, they are not discussed here because of their relatively minor impact. The interested reader is referred to Patrick, Rector, and Scarafiotti (1984). 
Table 9-8. Time of failure and failure load for Superinvar connecling rods that experienced stress-corrosion cracking lafter Patrick, Rector, and Scarafiotti, 1984).

\begin{tabular}{|c|c|c|c|}
\hline $\begin{array}{l}\text { GBE034 } \\
\text { plate }\end{array}$ & $\begin{array}{l}\text { Vallure atate } \\
\text { (YOC) }\end{array}$ & $\begin{array}{c}\text { Time to failure } \\
\text { (days) }\end{array}$ & $\begin{array}{l}\text { Eailure load } \\
\qquad l \mathrm{~b}(\mathrm{kN})]\end{array}$ \\
\hline GBE034 & 5.30 & 11.30 & $100(0.4)^{\mathrm{d}}$ \\
\hline 062 & 6.50 & 1570 & $520(2.3)^{10}$ \\
\hline GCE021 & 5.90 & $1350^{\circ}$ & $100(0.4)^{4}$ \\
\hline 02.3 & 5.03 & 1030 & $100(0.4)^{4}$ \\
\hline 041 & 6.50 & 15,0 & $469(2.1)^{\mathrm{h}}$ \\
\hline 042 & 5.42 & 1180 & $100(0.4)^{2}$ \\
\hline 051 & 4.94 & 1000 & $100(0.4)^{2}$ \\
\hline 052 & $5.90^{\prime}$ & $1,350^{\prime}$ & $100(0.4)^{2}$ \\
\hline 062 & 4.36 & 790 & $100(0.4)^{\prime \prime}$ \\
\hline 064 & 6.50 & 1570 & $470(2.1)^{\prime \prime}$ \\
\hline
\end{tabular}

"Nominal load due to spring tension. Failed in service.

"Failed in testing above nominal spring tension.

'Failed at nominal load after data acquisition was complete. Exact date of failure unknown.

\subsubsection{Convergence Monitors}

Convergence wire extensometers (CWEs) were designed and deployed to monitor relative displacements across the three drifts of the SFT-C facility. The design of the CWE units was such inat they could be oriented to measure displacements across horizontal, vertical, or angled spans. Onc enc of each CWE was a machined steel pin to which a length of 0.635 - $\mathrm{mm}$-diameter stainless-steel connecting wire was permanently attached. The pin was slipped into a mating machined block permanently affixed to the drift surface. The opposite, active end of each CWE consisted of a linear potentiometer housed in a brass weight that was attached to the opposite end of the stainless-steel connecting wire with a second nachined pin (Fig. 9-19). The potentiometer shaft, which was also dead-weight-loaded, rested on a machined plate that was part of the second reference point. The connecting wire passed over a threaded pulley, which allowed the CWE to be used in a variety of orientations while maintaining the vertical attitude of the dead weight system. Sixteen pairs of horizontally and vertically uriented CWEs were deployed (Figs. 9-9 and 9-10).

Three important features were incorporated in the CWE design to accommodate operating conditions at the SFT $-\mathrm{C}$ :

- Reference pins and tabs to permit removal and replacement without loss of "zero" reference (required in the canister drift instruments to permit fuel-handling operations).

- Four-wire resistance temperature measuring system to permit compensation for thermal expansion of the wire. CWEs.

- Provision for back-up tape extensometer readings between the active and inactive portions of the

Calibration. Pre-and post-test laboratory calibrations of the linear potentiometers were perfornued using the same procedure as described for laboratory calibration of rod extensometer transducers. These calibrations examined the transducers for possible clanges in slope (sensitivity).

The data reduction algorithms for the CWEs used the average pretest sensitivity determined wer the 25.4- $\mathrm{mm}$ range of each transducer. Comparing pre- and post-test sensitivities, we found that although the resulting: "'in error was small $(3.8 \mu \mathrm{m})$, the errors for individual transducers could be quite large. A range of erroi $\quad-6.6$ to $+35.7 \mu \mathrm{m}$ was reported (Patrick, Rector, and Scarafiotti, 1984). Becausc unly initial and final senstivities wore measured, we do not know how they changed as a function of time. If the observed changes were linear, the mean errors would not exceed one-half of the values reported.

Erro* Analysis. We identified eight sources of error for the CWE units: (1) the calibration coefficient; (2 and 3 ) excitation and signal voltages; (4) the coefficient of thermal expansion; (5) wire length. (6 and 7 ) 


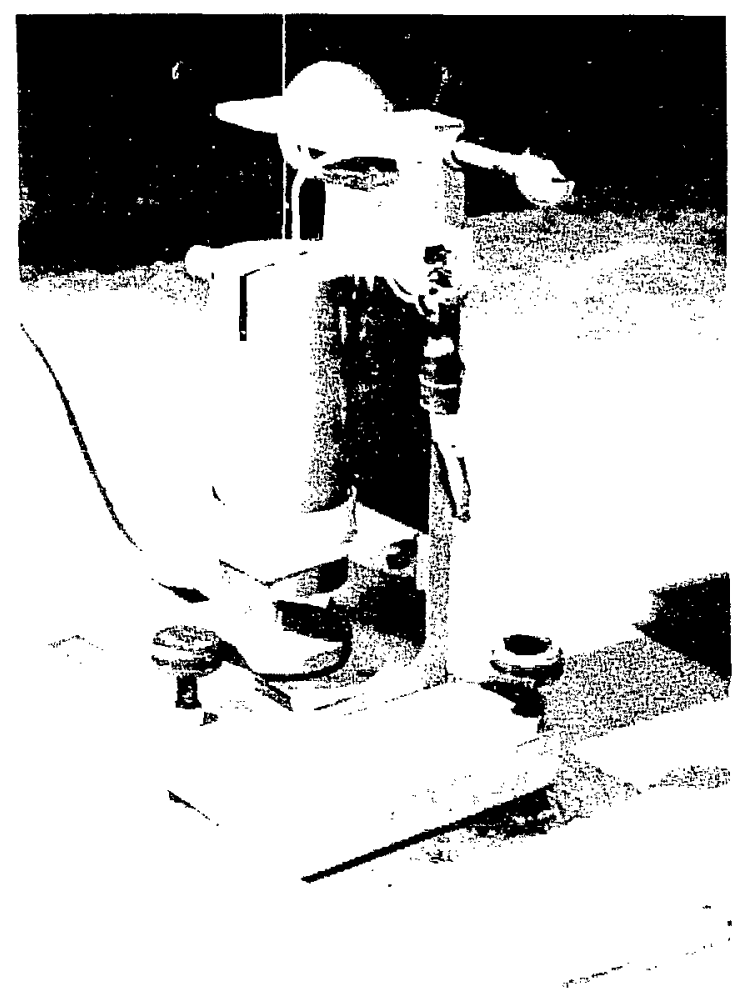

Figure 9-19. Typical canister drift vertical convergence wire extensometer installation (after Patrick, Rector, and Scarafiotti, 1984).

initial and current arerage wire temperatures: and (8) replacement and removal of the instruments. The latter was the largest surce of error for (WE that had to be removed for spent-fuel handling operations.

The maximum composite errurs calculated ty the RSS approach for wire lengths in the ranges from 2.9 to $3.5 \mathrm{~m}, 4.6$ to $5.9 \mathrm{~m}$, and $8.0 \mathrm{~m}$ were $84.2,30 \mathrm{~b}$, and $286 \mu \mathrm{m}$, respectively.

Because we used pretest sensitivities that were determined over the full range of the transducer and did not account for changes in transducer sensitivities, an additional mean error of $3.8 \mu \mathrm{m}$ and maximum error of $43.3 \mu \mathrm{m}$ exist. The maximum error value causes the calculated RSS uncertainties to increase slightly to 94.7, 309, and $289 \mu \mathrm{m}$, respectively.

Reliability. Of the 32 linear potentiometers deployed on the CWEs, 6 did not meet the post-test calibration acceptance criteria. Units CWE031 and CWE131 exhibited erratic, unstable readings during calibration. In addition, CWE(41, CWE051, and CWE112 were found to operate outside the specified 100-mV band for hysteresis and repeatability. Physical damage was evident un CWEOH. which had a damaged case that impeded the free movement of the shaft and wiper of the potentiometer. An examination of the data plots for each of these siv transducers showed noerratic behavior during the period of data acyuisition for the SFT-C. Furthermore. CWEO71 was responsive to the conling phase of the SFT-C. Thus we con-

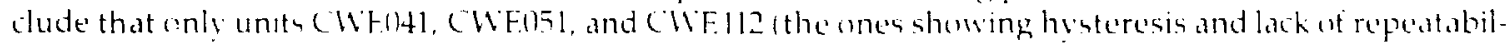
ity) mas have had problems while in servece. which, undeteded. degraded the yualits of thell data. All wher units fundioned reliably during the 3. $7-1 \cdot \mathrm{r}$ monotoring periont

\subsubsection{Fracture Monitors}

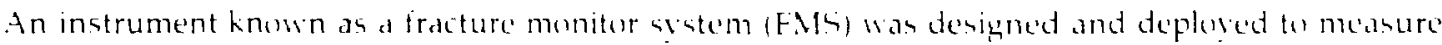

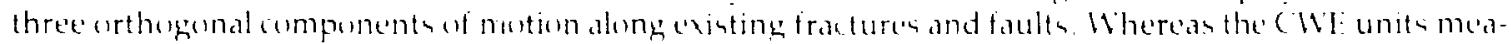

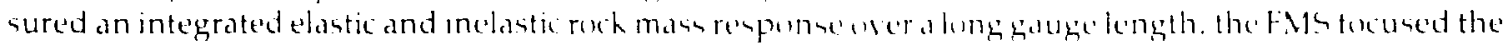




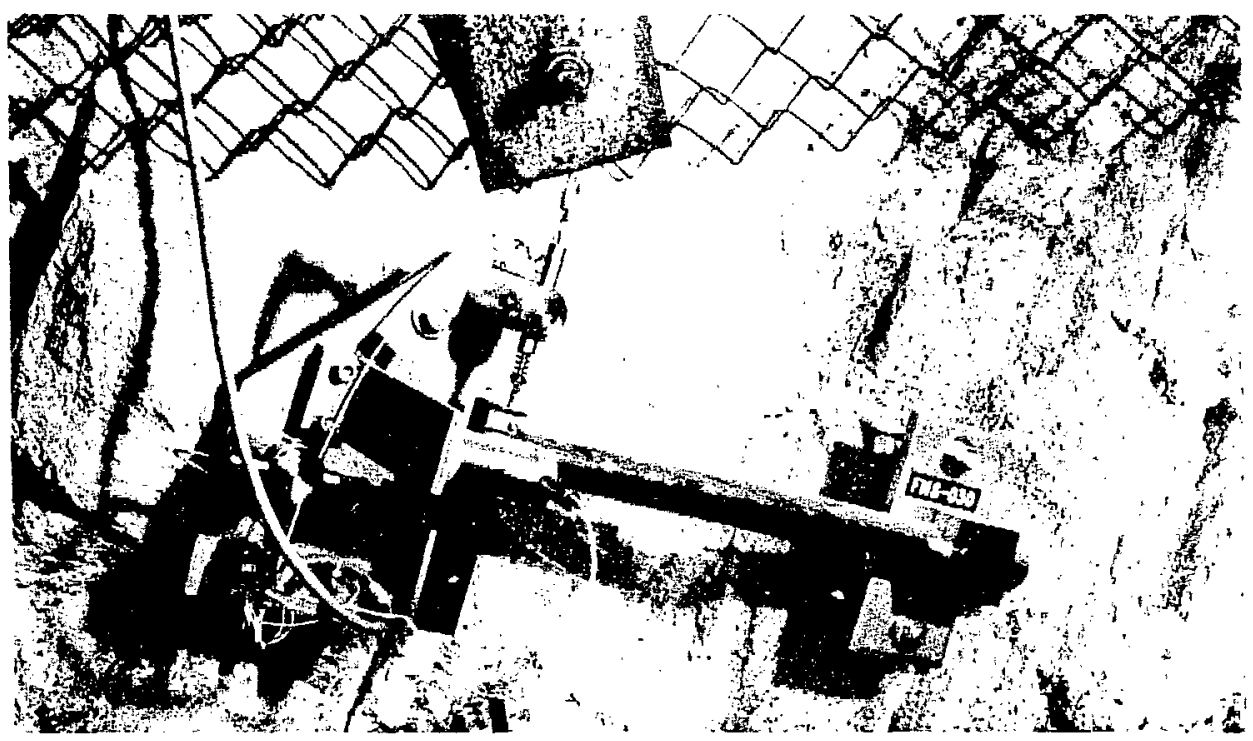

Figure 9-20. Typical fracture monitor system installation (after Patrick, Rector, and Scarafiotti, 1984).

measurement on a single, discrete geologic discontinuity or a closely spaced set of such discontinuities. The simple rugged design consisted of two anchorages on opposite sides of the geologic discontinuity: one housed the three transducers and the other supported a bracket that transfered the motions across the discontinuity to the transducers (Fig. 9-20). Because the transducer body moved with the first anchorage and the transducer shaft moved with the second anchorage, displacements of the two sides of the discontinuity were sensed relative to each other.

The FMS units were installed at seven selected locations to monitor faults or zones of intense jointing (Fig. 9-9). These units were mounted so that strike-slip, dip-slip, and normal displacements were sensed.

Mechanical components were fabricated from electroless-nickel-plated carbon steel. Although these components were short, thermal expansion was still important because anticipated rock displacements were also small. A single type-K thermocuuple was attached to each FMS to compensate for thermal expansion. The transducers were Bourns Model 5184 rectilinear potentiometers.

Calibration. No provision was made in the FMS design for field calibration. Instead, the linear potentiometers wer calibrated in the laboratory before and after the measurement period. Pre- and posttest calibrations were performed over the full $25.4-\mathrm{mm}$ range of the transducers in 2.54-mm steps.

As with the CWEs, the data reduction algorithm and associated sensitirity values were based on the average slope over the entire $25.4-\mathrm{mm}$ range of each transducer. Comparing pre- and post-test sensitivities, we found that the associated errors were very small: about $0.6 \% \mathrm{~m}$. The range of errors was -4.0 to $7.2 \mu \mathrm{m}$.

Error Analysis. The linear potentiometers were calibrated using the same procedure as for the (WE units. Sources of error included (a) calibration coefficient; (b) excitation voltage; (c) signal voltage: (d) cuefficient of thermal expansion; (e) component length; and (f) FMS temperature.

The maximum RSS uncertainty in the value of displacement measurements was calculated to be $9.63 \mu \mathrm{m}$. Because we used pretest sensitivities that were determined over the full range of the transducer and did not account for changes in transducer sensitivities, an additional mean error of $1.5 \mu \mathrm{m}$ and maximum error of $34.4 \mu \mathrm{m}$ may have existed (Patrick, Rector, Scarafiotti, 1984). These errors caused the calculated RSS uncertainty to increase to mean and maximum values of 9.75 and $35.7 \mu \mathrm{m}$, respectively

Reliability. Two of the 21 linear potentiometers deployed on FMSs did not pass the pust-test calibration acceptance criteria. The shaft of FMS023 was sticking, and it was found to uperate out side the specified $100-\mathrm{mV}$ band for hysteresis and repeatability. In addition, physical damage to the case of FM 5052 precluded movement of the shaft and wiper, so this unit could not be calibrated. Individual data plots for these 
units revealed no problems with FMS023. However, FMS052 began malfunctioning at 4.85 YOC (September 26, 1982) and was cleaned, lubricated, and returned to service at 5.36 YOC (March 31, 1983). It was functioning reliably when removed for recalibration. The malfunctions of both these units may have been related to events that took place after the test, possibly during disassembly of the instruments or shipment cf the components to the calibration laboratory.

\subsubsection{Borehole Closure Monitor}

A strain-gauged proving-ring instrument was designed and deployed to measure small diametrical displacements in the 0.61 -m-diameter by 4.9 -m-deep canister emplacement boreholes after the spent fuel was retrieved (Patrick and Rector, 1985). This instrument has been dubbed the canister borehole deformation gauge (CDG). The basic instrument consisted of a steel proving ring with a $203.2-\mathrm{mm}$ outside diameter, 190.5-mm inside diameter, and 25.4-mm ring width (Fig. 9-21). Sections of 25.4-mm-diameter bar stock and machined bearing surfaces were connected to the ring to transmit displacements from the borehole to the gauge. The proving ring was prestressed at the time of installation so that both positive and negative borehole displacements could be sensed.

Micro-Measurements' SK-06-125AD-350 "Karma" foil strain gauges were used to measure strains in the proving ring resulting from changes in borehole diameter. Gauges were applied in a full bridge configuration at positions $90^{\circ}$ from the load axis. The test environment was at $100 \%$ relative humidity with temperatures decreasing from 60 to $30^{\circ} \mathrm{C}$ during the planned 6-month deployment period. Four layers of protective coating were applied in accordance with manufacturer's suggestions to combat this environment. These consisted of M-Coat D (toluene-thinned acrylic), M-Coat W1 (microcrystalline wax), M-Coat FB (butyl rubber sealant), and $M$-Coat FN (Neoprene rubber sheet).

A single type- $K$ thermocouple was mounted to each set of three proving rings to provide data to compensate for the effects of thermal expansion of the gauge components.

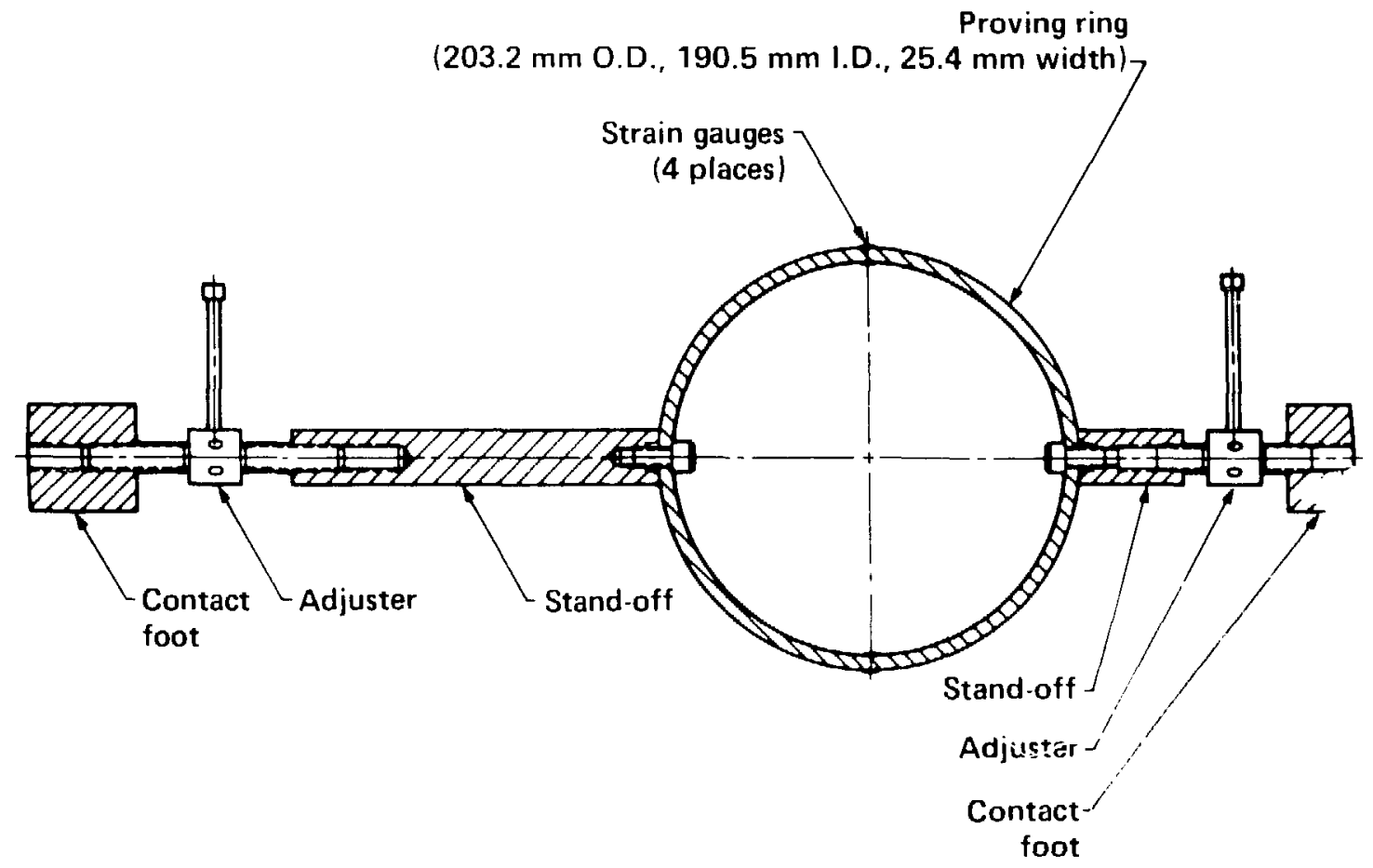

Figure 9-21. Schematic of canister deformation gauge showing strain-gauged proving-ring concept (after Patrick, Rector, and Scarafiotti, 1984). 
Two sets of three proving,-ring assembles were installed in each of two canister emplacement boreholes for a total of 12 gatuges. Fach set of threegauges was arranged on its support brackets in a fil-degree rosette. In adtitun. twogauges were matulled on a third borehole: one in an unloaded contiguration and wne in a dead-weight-foded configuration. Since neither of these gatuges interacted with the borehole, their output signals were used to monitur gauge drift and zero offset while the experiment was in progress. These data thus provided a degree of confidence (befure posi-test calibrations were performed) that the data from the other 12 gauges were reliable.

Calibration. Laturatury calibrationswere performed on the (1)G units before installation and on all units that survived the h-month deployment. The rings were calibrated on an Ormond beam-balance calibratur. A Buurns Model 141 rectilinear potentiometer was installed diametrically across the ring to measure ring displacements, and the ring was evercised 10 times through the $0.51-m m$ (0).(12-in.) range to ensure that all mechanical interfaces were stable. that the test frame hardware alignments were correct, and that the related hysteresis was minimized. Since the CDCs were deployed in an elevated-temperature environment, both ambient temperature $(23 \mathrm{C}$ ) and cevated-temperature (-49) C) calibrations were conducted. 1)etails of this calibration are provided by l'atrick, Rector, and Scarafiotti (1984). In general, errors associated with uperating the (DOis at elevated tomperatures were less than $0.7 \%$ of full scale and in no case

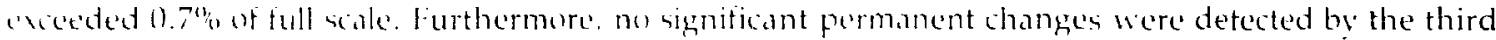
calibration. The mean transducer sensitwity was detorminet to be $8.811 \mathrm{mV}$ mm, with a standard deviation of $19.0988 \mathrm{mV} \mathrm{mm}(1.1 \%)$. Despite the imall variabilits in tranaducer sensitivity individual calibration coefficients were used for each CDC, unit in the data reduction algurithms.

Post-test calibrations were performed using the s ime technique outlined abore but only ambient temperature calibrations were performed.

Error Analysis. Five potential sources of error were identified: (a) calibration coefficient $\mathrm{K}$; (b) gauge length; (c) temperature; (d) excitation voltage; and (e) signal voltage. The composite RSS error was calculated to be $15.1 \mu \mathrm{m}$.

Reliability. Two criteria were applied in judging the reliability of the CDGs. First, the output signals of the devices were catclully examined to determine if there was any erratic behavior. Seven units survived the 189-day test period while the remaining seven had a mean time to failure of 102 days.

second. pust-test calibrations were made to evaluate transducers that survived the 189 -day test perind. Changes in sonsitivity ranged from $-10.751 \mathrm{t}-1.498 \%$, with an average of $-1.172 \%$. Shitts in zero offset ranged from $0.001 \mathrm{to} 1.0617 \mathrm{mV}$, with an average of $0.867 \mathrm{mV}$.

All failure were judged to be the direct result of moisture leaking into the strain gauge or, more commonly: into the area where the gauge leads were connected to tei minal strips. In future applications, additional environmental protection should correct this problem.

\subsection{Conclusions and Recommendations}

The three objectives of the instrumentation program were met despite malfunctions and changes in operating characteristics of several types of instrumentation. During the heating phase of the SFT $-\mathrm{C}$. stress changes were not adequately determined because the vibrating-wire stressmeters failed $t(0) 50(0)$ after deployment. This is the only data type that we believe was obtained with insufficient accuracy and for an insufficient time period. Although this shortfall precludes using changes in stress as a second independent basis, for evaluating the computer code used to model the thermomechanical response of the rock. the availability of a large amount of good quality displacement data will support the evaluation.

We offer several onclusions and suggestions based on our studies:

1. Currently waldate CAM and RAM sy'stems are adequate for radiation satey purpones when deployed in an underground environment. Provicions for periodic recalibrations must be induded in the monituring plan. The unith should be protected trom contact with corrosive ground waters

2. [.ang-term radation desimetry using the optical transmission technique (l.iF) should be augmented with short-term Tl.D measurements using CaF, thermoluminescent dosimeters.

7. The foril-type lang-term neutron dosimetry used at the SFT-C is inadequate for acturate deferminations af done. Pirtable duse rate instrumentalion provides adequate personnel neutron dosimetry. 
4. Commercially available RTDs, thermocouples, and thermistors provide reliable, accurate, longterm temperature data. Sheathe and environmental sealing materials must be carefully selected for the particular test environment.

5. The four-wire resistance measurement system developed for monitoring CWF temperatures was marginally adequate. Errors in temperature were a significant contributor to total error for the CWEs.

6. More accurate, higher resolution techniques are needed to calibrate turbine flowmeters. Inadequacy of existing field techniques required that we revert to manufacturer's specifications in the error analyses.

7. Systematic changes in Watt transducer calibrations (outside of manufacturer's specifications) occurred during the SFT-C. The'se changes suggest the need for periodic calibrations if an accuracy of better than about $5 \%$ is required for the energy balance.

8. Failure of $100 \%$ of the original O-ring-sealed vibrating-wire stressmeters led to a hermetically sealed design. These units functioned much more reliably with only 2 of 18 units providing erratic readings. (The possibility of filling the stressmeter cavity with fluid should be considered.)

9. An attempt at post-test calibrating the vibrating-wire stressmeters after retrieving them by means of an overcoring technique was a limited success. However, the attempt revealed major differences between the actual and assumed gauge sensitivities. Further development of calibration techniques is needed if these gauges are to be used with accuracy.

10. The burst-line technique for inflating hydraulic extensometers was found to be marginally adequate. A nitrogen-over-hydraulic systenr was deployed on a second sct wh itensometers to control inflation and maintain adequate anchor pressure. Anchorage was demonstrably better where controlled inflation was used, even when anchorage pressure later decreased to zero as a result of leakage.

11. Major losses of data resulted from failure of two types of linear potentiometers. These failures are believed to have resulted from degradation of the resistive element, which was brought on by chemical vapor action. (Consideration should be given to deploying fluid-filled transducers.)

12. Changes in transducer sensitivities occurred in potentiometers, LVDTs, and electromagnetic proximeters. While mean errors produced by these changes were a few tens of micrometres, extreme values were as large as one-half millimetre.

13. The coefficient of thermal expansion of borehole extensometer connecting rods must be better known. Substantial improvements in system accuracy will result.

14. Convergence wire extensometers proved to be reliable instruments for measuring displacements across underground openings. As noted in item 5, errors in temperature readings seriously degraded the potential accuracy of these units. It is also clear that the coefficient of expansion of the wire must be better known.

15. Fracture monitors functioned with excellent accuracy and reliability.

16. The borehole closure monitors developed for the SFT $-C$ functioned quite well for a prototype instrument. Improvement in environmental sealing should greatly extend the useful life of these specialty instruments. 


\section{Data Acquisition and Management Systems}

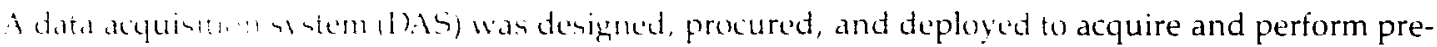
lumma!: "ucessing of data trom nearly 1000 analug devices. In addition, the DAS provided several other functions including alarming, calibrating instruments, and displaying data in near real time. The data management system (DMS) processed magnetic data tapes produced by the DAS to produce fully converted data for su! : fuent detailed a nalyses. The DMS also provided for file management, plotting, and archiving

\subsection{DAS Design and Specifications*}

The D.AS fulfilled critical roles, both in ensuring safe operations at the SFT-C by monitoring radiation levels and the status of critical test components, and in acquiring high-quality technical data with a high level of reliability In fulfilling these roles, the DAS performed eight basic functions: data acquisition, preliminury data processing, data verification, alarming for out-of-range values, display of critical real-time data - rtem control, calibration, and miscellaneous functions, such as data base reporting, system back up, and system maintenance.

As reported by Nyholm et al. (1982), the DAS hardware was specified to have the following 12 attributes:

1. Scan and measure at least 500 analog instrumentation signals with the capability to expand to at least 1500 channels without modifying the hardware on the existing units. An additional 20 channels of output signals were provided.

2. Measure instrumentation signals, and linearize, compensate, and convert these into appropriate engineering "rnits.

3. Measure, store, retrieve, reduce, analyze, display, and transmit to remote terminals via line modems, experimental data and status reports at preprogrammed intervals or on request by a user.

4. Remotely operate and control system scanning and measuring units at distances up to $1000 \mathrm{~m}$ by either of the two data acquisition system controllers using either of the two instrumentation communication buses. The DAS controllers were general-purpose minicomputers.

5. Accurately measure low- and high-level static, analog signals in the form of ac and dc voltages, ac and dc currents, and resistances generated by rock mechanics instrumentation and radiation monitoring equipment.

6. Electrically and mechanically interface the scanning and measuring units with the IEEE 488-1975 instrumentation bus. All hardware necessary to increase the effective length of the bus to $1000 \mathrm{~m}$ was provided and hardware was rack-mountable, with slide-rail kits.

7. Monitor selected channels as programmed, actuate remote controls, automatically establish telephone links to remote stations (at distances $>50 \mathrm{~km}$ ), and transmit alarms when established set-points were exceeded.

8. Permit the DAS controllers to be operated and programmed from both local and remote terminals via telephone line modems.

9. Permit program development and execution of various numerical codes independent of and simultaneously with data acquisition functions.

10. Once programmed, operate the system automatically without user response, unless desired. The system was located in a remote area and would not always be manned.

11. In the event of a power failure, automatically return the system to normal operation after restoration of power.

12. Run two subsystems in parallel that interact with each other, yet can perform alone in the event the other subsystem malfunctions. For this reason, dual controllers and independent peripherals, communication buses, and measuring equipment were provided. Subsystem "stand-alone" capability was used whenever feasible to minimize the possibility of total system failure.

- Contributed by R. A. Nyholm. 


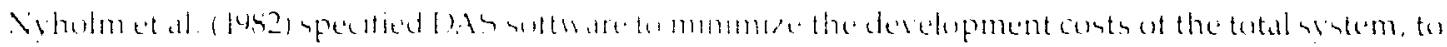

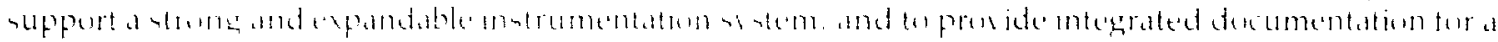

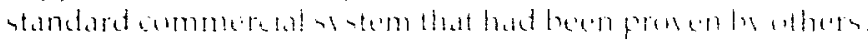

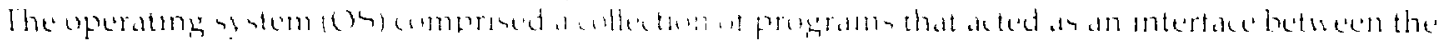
machene hardware and the user, smplitying the derigh, debughing, and maintenance of programs. The

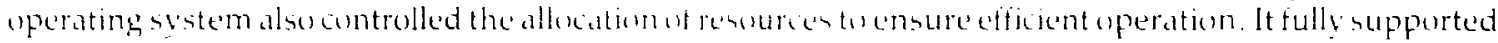
USe w FORTRAD, and Assembly language programs. All hardware interlaces were fully supported with

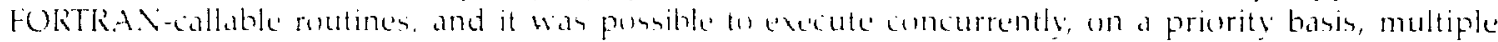

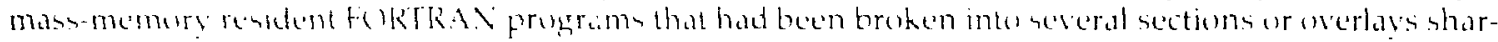
ing common data arede and several amaller, memury-resident programe aclivated by interrupts.

All programs were capable of being modifud, reanembled, and linked on the system as configured.

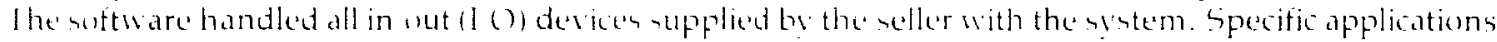
software was develuped by LI.Xil.

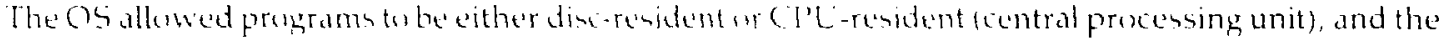

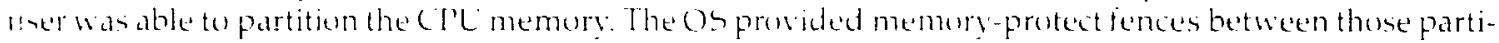
thomatoprevent user programs trom gaining illegal dicens to the partitions. The user was allowed to define two dasten ot partitions (cach class could have many subpartitions)-background and foreground.

The os was capable of a atumatically exhanging probrame between dise and C PL memurs. This feature simulated simultanewasly resident phenical memery in all disc-resident programs. All programs were

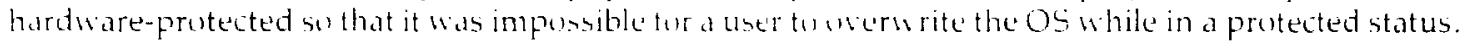

The system included a file management package to control manipulation of files on all mass storage devices. The commands :.ere executable either by operation from the systen console ur by program control, and were a ompanied by a series of error messages infurming the user of illegal action, thus preventing accidents.

FORTRANIV and Assembly language(s) were arailable as standard packages, and there were provisions for program werlay and chaining, task sicheduling, string handing and processing, and comprehensive 10 capability to any system device. Subroutine libraries were supplied to support standard mathematical calculations and scientific instructions.

The system software contained real-time: I () drivers to support all peripherals and peripheral interfaces and an interative editurwas provided for the creation and modification of source programs. A database management ustem (DBMS) was provided to allow logical access to data independent of physical dat. base structure. A comprehensive graphics displayed graphs, tables, and program listings, and also produced hard coppicen these displas's.

A distributive network communications ststem exchanged information between the interconnected DAS contrullers. This system was capable of supporting at least four computers of the type supplied without software modification. The link allowed renote program task scheduling/communications, file manipulation, and data base access.

Diagnostic and maintenance routines were made avalable to exercise and troubleshoot all hardware.

Finally, a complete set of reference manuals was provided for use by a system programmer. These manuals clearly and completely described all CPL instructions and timing, $1 / O$ and interrupt techniques. peripheral instructions, and other programming techniques for efficient operation of the system.

\subsection{DAS Configuration*}

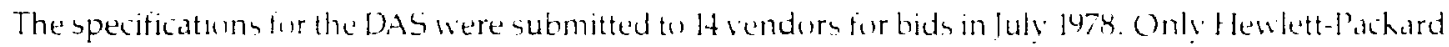

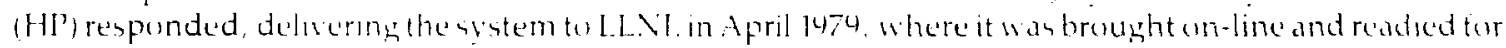

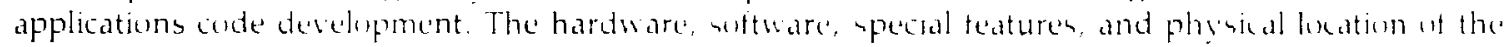
DAS are discused in detal by Vyholm est al. (14k2) and by Vifholm (1483), and are summarized here.

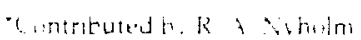




\subsubsection{Hardware Configuration}

The DAs hardware that wan provided in respone the the specifications was based on two HP $21 \mathrm{MX}$

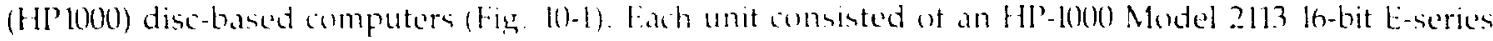

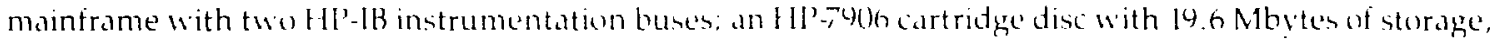
half of which were on a remuvable curtridge; a Texas Instruments $733 \mathrm{KSR}$ printing system terminal; an HP-2645/8 user display terminal with dual minicartridge tape drives (the HP-2648 provided graphics capability); an HP-7970 9-track, NRZ1, 8(0)-bpi, 45-ips digital magnetic tape unit; an HI' distributed systen interface via the HP-12665 P $^{2} \mathrm{CA}$; an HP-IB to HP-59309 digital clock and HP-3495 scanner (the latter used two 10-channel re!ay actuatur assemblies for the mudem and extender switching networks); an HP-IB interface with HP-3720) bus extenders to an HP-3455 h-1 2 digital woltmeter (DVM1) and either six (on Node 100) or seven (on Node 200) HP-3495 80-channel scanners: and a Vadic telecommunications system that is Bell-103 compatible, operating at 1200 baud. This svstem incorporated a custom modem-switching network (MSN) comprised of tw' HP-3495 scanners to aroid problems with the originally installed Vadic Multiple Automatic Calling Svstem.

In addition to these features, which are common to both Nodes, the Noder-100) unit was augmented with an HP-2608 132-column, 400-Ipm line printer and an IRAD stressmeter datalogger.

The Node-200 unit was augmented with two remote 17 -in. Conrac TV system-status monitors, an HP4872 four-pen graphics plotter, and an $H P^{2}-1310$ high-resolution graphics display.

Three remote communications terminals wefe provided to meet the needs of SFT-C experimenters and to ensure safe and reliable conduct of the test and the DAS. First, the principal remote alarm station was located at Control Point (CP) 40. Known as the NTS Radio Network Control Center, this location was staffed $24 \mathrm{~h} /$ day as part of normal NTS operations. To take advantage of this resource, we installed an HP2635 printing terminal operated with a Vadic modem and we provided an alarm-response manual and associated training. Depending on the nature of the alarm sent by the computers, the CP-40 staff notified staff at LLNL or emergency response personnel at the NTS. Second, an HP-2648 graphics display terminal and HP'-7310 graphics printer uperated with a Vadic modem were located in a room adjacent to the project offices in Livermore. Third. an Hl'-2645 display terminal operated with a Vadic modem was located underground in the instrumentation alcove to provide a work station to calibrate instrumentation and diagnose system problems.

\subsubsection{Software Description}

The DAS used both HP standard and special system software and LLNL special applications software. The HP software features included a real-time executive version IVB (RTE-IVB) operating svstem software; an Image-1000 database management system; a DS-1000 distributed-system software and firmware for network communications; a Graphics 1000 modular plotting support software; standard drivers to interface with peripherals; and special drivers to interface with remote scanners, DVMs, and the IRAD datalogger.

The LLNL special applications software was designed to provide eight functions:

1. Data acquisition to control instrument scanning and data accumulation.

2. Data processing to collate and provide preliminary conversions of data and archive it on magnetic tape.

3. Data verification to identify and facilitate correction of both DAS and instrumentation malfunctions.

4. Alarms to detect and alert personnel to out-of-limit data.

5. Displays to provide data and system-status information in real time.

6. Controls to provide access to and means to change system control and conversion parameters.

7. Calibration to prowide for obtaining instrumentation calibration parameters.

8. Miscellaneous small codes to provide for system backups, reporting, and maintenance capabilities.

The interested reader is referred to Nyholm (198.3) and Nyholn et al. (1982) for descriptions of the soltware that provided the cue functions. 


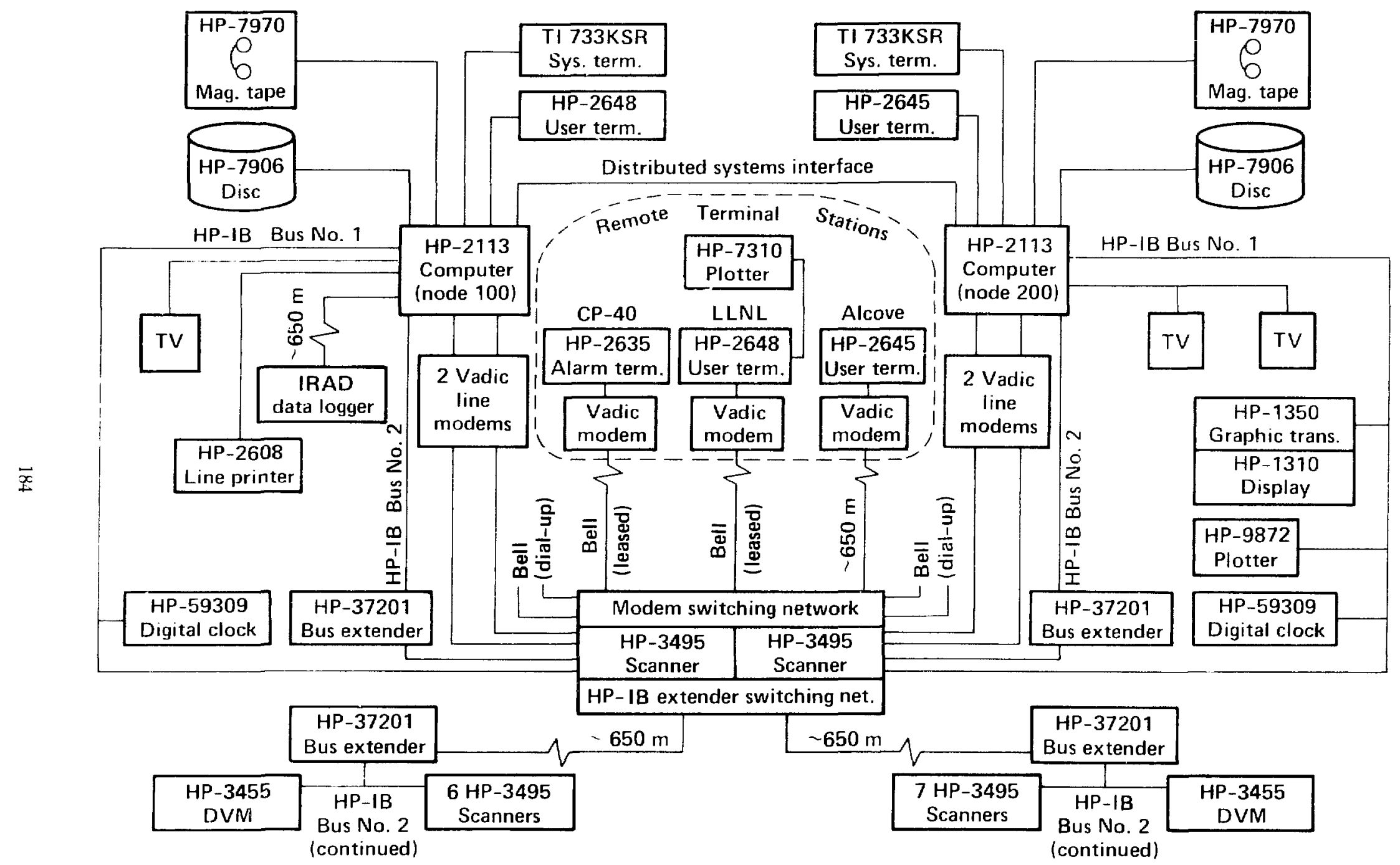

Figure 10-1. SFT-DAS hardware configuration (after Nyholm, 1983). 


\subsubsection{DAS Support Facilities}

Surface Systems. The computers system work stations, and supporting equipment were located in a $16-m \times 6-m$ double-wide trailer that was specially designed and fabricaced to meet the needs of a computer facility (Fig. 10-2). The floor plan allowed for a separate computer room, terminal room, office area, and electronics shop.

Although the personnel work areas required both heating and air conditioning, the computer room needed only to be cooled since the equipment generated sufficient heat. Two air conditioning/ humidification units operating in a lead-lag configuration were provided to ensure that proper environmental conditions were maintained. A temperature-sensitive trip circuit was provided to remove power trom the DAS if temperatures exceeded $35^{\circ} \mathrm{C}$.

To ensure that high-quality power was supplied to the DAS, even under outage conditions, an uninterruptible power supply (UPS) was provided in an air conditioned transportainer. A minimum 1-h battery backup was provided by this Deltec $7.5 \mathrm{~kW}$ system.

To meet DOE fire safety requirements for computer facilities, a Fenwal-Halon 1301 fire suppression sv'stem was installed. Smoke and heat detectors were used to trigger the Halon system and to provide local and remote alarms.

Subsurface facilities. To minimize the need for long cable runs for analog signals, we installed all scanners and DVMs in an underground alcove constructed of fire-resistant materials (Fig. 10-3). This 4-m by 9 -m enclosure housed the instrumentation terminal boxes and racks, and one of the remote terminal stations described above.

The underground air conditioning system provided a temperature of $23 \pm 1^{\circ} \mathrm{C}$ for these portions of the DAS. Since ambient rock temperature is about $24^{\circ} \mathrm{C}$, no heating was required. UPS and fire suppression systems were provided as with the surface DAS facilities. The UPS provided a minimum 2-h backup power capability using a lead-calcium battery bank.

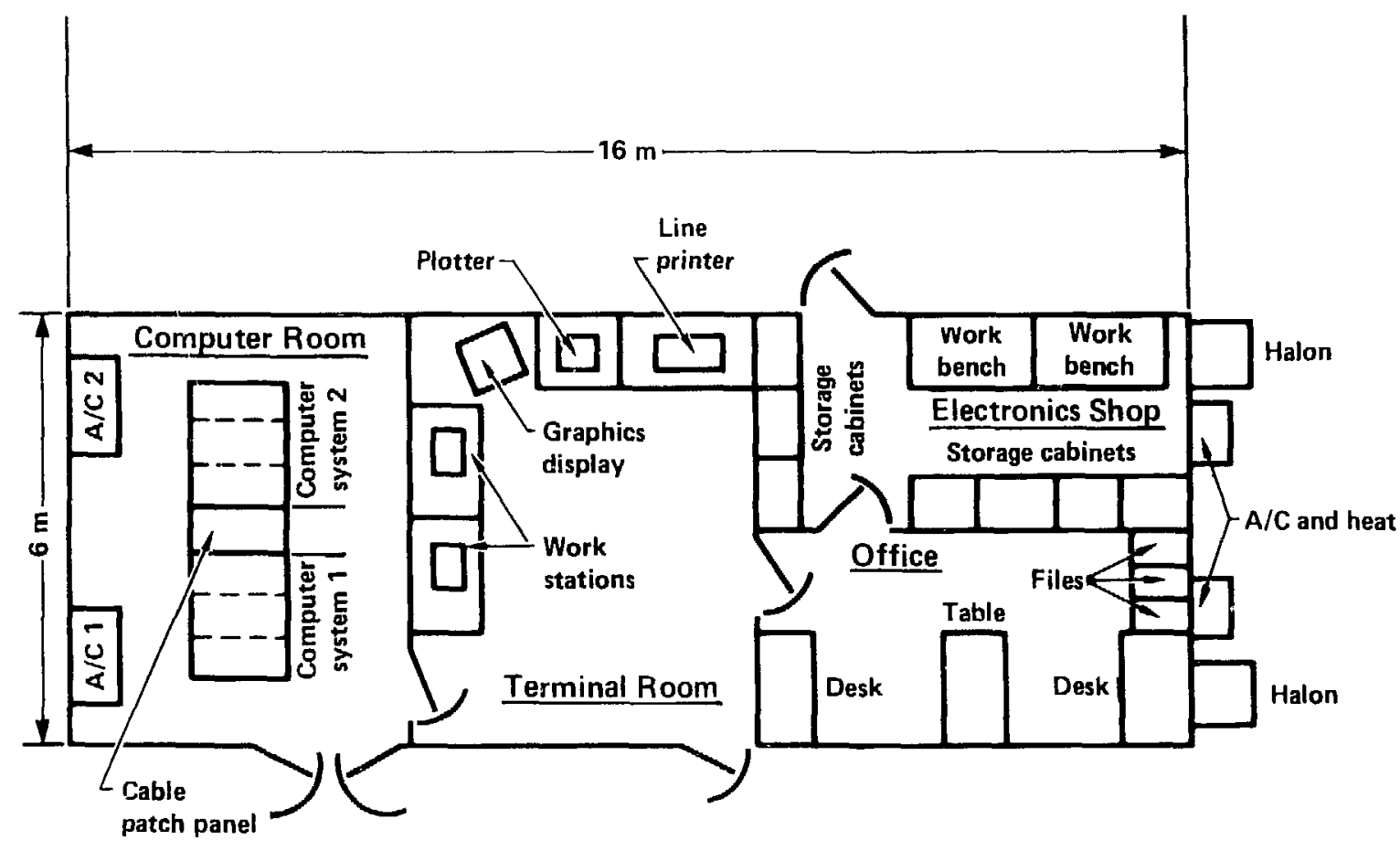

Figure 10-2. SFT-DAS computer trailer floor plan (after Nyholm et al., 1982). 


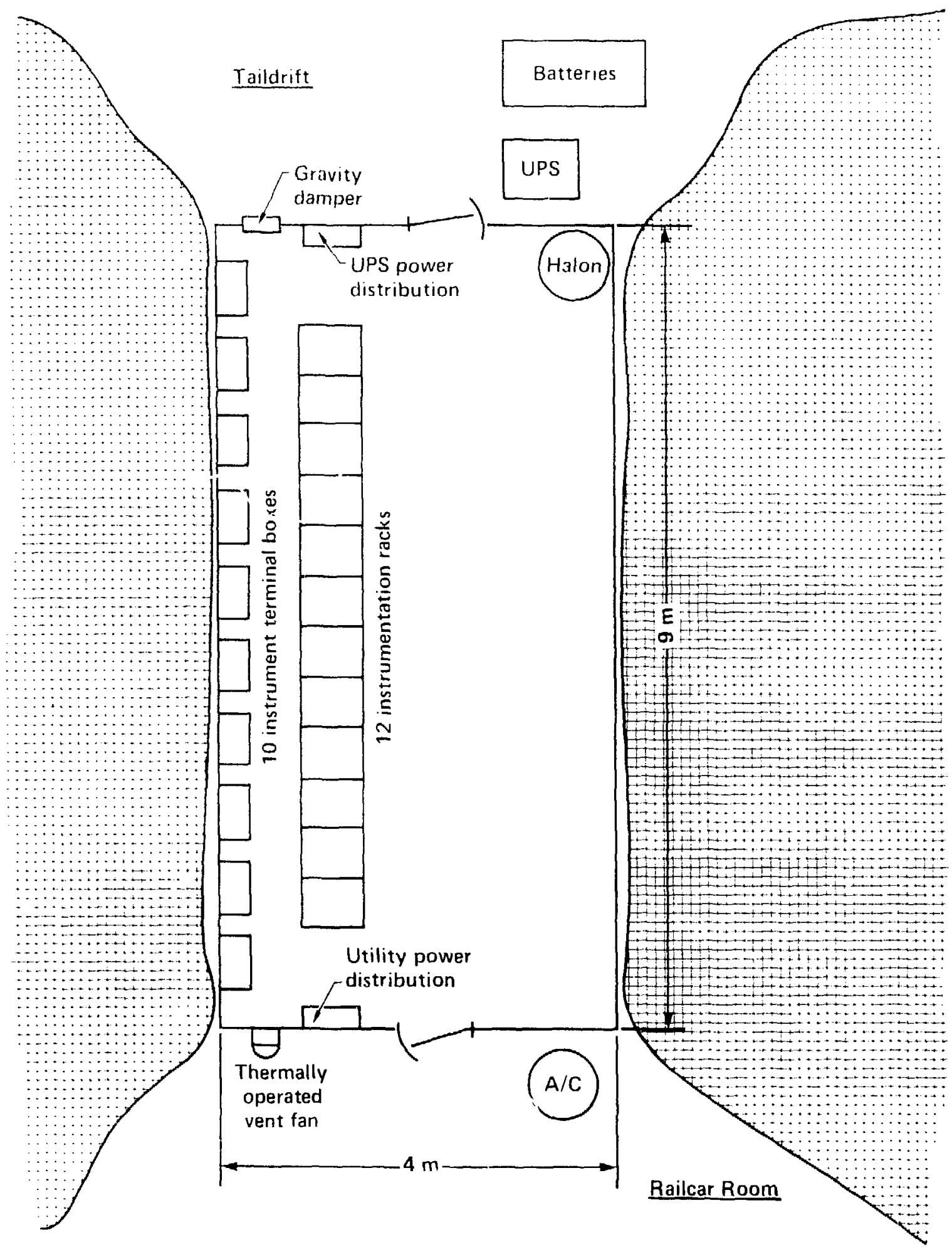

Figure 10-3. SFT-DAS instrumentation alcove floor plan (after Nyholm et al., 1982). 


\subsection{DAS Normal- and Fault-Mode Operations*}

In its normal mode of operation, the DAS ayuired and prexesed about 500 data points h from nearly '700 channels of instrumentation. Although most channels represent a single instrument, critical channels were scanned redundantly by the two computers.

The arquisition of data was controlled by the contents of scan tables and associated acyuisition software modules. For each instrument, which was designated by a unique six character alphanumeric "license plate," the san table contained the follewing information:

- Channel lugical state (off or on).

- Scan time interval.

- Time of last scan.

- Sanner channel to which instrument was wired.

- Type of reading (ac, de, 2-wire or 4-wire resistance).

- Processing algorithm code.

- List of reference instruments to be scanned.

When the acquisition module determined that it was time to sian a channel, it built a table of channels to be scanned (including reference instruments), requested the seans (by closing scanner box relays), received the raw data, and dispatched these dat a to the appropriate processing codes.

Atter accepting the raw data pachets, the processing codes retrieved conversion parameters from tables, accessed the acquired database to retriev'e reference channel data, expanded the data packet, and placed the converted data value in the packet.

Tests by the alarm modules then determined whethar the data were within specified limits. If not, alarm messages were sent to CP-40 terminal and logged in the alarm tile.

From time to time, one or both of the computers or closely related peripherals would malfunction, causing loss of data. We observed that these losses typically occurred when only one of the computers was down (Patrick et al. 1982). To improve this situation, an extender switching network (ESN) was designed and deployed to allow une computer node to carry on the entire acquisition if the other node malfunctioned.

The ESN was made to function in one of two ways. First, each computer node continually assessed the status of the other and, it a fault was deicted, connected itself to the other node's scanners and DVMs through the ESN scanner. This provided communication with otherwise inaccessible instrumentation on the other node. Second, the DAS operator could intentionally actuate the ESN, producing the same result. Operator-activated use of the ESN was useful during periods of preventive maintenance and scheduled system modifications. Scanning using the ESN is essentially the same as for normal-mode operation.

\subsection{DAS Performance History*}

The two principal measures of a DAS performance are its accuracy and reliability. These are measures of the quality of readings actually acquired and the quantity of data actually acquired compared to the quantity desired, respectively.

\subsubsection{Measurement Accuracy}

Although the DAS was capable of making measurements over a broad range of scales, its scientific data most heavily depended in de voltage readings in the millivolt range and on four-wire resistance readings in the 125-9 rang: To dssure long-term measurement accuracy, the DVMs were recalibrated every 90 days and were operated at $23 \pm 1 \mathrm{C}$. In addition, several system standard references were measured as part of the regular scanning seyuence to provide an ongoing evaluation of data quality. These included a precision

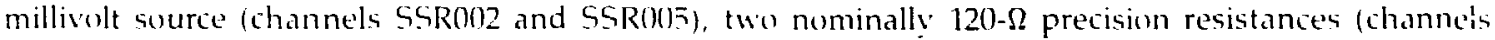

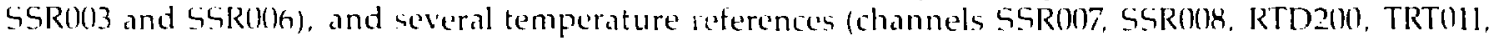
TRT012. and TRT(113). The millivolt soure was accurate $(0) 1 \mu V$, the resistane stardards were stable to 1). (o) lo 8 , and the temperature sensors were immersed in calibration baths (Chapter 9 ) or were deep in the roch, far from therm al atisturbances.

"Contrihuted hi R A Viswlm 
Figure l(1-4 illustrates the renultsobtained irom the de vollage and four-wire resistance references. The

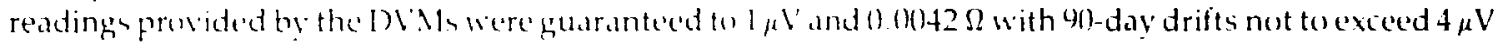

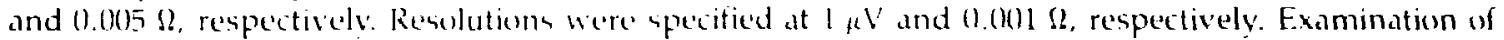
those 30.000 data points channel collected trom $2.7407 .862 \mathrm{Y}(\mathrm{C}$ show that the voltage source was always measured in the envelope $0.996 \mathrm{to} 1.1904 \mathrm{mV}$. Minor perturbations were observed, as expected, when DVMs were exchanged for calibration, as indicated by the upward arrow's. The four-wire resistance measurements should have been stable to $\pm 0.0092 \Omega$. However, several periods of out-of-limit readings were evident in Fig. 10-4. Variations in four-wire resistance references were an early indicator of potential hardware malfunction and were therefore caretully scrutinized on a daily basis.

\subsubsection{System Reliability}

The SFT-C DAS was operational for more than tyears and performed above the operational specification set forth by Hewlett-Packard. That specification called for a single-point mean-time-between-failure (MTBF) of 30 days, and downtime of 2104 days. The relatively long downtime estimate is a function of both the remote location of the test rea and the avalability of yualified service personnel. These figures translate to an average "functionally disabled index" (FDI) of approximalely 7\%. The FDI (Nyholm et al., $1982)$ is a measure of the likelihood that data cannot be properly recorded and archived on schedule by the DAS as designed. Thus, one computer nude or the other shuld have been capable of acyuiring data $93 \%$ of the time according to the specification.

Many factors that inflate the FUl had to be cunsidered to make a true estimate of the FDI (Patrick et al., 1984), including:

- Installation and development of software updates;

- Fuel handling operations-data channels of significant interest were scanned rapidly; others could be turned off;

- Hardware maintenance and/or calibration;

- Instrumentation maintenance and/or calibration;

- Cartridge disc unit backup to digital magnetic tape;

- Software failure; and

- Computer overburden.

Taken collectively, these factors should have accounted for approximately two additional FDI points, bringing the toial FDI to about $9 \%$ per computer system.

Figure 10- 5 illustrates observed monthly FDIs for the interval from May 1, 1980, through September 30 , 1983. The upper plot specifies the likelihood that a scheduled data point was not recorded and archived via the front-pn data acquicition hardware normally connected to computer Node 100 (Fig. 10-1). Similarly, the $m_{1} \quad$ plot reports identical information for data points collected via the acquisition hardware normally ، lected to computer node 200 . The bottom plot presents the likelihood that neither computer node was able to collect a scheduled data point; i.e., both computer nodes were disabled concurrently.

For the duration of the SFT $-C$, the average observed FDI (41 consecutive months) for Node 100, Node 200, and the DAS was 14.98, 8.79, and 4. .5\%, respectively. Recording outages through November 1982 have been previously reported (Patrick et al., 1983) and have been basically attributed to software difficulties and a variety of hardware failures. The vast majority of software cures were in place by May 1981 and the last was resolved on March 26, 1982. Since November 1982, principal system failures were attributed to faulty disc drives, notably on Node 200.

\subsection{DMS Design Considerations*}

The SFT-C project philosophy was to provide separately functioning data acyuisition and management systems (Ramspott et al., 1979). To achieve this, it was necessary to develop a DMS with the following capabilities:

- Contributed by W. C. Patrick 
$\frac{}{8}$

1.004

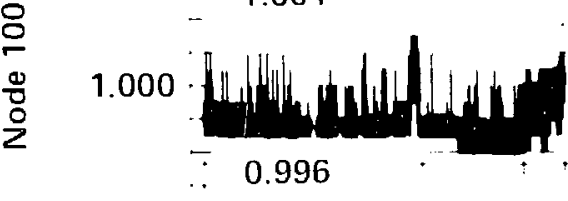
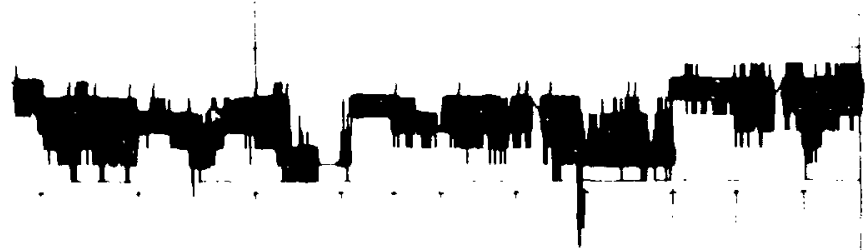

0.990

$\begin{array}{lll}2.7 & 3.0 & 3.3\end{array}$

3.6

3.9

4.2

4.5

4.8

5.1

5.4

5.7

$1.010-$

$1 \mathrm{mV}$ system standard reference

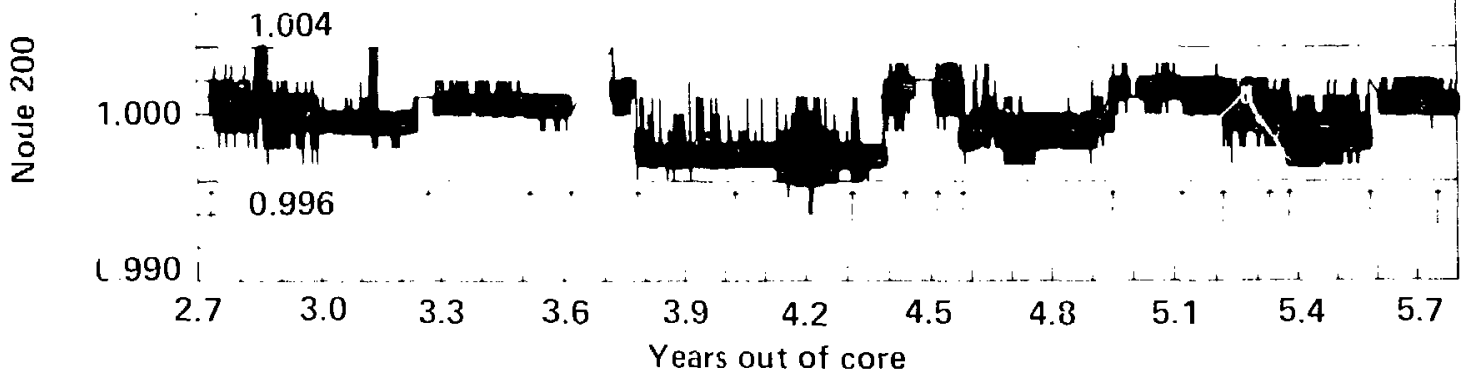

$120 \cong$ system standard reference
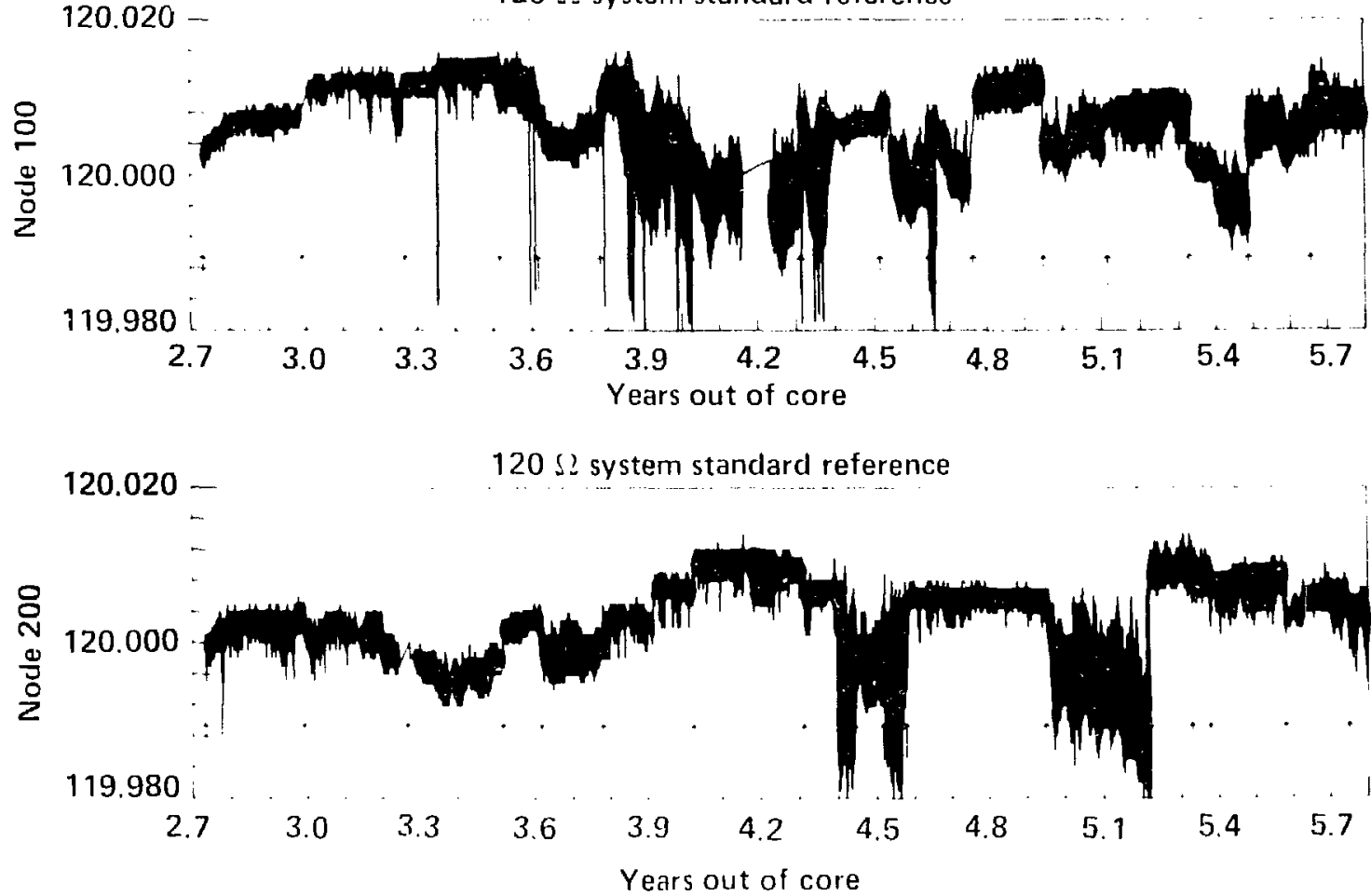

Figure 10-4. SFT-DAS System Standard References. Note: up arrows indicate DVM exchanges. 
50

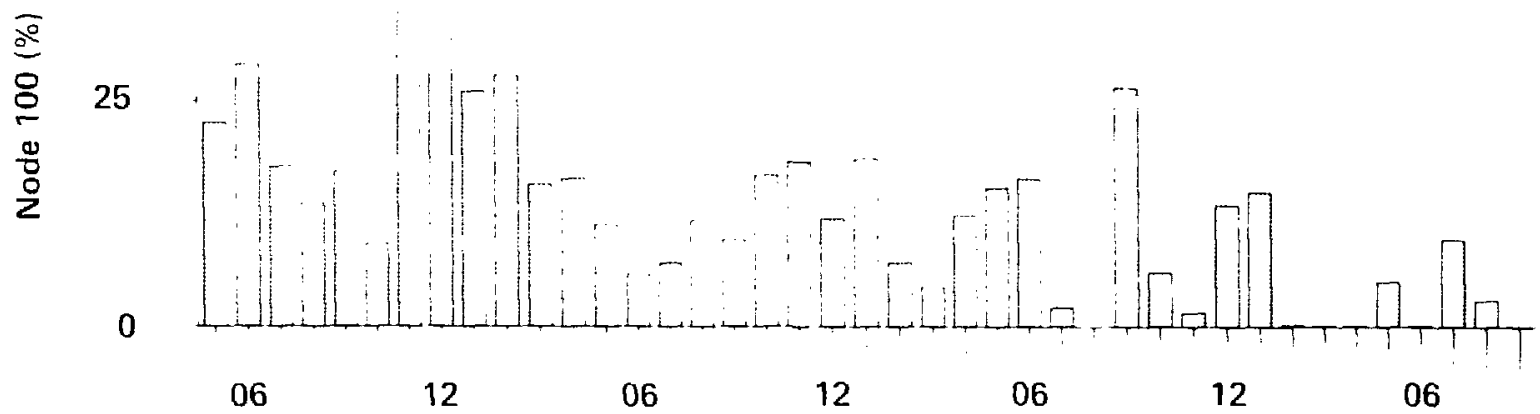

50

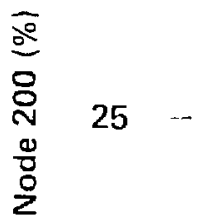

0

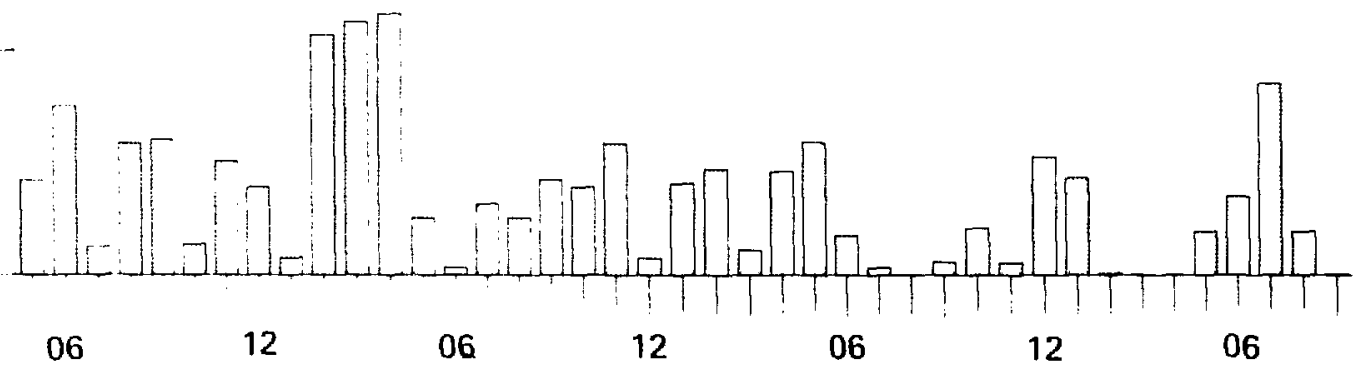

25

$\sum_{0}^{\infty} 12.5$

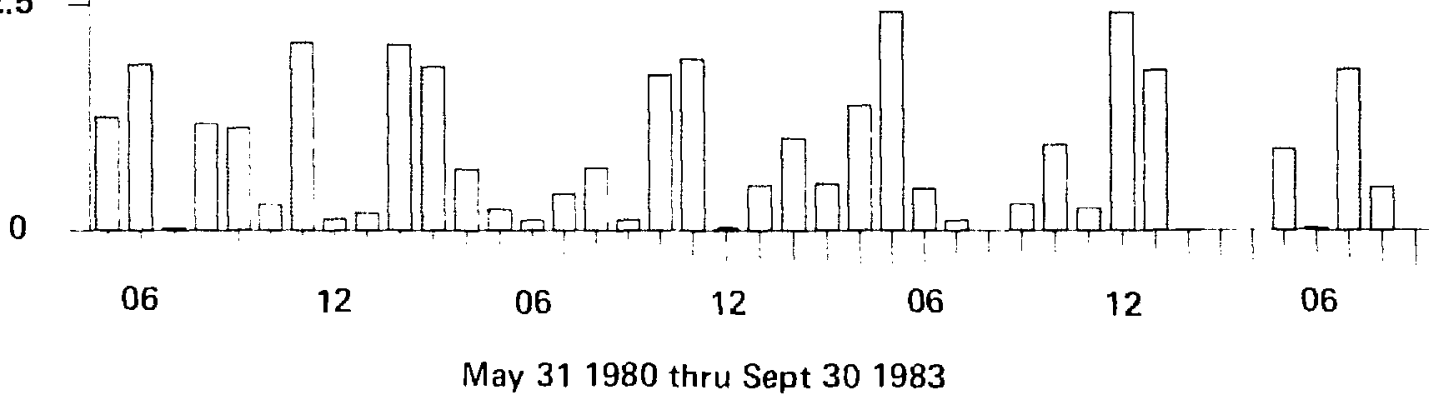

Figure 10-5. SFT-DAS front-end data acquisition hardware monthly FDI. 
- Accept and convert magnetic data tapen from the IIP-I0(0) system to becompatible with the LLNL computer network of Control Data Corp. (CDC: Thol)s;

- Screen out data system status and radiation monituring instruments that would not be subjected to subsequent analysis:

- Screen out or fix flawed data records, as appropriate;

- Convert the data format from HP ASCi! to CDC binary for more efficient processing;

- Process the data using best-available calibration data and algorithns to account for temperature effects;

- Reorganize data into a file structure comprising individual files for each instrument;

- Plus data in va، 1ous formats; and

- Archive cuica for future analysis and to meet project quality assurance requirements.

These design considerations led to development of three principal and several supporting sets of codes.

\subsection{DMS Description and Operation*}

The description and operation of the DMS are provided by Carlson (1985), and details of selected components of the DMS are provided by Hage (1983 and 1984). Wi summarize the DMS software and processing techniques here.

\subsubsection{Data Receipt and Preprocessing}

Upon receipt at LLNL (which occurred at approximately monthly intervals), the HP data tapes were copied using the utility TAPECOPY and assigned a sequence of file names cross-referenced to the HP tape number to facilitate tracking (Fig. 10-6). The 16-bit HP structure was converted to 60-bit CDC 7600 structure using a binary read code known as BREAD. The ASCII output of BREAD was appropriate for data display, file management, and correction of data errors but had to be converted to binary format by another code in preparation for processing by the data conversion code REVERT. Known as MFAB (for merge files convert ASCII to binary), this code also segmented the data into one 1 million word files for subsequent processing.

Following conversion to CDC format, BREAD's primary function was to screen the data based on several criteria:

- Legitimate logical channel number (a four-digit code);

- Part of scientific database;

- License plate in proper format and correct for given logical channel number;

- Time of record within range of data tape;

- Raw data value within conceivable range for instrument;

- Time gaps not exceeding 1 day for each instrument.

Depending on the results of these checks, one of five actions could be taken: pass the record as correct, correct errors in logical channel number or license plate, flag as questionable, discard because not part of scientific data base, or discard for failure to meet une of the other criterion. An interface file provided BREAD with discard options and parameter values on which to judge the acceptability of the data (Hage, 1983).

The BREAD code produced statistics and message files that were used both to make decisions related to data retention and to provide a permanent quality assurance record of the processing. In several cases, errors were detected that affected a group of similar instruments or, in one case, ail instruments. A small code was developed to repair these records based on a thorough evaluation of the problems. Examples of errors that could be fixed in this manner are ::tterchanged instrument wires, which were later corrected, and failure of the DAS system clock, which introduced a time offset. All such changes were documented by Carlson (1985). 


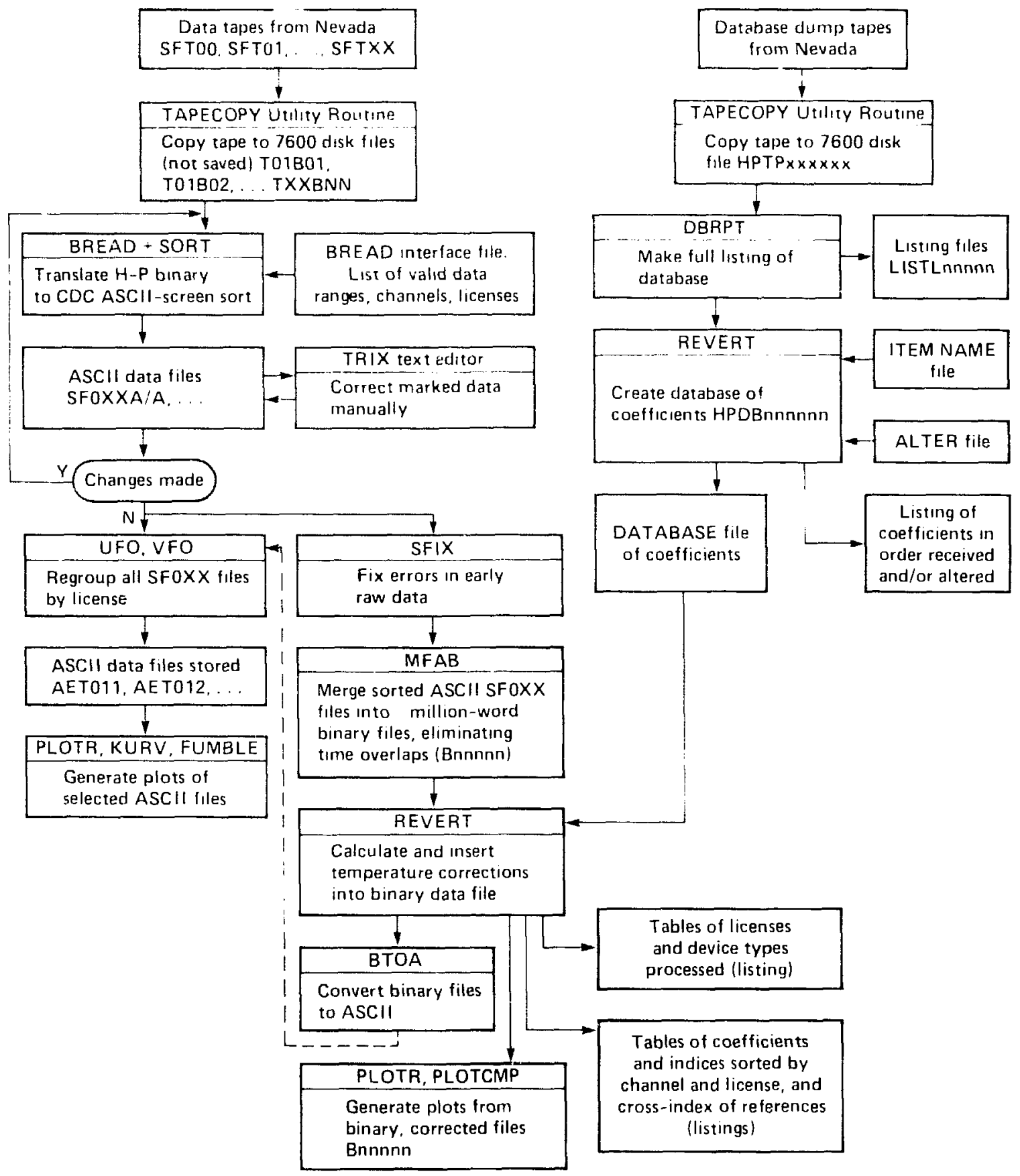

Figure 10-6. Block diagram of Data Management System (after Carlson, 1985).

\subsubsection{Data Conversion}

Although the HP system provided precise conversions of data from the relatively simple devices such as thermocouples, RTDs, and watt transducers, the DAS provided unly approximate (so-called "engineering conversions.") for instrumentation such as displacement and stress moniturs. Therefure, we developed a code to reconsert (REVERT) all data, incorporating individual instrument calibrations and algorithms to compensate for the effects of thermal expansion of instrument components. 


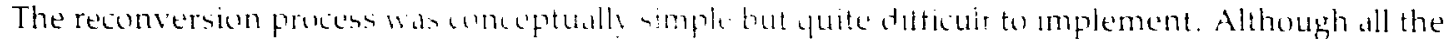

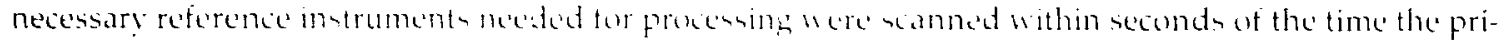

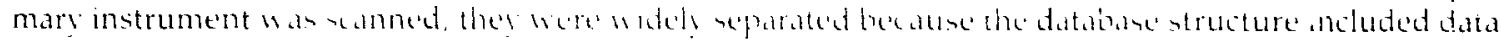

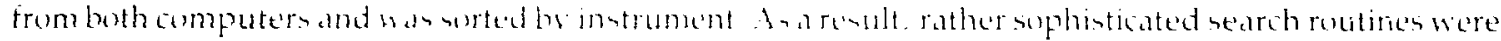
needed to find the reference instrument data tor a particular comsersion (1 tage, 1984). To further complicate the process, many instruments malfunctioned and were replacid and other instruments were added in the course of the SFT - $C$, thus producingesereral liste of instrumente and associated databases of conversion parameters

The operations performed by REVERT were hargely controlled by the ontents of the database of conversion parameters that were developed using the 22 HP dalabases received from NTS. The HP databases were a ugmented, merged. and modified befure processing test data with i:FVERT (Fig. 10 6).

In many cases, the REVERT algorithms were CDC Thof versions of the assuctated HP sonversion algorithms. Additional processing algorithms were develeped and tented promarily to compensate for the effects of thermal expansion on instrumentation components (1 Hoge, 1484t, and Carlson, 1485). The basic data processing proceeded in three passes:

1. Pass 1 devices could beconverted with no reference instruments. These included eicitations, watt transducers, and RTDs.

2. Pass 2 devices reguired at least one puss I device for comversion. For example, therancouples required RTD reference junction temperatures.

3. Pass 3 devices required at least une Pass 2 device for conversion. The principal examples were rodand wire-extensometers and stressmeters that referer ced from one fo seven thermocouples in addition to Pass 1 excitations.

A total of 46 REVERT runs were made to reconvert the $8.7 \times 10^{\text {t }}$ data recor $1 \mathrm{~s}\left(43.5 \times 10^{\mathrm{h}}\right.$ words $)$.

\subsubsection{Storage, Plotting, and Listing}

Many system utilities were available to plut and list data processed through BREAD or reconverted by the REVERT code. However, most such general-purpose data display codes require that the data be well organized.

To produce a data structure compatible with our need to produce large numbers of plots and data displays in various formats, D. Montan developed a set of processing codes to accept the ASCll ocitput of BREAD or the binary output of REVERT and to separate these time-ordered segr.ents of data into individwal files containing all data for a particular instrument. These codes accomplish the following functions:

- LFO reads a BREAD ur REVERT output file and rewrites it into a "uniformly formatted output" file.

- VFO (for "voluminous file output") uses these files and splits off the data records into individual license-plate-oriented files.

- WFO (for "we find out") is an error detection routine that checks for such problems as records not in time sequence.

The individual license-plate files were assembled into logicai groupings that formed the second tier of the data directory. These in turn were accessed through the root directory for the SFT $-C$ data archive.

Data acquired on the SFT $-C$ were archived at several stages of processing to provide adequate backups at each stage and to meet the developing needs of project experimenters. These stages iricluded:

- Both original and duplicate copy data tapes from the HP DAS. These induded ali raw data acquired and "engineering conversions"; Pass 1 and Pass 2 instrument conversions were complete.

- BREAD output, referred to as S-files, with contents similar to above but with all radiation nonitur data and flawed data deleted.

- REVERT output, known as R-files, with complete reconversion of all data records, including !'ass 3 instruments.

- L-files, which provided the one-file-per-instrument data structure intially for the S-files and latei for the R-files.

All data in the REVERT L-file struclure were plotted, microtiched, and incorpora. . a in the appendix in Carlson (1985) for use by other researchers. As Carlson noled, data tapes may also be requested from the LLNL fur additional andases. 


\subsection{Quantity and Quality of Data Received *}

Table $10-1$ is a statistical summary of the datu reveived during the SFT-C. The "discard" collumn primarily accounts for data trom radiation minture and varioun status devices that were not analyzed and reported. Though archived as raw data, the'se were discarded from the scientific database to reduce the volume of data processed. The resulting reduction was significant since these data comprised $43 \%$ of the data acyuired. The "Number of Errors" columns show those data lost because they were unreadable or obviuusly wrong and uncurrectable. Errors were tabuhated in four groups:

1. "TOR" designates that the acyusition time indicated in the record was outside the range for the data tape.

2. "VOR" indicates that the raw data value' was outside the range of phy'sical possibility (for example, a $25-\mathrm{mm}$ range displacement transducer giving a reading of $1 \mathrm{~m}$ ).

3. "License" indicates that the license plate designator in the data record was not one used during the test.

4. "License and channel" indicates that both the license plate and logical channel number were incorrect, precluding error recorery.

In total, these errors represented about 20 of the acyuired data. As show'n, 8,691,636 valid data points were accumulated during the 1300-day (3.56-year) period of the test, an werage of 6682 data points per dav:

Table 10-1. Summary of processed SFT-C data (after Carlson, 1985).

\begin{tabular}{|c|c|c|c|c|c|c|c|c|c|}
\hline \multirow{3}{*}{$\begin{array}{c}\text { File } \\
\text { name }\end{array}$} & \multirow{2}{*}{\multicolumn{2}{|c|}{ Time (absolute Julian day) }} & \multirow{2}{*}{\multicolumn{3}{|c|}{ Number of data points }} & \multicolumn{4}{|c|}{ Number of errors } \\
\hline & & & & & & \multicolumn{2}{|c|}{ Range } & \multirow[b]{2}{*}{ License } & \multirow{2}{*}{$\begin{array}{l}\text { License and } \\
\text { channel }\end{array}$} \\
\hline & Start & Stop & Copied & Discard & Total & $\overline{\mathrm{TOR}^{\mathrm{b}}}$ & $\overline{\mathrm{OOR}}$ & & \\
\hline J00A B & 44331.437 & 44569.498 & 30191 & 0 & 30191 & 0 & 0 & 0 & 0 \\
\hline $002 \mathrm{~A} E$ & 44342.196 & 44354.011 & 25393 & 11407 & 36800 & 0 & 144 & 39 & 0 \\
\hline $003 A C$ & 344.790 & 345.250 & 1692 & 2245 & 3937 & 0 & 0 & 0 & 143 \\
\hline $004 \mathrm{~A} C$ & 345.389 & 346.967 & 11181 & 6548 & 17729 & 32 & 90 & 32 & 149 \\
\hline $005 A \cdot C$ & 346.960 & 351.929 & 26491 & 13114 & 39605 & 18 & 21 & 0 & 0 \\
\hline $606 \mathrm{~A} C$ & 351.914 & 351.917 & 37567 & 7027 & 44594 & 0 & 81 & 0 & 0 \\
\hline 007A D & 357.845 & 358.507 & 7145 & 1636 & 8781 & 0 & 4 & 0 & 0 \\
\hline 008A D & 358.485 & 360.566 & 8,983 & 2427 & 17310 & 0 & 231 & 0 & 0 \\
\hline $009 A: D$ & 359.926 & 361.134 & 17231 & 5971 & 23252 & 0 & 1451 & 0 & 0 \\
\hline 010A/C & 361.143 & 370.452 & 119807 & 45263 & 175070 & 0 & 54 & 0 & 0 \\
\hline $011 \mathrm{~A} / \mathrm{D}$ & 370.452 & 375.167 & 50161 & 18770 & 68931 & 0 & 44 & 0 & 0 \\
\hline $012 \mathrm{~A} / \mathrm{C}$ & 375.161 & 388.456 & 150312 & 57590 & 207902 & 0 & 141 & 0 & 0 \\
\hline $013 \mathrm{~A} / \mathrm{C}$ & 388.196 & 409.271 & 159424 & 58090 & 217514 & 0 & 300 & 33 & 0 \\
\hline 014A/D & 409.266 & 416.590 & 91569 & 28941 & 120510 & 0 & 73 & 196 & 0 \\
\hline $015 \mathrm{~A} / \mathrm{C}$ & 416.590 & 421.242 & 45953 & 14735 & 60688 & 0 & 28 & 67 & 0 \\
\hline $016 \mathrm{~A} / \mathrm{C}$ & 421.246 & 438.653 & 182950 & 68700 & 251650 & 0 & 108 & 409 & 0 \\
\hline $016 \mathrm{~B} / \mathrm{C}$ & 438.648 & 451.121 & 138409 & 52772 & 191181 & 0 & 79 & 320 & 0 \\
\hline $017 \mathrm{~A} / \mathrm{C}$ & 451.107 & 467.378 & 178992 & 68629 & 247621 & 0 & 50 & 0 & 0 \\
\hline $017 \mathrm{~B} / \mathrm{C}$ & $\$ 67.161$ & 474.286 & 72545 & 23302 & 95847 & 3 & 10 & 0 & 0 \\
\hline 018A F & 474.278 & 490.198 & 154345 & 56843 & 211188 & 6 & 35 & 220 & 205 \\
\hline $019 \mathrm{AC}$ & 490.193 & 501.576 & 118107 & 40305 & 158412 & 0 & 58 & 24 & 0 \\
\hline 020A B & 501.563 & 513.328 & 97757 & 48058 & 145815 & 0 & 7 & 21 & 0 \\
\hline 021A B & 513.321 & 526.480 & 156160 & 69170 & 225330 & 0 & 2 & 0 & 0 \\
\hline $022 \mathrm{~A} \cdot \mathrm{B}$ & 526.478 & 541.537 & 172533 & 64458 & 236991 & 0 & 5 & 0 & 1 \\
\hline 022B A & 541.532 & 550.332 & 115831 & 73133 & 188964 & 0 & 4 & 0 & 0 \\
\hline $023 \mathrm{~A} \mathrm{~B}$ & 550.252 & 562.241 & 113601 & 50159 & 163760 & 0 & 24 & 161 & 0 \\
\hline
\end{tabular}

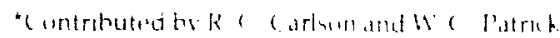


Table 10-1. (Continued.)

\begin{tabular}{|c|c|c|c|c|c|c|c|c|c|}
\hline \multirow{3}{*}{$\begin{array}{c}\text { File } \\
\text { name }\end{array}$} & \multirow{2}{*}{\multicolumn{2}{|c|}{ Time (absolute Julian day)" }} & \multirow{2}{*}{\multicolumn{3}{|c|}{ Number of data poinls }} & \multicolumn{4}{|c|}{ Number of errors } \\
\hline & & & & & & \multicolumn{2}{|c|}{ Range } & \multirow[b]{2}{*}{ License } & \multirow{2}{*}{$\begin{array}{l}\text { License and } \\
\text { channel }\end{array}$} \\
\hline & Start & Stop & Cupied & Discard & Total & $\overline{\mathrm{TOR}}$ & $\mathrm{VOR}^{6}$ & & \\
\hline $024 \mathrm{~A} / \mathrm{B}$ & 557.484 & 576.247 & 72353 & 31718 & 102071 & 0 & 38 & 2 & 0 \\
\hline $025 \mathrm{~A} / \mathrm{C}$ & 529.807 & 590.272 & 104444 & 31095 & 135539 & 0 & 60 & 39 & 0 \\
\hline $026 \mathrm{~A} / \mathrm{C}$ & 577.327 & 610.26 .3 & 84131 & 117970 & 202101 & 0 & 13 & 8 & 0 \\
\hline $027 \mathrm{~A} / \mathrm{C}$ & 610.564 & 618.247 & 40686 & 203970 & 244650 & 12 & 8 & 84 & 229 \\
\hline $028 \mathrm{~A} / \mathrm{C}$ & 618.247 & 632.397 & 84205 & 165522 & 249727 & 2 & 16 & 204 & 0 \\
\hline $029 \mathrm{~A} / \mathrm{C}$ & 632.368 & 651.453 & 88284 & 164419 & 252703 & 0 & 11 & 12 & 0 \\
\hline $029 \mathrm{~B} / \mathrm{C}$ & 650.669 & 661.224 & 30935 & 53536 & 84471 & 0 & 266 & 3 & 0 \\
\hline $030 \mathrm{~A} / \mathrm{C}$ & 656.339 & 686.187 & 90861 & $157+47$ & 248308 & 1 & 7 & 3 & 47 \\
\hline $030 \mathrm{~B} / \mathrm{B}$ & 686.067 & 695.245 & 45207 & 95148 & 140355 & 0 & 4 & 3 & 0 \\
\hline $031 \mathrm{~A} / \mathrm{C}$ & 695.350 & 705.889 & 48881 & 43058 & 91942 & 14 & 186 & 19 & 606 \\
\hline $032 \mathrm{~A} / \mathrm{C}$ & 703.304 & 722.290 & 78070 & 80297 & 158367 & 3 & 8 & 102 & 23 \\
\hline 033A/C & 722.617 & 781.117 & 124320 & 123839 & 248159 & 1 & 37 & 1 & 160 \\
\hline 034A B & 723.271 & 772.087 & 141038 & 108318 & 249356 & 0 & 79 & 11 & 0 \\
\hline 034B!B & 772.087 & 781.122 & 22451 & 20664 & 43115 & 0 & 2 & 1 & 0 \\
\hline $035 \mathrm{~A} / \mathrm{C}$ & 781.126 & 801.610 & 72433 & 56439 & 128872 & 0 & 22 & 1 & 245 \\
\hline $036 \mathrm{~A} / \mathrm{C}$ & 781.122 & 802.173 & 45460 & 54589 & 100049 & 0 & 286 & 3 & 678 \\
\hline 037A/B & 802.184 & 826.246 & 125763 & 122361 & 248124 & 0 & 6 & 3 & 0 \\
\hline 037B/B & 826.180 & 842.202 & 60618 & 60467 & 121085 & 0 & 5 & 184 & 0 \\
\hline $038 \mathrm{~A} / \mathrm{C}$ & 837.205 & 852.215 & 59890 & 51625 & 111515 & 1 & 2 & 1 & 0 \\
\hline $039 \mathrm{~A} / \mathrm{B}$ & 852.223 & 873.582 & 106996 & 129470 & 236466 & 0 & 12 & 206 & 0 \\
\hline 039B B & 873.582 & 890.343 & 139520 & 72851 & 212371 & 1 & 28 & 28 & 0 \\
\hline $040 \mathrm{~A} / \mathrm{A}$ & 890.566 & 905.159 & 65577 & 89464 & 155041 & 0 & 10 & 20 & 0 \\
\hline 041A A & 905.151 & 932.186 & 137485 & 114641 & 252126 & 0 & 31 & 6 & 0 \\
\hline $041 \mathrm{~B} / \mathrm{B}$ & 932.184 & 939.266 & 30576 & 27134 & 57710 & 0 & 2 & 1 & 0 \\
\hline U42A/B & 939.300 & 965.522 & 119826 & 124187 & 244013 & 2 & 102 & 80 & 0 \\
\hline $042 \mathrm{~B} / \mathrm{A}$ & 965.484 & 984.225 & 78904 & 82118 & 161022 & 0 & 5 & 75 & 0 \\
\hline $043 A^{\prime} E$ & 990.234 & 5005.301 & 101456 & 119178 & 220634 & 1 & 117 & 1869 & 12 \\
\hline $044 \mathrm{~A}: \mathrm{B}$ & 45005.305 & 5053.225 & 132236 & 114582 & 246818 & 2 & 6 & 109 & 166 \\
\hline $045 \mathrm{~A} / \mathrm{A}$ & 45005.260 & 45030.390 & 87612 & 48097 & 135709 & 0 & 44 & 333 & 0 \\
\hline $045 B / A$ & 45030.397 & 45053.204 & 81367 & 47567 & 128934 & 0 & 72 & 0 & 0 \\
\hline 046A/D & 45053.229 & 45077.681 & 186845 & 59844 & 246689 & 1 & 111 & 59 & 46 \\
\hline 046B/B & 45077.681 & 45080.213 & 137590 & 112400 & 149990 & 0 & 14 & 0 & 0 \\
\hline 047A/D & 45053.207 & 45080.231 & 116475 & 79060 & 195535 & 1 & 562 & 3 & $4 b$ \\
\hline 048A/A & 45080.271 & 45084.987 & 115728 & 12690 & 28418 & 0 & 13 & 319 & 0 \\
\hline 049A/B & 45080.683 & 45106.363 & 84845 & 166315 & 251160 & 1 & 154 & 16 & 493 \\
\hline $049 \mathrm{~B} / \mathrm{A}$ & 45106.361 & 45109.549 & 21836 & 16270 & 38106 & 0 & 15 & 1 & 0 \\
\hline $050 \mathrm{~A} / \mathrm{B}$ & 45085.646 & 45103.386 & 44184 & 34166 & 78350 & 1 & 49 & 16 & 217 \\
\hline 051A/A & 45110.252 & 45133.155 & 187505 & 67807 & 255311 & 0 & 260 & 66 & 0 \\
\hline 051B/B & 45133.153 & 45152.179 & 149434 & 58448 & 207882 & 0 & 82 & 104 & 0 \\
\hline 052A/A & - & - & 0 & 125108 & 125108 & 8738 & 20 & 8775 & 112568 \\
\hline $053 \mathrm{~A} / \mathrm{B}$ & 45129.603 & 45148.636 & 177163 & 55377 & 232540 & 1 & 51 & 1 & 46 \\
\hline 054A/A & 45152.319 & 45177.430 & 28130 & 23752 & 51882 & 0 & 2 & 0 & 0 \\
\hline $055 \mathrm{~A} / \mathrm{C}$ & 45152.182 & 45169.359 & 161569 & 91101 & 252670 & 433 & 24 & 576 & 5035 \\
\hline $055 B / C$ & 45169.354 & 45177.468 & 38772 & 93132 & 131904 & 1731 & 22 & 1769 & 65921 \\
\hline $056 \mathrm{~A} / \mathrm{A}$ & 45177.431 & 45201.199 & 77471 & 68863 & 146334 & 0 & 65 & 773 & 0 \\
\hline 057A:A & 45177.411 & 45201.192 & 70506 & 61908 & 132414 & 0 & 97 & 168 & 0 \\
\hline 058A A & 45201.192 & 45221.369 & 36943 & 62424 & 119367 & 0 & 39 & 162 & 0 \\
\hline 059A A & 45201.199 & 45218.443 & 50135 & 204568 & 254703 & 0 & 5 & 189 & 0 \\
\hline $060 \mathrm{~A} A$ & 45226.448 & 45256.339 & 76218 & 88038 & 164256 & 0 & 4 & 21 & 0 \\
\hline $061 \mathrm{~A} \mathrm{~A}$ & 45221.416 & +5256.336 & 99734 & 92536 & 192270 & 0 & 49 & 0 & 0 \\
\hline
\end{tabular}


Table 10-1. (Continued.)

\begin{tabular}{|c|c|c|c|c|c|c|c|c|c|}
\hline \multirow{3}{*}{$\begin{array}{l}\text { File } \\
\text { name }\end{array}$} & \multirow{2}{*}{\multicolumn{2}{|c|}{ Time (absolute fulian dayl" }} & \multirow{2}{*}{\multicolumn{3}{|c|}{ Number of data points }} & \multicolumn{4}{|c|}{ Number of errors } \\
\hline & & & & & & \multicolumn{2}{|c|}{ Range } & \multirow[b]{2}{*}{ License } & \multirow{2}{*}{$\begin{array}{l}\text { License anc } \\
\text { channel }\end{array}$} \\
\hline & Start & Stop & Copied & Discard & Total & $\mathrm{TUR}^{\mathrm{K}}$ & VOR' & & \\
\hline $062 \mathrm{~A} A$ & 45256.339 & 45288.544 & $1+1186$ & $1061+8$ & 247334 & 1 & 12 & 245 & 46 \\
\hline $062 B / A$ & 45288.533 & 45292.298 & 19574 & 199242 & 39498 & 0 & 5 & 167 & 0 \\
\hline $063 \mathrm{~A} A$ & 45256.339 & $+5285,208$ & 62320 & 55826 & 118146 & 0 & 30 & 109 & 0 \\
\hline $064 \mathrm{~A} A$ & +5292.298 & 45331.300 & 115960 & 125014 & 240774 & 1 & 1191 & 29 & 46 \\
\hline 065A $/ \mathrm{A}$ & 45292.219 & 45339.403 & 127878 & 127829 & 255707 & 1 & 83 & 7 & 46 \\
\hline $065 B / A$ & 45339.406 & 45340.228 & 1297 & 481 & 1784 & 0 & 0 & $\mathbf{0}$ & 0 \\
\hline $066 \mathrm{~A} / \mathrm{A}$ & 45341.326 & 45359.430 & 27484 & 27326 & 54810 & 0 & 0 & 22 & 0 \\
\hline $067 \mathrm{~A} / \mathrm{A}$ & 45340.229 & 45379.239 & 141259 & 109019 & 250278 & 0 & 4299 & 1 & 0 \\
\hline $067 \mathrm{~B} / \mathrm{A}$ & 45379.239 & 45396.197 & 52839 & +1121 & 93960 & 0 & 17 & 0 & 0 \\
\hline $068 \mathrm{~A} / \mathrm{B}$ & 45359.430 & 45396.235 & 97187 & 103609 & 200796 & 1 & 14 & 319 & 46 \\
\hline 069 A B & 45397.554 & 45436.390 & 126985 & 127955 & 254940 & 45 & 7 & 413 & 88 \\
\hline 069B/B & 45436.390 & 45453.232 & 42422 & 20740 & 63162 & 0 & 0 & 0 & 0 \\
\hline 070A:B & 45396.197 & 45429.555 & 137282 & 112707 & 249989 & 0 & 89 & 140 & 0 \\
\hline 070B / B & 45429.558 & 45453.226 & 74244 & 282.42 & 102486 & 0 & 40 & 258 & 0 \\
\hline 071A:B & $45+53.235$ & 45521.314 & 167626 & 86240 & 253866 & 0 & 119 & 0 & 0 \\
\hline $071 B / B$ & 45521.312 & 45533.418 & 198636 & 24606 & 223242 & 0 & 819 & G & 0 \\
\hline 072A/D & 45453.229 & 45527.182 & 178901 & 75150 & 254051 & 349 & 304 & 327 & 14331 \\
\hline 072B/B & 45527.184 & 45544.350 & 33302 & 10198 & 43500 & 0 & 428 & 66 & 0 \\
\hline $073 \mathrm{~A} / \mathrm{B}$ & 45533.418 & 45596.208 & 169408 & 84416 & 253824 & 0 & 591 & 112 & 0 \\
\hline 073B/A & 45596.208 & 45632.198 & 36513 & 44286 & 80799 & 0 & 524 & 168 & 0 \\
\hline $074 \mathrm{~A} / \mathrm{B}$ & 45544.350 & 45613.077 & 165178 & 55213 & 220391 & 1 & 746 & 2660 & 54 \\
\hline $075 \mathrm{~A} / \mathrm{A}$ & 45613.080 & 45632.194 & 7404 & 14671 & 22075 & $\mathbf{0}$ & ग & 0 & 0 \\
\hline \multicolumn{10}{|l|}{ Totals } \\
\hline $00-45$ & 44331.437 & 45053.225 & 4785368 & 3601064 & 8386932 & 99 & 4599 & 4933 & 2663 \\
\hline $46-65$ & 45053.229 & 45340.228 & 2249098 & 2009035 & 4258133 & 10910 & 3056 & 14075 & 184510 \\
\hline $66-75$ & 45341.326 & 45632.194 & 1656670 & 965499 & 2622169 & 395 & 7997 & 4486 & 14519 \\
\hline overall & 44331.437 & 45632.194 & 8691636 & 6575598 & 15267234 & 11404 & 15652 & 23494 & 201692 \\
\hline
\end{tabular}

‘ The absolute Julian day minus $2,400,000$ was used to limit the number of significant digits in the archived data string.

' TOR, time out of range.

'VOR, value out of range.

\subsection{Considerations for Future Studies*}

Based on our experiences in developing and using data acquisition and data management systems, we offer the following observations. First, the dual computer-based DAS provided exceptional reliability, even though deployed in a remote location and largely left unattended. Second, segmenting the DAS into a down-hole component for digitizing signals and a surface-based component for controlling acquisition and archiving functions played a key role in ensuring high-quality data with minimai sine loss and electrical noise problems. Third, an extender switching network produced substantial improvements in system reliability. Fourth, the particular needs and priorities of a future project should be carefully considered in deciding whether or not to integrate the DAS and DMS. At the SFT-C, separation of these systems allowed the test to proceed on schedule, with no delays associated with DMS software development. However, additional technical difficulties, and both equipment and human interfac s problems, resulted from the separation.

"Contributed by W C Patrick 


\section{Spent-Fuel Handling Experience*}

Spent-fuel handling e'veriences at the SFT--( directly address the principal objective of the test: demonstration of the feasibility of safe and reliable transport, storage, and retrieval of spent nuclear fuel. To achieve this demonstration, we emplaced, stored for 3 years, and retrieved 11 canistered spent-fuel assemblies. Three exch anges of spent-fuel assemblies between EMAD and the SFT-C were conducted at regular intervals to further this demonstration and to maintain readiness of personnel and equipment for retrieval.

\subsection{Operating Procedures and Training}

In addition to the mechanical and electrunics systems described in Chapter 7 , we developed operating procedures and provided for personnel prequalitication and training to ensure safe and reliable handling of the spent fuel.

We developed the following detailed technical operating procedures (TOPs):

- Access Controls During Controlled SFT-C Operations, LLL-TOP-001.

- Transfer of Fuel Canister Assemblies Between Area 25 (EMAD) and Area 15 (SFT-C) at NTS, LLL-TOP-002.

- Transfer of Spent-Fuel Canister from Surface Transport Vehicle to Storage Hole, LLL-TOP-003.

- Retrieval of Spent-Fuel Canister From Storage Hole to Surface Transport Vehicle, LLL-TOP-004.

- Remove Spent-Fuel Canister From Storage Hole for Examination and Reemplace, LLL-TOP-005.

- Remove Spent-Fuel Canister from Storage Hole and Transfer to Another Storage Hole, LLL-TOP-006.

These TOPs, although not referenceable documents, were retained in the SFT-C project records. Because the TOPs comprise detailed checklists and written instructions for each step of the handling operation, the completed TOPs constitute a thorough record of each handling operation. Any exceptions, abnormal occurrences, or overriding of control system interlocks were documented in these records.

For handling operations at the EMAD facility, Westinghouse operators were trained to use the handling systems that were unique to the SFT -C. A Westinghouse supervisor/observer and operations controller were available. In addition, an LLNL cognizant engineer and a technician who were familiar with the mechanical and electronic aspects of the handling system were present. At the SFT $-C$, the team consisted of two operators and a control room supervisor, under the administrative control of the SFT -C Task Director. Any abnormal occurrences required direct intervention by the Task Director who had custody of the key needed to override the automatic system interlocks.

The operations team at the SFT-C and the STV driver and escort were selected based on technical skills and medical prequalification. All electronic and mechanical technicians and engineers who filled the operations team positions had previous direct involvement in design, fabrication, or testing of the pertinent systems.

The final stage of operator training (and system evaluation) was a "dry run" in which a simulated spent-fuel assembly was emplaced. This simulated canister was fabricated to have the same physical dimensions as a spent-fuel canister and was appropriately weighted with lead shot.

\subsection{Receipt and Packaging Spent Fuel at EMAD}

Thirteen spent-fuel assemblies from the Turkey Point Unit 3 pressurized water reactor were received at EMAD following shipment from the reactor. These shipments of individual spent-fuel assemblies were made in NRC-licensed shipping casks in accordance with Dept. of Transportation regulations. Table 11-1 provides the schedule for receipt. calorimetry, encapsulation, and removal of these assemblies from canisters.

Following removal from the truck-mounted shipping cask and inspection, each spent-fuel assembly was encapsulated in a stainless steel canister (Chapter 7). Once the threaded lid was installed, the canister

\footnotetext{
"Contributed by W. C. Patrick
} 
Table 11-1. Receipt, encapsulation, and testing history of spent-fuel assemblies for the SFT-C.

\begin{tabular}{|c|c|c|c|c|}
\hline $\begin{array}{l}\text { Fuel assembly } \\
\text { serial number }\end{array}$ & $\begin{array}{c}\text { Daterecoived } \\
\text { at finta }\end{array}$ & $\begin{array}{c}\text { Date } \\
\text { concipoulated }\end{array}$ & $\begin{array}{l}\text { Date removed } \\
\text { trom eanister }\end{array}$ & $\begin{array}{c}\text { Calorimetry } \\
\text { date }\end{array}$ \\
\hline . & & 20 & & $\cdots-\cdots$ \\
\hline Du1 & 121274 & 121274 & 51484 & - \\
\hline Dut & 121174 & $121174(52380)^{4}$ & 52184 & 52080,82885 \\
\hline D06 & 113079 & $1130-4$ & 62183 & - \\
\hline D04 & 100974 & 100474 & $3+85$ & - \\
\hline D 15 & 112679 & $112774(1 ; 81)$ & 72683 & $\begin{array}{c}7880,1.681 \\
72883,82285\end{array}$ \\
\hline DI6 & 102274 & $1022-4$ & $b+85$ & - \\
\hline D18 & 102079 & 102079 & 6785 & - \\
\hline $\mathrm{D} 22$ & 111274 & $111274(8780) "$ & 225.85 & $74: 80,8: 2985$ \\
\hline D34 & 110179 & $110174(+180)^{4}$ & 326.84 & $\begin{array}{c}4180,3: 29: 84^{\mathrm{h}} \\
8: 21: 85\end{array}$ \\
\hline D35 & 111574 & 111579 & b $12: 85$ & - \\
\hline$D+0$ & $4 \geq 179$ & 92179 & 7.17 .85 & - \\
\hline D46 & 42579 & 92579 & $7 \cdot 31: 85$ & - \\
\hline $\mathrm{D}+7$ & 10179 & 10174 & 8285 & - \\
\hline
\end{tabular}

t Second date indicates welding date for those cases where the lid was not initially welded to permit calorimetry and other testing.

${ }^{b}$ Calorimeter results were invalid.

was remotely seal-welded, evacuated, backfilled with helium gas, and lezk-tested. Calorimetry and dosimetry were conducted on selected spent-fuel assemblies before encupsulation and at later times (Chapter 6). The reader is referred to Bensky et al. (1979) and NVO-198 (1978) for further information on EMAD receipt, ercapsulation, and testing operations.

\subsection{Initial Spent-Fuel Emplacement}

Following receipt and encapsulation of the Turkey Point spent-fuel assemblies and preparation of the SFT-C facilities, emplacement of spent fuel began on April 18, 1980. In addition to the "dry run" with a simulated spent-fuel assembly, a "hot" dry run was conducted using spent-fuel assembly D40. This assembly was transported from EMAD to the SFT-C, temporarily emplaced in canister emplacement hole (CEH) number 11 on April 15, 1980, and retrieved on April 17, 1980. Emplacement and retrieval of D40 in CEH11 was the final confirmation that all systems were ready for the first official emplacement.

On April 18, 1980, full press, radio, and television coverage was provided by local and national media representatives. On the days that followed, emplacement activities continued until all 11 spent-fuel assemblies were in storage without incident or significant radiation exposure to operating personnel (Table 11-2). The eleventh spent-fuel assembly was emplaced May 28, 1980, completing the six-week activity. As discussed in Chapter 12, the electrical simulators located in CEH02, 04, 06, 13, 15, and 17 were energized during the same time frame.

\subsection{Spent-Fuel Exchanges}

To ensure a continued state of readiness for both personnel and equipment, we exchanged spent fuel at regularly scheduled intervals of 9 to 10 months. These exchanges were conducted during two-week periods. The first week was spent demothballing and testing the equipment, including a full "dry run" using the spent-fuel simulator described previously. During the second week, a spent-fuet assembly was retrieved, raised to the surface, transported to EMAD, and placed in dry storage in the lay storage area in the floor of the EMAD shielded highbay. Another spent-fuel assembly canister was then loaded into the STV, transported to the SFT-C, and emplaced in the designated canister emplacement hole. Three exchanges were conducted during the 3-vear storage period. 
Table 11-2. Spent-fuel emplacement schedule.

\begin{tabular}{ccc} 
Location & $\begin{array}{c}\text { Fuel assembly } \\
\text { serial number }\end{array}$ & $\begin{array}{c}\text { Fmplacement } \\
\text { date }\end{array}$ \\
\hline CEH03 & DH0 & +1880 \\
CEH16 & D18 & 42280 \\
CEH01 & D34 & +2580 \\
CEH05 & 046 & +2980 \\
CEH12 & D04 & 50180 \\
CEH14 & D35 & 50680 \\
CEH09 & 047 & 50880 \\
CEH07 & D06 & 51380 \\
CEH10 & $D 01$ & 51580 \\
CEH08 & $D 16$ & 52080 \\
CEH11 & D04 & 52880 \\
\hline
\end{tabular}

The first exchange was successfully completed January 12-14, 1981, about eight months after the initial spent-fuel emplacement. At that time, fuel assembly serial number ( $/ N) D 09$ was retrieved and returned to EMAD, and S/N 215 replaced it in CEH12. Nine months later, on October 26-28, 1981, S/N D06 was retrieved from $\mathrm{CEH} 07$ and was replaced by S/N D09, which had been removed from the array in the previous exchange.

The final exchange took place 10 months later, in August 1982, which was about 7 months before all of the spent fuel was retrieved. This exchange was somewhat more complex than the previous two. On August 16, 1982, fuel assembly S/N D04 was removed from CEH11 and returned to EMAD lag storage. Fuel assembly S/N D 18 was then moved from CEH16 to CEH11 on the sanie day to maintain the same decay heat level in the middle portion of the test array. On August 18, 1982, fuel assembly S/N D22, with a known lower burnup and lower power output, was emplaced in CEH16. By placing it near the end of the array, the effect of its lower power output was minimized.

During this same period, S/N D34 in CEH01 was removed and inspected, using closed-circuit television and remote swipe sampling. This was done to evaluate potential damage to the canister that may have occurred as a result of a leaking emplacement borehole liner (Chapter 18). No problems were revealed during the inspection.

All exchanges were completed without incident or significant personnel radiation exposure.

\subsection{Spent-Fuel Retrieval Operations}

The SFT $-\mathrm{C}$ was originally planned to last from 3 to 5 years, depending on when peak thermal and thermomechanical effects were observed (Ramspott et al., 1979). When it became evident that peak conditions were occurring, plans were made for a nominal 3-year test duration (Ballou et al., 1982).

Beginning in late February 1983, we demothballed and tested the handling systems. Because of the duration of the project, several personnel were no longer available to fulfill their usual roles. New personnel were selected, trained, and qualified in preparation for retrieval operations.

Following a "dry run" operation, spent-fuel retrieval began with the removal of S/N D34 from CEH01. The retrieval schedule displayed in Table 11-3 was followed until all 11 spent-fuel assemblies had been resmoved and returned to EMAD lag storage. In 1986, the 13 spent-fuel assemblies used in the SFT-C were shipped to the Idaho National Engineering Laboratory. All retrievals were accomplished without incident or significant radiation exposure.

As discussed in Chapter 12, the electrical simulators located in CEH(02, 04, 06, 13, 15 , and 17 were deenergized and removed during this time frame. The 20 auxiliary heaters in the side drifts were also deenergized and removed. In addition, the emplacement hole liners were extracted for examination and to facilitate post-test geolugical sampling. 
Table 11-3. Spent-iuel retrieval schedule.

\begin{tabular}{|c|c|c|}
\hline Location & $\begin{array}{l}\text { Fuet ansembly } \\
\text { serial number }\end{array}$ & $\begin{array}{c}\text { Retrieval } \\
\text { date }\end{array}$ \\
\hline CEHOI & B.34 & 30.383 \\
\hline CEHIG & 022 & 30783 \\
\hline CEH03 & $D 40$ & 31083 \\
\hline CFHOS & $19+6$ & 31483 \\
\hline CEH1; & 1135 & 31683 \\
\hline CEH12 & $\mathrm{D} 15$ & $\begin{array}{ll}32283 \\
\end{array}$ \\
\hline CEH $0^{\circ}$ & D.t & $32+83$ \\
\hline CEHOT & {$[04$} & 32483 \\
\hline CEH॥ & D18 & 33183 \\
\hline CEH08 & D16 & +0483 \\
\hline CEHU & no1 & +0683 \\
\hline
\end{tabular}

During, these retrieva operations, we installed additional instrumentation in two of the canister emplacement boreholes (see Chapters 4 and 16). To capture the early-time cooling response of the rock surrounding these boreholes, it was necessary to have personnel underground while a spert-fuel assembly. was in the UTV. Persc nnel dose rates were still maintained at very low levels by parking the UTV as far as possible from the work area.

\subsection{Personnel Health and Safety}

The spent-fuel handlirig syste in concepts used at the SFT-C (Chapter 7) minimized the exposure of operating personnel to ionizing radiation from the spent-fuel assemblies (Chapter 6). As reported by Raschke et al. (1983), a variety of instrumentation was deployed to determine the radiation dose rates throughout the test array during the different phases of operations, and to quantify and limit the personnel exposures.

The shielding design resulted in the neutron contribution to total dose being greater than the gamma contribution. This is shown in Fig. 11-1, which displays dose rates on contact with a transfer cask. In many cases, the gamma dose rate was too small to be measured so it was inferred from the neutron-gamma ratio measured in other locations.

Total radiation exposures were less than 0.4 person-rem for the entire project (Raschke et al. 1983). Although the highest individual exposure was $10 \mathrm{mrem} /$ operation, the average was about $30 \%$ of this value (Fig. 11-2). An "operation" is considered here to be the emplacement or retrieval of a single spentfuel assembly. Maximum personnel doses and area radiation levels at various times and locations are given in Table 11-4.

If we compare Fig. 11-2 with Table 11-4, we see that only part of the reduction in personnel fose during retrieval operations is attributable to decay. In the case of neutron dose, we see a decrease of a factor of four while the contact dose : ate decreases by only a factor of two. We attribute the factor-of-two difference between these values to a decrease in exposure time during retrieval operations.

Following spent-fuel handling operations, team members submitted urine samples that were analy:ed for gamma-emitting isotopes and tritium (HTO). These bioassays led to the conclusion that no measureable internal dose was received by any SFT $-C$ team member.

Raschke et al. (1983) compared the dose commitment associated with spent-fuel storage to that received during reactor operations. Their analysis was based on SFT-C data for fli al aged 2.5 to 5.5 YOC and assumed an operator in a full-scale repository would conduct 1000 emplacernents per year. This hypothetical operator would have a normalized dose commitment of 0.002 person-rem/MW $y$ (electric), a very small fraction of the one-to-four person-rem $/ \mathrm{MW} \cdot \mathrm{y}$ (electric) received during nuclear power plant operations (Cross, 1980). 


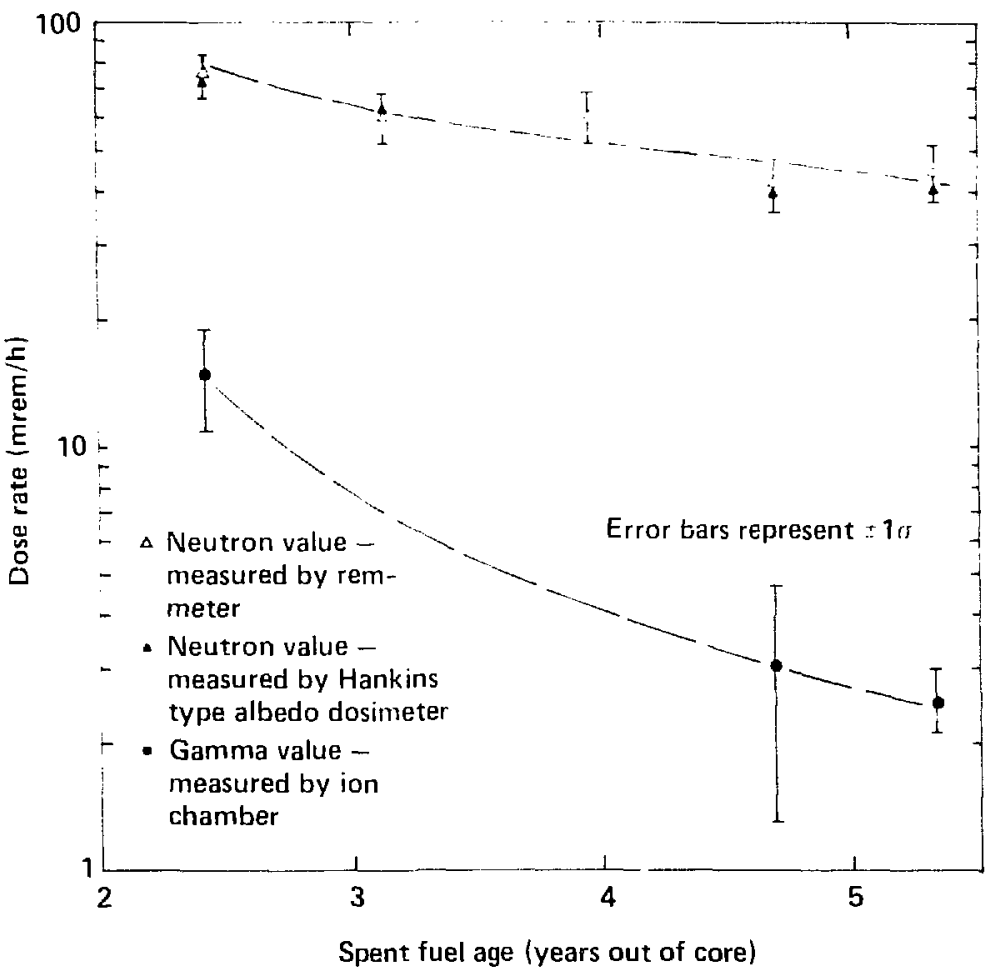

Figure 11-1. Contact dose rates at transfer cask containing fuel assembly (after Raschke, et al., 1983).

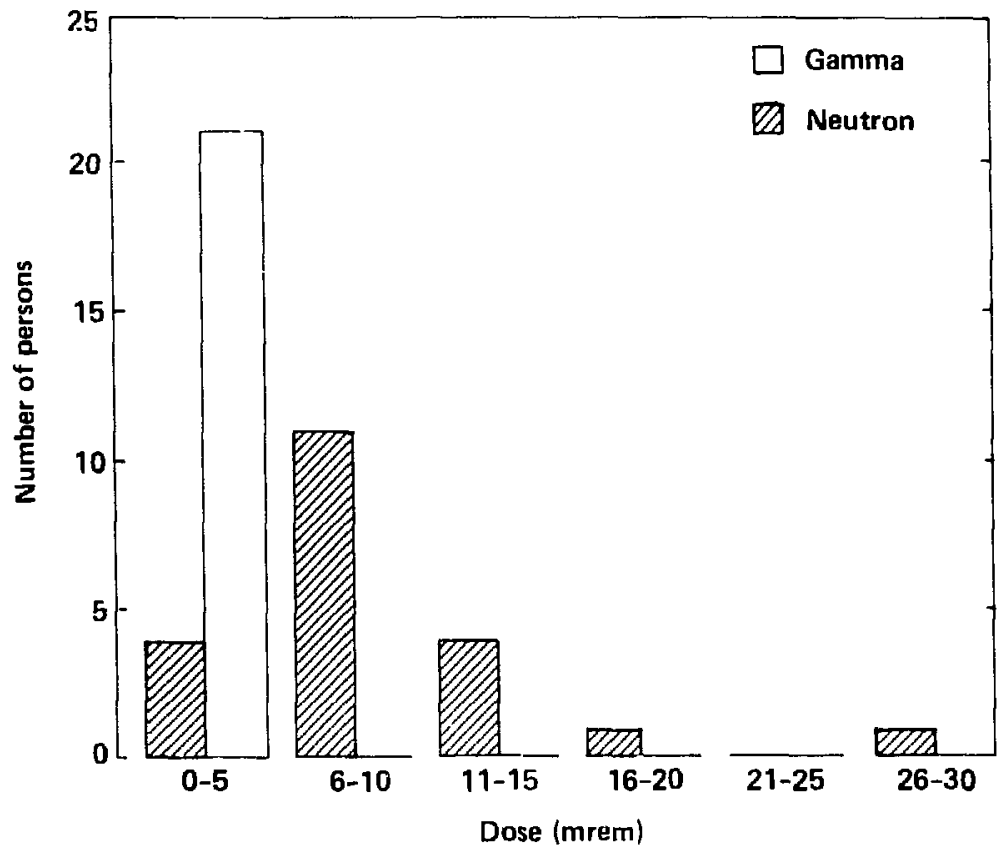

Figure 11-2. SFT-C personnel dose distribution during spent-fuel retrieval (after Raschke, et al,, 1983). 
Table 11-4. Maximum personnel doses and area cadiation levels associated with spent-fuel handling operations ${ }^{\text {` }}$ (after Raschke et al., 1983).

Operation

Fuel emplacement

Fuel storage

Fuel retrieval

Location

Transfer casks (at contact), mrem h

Truck (inside cab), mrem $h$

Access hole headframe (top), mrem operation

Underground canister drift area

at top of shield plug, mrem $h$

During emplacement, mrem aperation

During storage, mrem h

During retrieval, mrem operation

Other monitored underground locations

Personnel doses

(mrem operation)

$\begin{array}{ccc}\text { Gamima } & \text { (mrem operation) } & \text { Neutron } \\ 2 & & 8 \\ 0 & & - \\ 0.1 & \text { Radiation Levels } & 2\end{array}$

15

0.1

75

0.3

1

1

0

$0.3+5$

0 0 0

- Natural background levels have been subtracted from these values.

- Neutron exposures were measured with albedo dosimeters; personnel gamma exposures were estimated from measured neutron gamma ratios.

'Not measured. 


\section{Thermal Sources*}

Three principal heat sources were teployed to produce the thermal condiinons necessary to support the test objective of simulating the effects if a panel of a full-scale repository. In addition to the spent-fuel assemblies, electrical simulators, and auxiliary heaters, several incidental sources of heat were also present. Each source is described briefly below:

\subsection{Pressurized Water Reactor Fuel Assemblies}

Since the SFT $-\mathrm{C}$ was designed to simulate the first rew years of disposal in an actual repository, it was necessary to produce thermal conditions that would meet or exceed repository conditions. As described in Chapter 3, we determined that spent-fuel assemblies having cooling times of 2 to 2.5 years at the time of emplacement would provide the required thermal conditions.

Pressurized water reactor (PWR) fuel assemblies from the Florida Power and Light Co. Turkey Point Unit No. 3 were chosen because they would provide the required decay-heat level and were readily available during the time trame of test emplacement. A total of 13 Zircaloy-clad Westinghouse assemblies were shipped to the NTS to be used at the SFT-C. At any given time, no more than 11 of these assemblies were in place at the SFT-C. Additionai information on the characteristics of these assemblies is provided in Chapter 6.

Once received at the EMAD facility at NTS, each assembly was inspected and encapsulated in a stainless steel canister (NVO-210, 1980). These canisters consisted of a 356-mm-outside diameter (14-in.), 9.52-mm (0.375-in.) wall, 304L stainless steel pipe section $3.91 \mathrm{~m}$ (154 in.) long with a $9.52-\mathrm{mm}(0.375$-in.) wall ellipsoidal end cap of the same material. To accommodate a threaded top closure and shield plug fixture, an upper body assembly with 356-mm-outside diameter (14-in.), 23.8-mm (0.937-in.) wail, 304L stainless steel pipe section $229 \mathrm{~mm}$ ( 9 in.) long was welded to the main body (Fig. 12-1). Internal fixtures to stabilize the fuel assembly, thermocouple guide tubes, and an evacuation/back filling port were also included in the canister design (Chapter 7).

Initial calculations indicated that these spent-fuel assemblies would generate about $2.1 \mathrm{~kW}$ of decay heat at the scheduled date of emplacement. Revised calculations (Schmittroth et al., 1982) and calorimetry of selected assemblies (Patrick et al., 1984) established that the actual power level was about $1530 \mathrm{~W}$ at the time of emplacement of the center spent-fuel assembly $2.46 \mathrm{YOC}$. The revised calculated decay heat curve for the spent-fuel assemblies is shown as the smooth curve in Fig. 12-2.

During the period from April 18 to May 28, 1980, 11 spent-fuel assemblies were emplaced in lined boreholes in the canister storage drift of the SFT-C at a rate of two per week (Table 12-1). The storage geometry is as shown in Fig. 12-3. As the test progressed, exchanges of spent fuel were conducted on a regularly scheduled basis (Chapter 11). The three exchanges were:

- Serial number (S/N) D09 was replaced with S/N D15 in emplacement hole CEH12, January 12-14, 1981.

- S/N D06 was replaced with S/N D09 in emplacement hole CEH07, October 26-28, 1981.

- S/N D04 in CEH11 was removed and replaced with S/N D18 from CEH16, and S/N D22 was emplaced in CEH16, August 16-18, 1982.

Following a 3-year storage period, the spent fuel was retrieved and returned to EMAD during MarchApril 1983. The retrieval schedule was as shown in Table 12-2. Power output ranged from $1564 \mathrm{~W}$ at emplacement of the first assembly (2.412 YOC) to $638 \mathrm{~W}$ at the retrieval of the last assembly (5.372 YOC).

After retrieval, boiling-water calorimetry of spent-fuel assembly S/N D15 was performed July 28, 1983 (fuel age $5.687 \mathrm{YOC}$ ) at the Westinghouse EMAD facility. Data obtained from four consecutive condensate collection periods that agreed within $\pm 3 \%$ indicated a decay-heat generation rate of $625 \mathrm{~W}$. This agrees within $3 \%$ of the $609-W$ decay-heat generation rate calculated using the ORIGEN2 code (Chapter 6 ), and used as input to all SFT-C thermal and thermomechanical calculations. The calculated average spent-fuel decay curve, adjusted for all calorimeter results except this most recent minor difference, is shown in Fig. 12-2.

\footnotetext{
*Contributed br II. (. Patric.
} 


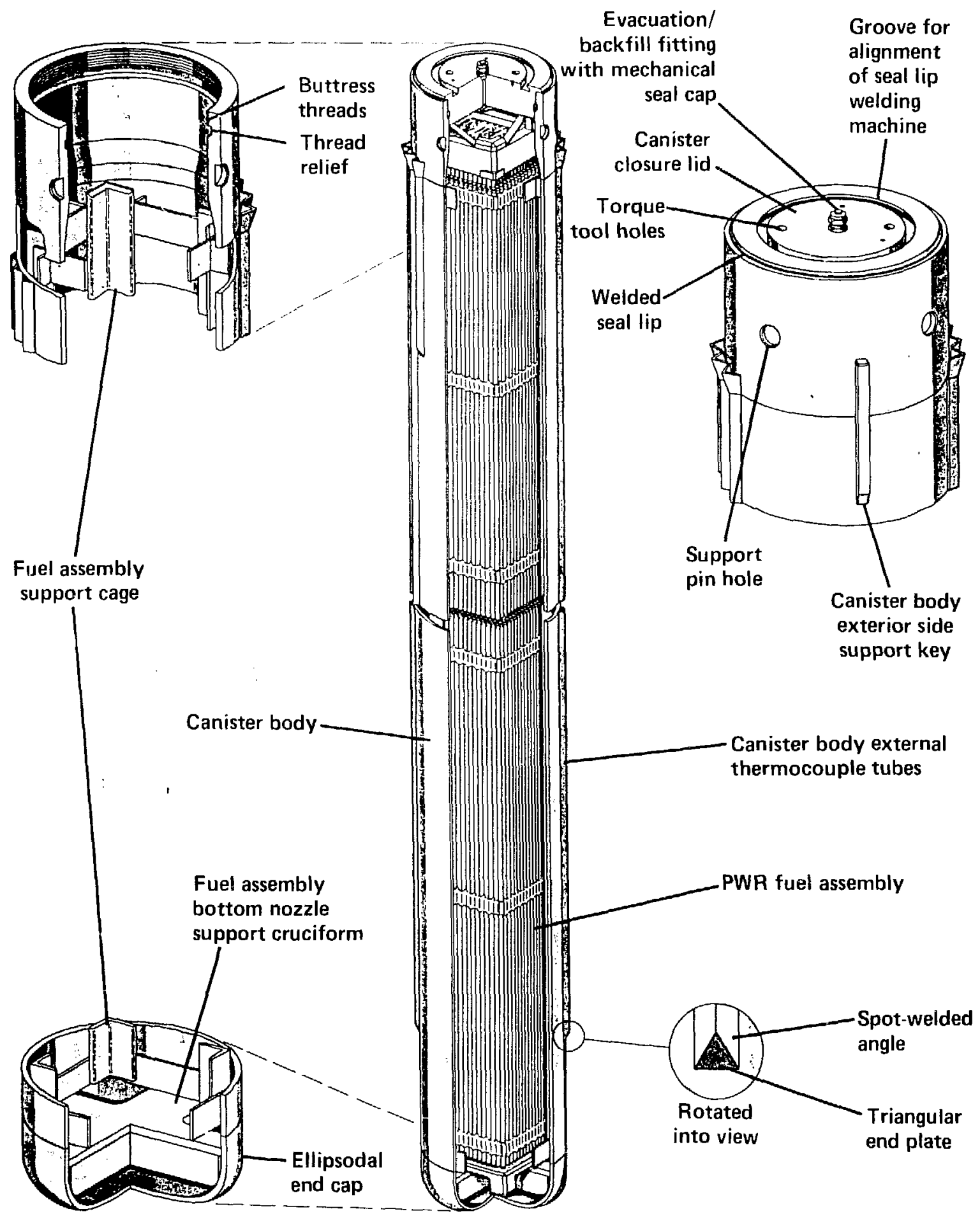

Figure 12-1. Spent-fuel canister assembly (after NVO-210, 1980). 


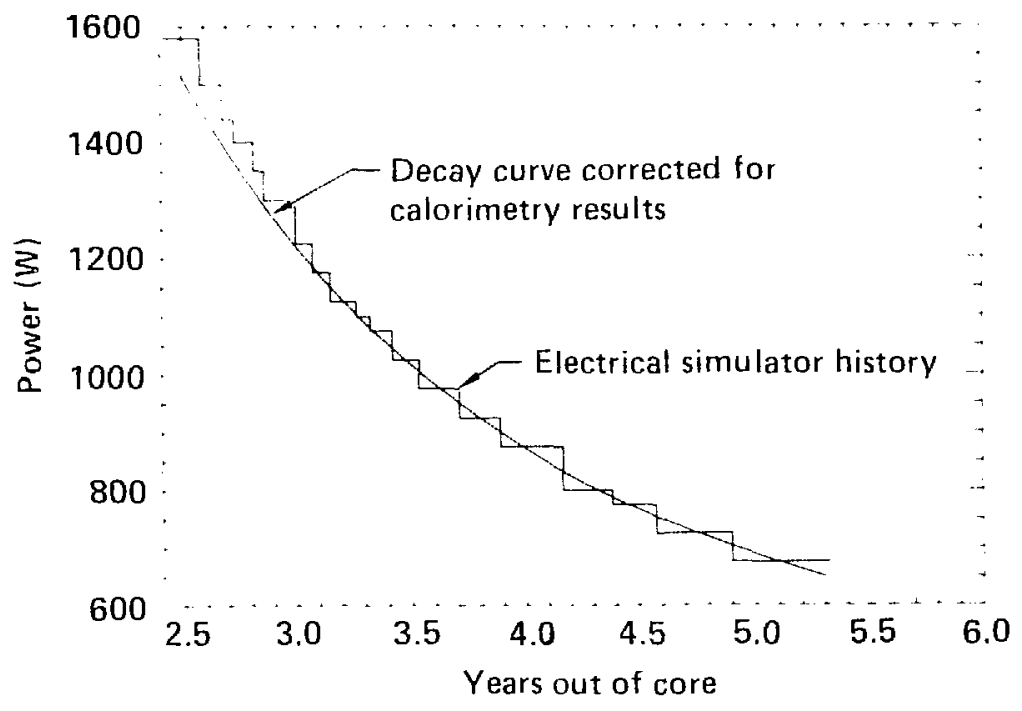

Figure 12-2. PWR fuel assembly and electrical simulator power history.

Table 12-1. Schedule of spent-fuel emplacement and energizing of electrical simulators.

\begin{tabular}{lccc}
\hline \multirow{2}{*}{ Date } & \multicolumn{2}{c}{ Spent fuel emplaced } & Electrical sinulator energized \\
\cline { 2 - 4 } & Emplacement hole & Serial number & CEH15 \\
$4 / 18 / 80$ & CEH03 & D40 & CEH02 \\
$4 / 22 / 80$ & CEH16 & D18 & CEH17 \\
$4 / 25 / 80$ & CEH01 & D35 & CEH13 \\
$4 / 29 / 80$ & CEH05 & D46 & CEH06 \\
$5 / 01 / 80$ & CEH12 & D09 & CEH04 \\
$5 / 06 / 80$ & CEH14 & D35 & - \\
$5 / 08 / 80$ & CEH09 & D47 & - \\
$5 / 13 / 80$ & CEH07 & D06 & - \\
$5 / 15 / 80$ & CEH10 & D01 & - \\
$5 / 20 / 80$ & CEH08 & D16 & - \\
$5 / 28 / 80$ & CEH11 & D04 & \\
\hline
\end{tabular}

\subsection{Electrical Simulators}

To evaluate the effects of heat alone, compared with the combined effects of heat and ionizing radiation, it was necessary to deploy electrical simulators in the test array. A total of six simulators were installed in alternating storage boreholes near the far ends of the canister storage drift (Fig. 3-1).

The simulator heating elements consisted of four tubular resistance heaters mounted in a stainless steel frame that was baffled and shrouded to approximate the heat transfer characteristics of a spent-fuel assembly (Carlson et al., 1980). These heater elements were encapsulated in stainless steel canisters essentially identical to those used for the spent-fuel assemblies and were emplaced in the same storage configuration.

All the simulators were preemplaced and each was energized in sequence when its counterpart spent-fuel assembly was emplaced (Table 12-1). Based on preliminary calorimetry data, the simulators were energized at about $1600 \mathrm{~W}$. When better data became available, the power was reduced. The nominal power levels associated with each set point of the simulator controllers are shown as a stair-step history in Fig. 12-2. Figure 12-4 is a composite of actual 10-day-average power levels for each of the 6 simulators. 


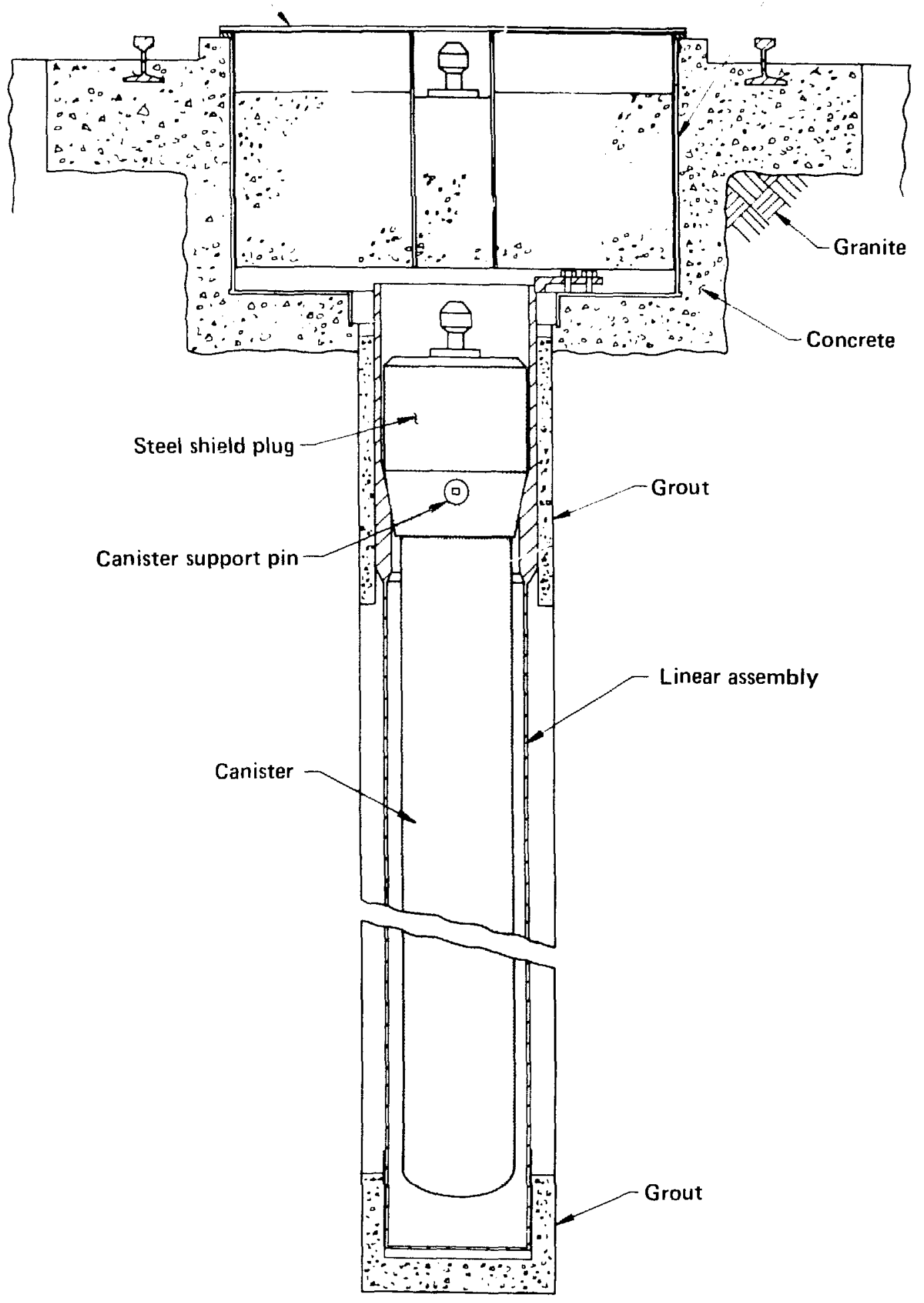

Figure 12-3. Canister storage configuration (Westinghouse Advanced Energy Systems, Pittsburgh, PADwg. No. 615339-1B). 
Table 12-2. Schedule of retrieval of spent fuel and deenergizing of electrical simulators.

\begin{tabular}{ccc} 
Date & $\begin{array}{c}\text { Spent-fuel } \\
\text { retrieved }\end{array}$ & $\begin{array}{c}\text { Electrical simulator } \\
\text { deenergized }\end{array}$ \\
\hline $03 / 03 / 83$ & CEH01 & CEH17 \\
$03 / 07 / 83$ & CEH16 & CEH02 \\
$03 / 09 / 83$ & - & CEH15 \& CEH13 \\
$03 / 10 / 83$ & CEH03 & - \\
$03 / 11 / 83$ & - & CEH04 \& CEH06 \\
$03 / 14 / 83$ & CEH05 & - \\
$03 / 16 / 83$ & CEH14 & - \\
$03 / 22 / 83$ & CEH12 & - \\
$03 / 24 / 83$ & CEH09 & - \\
$03 / 29 / 83$ & CEH07 & - \\
$03 / 31 / 83$ & CEH11 & - \\
$n 4 / 4 / 83$ & CEH08 & - \\
$04 / 6 / 83$ & CEH10 & -
\end{tabular}

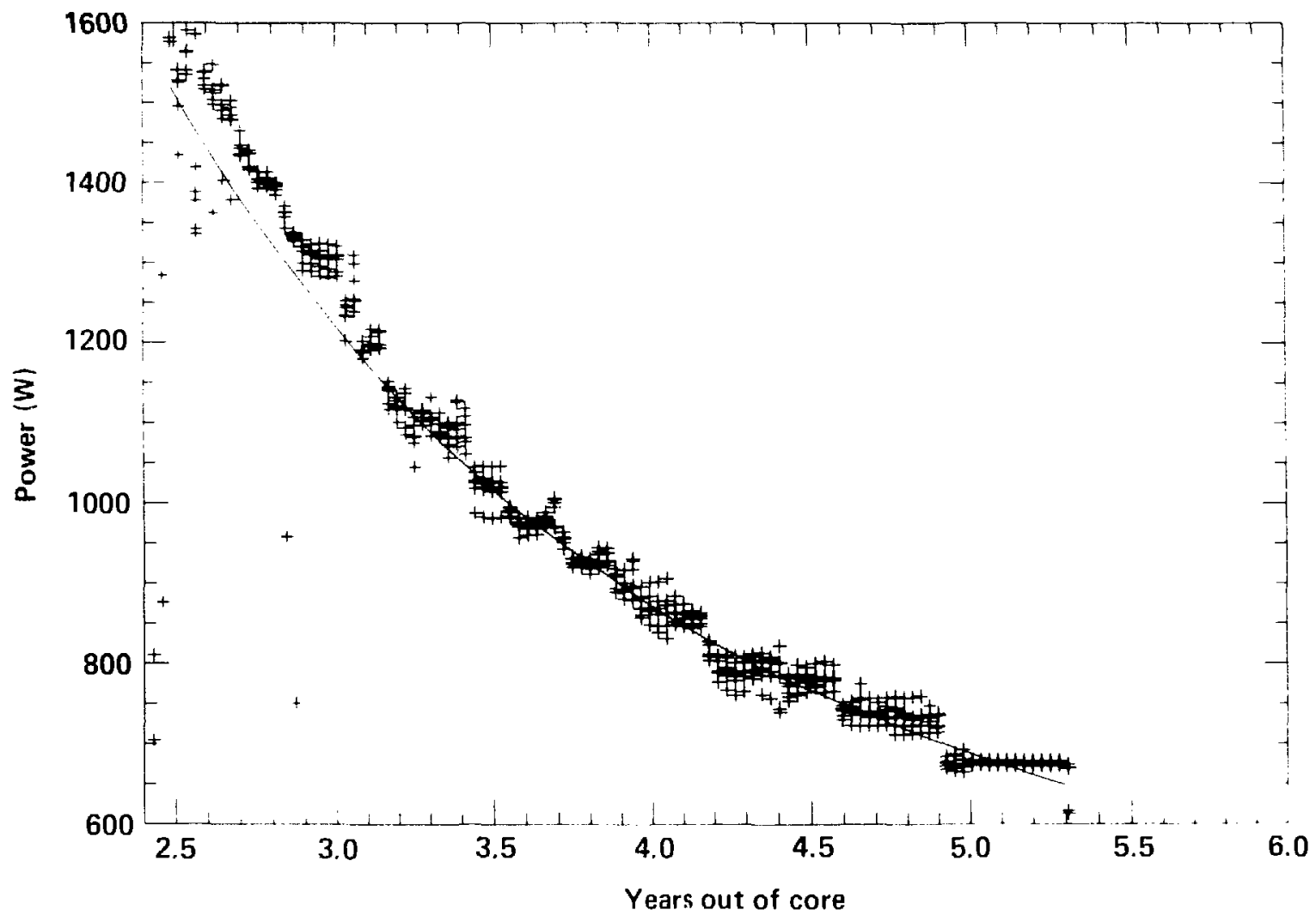

Figure 12-4. Electrical siriulator power history showing effect of loop controller addition at 5.0 YOC. 
Witf minor exceptions, the simulators closely tracked the spent-fuel decay curve. The marked improveme'u in agret'ment between simulator and spent-fuel power levels after 3.1 YOC reflects adjustment of the original calculated curve for calorimeter results and a commensurate adjustment in simulator power levels.

Near the end of the test, a set of loop controllers with power-sensing feedback was installed to provide better control of simulator power (Chapter 9). These controllers substantially reduced variations in simulator power. The data beyond 5.0 YOC in Fig. 12-4 confirms the marked reduction in variability achieved with the new controllers. At the completion of the SFT $-C$, the simulators were deenergized and removed from their respective emplacement boreholes (Table 12-2).

\subsection{Auxiliary Heaters}

Each of the 2 parallel heater drifts was equipped with 10 electrical heaters located in small-diameter boreholes on 6-m centers. Loop-type electrical resistance heaters were used with metal disks positioned along the heater elements to center them in the borehole (Brough and Patrick, 1982). These auxiliary heaters were positioned with their centers at the same vertical depth as the spent-fuel and electricalsimulator canisters in the center drift. To complete the simulation, the auxiliary heaters were operated on the power schedule shown in Table 12-3.

The 20 auxiliary heaters functioned reliably throughout the test. No heaters failed or exhibited erratic performance, and inspection of the heaters after they were extracted at the end of the test revealed no corrosion of the resistive heating elements. One unit, which was in a hole intersected by a water-bearing fracture, was lightly coated with carbonate minerals, but there was no evidence that this degraded heater performance. As reported by Patrick, Rector, and Scarafiotti (1984) and summarized in Thapter 9, several problems were encountered with the heater controllers. The resulting power spikes were of short duration and, hence, did not have a negative impact on the quality of the simulation.

\subsection{Incidental Heat Sources}

Facility lighting, air conditioning discharges, and electronics were additional sources of heat during the test. As discussed bolow, even the largest contributor (facility lighting) introduced only a minor amount of energy during the 3 -year test.

\subsection{Energy Deposition}

Total thermal energy input to the test array was $1041 \mathrm{MW} \cdot h$ through retrieval, with an additional $19 \mathrm{MW} \cdot \mathrm{h}$ added during the 6-month cooldown period. This total is the aggregate of 4 sources: the decay heat of 11 spent-fuel assemblies from a PWR, 6 electrically heated simulators, 20 electrical guard or auxiliary heaters, and the facility lights. The partition of these thermal loads is summarized in Table 12-4 and is shown graphically as a function of time in Fig. 12-5.

By examining Fig. 12-5, we can readily see how the relative contributions of these heat sources changed as the test progressed. Initially, the spent fuel and electrical simulators were the principal contributors, but as radioactive decay progressed, this contribution diminished. On the other hand, the energy contribution of the auxiliary (guard) heaters increased with time to produce the desired simulation.

Facility lights represented a major component of the facility power requirement, but since they were used relatively little (during routine test operations and tours), their energy contribution was fairly constant and accounted for only $29 \mathrm{MW} \cdot \mathrm{h}$ or $2.8 \%$ of the total during the approximately 3-year spent-fuel storage phase of the test. In the 6 months following retrieval, post-test sampling and characterization activities required nearly continuous access to the subsurface. As a result, the cumulative energy input from the lighis increased by $19 \mathrm{MW} \cdot \mathrm{h}$, a $6.5 \%$ increase over the previnus 3 years. 
Table 12-3. Auxiliary heater power table.

\begin{tabular}{lcc}
\hline Date of change & lower $(w)$ & Comments \\
\hline 062780 & 1850 & Set too high \\
$07 / 02 / 80$ & 925 & Target power \\
$12 / 16 / 80$ & 1250 & Target power \\
$02 / 19 / 82$ & 925 & Set too low \\
$03 / 01 / 82$ & 1400 & Compensating power \\
$04 / 08 / 82$ & 1350 & Target power \\
\hline
\end{tabular}

Table 12-4. Cumulative energy input to the SFT $-\mathrm{C}$ by source.

\begin{tabular}{|c|c|c|c|c|}
\hline \multirow[t]{2}{*}{ Source } & \multicolumn{2}{|c|}{$\begin{array}{c}\text { Cumulative energy } \\
\text { through retrieval }\end{array}$} & \multicolumn{2}{|c|}{$\begin{array}{l}\text { Cumulative energy } \\
\text { through cooldown }\end{array}$} \\
\hline & $\overline{M W \cdot h}$ & $\sigma_{0}$ of total & $\mathrm{MW} \cdot \mathrm{h}$ & $\%$ of total \\
\hline PWR fuel assemblies (11) & 263.4 & 25.3 & 263.4 & 24.8 \\
\hline Electrical simulators (6) & 148.0 & 14.2 & 148.0 & 14.0 \\
\hline Guard heaters (20) & 600.6 & 57.7 & 600.6 & 56.7 \\
\hline Facility lights & 29.0 & 2.8 & 48.0 & 4.5 \\
\hline Totals & 1041.0 & 100.0 & 1060.0 & 100.0 \\
\hline
\end{tabular}

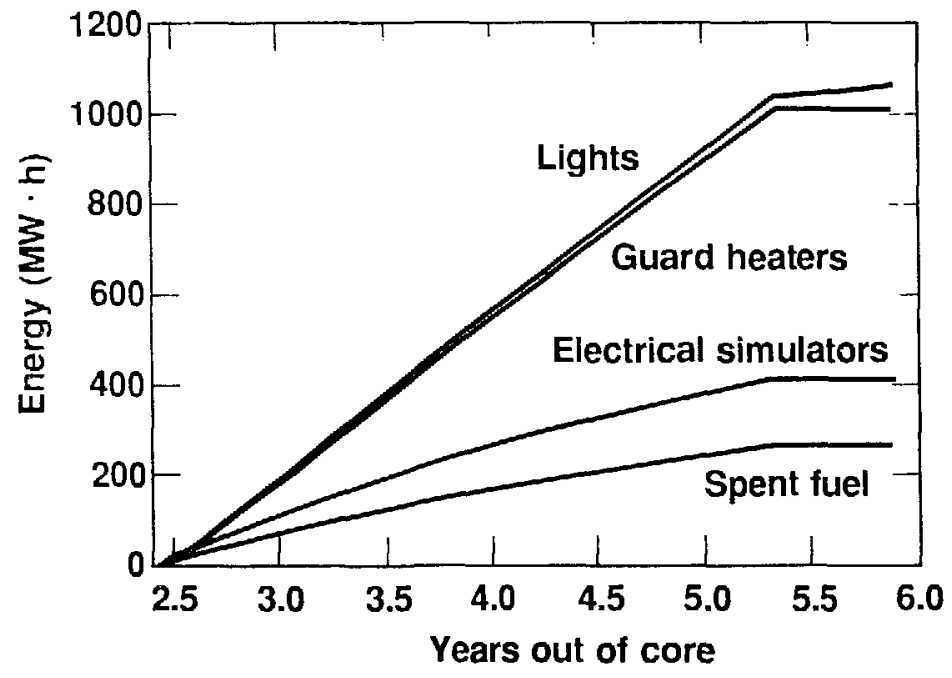

Figure 12-5. Cumulative thermal input by source. 


\section{Heat Transfer Analyses and Measurements*}

Heat transfer calculations were performed for all phases of the SFT-C. As described in Chapter 3, the earliest test design calculations used simplified models and assumed or laboratory-derived input properties and related parameters. The as-built calculations and the post-test calculations incorporated progressive refinements in the calculational approach and input values (Montan and Patrick, 1981 and 1986). Although even the initial calculations provided good agreement with measurements (Patrick et al., 1982 and 1983), the comparisons presented here are based on the most recent calculations of Montan and Patrick (1986), which show an improved level of agreement.

\subsection{Measurement System and Instrumentation}

The Type $\mathrm{K}$ thermocoupies, which were the primary temperature measuring devices deployed at the SFT-C, provided excellent quality data for use in comparisons with calculated temperatures (Chapter 9). Pre- and post-test thermocouple calibrations established that accuracies were within the ISA special limits of error of $\pm 1.1^{\circ} \mathrm{C}$. At temperatures below $100^{\circ} \mathrm{C}$, errors generally did not exceed $\pm 0.2^{\circ} \mathrm{C}$ and only at the $150^{\circ} \mathrm{C}$ calibration temperature did we see many errors in excess of $\pm 0.5^{\circ} \mathrm{C}$. Furthermore, instrument reliability was essentially $100 \%$, and very few data were lost or rendered invalid by the data acquisition and data management systems (Chapter 10).

The reader is referred to Chapter 9 of this report for further information on the locations and performance of temperature-measuring devices.

\subsection{Calculational Results}

Chapter 3 summarizes the sequence of calculations used to design the SFT $-\mathrm{C}$ and to compare with test data. Our comparisons here will consider TRUMP finite-difference calculations of a three-dimensional infinite-length and a three-dimensional finite-length model of the SFT-C.

From the outset of the test, an infinite-length representation of the SFT-C has been modeled using the TRUMP code (Edwards, 1972). At the completion of the test, Montan and Patrick (1986) conducted a series of eight calculations to parametrically examine the influence of conductivity, initial mesh temperature, precooling of the rock during construction, a "skin" of low conductivity material lining the drifts, heat capacity, ventilation flowrate, and the convection coefficient. Based on the results of this study, a calculation having the following attributes was determined to provide the best overall agreement with the data:

- $\mathrm{k}=3.11 \mathrm{~W} / \mathrm{m} \cdot \mathrm{K}$;

- $\mathrm{C}=930 \mathrm{~J} / \mathrm{Kg} \cdot \mathrm{K} ;$

- ventilation $=0.026 \mathrm{~m}^{3} / \mathrm{s} \cdot \mathrm{m}$ (to the unit cell, using partial-flow model);

- ambient rock temp. $=24.7^{\circ} \mathrm{C}$;

- inlet air temp. = history as measured during test with a "precooling" period associated with construction;

- Nusselt number $=0.13 \mathrm{R}_{\mathrm{a}}^{1 / 3}$.

The finite-length model represented an initial attempt to include a more correct representation of heat flow from the ends of the array. Because the infinite-length array assumed that heat sources existed far beyond the actual ends of the SFT $-\mathrm{C}$, measured temperatures outside the middle one-third to one-half of the array were considerably lower than calculated, with the level of agreement becoming worse as the end of the array was approached.

The finite-length model could not take advantage of many of the symmetries present in the infinitearray case. As a result, some 22,500 zones were required for this calculation. This required two major simplifications to be made. First, radiative heat transfer was treated as a conductive process by assigning the drift nodes very high conductivities and low densities. Second, selected drift nodes were connected to external nodes whose temperatures tracked the inlet air temperature history to simulate ventilation.

\footnotetext{
${ }^{\star}$ Contributed by W. C. Patrick.
} 


\subsection{Comparison of Data and Calculations}

Three types of comparisons between measured and calculated temperatures allow us to examine how well the heat transfer has been mudeled at the SFT-C: These comparisons are temperature histories at selected locations, contururs of calculated temperatures with measured temperatures superposed at selected times, and cross-plots of measured iscolculated temperature changes at selected locations.

\subsubsection{Near-Field Comparisons with Infinite Array Model}

Figure 13-1 displays measured and calculated near-field temperatures at the center canister emplacement hole (CEHO9) for the duration of the heating and post-test cooling phases of the SFT-C. The designators TOP, MID, and BOT refer to locations $0.3 \mathrm{~m}$ below the top, at the midheight, and $0.3 \mathrm{~m}$ above the bottom of the active heated length of the spent-fuel assembly, respectively. The radial positions displayed are the surfaces of the canister and the liner, and positions 200 and $360 \mathrm{~mm}$ into the rock.

Several observations may be made concerning this comparison. First, the agreement is excellent at the MID position, with differences generally less than $2^{\circ} \mathrm{C}$ during the heated phase and itcreasing to about $5 \mathrm{C}$ during the post-retrieval cooling phase. Second, while both the TOP and BOT positions on the canister and liner are coller than the middle, the measured temperatures are considerably warmer near the top of the emplacement borehole than near the bottom. This is in marked contrast to the calculated results, which show the bottom position to be warmer. These results are consistent with the concept that the drift surface, being ventilated, produces cooler temperatures near the top of the heat sources. On the other hand, the data are consistent with the concepts of convective heat transfer with in the emplacement borehole, which would tend to elevate the temperature of the top of the carister. The latter view is also supported by a calculation reported by Montan and Patrick (1986), which indicates that the temperatures near the top of the canister can be increased by assigning the concrete drift floor a somewhat lower conductivity than the rock mass. Third, in all cases the measured and calculated histories are nearly parallel; either converging or diverging slightly during the 3.5 year test. This encourages us to believe that fundamental aspects of heat flow are being properly modeled and should provide continued good agreement for much longer time periods.

Turning to Fig. 13-2, similar comparisons may be made for one of the electrical simulators located nea1 the central region of the array. Although th: simulated decay curve is somewhat more erratic than the radioactive decay curve associated with Fig. 13-1, it is evident that the quality of the simulation is very good. The comments made above for the spent-fuel assemblies generally apply for the simulators, with a tew clarifications. First, it appears that the temperatures measured at the TOP position near the simulator are somewhat higher than those near the spent-fuel assembly, causing the differences in comparison with calculations to be greater for the simulators. Likewise, at the BOT position the measured temperatures are lower. This, too, increases the differences between measured and calculated temperatures. Potential causes for these differences include the absence of helium fill gas in the simulators and deposition of thermal energy directly into the rock via attenuation of gamma radiation from the spent-fuel assemblies (Patrick et al., 1983). Second, the effects of fluctuations in power level are observable for several tenths of a metre into the rock but rapidly dissipate with distance.

The second heat source from the inlet end of the array provides an example of how the quality of the infinite-array model degrades near the ends of the facility (Fig. 13-3). Here we see a consistent underestimation of actual temperatures as a direct result of the absence of additiona! heat sources that would cause two-dimensional heat flow with an attendant suppression of heat flow out the ends of the SFI" $-\mathrm{C}$. Note that the break and vertical deflection in the curves at about $4.75 \mathrm{YOC}$ is the result of a spent-fuel exchange (Chapter 11), when a fuel assembly of lower burnup was emplaced in this borehole.

\subsubsection{Intermediate-Field Comparisons}

Although near-field temperature conditions are important to understand the behavior of waste forms and certain types of canister and overpack materials, the response of the repository system is influenced by temperatures on a large scale. We discuss here comparisons between measured temperatures and those calculated using both the infinite-length and finite-length array models.

Using the same infinite-length array calculation as in the previous section, we can examine the development of the thermal regime by contouring calculated temperatures and superposing measured temperatures toum two heavily instrumented cross sections of the array (Stations $2+83$ and $3+45$ ). Figures $13-4$ a 

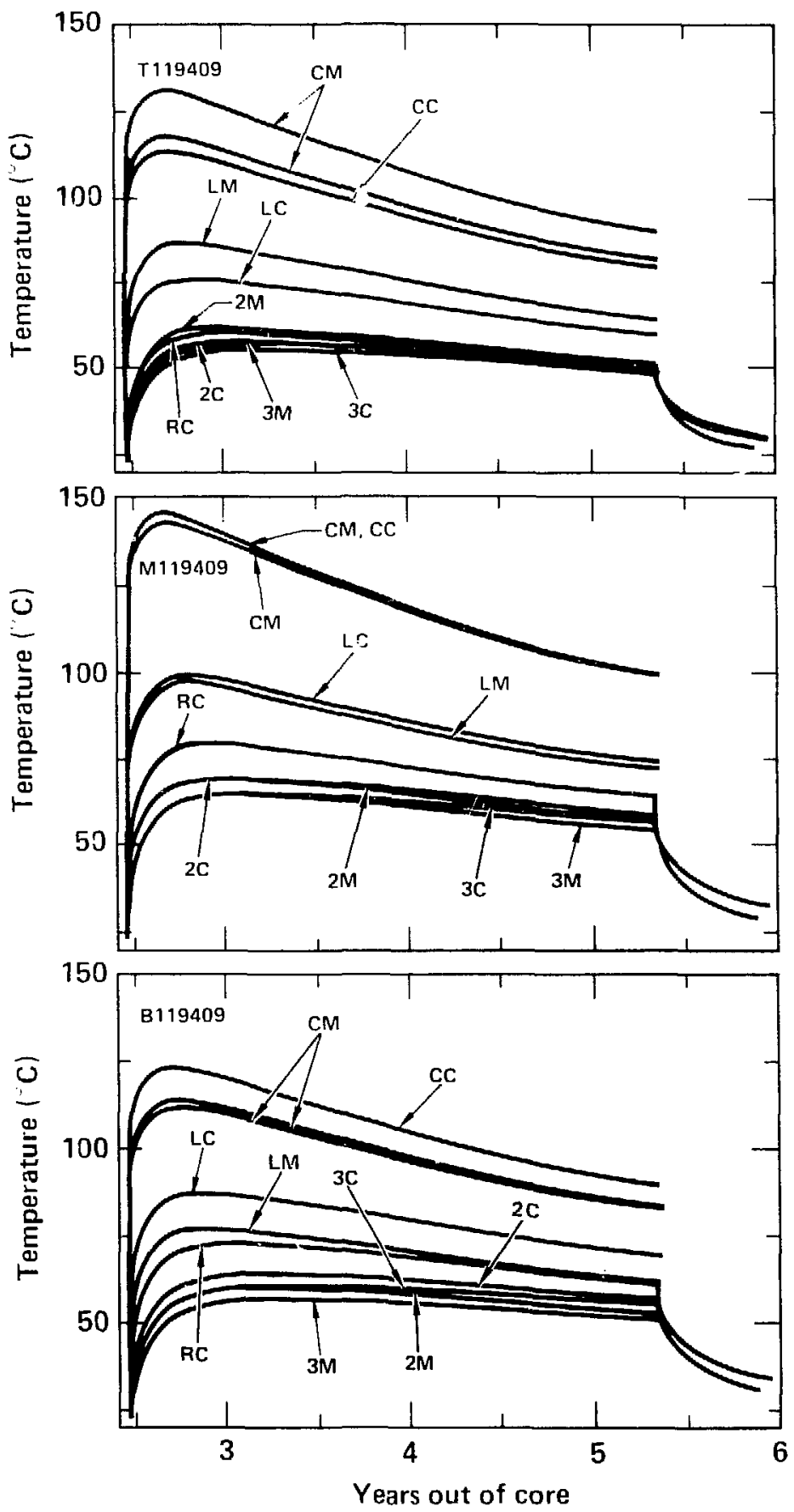

Figure 13-1. Comparison of measured and calculated near-field temperature histories, CEH09, CN1194.

and 13-5a show the effect of cooling the rock mass during construction from its initial value of $24.7^{\circ} \mathrm{C}$. The 23 and $24^{\circ} \mathrm{C}$ contours are in good agreement with measured temperatures (positions of measurements are noted by the + symbols). The progressive increases in temperatures during the three-year heated phase are shown sequentially for Stations $2+83$ and $3+45$ in Figs. 13-4b through $f$ and $13-5 b$ through $f$, respectively. Finally, the results after the 6-mont' post-retrieval cooling phase are shown in Figs. 13-4g and 13-5g. 

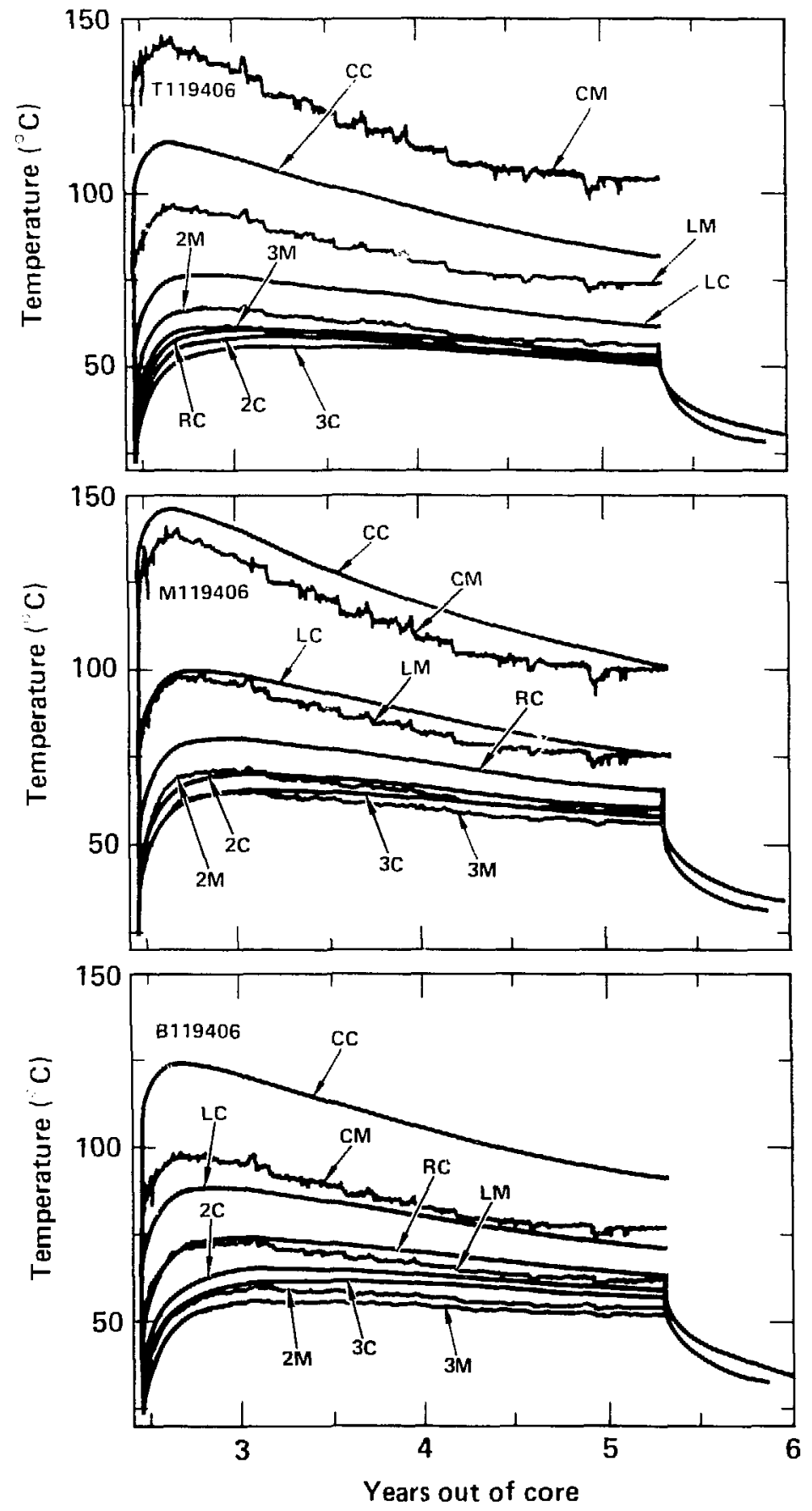

Figure 13-2. Comparison of measured and calculated near-field temperature histories, CEH06, CN1194.

Several observations may be made based on Figs. 13-4 and 13-5. First, it is clear that excellent agreement between measured and calculated temperatures was achieved at all times and locations associated with these two stations. Second, the proper treatment of radioactive heat transfer within the drifts produced temperature contours that paralleled the drift surfaces. As reported by Patrick, Montan, and Ballou (1981), the more typical treatment of a drift as an insulator produced contours perpendicular to the drifts, 

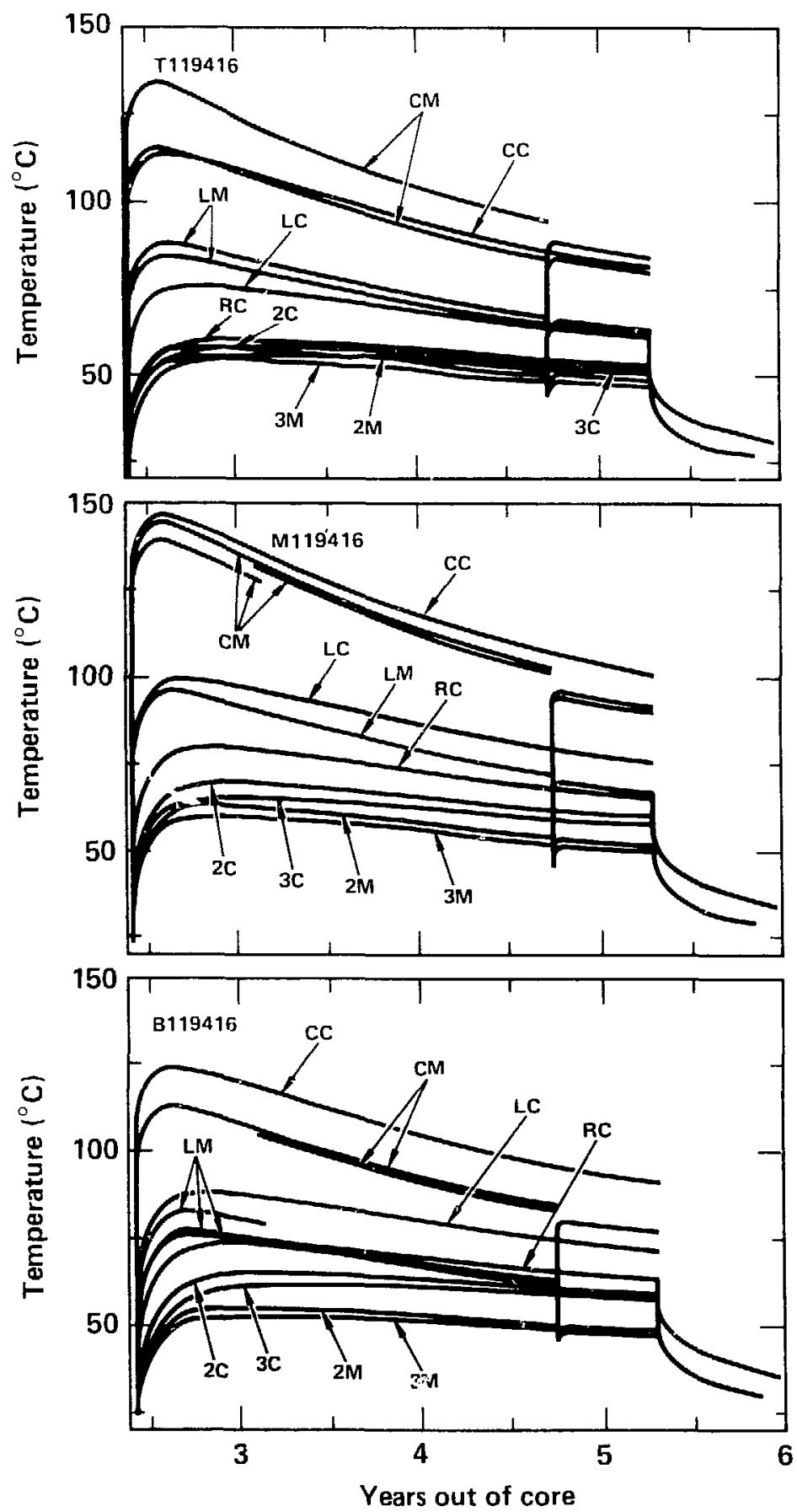

Figure 13-3. Comparison of measured and calculated near-field temperature histories, CEH16, CN1194.

resulting in markedly different thermal stresses. Third, heat removal by the ventilation airstream had a pronounced effect on both the calculation and the measurements. During the cooling phase when ventilation rates were about doubled (Figs. 13-4g and 13-5g), this effect was even stronger. Fourth, temperatures in the pillars between the drifts were consistently lower than calculated at all times during the heating and cooling phases. This implies that heat transfer into the airstream was more effective than the calculations 
indicate. As discussed in Chapter 14, this appears to be inconsistent with the observation that the calculated amount of thermal energy removed exceeded the measured amount.

These effects may be examined more succinctly with cross-plots of measured and calculated temperature changes for all the points shown in the previous figures. Although Montan and Patrick (1986) present plots for all times and locations, we show here composite cross-plots for the cwo stations (using data and calculations from 6-month intervals during the heated phase) and at the end of the cooling phase. During the heated phase of the SFT-C, temperature increases were slightly less or about equal to calculated at Strin 2+83 (Fig. 13-6a), and were consistently less than calculated at Station 3+45 (Fig. 13-7a), as evidenced by slope (A1) values of unity in the former case and less than unity in the latter case (considering the intercept $\mathrm{AO}$ also). Cooler temperatures at Station $3+45$ are a reflection of "end effects" that were not adequately treated in the infinite array model. We see that during the cooling phase, the measured values were consistently lower than those calculated at both locations but were lowest at Station 3+45 (Figs. 13-6b and $13-7 \mathrm{~b})$. These figures also indicate the quality of the data: the $R^{2}(R R)$ values range from 0.93 to 0.98 and the root-mean errors (RM) range from 0.96 to $2.3^{\circ} \mathrm{C}$. These $R M$ values approach the specified $15 \mathrm{~A}$ special limits of error of the thermocouples, which is $1.1^{\circ} \mathrm{C}$. Similar trends were reported for data obtained at other times (Montan and Patrick, 1986).

Although we believe that these results from the infinite-length array are excellent and adequate for design purposes, the finite-length model produced remarkably better results at several locations. The anticipated improvement near the ends of the heated array is clearly evident in Figs. 13-8 and 13-9. These figures show calculated and measured temperatures at positions 2.1 and $13.3 \mathrm{~m}$ below the emplacement drift and about $2.0 \mathrm{~m}$ off the drift centerline. In the upper part of Fig. 13-8, the rapid changes in temperature at 2.5 and 5.3 YOC are associated with emplacement and retrieval of spent-fuel assemblies in an infinite array. The lower part of this figure shows the excellent agreement with data that we obtained when the calculation properly considered that the last spent-fuel assembly of the array was more than $6 \mathrm{~m}$ away from the measurement location. Figure 13-9 shows a similar, though less pronounced effect at the 13.3-m depth.

Significant improvements were not expected near the central parts of the array where the infinitelength assumption was basically correct. However, at locations such as instrument CETO11, which was positioned $1.8 \mathrm{~m}$ laterally from the drift centerline and $2 \mathrm{~m}$ below the floor, the 5 to $8^{\circ} \mathrm{C}$ difference produced by the infinite-length model was reduced to about 2 to $3^{\circ} \mathrm{C}$ by the finite-length model (Fig. 13-10). Similar results were seen in the center of the pillar (Fig. 13-11), above the pillar (Fig. 13-12), and beneath the pillar, midway between the linear arrays of heat sources (Fig. 13-13). In all cases, we see that the finite-length model produced cooler temperatures than its infinite-length counterpart. These improvements near the central portion of the array are related to the ventilation model (Chapter 14).

\subsection{Assessment of Models}

These results lead us to conclude that available finite-difference codes and associated models can accurately simulate the conditions that will be present in future test areas and full-scale repositories. This conclusion is supported by a three-way logical comparision. First, as shown in Chapter 3 , the model for the central 15-by-15-m module of the SFT $-C$ provided nearly identical results to those produced by a model of the 8,000-canister array in a full-scale repository. Second, we have shown in this chapter that the SFT-C model results are in excellent agreement with the field measurements. Third, it follows that the field measurements approximate the conditions of the 8,000-canister repository and, hence, validate its model.

This study indicates that a finite-length model can be an important adjunct to less costly infinite-length approximations if the analyst must determine conditions near the edges of the problem. Otherwise, it appears that infinite-length models with their attendant symmetries can reduce the cost of modeling while allowing greater sophistication (such as thermal radiation and convection and finer zoning) of the model. 


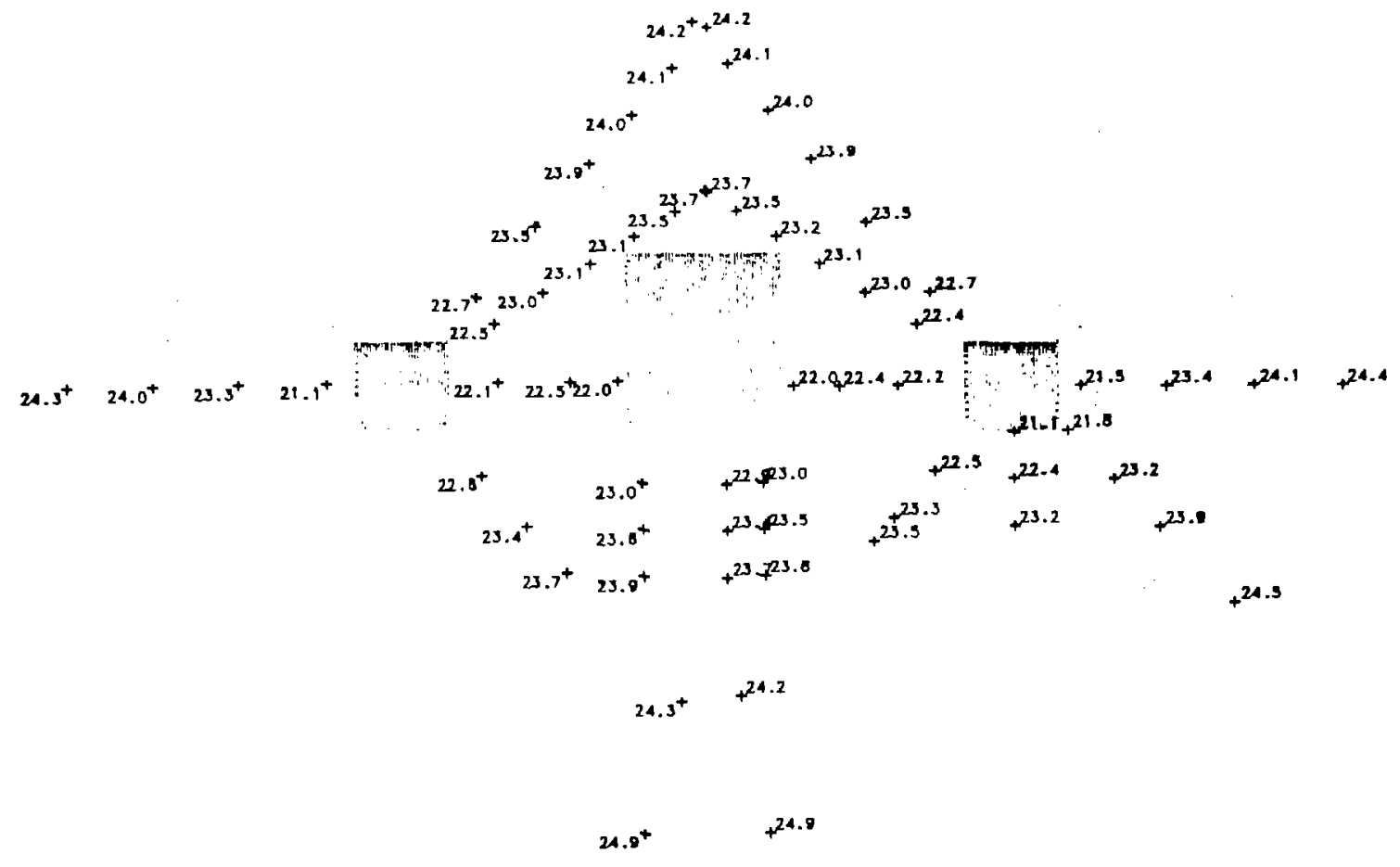

Figure 13-4a. Measıred temperatures and contours of calculated temperatures at 2.46 YOC, Station $2+83$.

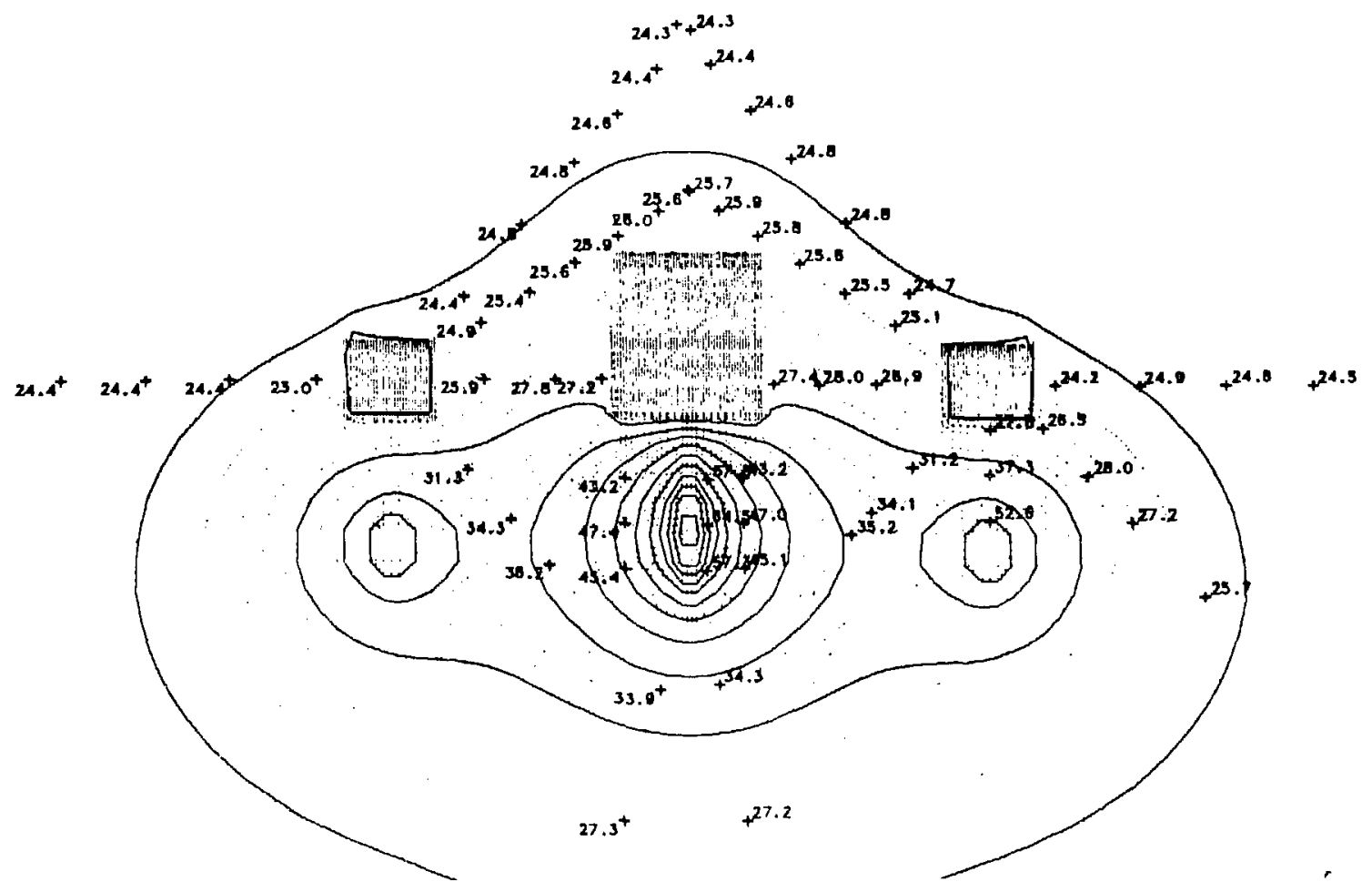

Figure $13-4 \mathrm{~b}$. Measured temperatures and contours of calculated temperatures at 3.00 YOC, Station $2+83$. 


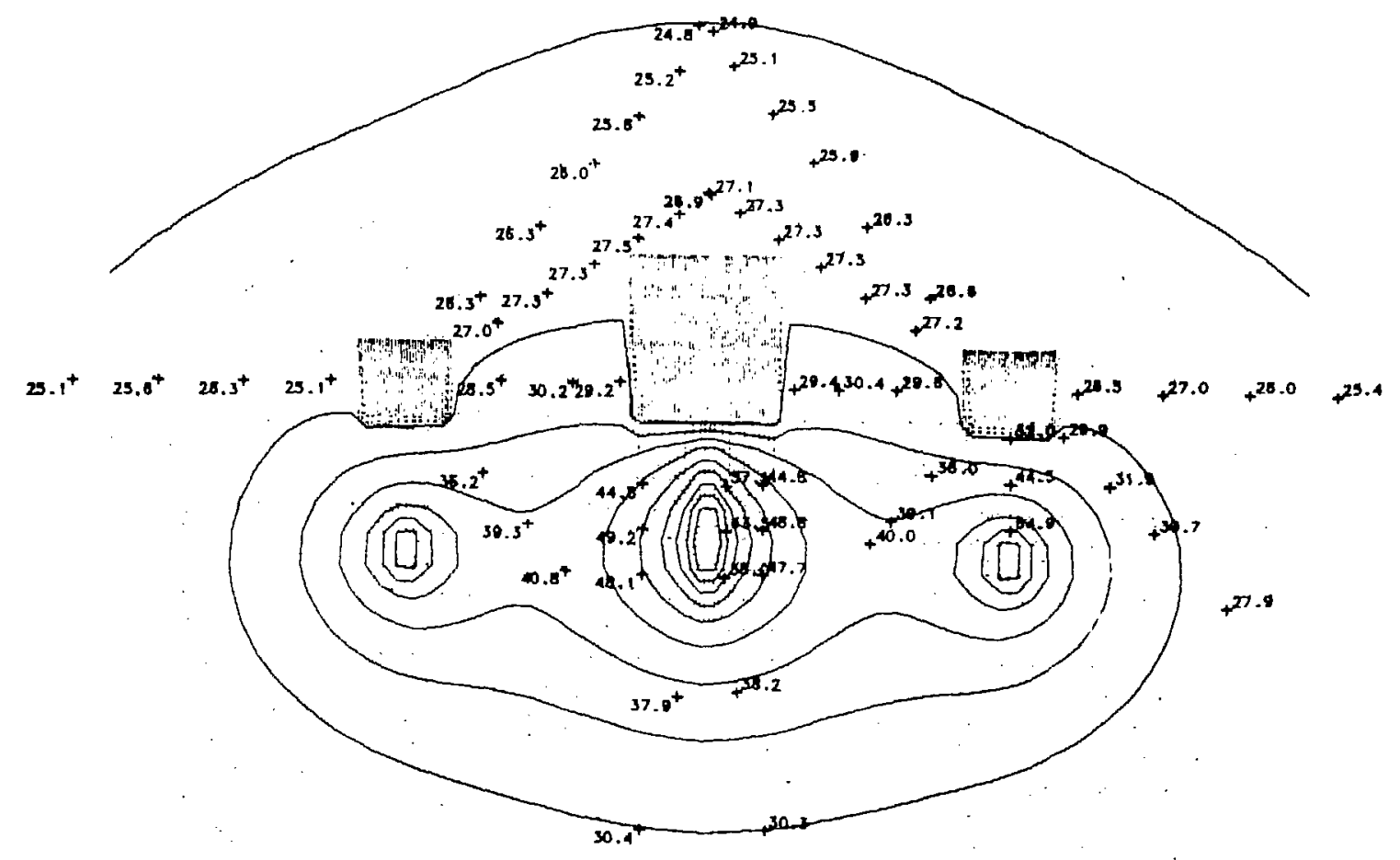

Figure 13-4c. Measured temperatures and contours of calculated temperatures at 3.50 YOC, Station $2+83$.

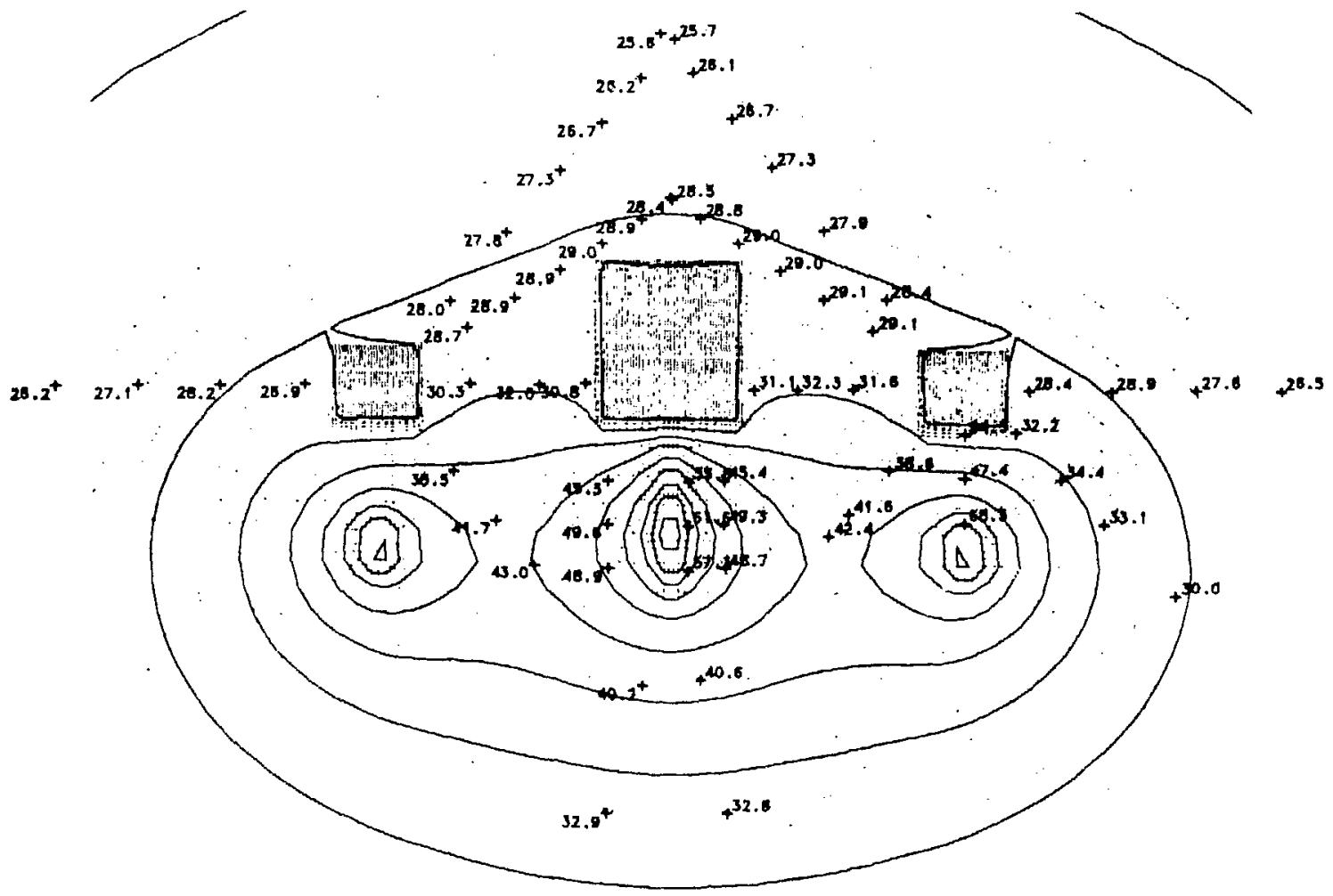

Figure 13-4d. Measured temperatures and contours of calculated temperaiures at 4.00 YOC, Station $2+83$. 


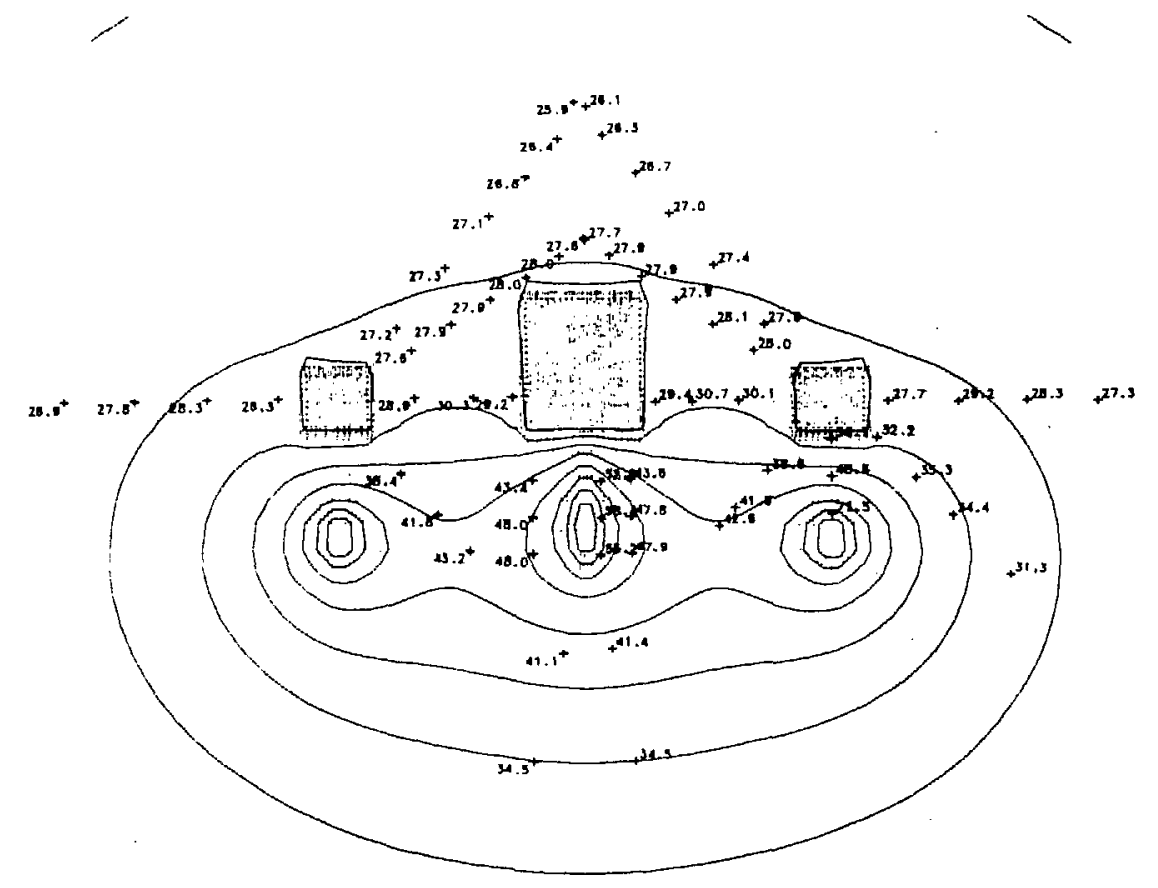

Figure 13-4e. Measured temperatures and contours of calculated temperatures at 4.50 YOC, Station $2+83$.

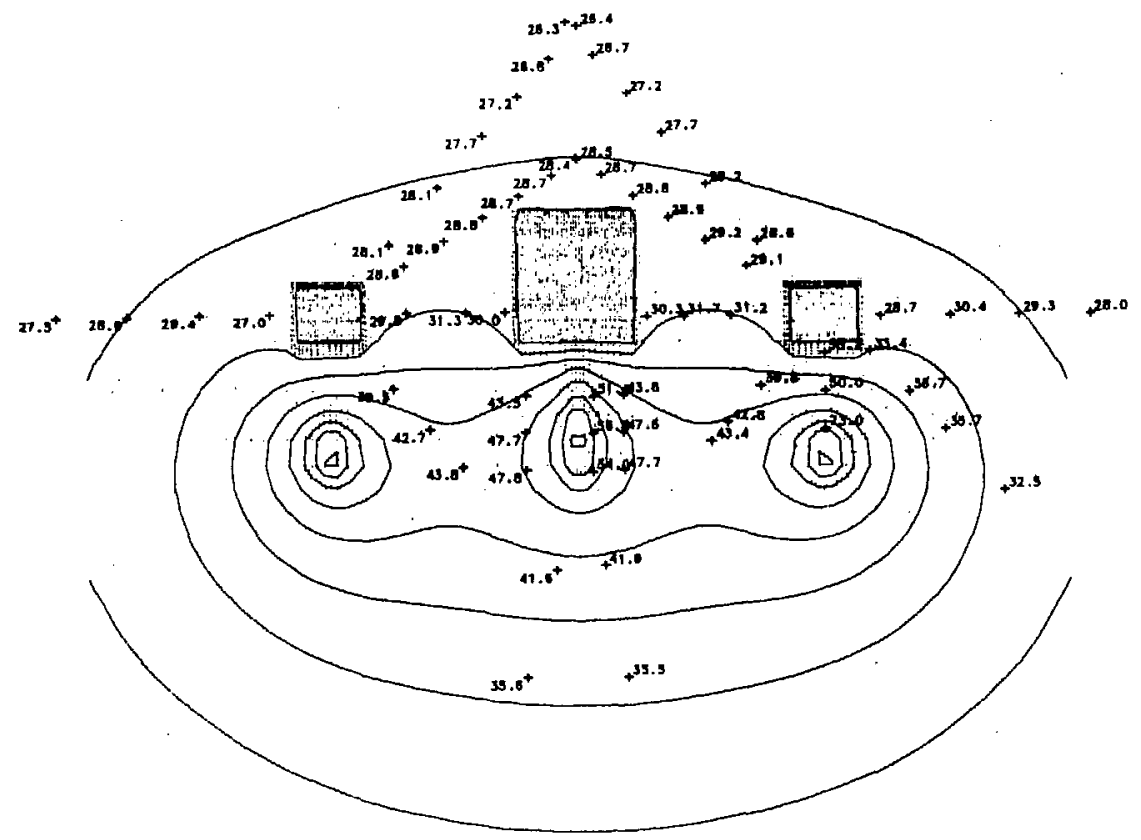

Figure 13-4f. Measured temperatures and contours of calculated temperatures at 5.00 YOC, Station $2+83$. 


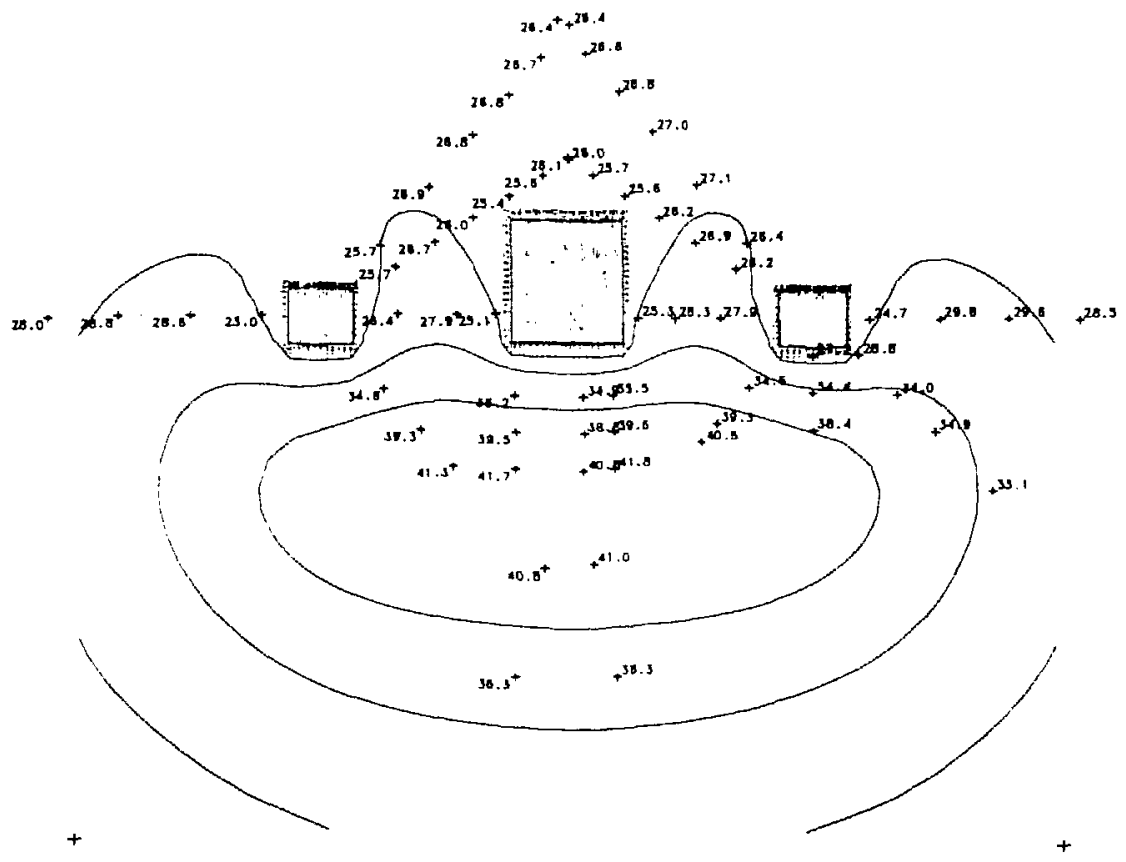

Figure 13-4g. Measured temperatures and contours of calculated temperatures at 5.50 YOC, Station $2+83$.

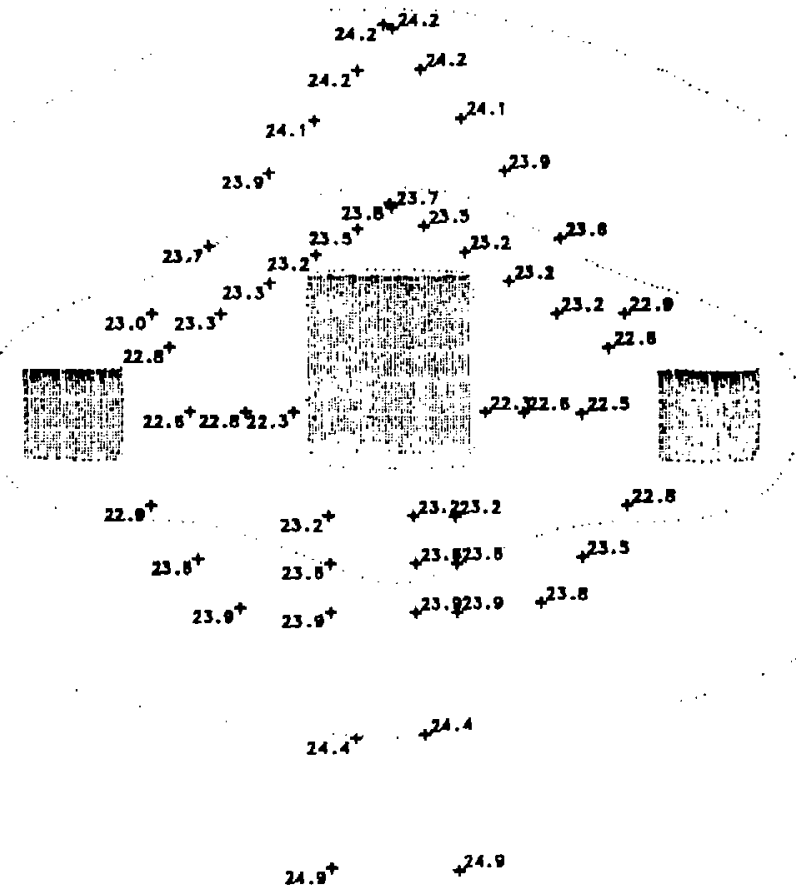

Figure 13-5a. Measured temperatures and contours of calculated temperatures at 2.46 YOC, Station $3+45$. 


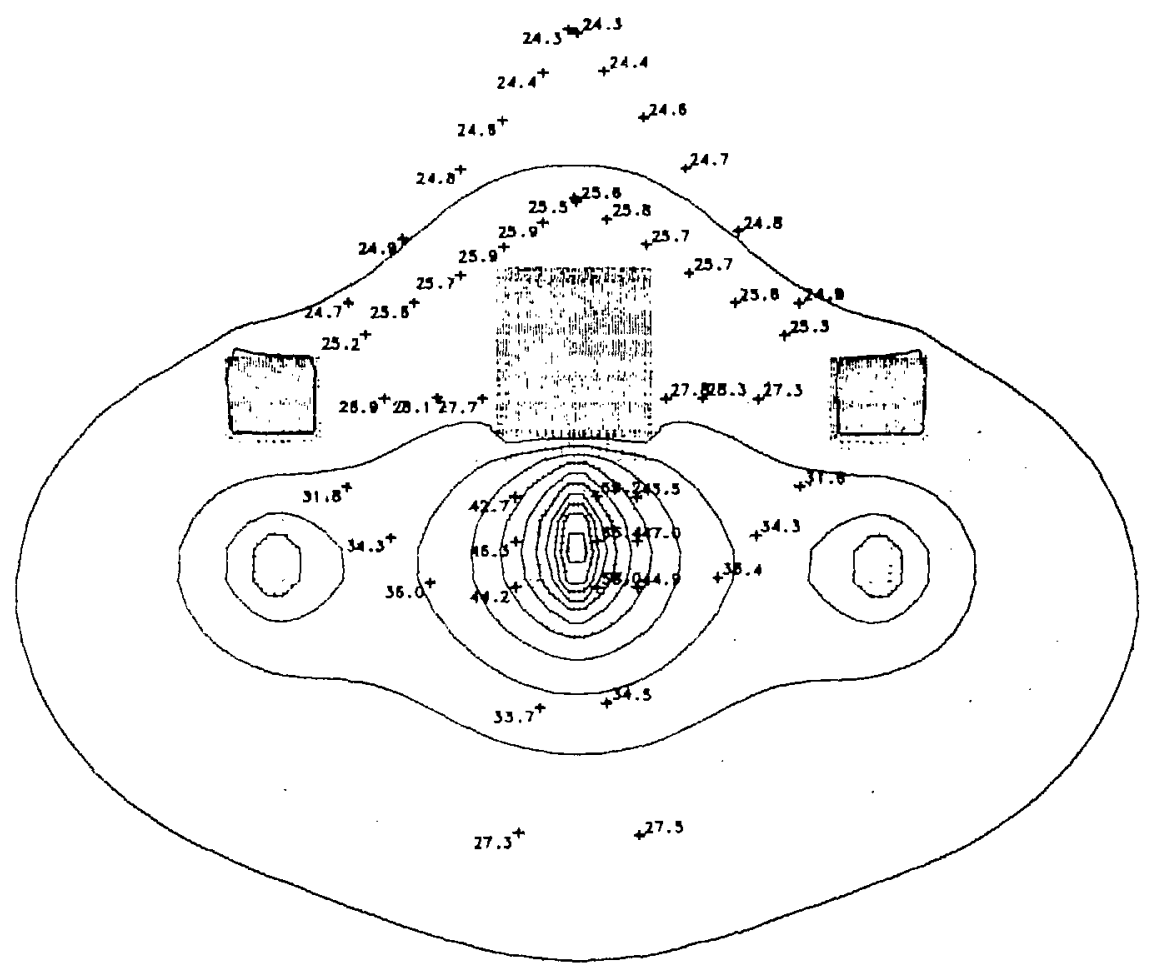

Figure 13-5b. Measured temperatures and contours of calculated temperatures at 3.00 YOC, Station $3+45$.
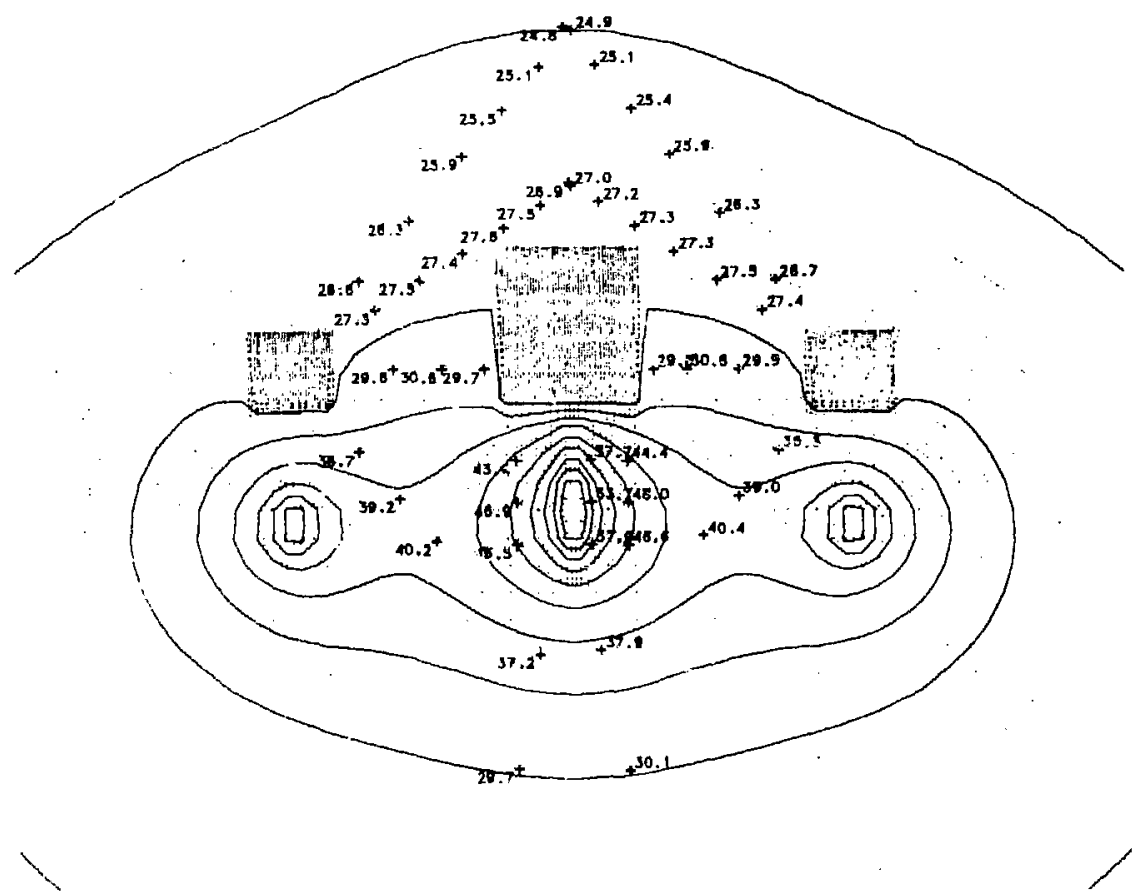

Figure 13-5c. Measured temperatures and contours of calculated temperatures at 3.50 YOC, Station $3+45$. 


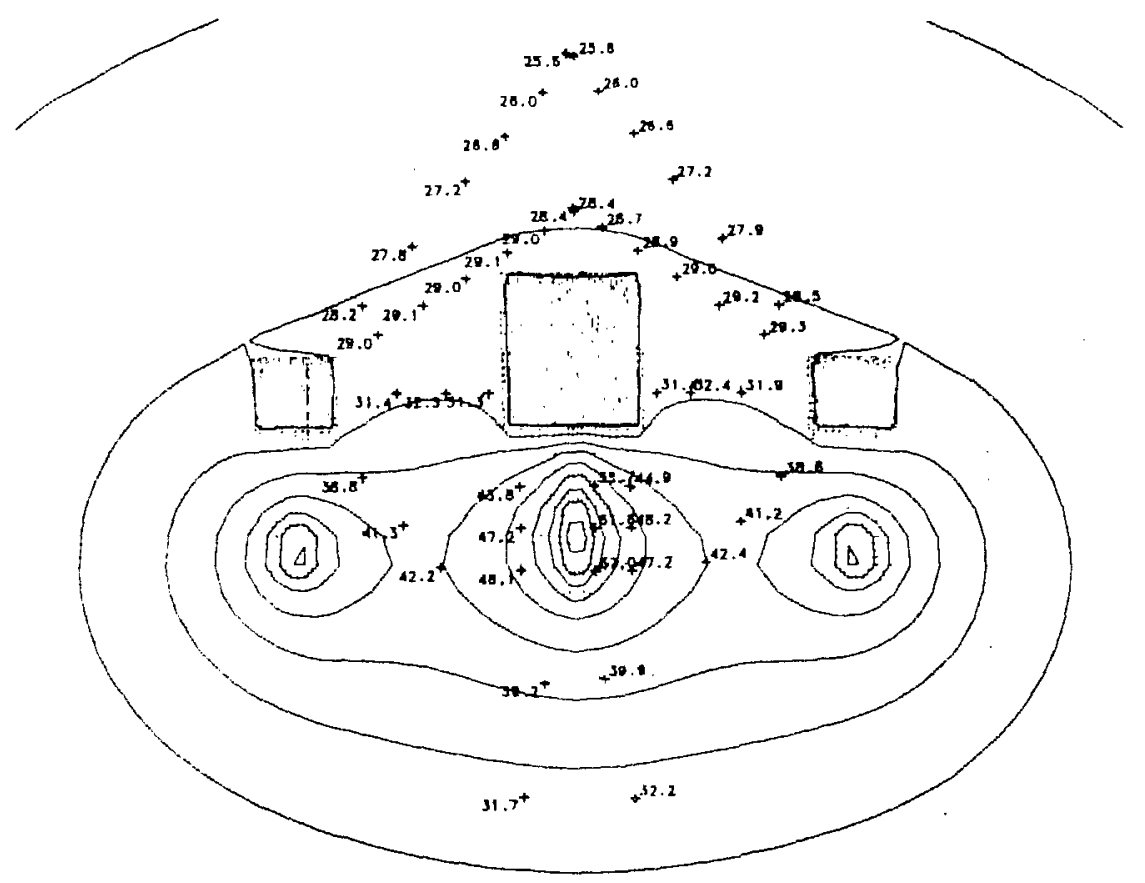

Figure 13-5d. Measured temperatures and contours of calculated temperatures at 4.00 YOC, Station $3+45$.

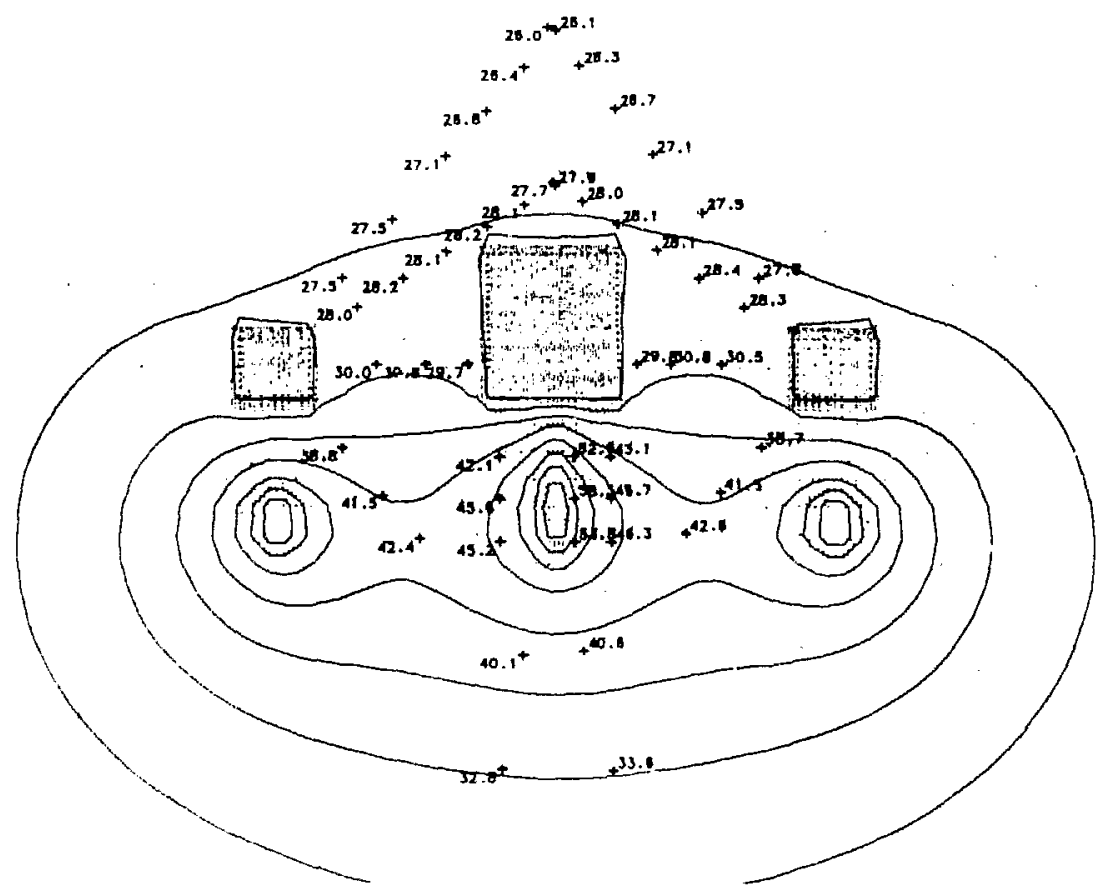

Figure 13-5e. Measured temperatures and contours of calculated temperatures at 4.50 YOC, Station $3+45$. 


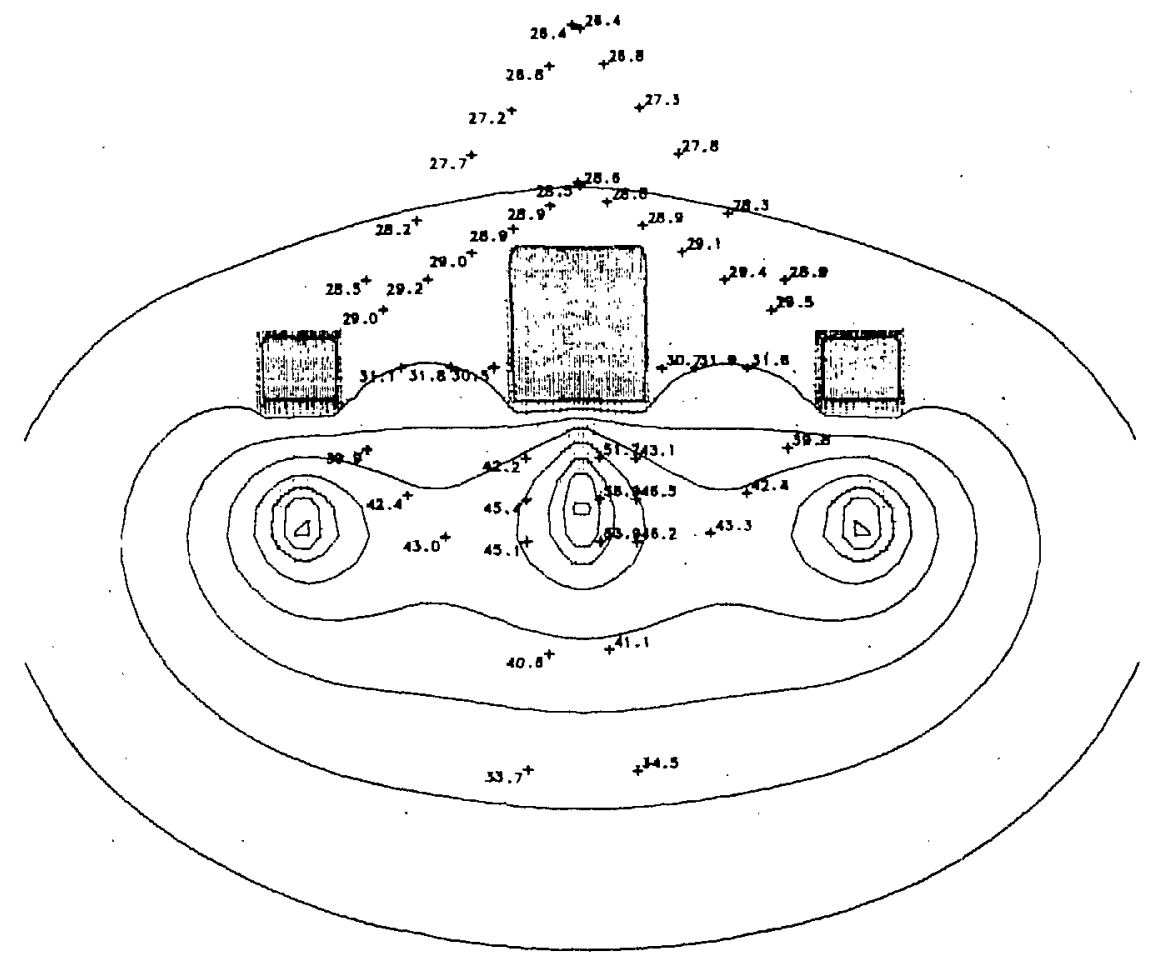

Figure 13-5f. Measured temperatures and contours of calculated temperatures at 5.00 YOC, Station $3+45$.

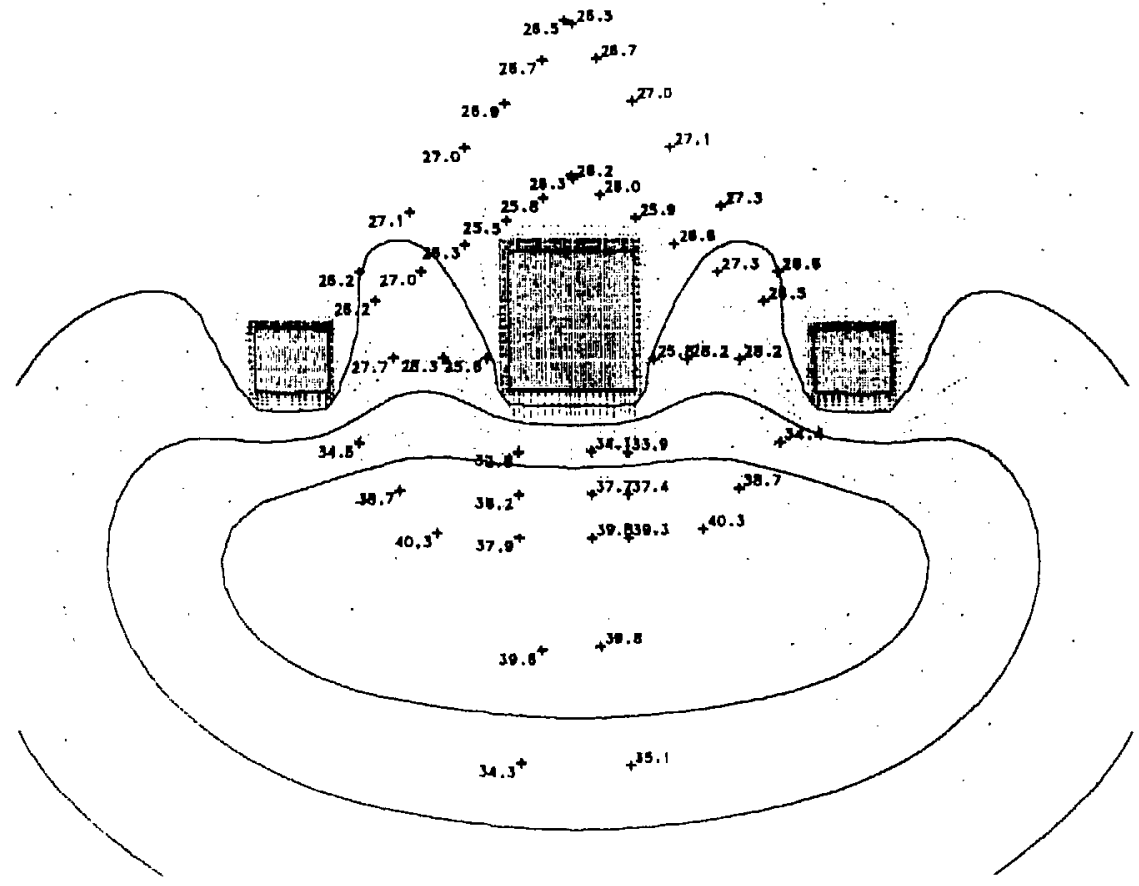

Figure 13-5g. Measured temperatures and contours of calculated temperatures at 5.50 YOC, Station $3+45$. 


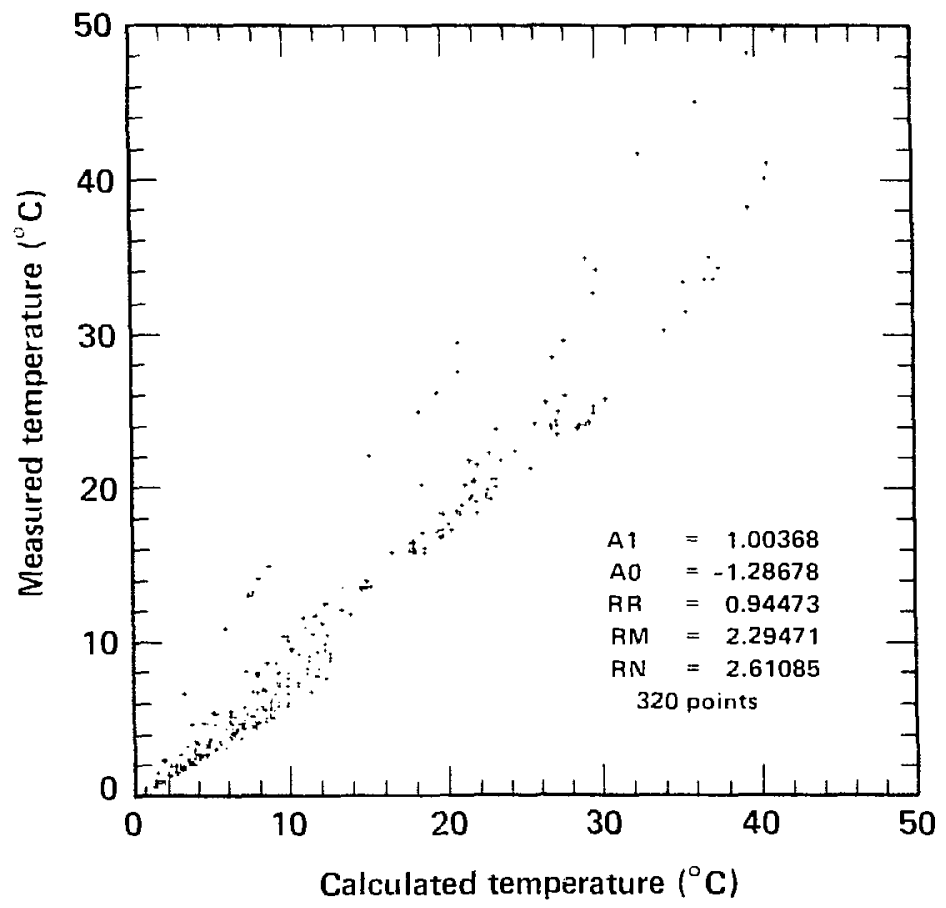

Figure 13-6a. Measured vs calculated (CN1194) temperature rises at 3.0, 3.5, 4.0, 4.5 and 5.0 YOC, Station $2+83$.

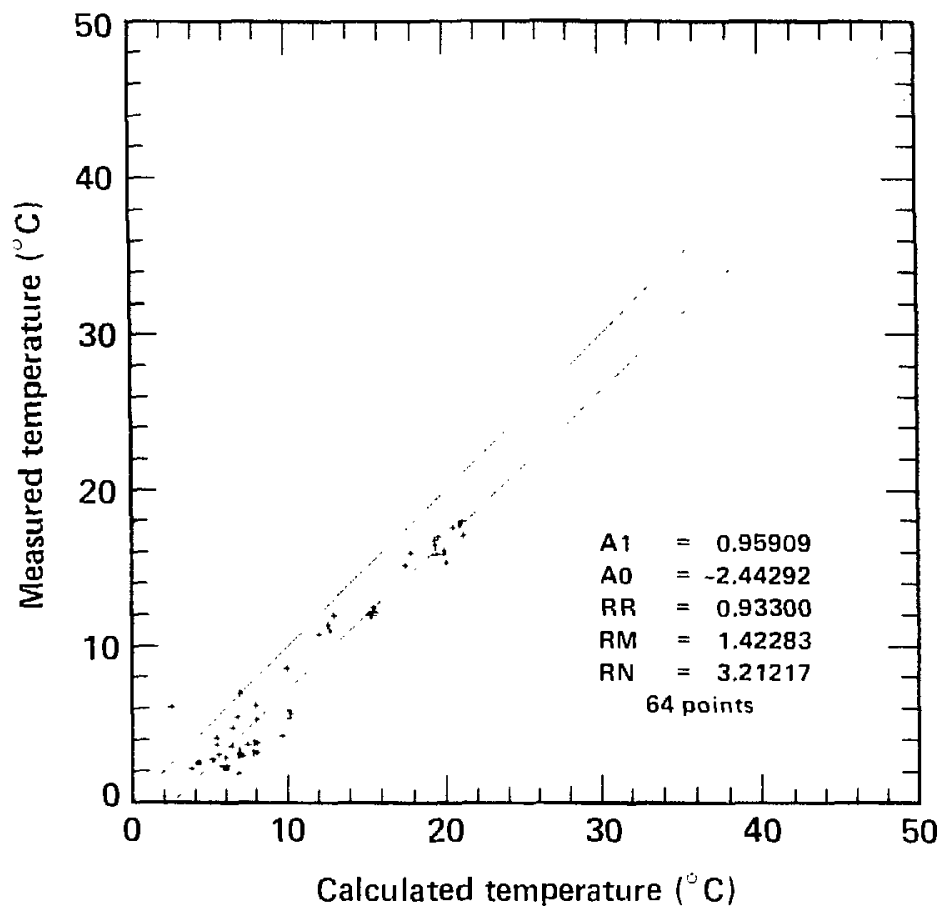

Figure 13-6b. Measured vs calculated (CN1194) temperature rises at 5.50 YOC, Station $2+83$. 


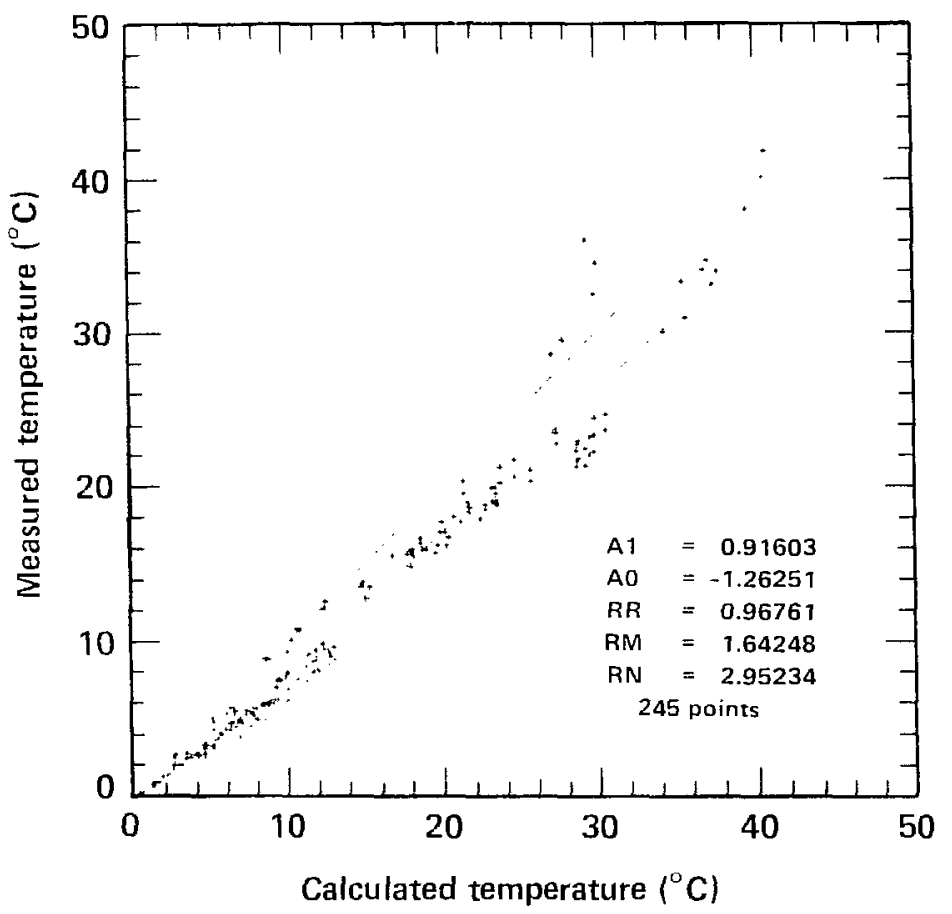

Figure 13-7a. Measured vs calculated (CN1194) temperature rises at 3.0, 3.5, 4.0, 4.5 and 5.0 YOC, Station $3+45$.

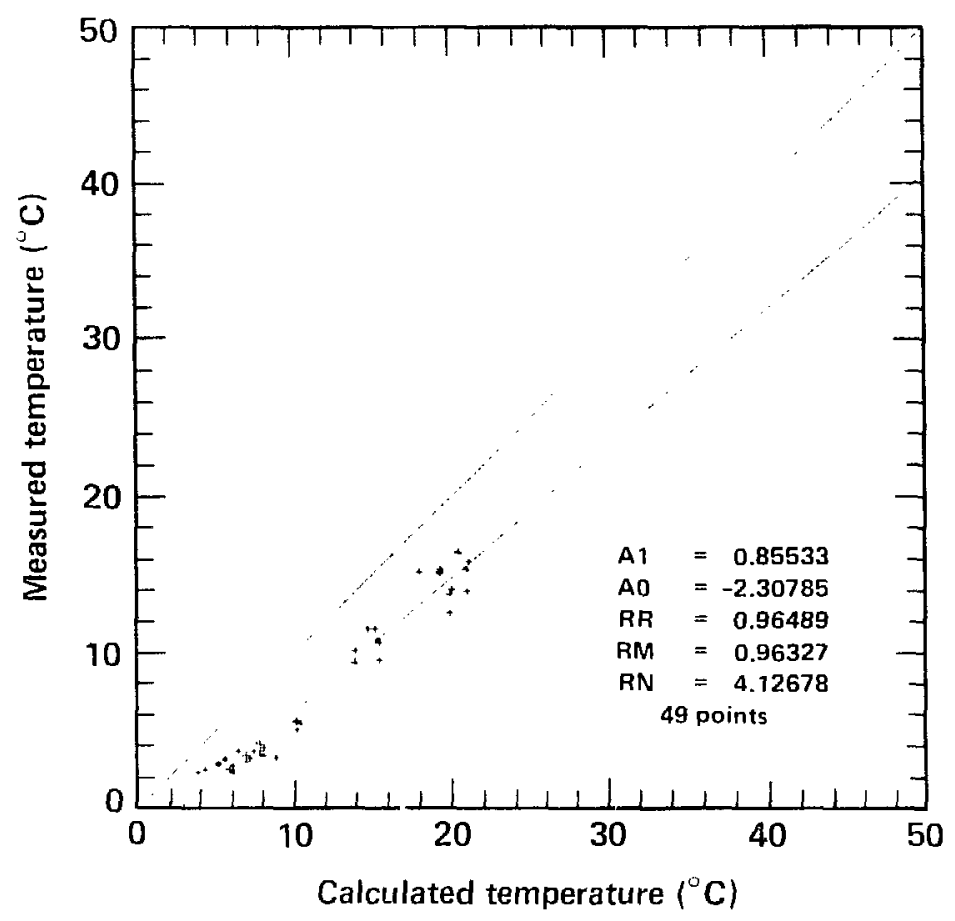

Figure 13-7b. Measured vs calculated (CN1194) temperature rises at 5.50 YOC, Station $3+45$. 

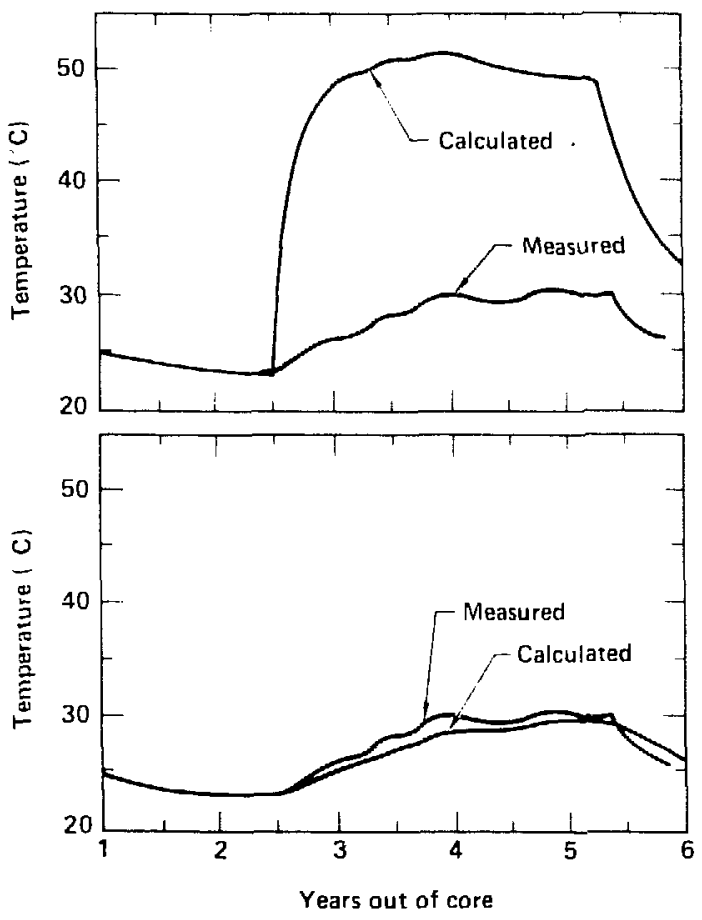

Figure 13-8. Measured and calculated temperature histories at a position $2.1 \mathrm{~m}$ below the floor near the end of the SFT-C array. The top figure is the infinite-length model and the bottom figure is the finite-length model.
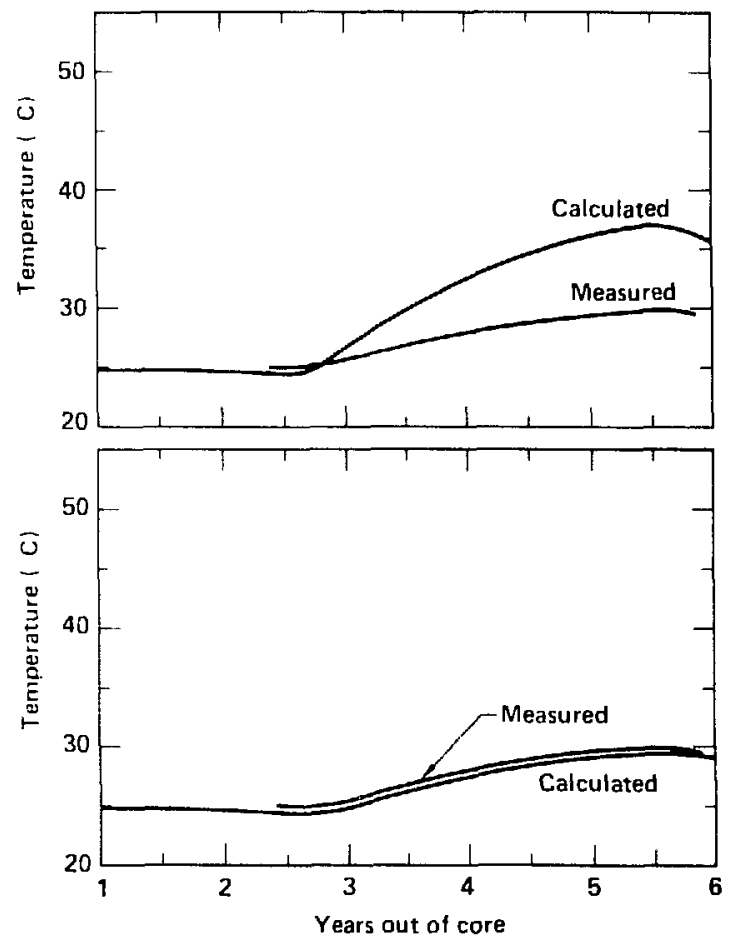

Figure 13-9. Measured and calculated temperature histories at a position $13.3 \mathrm{~m}$ below the floor near the end of the SFT $-C$ array. The top figure is the infinite-length model and the bottom figure is the finite-length model. 

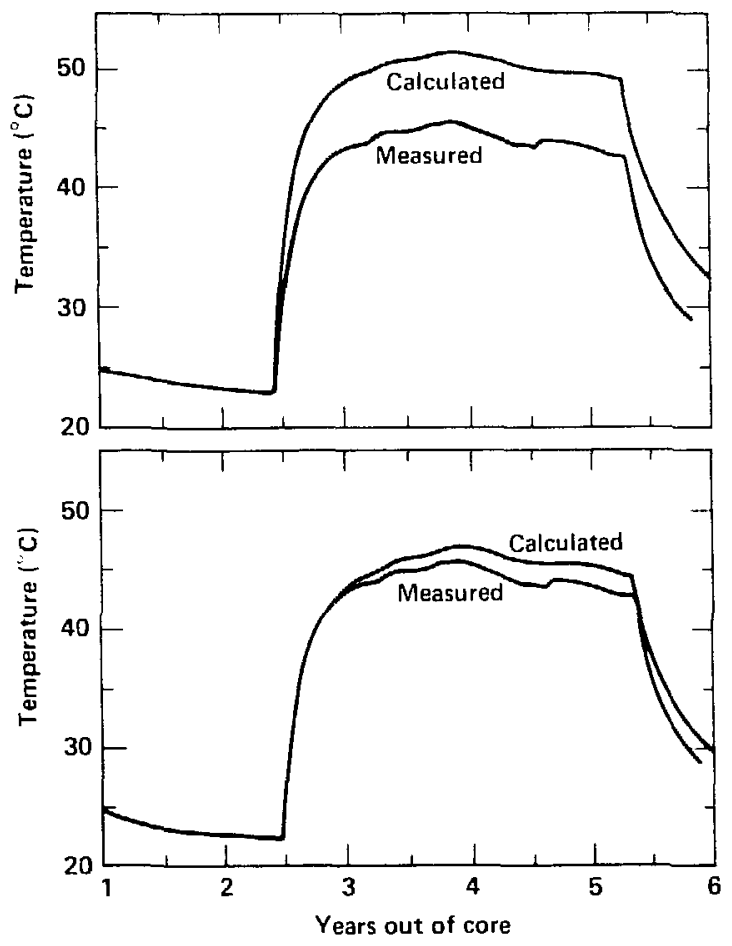

Figure 13-10. Measured and calculated temperature histories at a position $2.0 \mathrm{~m}$ below the floor near the end of the SFT - C array. The top figure is the infinite-length model and the bottom figure is the finite-length model.
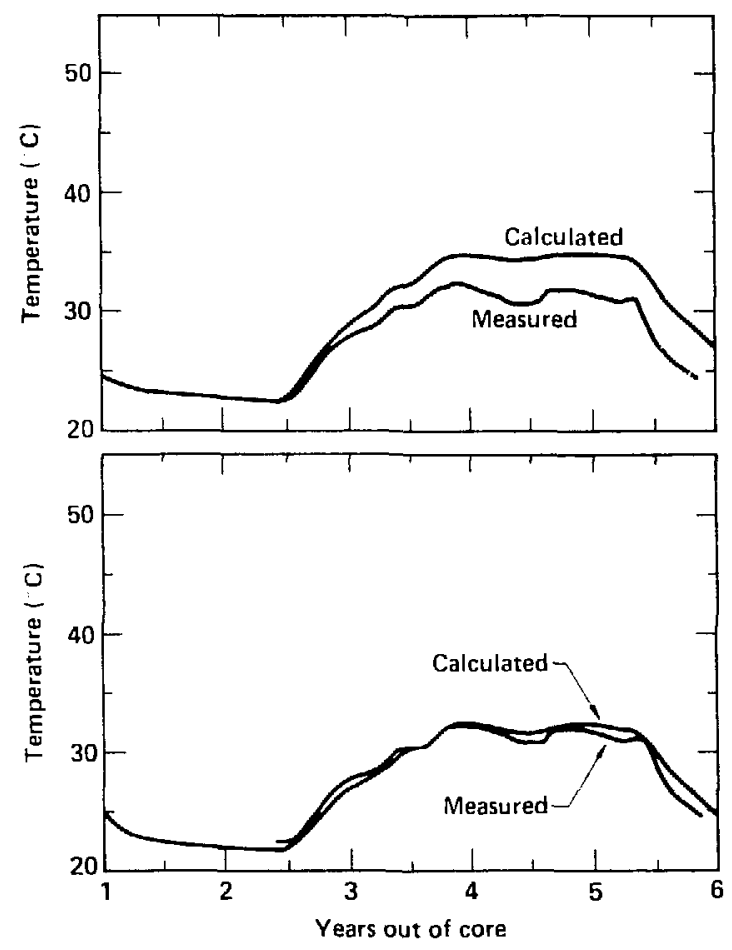

Figure 13-11. Measured and calculated temperature histories at a position near the center of the pillar between two drifts. The top figure is the infinite-length model and the bottom figure is the finite-length model. 

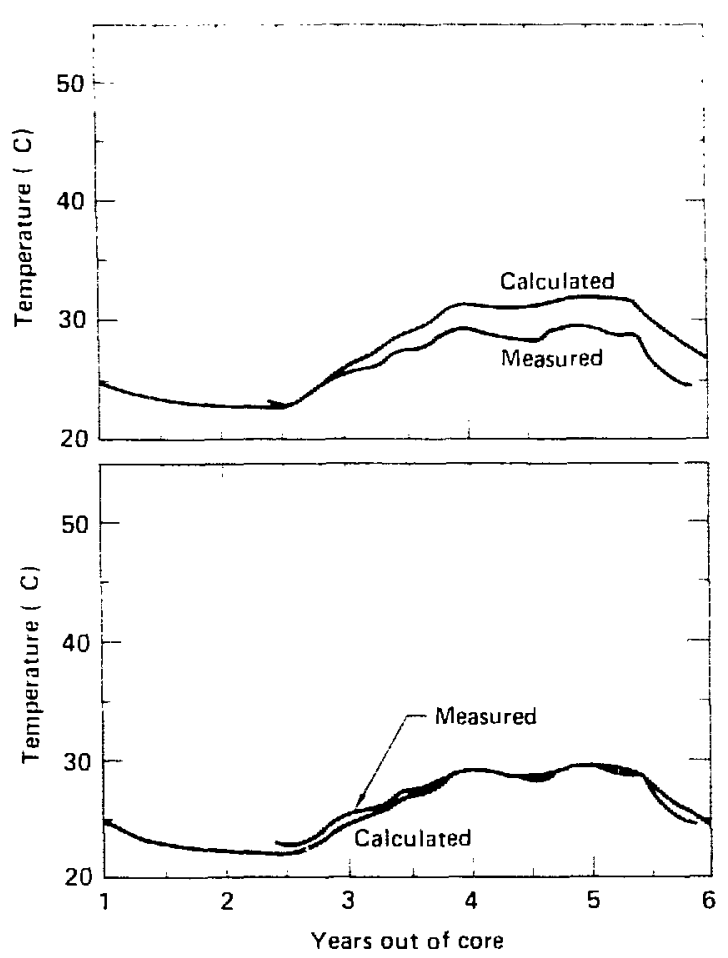

Figure 13-12. Measured and calculated temperature histories at a position near the center of the pillar between two drifts. The top figure is the infinite-length model and the bottom figure is the finite-length model.
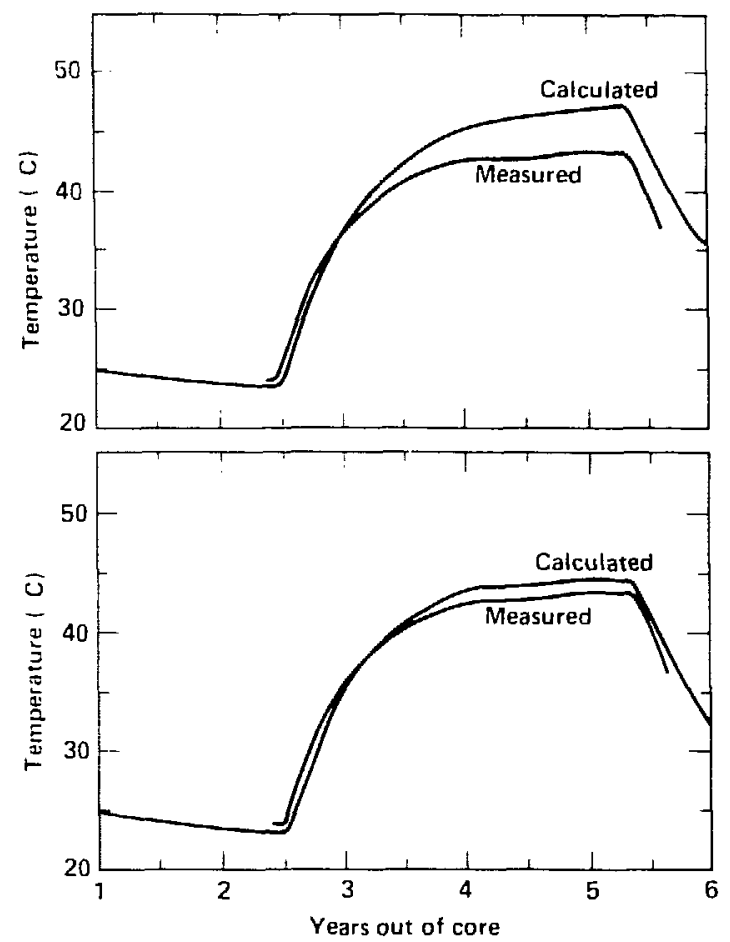

Figure 13-13. Measured and calculated temperature histories at a position $4.8 \mathrm{~m}$ below the pillar midway between the center and north heater drifts. The top figure is the infınite-length model and the bottom figure is the finite-length model. 


\section{Ventilation System Analyses and Measurements*}

The measurements and calculations discussed in the previous chapter focused primarily on conductive, radiative, and convective heat transier processes. The removal of thermal energy by the ventilation airstream, which was also treated in those calculations, is discussed in this chapter.

\subsection{Measurement System and Instrumentation}

During the construstion of the SFT-C facility, the underground workings were ventilated to remove the effluents from operating equipment and the detonation prodicts of high explosives, and to provide fresh air for the workers (Chapter 5). Once the facility was outfitted, a much smaller squirrel-cage-type blower was used to provide a flow of air to keep air tempar atures low enough for continued access to the facility, while minimizing the amount of energy removed. 1 te ventilation system was augmented after the spent fuel was retrieved so the rock mass could be cooled in as short a time as possible (Ballou et al., 1982).

A measurement system was installed to measure airflow rate, inlet and outlet dry-bulb temperatures, and inlet and outlet dewpoints during the heating and cooling phases of the SFT-C (Chapter 9). During construction, no measurements were obtained.

With the exception of a few, relatively minor malfunctions, the turbine flowmeters provided reliable performance during the test. As noted in Chapter 9, accurate calibration of these units was not possible with the low-sensitivity equipment that was available for use on the test.

The measurement of dry-bulb temperatures was accomplished using the same Type K Inconel 600sheathed thermocouples as were deployed elsewhere. High accuracy and precision were obtained by using individual calibrations for these units.

Latent heat of vaporization calculations required that changes in moisture content of the air be known. Lithium chloride dewpoint cells at the inlet and outlet of the three-drift facility provided reliable data on changes in moisture content (the vapor pressure).

The reader is referred to Chapter 9 of this report and to Brough and Patrick (1982) and Patrick, Rector, and Scarafiotti (1984) for details concerning the instruments used to monitor the ventilation airstream.

\subsection{Ventilation System Measurements}

With periodic preventive maintenance, the ventilation system operated reliably for the duration of the test. Because two fans and appropriate valving provided a redundancy in the system, unplanned ventilation outages did not occur. During spent-fuel exchanges and retrievals, it was necessary to periodically check the flow straightener, which was immediately upstream from the turbine flowmeter in the main ventilation duct. This requirement arose because pieces of graphite shim, used as gasketing material on the spent-fuel canister shield block, would at times be sucked into the ventilation take-off box and lodge against the flow straighteners. This caused local increases in the air velocity.

The ventilation fiowrate through the canister access shaft is shown in Fig. 14-1. The effects of changes in flowrate are annot ated. As indicated by the increase in flowrate at about 5.3 YOC, the two squirrel-cage blowers were run in series to maximize flow through the central drift of the facility during the postretrieval period. During post-retrieval cocling, two additional turbine flowmeters measured the flowrate in each of the heater drifts.

Inlet and outlet dry-bulb temperatures measured during the test are shown in Figs. 14-2a and 14-2b, respectively. In addition to the seasonal variations in temperatures indicated by the peaks and troughs, it is also clear that there was a pronounced warming of the inlet airstream as conductive heat flow through the rock caused some preheating of the air outside the ventilation control door where the inlet air temperature measurement was made. This effect is dramatically reversed following retrieval operations when the increased flowrate allowed no "tempering" of the inlet airstream. As a result, inlet temperatures quickly dropped below the pretest values. Outlet air temperatures were also measured in each of the heater drifts during the 6-month cooling period.

\footnotetext{
- Contributed by W. C. Patrick
} 


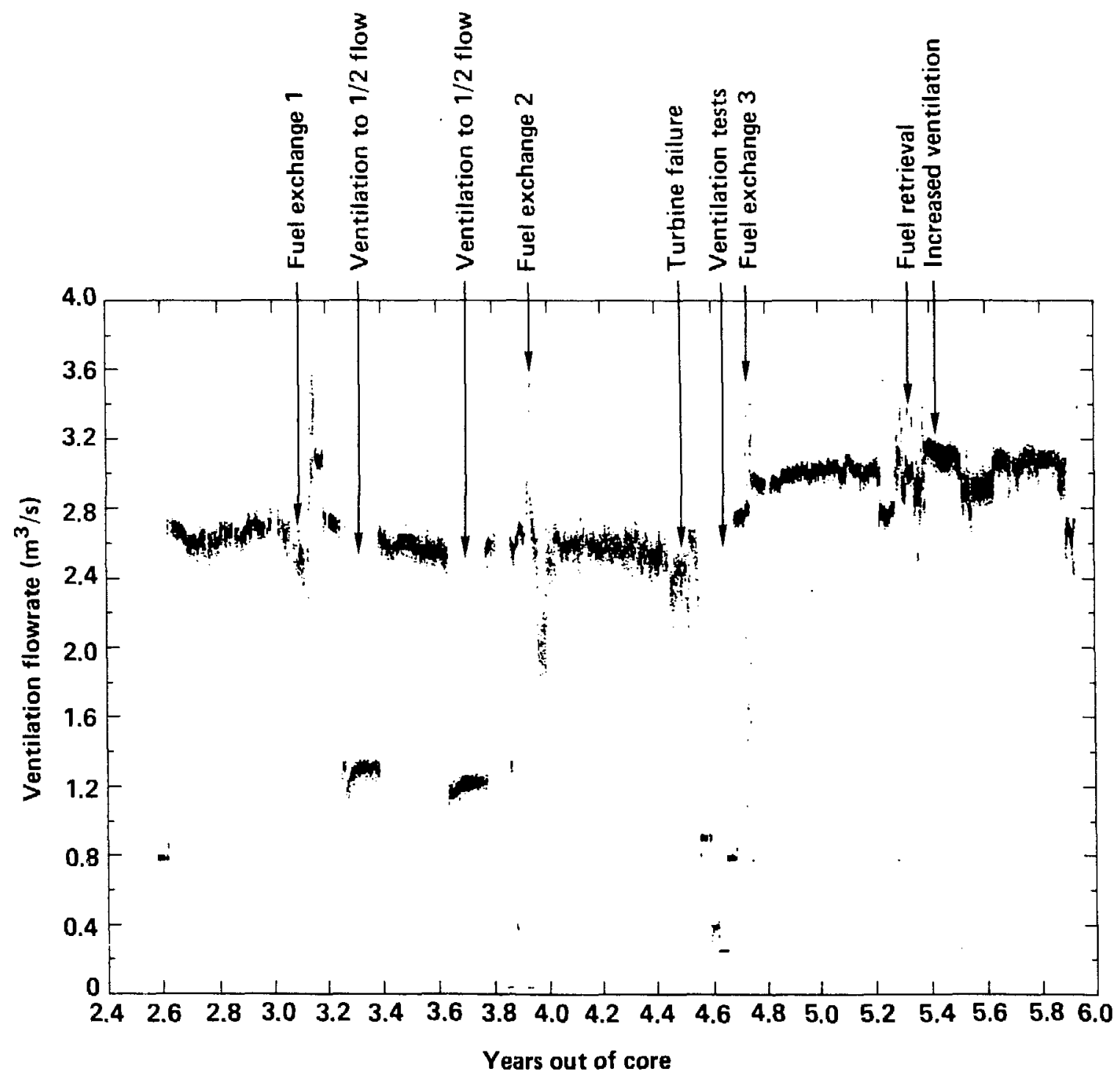

Figure 14-1. Ventilation flowrates through the canister access shaft.

The history of inlet and outlet dewpoint temperatures are shown in Figs. 14-3a and 14-3b, respectively. Once again, we see seasonal variations in dewpoint. Increases in flowrate tend to depress both the inlet and outlet dew points, presumably because the air has less opportunity to gain moisture as it flows thirough the facility. Consistent with this observation, decreases in flowrate during the ventilation tests raised the dewpoint. The increase in dewpoints at about 5.7 to $5.8 \mathrm{YOC}$ is caused by additional water being added to the ventilation airstream as a result of post-retrieval drilling operations. As discussed below, this water appeared to be present at both the inlet and outlet points and, therefore, did not significantly contribute to energy removal.

Using the dry bulb, dew point, and flowrate data presented above, it is possible to calculate the quantities of sensible and latent heat removed by the ventilation airstream (Patrick, Rector, and Scarafiotti, 1984). "Sensible heat" is the energy associated with increasing the temperature of air at a constant water content, whereas the "latent heat" is the energy associated with vaporizing water and adding it to the airstream. 


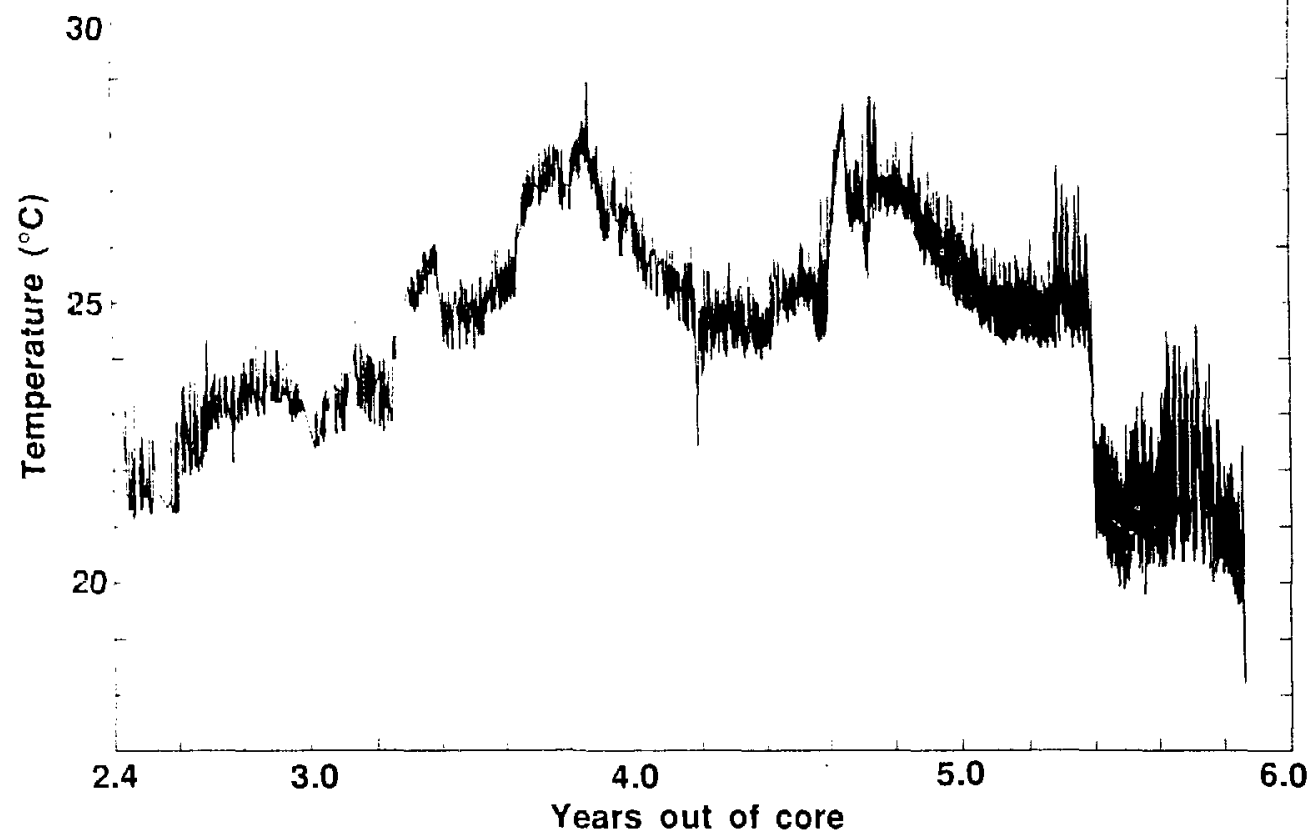

Figure 14-2a. Inlet air temperature.

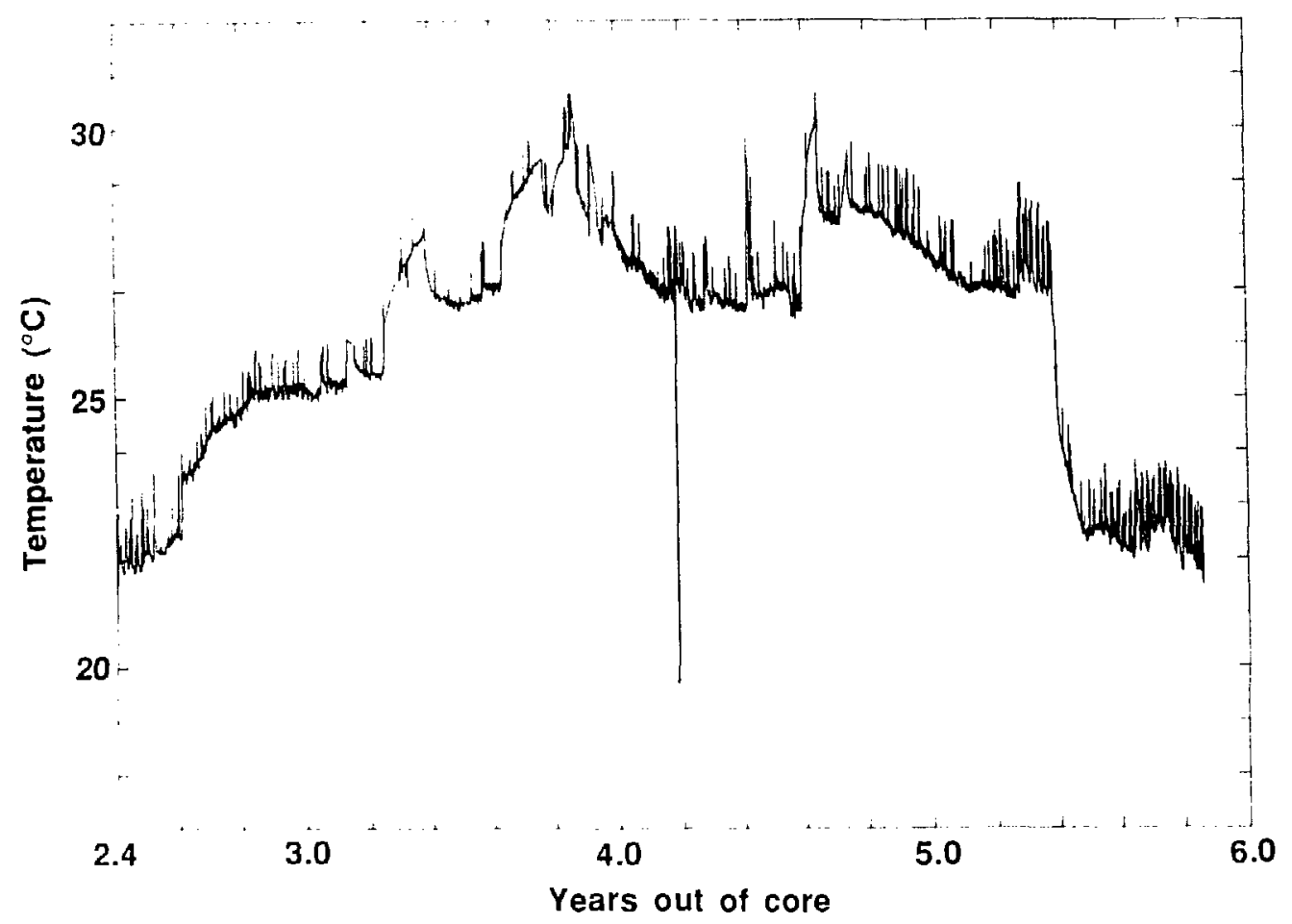

Figure 14-2b. Outlet air temperature. 


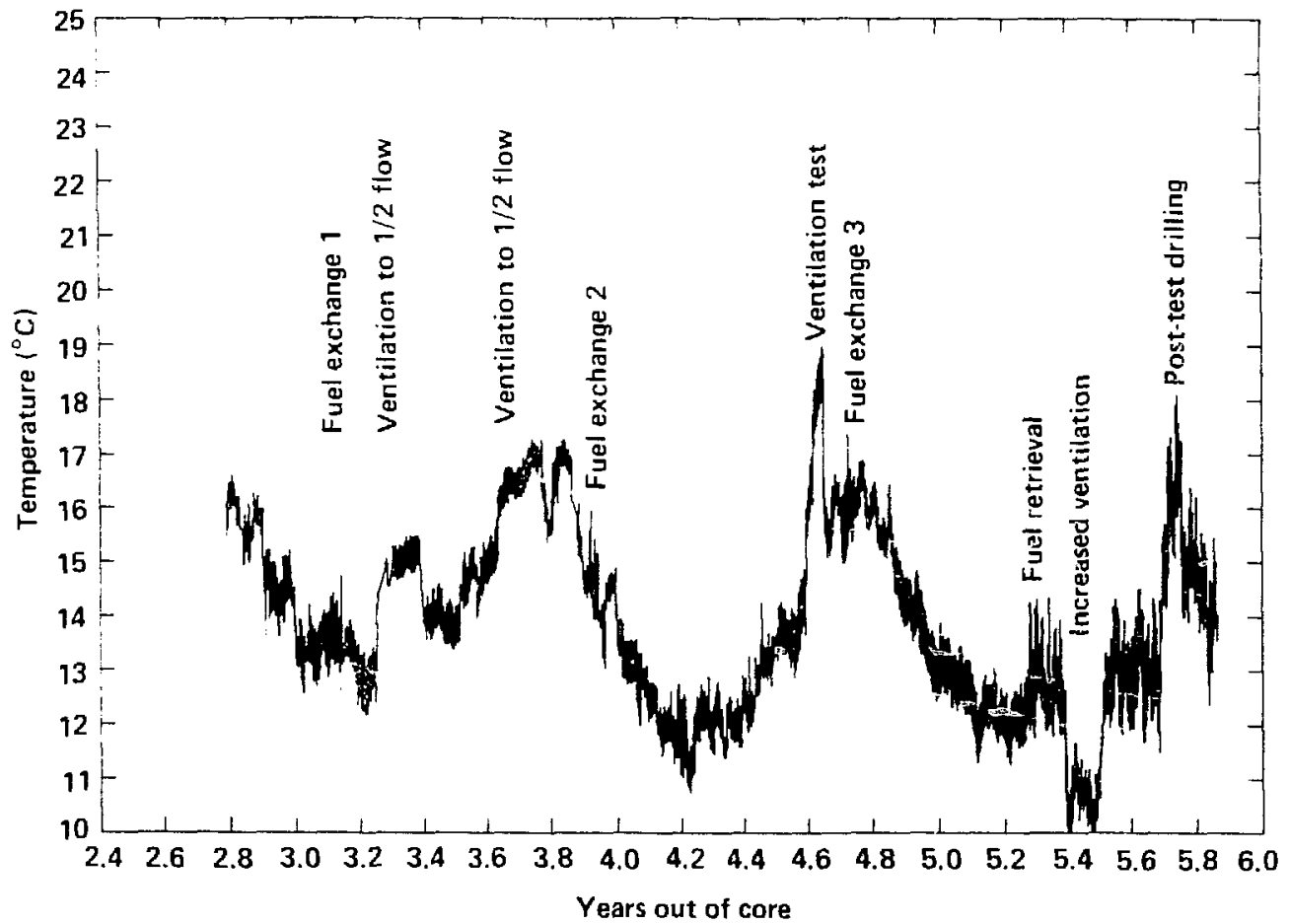

Figure 14-3a. Inlet air dewpoint temperature.

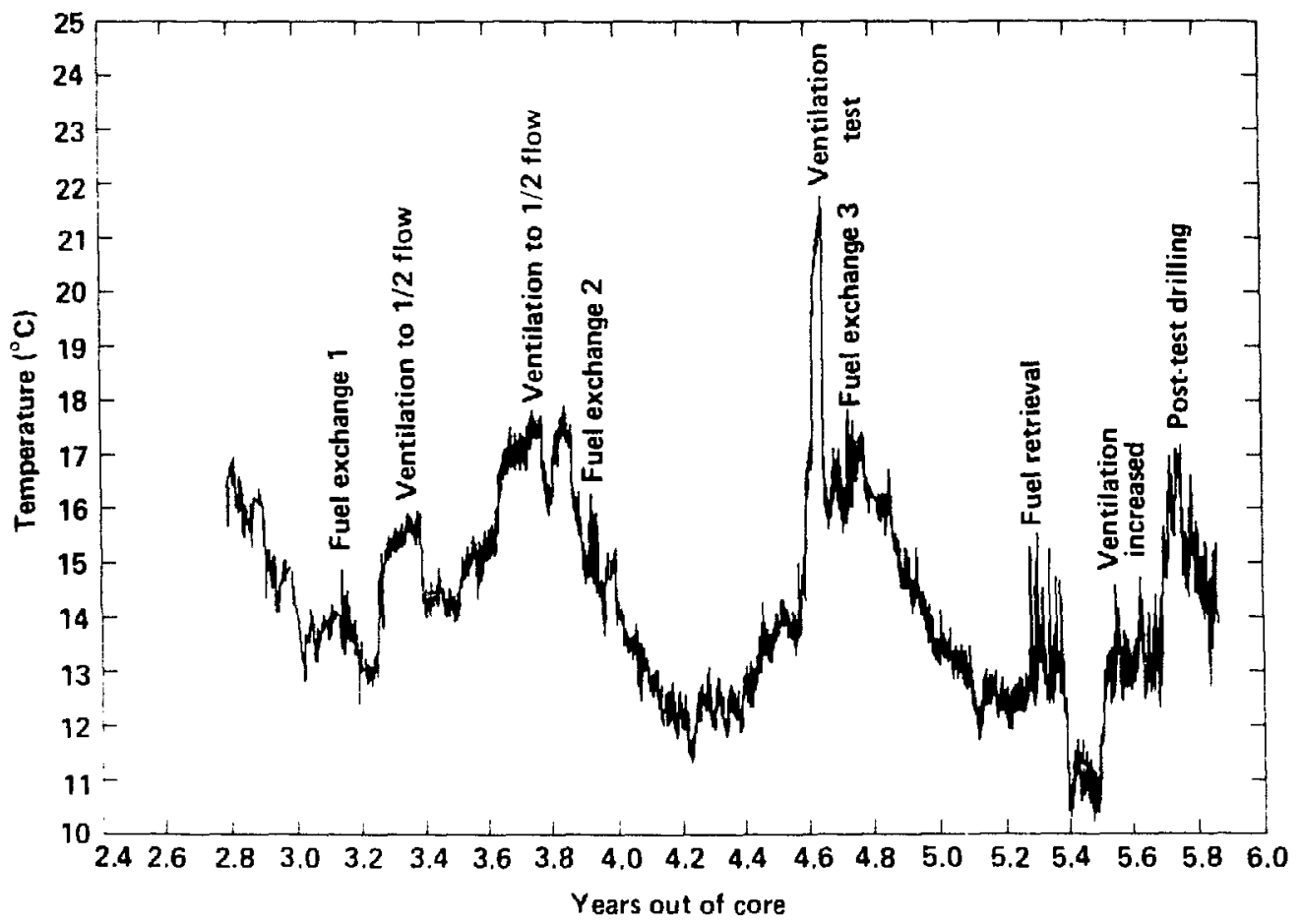

Figure 14-3b. Outlet air dewpoint temperature. 
The history of energy removal by both these mechanisms is shown in Fig. 14-4. Through retrieval operations at about 5.4 YOC, about $76.7 \%$ of the energy was associated with sensible heat, and $23.3 \%$ was associated with the heat of vaporization. During the post-retrieval cooling period, the sensible heat fraction increased to about $78.2 \%$ as a result of increased cooling associated with the increased ventilation rate. Another contributing factor was the increased use of facility lighting, which tends to deposit energy where it is easily removed: directly into the airstream and at surfaces in contact with the airstream. As noted earlier, minor decreases occurred in energy removal as latent heat, despite increases in the availability of water due to drilling operations. This decrease is evident in Fig. 14-5 at times later than about 5.5 YOC.

The history of the rate of energy deposition described in Chapter 12, and the history of the rate of energy removal shown in Fig. 14-4, are shown as 10-day averages in Fig. 14-6. These input and output

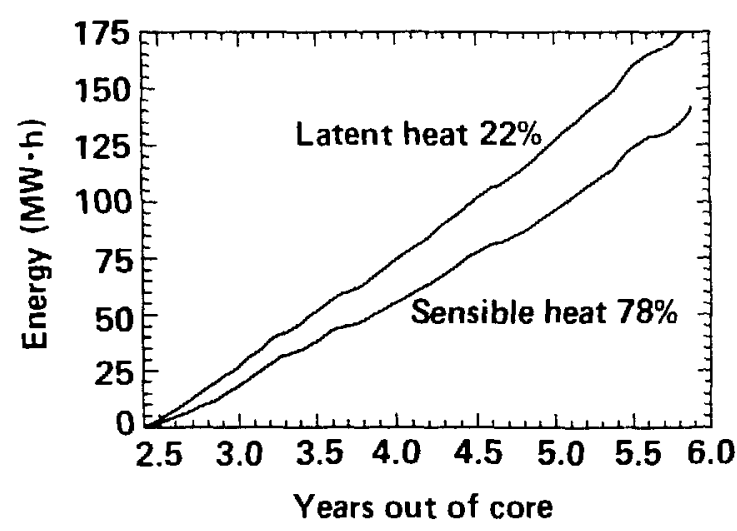

Figure 14-4. Cumulative thermal energy removed by ventilation.

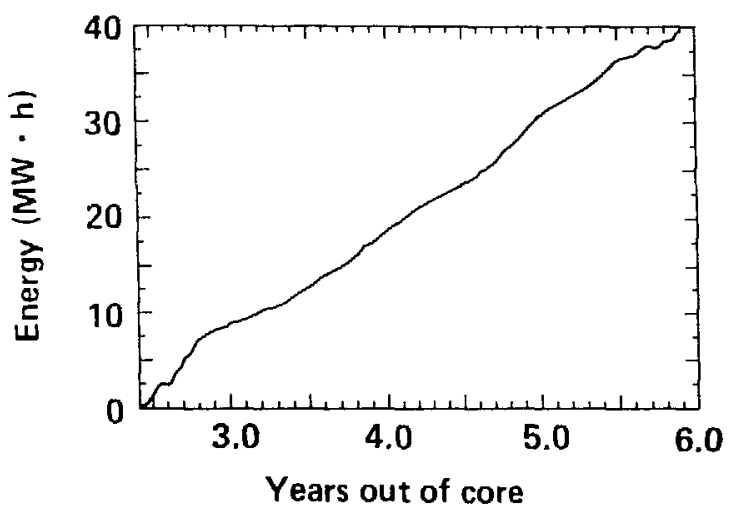

Figure 14-5. History of cumulative thermal energy removed by vaporization of water.

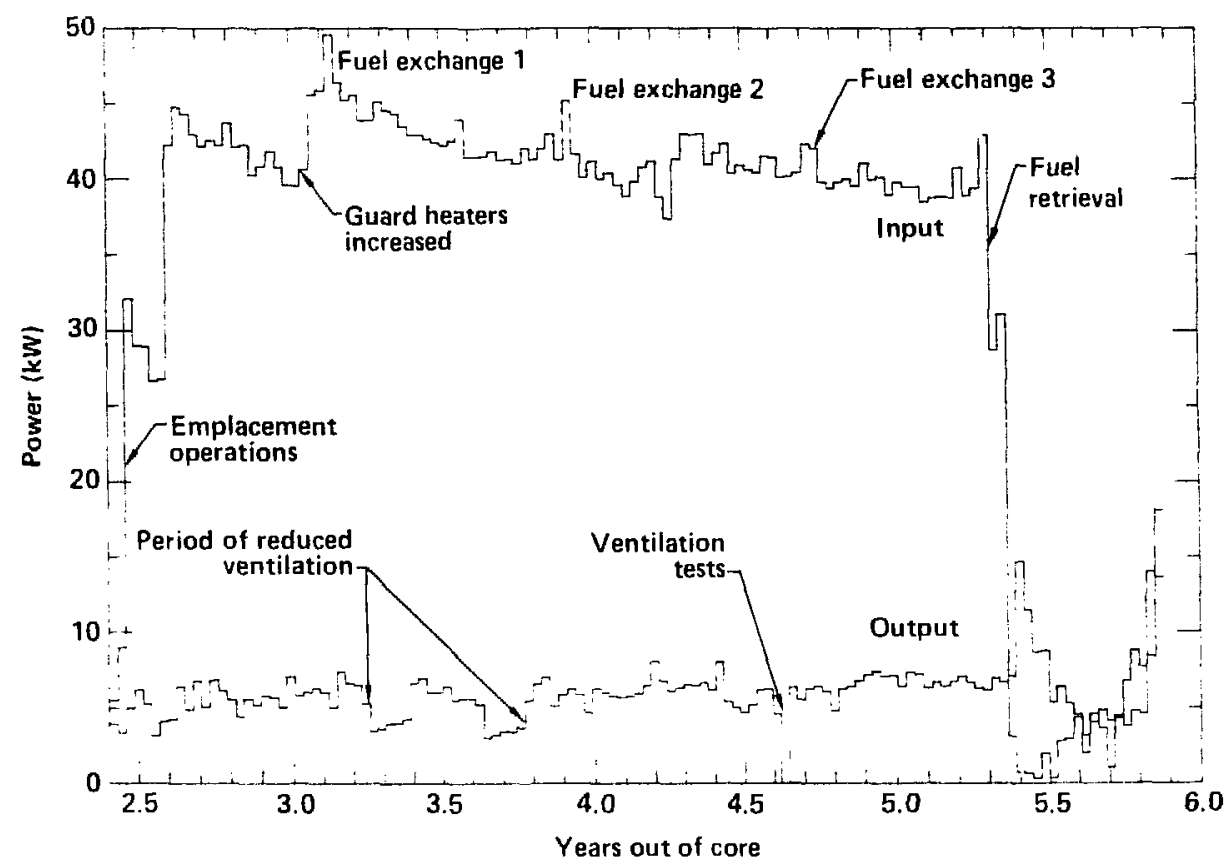

Figure 14-6. Power input and removal history annotated for significant events. 
powers clearly show the relative effects of perturbations on the system, as noted. Following spent-fuel retrieval, the sole contribution to input power was the facility lights. As a result, the power removed exceeded the power input during the post-retrieval period.

\subsection{Ventilation Calculations}

Chapter 3 summarizes the sequence of calculations used to design the SFT-C and to compare with test data. The reader is referred to Montan and Patrick (1981 and 1986) for details of the calculations, particularly the details of the ventilation models that were employed. Our discussion and comparisons presented here focus on two of the models: a TRUMP three-dimensional infinite-length representation and a TRUMP three-dimensional finite-length representation of the SFT-C.

We have used the finite-difference code TRUMP (Edwards, 1972), beginning with the detailed design calculations and progressing through post-test calculations. Although no actual "flow" of air occurred in the model, the effect could be modeled with what Montan and Patrick (1981) dubbed a "partial flow" model. This formulation was effectively implemented with the infinite-length model where the many planes of symmetry kept the model small, allowing more details to be represented. In employing the finitelength representation of the SFT-C test array, Montan and Patrick (1986) found it was necessary to eliminate many of these refinements. Ventilation was sirnulated by treating the drifts as highly conductive materials with central nodes connected through a heat-transfer cuefficient to external nodes whose temperatures were controlled to the ambient inlet air temperature. Montan and Patrick (1986) also describe how heat sinks within each drift were used to model ventilation with analytical solutions. These sinks were assigned negative power histories based on the measured energy removal rates.

\subsection{Comparison of Data and Calculations}

Figure 147 provides a direct comparison of the measured and calculated energy removal rates for each of the models. The curves for the infinite-length model $(U)$ and the finite-length model $(X)$ indicate that during the construction period there was an initially high rate of energy removal (power) that quickly decreased as the nearby ambient rock temperatures decreased to near the inlet air temperatures. As heating of the rock mass begins at about $2.5 \mathrm{YOC}$, we see an increasing trend in the power curves as the rock near the drift surfaces becomes warmer. The finite-length model removes somewhat more energy than its

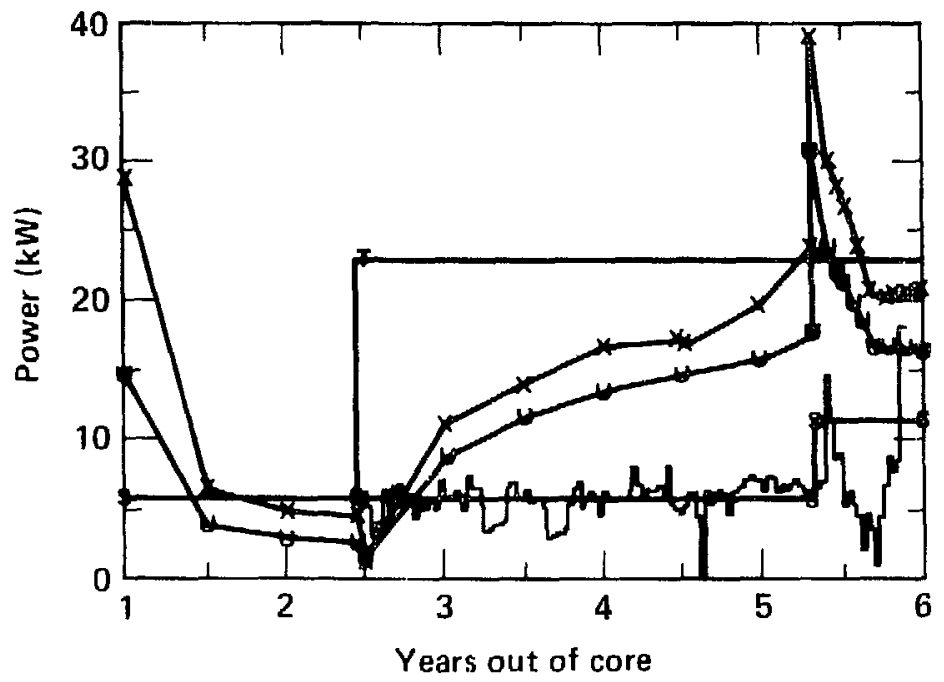

Figure 14-7. Energy removal rates calculated using four techniques and measured. 
infinite-length counterpart. The curves labeled $S$ and $T$ represent energy removal rates for two analytical models (Montan and Patrick, 1986).

The modeled trends ( $U$ and $X$ ) are in marked contrast to the measured energy removal rate. With the notable exception of short-duration decreases associated with decreases in the ventilation flowrate (Fig. 14-6), the data indicate a relatively flat response. Although this measured response appears unreasonable (more heat should be available for removal as the drift surface temperature increases with time), there was no indication of instrumentation malfunction that would lead us to question the data (Chapter 9).

The cumulative effect of differences between the measurements and the finite-difference models are shown in Figs. 14-8 and 14-9 for the infinite-length and finite-length representations, respectively. In

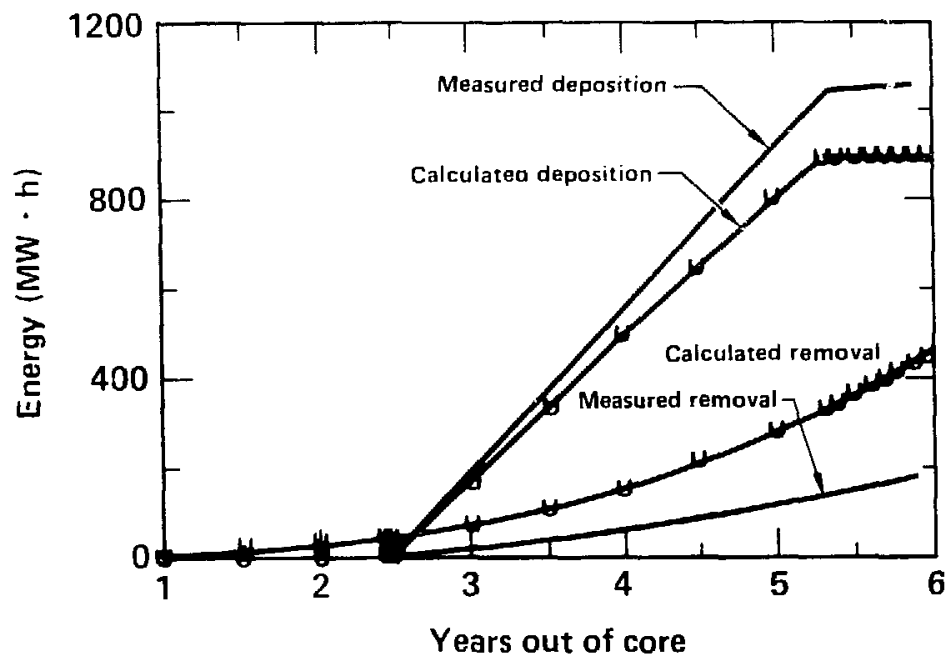

Figure 14-8. Cumulative energy deposition and removal as calculated by an infinite-length representation of the SFT-C and as measured.

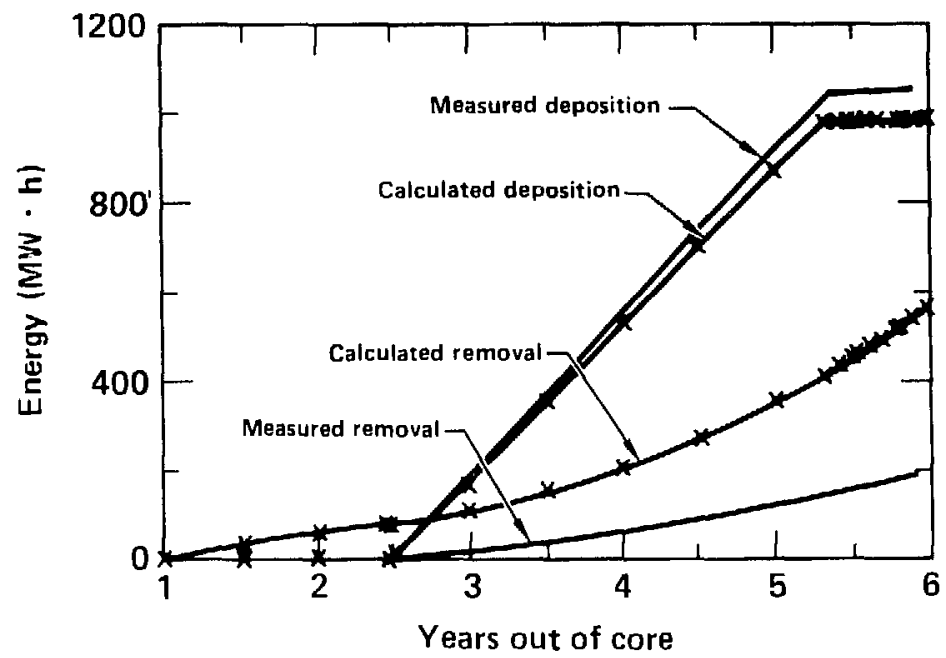

Figure 14-9. Cumulative energy deposition and removal as calculated by a finite-length representation of the SFT $-\mathrm{C}$ and as measured. 
Fig. 14-8, we see that the cumulative input energy curve for the model is somewhat lower thari the data. This occurs because of the way the auxiliary heaters were treated in the model (Montan and Patrick, 1981). The cumulative energy removal by the model deviates increasingly from the data until, at the end of the test, it is more than double the measured value.

Figure 14-9 indicates the more exact energy input provided by the finite-length model; the difference between these curves is nearly all the result of not including the effects of lighting in the calculation (Chapter 12). However, differences between measured and calculated cumulative energy removal are even more pronounced than in Fig. 14-8. Nearly three times as much energy is removed by the calculation as was measured.

Despite the lack of agreement between measured and calculated energy removal, we must recognize that these two models provide excellent agreement between measured and calculated temperatures throughout the test array. As discussed in the previous chapter, we see the best agreement with the finitelength representation of the SFT $-\mathrm{C}$, which also provides the greatest discrepancy with regard to energy removal.

Turning to the more simplistic analytical solutions, we can evaluate how well a completely different formulation can calculate energy removal. In this case, we are not simulating the physical mechanisms of energy removal but are simply extracting energy by means of a "negative source" in each drift. Curve $\mathrm{S}$ in Fig. 14-7 represents the rate of energy removal used in a calculation to approximate the measured rate of energy removal. As reported by Montan and Patrick (1986) and summarized in Chapter 3, this low rate of energy removal resulted in substantially higher temperatures throughout the rork mass comprising the SFT-C. Thus, while one can force the measured and calculated energy removal rates to be the same, the effect on the quality of temperature predictions is unacceptable.

Using the same analytical technique, Montan and Patrick (1986) quadrupled the energy removal rate (curve $T$ in Fig. 14-7). Even a change as coarse as this one produced marked improvement in the level of agreement between measured and calculated temperatures throughout the rock mass.

\subsection{Assessment of Models}

It should be clear from the preceding discussion that there is a conflicting judgment concerning our ability to model the effects of ventilation on a heated rock mass. The ventilation models used for both the infinite- and finite-length TRUMP calculations result in excellent agreement between measured and calculated temperatures throughout the heated rock mass and appurtenant engineered features of the SFT-C. However, the energy removal associated with these models disagrees in both form and magnitude with the measured energy removal. Although it is tempting to conclude that the energy removal data are in error, we have detected no instrumentation malfunctions or errors that could produce such errors in the data.

Based on this analysis, we conclude that the models reported by Montan and Patrick (1981 and 1986) provide accurate representations of the effects of ventilation on heat transfer within the rock mass and engineered structures comprising a simulated repository. However, the energy removal calculated by those same models does not agree with the measured removal cf energy in the airstream. We have not yet been able to explain this discrepancy despite a dilligent effort to model the phenomena. 


\section{Radiation Transport Calculations and Measurements*}

Together with heat transfer and ruck mechanical response, radiation transport was a principal phenomena studied at the SFT $-C$. By comparing calculations of radiation transport with measurements of radiation doses and dose rates, we were able to confirm our radiation shielding design, assess the current state of the art in both calculations and measurements, and further our understanding of the behavior of crystalline rocks in the presence of intense ionizing radiation.

\subsection{Radiation Dose to Granite}

Radiation-dose-to-granite calculations using a Monte Carlo technique (Wilcox and Van Konynenburg, 1981) were believed to accurately predict the dose rates and cumulative doses that would be received by the rock surrounding the emplacement boreholes. As a result of peer review comments, we incorporated radiation dosimetry in the instrumentation program of the SFT - C (Brough and Patrick, 1982). The performance of the measurement system and comparison of data and calculations are summarized below.

\subsubsection{Measurement System}

A gamma and neutron dosimetry system was developed and fielded at the SFT-C by EG\&G-Santa Barbara Operations under contract to LLNL. This suite of instrumentation consisted of: $(1)^{>} \mathrm{LiF}$ dosimeters that operate on the concept of photoabsorption response to ionizing radiation; and (2) manganese, cobalt, and silver neutron foils.

As described in Chapter 9, five of 17 emplacement boreholes were instrumented with seven dosimeter strings. Although four emplacement boreholes contained spent-fuel assemblies, the fifth contained an electrical simulator, thus, serving as a control to detect possible instrumentation problems. The dosimeters in this borehole were exposed to $4 \times 10^{6}, 3 \times 10^{7}$, and $3 \times 10^{8}$ rad prior to emplacement.

Quam and DeVore (1981, 1982, and 1984a) found that the ${ }^{7} \mathrm{LiF}$ dosimetry faded as a result of postirradiation heating and also exhibited temperature sensitivity due to irradiation at elevated temperature. As a result, they fielded short-term gamma dosimeters that operated on the principal of thermoluminescence (Quam and DeVore, 1984b).

Neutron foil dosimetry was determined to provide inadequate results. Counting statistics were so low that accurate measurements were not possible (Quam and DeVore, 1981). However, it was determined that the neutron dose rates were negligible compared to the gamma dose rates in the emplacement boreholes.

The interested reader is referred to reports by Quam and DeVore (1981, 1982, 1984a, and 1984b) for details concerning the long-term gamma and neutron dosimetry, and the short-term dosimetry, respectively. The description and performance of these instruments are summarized in Chapter 9 of the present report.

\subsubsection{Comparison of Data and Calculations}

Using the calculations of Wilcox and Van Konynenburg (1981) as a basis (Chapter 3), Van Konynenburg (1982 and 1984) evaluated the measurements reported by Quam and DeVore that were discussed above. His initial comparisons identified the influence of temperature on the long-term measurements.

Pretest thermoluminescent dosimetry (TLD) at the Battelle facility on September 12, 1979, produced an average contact dose rate of about $0.21 \mathrm{~Gy} / \mathrm{s}$ in $\mathrm{LiF}$, in excellent agreement with the calculated $0.211 \mathrm{~Gy} / \mathrm{s}$. Following retrieval of the spent-fuel assemblies, a similar measurement at EMAD indicated a dose equivalent to $0.055 \mathrm{~Gy} / \mathrm{s}$ in $\mathrm{LiF}$, exactly the calculated value. Given the $\pm 25 \%$ uncertainty in the calculations and $\pm 11 \%$ uncertainty in the measurement, this is excellent agreernent.

Comparison between in-situ long-term dosimetry and calculations are not nearly as good. Table 15-1 summarizes these comparisons by presenting the ratios of measured to calculated doses at the various measurement positions for the three time-periods during which measurements were made. We see here, and graphically in Figs. 15-1, -2, and -3, that the measurements are consistently about a factor of two less than the calculation. Furthermore, there is substantial scatter in the data. Van Konynenburg (1984) concluded that this is the result of the inability to accurately correct the data for fade.

* Contributed by W. C. Patrick. 
Table 15-1. Ratios of doses measured by optical absorption technique to doses calculated using Monte Carlo simulation. Where two values are shown, they correspond to two separate absorbtion peaks.

\begin{tabular}{|c|c|c|c|c|}
\hline \multirow{2}{*}{$\begin{array}{l}\text { Emplacement hole } \\
\text { number, radial } \\
\text { pasition }(\mathrm{m})\end{array}$} & \multirow{2}{*}{$\begin{array}{l}\text { Vertical distance } \\
\text { trom midplanẹ, } \\
\text { (m) }\end{array}$} & \multicolumn{3}{|c|}{ Measurement period } \\
\hline & & $\begin{array}{l}+80 \text { to } \\
1.7281\end{array}$ & $\begin{array}{c}1 / 12 / 81 \text { to } \\
10 / 23 / 81\end{array}$ & $\begin{array}{c}10 / 23 / 81 \text { to } \\
3 / 8 / 83\end{array}$ \\
\hline \multirow[t]{3}{*}{ CEH01, 0.30 (wall) } & +1.22 & 0.56 & 0.54 & 0.49 \\
\hline & 0 & 0.67 & 0.62 & 0.56 \\
\hline & -1.22 & 0.56 & 0.57 & 0.55 \\
\hline \multirow[t]{5}{*}{ CEH03, 0.30 (wall) } & +1.22 & 0.65 & 0.53 & 0.54 \\
\hline & +0.66 & 0.69 & 0.53 & 0.62 \\
\hline & 0 & 0.75 & 0.67 & 0.65 \\
\hline & -0.66 & 0.71 & 0.69 & 0.65 \\
\hline & +1.22 & 0.73 & 0.64 & 0.62 \\
\hline \multirow[t]{3}{*}{ CEH03, 0.51} & +1.22 & $0.55,0.47$ & $0.65,0.51$ & $0.38,0.41$ \\
\hline & 0 & 0.40 & 0.58 & $0.30,0.25$ \\
\hline & -1.22 & $0.39,0.40$ & 0.63 & $0.35,0.25$ \\
\hline \multirow[t]{3}{*}{ CEH03, 0.66} & +1.22 & 0.51 & 0.68 & 0.79 \\
\hline & 0 & 0.60 & 0.66 & 0.72 \\
\hline & -1.22 & 0.66 & 0.55 & 0.52 \\
\hline \multirow[t]{3}{*}{ CEH07, 0.30 (wall) } & +1.22 & 0.64 & 0.55 & 0.56 \\
\hline & 0 & 0.66 & 0.55 & 0.60 \\
\hline & -1.22 & 0.75 & 0.58 & 0.64 \\
\hline \multirow[t]{3}{*}{ CEH11, 0.30 (wall) } & +1.22 & $\therefore 66$ & 0.53 & 0.55 \\
\hline & 0 & 0.74 & 0.60 & 0.58 \\
\hline & -1.22 & 0.62 & 0.57 & 0.55 \\
\hline
\end{tabular}

The two sets of short-term TLD measurements provided much better agreement with the calculations. Table 15-2 displays ratios of dose rates measured with $\mathrm{CaF}_{2}$ TLD to those calculated. In addition, the data are shown graphically in Figs. 15-4 and 15-5. We see the best agreement with the data obtained March 8, 1983: the best-controlled, best-calibrated set of measurements (Van Konynenburg, 1984; and Quam and DeVore, 1984b). Because the half-lives of the significant radionuclides are well known, and good agreement was obtained between calculations and measurements for these two intermediate points at the beginning and at the end of the test, we believe that the calculated doses and dose rates are an accurate reflection of the true values absorbed by the rock.

\subsubsection{Dose to Granite}

Van Konynenburg (1984) presented the calculated total absorbed doses to the rock at the wall of each emplacement borehole. These total doses account for differences in spent-fuel source strengths, differing emplacement and retrieval times, and the occurrence of spent-fuel exchanges at some positions (Table 15-3).

\subsection{Areal Dosimetry and Radiation Monitoring}

A variety of instrumerts was used to continuously monitor: (a) the radiation levels in the underground storage area and in the vicinity of spent-fuel handling operations, and (b) potential releases to the atmosphere. The principal monitoring system used continuous air monitors (CAMs) and remote area monitors (RAMs) to confirm that no radioactive effluents had escaped and that radiation dose rates were near background levels (Chapter 9). 


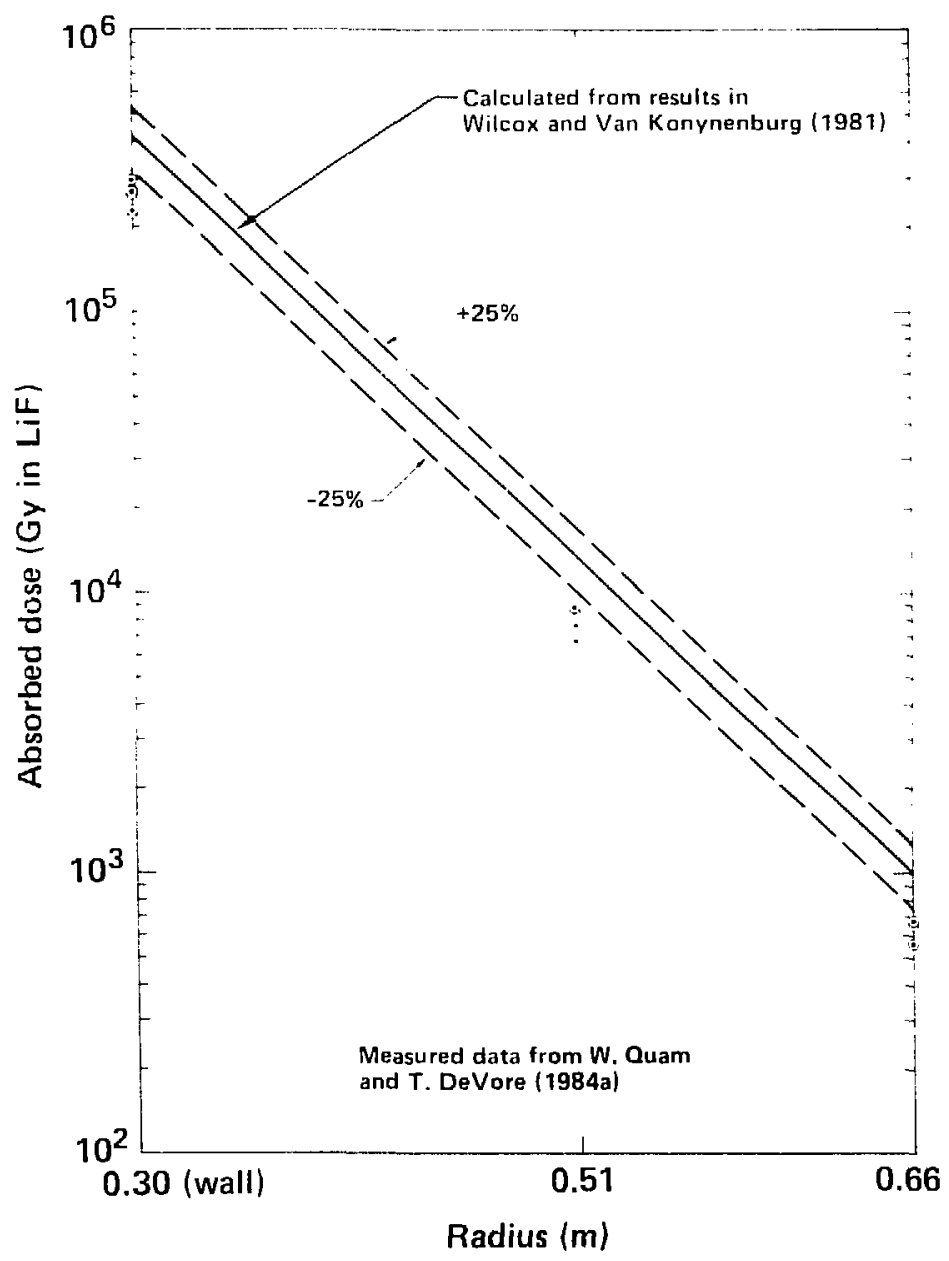

Figure 15-1. Comparison of calculated and optical-absorption-measured doses for hole CEH03 for the period from April 1980 to January 12, 1981 (after Van Konynenburg, 1984).

In preparation for operations related to the SFT-C, background radiation-survey data were obtained at selected locations. These were later augmented by sampling from the CAMMs and from the liner-rock annular spaces of the emplacement boreholes. As indicated in Table 15-4, most values were at or near background levels. The slightly elevated ${ }^{137} \mathrm{Cs}$ and tritium levels are attributed by Raschke et al. (1983) to previous nuclear weapons effects testing at the same underground level. Dosimetry indicated background beta-gamma dose rates of about $0.04 \mathrm{mR} / \mathrm{h}$ and gamma dose rates of about $0.02 \mathrm{mR} / \mathrm{h}$ in the spent-fuel storage drift.

\subsection{Summary of Personnel Radiation Exposures}

Radiological monitoring and personnel dosimetry were an ongoing part of the SFT-C operation. The radiological safety program used personnel and area dosimeters, bioassays, continuous monitoring with RAMs and CAMs, routine surveys with portable instruments, swipes, and sampling of air, soil, rock, water, and appropriate test hardware. 


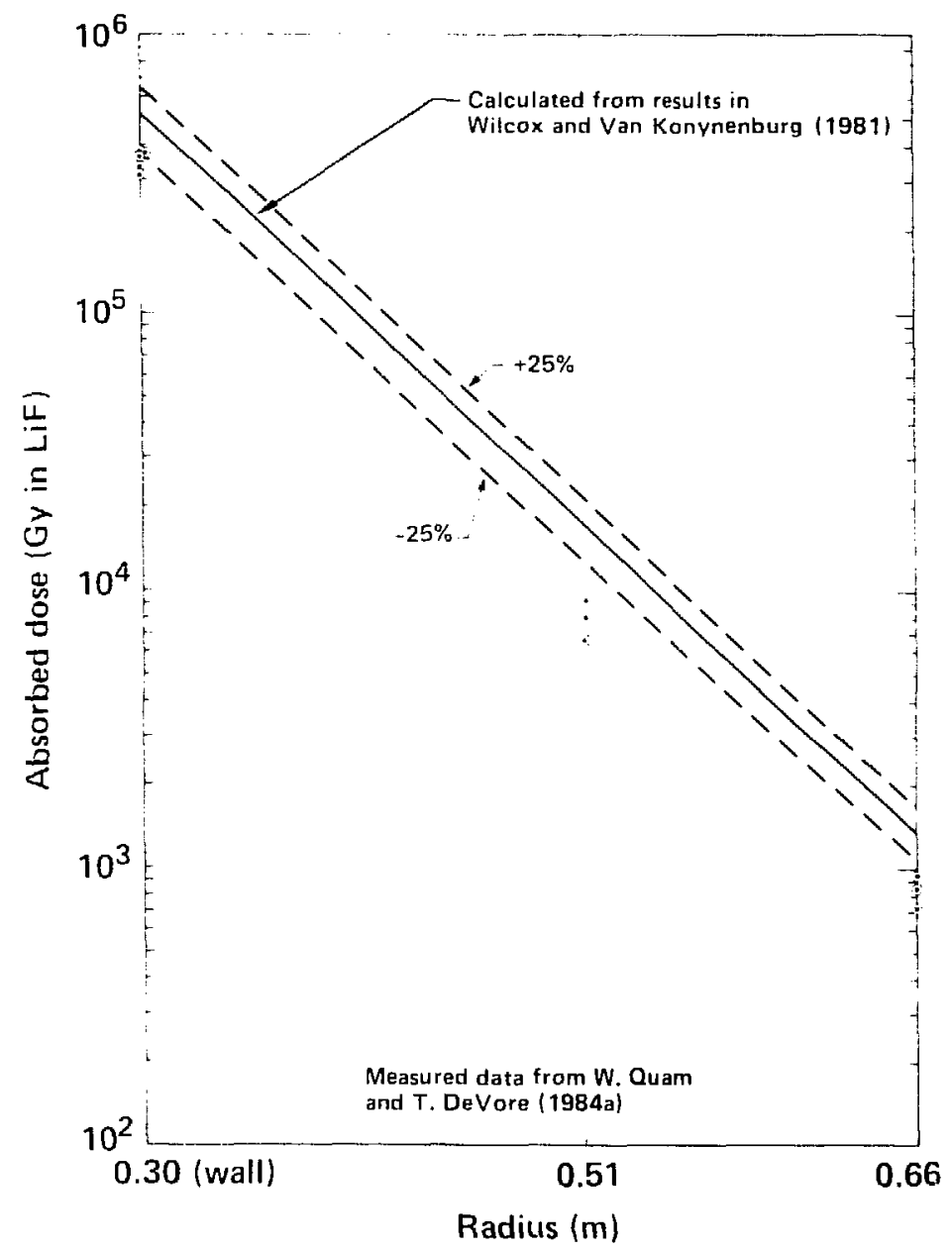

Figure 15-2. Comparison of calculated and optical-absorption-measured doses for hole CEH03 for the period from January 12, 1981 to October 23, 1981 (after Van Konynenburg, 1984).

Maximum occupational exposure data obtained during spent-fuel emplacement, storage, and retrieval operations are shown in Table 15-5 (Raschke et al., 1983). These data are normalized to an "operation" involving the emplacement or retrieval of a single spent-fuel assembly. The reduction in exposure during retrieval is due partially to a factor of 2 decay in the source term and an apparent reduction in exposure time by an additional factor of 2 or more (Chapter 11).

Figure 15-6 expands on the tabulated maximum exposure data by providing the distribution of gamma and neutron exposures during the retrieval operation. The two relatively high exposures were received by the health and safety officer and the operations coordinator, whose roles in the retrieval resulted in their being nearer the shielded spent fuel for longer periods of time than most of the crew.

Radiation exposures for the duration of SFT-C were less than 0.4 person-rem or, on average, less than 0.016 person-rem/operation (Raschke et al., 1983, and Chapter 11). These measurements confirm the adequacy of the designs of equipment and storage-hole configuration discussed in Chapters 3 and 7. 


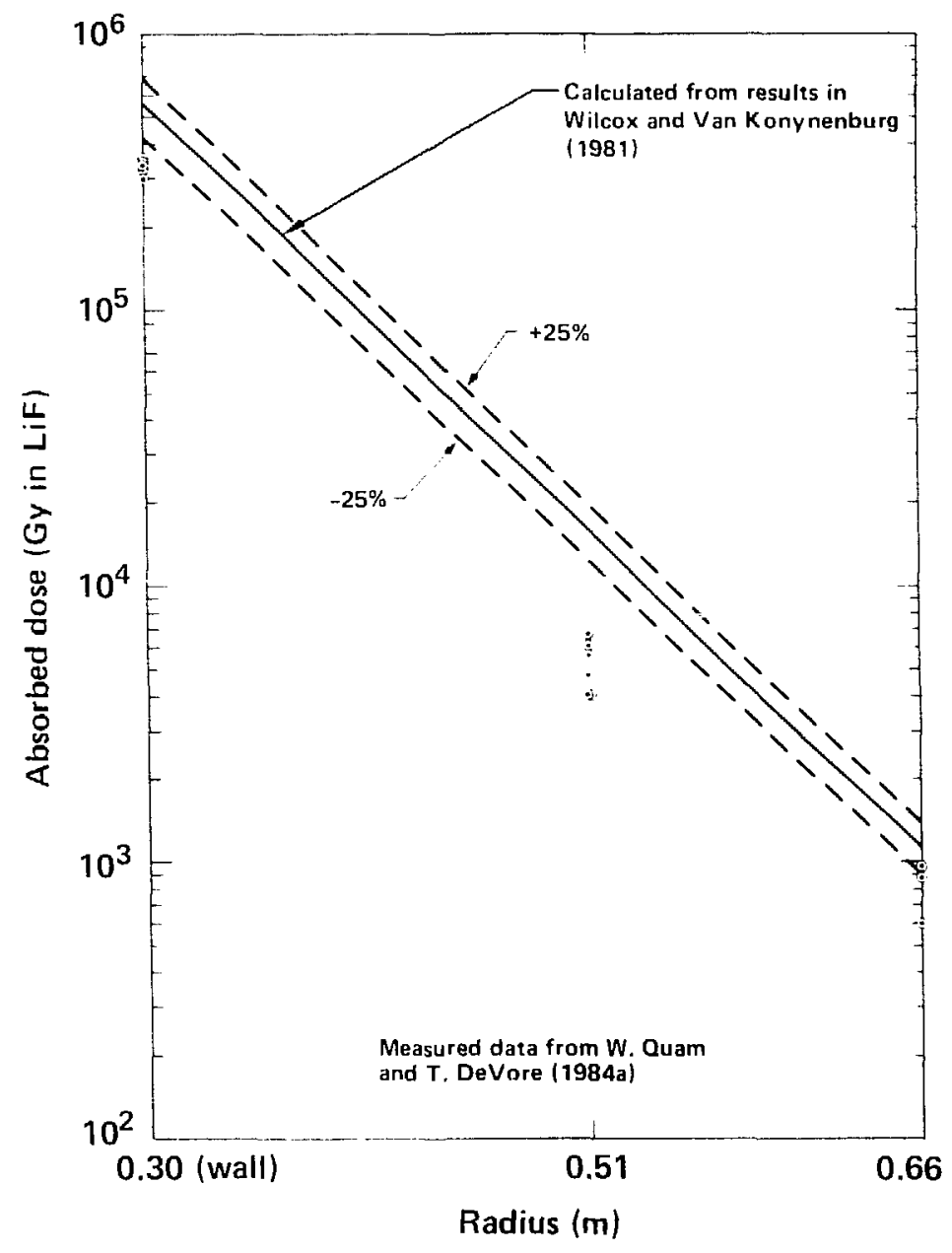

Figure 15-3. Comparison of calculated and optical-absorption-measured doses for hole CEH03 for the period from October 23, 1981 to March 8, 1983 (after Van Konynenburg, 1984).

Table 15-2. Ratios of dose rates measured by $\mathrm{CaF}_{2}$ TLD to dose rates calculated using Monte Carlo simulation.

\begin{tabular}{cccc}
\hline $\begin{array}{c}\text { Emplacement hole } \\
\text { number, radial } \\
\text { position (m) }\end{array}$ & $\begin{array}{c}\text { Vertical distance } \\
\text { from midplane, } \\
(\mathbf{m})\end{array}$ & \multicolumn{2}{c}{$\begin{array}{c}\text { Measurement } \\
\text { period }\end{array}$} \\
\hline CEH01, 0.30 (wall) & +1.22 & 1.19 & 0.97 \\
& 0 & 1.34 & 1.10 \\
& -1.22 & 1.57 & 1.11 \\
\hline CEH03, 0.51 & +1.22 & 0.89 & 0.94 \\
& 0 & 0.77 & 0.77 \\
& -1.22 & 0.87 & 0.89 \\
\hline CEH03, 0.66 & +1.22 & 1.31 & 1.25 \\
& 0 & 0.94 & 0.88 \\
& -1.22 & 1.00 & 1.07 \\
& -1.25 & &
\end{tabular}




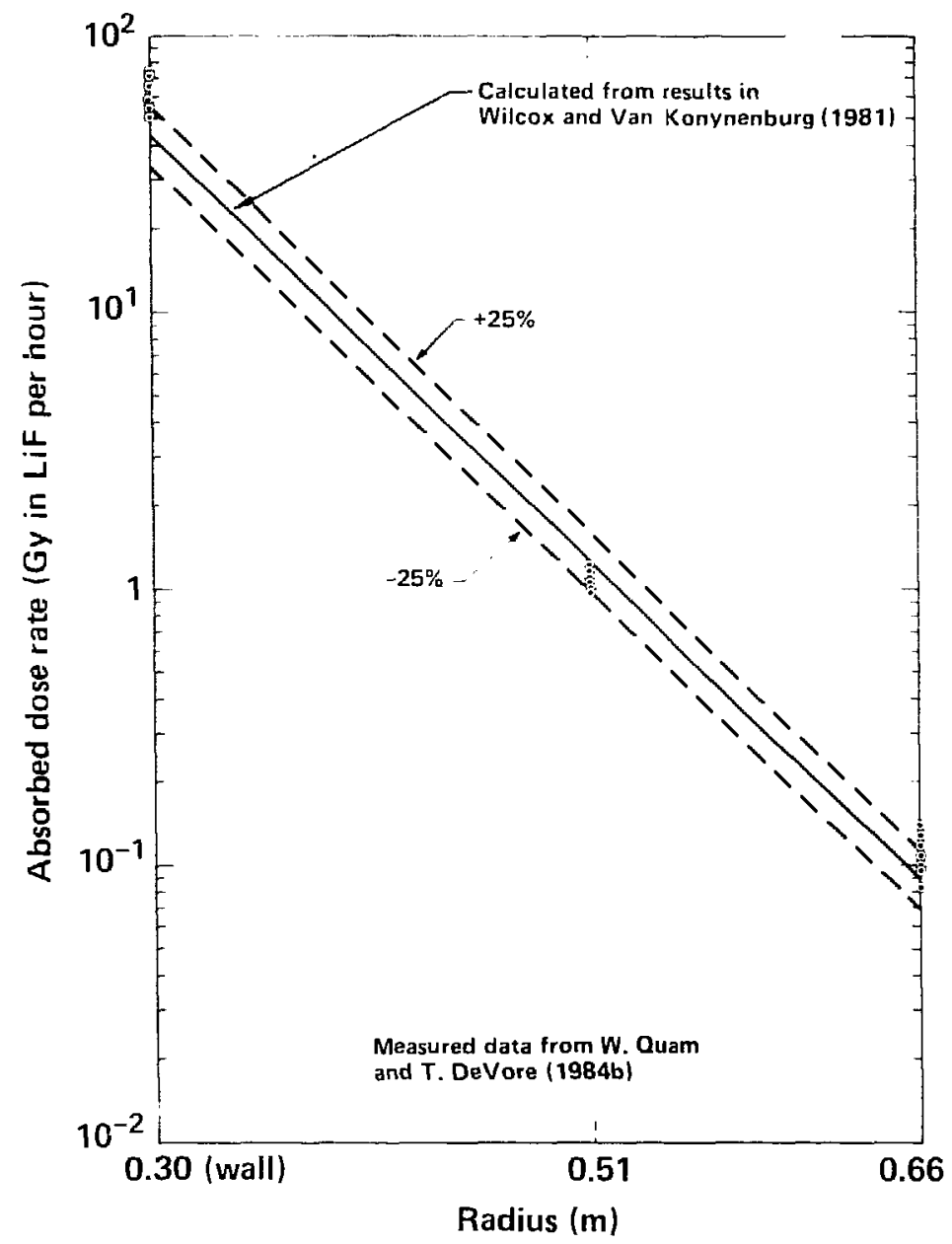

Figure 15-4. Comparison of calculated and thermoluminescence-measured dose rates for hole CEH03 on August 13, 1982 (after Van Konynenburg, 1984).

\subsection{Radon-Thoron Measurements}

Radon-thoron concentrations in the subsurface areas of the SFT- $C$ were monitored to ensure that no health hazards resulted from this natural source of radiation. The measurements indicate a gradual increase from $1 \times 10^{-10} \mathrm{Ci} / \mathrm{m}^{3}$ to about $6 \times 10^{-10} \mathrm{Ci} / \mathrm{m}^{3}$ as the rock mass was heated. These data, obtained at a nominal ventilation flowrate of $1.3 \mathrm{~m}^{3} / \mathrm{s}$ through the canister drift, were augmented by measurements during a ventilation-effects test in which flowrates were varied from 0 to $3.2 \mathrm{~m}^{3} / \mathrm{s}$ (Raschke et al., 1983). There was a definite trend to decreasing radon-thoron concentration with increasing ventilation flowrate up to $1.3 \mathrm{~m}^{3} / \mathrm{s}$ (Fig. 15-7). An additional measurement at $3.2 \mathrm{~m}^{3 / 3} \mathrm{~s}$ indicated a radon-thoron concentration of $6 \times$ $10^{-10} \mathrm{Ci} / \mathrm{m}^{3}$, whereas the expected value from this $\log$-linear relationship would be about $10^{-11} \mathrm{Ci} / \mathrm{m}^{3}$. This suggests that a minimum practically achievable concentration exists at flowrates in excess of about 1.0 to $1.5 \mathrm{~m}^{3} / \mathrm{s}$. Hypothetically, such a minimum could result when the flow was such that the increased emanation of radon, which is enhanced by the negative-pressure ventilation, is balanced by the increased volumetric dilution of the radon. It is important to note that the peak radon-thoron concentrations, which occurred during a 12-day period of no ventilation, were $75 \%$ of one maximum permissible concentration ( $1 \times$ $10^{-8} \mathrm{Ci} / \mathrm{m}^{3}$ for nonradiation workers) and were very much lower even with low ventilation rates. 


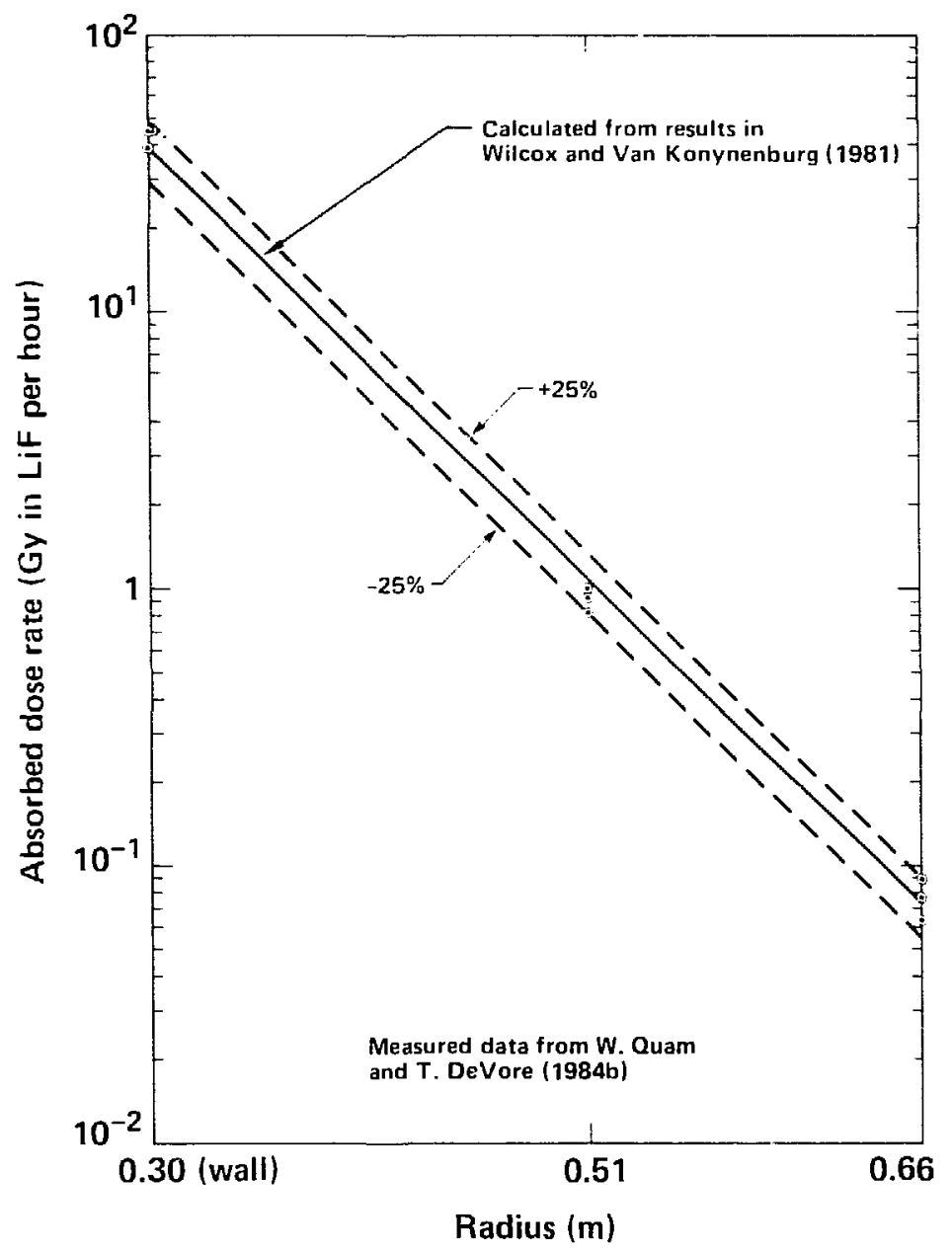

Figure 15-5. Comparison of calculated and thermoluminescence-measured dose rates for hole CEH03 on March 8, 1983 (after Van Konynenburg, 1984). 
Table 15-3. Calculated total absorbed doses to wall of emplacement boreholes for entire period of emplacement (after Van Konynenburg, 1984).

\begin{tabular}{lc}
\hline Hole number & Absorbed dose in granite iil $(G y)$ \\
\hline CEH01 & 1.55 \\
CEH03 & 1.62 \\
CEH05 & 1.59 \\
& \\
CEH07 & 1.55 \\
CEH08 & 1.53 \\
CEH09 & 1.58 \\
CEH10 & \\
CEH11 & 1.58 \\
CEH12 & 1.60 \\
CEH14 & 1.57 \\
CEH16 & \\
\hline
\end{tabular}

Table 15-4. Results of tests for radiation contamination (after Raschke et al., 1983).

\begin{tabular}{|c|c|c|c|}
\hline \multirow[b]{2}{*}{ Sample source } & \multicolumn{3}{|c|}{ Tritium (mCi $\mathrm{cm}^{\prime)}$} \\
\hline & Background & Maxinum & Average \\
\hline \multicolumn{3}{|c|}{ Water (from CAM } & $3.4 \times 10^{4}$ \\
\hline \multicolumn{2}{|l|}{ Air (from CAM } & $1 \times 10^{-10}$ & $<1 \times 10^{-110}$ \\
\hline \multicolumn{4}{|l|}{ Liners } \\
\hline HTO & - & $14 \times 10^{-4}$ & $6 \times 10^{-4}$ \\
\hline \multirow[t]{2}{*}{ HT } & $-b$ & $3.1 \times 10^{-4}$ & $2 \times 10^{-4}$ \\
\hline & \multicolumn{3}{|c|}{ Gamma (pCilg) } \\
\hline Sample source & \multicolumn{2}{|c|}{$\begin{array}{l}\text { PILEDRIVER Shaft } \\
\text { (personnel lift) }\end{array}$} & $\begin{array}{c}\text { Canister } \\
\text { drift }\end{array}$ \\
\hline \multicolumn{4}{|l|}{ Rock } \\
\hline${ }^{117} \mathrm{Cs}_{3}$ & \multicolumn{2}{|c|}{3.3} & 0.02 \\
\hline$" W \mathrm{U}$ & \multicolumn{2}{|c|}{$<0.02$} & 0.2 \\
\hline${ }^{226} \mathbf{R a}$ & \multicolumn{2}{|c|}{0.5} & 2.3 \\
\hline \multicolumn{3}{|c|}{ Water from liners } & 0.4 of ${ }^{137} \mathrm{Cs}$ \\
\hline \multicolumn{3}{|c|}{ Access hole filings } & 0.04 of ${ }^{137} \mathrm{Cs}$ \\
\hline
\end{tabular}

Table 15-5. Maximum personnel doses associated with spent-fuel handling operations (after Raschke et al., 1983).

\begin{tabular}{lcc}
\hline & \multicolumn{2}{c}{ Dose, mrem/operation } \\
\cline { 2 - 3 } Handling operation & Gamma $^{\mathrm{c}}$ & Neutron $^{c}$ \\
\hline Fuel emplacement & 2 & 8 \\
Fuel storage & 0 & $-\mathrm{d}$ \\
Fuel retrieval & 0.1 & 2 \\
\hline
\end{tabular}

"An "operation" is the emplacement or retrieval of a single spent-fuel assembly.

b Natural background levels have been subtracted from these values.

' Neutron exposures were measured with albedo dosimeters; personnel gamma exposures were estimated from measured neutron/gamma ratios since no gamma exposure exceeded the $\mathbf{3 0} \mathrm{mR}$ threshold of the film badges.

d Not measured. 


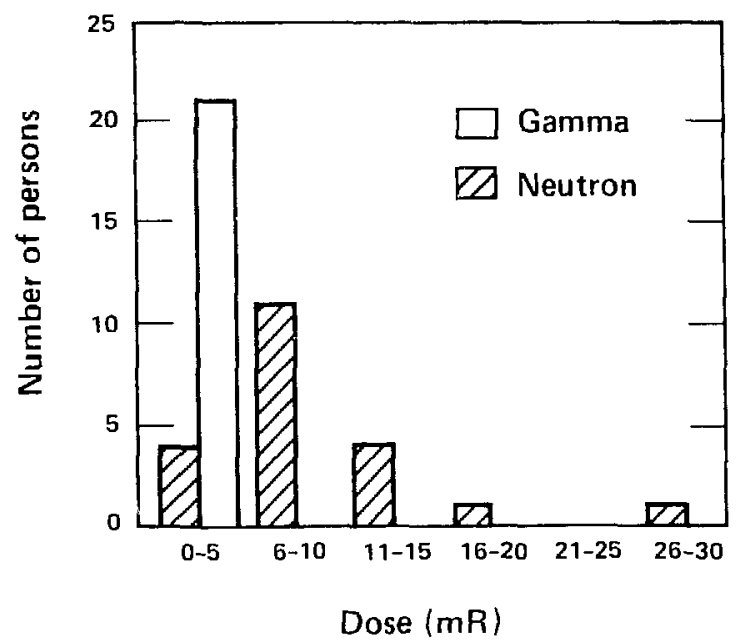

Figure 15-6. SFT -C personnel dose distribution during spent-fuel retrieval (after Raschke et al., 1983).

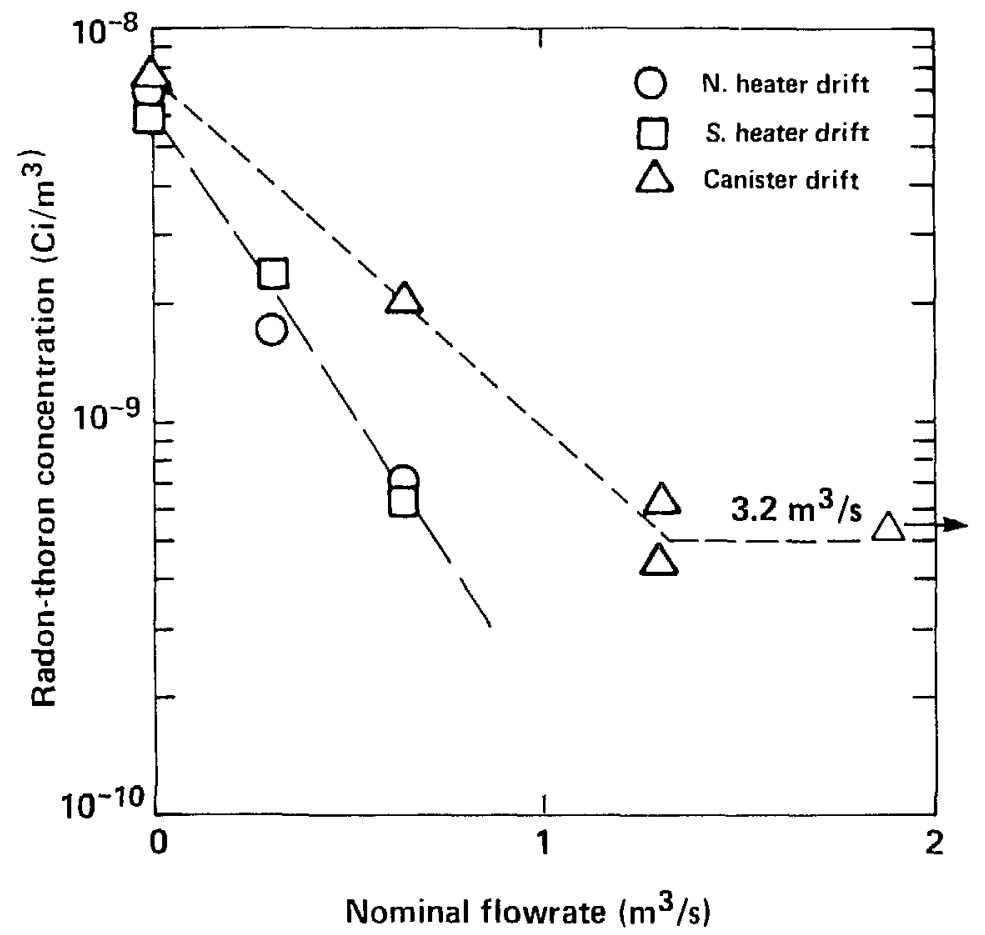

Figure 15-7. Radon-thoron concentration vs ventilation flowrate (after Raschke et al., 1983). 


\section{Rock Mechanical Response Analyses and Measurements}

The response of the rock mass to excavation for the underground facilities and subsequent deposition of more than one gigawatt-hour of energy was calculated and measured as part of the SFT-C operation. Several types of instruments were deployed to record the displacements and stress changes that resulted from excavating and heating the underground facility (Chapter 9). Likewise, a variety of finite-element models were employed to perform the calculations (Chapter 3) using available material properties, stresses, and temperature conditions. These measurement systens and calculations are briefly summarized here and the resulting measurements are compared with the corresponding calculations.

\subsection{Measurement System*}

To record the response of the rock mass and selected geological discontinuities, we deployed a variety of instrument types throughout the three-drift complex (Figs. 16-1 and 16-2). During the "mine-by" experiment, 12 borehole rod extensometers were installed to measure displacements within the rock immediately surrounding the central drift. Three vibrating-wire stressmeters were also deployed. Although originally not intended for use during the heated phase of the SFT-C, the mine-by extensometers were refurbished and used.

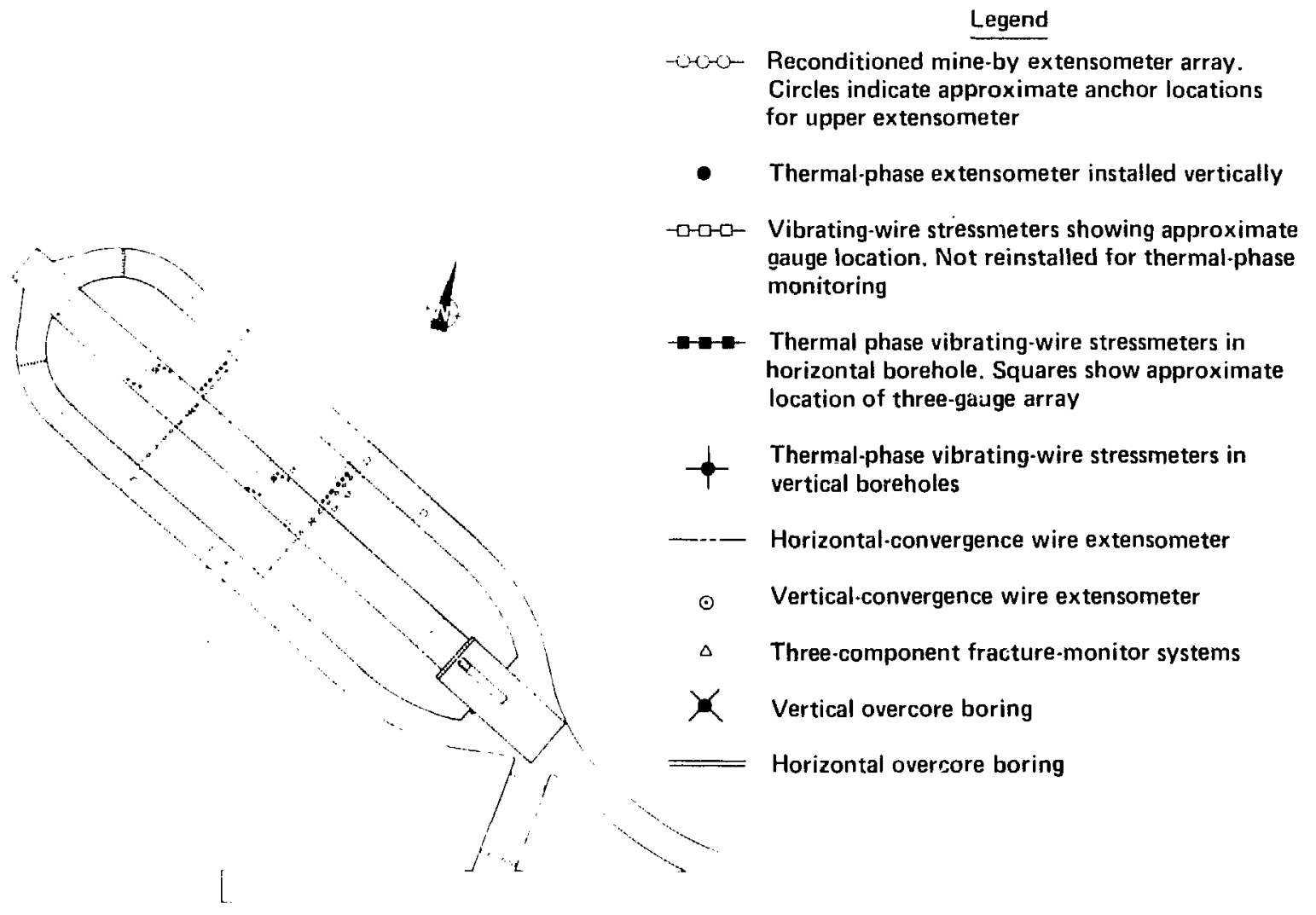

Figure 16-1. Location of thermal phase instrumentation.

\footnotetext{
*Contributed by W. C. Patrick.
} 


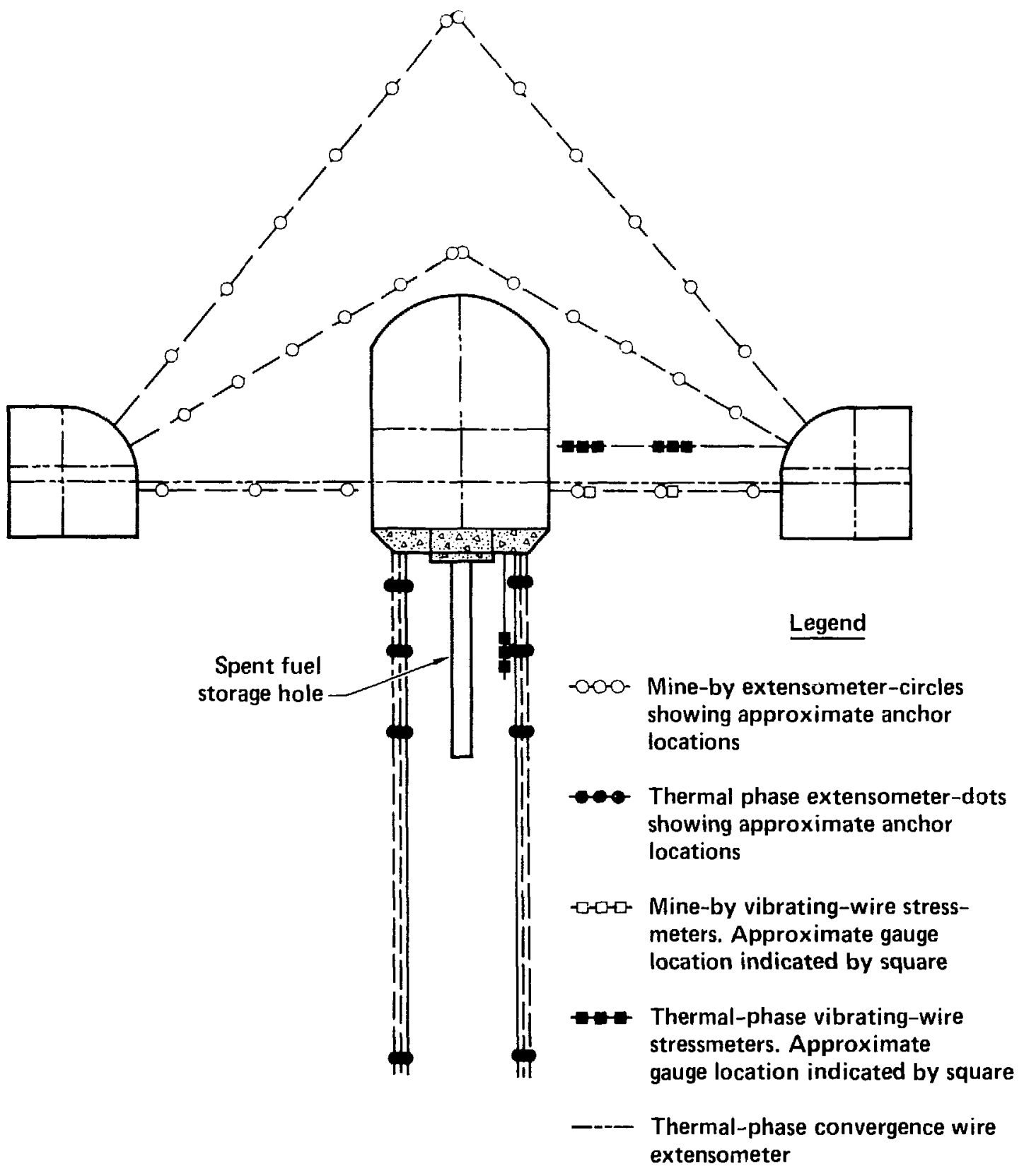

Note: lines dashed when borehole is out of the plane of the cross-section

Figure 16-2. Cross section showing thermal-phase and Mine-by instrumentation arrays.

Measurements of displacements within the rock were augmented by two sets of six four-anchor borehole extensometers grouped near the center CEH09 (designated GCE) and near the end (CEH03) of the canister drift (designated GBE). In addition, single four-anchor units were installed at the far ends of the facility to monitor displacements where temperature changes were relatively small (designated GAE and $\mathrm{GDE})$. 
Additional vibrating-wire stressneters were installed as rosettes of three: two sets about $0.7 \mathrm{~m}$ from the caniater drift rib in the nurth pillar (designated $N S C$ ), two sets near the center of the north pillar (designated NSG), and one set at the depth of the center of spent-fuel assemblies stored in CEH03 and CEHO9 (designated CSG). The stressmeters used during the mine-by experiment were removed for evaluation and were not replaced.

From a facility operational point of view; drift closure is often more important than displacements, which occur far from the drift surface. To monitor relative displacement hetween opposite surfaces of the drifts, convergence-wire extensometers (CWE) were designed, fabricated, and installed. Five sets of horizontal and vertical CWEs were installed in each drift and one unit was placed in the Receiving Room near the base of the canister access shaft where a fault zone was identified during mining (Chapter 4). At each of these locations, provision was made for manuaily acquired tape extensometer readings (Chapter 9). In addition, two so-called "through-hole extensometers" were installed to span from the far south to the far north ribs of the three-drift array. Excessive irictional effects on the portions of the catenary that passed through the pillars resulted in data of limited value, so these are not discussed further.

Three orthogonal components of displacement at selected locations on five discrete geological fractures were measured using seven fracture monitor systems (FMSs). These units were developed and deploved to monitor displacemenis that were associated with possible discontinuum responses.

When the concrete floor overlying the canister drift invert began cracking during the early stages of heating, we installed reference pins and recorded relative displacements across the cracks with a Whittemore gauge. Although no attempt was made to calculate the measured phenomena, crack development and response were consistent with the other aspects of calculations and measurements, as discussed later in the chapter.

Following retrieval of the spent-fuel assemblies, we installed two rosettes of three instruments in CEH03 and CEH09 to measure displacements within the $0.61-\mathrm{m}$ diameter boreholes as cooling progressed (CDGs). These highly sensitive instruments provided data on the very-near-field response.

The calculated root-sum-square (RSS) errors and measured calibration errors for the various rock mechanical instrument types are provided in Table 16-1. In comparing data with calculations, it is essential that these errors be considered. It is impossible for the calculations and measurements to display any better agreement than is permitted by the inherent errors in the measurement system. Reliability data and other details are provided in Chapter 9.

\subsection{Summary of Calculational Results*}

A variety of calculations was undertaken to guide the design of, and to assist in the interpretation of, data obtained from the SFT $-C$. The discussion here will focus on finite-element calculations completed for analyses of the mine-by and the heating, and subsequent cooling, phases of the test.

As described in Section 3.3.3, both continuum and discrete-joirit models of the mine-by were used. Because these calculations were two-dimensional, exact treatment of the major geological features was not possible. Instead, these features were modeled as though they were parallel to the axis of the drifts (Heuze, Butkovich, and Peterson, 1981). In the discussion on mine-by results, these discontinuum calculations and the continuum calculations given in the same report are used as a basis of comparison.

Post-test calculations reported by Butkovich and Patrick (1985) are the basis of discussion of heatingand cooling-phase results. As noted in Section 3.3.6, these calculations employed the best-available material properties and in-situ stresses. Rather than attempt to model heat flow processes exactly, we chose to vary the effective parameters to provide the best possible agreement between measured and calculated temperatures. This approach minimized the contribution of temperature errors to the total inaccuracies of the model. As reported by Butkovich and Patrick (1985), the mean-square errors between measured and calculated temperatures were within the Instrument Society of America (ISA) special limits of error of $1.1^{\circ} \mathrm{C}$ for the thermocouples. For the heating and cooling phases, most comparisons of data and calculations use the Butkovich and Patrick (1985) Calculation 2. Deformation modulus and Poisson's ratio were, respectively, $38 \mathrm{GPa}$ and 0.25 for the rock mass, and $19 \mathrm{GPa}$ and 0.35 for an explosively damaged zone around each drift. Application of a vertical mesh loading of 6.21 MPa provided a stress of about 7.84 MPa at the midheight of the underground openings. Based on in-situ stress measurements, a horizontal-tovertical stress ratio of 1.2 was used. 
Table 16-1. Summary of calculated errors and calibratı $n$ errors for rock mechanical instrumentation deployed on the SFT $-C$.

\begin{tabular}{|c|c|c|c|}
\hline Instrument type & $\begin{array}{l}\text { Number } \\
\text { deployed }\end{array}$ & $\begin{array}{c}\text { Calculated RSS } \\
\text { error }\end{array}$ & $\begin{array}{c}\text { Mean (standard deviation) } \\
\text { calibration error }\end{array}$ \\
\hline $\begin{array}{l}\text { Mine-by series } \\
\text { extensometers (data } \\
\text { for typical 5-m rod) }\end{array}$ & $\begin{array}{l}12 \text { units, } \\
60 \text { anchors }\end{array}$ & $56 \mu \mathrm{m}$ & $-5.6(55.3) \mu \mathrm{m}^{*}$ \\
\hline $\begin{array}{l}\text { G x E extensometers } \\
\text { with potentiometers }\end{array}$ & $\begin{array}{l}8 \text { units, } \\
32 \text { anchors }\end{array}$ & $33 \mu \mathrm{m}$ & $-8.6(36.3) \mu \mathrm{m}^{2}$ \\
\hline $\begin{array}{l}\text { G } \times \text { E extensometers } \\
\text { with LVDTs }\end{array}$ & $\begin{array}{l}3 \text { units, } \\
12 \text { anchors }\end{array}$ & $112 \mu \mathrm{m}$ & $-3.6(7.6) \mu \mathrm{m}^{4}$ \\
\hline $\begin{array}{l}\text { GxE extensometers } \\
\text { with proximeters }\end{array}$ & $\begin{array}{l}3 \text { units, } \\
12 \text { anchors }\end{array}$ & $63 u m$ & $176.9(309.0) \mu \mathrm{m}^{2}$ \\
\hline $\begin{array}{l}\text { Convergence-wire } \\
\text { extensometers }\end{array}$ & 32 & 84 to $306 \mu \mathrm{m}^{b}$ & $3.8 \mu \mathrm{m}^{\varepsilon}$ \\
\hline $\begin{array}{l}\text { Fracture monitor } \\
\text { system }\end{array}$ & $\begin{array}{l}7 \text { units, } \\
21 \text { components }\end{array}$ & $10 \mu \mathrm{m}$ & $0.8 \mu \mathrm{m}^{\mathrm{c}}$ \\
\hline $\begin{array}{l}\text { Borehole closure } \\
\text { monitor }\end{array}$ & $\begin{array}{l}14 \text { (including two } \\
\text { for instrument } \\
\text { evaluation) }\end{array}$ & $15 \mu \mathrm{m}$ & $1.2 \mu \mathrm{m}^{\mathrm{c}}$ \\
\hline $\begin{array}{l}\text { Vibrating-wire } \\
\text { stressmeters }\end{array}$ & 18 & $0.02 \mathrm{MPa}$ & $\begin{array}{l}+38 \text { to }-58 \% \text { of } \\
\text { reading }\end{array}$ \\
\hline
\end{tabular}

\subsection{Comparison of Data and Calculations*}

The measurement systems and calculations described above provided displacements and stress changes that may be compared to assess the capabilities of the models, and to determine the degree of correctness of the underlying assumptions of those models. Comparisons are made for the excavation, heating, and cooling phases of the experiment. The interested reader is referred to numerous previous reports for additional discussions (see the Bibliography).

\subsubsection{Response During the Mine-By Experiment}

The mine-by, or excavation response, experiment was conducted by instrumenting the rock mass between the two heater drifts and measuring how the rock displaced and how stresses changed as the central drift was mined. To mine the center $\mathrm{drift}$, an upper heading and a bench were removed using conventional drill-and-blast techniques (Chapter 5). Prior to conducting the mine-by experiment, ADINA calculations were performed to determine the ranges and preferred orientations of the instrumentations. These continuum calculations were later the basis of comparisons with data shown here. When these comparisons showed that the measured displacements within the pillars were opposite in sign to those calculated, discrete joint modeling of the experiment was undertaken by Heuze, Butkovich, and Peterson (1981).

The results of both the calculations and the data presented by Heuze, Butkovich, and Peterson (1981) are summarized for nondilatant joints at two stations in Figs. 16-3 and 16.4 and for dilatant joints at one station in Fig. 16-5. For the upward angled extensometers, we see quite good agreement between the ADINA calculation and the measurements. Although only about half agree within a factor of 2 , many of 

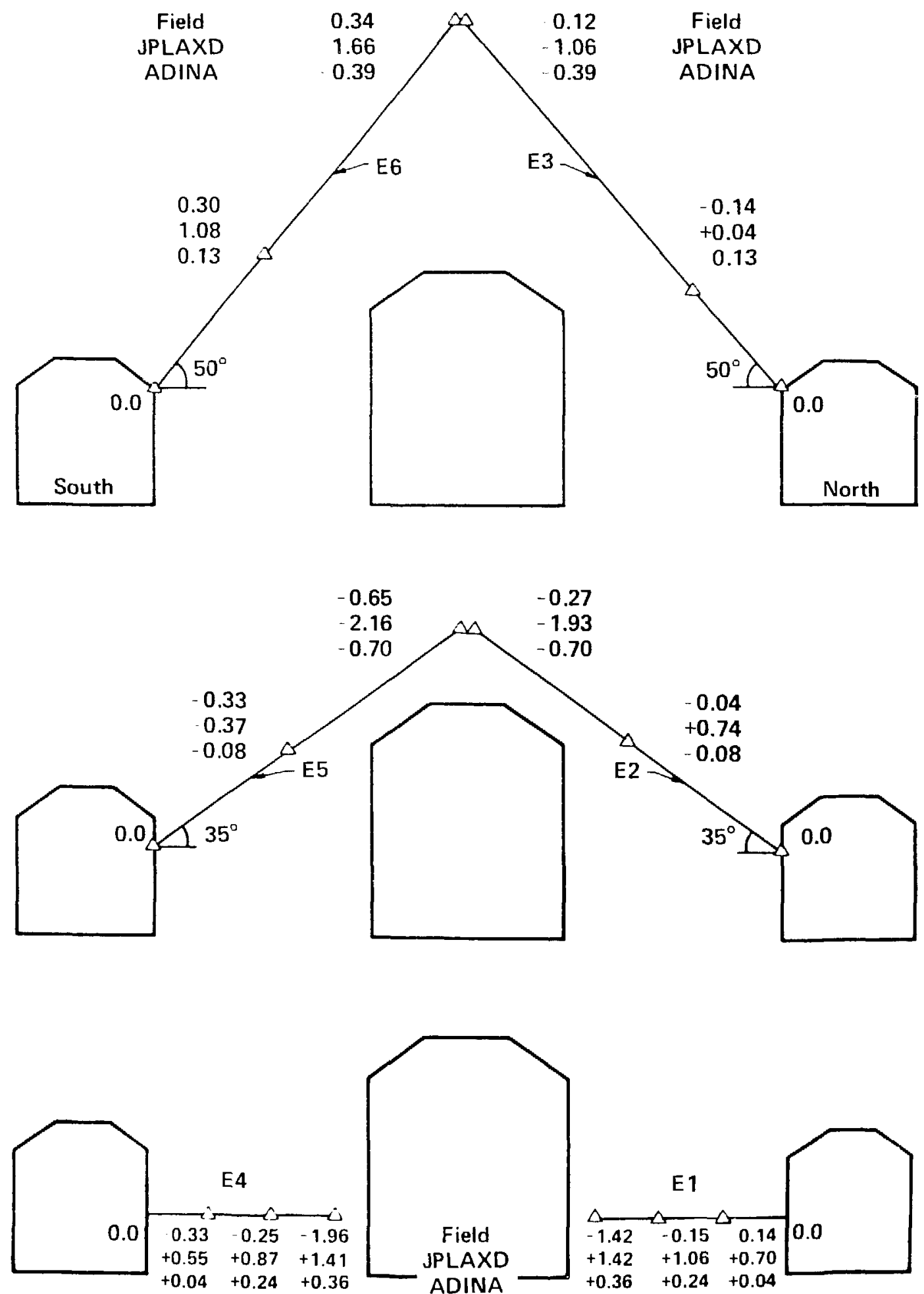

Figure 16-3. Comparison of field observations witr j?LAXD and ADINA calculations, for the relative movements (in mm) of MPE anchors during the m.i 1e-by. Station $2+83$, nondilatant joints (after Heuze, Butkovich, and Peterson, 198î). 

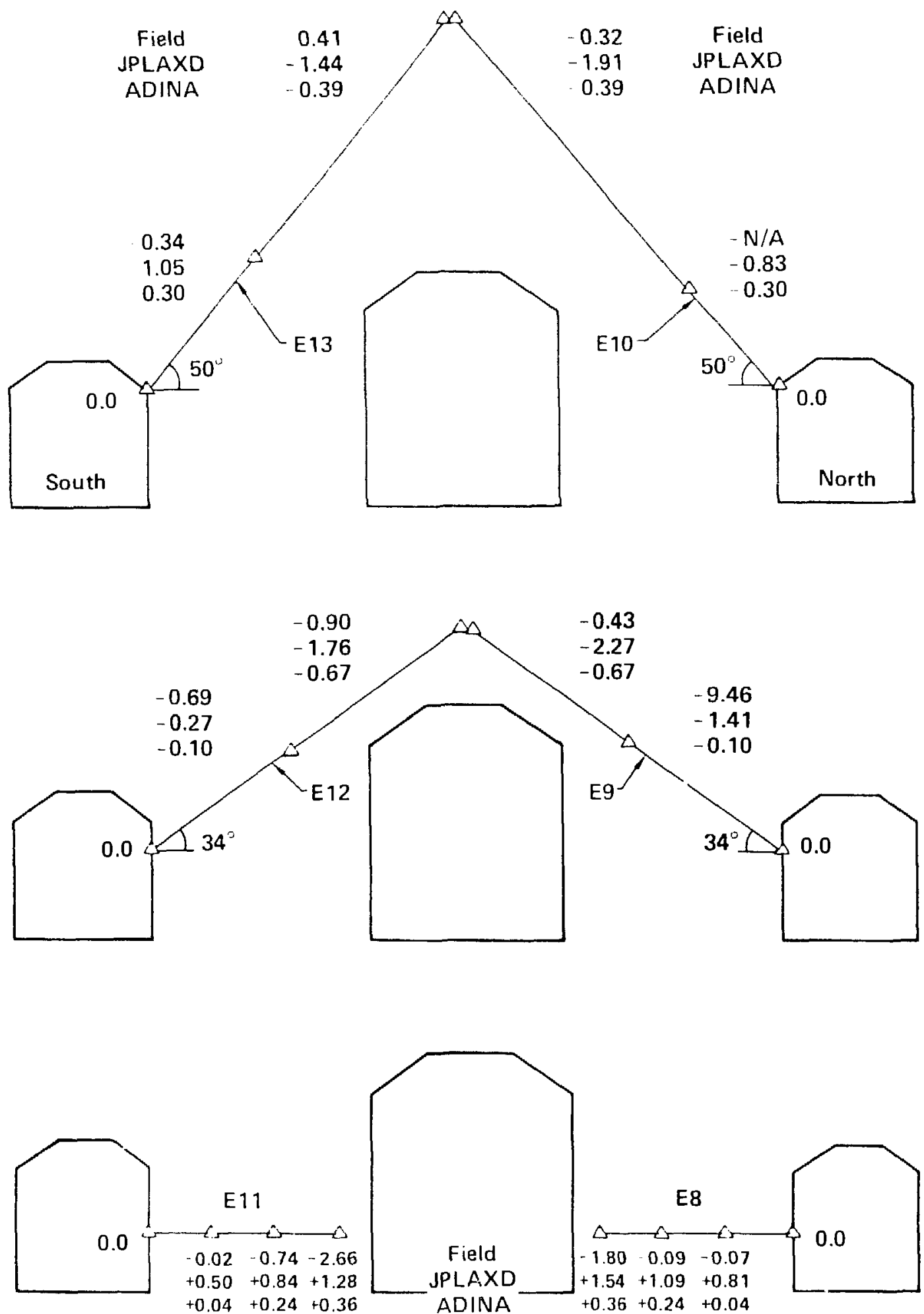

Figure 16-4. Comparison of field observations with JPLAXD and ADINA calculations for the relative movements (in mm) of MPE anchors during the mine-by. Station 3+45, nondilatant joints (after Heuze, Butkovich, and Peterson, 1981). 

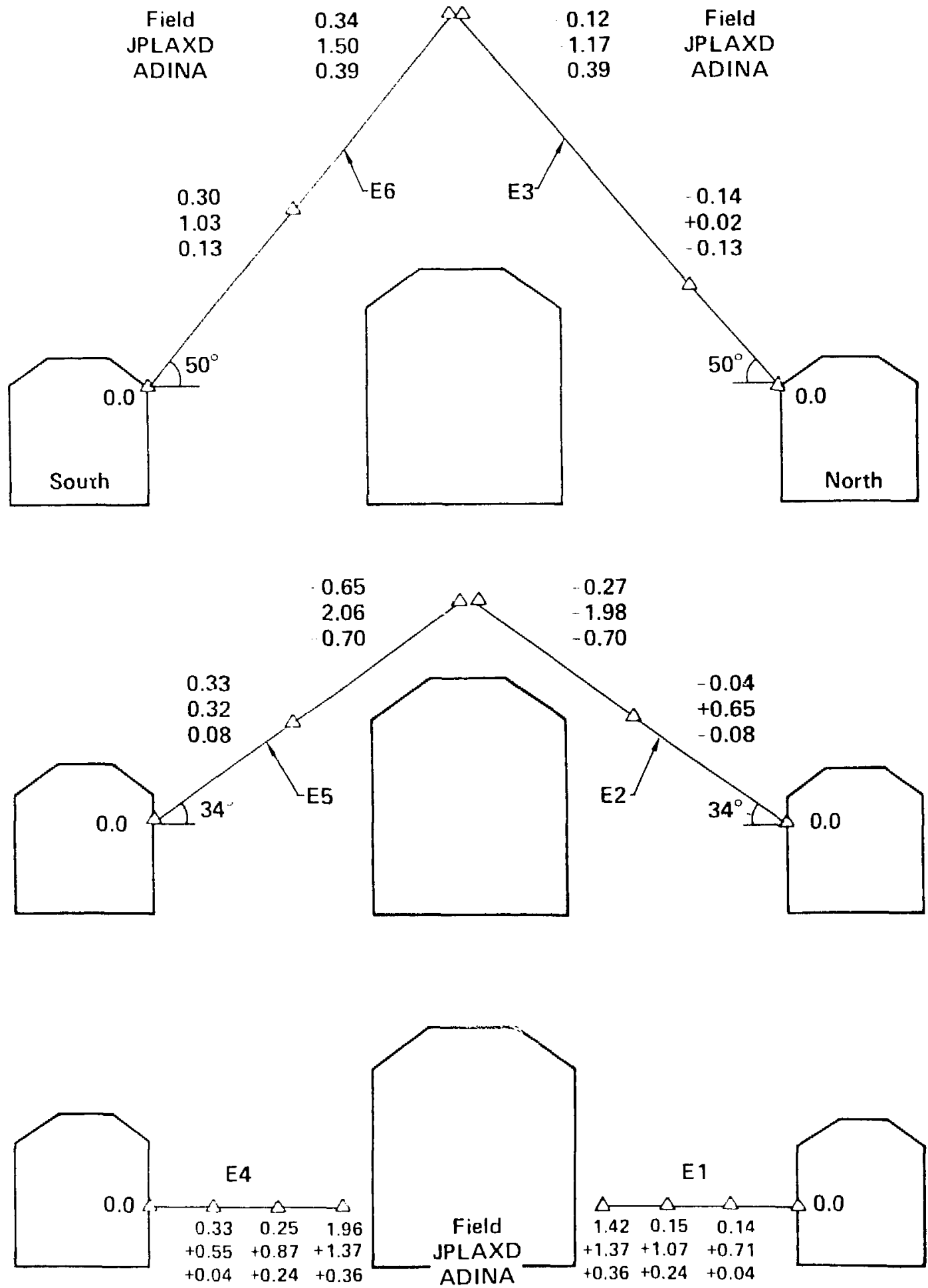

Figure 16-5. Comparison of field observations with JPLAXD and ADINA calculations for the relative movements (in $\mathrm{mm}$ ) of MPE anchors during the mine-by. Station $2+83$, dilatant joints (after Heuze, Butkovich, and Peterson, 1981). 
the measurements are near the limits of accuracy of the extensometers (Table 16-1). The measured displacements are oppusite in sign of thuse calculated to occur at the locations of the horizontally oriented extensometers at both stations.

Examination of the JPLAXD discrete-joint models shows that these calculations provide considerably larger displacements at most locations. Although the JPLAXD results are opposite in sign from the ADINA results (and the data) at some inclined extensometer locations, the measured narrowing of the pillars was not calculated. Taken in total, the JPLAXD results indicate a poorer level of agreement than the ADINA results. The former agreed with the measurements within a factor of 2 at less than $15 \%$ of the locations where inclined extensometers were present. Furthermore, disagreement in sign at the horizontal borehole locations was the same as for the ADINA calculation.

Heuze, Butkovich, and Peterson (1981) do report that pillar stresses were calculated to decrease at locations near the ribs of the center drift and near the center of the south pillar. The near-rib decrease agrees with measured decreases at tnese locations, but the measured decrease in the center of the north pillar was not calculated to occur.

\subsubsection{Response at Elevated Temperatures}

The' response of the ruck to extensive heating and subsequent couling was calculated and measured. Since the locations and scales of measurements varied considerably, the following discussion is organized according to location and scale.

Displacements and stress changes within the rock mass. Displacements within the rock mass were recorded by bor. in.le extensometers that referenced anchor-point displacements to head assemblies located at the suri: :" of the drifts. Stress changes were recorded by vibrating-wire stre.smeters (Figs. 16-1 and 16-2).

Typical results of relative displacement measurements and calculations are displayed in Figs. 16-6 and 16-7 for Stations $2+83$ and $3+45$, respectively. The indicated displacements occurred between a time of 3.0 YOC (about 6 months into the heating phase when all instruments were operating) and 5.25 YOC (the end

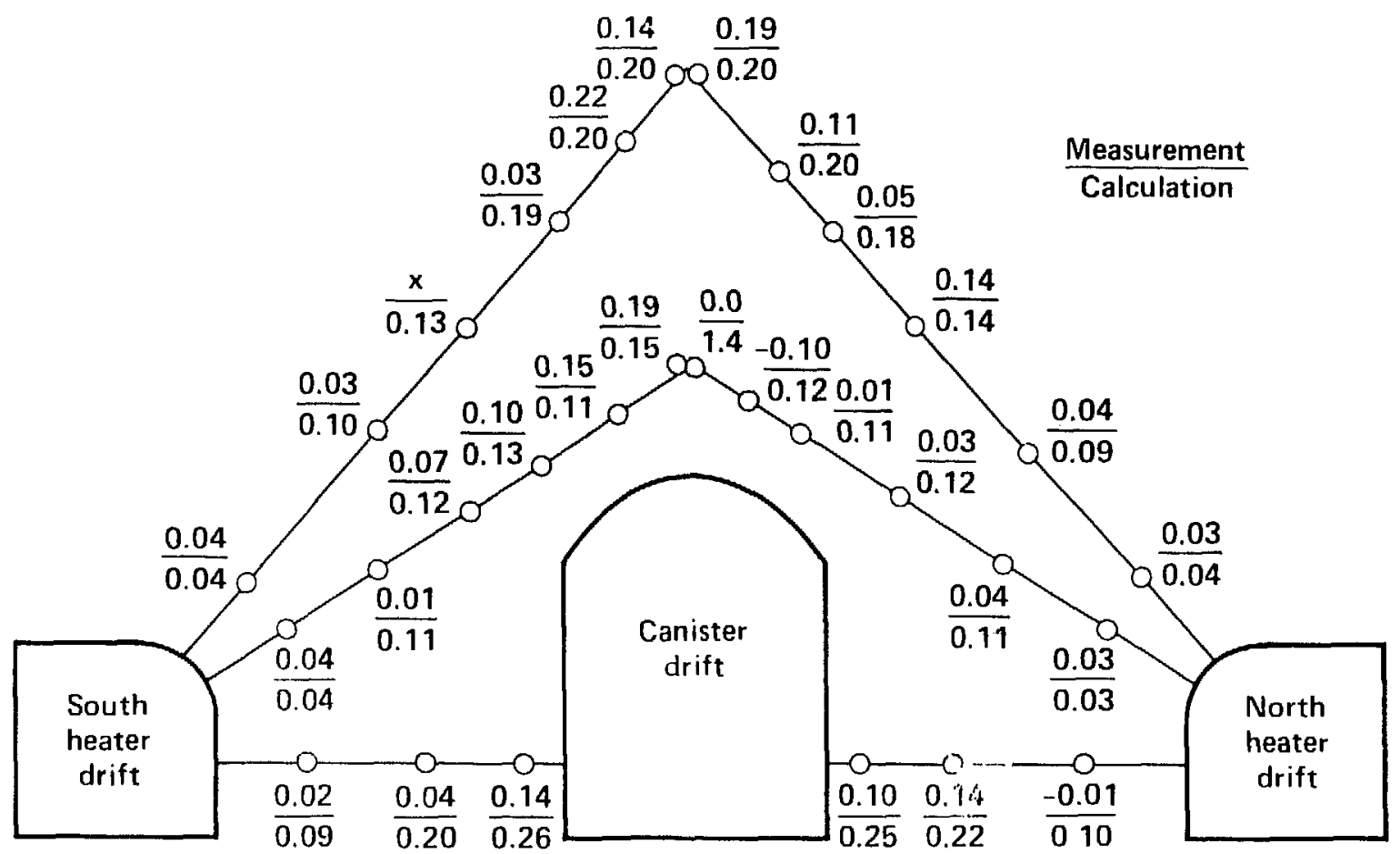

Figure 16-6. Results from Calculation 2 for Station $2+83$ at 5.25 YOC (after Butkovich and Patrick, 1985). 


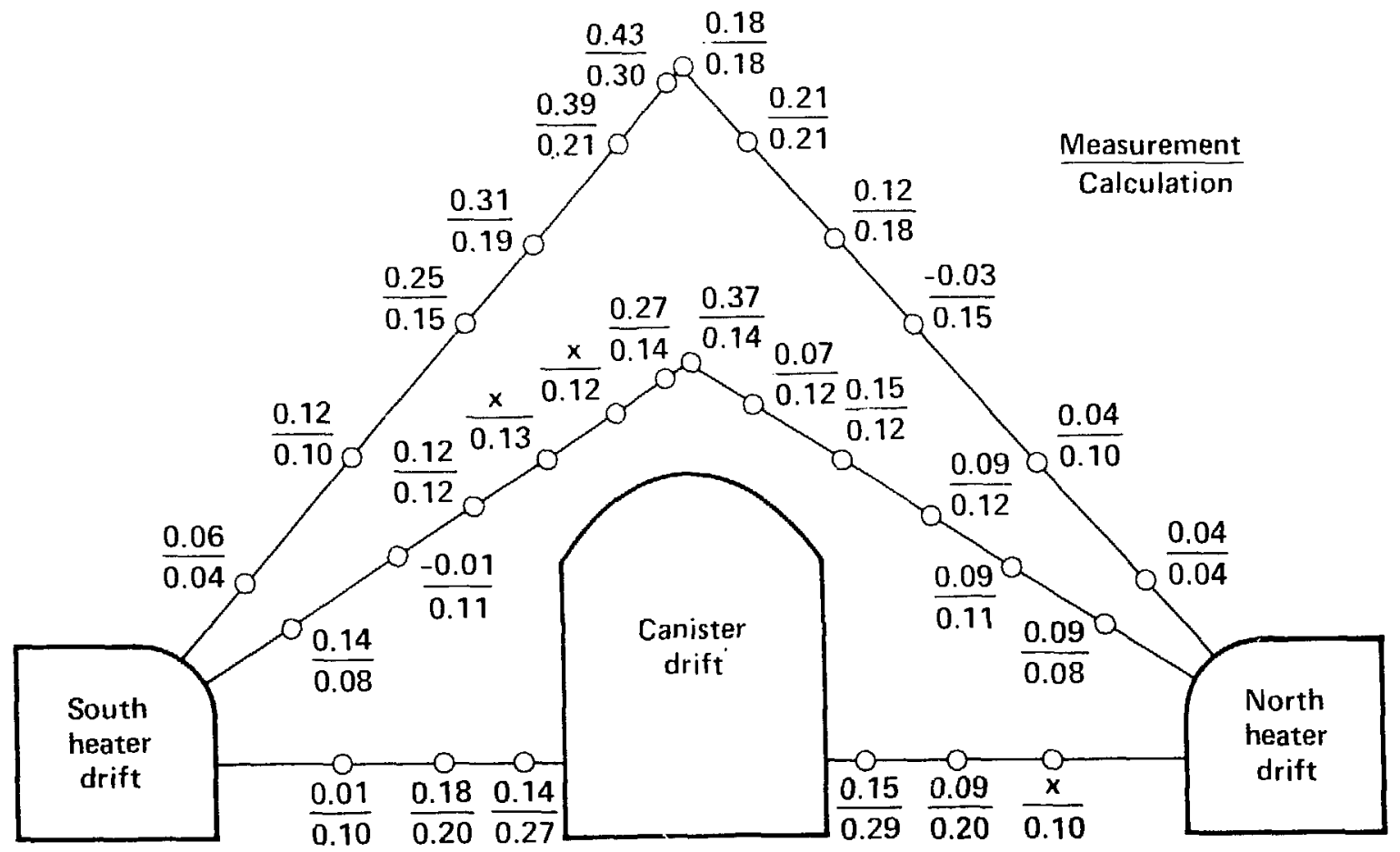

Figure 16-7. Results from Calculation 2 for Station 3+45 at 5.25 YOC (after Butkovich and Patrick, 1985).

of the heated phase). In general, we see good agreement between measurements and calculations. In the three cases where there is a disagreement in sign, the measurements are near or below the limit of accuracy of the instruments. There is a clear tendency for measured displacements to be less than calculated at all locations other than above and at the south of the canister drift at Station $3+45$.

To more quantitatively examine the level of agreement, cross plots of the measurements and data were prepared and lines were fitted to the resulting paired values. Figure 16-8 is a composite of all pairs at 3.5 , $4.5,5.25$, and $5.86 \mathrm{YOC}(12,24$, and 33 months into heating and 6 months into cooling phases). The accompanying statistics indicate excellent overall correlation between the measurements and calculation: the slope (A1) is near unity. Although there is considerable scatter in the data, the root-mean-error (RM) of 78 $\mu \mathrm{m}$ is not much larger than would be expected from considerations of the accuracy of the instruments (Table 16-1).

While the data presented above represent "snap shots" in time, Wilder and Yow (1986) presented time-series plots for these same instruments. A typical example displays several features that are common to these data (Fig. 16-9). First, only about a third of the total displacement occurred before 3.0 YOC, the base time for the data reported in detail above. Second, the curves are, in general, separated and in order of increasing depth. This is an important indicator of consistency in the data. Third, while nearly complete recovery to the initial position occurs for anchors near the drift surfaces, only partial recovery is observed at greater depths where cooling and the concommitant decrease in thermal stresses are less complete.

Because of instrumentation failures (Patrick, Rector, and Scarafiotti, 1984), data records are discontinuous for the GxE-series extensometers located vertically downward in the canister drift. Wilder and Yow (1986) have merged the segments of these records, using certain assumptions to match early time trends to the trends observed later with the replacement instrumentation. A typical example of the resuiting timeseries plots is displayed as Fig. 16-10. As with the previous plot (Fig. 16-9), there are several indicators that the data are consistent both before failure of the transducers and after 'heir replacement. It is important to note that the vertical position of the group of curves for the later times was adjusted but that the relative positions of the individual curves were not changed. 


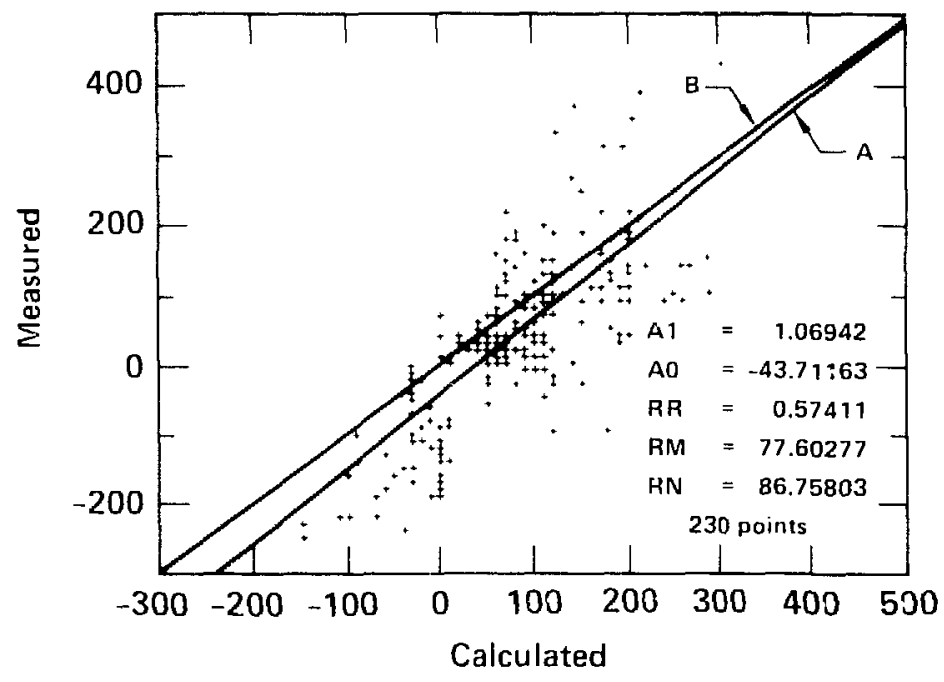

Figure 16-8. Comparison of measured displacements with the results of Calculation 2, (units in $\mu \mathrm{m}$ ). Coefficients $A 1$ and $A 0$ give the slope and $Y$ intercepts respectively for best fit line $A$. Line $B$ has values of 1.0 and 0.0 (after Butkovich and Patrick, 1985).

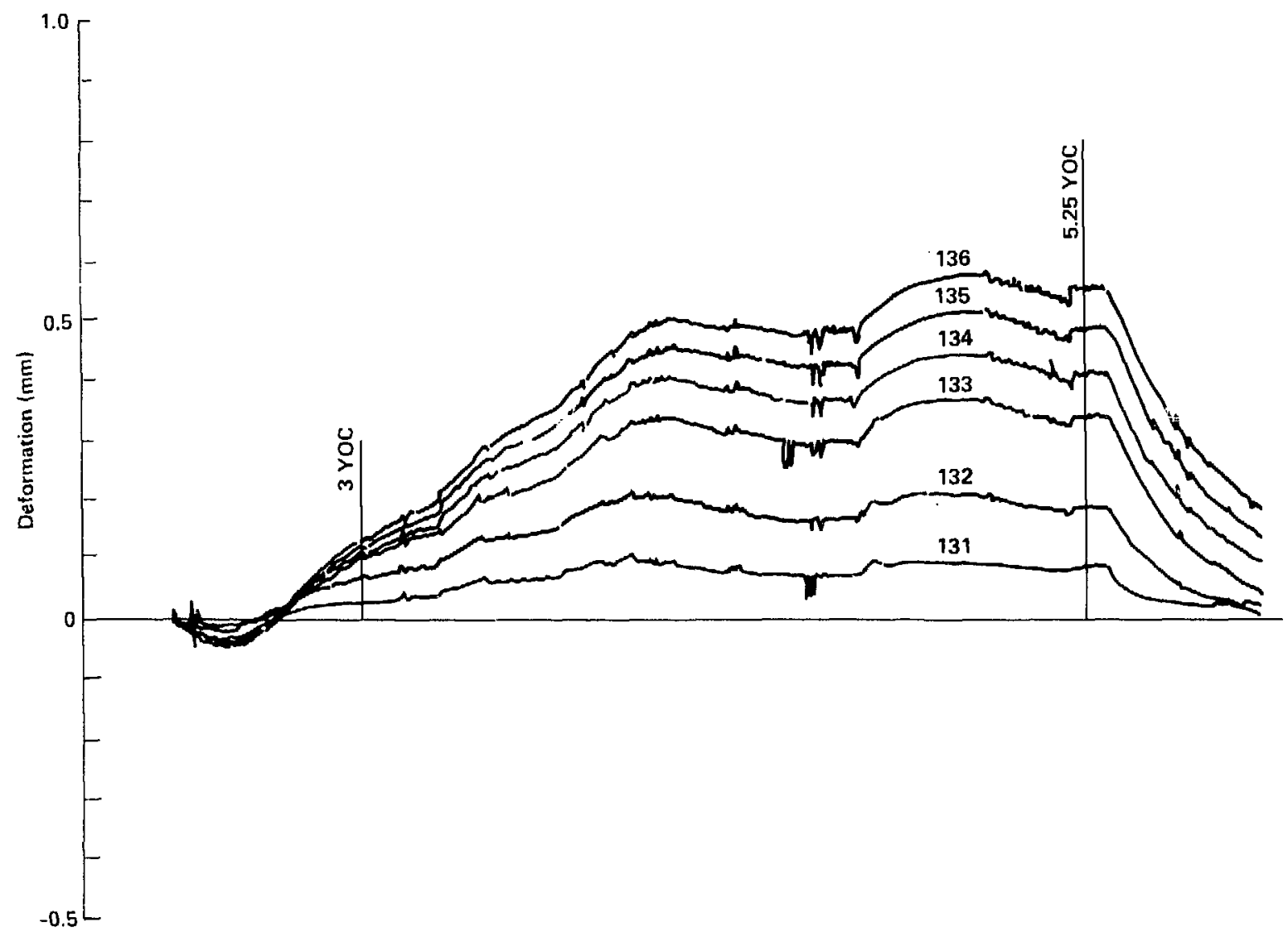

Figure 16-9. Time-series of relative displacements recorded by the six- anchor extensometer MBI13 (after Wilder and Yow, 1986). 


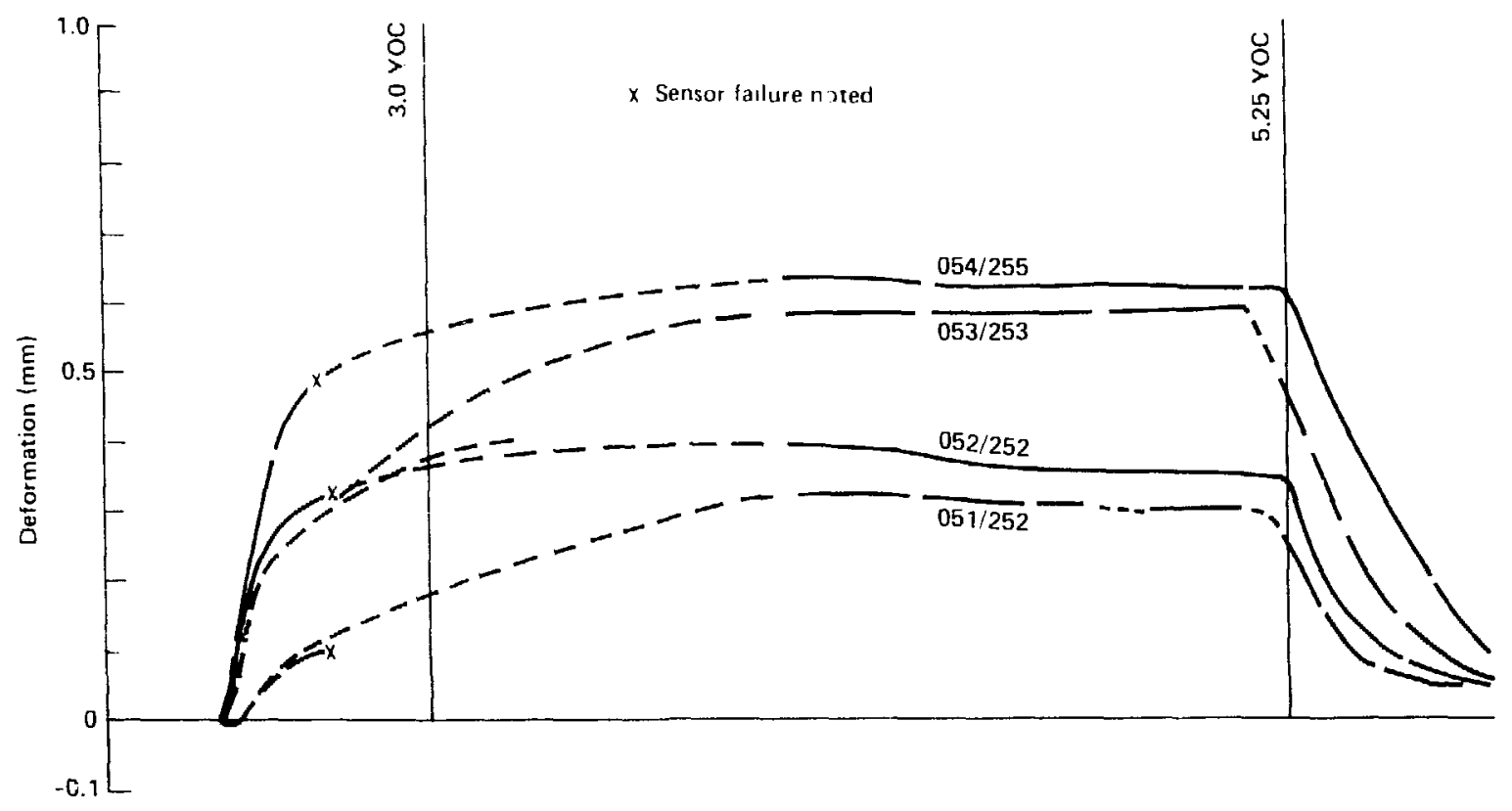

Figure 16-10. Time series of relative displacements recorded by the four- anchor extensometer GBE05. Note that segments of data have been merged because of instrument failures at early times (after Wilder and Yow, 1986).

Changes in stress were also measured at selected locations for comparison with calculational results. Comparisons are limited to the cooldown period because the stressmeters that were initially installed failed and were replaced (Patrick, Rector, and. Scarafiotti, 1984). As indicated in Table 16-2, agreement between measured and calculated cooling stres.ies was quite good, particularly when one considers the accuracy of this instrumentation (Table 16-1). The average values for the first two entries are exactly the calculated values. At the midpillar location, the average measured value is only about one third the calculated value.

Room-scale closure. Room-scale closure was continuously measured with sets of CWEs, which spanned the width and height of the three drifts at several locations (Figs. 16-1 and 16-2). At each CWE, manual readings were periodically obtained by means of a tape extensometer connected to spherical seats. Air temperatures varied with position along these instruments and also varied in time as the drifts were heated and subsequently cooled. Four-wire resistance measurements provided average wire temperatures for the CWEs, and a thermistor clipped to the tape extensometer provided a single-point estimate of its temperature. Temperatures recorded in this manner were used to correct for the effects of thermal expansion of instrument components (Chapter 9 and Carlson, 1986).

Because the manually acquired data and associated temperature readings were few in number and the conversion algorithm was simple, tape extensometer results were available quite early in the test (Yow and Butkovich, 1982; and Patrick et al., 1982). Arithmetically averaged, temperature-corrected measurements obtained by various operators are used here to produce single curves for comparison with the calculational results.

The calculations indicate that as much as two thirds of the maximum closures took place before the first tape extensometer readings were obtained, which was about 6 weeks after emplacement of the first spentfuel assemblies. As a result, it was necessary to add the amount of closure that was calculated to occur to the averaged measured values in order to facilitate comparison. The resulting comparisons are shown in Figs. 16-11, 16-12, and 16-13 for the canister drift, north heater drift, and south heater drift, respectively.

Despite the somewhat erratic appearance of the data, which results from the marginally acceptable accuracy if the tape extensometer, the calculations and data track each other quite well. For measurements 
Table 16-2. Comparison of measured and calculated stress changes that occurred during the cGoling phase of the SFT-C (after Butkovich and Patrick, 1985).

\begin{tabular}{lcc}
\hline Location & $\begin{array}{c}\text { Measured stress } \\
\text { change, } \mathrm{MPa}\end{array}$ & $\begin{array}{c}\text { Calculated stress } \\
\text { change, } \mathbf{M P a}\end{array}$ \\
\hline Station $3+58$ & 3.5 & $\begin{array}{c}\text { Horizontal in-plane stress } 1.18 \mathrm{~m} \text { from spent fuel at midpoint elevation } \\
\text { Station } 2+98\end{array}$ \\
\hline & 3.3 \\
\hline Station $2+85$ & Vertical in-plane stress at midheight in rib $0.7 \mathrm{~m}$ from canister drift \\
Station $3+47$ & 2.1 \\
\hline & 0.9 \\
\hline Station $2+85$ & Vertical in-plane stress at midheight of rib at middle of pillar \\
Station $3+47$ & 0.6 \\
\hline
\end{tabular}

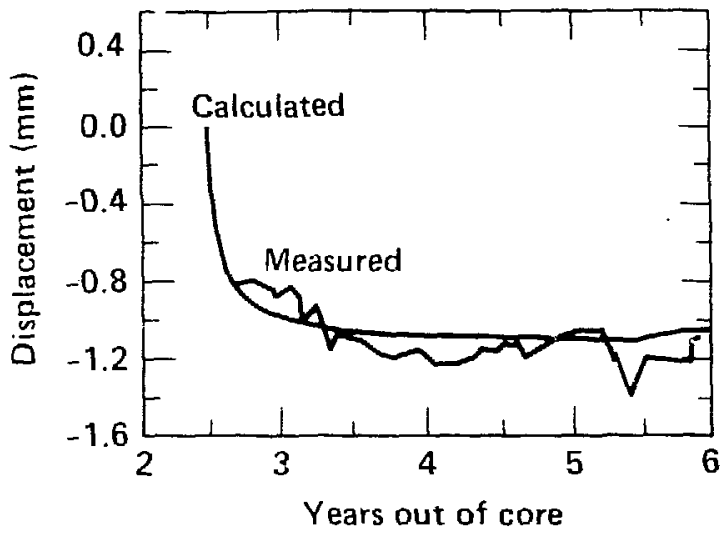

Figure 16-11a. Calculation 2 results compared with measured horizontal closure of the canister drift (after Butkovich and Patrick, 1985).

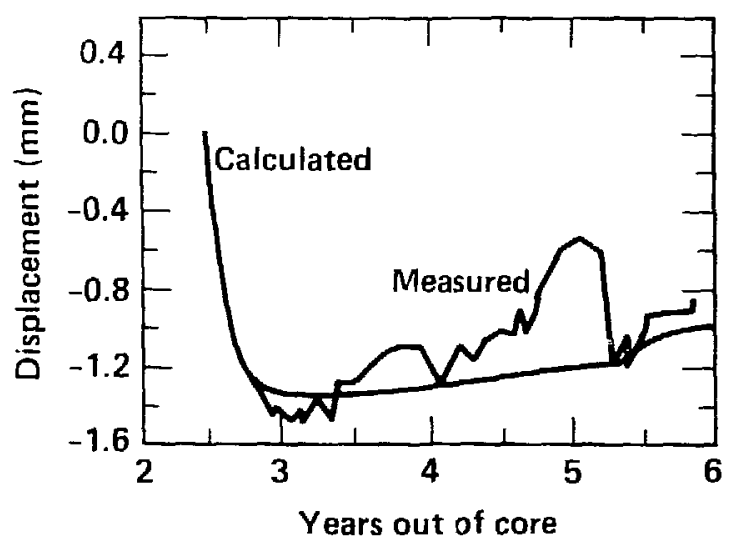

Figure 16-11b. Calculation 2 results compared with measured vertical closure of the canister drift (after Butkovich and Patrick, 1985).

showing closure during the entire heating phase, $t^{\prime}$ ' calculational results show a similar effect. Likewise, where the measurements show closure followed by dilation, the calculations indicate the same response. The rather pronounced upward deviation in the data trends centered around 5.0 YOC appear to relate to variation in the ventilation rate at this time (Chapter 14). A similar, less obvious deviation is seen at about 3.5 YOC when an earlier modification was made to the ventilation system.

Wilder and Yow (1986) analyzed the CWE data that provide hoth a more continuous record (a higher density of data) and data somewhat earlier than were available from the tape extensometers. In addition, they used the CWE data obtained from individual stations to examine potential spacial or geological effects on rock response. Figure 16-14 displays the maximum displacements that occurred during the heating phase of the test. With the exception of the end stations in the canister and north heater drifts, relatively little variation as a function of position is seen in the vertical direction (Fig. 16-14a). In light of the accuracy of these instruments, the consistency is quite remarkable. The substantially larger closures seen near Station $4+00$ in the canister and north heater drifts is directly attributable tu the presence of the Receiving Room fault (Chapter 4).

Considerably more variability is seen in the horizontal displdcements that occurred during the heated phase (Fig. 16-14b). While Wilder and Yow (1986) found that many of these variations were associated with 


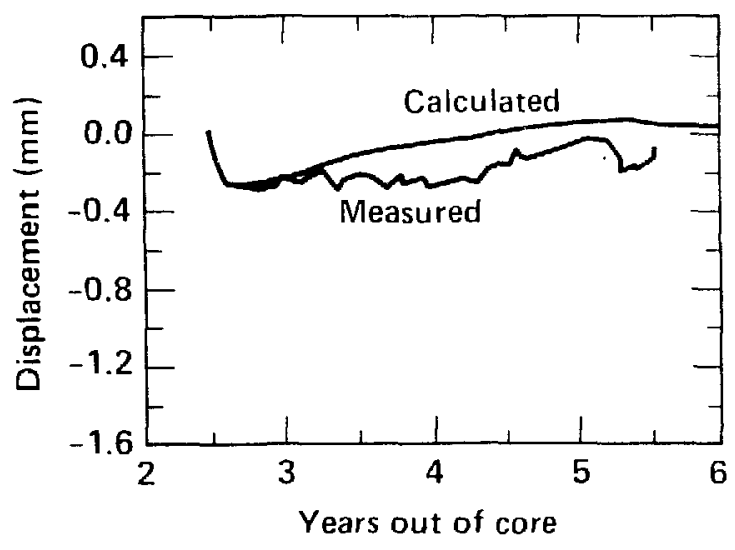

Figure 16-12a. Calculation 2 results compared with measured horizontal closure of the north heater drift (after Butkovich and Patrick, 1985).

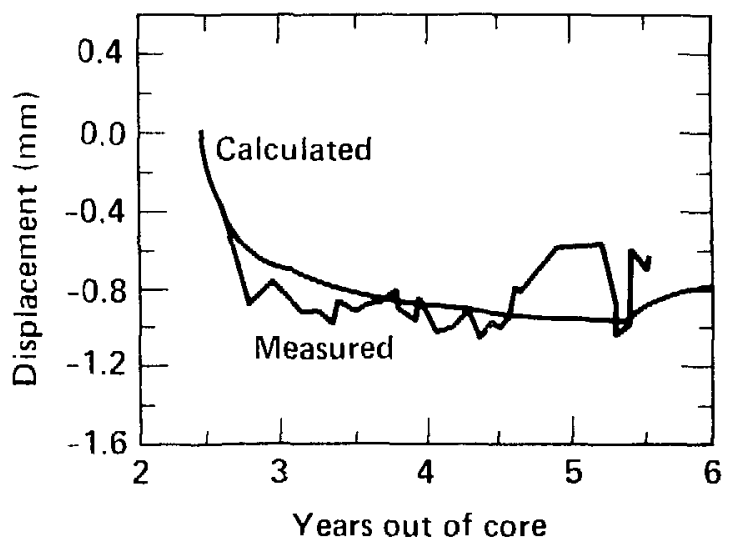

Figure 16-12b. Calculation 2 results compared with measured vertical closure of the north heater drift (after Butkovich and Patrick, 1985).

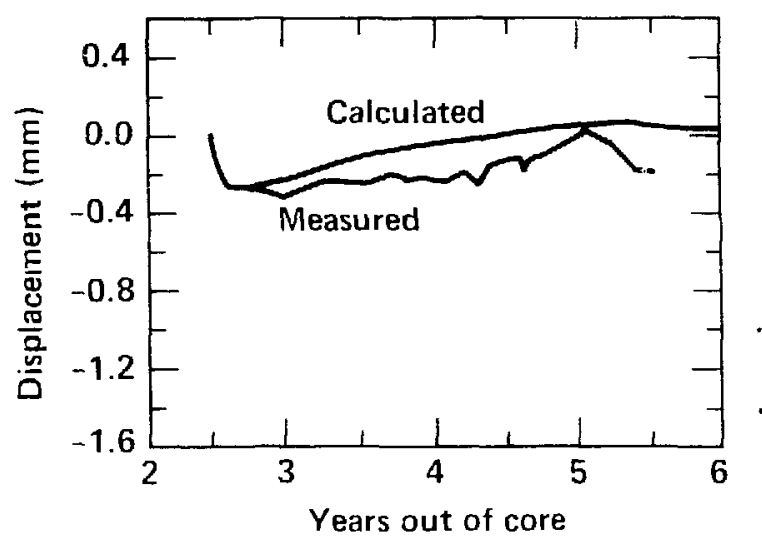

Figure 16-13a. Calculation 2 results compared with measured horizontal closure of the south heater drift (after Butkovich and Patrick, 1985).

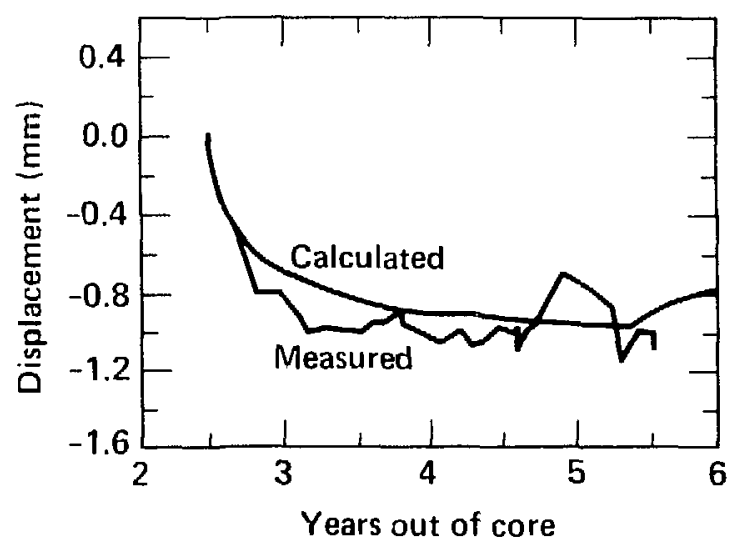

Figure 16-13b. Calculation 2 results compared with measured vertical closure of the south heater drift (after Butkovich and Patrick, 1985).

identified shear and fault zones, the relationship was not completely consistent. The larger closure near Stations $3+50$ and $4+00$ is related to the presence of the Receiving Room fault. Although the proximity of the ends of the heated array may suggest a possible cause for the upward deflections of the curves for the north and south heater drifts at Stations $2+50$ and $3+75$, respectively, this effect is absent in the canisterdrift data in Figs. 16-14a and b.

Similar comparisons may be made for the displacements recorded during the cooling phase of the SFT-C (Fig. 16-15). The total displacements are typically less than half the heating phase values and are consistently opposite in sign, indicating the anticipated recovery upon cooling the rock mass. Of particular interest is the suppressed recovery of the vertical canister drift and north heater drift displacements. This response is attributed by Wilder and Yow (1986) to the presence of the fault that, conceptually, would have experienced inelastic deformation during the heated phase.

Response of discrete geological features. The FMSs provided measurements of three orthogonal components of displacement at a total of seven locations on five geological features, which are principally shear and fault zones. As reported by Wilder and Yow (1986), the response of these features as recorded by 


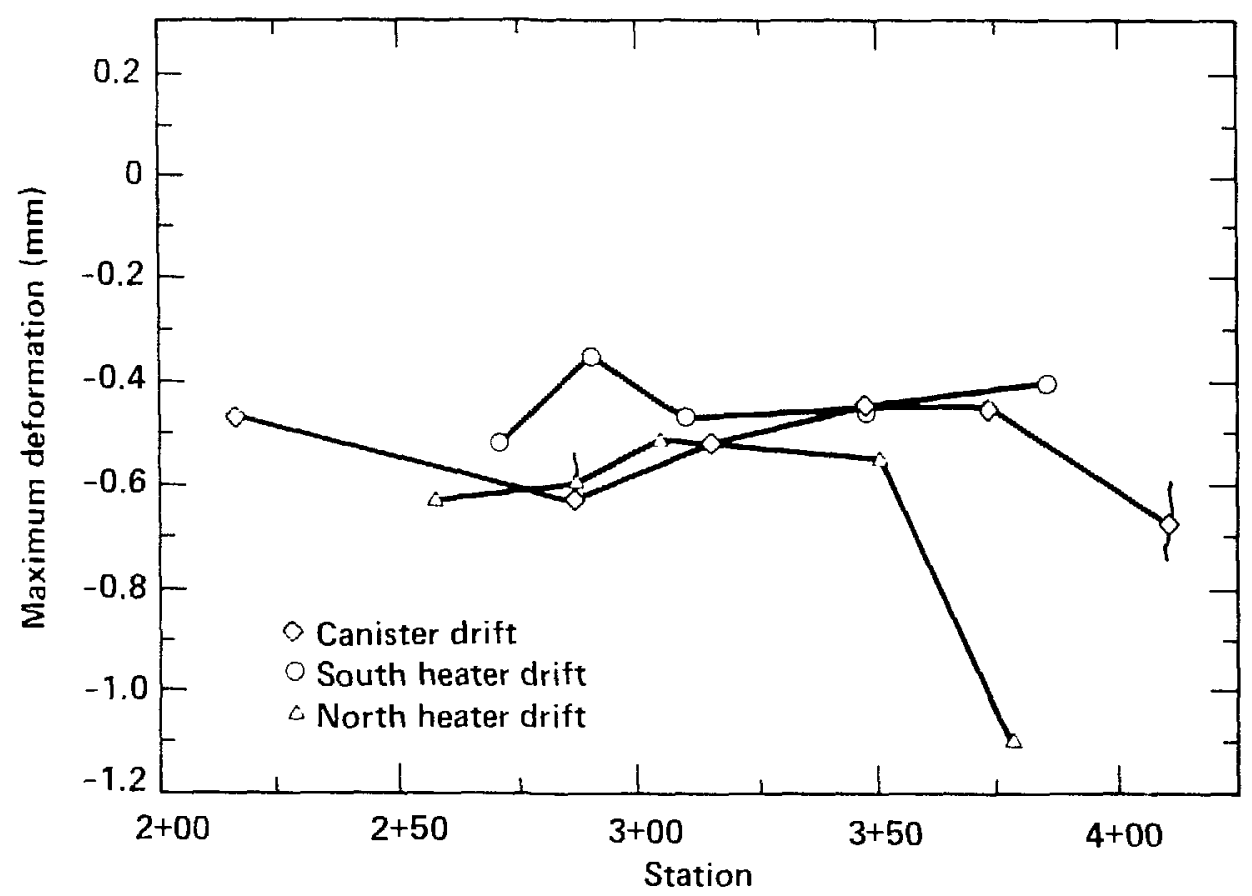

Figure 16-14a. Maximum vertical closures of the excavations recorded by CWEs during the heating phase (after Wilder and Yow, 1986).

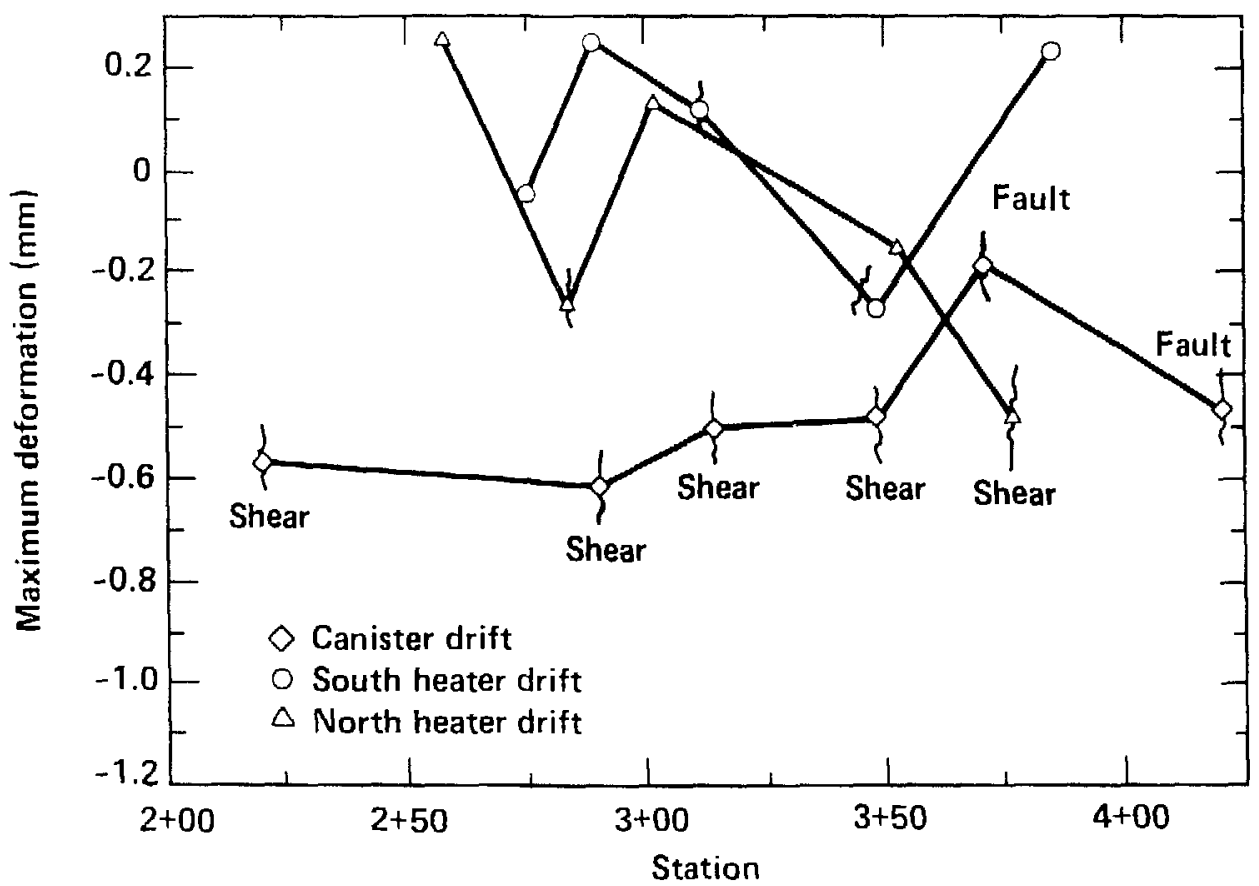

Figure 16-14b. Maximum horizontal closures of the excavations recorded by CWEs during the heating phase (after Wilder and Yow, 1986). 


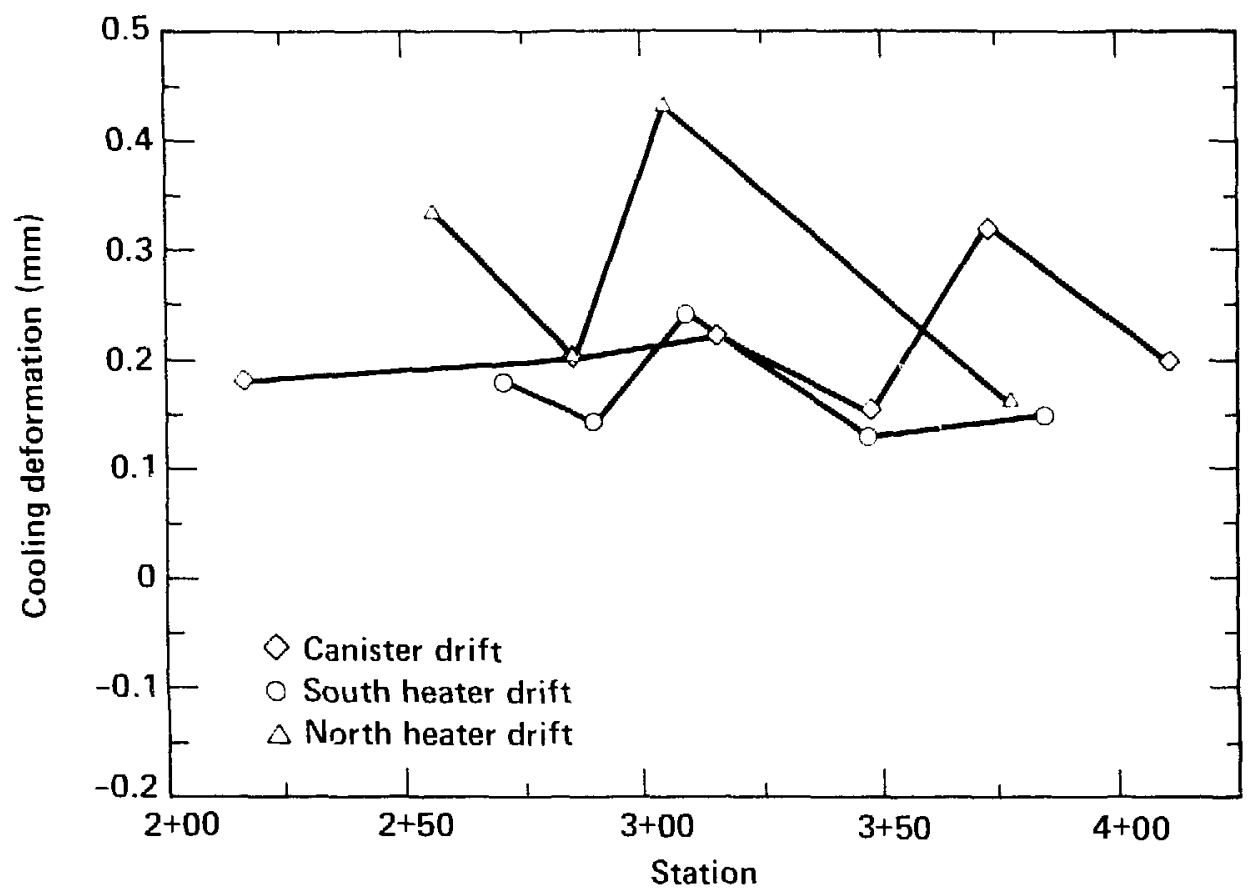

Figure 16-15a. Maximum vertical reopening of the excavations recorded by CWEs during the heating phase (after Wilder and Yow, 1986).

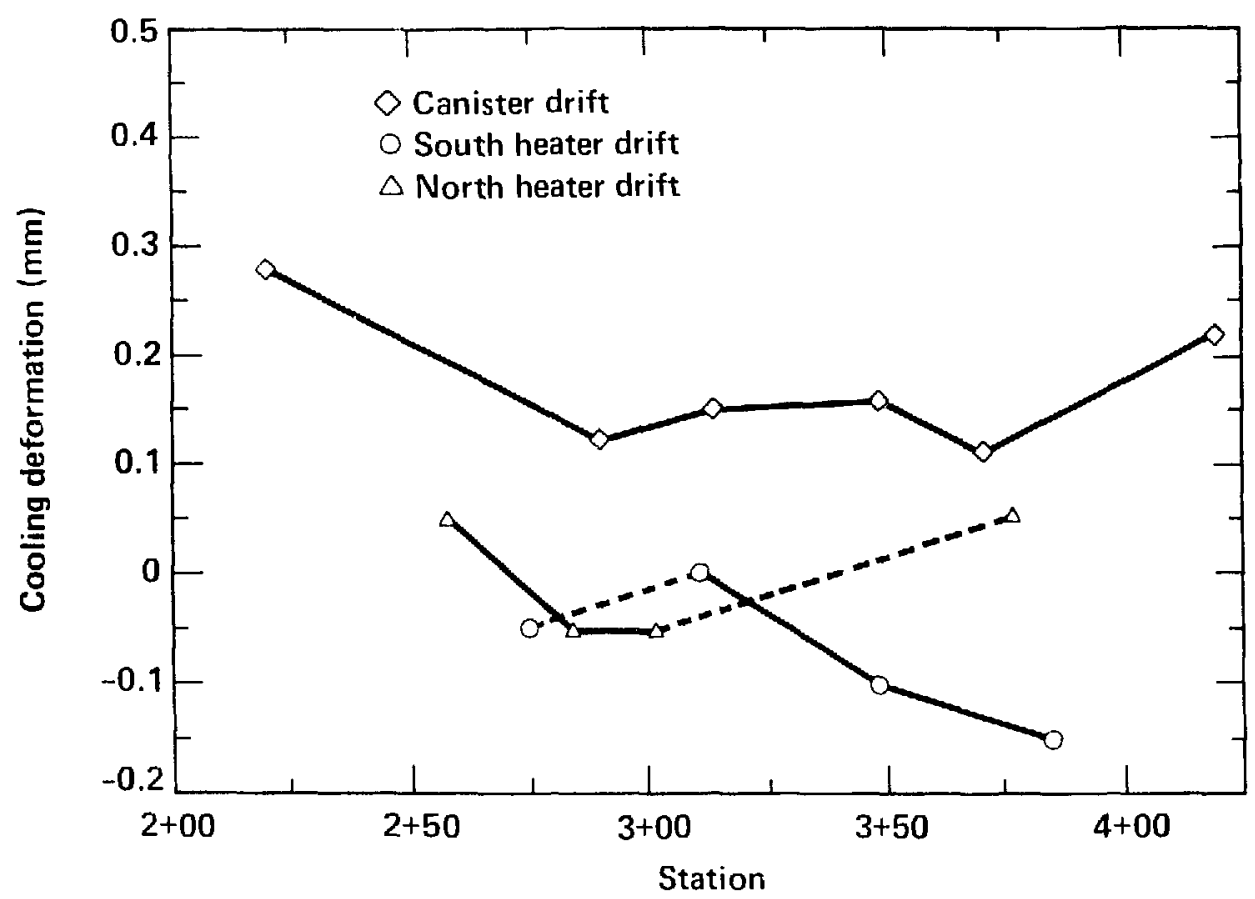

Figure 16-15b. Maximum horizontal reopening of the excavations recorded by $C W E s$ during the heating phase (after Wilder and Yow, 1986). 
the FMS unit was highly complex and not fully understood. Fven so, the timing and direction of the responses were repurted wo be generally consistent with each other and with other displacement measurements.

They also report that while the Receiving Room fault closed at locations near the invert (and, hence, near the greatest thermal perturbation), normal-displacement measurements indicated that this feature opened slightly near th roof line. These two observations are consistent with a block rotation mechanism. Similar responses were recorded near the center of the heater array where fracture closure and up-dip motion were recorded at some locations, while slight opening and up-dip motion were observed nearby on the same fractures.

Crack formation and growth in the concrete floor. When fractures hegan to form in the concrete floor near the spent-fuel CEHs, reference pins were installed to permit perjodic monitoring with a manual Whittemore gauge. From the time the fractures were originally observed at about 60-deg intervals around the CEHs, they grew until they intersected or coulesced with similar fractures from adjacent holes. Eventually, the continuation of fracture development changed the original radial geometry to a roughly rectangular pattern in the region of the floor between the emplacement holes (Chapter 5).

A typical history of change in fracture aperture is provided in Fig. 16-16. The overall trand of fracture upening is evident as time and heating progress. This is consistent with the calculated response of the underlving rock, which expands and bows upward as a result of heating, thus, subjecting the upper layer of concrete to tensile stresses that initiate fractures and cause subsequent fracture opening.

After retrieval of the spent-fuel assemblies at about 5.2 YOC, rapid closure was observed at all six measurement stations. This response reflects the contraction and lowering of the drift floor that accompanied cooling of the underlying rock. As the rate of cooling slowed deep in the rock and as the high rate of ventilation continued to rapidly cool the concrete floor, a slight reopening of the cracks occurred, as noted by the slight upturn in the curve.

When ventilation experiments were in progress at about 4.5 YOC (Chapter 14), a response similar in shape and magnitude was observed (Fig. 16-16). However, the mechanism causing fracture closing was quite different. It appears that the reductions in ventilation rate and resulting increases in air temperatures caused the concrete to expand, thus, partially closing the fractures. When ventilation was restored to its original rate, this response was quickly reversed. By about $5.0 \mathrm{YOC}$, the trend of aperture opening was essentially the same as before the reduction in ventilation rate.

Borehole-scale response to cooling. Strain-gauged proving-ring assemblies were deployed to measure deformations in the $0.61-\mathrm{m}$ diameter CEHs subsequent to spent-fuel retrieval (Chapter 9 and Patrick and Rector, 1985). Although several of these units malfunctioned before the 6 -month data acquisition period was completed, all provided high-quality data for a sufficient period of time to facilitate analysis.

Figure 16-17 provides a typical example of the behavior of an emplacement borehole following retrieval of the spent-fuel assembly. The rapid initia! rate of change in borehole diameter decreases to near zero during the first 6 months, closely following the decrease in cooling rate discussed in Chapter 13. (As noted

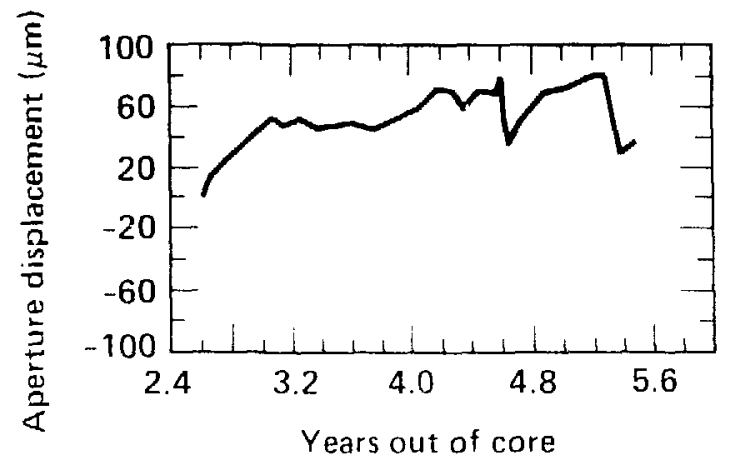

Figure 16-16. Typical change in fracture aperture as recorded by a Whittemore gauge at station WAP1415 on the concrete floor of the canister drift (after Patrick et al., 1984). 


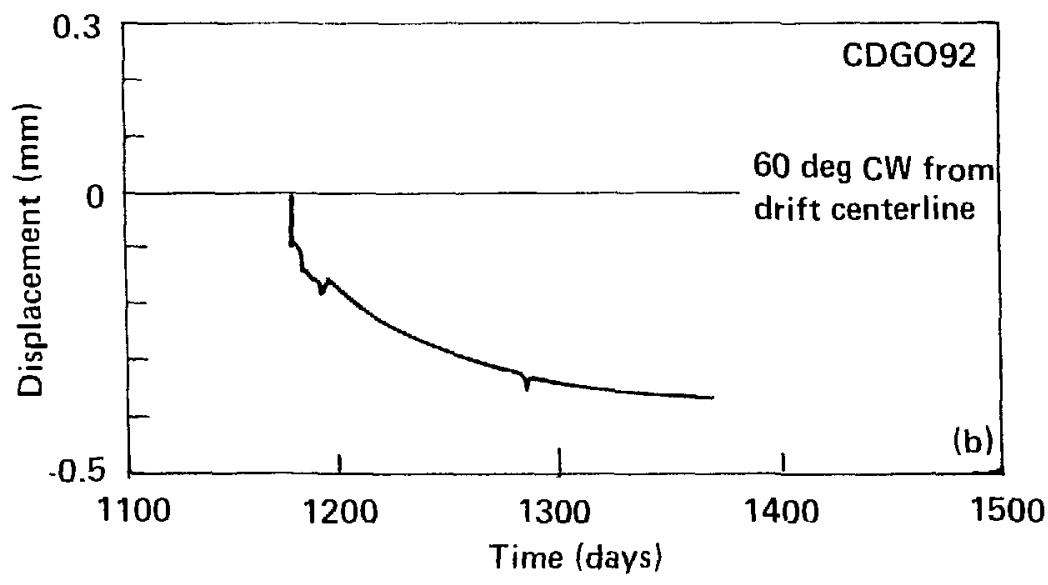

Figure 16-17. Typical example of closure history from instrument CDG092 in canister emplacement borehole CEH09 (after Wilder and Yow, 1986).

in Chapter 3, the duration of the post-retrieval couling period was selected based on calculations that showed this same style of rock mechanical behavior.)

Wilder and Yow (1986) report that observed displacement trends are qualitatively similar to near-field analytical solutions for borehole diameter changes. However, the magnitudes of measured diametral changes were typically three to four times larger than those calculated. The authors attribute this disagreement in magnitudes to the material properties or stress boundary conditions used in the analytical solutions.

To allow direct comparisons of data from each of the two levels in the two instrumented boreholes, Wilder and Yow (1986) selected data from two equally spaced time intervals when all 12 gauges were operational. These data and the resulting "principal displacements" are shown in Table 16-3. For each of these two couling periods, borehole convergences in the direction parallel to the axis of the canister drift are nearly identical for the four locations. Displacements in the other directions vary considerably (one to eight times the calculated maximum RSS error of $15 \mu \mathrm{m}$, Chapter 9), with the possible exception of the CEH09 location at 73 days cooling time. As a result of these variations, the principal directions change, both within a given borehole and between boreholes (with the exception of CEH09). Although the in-situ state of stress is highly anisotropic (Chapter 4), the superposed thermal stresses are probably quite uniform due to the test geometry (Chapter 3). In the absence of detailed analysis of these displacements in the context of the local geological features and the three-dimensional geometry of the borehole and drift, it is not possible to definitively establish the cause of the observed variations.

\subsection{Assessment of Modeling Capabilities*}

Based on the comparisons between data and calculations presented in this chapter, an assessment may be made of the capabilities to model facilities similar to the SFT - C with codes such as those used here. It appears that the continuum and discrete joint models used here can provide estimates of the displacement and stress responses of fractured hard rock such as granite. There was an apparent tendency for the discrete joint models (using either dilatant or nondilatant joints) to overestimate the displacements that were observed to result from excavation of the underground openings. Although neither formulation predicted the observed lateral contraction of the pillars between the drifts, overall agreement with the displacement data was better with the ADINA results.

During the heated phase of the experiment, an ADINA continuum formulation provided calculational results that were in good agreement with field data. This observation is tempered by the realization that

\footnotetext{
*Contributed by W. C. Patrick
} 
Table 16-3. Canister emplacement borehole diameter changes following spent-fuel retrieval (after Wilder and Yow, 1986).

\begin{tabular}{|c|c|c|c|c|}
\hline \multirow[t]{2}{*}{ Emplacement holn. } & \multicolumn{4}{|c|}{ ergence 36.5 days after fuel removal" } \\
\hline & CEH03 & СEH03 & CEH09 & CEH09 \\
\hline Parallel to axis ( $\mathrm{mm}$ ) & 0.200 & 0.205 & 0.195 & 0.200 \\
\hline$+60-$ deg from axis $(\mathrm{mm})$ & 0.165 & 0.190 & 0.220 & 0.195 \\
\hline -60-deg from axis (mm) & 0.155 & 0.215 & 0.140 & 0.170 \\
\hline Major principal (mm) & 0.200 & 0.220 & 0.230 & 0.210 \\
\hline Minor principal (mm) & 0.145 & 0.190 & 0.140 & 0.170 \\
\hline Theta from axis ${ }^{\mathrm{b}}$ (deg) & cw 6 & $\operatorname{ccw} 42$ & cw 39 & cw 26 \\
\hline \multicolumn{5}{|c|}{ Emplacement hole convergence 73 days after fuel removal’ } \\
\hline & CEH03 & $\mathrm{CEH} 03$ & CEH09 & CEH09 \\
\hline Parallel to axis (mm) & 0.255 & 0.250 & 0.255 & 0.260 \\
\hline +60-deg from axis (mm) & 0.220 & 0.250 & 0.300 & 0.280 \\
\hline -60-deg from axis (mm) & 0.210 & 0.315 & 0.205 & 0.235 \\
\hline Major principal (mm) & 0.255 & 0.315 & 0.310 & 0.285 \\
\hline Minor principal (mm) & 0.200 & 0.230 & 0.200 & 0.230 \\
\hline Theta from axis ${ }^{\mathrm{b}}$ (deg) & cw 6 & $\operatorname{ccw} 60$ & cw 44 & cw 43 \\
\hline \multicolumn{5}{|c|}{$\begin{array}{l}\text { All convergence values are rounded to the nearest } \\
0.005 \mathrm{~mm} \text {. }\end{array}$} \\
\hline
\end{tabular}

data were not available for comparison of the initial several weeks of response and the accuracies of some of the instruments were marginally acceptable.

A particularly important observation is that the geological structure, which appeared to dominate the excavation response, was less active during the heated phase of the test. This indicates that it is more important to include geological features when the rock is subjected to dynamic loading (such as drill-andblast mining) than when the loading is quasistatic. Furthermore, Wilder and Yow (1986) conclude that the role of geologic features tends to be greater when they are subjected to stress decreases than when they are subjected to stress increases. 


\section{Acoustic Emission and Wave Propagation Monitoring*}

This experiment was conducted as part of the SFT-C to determine if acoustic emission and wavepropagation monitoring could, in concept, provide a reliable means for assessing changes in conditionssuch as rock stability and permeability - in and around a nuclear waste repository. The results and conclusiuns of uver 3-1/2 years of continuous monitoring of acoustic emission and wave-propagation characteristics are summarized here together with a description of the instrumentation and experimental procedures. Further details and analy'ses are provided elsewhere (Majer et al., 1981 and 1982; Patrick et al., 1982 and 1984).

\subsection{Background}

A potential repository monitoring method that possesses the natural advantage of concentrating expected long-term effects into less frequent, (yet much larger) transient effects is based on the observation of acoustic emission (AE) or microearthquake (ME) phenomena. Differing only in frequency and distance scales ( $A E$ involves kilohertz trequencies and centimeter distances; $M E$ involves hertz frequencies and kilometer distances), both phenomena represent strain relief through discrete faults or failure events within the respective media. There are well-established methods (Johnson, 1979) in ME seismology for locating and describing the nature of such sources of elastic wave radiation. With proper scaling, these methods are thought to be applicable in investigating AE events from an underground repository. The SFT $-C$ study addressed the applicability of ME seismology techniques to AE in monitoring the integrity of an underground waste repository.

Few studies of seismic activity on this scale have been reported. One such experiment at the Stripa iron ore mine in Sweden was conducted by the Lawrence Berkeley Laboratory (LBL) of the University of California and the Sw'edish Nuclear Fuel Safety Agency (KBS). This experiment employed electrical heaters in granite to study thermal stress effects, but the associated AE studies were begun well after the heaters were turned on and only one sensur was used. However, considerable AE activity was still observed during the later stages of the heating phase. Activity increased during the initial stages of the cool-down period (Paulsson and King, 1980).

Two mechanisms are generally thought to be responsible for $\mathrm{AE}$ activity induced by heating: (1) contrasting thermoelastic behavior of different minerals within the rock, and (2) thermal gradient effects. Yong and Wang (1980) investigated AE from air-dried Westerly granite at atmospheric pressure and over the temperature range of 20 to $120^{\circ} \mathrm{C}$. An abrupt increase in $\mathrm{AE}$ was observed at a threshold temperature of approximately $70^{\circ} \mathrm{C}$. Yong and Wang (1980) found that above this threshold temperature, the rate of $\mathrm{AE}$ depended strongly on the rate of heating.

In further experiments, Yong and Wang (1980) compared AE from specimens of air-dried and watersaturated Westerly granite. The rate of $A E$ in a dry specimen was observed to be higher than for one that had been water-saturated at the same temperature and heating rate. This behavior was attributed to differences in thermal gradient within the specimen (the thermal gradient being smaller in the water-saturated specimen than in the dry specimen).

\subsection{Measurement System and Instrument Locations}

The equipment selected to monitor AE activity included accelerometers, charge amplifiers, and a 15channel transicnt-waveform recorder system interfaced to a microprocessor-based autumated seismic processor(ASI'). The specitications of the eyuipment are listed in Table 17-1, and the frequency response of the system and a syotem diagram are shown in Figs. 17-1 and 1\%-2, re'spectively.

After consideration had been given to the froquency content of the background noise, the attenuation propertion of the granite. and source dimensions of the expected cracking, we decided to concentrate on

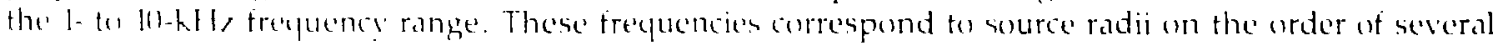

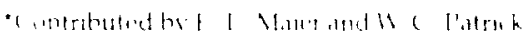




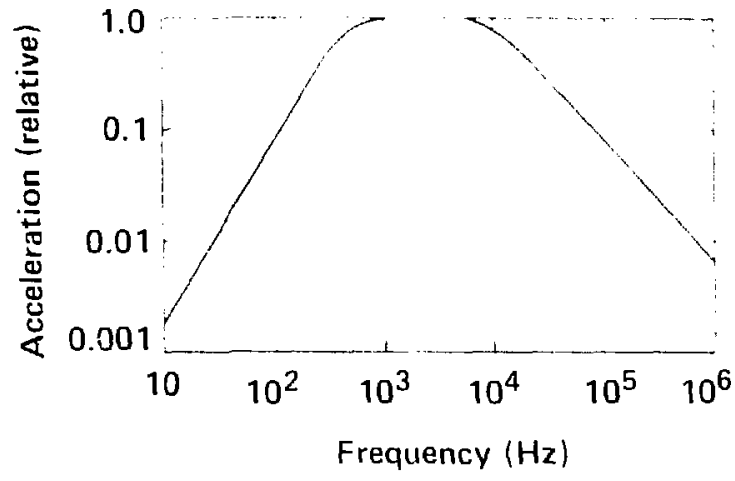

Figure 17-1. System response (acoustic emission sensor mounted on stainless steel plus preamplifier), obtained by placing the mounted sensor on a block of granite and pulsing the system for 1-ms. The rock seems to act as an effective anti-alias filter. Units are in $\mathrm{Hz}$ and acceleration response is relative (after Patrick et al., 1982).
Table 17-1. Specifications for accelerometers and charge amplifier. (After Patrick et al., 1982.)

\begin{tabular}{ll}
\hline Columbia 5002 accelerometer & \\
\hline Sensitivity & $13 \mathrm{pC} / \mathrm{g}^{2}$ \\
Frequency response & 2 to $10 \mathrm{kHz}\left( \pm 5^{\circ} \%\right)$ \\
Resonant frequency & $50 \mathrm{kHz}$ \\
Capacitance & $850 \mathrm{pF}$ \\
Output resistance & $2 \times 10^{111} \Omega$ \\
& \\
Columbia 902l charge amplifier & \\
\hline Source impedance & \\
$\quad$ (capacitive device) & $500 \mathrm{pF} \max$ \\
Charge gain & $100 \mathrm{mV} / \mathrm{pC}(40 \mathrm{~dB})$ \\
Output impedance & $125 \Omega$ \\
Frequency response & 1 to $10 \mathrm{kHz}( \pm 5 \%)$
\end{tabular}

" $g$ = acceleration of gravity.

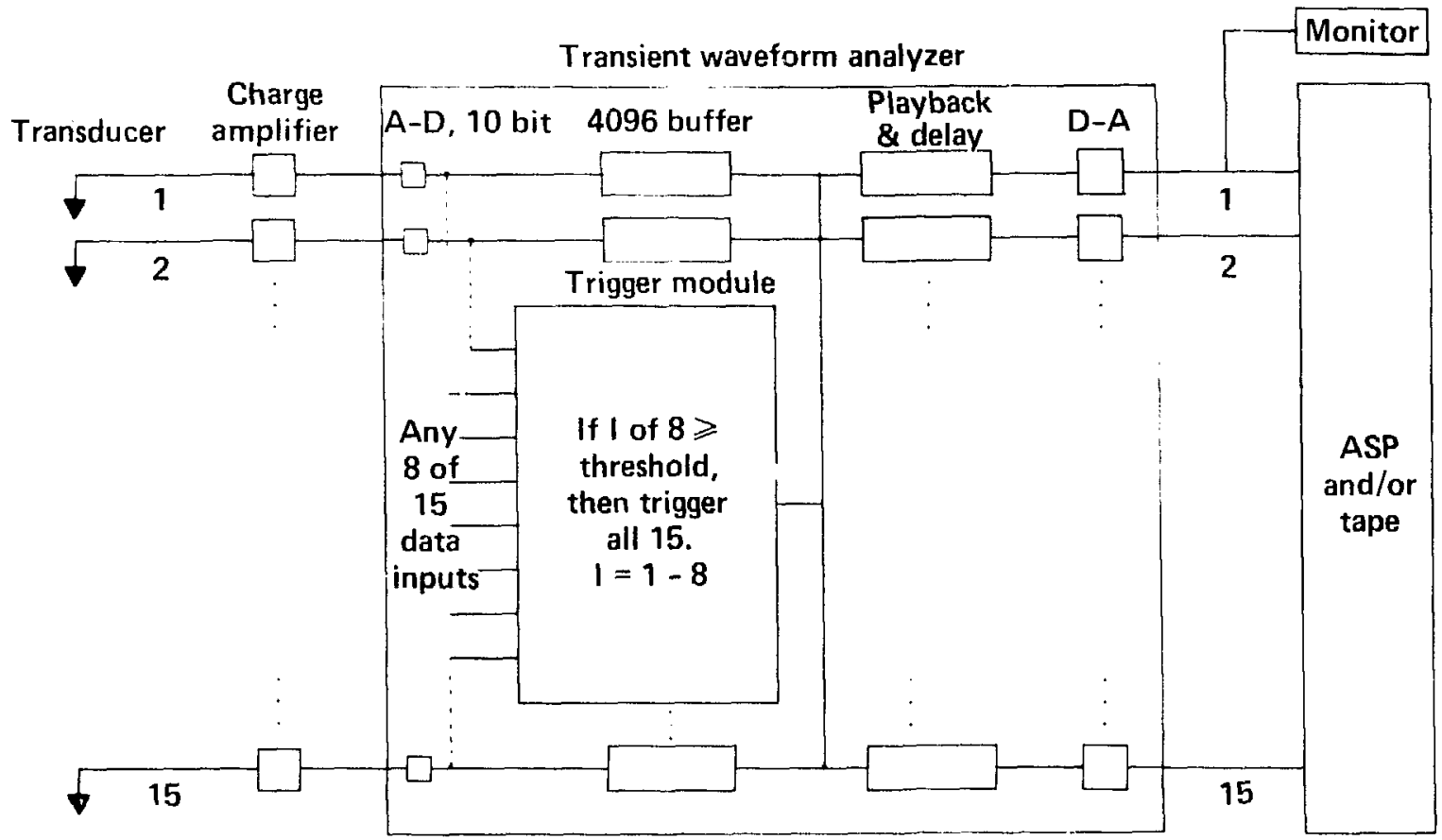

Figure 17-2. Total system showing the AE sensor (transducer), preamplifiers (mounted as close as possible to the sensor), transient waveform analyzer (Physical Data 515-A), and data handling device (either a tape recorder or the automated seismic processor (ASP)] (after Patrick et al., 1982). 
centimeters, using the static modd of Brune (1970 and 1971). Although much higher frequencies are genterated by smaller fractures, they would remain undetected in the $50-\times 20-\times 10-\mathrm{m}$ array employed in this experiment. The lower frequency was selected on the basis that sources larger than several meters would probably be too infrequent at the stress leyels encountered at the 420 - $m$ subsurtace. Furthermore, ambient background noises are a problem at frequencies less than $1 \mathrm{kHz}$.

The accelerometers were mounted in 4(1-mm-diameter stainless-steel stock, which were epoxycemented into 48-mm-diameter drill holes, shown in Figs. 17-3 and 17-4. Those sensors numbered 1, 2, 3, 8 , $9,10,11,12,17.18$, and 19 were shallow and horizontal, 0.3 to $0.6 \mathrm{~m}$ above the mine floor. Those sensors numbered $4,5,6,7,13,14,15$, and 16 were placed in inclined holes 6.5 - to 7 -m deep, drillert from the side drifts to a level even with the bottoms of the canisters. The deep sensors numbered $5,6.1 \%$, and 15 contained accelerometers, and the one numbered 13 contained a piezoelectric source for velos $1 \%$ and attenuation monitoring. In total, 15 accelerometers were installed to form a three-dimensional ariay centered on the row of canisters.

The amplified signals from the sensors were sent to the instrument alcove and digitized to 10-bit accuracy at 100,000 samples/s by the transient waveform analyzer. If the signal level rose above a preset threshold, a 4096-point data window was captured by the waveturm analyzer and played back at 20 samples/s to a slow'speed, 14-channel tape recorder (frequency response dc to $40 \mathrm{~Hz}$ ) or to the automated seismic processor at 200 samples/s. A triggering module monitored eight of the fifteen stations. If the signals of any one or more of these eight selectable stations ruse above a preset threshold, the event triggered playback at the reduced rate for the 4096-point data window on all fifteen channels. Between events, the raw data were sent real-time to the recorder and ASP. A visual monitor on one of the trigger stations provided a continuous record of events so that they could easily be located on the magnetic tapes. Except for the transient waveform analyzer, the system was identical to that used to monitor and record earthquakes. The waveform analyzer permitted the scale-down from high $\mathrm{AE}$ frequencies to the much lower earthquake irequencies.

Unfortunately, when many events occur, full processing of the data becomes tedious, timeconsuming, and far too labor-intensive. A similar problem was encountered in applying passive seismic technique's to geothermal exploration (Majer and McEvilly, 1979). During that study, fully processing 100

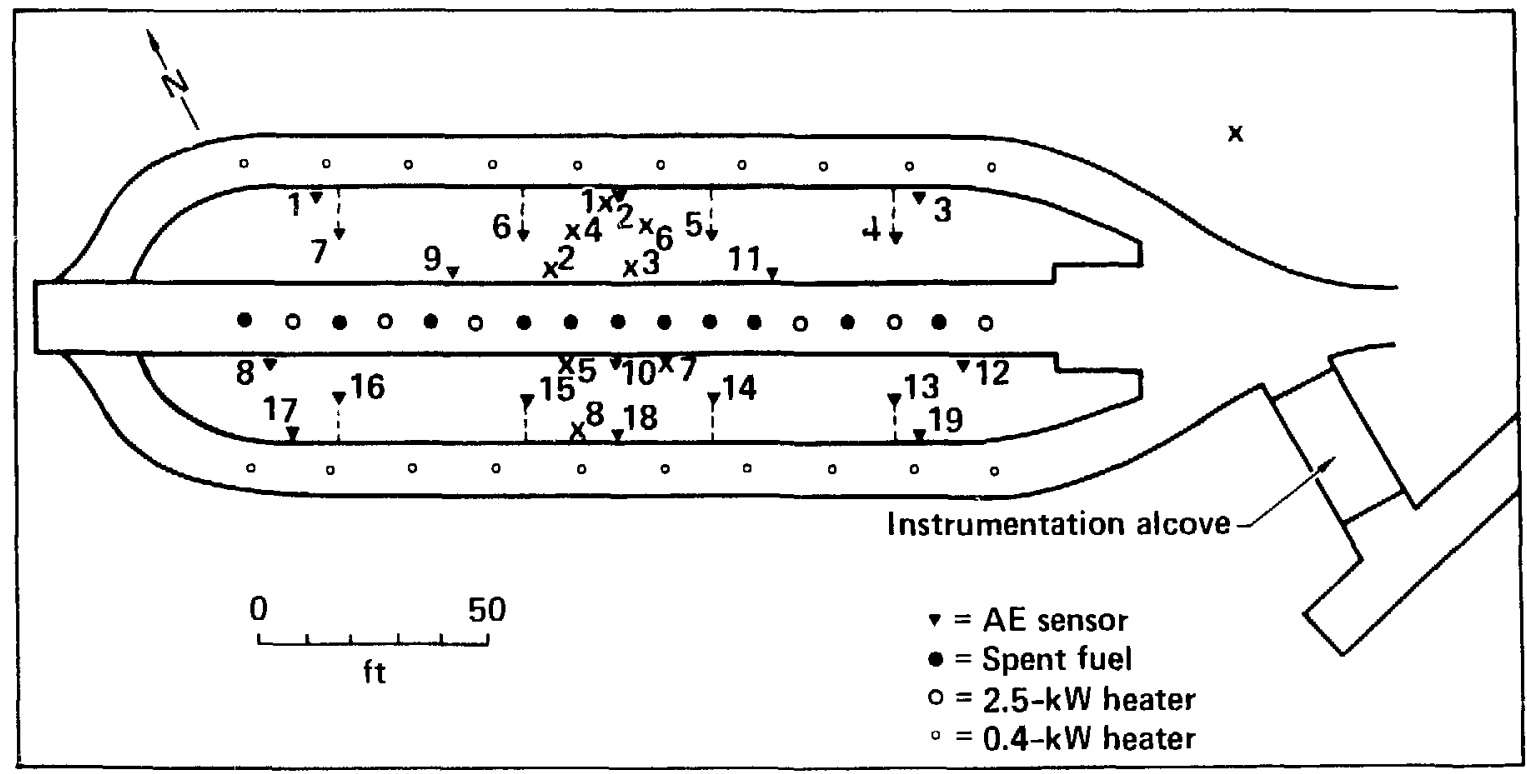

Figure 17-3. Plan view of Climax experiment showing waste canisters, heaters, and acoustic emission sensors. Signals from the AE sensors are hardwired to the instrumentation alcove (after Patrick et al., 1982). 


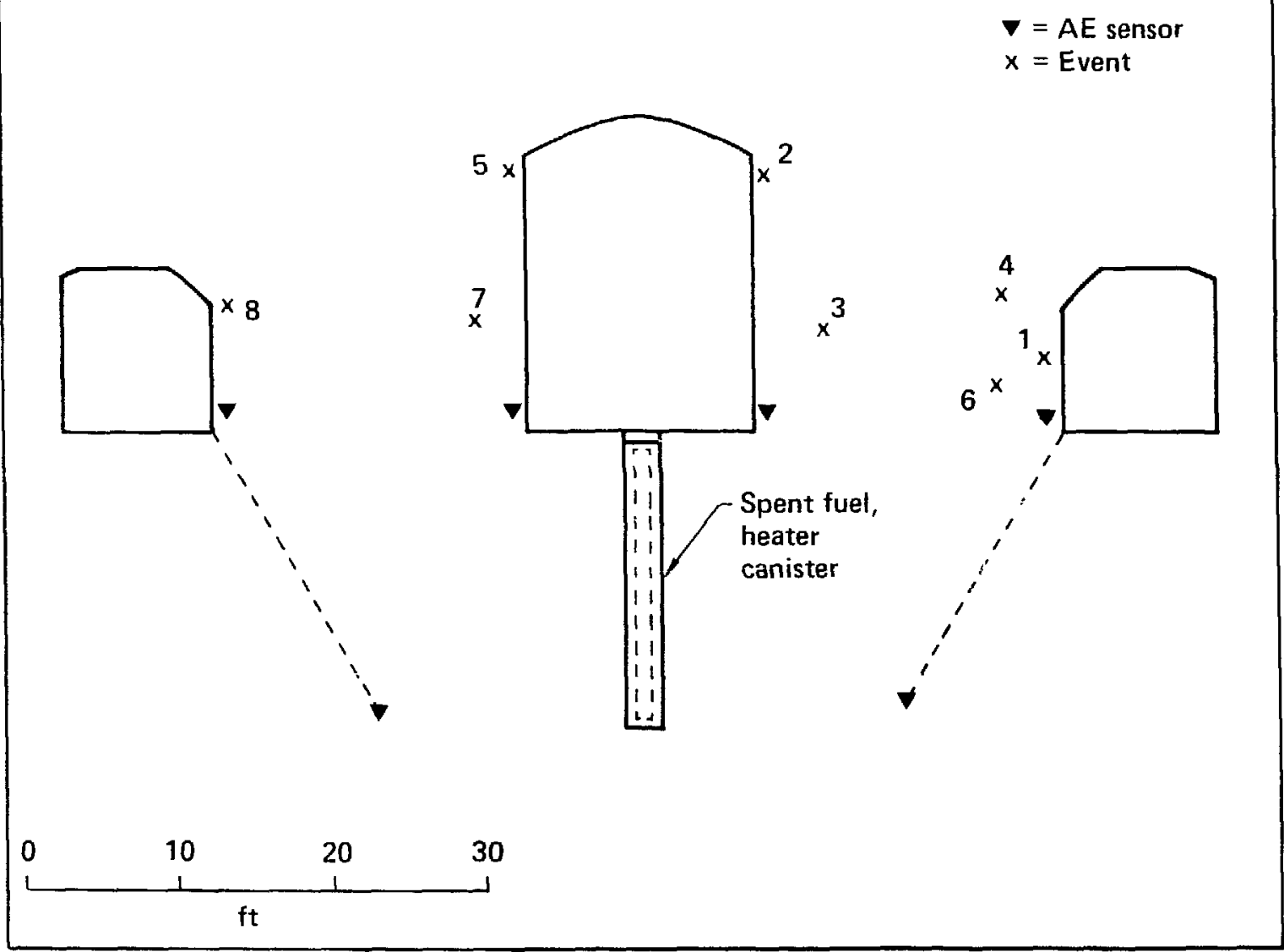

Figure 17-4. Cross section of mine openings showing AE sensor locations in "deep" holes (dashed lines) and on the surface (after Patrick et al., 1982).

events recorded at twelve stations required several months of work. Therefore, we designed and fabricated an in-field processing and virtual real-time display of seismic-event source parameters. This ASP is a microprocessor-based, parallel-processing computer. It is self-contained, low-power (CMOS, $1 \mathrm{~W} / \mathrm{channel}$ ), capable of providing sophisticated data analysis, and it eliminated the need for peripheral data storage devices or computers. Basically, a set of real-time algorithms perform event detection, $P$-and $\mathrm{S}$-wave timing, and amplitude functions. Then Fourier transforms are calculated and processed to letermine source parameters for the events. The available modes of calculation were:

1. Event count, number of events (from test initiation) that have met amplitude and occurrence criteria.

2. Event location, $x, y$, and $z$ coordinates, $t$, and the residuals.

3. Cumulative and interval b-values, for $P$ - and $S$-wave amplitudes (maximum-likelihood method).

4. Source properties from spectral data; i.e., using dc level, corner irequency, and high-frequency slope to estimate the moment, source area, displacement, and stress drop.

5. First-motion polarity for fault plane solution.

6. Debug mode (all raw data are printed out).

A more detailed description of the ASP is provided by Majer et al. (1981). 


\subsection{Summary Results of Acoustic Emission Monitoring}

Continuous monitoring of $\mathrm{AE}$ activity began about 3 months hefore spent-fuel emplacement, was conducted throughout the 3-year storage phase of the SFT-C, and was completed about 5 months subsequent to spent-fuel retrieval. The locations of seismic events are shown in relation to the thermal sources deployed at the SFT - C, in Figs. 17-5 and 17-6. Lucations were calculated using raw data acquired by the ASP in conjunction with calibration data obtained by recording the signals resulting from hammer blows at known locations. This technique resulted in determination of locations to within $\pm 0.5 \mathrm{~m}$.

Although the clustering of events near the canister emplacement holes was expected, the spatial segregation of AE activity in plan view is striking. Despite a uniform distribution of AE sensors, nearly all events are located in the southeastern region of the test array. Geologic structural data reported by Wilder and Yow (1981) provides a possible reason for this segregation (Chapter 4). All events reported here are located to the south of a NE-SW trending fault that passes between CEH05 and CEH06. In addition, nearly all events are east of a NE-SW trending shear zone that passes through CEH09 (the center hole). It appears that although the thermal load is relatively uniform throughout the test array (Chapter 13), stresses and/or strength (which govern rock tailure and, hence, AE) are not uniform. Stress differences under uniform loading conditions could be the direct result of differences in rock-mass deformation moduli, whereas strength differences may be the result of spatially varying fracture intensities and orientations, both of which may be related to the fault or shear zones, particularly ones oriented N 55-deg E. Insufficient data are available to conclude whether or not variations in moduli and strength may be the cause of the observed anomaly in AE activity.

The time-varying nature of AE activity is clearly shown in Fig. 177. Several peaks of activity superposed on a background of two to three events per week are evident. The major peaks at the beginning and end of the storage phase of the test demonstrate the sensitivity of the monitoring technique to rapid changes in thermal stresses induced in the rock. The three short-duration peaks that occur late in 1980 , 1981, and 1982 are the direct result of rapid thermal transients resulting either from increasing the thermal uutput of heaters or from loss of power to several of these thermal sources.

Two distinct types of events were recorded during this study (Majer et al., 1982). Type 1 events had characteristics similar to what one would observe in a ME: clear P-and S-wave arrivals, impulsive onsets, and b-values near unity. Type 2 events occurred in "swarms" with quite different characteristics: poorly detined S-wave, emergent onset of the P-wave, and restricted range of magnitudes. Although attenuation could be expected to produce similar differences in characteristics, this does not appear to be the case here. Comparing Type 1 and Type 2 events with similar travel path lengths, the latter are generally of greater magnitude and lower frequency content than the former.

It is interesting to note that although laboratory research (Yong and Wang, 1980) indicates that AE activity does not begin until about $70^{\circ} \mathrm{C}$, we observed significant activity at lower temperatures. We hypothesize that the incremental thermal stress superposed on tectonic and excavation-induced stresses was sufficient to produce AE at lower temperatures. An additional contributing factor is the existence of macroscopic fractures in the rock mass, which were absent in the laboratory specimens. Majer et al. (1982) have previously reported that the AE events appear to cluster on or near such geologic features.

\subsection{Summary Results of Wave Propagation Studies}

Wave propagation studies were initiated about 6 months followirg spent-fuel emplacement. The source for monitoring amplitudes and arrival timis a $\mathrm{AE}$ sensors throughout the test array was provided by a piezoelectric crystal installed in the bottom of sensor hole $A E 13$ and pulsed with a $1.6 \mathrm{kV}, 3-\mu \mathrm{s}$ rise-time power supply. Because of concern for possible recording and source-receiver coupling variations, P-wave amplitude data are reported relative to data received at acoustic emission serisor AE19. It is important to note in the following discussion that it was not possible to locate the path between sensors AE13 and AE19 outside the thermally affected zone. Therefore, ratios of the data may cancel out thermal effects on P-wave amplitude that might otherwise have been observed.

In examining Figs. 17-8a through 17-8c, we discern no trend in $\mathrm{P}$-wave amplitude relative to the $\mathrm{P}$-wave amplitude at AF 19. As ubserved above, this is very likely the result of experiment bias. The S-wave to Pwave amplitude ratios shown in the same figures display a definite increasing trend during the early 


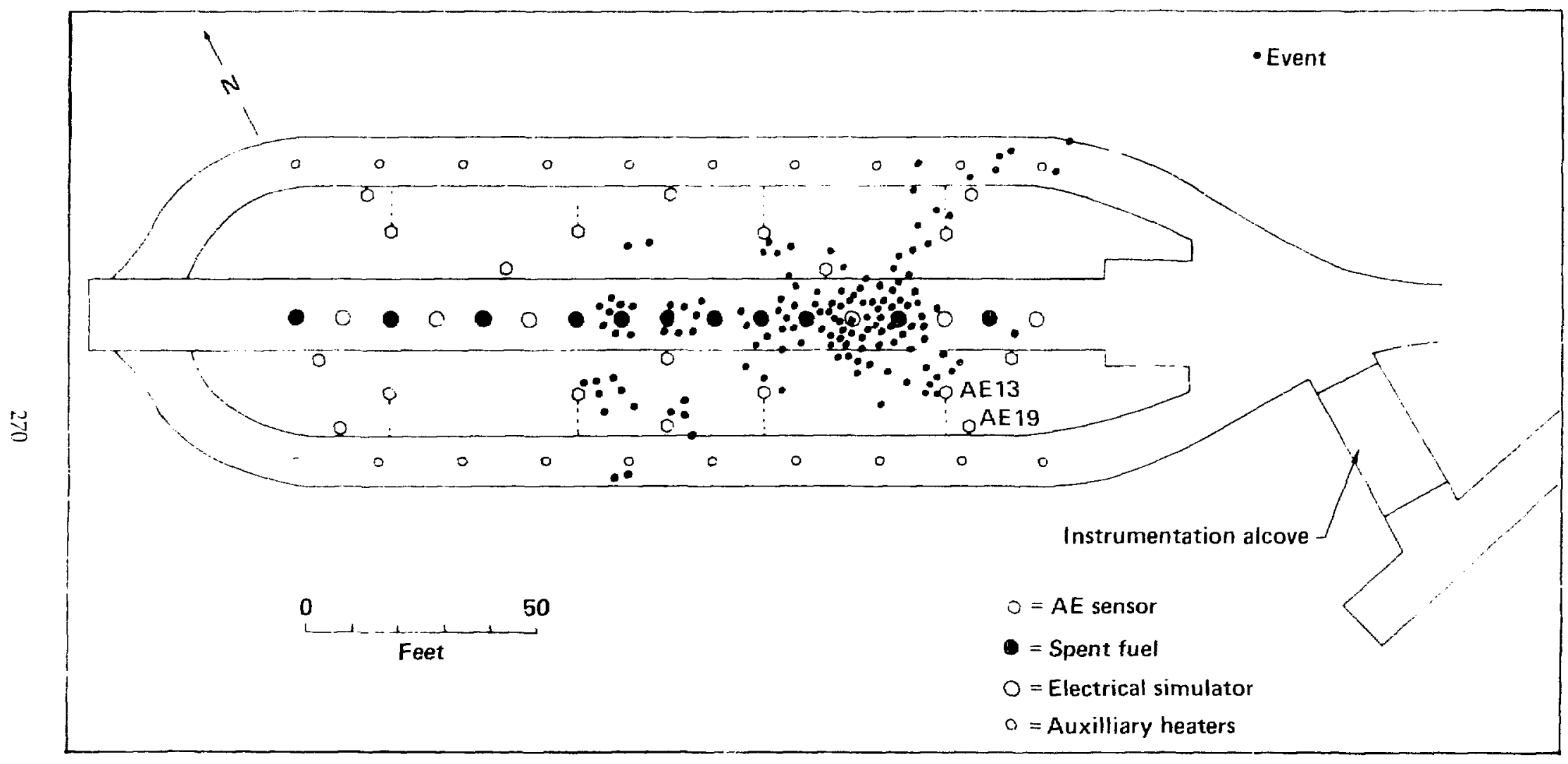

Figure 17-5. Plan view of acoustic instrumentation locations and zones of principal seismic activity (afıer Patrick et al., 1984). 


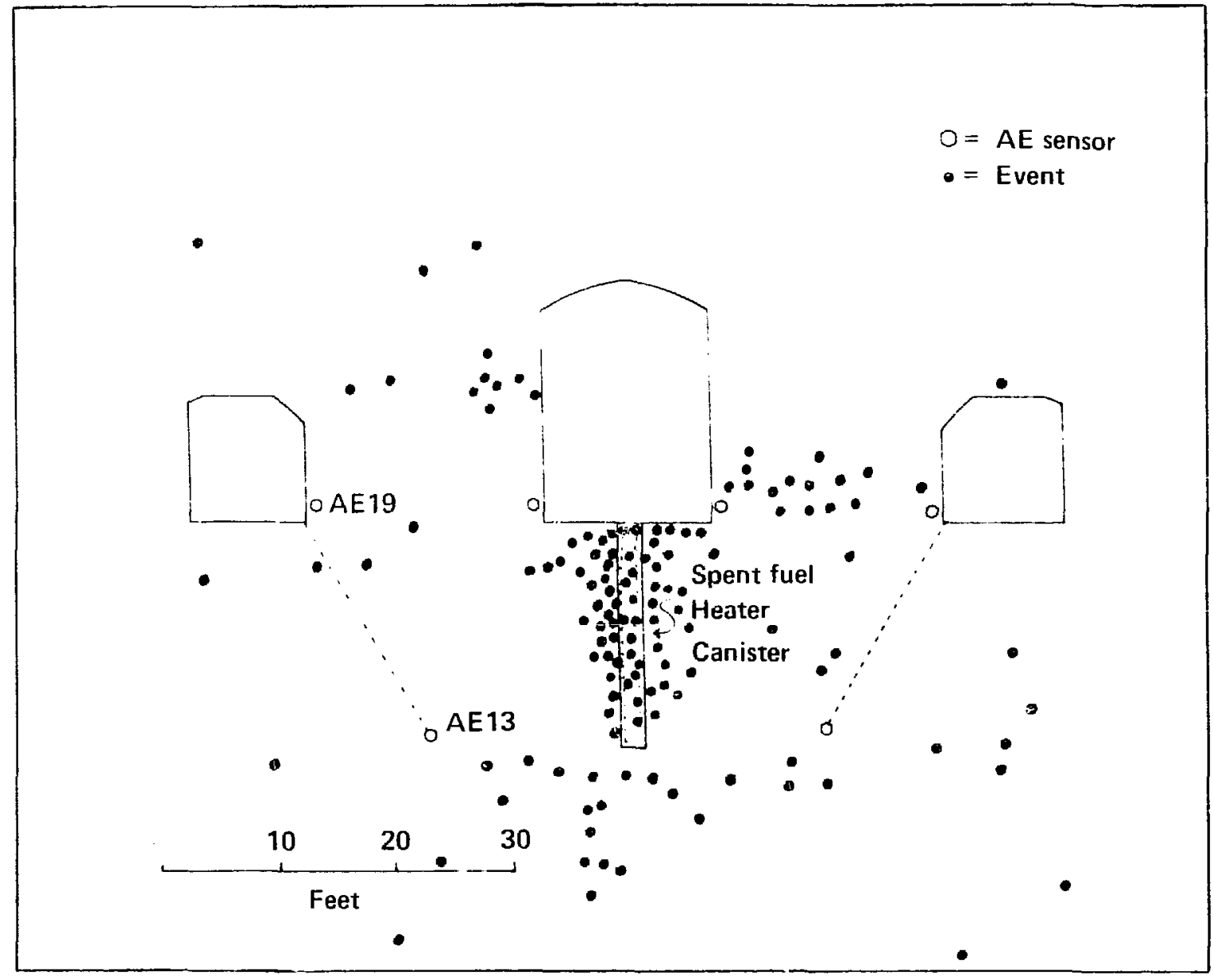

Figiure 17-6. Cross-sectional view of acoustic emission instrumentation locations and zones of principal seismic activity (after Patrick et al., 1984).

phases of the test, followed by a broad, somewhat erratic plateau, and ending in a slight downturn. This irend in S/P amplitude ratio approximates the iemperature trend in the central region of the SFT $-\mathrm{C}$. Only minor variations in S/P amplitude ratio are observed at AE19, probably because the path between AE19 and the source in $\mathrm{AE} 13$ is much shorter than the other paths. It is interesting that, although the trend of S/P amplitude ratios follows that of temperatures, the S/P ratio at the end of the test is definitely greater than at the beginning of the 'est. This difference remains although temperatures are only slightly $\left(10\right.$ to $\left.15^{\circ} \mathrm{C}\right)$ above ambient, indicating a more, or less permanent change in the wave propagation characteristics of the rock mass in the vicinity of the SFT $-C$. This conclusion is substantiated by Wilder and Yow (1986) who report that geologic features tended to not fully recover following the episode of heating and subsequent cooling.

In addition to these amplitude data, arrival times were also recorded. Based on a digitizing rate of $100,000 \mathrm{sampies} / \mathrm{s}$, or $10 \mu \mathrm{s}$, and a maximum travel time of $3 \mathrm{~ms}$, we were able to resolve velocity changes to better than $1 \%$. No changes in $\mathrm{P}$ - or $\mathrm{S}$-wave velocities were recorded throughout the monitoring period. 


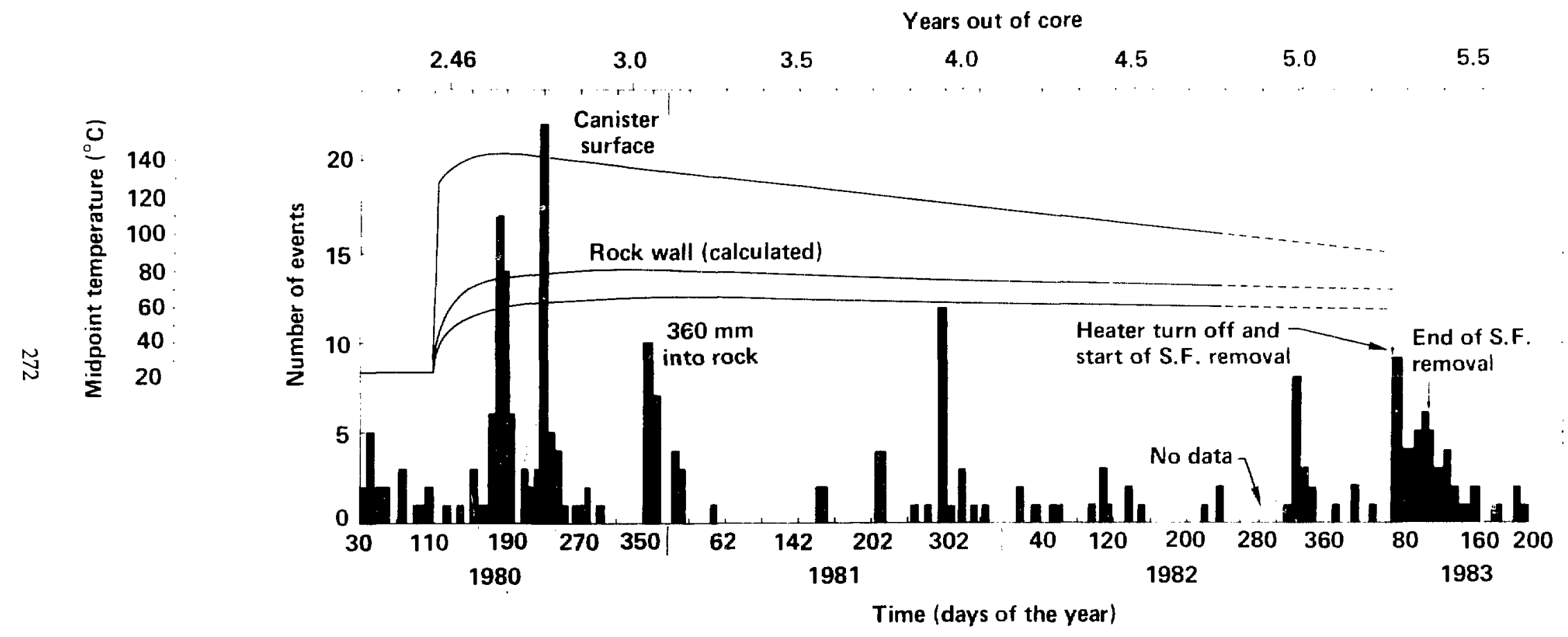

Figure 17-7. AE activity and temperatures from January 1980 through June 1983 (after Patrick et al., 1984). 


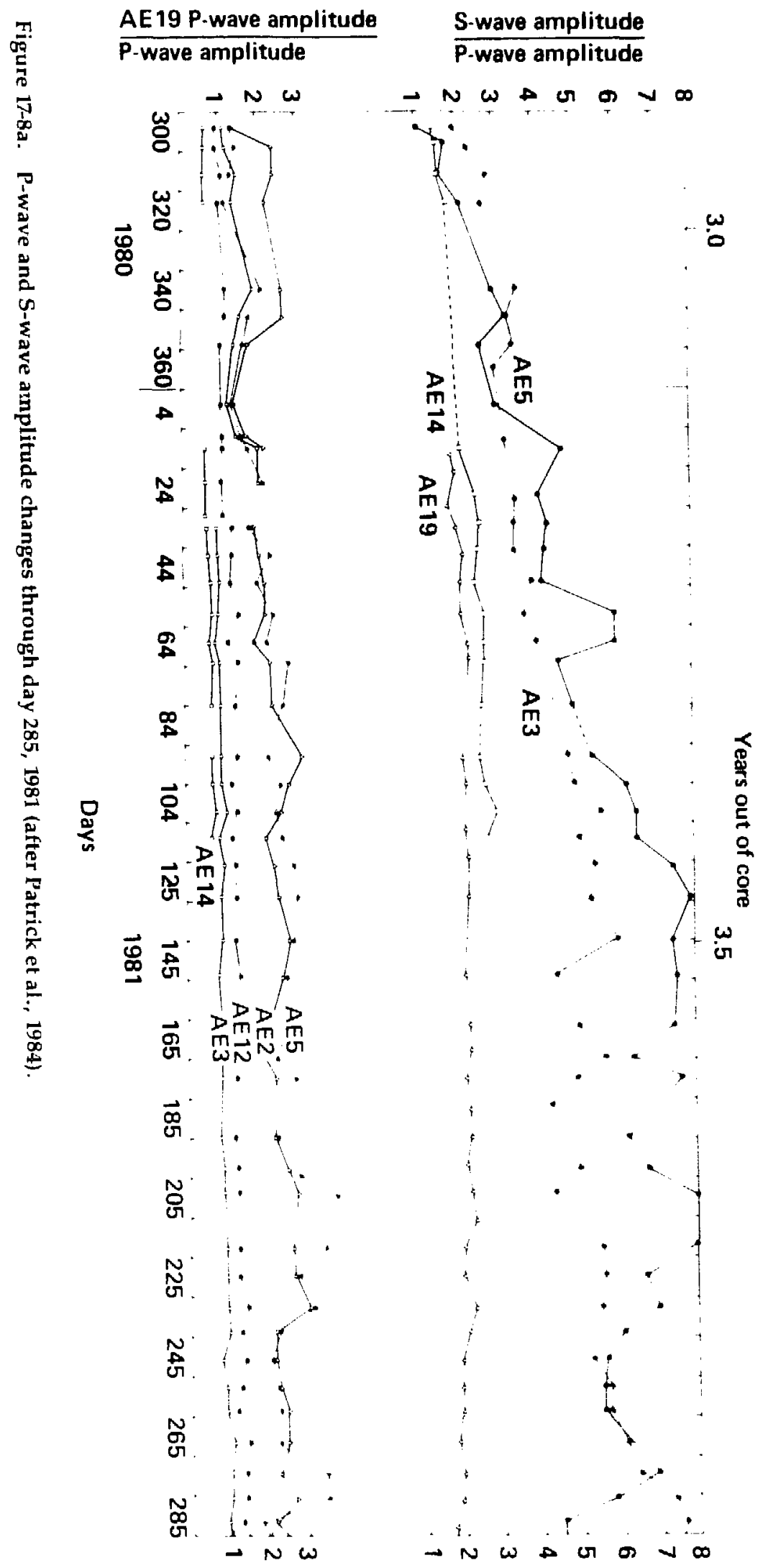




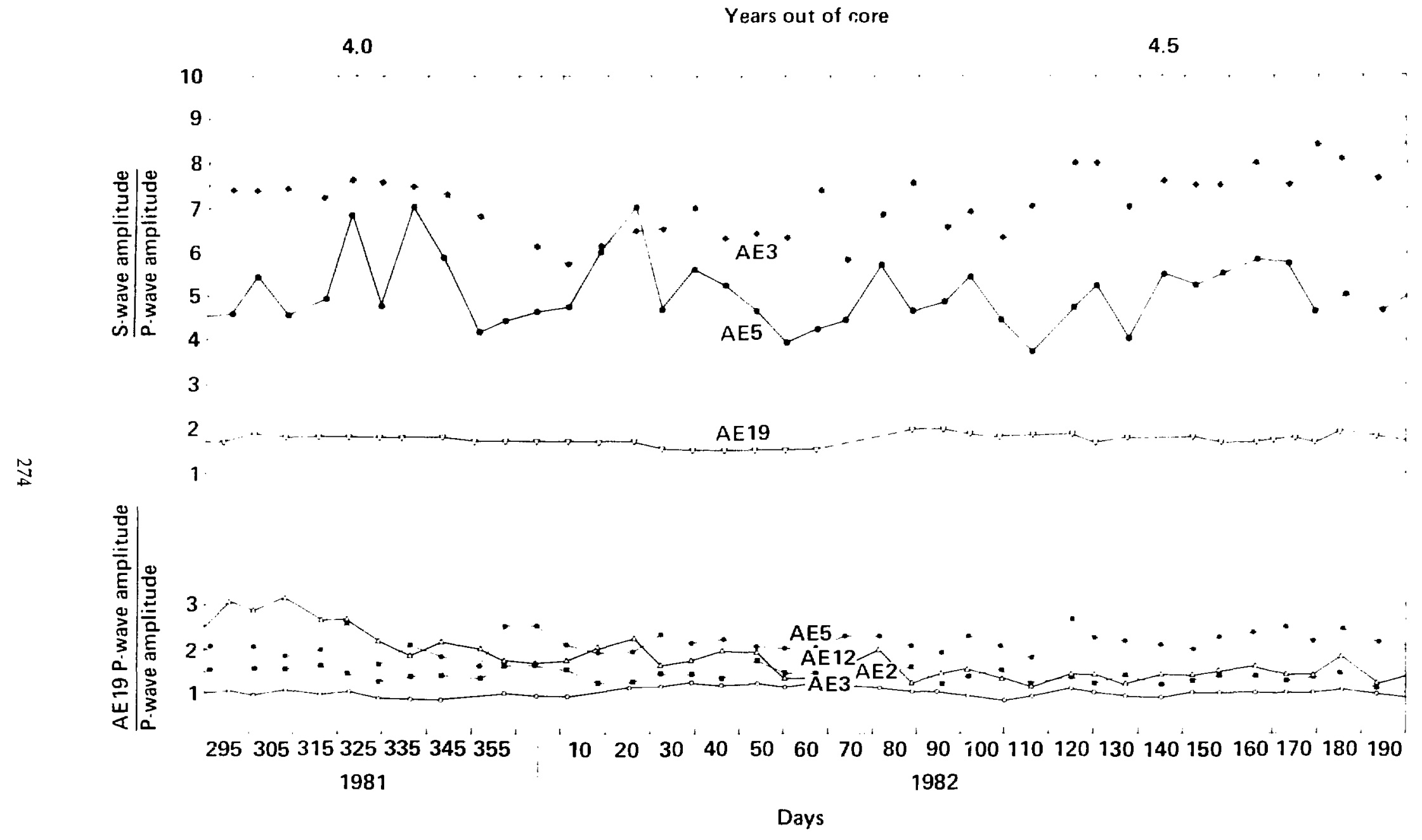

Figure 17-18b. P-wave and S-wave amplitude changes from day 285, 1981, through day 190, 1982 (after Patrick et al., 1984). 


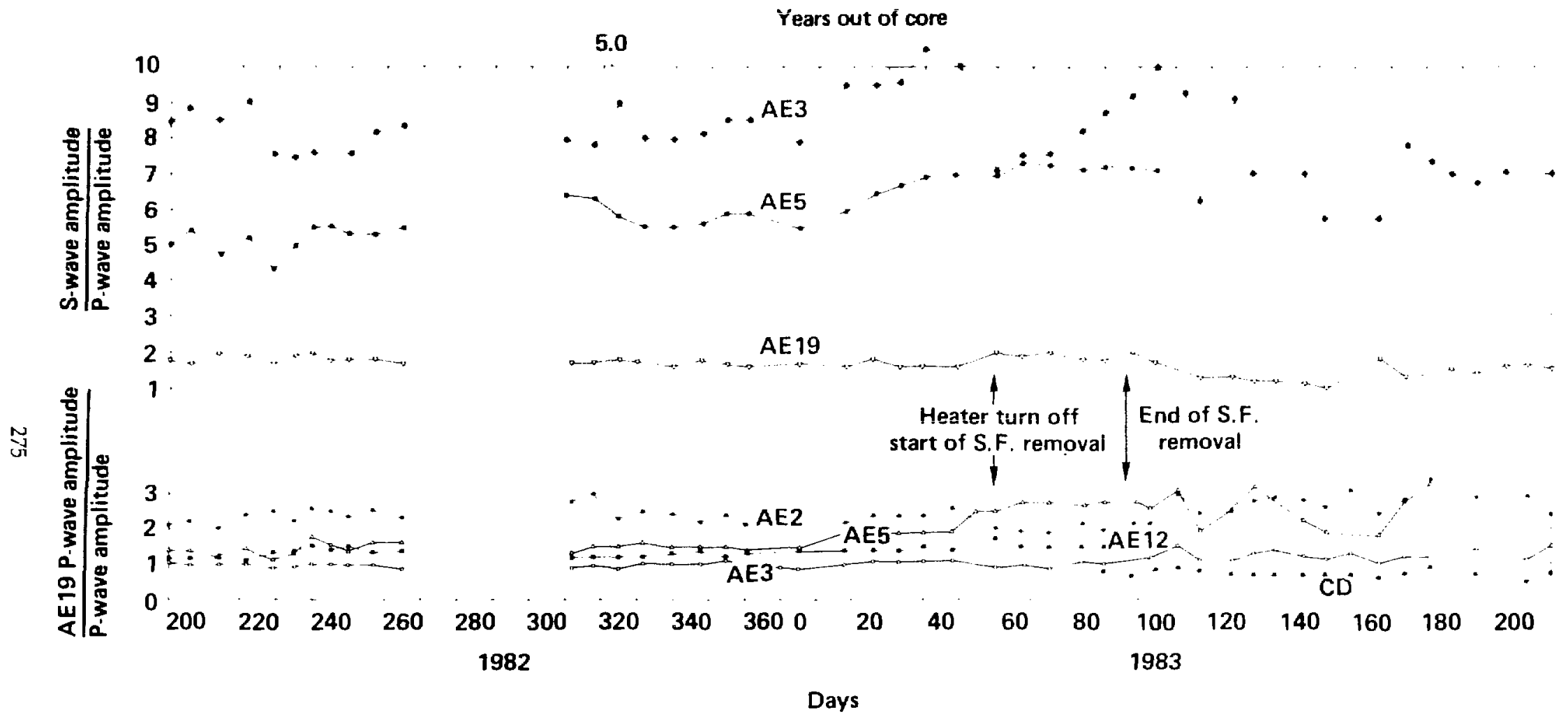

Figure 17-18c. P-wave and S-wave amplitude changes from day 190, 1982, through day 215, 1983 (after Patrick et al., 1984). 


\subsection{Conclusions and Recommendations}

The trequency of AE activity is directly related to change's in energy deposition to the ruck mass. Changes in AE frequency rapidly followed such changes in the rate of energy deposition. Spatial variations in AE activity appear to relate to variations in rock-mass strength and deformation characteristics, although insufficient data exist to conclusively establish this relationship. Previous analyses of the AE data (Patrick et al., 1983) indicate small-scale shear or fracturing on the order of 0.01- to 0.05-mm per event with source dimensions of several centimeters.

Monitoring revealed that no variations in $\Gamma$ - and S-wave velocities occurred at the scale and temperature ranges of the SFT-C. Measurable changes in the S/P amplitude ratios were recorded where path lengths exceeded several meters. These changes are hypothesized to be due to closure of fractures and/or drying of the rock mass at elevated temperatures. Changes in P-wave amplitudes could not be clearly determined, because the reference path could not be located outside the zone of influence of the SFT-C.

If future studies are undertaken, the following are reconmended:

1. Monitor before, during, and after any thermal disturbances.

2. Station spacing be on the order of several meters.

3. If velocity variation is monitored, the resolution be on the order of $1 \mu \mathrm{s}$.

4. Total processing be carried out. [Event count or occurrence rate is not adequate at the scales involved; fault-plane solution and moment tensor analysis related to available stress and displacement measurements are also required. Such analysis was attempted but too few events occurred at the scales involved (tens of meters) to obtain any conclusive results.]

5. Once zones of $A .5$ have been determined, a smaller-scale array be emplaced to collect information for comprehensive data analysis.

6. A larger number of sources be used for controlled velocity and amplitude monitoring, and a reference path be established well outside the zone of influence of the experiment.

In general, we conclude that seismic measurements can provide useful information on the overall stability and integrity of a rock mass subjected to stress changes from excavation activities either alone or in combination with thermal loads. It also appears that the techniques employed at the SFT-C have broad use in monitoring suspected zones of weakness. Application of these techniques for delineating individual small tractures does not appear to be possible nor particularly useful at this time. 


\section{Metallurgical Investigations*}

Metallurgical investigations were conducted to address three areas of concern: water leaking into the interior of a welded emplacement borehole liner, subsequent corrosion of the canister inside the liner, and corrosion of the thermocouple sheaths and connecting rods of borehole extensometers.

\subsection{Analysis of Emplacement Borehole Liner Weld}

Each of the 0.61-m-diameter canister emplacement holes (CEH) was lined with a 0.46-m-diameter 6.4-mm-thick carbon steel liner constructed of tubular pipe sections with a flat $6.4-\mathrm{mm}$-thick plate welded to the bottom. Although the liners were specified to be watertight, temperature measurements on CEH01 indicated that the liner leaked within the first month following spent-fuel emplacement (Fig. 18-1; Patrick et al., 1983). Further monitoring of temperatures indicated that the water was present at least until 3.1 $Y O C$. This conclusion is based on the observation that the canister temperature did not rise above the lical boiling point of water. At 3.1 YOC, the heat output decayed to a level where boiling ceased at the canister surface. The break in trend on the liner temperature curve at this time also indicates that water was being evaporated from the annulus between the liner and canister.

We inspected the CEH01 canister and liner during a scheduled spent-fuel exchange in August 1982 (Chapter 11). Although it appeared undamaged during a remote videotape examination, numerous "high water marks" formed by iron oxide stains were present on the stainless steel canister. The interior of the liner was completely dry despite the presence of water to a height of about $2 \mathrm{~m}$ in the liner/emplacement hole annulus. There was an abundance of iron oxide materials that resulted from partial corrosion of the inside of the liner. No radioactive products were present.

Following retrieval of the spent-fuel assemblies during March and April 1983, all 17 CEH liners were extracted. In the process, the bottom weld on the CEH01 liner broke loose and water from outside the liner once again entered. Inspection of the other liners revealed partially broken welds and, more typically, a fine line of iron oxide on the exterior of the liner at the location of the weld.

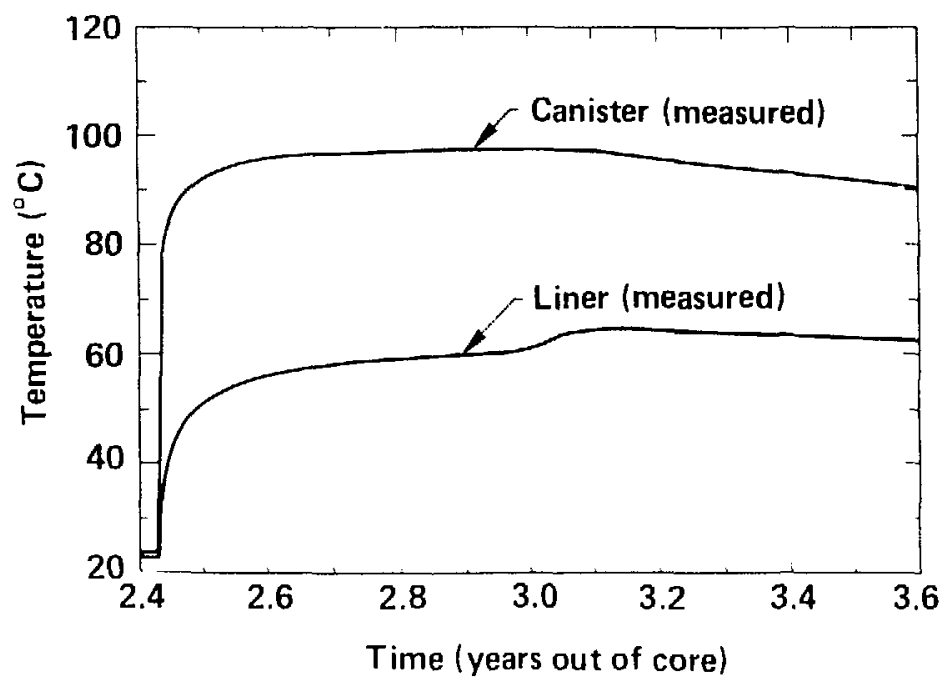

Figure 18-1. Temperature histories of the canister and borehole liner located in CEH01. Note the break in the trends of the curves at about 3.0 YOC which result from water being boiled out of the canister-liner annulus (after Weiss et al., 1985).

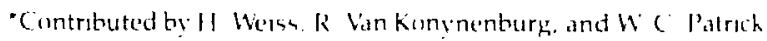


A carbide-tipped saw was used to obtain samples of the CEHOI liner that were returned to L.LNL for analysis of corrosion and weld integrity: The question of corrosion was simple and derect to answer: the corrosion was limited in extent and normal in character. There was no evidence of pitting or crevice attack. The question of weld quality was investigated further to determine the cause of the weld failure and to determine if failure could be avoided in future applications.

The weld specification called for an nondimensioned chamfer and a dye penetrant inspection. This type of test is useful in determining surface cracks, but not weld penetration. In this particular case, there was no reference on the drawing to a required penetration other than filling the chamfer:

Figure 18-2 shows a cross section of a typical section of the CEH01 liner weld. This cross section indicates the lack of penetration: part of the chamfer is still in evidence (note the dotted line). There is a corrosion crack in the weld that was probably generated as a result of the crevice and high stresses (Fig. 18-3). This latter figure shows why the welded parts separated: the crack almost reached the outer surface of the liner. As a result of the narrow crevice created by the shallow weld, selective corrosion of an intergranular and transgranular nature occurred in the joint.

An ultrasonic technique was developed and evaluated to provide $100 \%$ field inspection of welds of this type using a combination of shear-wave angle beam and longitudinal-wave normal incidence search units. Beciause plate thickness may vary as a result of corrosion or metal-forming processes, it was necessary to determine actual plate thickness at each point where lack of penetration (LP) was to be measured. This was done with a normal incidence search unit. Knowing the plate thickness, the $45^{\circ}$ angle-beam search unit was used to find and measure the extent of LP. Accuracy of the LP measurement was a function of three variables: material thickness, refracted angle of the search unit, and length of the sound path of the LP indication. All must be accurately known. Our test geometry provided LP accuracy of \pm 0.010 in.

In conclusion, it appears that the adequacy of the canister-emplacement-hole liner weld could have been ensured by taking three basic steps, which we recommend for future welding in tests and full-scale nuclear waste storage schemes. First, provide proper welding instructions in the drawings. Second, specify testing appropriate to the function the weld must fulfill. Third, inspect $100 \%$ of the parts using the proposed ultrasonic technique when a high level of certainty is required.

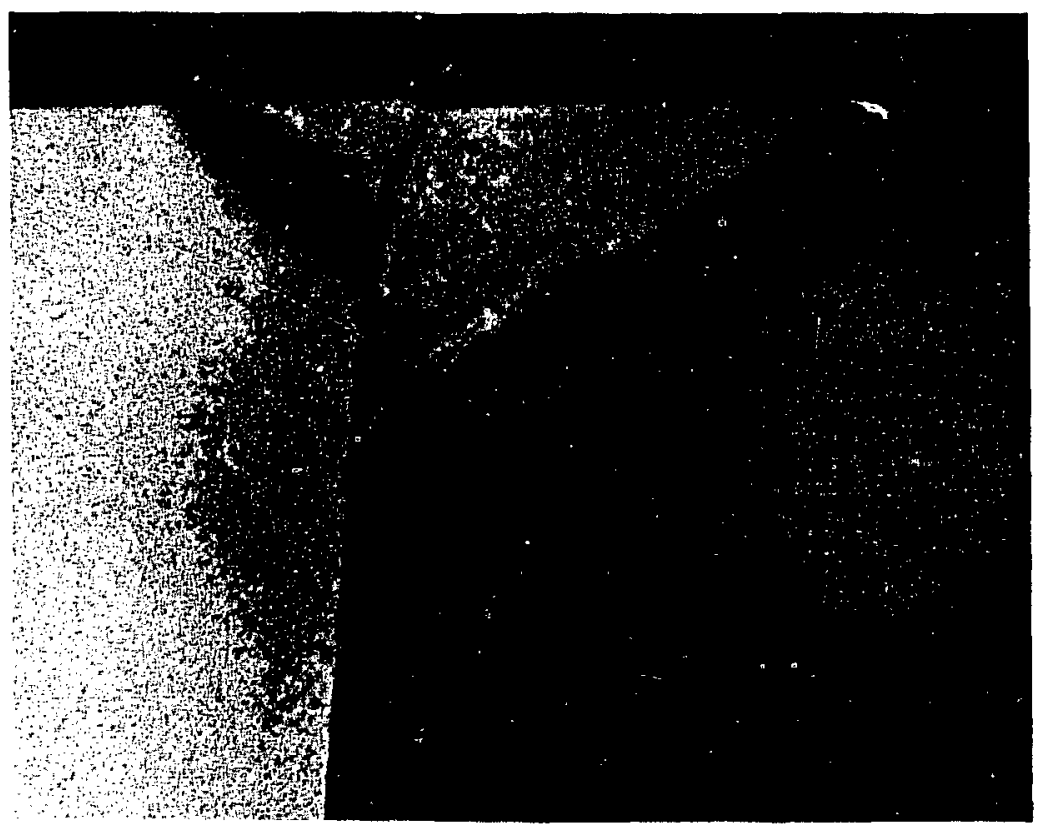

Figure 18-2. Lack of weld penetration and remnant chamfer associated with CEH01 liner weld $(10 \times)$ (after Patrick et al., 1984). 


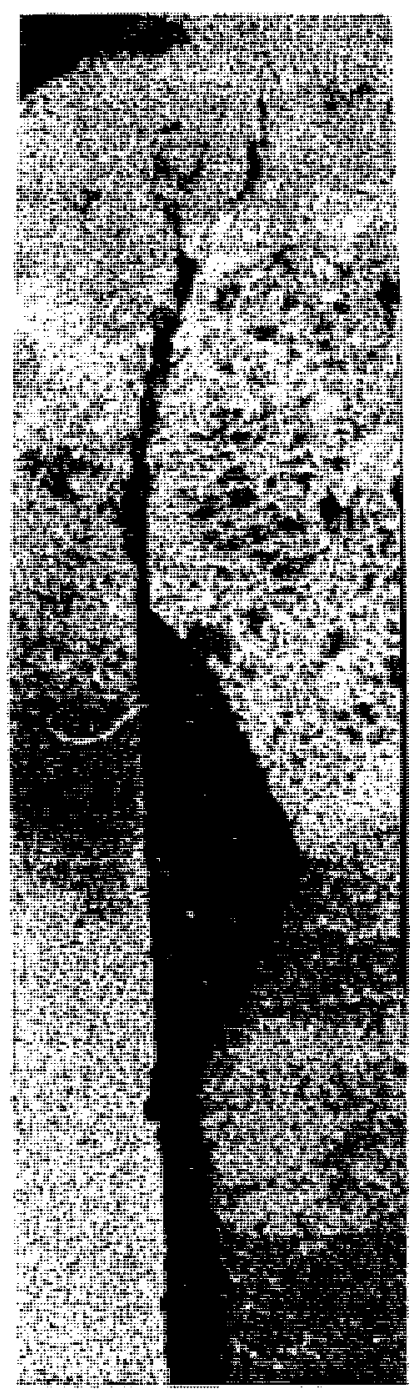

Figure 18-3. Corrosion crack in the crevice of the CEH01 liner weld. Note remnant of chamfer $(33 x)$ (after Patrick et al., 1984).

\subsection{Corrosion of Emplacement Borehole Liners}

After the borehole liners were extracted following retrieval of the spent-fuel assemblies, we found that each of the 11 liners that had contained spent fuel showed significant corrosion in a 3-4-cm-wide band around its outer surface, at the transition between the thicker, top section and the thinner, bottom section (Chapter 7). In sume places, the corrosion was about $5 \mathrm{~mm}$ deep. None of the six liners that had contained electrical heaters exhibited such corrosion. Since the temperature histories and the initial chemical environments of the spent-fuel liners and the heater liners were essentially the same, the corrosion appears to have been related to the gamma irradiation present around the spent-fuel liners.

The most likely explanation appears to be that the gamma irradiation fixed a small fraction of the nitrogen in the liner-rock annulus as $\mathrm{NO}_{2}$ and nitric acid (Jones, 1959), and that these species condensed with water on the coolest accessible surface. As a result of enhanced heat conduction in the thicker section and end effects, the coolest surface was the band where the corrosion was observed. Dilute nitric acid is 


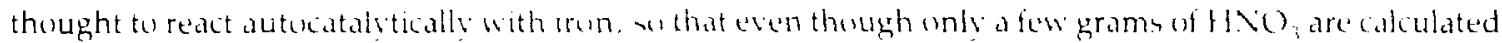

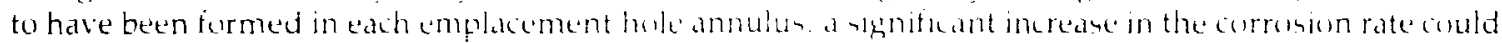
occur(Evans, 1960). We did not perform any experments loverify this hypothesis, but radiation-enhanced corrosion by the nitric acid mechanism has been studied and decumented by whers (Byalubeheskii, 1970 ).

\subsection{Metallurgical Analysis of Spent-Fuel Canister}

After the spent fuet was retrieved trum the SFT-C. the canister hocated in (EFtol idescribed abuse) was cut open, the fuel assembly remored, and the canister decontaminated and sectioned for metallurgical analyses. These andyses were repurted by Moish. Van Kunynenburg, and MeCright (1985) and are summarized here.

The main hody of the $304 \mathrm{~L}$ stainless steel canister was constructed from a $3.42-\mathrm{m}-\mathrm{long}$ standard $356-$ mm-outside diameter, $9.52-\mathrm{mm}$ wall pipe secton (Chapter 7 ). An ellipsoidal end cap of the same material, a 230-mm-long upper section of 356-mm-outside diameter, 23.8 - $\mathrm{mm}$ wall 304L pipe section, and a threaded top closure completed the canister.

The temperature history of the canister was an noted in Fig. 18 - 1 . At the canister midsection, the

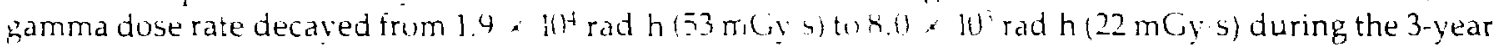
storage period (Van Konynenburg, 1984).

After retrieval and removal of the spent-fuel assembly, the canister was cut intu seven cylindrical sections and the bottom dome section, which were steam cleaned to remove contamination and shipped to LLNL for evaluation. The longitudinal autogenous welds were found to be sound with no fissures, but penetration through the pipe wall was incomplete. The "high-water marks" observed during the August 1982 inspection were not visible, possibly because they were removed by the steam cleaning process. In addition, a suspected "corrosion pit" was examined. Under magnification, this feature was determined to be an arc strike mark, and no evidence of pitting or intergranular corrosion was observed.

We conclude that the $304 \mathrm{~L}$ stainless stee $l$ canisters provided excellent performance during the threevear storage phase of the SFI-C, even when the emplacement borehole liner allowed boiling groundwater to cume in contact with a canister.

\subsection{Corrosion of Instrument Components}

\subsubsection{Analysis of Extensometer Connecting-Rod Failures}

The 6.35 -mm-diameter connecting rods assuciated with the borehole extensometers located in the canister drift of the SFT-C began to experience failures shortly before spent-fuel retrieval uperatiuns began. By the end of the data acquisition period, six rods had failed. Another failed after completion of the SFT-C, and three more fractured during post-test evaluations (Chapter 9, and Patrick, Rector, and Scarafiotti, 1984).

Metallographic sections of the failure surfaces revealed classic stress-corrosion cracking to be the mechanism of failure in this $31.5 \% \mathrm{Ni}, 5 \% \mathrm{Co}$, iron alloy (Superinvar). The environment to which the rods were subjected was relatively benign: temperatures fairly uniform in the range of 45 to $55 \mathrm{C}$, low tensile stresses, sealed (at least at installation) from ground water, and test duration of about 3 years. The presence of a small amount of calcium carbonate in the root of the corrosion cracks led us to believe that the sealing had failed at some time during the test, allowing ground water to contact the rods and possibly causing galvanic coupling with the copper hydraulic anchorage system and zinc-plated hardware present on the outside of the extensometer.

We attempted to reproduce in the laboratory the type of failure observed in the field instrumentation in an effort to determine the conditions that contributed to the failures. We conducted two series of uxperiments using virgin Superinvar ubtained from the same lot as was used in the field instrumentation. A variety of couplings and specimen surface preparations were evaluated, as described below, but all specimens had in common exposure to Climax ground water and temperatures of $50 \mathrm{C}$

In the first series of experiments, single Superinvar specimens turned to a reduced diameter of $0.76 \mathrm{~mm}$ were dead-weight-loaded to attain stresses of $90 \%$ of tensile yield strength. Five cells were set up 
for this sere's. Call 1 combaned only Superinvar: cell 2, Superinvar coupled to copper; cell 3, Superinvar coupled to 1120 steel; cell 4 , Superinvar coupled to anc-costed 1020 sted; cell 5, Superinvar coupled to copper, steel, and zinc.

The specimen in cell 2 (coupling with copper) failed after $550 \mathrm{~h}$ of exposure. Fractography of the failed surface indicated that corrosion did influence the failure, but that the fracture was mostly ductile and not like the fractured surfaces trom the extensometer ruds that failed in the field. This test was repeated with notailure noted.

A second test apecimen failed after $2000 \mathrm{~h}$. This unit had both copper and carbon stecl segments attached to the test trame. The surtace morphology of this specimen was one of stress corrosion cracking and ductile failure of the reduced cross section. Intergranular and transgranular fractures dominated the morphology, with evidence of ductile deformation present in the form of "dimples." The surface morphology of the specimens that failed in the field was primarily transgranular, that is, flat and across the grains. Thus, the failure mechanism was somewhat different in the laboratory test, making extrapolation to the field tenuous. However, if one extrapolates from the observed corrosion rate of 0.30 to $0.56 \mathrm{~mm}$ per year, then the'se data are consistent, in terms of time to failure, with tailures observed in the field.

In the second se ries of experiments, the Superinvar specimens were loaded in proving ring assemblies to a il ress calculated to be $50 \%$ of tensile vield strength. The proving ring its. If was covered with an impermeable silicone cuating and the assemblies were placed in cells containing Climax ground water at $50^{\circ} \mathrm{C}$. Three cells were set up for this experimental series. Cell 1 contained three proving rings with rods having a treshly machined Superinvar surface and three proving rings of the as-exposed (scaled and oxidized) Superinvar. Three specimens each were used for replication of results. Cell 2 contained three proving rings with rods having as-exposed Superinvar surfaces galvanically coupled to copper. Cell 3 contained three proving rings with rods having as-exposed Superinvar surfaces coupled to zinc-coated steel.

When no failures had occurred after several thousand hours of testing these full 6.35 -mm-diameter specimens, the ground water in the test cells was made more hostile by adding $94 \mathrm{~g} / \mathrm{L} \mathrm{CuCl}{ }_{2}-2 \mathrm{H}_{2} \mathrm{O}$. Corrosion progressed very rapidly and two failures uccurred and were analyzed. Corrosion and oxidation of the fracture surfaces were very severe. After cleaning, the fracture surfaces were examined by both optical and scanning electron microscopes.

Figures 18-4 and 18-5 are photomicrographs of the first rod that failed in the field application, and Figs. 18-6 and $18-7$ are photomicrographs of the lahoratory-tested specimen in ground water plus $\mathrm{CuCl}_{2}$ $2 \mathrm{H}_{2} \mathrm{O}$. Although, the latter is much more severely attacked, both SEM photographs show a similar combination of intergranular- and transgranular-type fracture. The photomicrographs also show the combination of both types of stress corrosion cracking. However, the more severely attacked laboratory specimen shows some pitting along the fracture path, which is related to the presence of chloride ion. The laboratory specimen shows no evidence of a ductile failure. Its fracture surface is similar in morphology to that of the tield failure sample.

Understanding that there are some caveats, it is interesting to compare our failure with the wellknown breaking-time curve for nickel alloys (Fig. 18-8; Copson, 1959). This suggests that a Fe-Ni-Cr alloy under a very hostile environment would be very sensitive to stress corrosion cracking. Our particular material does not have the chromium to form a passive layer, which certainly would have some effect on the time-to-failure. The point to be made is that, in a chloride environment with applied stress, Superinvar is not a good choice of material for corrosion resistance. In our particular application, we selected Superinvar based on thernal expansion rather than corrosion characteristics. Inadvertant leakage through seals apparently allowed the entrance of ground water with its associated minerals, leading to the eventual failure of the rind. Clearly, exclusion of ground water from the extensumeter could have prevented the observed bailures.

\subsubsection{Thermocouple Sheathing Corrosion}

Nearly $=00$ Typo K thermocouples were deployed to monitor temperatures throughout the lest array. All were specified to be sheathed in Inconel fol) with $\mathrm{Mg(})$ electrical insulation.

Although no thermocouple failures occurred during the data acquisition period, four sheaths were found to be corroded during post-test calibration activities (Fig. 18-9). All four were located in spent-fuel storage bureholes: three on the outer surface of a liner up to the time corrosion was noted and one on a liner followed by subsequent redeployment in the empty borehole to nonitor another instrument. In these positions, temperature's ranged from $8(1)$ to 100$)\left(C\right.$ and total gamma dose was cestimated at $2 \times 10^{k}$ rad during 
the 3-year storage period. The fourth thermocouple experienced a subsequent 6-month exposure to temperatures, declining from 60 to $30 \mathrm{C}$.

Metallurgical analyses of the sheaths revealed that while two were Inconel 600 , as specified, the other two were 304-series stainless steel. We speculate that the latter two units were erroneously sheathed at the time of manufacturing. The extent to which incorrect sheathing was used for the nearly 500 thermocouples is unknown since it was not confirmed by subsequent sampling, a process deemed unnecessary because none of the remaining thermocouples exhibited corrosion or any other problem at the time of post-test calibration.

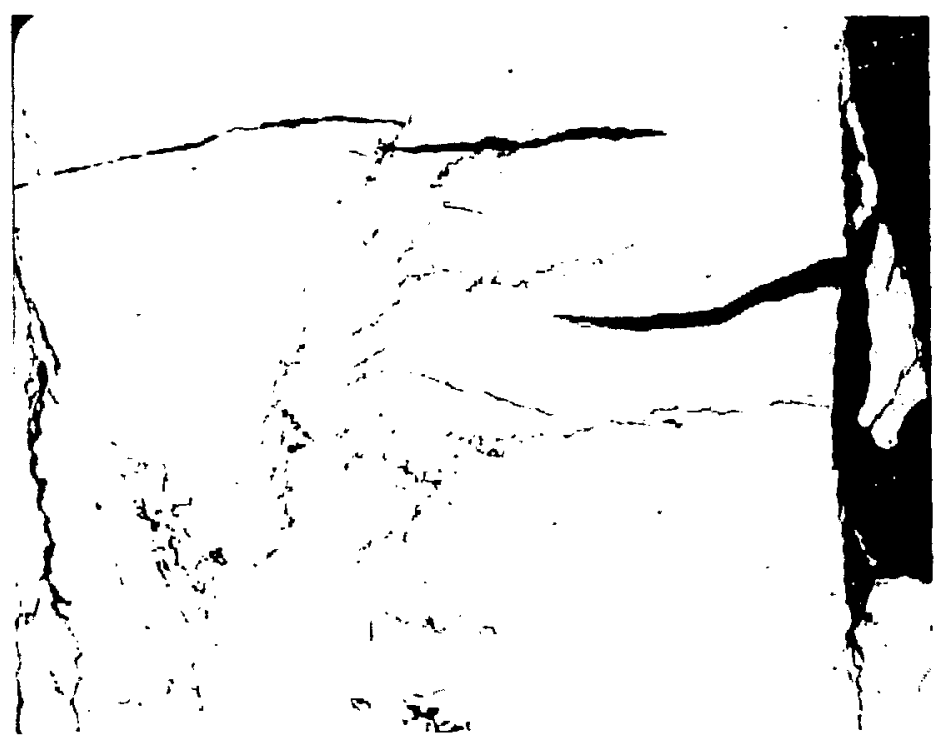

Figure 18-4. Fracture developed in a Supe rinvar extensometer rod which failed in service $(40 \times)$ (after Patrick et al., 1984).

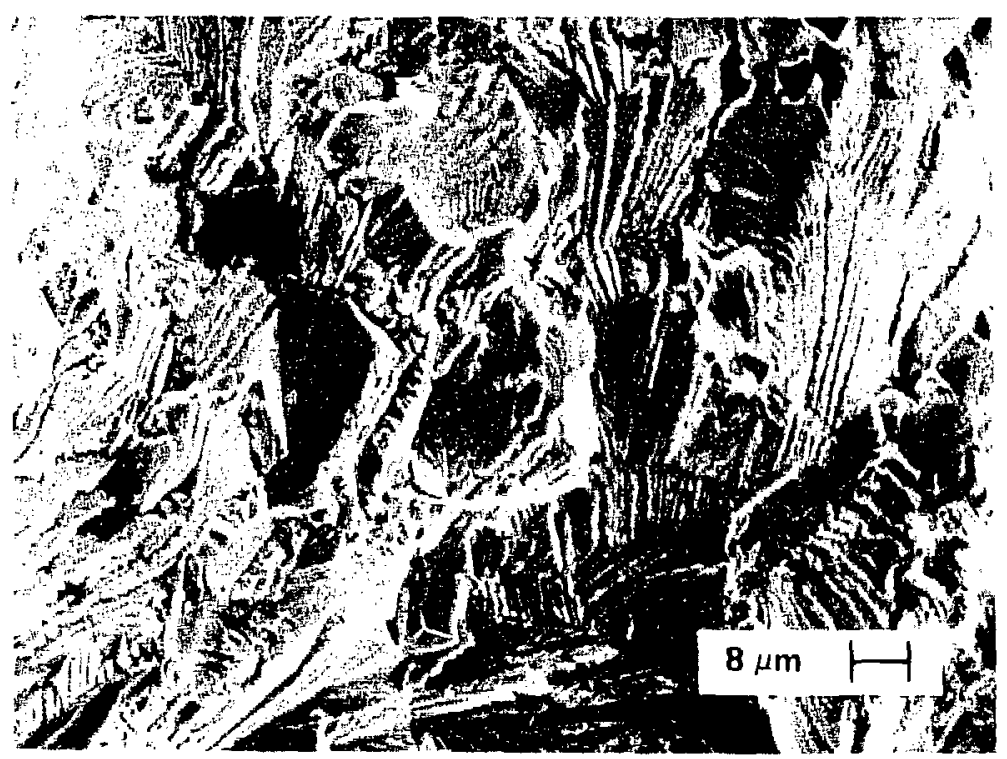

Figure 18-5. Micrograph of stress corrosion cracking in a Superinvar extensometer rod which failed in service (:000 X) (after Patrick et al., 1984). 


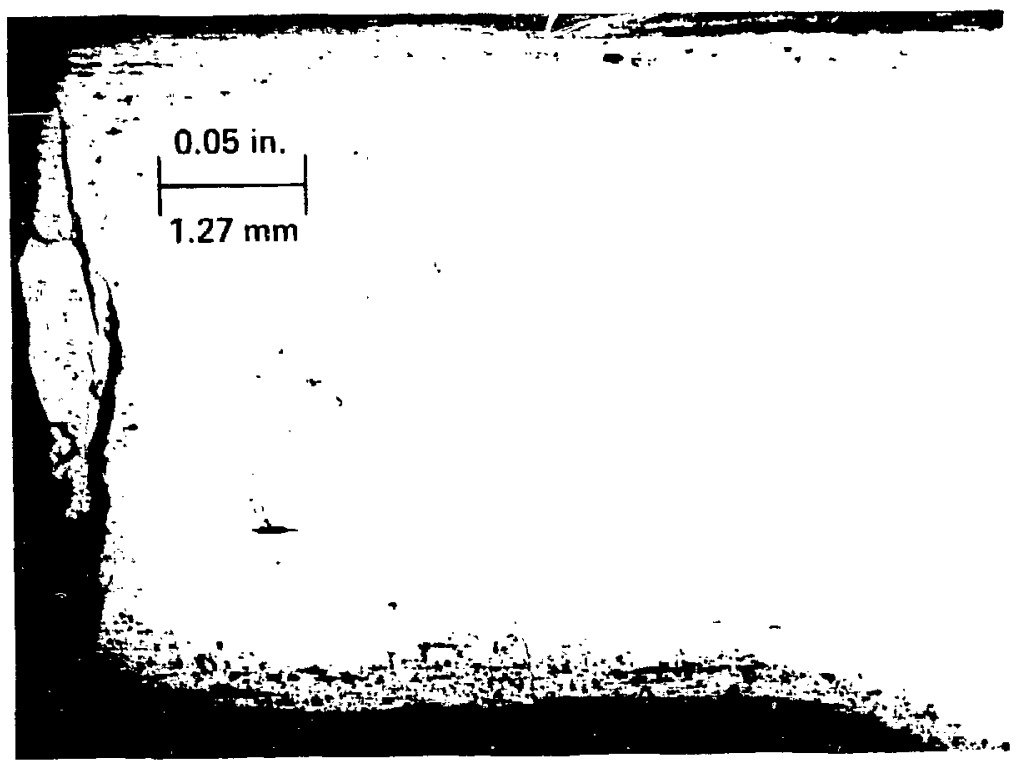

Figure 18-6. Fracture development in a Superinvar rod which failed during testing $(21 \times)$ (after Patrick et al., 1984).

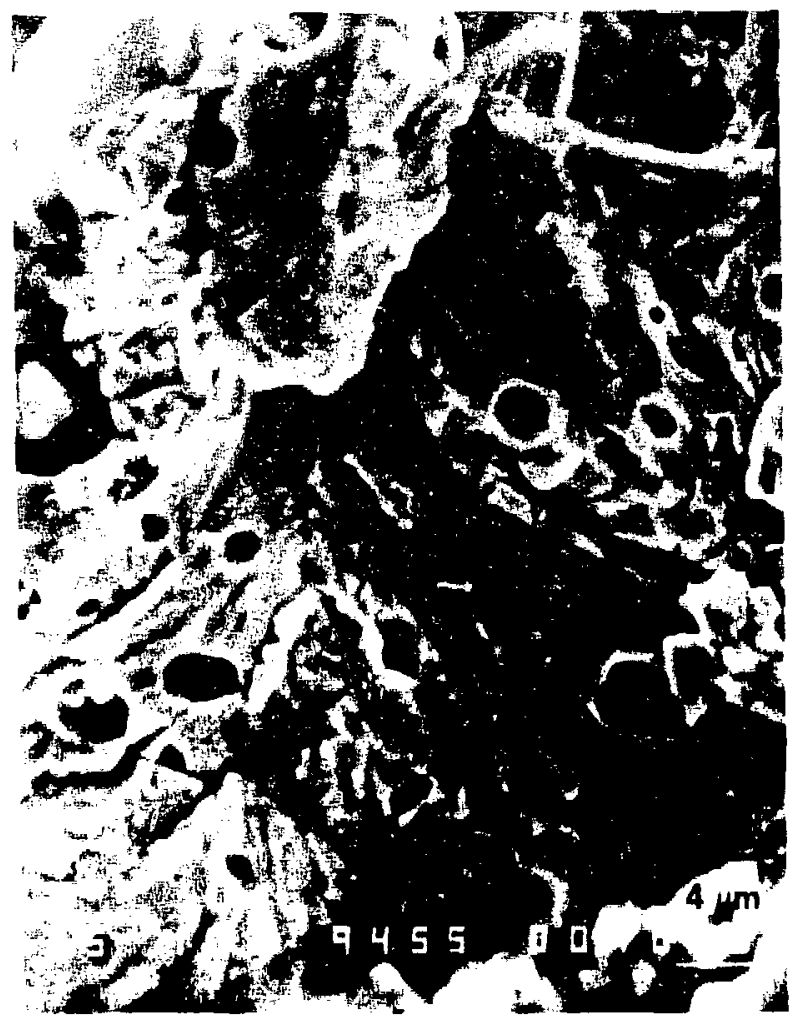

Figure 18-7. Micrograph of fracture surface of Superinvar rod which failed during testing $(1000 \times)$ (after Patrick et al., 1984). 


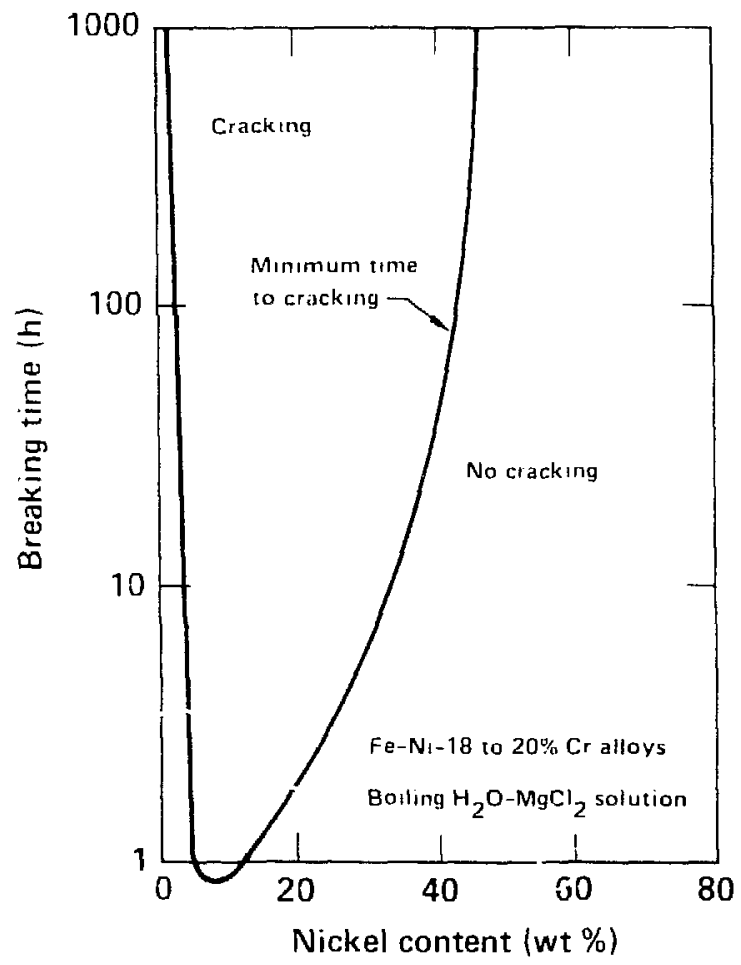

Figure 18-8. Relationship between breaking time and nickel content (after Copson, 1959).

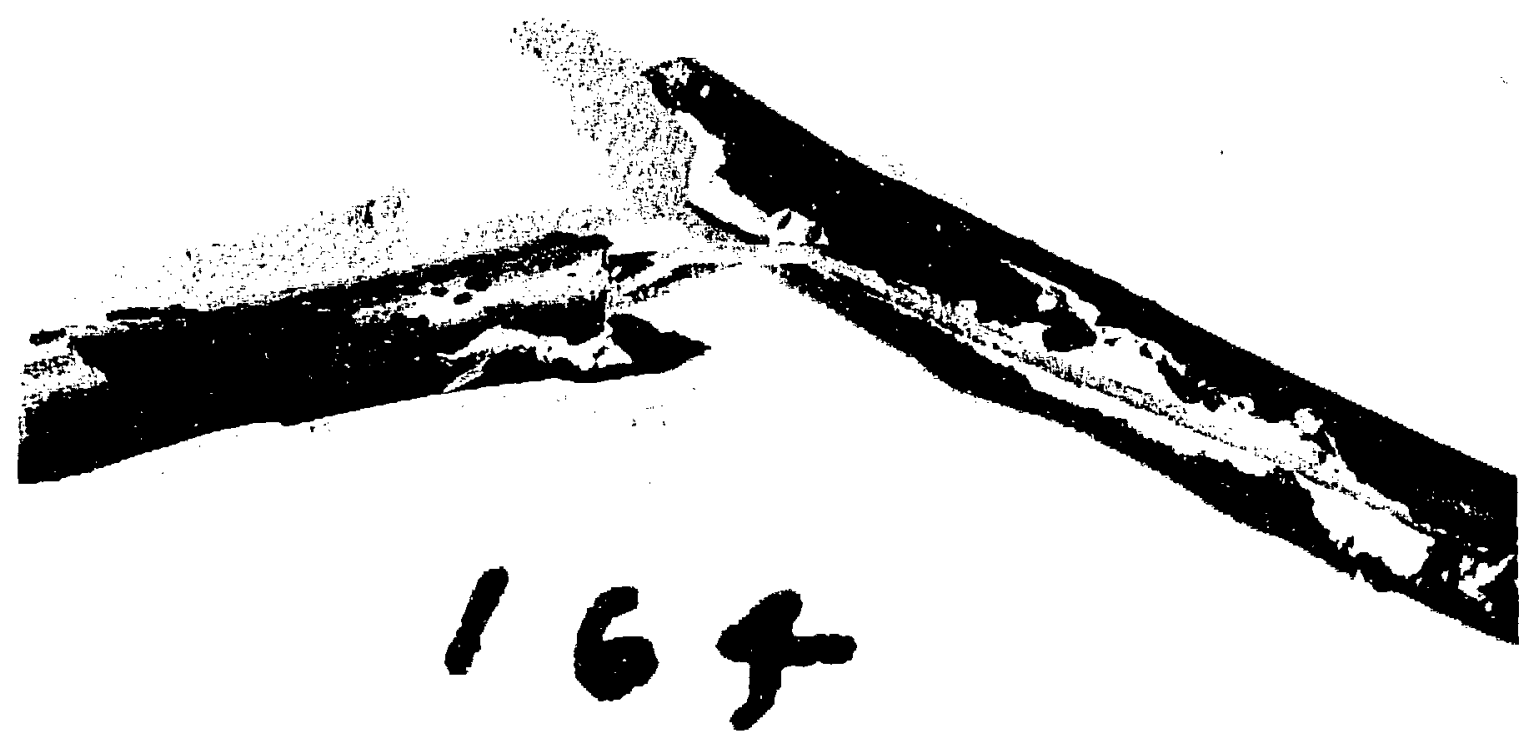

Figure 18-9. Corroded stainless steel thermocouple sheath shnwing exposed thermocouple wires and magnesium oxide insulation. 


\section{References}

Abey, A. E., and J. R. Washington (1980), Stressmet.r Placement at Spent Fuel Test in Climax Granite, Lawrence Livermore National Laboratory, Livermore, CA, UCID-18629.

Allingham, J. W., and I. Zietz (1962), "Geophysical Data on the Climax Stock, Nevada Test Site, Nye County. Nevada," Geophysics 27, 599-610.

Anony mous (1978), Safety. Assessment Document for the Spent Fuel Handling and Packaging Program Demonstration at the Nerada Test Site, U.S. Department of Energy Report, NVO-198.

Anonymous (1980), Safety Assessment Document for the Spent Reactor Fuel Geologic Storage Test in the Climax Granite Stock at the Nerada Test Site', U.S. Department of Energy Report NVO-210.

Ballou, L. B., W. C. Patrick, D. N. Montan, and T. R. Butkovich (1982), Test Completion Plan for Spent Fuel Test-Climax, Netada Test Site, Law'rence Livermore National Laboratory, Livermore, CA, UCRL-53367.

Ballou, L. B. (1984), "Handling Encapsulated Spent Fuel in a Geologic Repository Environment," Radioactive Waste Management 3, 462-472, IAEA-CN-43/223, International Atomic Énergy Agency, Vienna; also in Lawrence Livermore National Laboratory, Livermore, CA, UCRL-87872.

Barnes, H., and F. G. Poole (1968), "Regional Thrust-Fault Svstem in Nevada Test Site and Vicinity," GSA Memoir 110, pp. 233-238.

Bathe, K. J. (1977), ADINAT, A Finite Elcment Progran for Automatic Dynamic Incremental Nonlinear Analysis of Temperature, Massachusetts Institute of Technology, Cambridge, MA, Report No. 82448-5.

Bathe, K. J. (1978), ADINA, A Finite Element Program for Automatic Dyanmic Incremental Nonlinear Analysis, Massachusetts Institute of Technology, Cambridge, MA, Report No. 82448-1.

Beiriger, J. M., and W. B. Durham (1984), SEM Studies of Stressed and Irradiated Climax Stock Quartz Monzonite, Lawrence Livermore National Laboratory, Livermore, CA, UCID-20052.

Beiriger, J. M., W. B. Durham, F. J. Ryerson (1985), Physical and Chemical Changes to Rock Near Electrically Heated Boreholes at Spent Fuel Test-Climax, Lawrence Livermore National Laboratory, Livermore, CA, UCID-20412.

Bensky, M. S., W. J. Kurzeka, A. A. Bauer, J. A. Carr, and S. C. Matthews (1979), Spent Fuel Storage and Isolation, in Waste Management 80.

Borg, I. Y., R. Stone, H. B. Levy, and L. D. Ramspott (1976), Information Pertinent to the Migration of Radionuclides in Ground Water at the Nevada Test Site, Lawrence Livermore National Laboratory, Livermore, CA, UCRL-52078.

Brough, W., and W. Patrick (1982), Instrumentation Report \#1: Specification, Design, Calibration, and Installation of Instrumentation for an Experimental, High Level, Nuclear Waste Storage Facility, Lawrence Livermore National Laboratory, Livermore, CA, UCRL-53248.

Butkovich, T. R., and D. N. Montan (1980), A Method for Calculating Intemal Radiation and Ventilation with the ADINAT Heat-Flow Code, Lawrence Livermore National Laboratory, Livermore, CA, UCRL-52918.

Butkovich, T. R. (1981a), As-Built Mechanical and Thermomechanical Calculations of a Spent Fuel Test in Climax Stock Granite, Lawrence Livermore National Laboratory, Livermore, CA, UCRL-53198.

Butkovich, T. R. (1981b), Mechanical and Thermomechanical Calculations Related to the Storage of Spent Nuclear Fuel Assemblies in Granite, Lawrence Livermore National Laboratory, Livermore, CA, UCRL-52985 Rev. 1.

Butkovich, T. (1982), The Effects of Boundary Conditions on Thennumechanical Calculations: Spent Fuel TestClimax, Law'rence Livermore National Laboratory, Livermore, CA, UCRL-53338.

Butkovich, T. R. and W. C. Patrick (1985), Post-Test Thermomechanical Calculations and Preliminary Data Analyses for the Spent Fucl Test-Climax, Lawrence Livermore National Laboratory, Livermore. CA. UCRL53688

Butkovich, 1. R. (1985), Spent Fuel Test-Climax - Minety Rezisited, Lawrence Livermore National Laboratory, Livermore, CA, UCID-20673.

Byalobzheskii, A. V. (1970), Radiation Corrosion, Israel Program for Scientific Translations, Jerusalem.

Campbell, K. W. (1980). Setsmic Hazarit Analysis for the NTS Spent Reactor Fuel Test Site, Law'tence Livermore National Laboratory; Livermore, CA, Contractor Report UCRL-15260.

Carison, R. C., W. C. Patrick, D. G. Wilder. W. Brough, D. N. Montan, P. Harben L. B. Ballou, and H. C. Heard (1980), Spent Fuel Test-Climax: Technical Measurements Interim Report, Fiscal Year 1980 , Lawrence Livermore ivational Laboratory, Livermore, CA, UCRL-53064. 
Carlson, R. C. (1985). Spent Fidel Tint-Cimax: Tromial Measuriments Data Management System Description and Datil P'resutation, Lawence Livermore National Laboratory, Livermore, CA, UCID-20712.

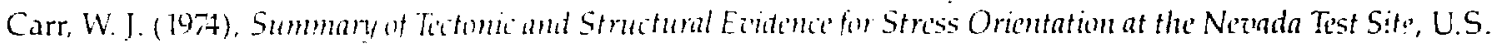
Geological Survey Open File Report 74-176.

Connolly, j. A. (1981), Otserationson the Geolegy of the Climax Stack Grante about the Spent inel Test Site, Area 15. NTS, Neidat Law rence Livermore National Laboratoy, Livermore, CA, unpublished report.

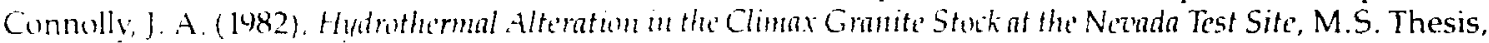
Arizona State Lniversity, Tempe. AZ.

Copson, H. R. (1459), Phusical Metallhurgy of Stros Comosion Fracture (Interscience, New York), p. 247.

Cook, N. C. W. (1983), "Questions in Experimental Rock Mechanics," 2.3ril U.S. Symposium on Rock Mcchanics, Berkelev, CA, Iune 1982

Creveling, I. B., F. S. Shuri, K. M. Foster, and S. V. Mills (1984), In Situ Stris Measurements at the Spent Fiel Test-Climax Facility, Lawrence Livermore National Laboratory, Livermore, CA, Contractor Report LCRL-15628.

Cruss, L. A. (1980), "Comparing Nuclear Power Plaat Exposure Histories," Proceddings of the hnternational

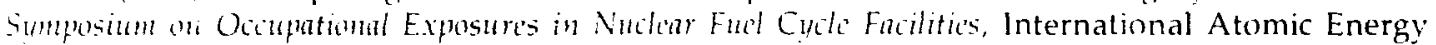
Igency, Vienna, Austria, IAEA-SM-242:29.

Davis, R. B. (1980), Pretest Nontestructive Examination Data Summary Report on Turkey Point Spent Fuel Assemblies D01, D04, and D06 for the Climax-Spent Fwel Test. Hanford Engineering Development Laboratory, Richland, WA, HEDL-TME 80-83.

DuBois, A. O., M. Hood, E. P. Binall, and L. Anderson (1981), Extensometer Performance During Heater Experime'nts at Stripa, Lawrence Berkeley National Laboratory, Berkeley, CA, LBL-13531.

Durham, W. B., and A. E. Abey (1981), "The Effect of Pressure and Temperature on the Thermal Properties of a Salt and a Quartz Monzonite," Proceedings of the 22nd U.S. Symipositum on Rock Mechanics, Cambridge, MA, June 29-July 2, 1981, pp. 79-84; also in Lawrence Livermore National Laboratory, Livermore, CA, UCRL-85285.

Durham, W. B., and A. E. Abey (1983), "Thermal Conductivity and Diffusivity of Climax Stock Quartz Monzonite at High Pressure and Temperature," Thermal Conductivity 17, Proceedings of the 17th lntematimal Thermal Conductivity Comference, Gaithersburg, MD, June 15-19, 1981, pp. 459-468; also Lawrence Livermore National Laboratory, Livermore, CA, UCRL-86619.

Dutham, W. B., and A. E. Abey (1981), Thermal Properties of Rock Salt and Quartz Monzonite to 573 K and 50 MPa Comfining Pressure, Lawrence Livermore National Laboratory, Livermore, CA, UCRL-85191.

Durham, W. B. (1982), Thermal Properties of Climax Stock Quartz Monzonite to $523 \mathrm{~K}$ and 50-MPa Confining Pressure, Lawrer :e Livermore National Laboratory, Livermore, CA, UCRL-53349.

Durham, W. B ' Beiriger, and H. C. Weed (1984), "A Rapid Technique for Counting Cracks in Granitic Rocks," Se is Electron Microscopy I-1985, 133-142; also in Lawrence Livermore National Laboratory, Liverrore, CA, UCRL-90257.

Durham, W. B., J. M. Beiriger, M. Axelrod, and S. Trettenero (1986), "The Effect of Gamma Irradiation on the Strength and Elasticity of Climax Stock ar "Westerly Granites," Nutl. and Chem. Waste Manage. 6, pp. 159-168.

Dutta, P., R. Hatfield, and P. Runstadler, Jr. (1981), Calibration Characteristics of IRAD Gage Vibrating Wire Stressmeter at Normal and High Temperature, Lawrence Livermore National Laboratory, Livermore, CA, Contractor Report UCRL-15426.

Edwards. A. L. (1972), A Computer Program for Transient and Steady State Temperature Distribution in Multidimensional Systems, Lawrence Livermore National Laboratory, Livermore, CA, UCRL-14754, Rev. 3.

Ekren, E. B. (1968), "Geologic Setting of Nevada Test Site and Nellis Air Force Range," GSA Memoir 110, PP. $11-19$.

Ellis, W. L., and I. E. Magner (1982), Deternination of the in Situ State of Stress at the Spent Fucl Test Climax Site. Climax Stock, Nerada Test Site, U.S. Geological Survey Open File Report 82-458.

Evans, U. R. (1960), "The Corrosion and Oxidation of Metals," F.dward Amold, London, p. 328

Ganow, H. C. (1985), Negatize Hysteresis Effect Observed During Calitration of the U.S. Burean of Mine's Borthole Defonnation" Gauge, Lawrence Livermore National Laboratory, Livermore, CA, UCID-20523.

Gladwin, M. 1. (1982), "Ultrasonic Stress Monitoring in Underground Mining," Intern. I. of Rock Mech. Min. sei. EGeomech., (abstr.), 19, 221-228. 
Hage, G. L. (1983), BREAD, a CDC 7600 Program That Processes Spent Fuel Test-Climax Data, Lawrence Livermore National Laboratory, Livermore, CA, UCID-19814.

Hage, G. L. (1984), A User's Guide to REVERT: A CDC 7600 Program for Converting SFT_C Data to Engineering Units, with Corrections, Lawrence Livermore National Laboratory, Livermore, CA, UCID-30206.

Heard, H. C. (1980). Thennal Expansion and Inferret Permeability of Climax Quartz Monzonite to 300 K and 27.6 $M P a$, Lawrence Livermore National Laboratory, Livermore CA, UCRL-83697.

Heuze, F. E., T. R. Butkovich, and J. C. Peterson (1981), An Analysis of the 'Mine-by' Experiment, Climax Granite, Nevada Test Site, Lawrence Livermore National Laboratory, Livermore, CA, UCRL-53133.

Heuze, F. E., W. C. Patrick, R. V. De la Cruz, and C. F. Voss (1981), In Situ Geomechanics, Climax Granite, Nevada Test Site, Lawrence Livermore National Laboratory, Livermore, CA, UCRL-53076.

Heuze, F. E., and B. Amadei (1984), The NX Borehole lack: A Lesson in Trial-and-Errors, Lawrence Livermore National Laboratory, Livermore, CA, UCRL-90282.

Houser, F. N., and F. G. Poole (1960), "Preliminary Geologic Map of the Climax Stock and Vicinity, Nye County, Nevada," U.S.G.S. Miscellaneous Geologic Investigations, Map 1-328, Washington, DC.

Houser, F. N., and F. G. Poole (1961), "Age Relations of the Climax Composite Stock, Nevada Test Site, Nye County, Nevada," Short Papers in the Geologic and Hydrologic Sciences, USGS Professional Paper 424-B, PP. B176-177.

Isherwood, D., J. Harro.r, and E. Raber (1982), Characterization of Climax Granite Ground Water, Lawrence Livermore National Laboratory, Livermore, CA, UCRL-53309.

Jones, A. R. (1959), "Radiation-Induced Reactions in the $\mathrm{N}_{2}-\mathrm{O}_{2}-\mathrm{H}_{2} \mathrm{O}$ System," Radiation Research 10, p. 655.

Kibbe, R. K., and A. L. Boch (1978), Technical Support for GEIS: Radioactive Waste Isolation in Geologic Fonnations, Vol. 1, Office of Waste Isolation, Oak Ridge, TN, Y/OWI/TM-36/1.

Knauss, K. G. (1981), Dating Fult Associated Quaternary Material From the Nevada Test Site Using UraniumSeries Methods, Lawrence Livermore National Laboratory, Livermore, CA, UCRL-53231.

LaPointe, P. R., and J. A. Hudson (1981), Characterization and Interpretation of Rock Mass Jointing Patterns, University of Wisconsin, Madison, WI.

Lederer, C. M., and V. S. Shirley, Eds. (1978), Table of Isotopes, Seventh Edition (John Wiley and Sons, New York, NY).

Majer, E. L., T. V. McEvilly (1979), "Seismological lnvestigations at the Geysers Geothermal Field," Geophysics, 44, 246-269.

Majer, E. L., T. V. McEvilly, and M. S. King (1981), "Monitoring an Underground Repository with modern Seismological Methods," Inter. J. of Rock Mech. and Mining Sciences 18, 517-527.

Majer, E., T. McEvilly (1984), Acoustic Emission and Wave Propagation Monitoringat the Spent Fuel Test-Climax, Lawrence Berkeley Laboratory, Berkeley, CA, LBL-17546.

Majer, E. L., i. S. King, and T. V. McEvilly (1982), Monitoring Acoustic Emissions and Wave Propagation Characteristics at the Climax Stock, in Proceedings of the Third Conference on Acoustic Emission/ Microseismic Activity in Geologic Structures and Material Transtech Publications, ClausthalZellerbach, Clausthal, W. Germany.

Maldonado, F. (1977), Summary of Geology and Physical Properties of the Climax Stock Nevada Test Site, U.S. Geological Survey Open File Report 77-356.

Maldonado, F. (1981), "Geology of the Twinridge Pluton Area, Nevada Test Site, Nevada," U.S.G.S. OpenFile Report 81-156, Washington, DC.

Mao, N. (1984), Overcoring and Calibration of IRAD Gage Stressmeters at Spent Fuel Test in Climax Granite, Lawrence Livermore National Laboratory, Livermore, CA, UCID-20318.

Montan, D., and W. Patrick (1981), Thermal Calculations for the Design, Construction, Operation, and Evaluation of the Spent Fuel Test-Climax, Nevada Test Site, Lawrence Livermore National Laboratory, Livermore, CA, UCRL-53238.

Montan, D. N., and W. E. Bradkin (1984), Heater Test 1, Climax Stock Granite, Nevada, Lawrence Livermore National Laboratory, Livermore, CA, UCRL-53496.

Montan, D. N., and W. C. Patrick (1986), Post-Test Thermal Calculations and Data Analyses for the Spent Fuel Test-Climax, Lawrence Livermore National Laboratory, Livermore, CA, UCRL-53728.

Murray, W. A. (1981), Geohydrology of the Climax Stock Granite and the Surrounding Rock Formations, Nevada Test Site, Lawrence Livermore National Laboratory, Livermore, CA, UCRL-53138.

Nyholm, R. A., W. G. Brough, and N. L. Rector (1982), Spent Fuel Test-Climax Data Acquisition System Integration Report, Lawrence Livermore National Laboratory, Livermore, CA, UCRL-53304. 
Nyholm, R. A. (1983), Spent Fuel Test-CImax Data Achuisition System Opurations Nianual, Lawrence Livermore National Laboratory. Livemore. CA. LCID-19834.

Orkild, P. P. (1983), "Summary of Geologic and Geophysical lnvestigations," Geologic and Geophysial iniestigatums of Climax Stoch Intmisie', Li.S. Cienlogical Survey, Nevada, Open File Report 83-377.

Page, L. E., and H. C. Heard (1981). "Elastic Moduli. Thermal Expansion and Inferred Permeability of Climax Quartz Monzonite and Sudbury Gabbro to $500 \mathrm{C}$ and $55 \mathrm{MPa}$," Procedings of 22nt U.5. Symposium on Rock Mechanics. MT, Cambridge, MA, June 29-July 2, 1981, pp. 47-104; also in Lawrence Livermore National Laboratory, Livermore, CA, UCRL-85736.

Patrick, W. R. Carlson, and N. Rector (1981), Instrumentution Report $\# 2$ : Itentification, Evaluation, and Remedial Actions Related to Transducer Failures at the Shnt Fud Test-Climnx, Lawrence Livermore National Laboratory, Livermore, CA, UCRL-53251.

Patrick, W. C., and M. C. Mayr (1981), Excatation and Drilling Activitiesat a Sphent Fuel Test Facility in Granitic Rock, Lawrence Livermore National Laboratory; Livermore, CA, UCRL-53227.

Patrick, W. C., L. B. Ballou, T. R. Butkovich, R. C. Carlson, W. B. Durham, G. L. Hage, E. L. Majer, D. N. Montan, R. A. Nyholm, N. L. Rector, D. G. Wilder, and J. L. Yow (1982), Spent Fuel Test-Climax; Technical Measurements Interim Report. Fiscal Year 1981. Lawrence Livermore National Laboratory, Livermore, CA, UCRL-53294.

Patrick, W. C., L. B. Ballou, T. R. Butkovich, R. C. Carlson, W. B. Durham, G. L. Hage, E. L. Majer, D. N. Montan, R. A. Nyholm, N. L. Rector, D. G. Wilder and J. L. Yow; Jr. (1983), Spent Fuel Test-Climax: Technical Measurements Interim Report, Fiscal Year 82, Lawrence Livermore National Laboratory, Livermore, CA, UCRL-53294-82.

Patrick, W. C., T. R. Butkovich, R. C. Carlson, W. B. Durham, H. C. Ganow, G. L. Hage, E. L. Majer, D. N. Montan, R. A. Nyholm, N. L. Rector, F. J. Ryerson, H. Weiss and J. L. Yow, Jr. (1984), Spent Fuel Test-Climax: Technical Measurements Interim Report, Fiscal Year 83, Lawrence Livermore National Laboratory, Livermore, CA, UCRL-53294-83.

Patrick, W. C., and N. L. Rector, "Measurement of Displacement in Large Boreholes with a Strain Gauged Proving Ring," Experimental Techniques 9(2), February 1985.

Patrick, W. C., N. L. Rector, and J. J. Scarafiotti (1984), Instrumentation Report No. 3: Performance and Reliability of Instrumentation Deployed for the Spent Fuel Test-Climax, Lawrence Livermore National Laboratory, Livermore, CA, UCRL-53637.

Patrick, W. C., J. L. Yow, Jr, and M. Axelrod (1985), Estimates of In Situ Deformability with an NX Borehole Jack SFT-C - NTS, Lawrence Livermore National Laboratory, Livermore, CA; UCRL-53673.

Paullson, B. N. P., and M. S. King (1980), A Cross-Hole Investigation of a Rock Mass Subjected to Heating, Lawrence Berkeley Laboratory, Berkeley, CA, LBL-10849.

Quam, W., and T. DeVore (1981), Climax Spent Fuel Dosimetry-Progress Report, September 1980-September 1981, EGG 1183-2432, Lawrence Livermore National Laboratory, Livermore, CA, Contractor Report UCRL-15419.

Quam, W., and T. DeVore (1982), Climax Spent Fuel Dosimetry-Progress Report, September 1981-September 1982, EGG 1183-2455, Lawrence Livermore National Laboratory, Livermore, CA, Contractor Report UCRL-15419-1.

Quam, W., and T. DeVore (1984a), Climax Spent Fuel Dosimetry Progress Report Sept. 82-Jan 84, EGG 102822042, Lawrence Livermore National Laboratory, Livermore, CA, Contractor Report UCRL-15419-2.

Quam, W., and T. DeVore (1984b), Climax Spent Fuel Dosimetry, Short Term Exposure, EGG 10282-2041, Lawrence Livermore National Laboratory, Livermore, CA, Contractor Report UCRL-15419-3.

Ramspott, L. D., L. B. Ballou, R. C. Carlson, D. N. Montan, T. R. Butkovich, J. E. Duncan, W. C. Patrick, D. G. Wilder, W. G. Brough, and M. C. Mayr (1979), Technical Concept for a Test for Geologic Storage of Spent Reactor Fuel in the Climax Granite, Nevada Test Site, Lawrence Livermore National Laboratory, Livermore, CA, UCRL-52796.

Ramspott, L. D. (1980), The Spent Fuel Test Project, Climax Granitic Stock, Netada Test Site, Lawrence Livermore National Laboratory, Livermore, CA, UCRL-85078, in Proceedings of the International Symposium for Environmental Protection, Low Cost Storage \& Energy Savings (Rockstore 80), Stockholm, Sweden.

Ramspott, L. D., and L. D. Ballou (1980), "Test Storage of Spent Reactor Fuel in the Climax Granite at the Nevada Test Site," Waste Management 80: The State of Waste Disposal Technology, Mill Tailings, and Risk Analysis Models V. 2, M. E. Wacks and R. G. Post, Eds, University of Arizona, Tucson, AZ, 515; also in Lawrence Livermore National Laboratory, Livermore, CA, UCRL-83976. 
Ramspott, L. D., L. B. Ballou, and W. C. Patrick (1981). Status Report on Spent Fucl Test-Climux: A Te'st of

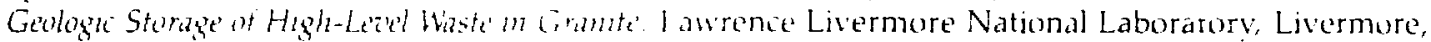
CA, UCRL-85516, presented at the 110thi Anmwal AME Meeting, Chicago, Illinois, Februar, 22, 1981.

Raschke, K. E., W. C. Patrick. T. C. Roy, and T Stritume (1483). Ratiatom Dusmetry and Monituring for a Te'st of Geologic Sturage of Spent Vultal Fut I awence Livermore National Laboratory: Livermore, CA. UCRL-53498.

Raschke, K., and T. Straume (1985), Radutim Satety Consideratims for a Test of Decp Giologic Storage of Spent Nuclear Fud, Lawrence Livermore National Laboratory, Livermore, CA. LCRL-92003, submitted to Nuclear Science and Enginering

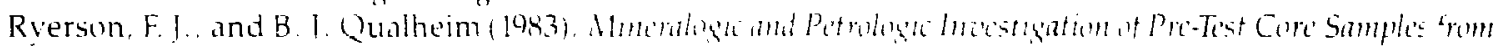

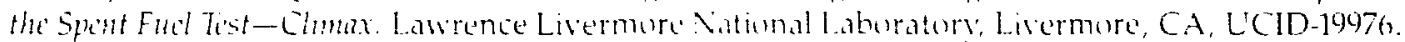

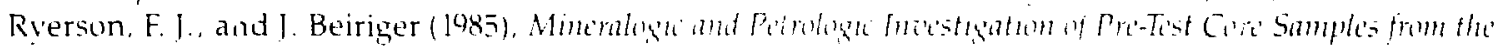
Spent Fial Te'st-Climax, Lawrence Livermure National Laboratory: Livermure. CA ICCRL-53625.

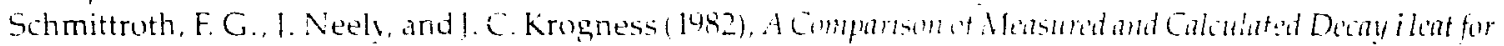

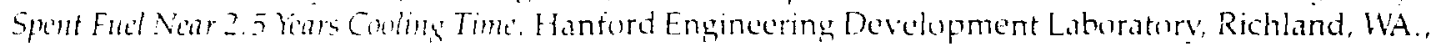
HEDL-7202.

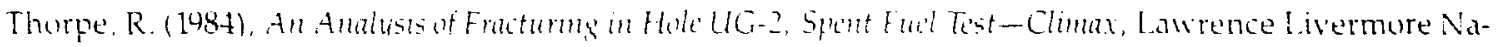
tional Laboratorv, Livermore, (A, LCID-2) I313).

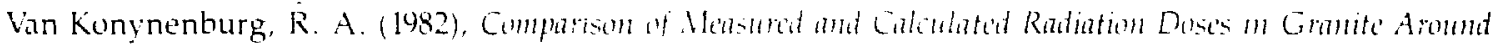

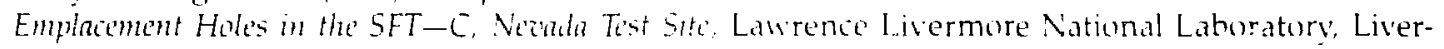
more, CA, UCRL-53341.

Van Konynenburg, R. (1984), Radiation Doses in Grante Around Emplaciment Hols: in the Spent Fuel TestClimiax (Final Report), Law'rence Livermore National Laboratory, Livermore, CA, UCRL-53580.

Weed, H. C., and W. B. Durham (1982), Drilling-Induced Borehole-Wall Damage at Spent Furl Test--Climax, Lawrence Livermore National Laboratory, Livermore, CA, UCID-19672.

Weiss, H., R. Van Kony'nenburg, and D. McCright (1985), Metallurgical Analysis of a 304L Stainless Steel Canisfer from the' Spent Fuel Test-Climax, Lawrence Livermore National Laboratory, Livermore, CA. UCID20436.

Wilcox, T., and R. Van Konynenburg (1981), Radiation Dose Calculations for Geologic Media Around Spent Fuel Emplacement Holes in the Climax Granite, Neradn Test Site, Lawrence Livermore National Laboratory, Livermore, CA, UCRL-53159.

Wilder, D. G., and W. C. Patrick (1981), "Geotechnical Status Report for Test Storage of Spent Reactor Fuel in Climax Granite, Nevada Test Site," AEG Bulletin XVIII, 4, pp. 355-367; also in Lawrence Livermore National Laboratory, Livermore, CA, UCRL-8506.

Wilder, D. G., and J. L. Yow, Jr. (1981), Fracture Mapping at the Spent Fud Test-Climax, Lewrence Livermore National Laboratory, Livermore, CA, UCRL-53201.

Wilder, D. G., J. L. Yow, Jr., and R. K. Thorpe (1982), Core Logging for Site Investigation, Spent Fuel TestClimax, Lawrence Livermore National Laboratory, Livermore, CA, UCID-19646.

Wilder, D. G., and J. L. Yow, Jr. (1984), Structural Geology Report, Spent Fud Test-Climax, Lawrence Livermore National Laboratory, Livermore, CA, UCRL-53381.

Wilder, D. G., and J. L. Yow, Jr. (1986), Geomechanics of the Spent Fuel Test-Climax, Lawrence Livermore National Laboratory, Livermore, CA, UCRL-53767.

Winograd, I. J., and W. Thordarson (1975), Hydrologic and Hydrochemical Framework, South Central Great Basin, Nevada-Cal:fomia, wit's Special Reference to the Nevada Test Site, USGS Professional Paper 712-C, U.S. Geological Survey, Denver, CO.

Worotnicki, G., and R. J. Walton (1979), Virgin Rock Stress Measurements at the Warrego Minc, Conmonwealth Scientific and Industrial Research Organization, Austrailia, CSIRO Technical Report No. 93.

Yong, C., and C. Wang (1980), Acoustic Emission in Thermal Cracking Processes of Westerly Granite, unpublished report, University of California, Berkeley, CA.

Yow, J., Jr., and T. Butkr vich (1982), "Calculated and Measured Drift Closure During the Spent Fuel Test in Climax Granite," Procedings of 23 rd Sympositum on Rock Mechanics, University of California, Berkeley, CA, August 25-27, 1982, Chap. 86, pp. 855-863; also in Lawrence Livermore National Laboratory; Livermore, CA, UCRL-87179.

Yow, J. L., Jr. (1984), Geologic Structure Mapping Database, Spent Fuel Test-Climax. Nernda Test Site, Lawrence Livermore National Laboratory, Livermore, CA, UCID-20301. 
Zoback, M. L., and M. Zoback (1980), "State of Stress in the Conterminous United States," Jour. Geophysich ㄴ. 85 (B11), 6113-6156.

Zucca, J. J. (1984). Prttte Sismulu Hiasurements at the Spent Fud Te'st-Climax, Law'rence Livermore National Laboratory, Livermore. CA, LCRL-53797.

\title{
Publication List
}

All publications from the SFT - C are listed below, categorized as format reports (FR numbers), informal reports (IR numbers), journal article's (I numbers), society and symposium proceedings (SP numbers), DOE symposium proceedings (DSP numbers), contractor repurts (CR numbers), related reports by other agencies (OA numbers), and documentary tilms (DF numbers). Within a category. reports are isted chronologically: Individual repurts can he ordered from:

\author{
National Technical Information Service \\ U.S. Department of Eommerce \\ 5285 Port Roval Ruad \\ Springfield, VA 22161
}

\section{Formal Reports}

FR-1 L. D. Ramspott, L. B. Batlou, R. C. Carlson, D. N. Montan, T. R. Butkovich, J. E. Duncan, W. C. Patrick, D. G. Wiider, W. G. Brough, and M. C. Mayr, Technical Concept for a Test of Geologic Stornge of Spent Reactor Fuel in the Clinux Granite, Nezada Test Site, Lawrence Livermore National Laboratory, Livermore, CA, UCRL-52796 (June 1979).

FR-2 T. R. Butkuvich and D. N. Montan, A Method for Calculating Internal Radiation and Ventilation zwith the ADINAT Heat-Flow' Code, Lawrence Livermore National Laboratory, Livermore, CA, UCRL-52918 (April 1980).

FR-3 W. C. Patrick and W. G. Brough, Response of Borehole Extensometers 's Explosively Generated Dynamic Loads, Law'rence Livermore National Laboratory, Livermore, CA, UCRL-53087 (August 1980).

FR-4 R. C. Carlson, W. C. Patrick, D. G. Wilder, W. G. Brough, D. N. Montan, P. Harben, L. B. Ballou, and H. C. Heard, Spent-Fuel Test-Climax: Technicill Mcasurements Interim Report, FY 1980, Lawrence Livermore National Laboratory, Livermore, CA, UCRL-53064 (December 1980).

FR-5 F. E. Heuze, W. C. Patrick, R. V. De la Cruz, and C. F. Voss, In Situ Geomechanics, Clinnx Granite, Nevada Test Site, Lawrence Livermore National Laboratory, Livermore, CA, UCRL-53076 (Âpril 1981).

FR-6 W. A. Murray, Geohydrology of the Climax Stock Granite and the Surrounding Rock Fommations, Neziada Test Site, Lawrence Livermore National Laboratory, Livermore, CA, UCRL-53138 (May 1981).

FR-7 T. Wilcox and R. Van Konynenburg, Ratiation Dose Calculations for Geologic Medin A round Spent-Fuel Emplacement Holes in the Climax Granite, Nernda Tes: Site, Lawrence Livermore National Laboratory, Livermore, CA, UCRL-53159 (May 1981).

FR-8 D. Wilder and J. Yow, Jr., Fractur Mapping at the Sp'nt-Fuel Test-Climax, Lawrence Livermore National Laboratory, Livermore, CA, UCRL-53201 (May 1981).

FR-9 F. E. Heuze, T. R. Butkovich, and J.C. Peterson, An A inalysis of the 'Mine-hy' Experiment. Climax Granite. Nezada Test Site, Law'rence Livermore Nationa! Laboratory, Livermore, CA, UCRL-53133 (June 1981). 
FR-10 T. R. Butkovich, Nethanical and Thermomechamial Calculatoms Relnted to the Storage of Spent Nuctear Fuel Assemblie's in Granite, Lawrence Livermore National Laboratury, Livermore, CA, LCRL-52985 Rev. 1 (August 1981).

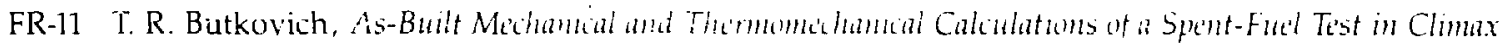
Stock Grantite, Lawrence Livermore National Laburatory, Livermore, CA, UCRL-53198 (September 1981).

FR-12 D. Montan and W. Patrick, Thermal Calculations for the Design, Construction, Operation, and Ezaluation of the Spent-Fuel Test-Climax, Nerada Test Site, Lawrence Livermore National Laboratory, Livermore, CA, UCRL-53238 (September 1981).

FR-13 W. C. Patrick and M. C. Mayr, Excavation and Diillng Actirities of a Spent-Fuel Test Facility in Granitic Rock, Lawrence Livermore National Laboratory. I ivermore, CA, UCRL-5322.7 (November 1981).

FR-14 W. Patrick, R. Carlson, and N. Rector, instrumentation Report \#2: Identification, Evaluation, and Reriatial Actions Related to Transducer Failures at the Spent-Fuel Test-Climax. Larvrence Livermore National Laboratory, Livermore, CA, UCRL-53251 (November 1981).

FR-15 W. Brough and W. Patrick, Instrumentation Report \#1: Specification. Desi̧n, Calibration, and Installation of Instrumentation for an Experimental, High Level, Nuclear Waste Storage Facility, Lawrence Livermore National Laboratory, Livermore, CA, UCRL-53248 (January 1982).

FR-16 W. Patrick, L. Ballou, T. Butkovich, R. Carlson, W. Durham, G. Hage, E. Majer, D. Montan, R. Nyholm, N. Rector, D. Wilder, and J. Yow, Jr., Spent-Fuel Test-Climax Technical Measurements Interim Report FY81, Lawrence Livermore National Laboratory, Livermore, CA, UCRL-53294 (April 1982).

FR-17 D. Isherwood, E. Raber, R. Stone, D. Lord, N. Rector, and R. Failor, Engineering Test Plan for Field Radionuclide Migration Experiments in Climex Grante, Lawrence Livermore National Laboratory, Livermore, CA, UCRL-53286 (June 1982).

FR-18 R. A. Nyholm, W. G. Brough, and N. L. Rectcr, SFT-Climax Data Acquisition System Integration Report, Lawrence Livermore National Laboratory, Livermore, CA, UCRL-53304 (June 1982).

FR-19 R. Failor, D. Isherwood, E. Raber, and T. Vandergraaf, Laboratory Studies of Radionuclide Migration in Fractured Climax Grunite, Lawrence Livermore National Laboratory, Livermore, CA, UCRL-53308 (June 1982).

FR-20 D. Isherwood, J. Harrar, and E. Raber, Characterization of Climax Granite Ground Water, Lavrrence Livermore National Laboratory, Livermore, CA, UCRL-53309 (August 1982).

FR-21 L. B. Ballou, W. C. Patrick, D. N. Montan, and T. R. Butkovich, Test Completion Plan for Spent-Fuel Test-Climax, Nevada Test Site, Lawrence Livermore National Laboratory, Livermore, CA, UCRL-53367 (September 1982).

FR-22 T. Butkovich, The Effects of Boundary Conditions on Thermomechanical Calculations: Spent-Fuel TestClimax, Lawrence Livermore National Laboratory, Livermore, CA, UCRL-53338 (October 1982).

FR-23 R. A. Van Konynenburg, Comparison of Measured and Calculated Radiation Doses in Granite Around Emplacement Holes in the SFT $-\mathrm{C}$, Neziada Test Site, Lawrence Livermore National Laboratory, Livermore, CA, UCRL-53341 (October 1982).

FR-24 W. B. Durham, Thermal Properties of Climax Stock Quartz Monzonite to $523 \mathrm{~K}$ and 50-MPa Confining Pressure, Lawrence Livermore National Laboratory, Livermore, CA, UCRL-53349 (October 1982). 


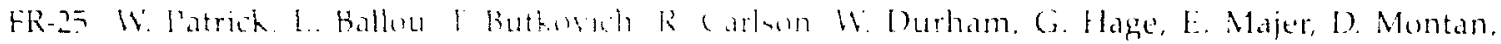

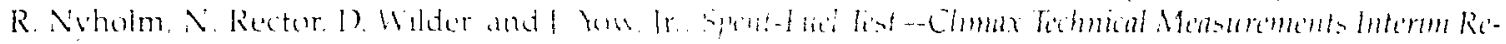

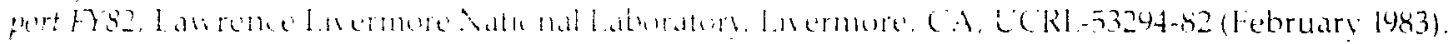

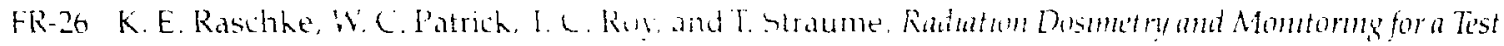

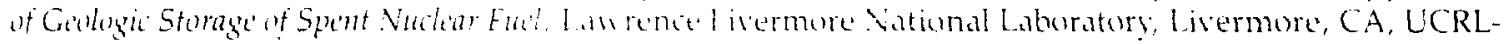
53498 (Noventer 1983 ).

FR-27 W. C. Patrich. T.R. Buthwich, R. C. Carlsm. W. B. Durham, H. C. Ganow, G. L. Hage, E. L. Majer, D. N' Monian, K. A. Viholm, X. L. Retur. F. I. Ryerson, H. Weiss, and I. L. Yow, Jr, Spent-Fuel Test-

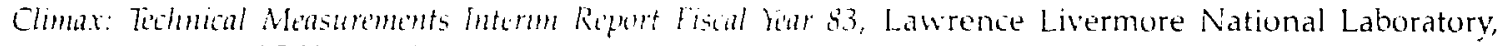
Livermore, CA, LCRL-53294-83 (February 1484).

FR-28 R. Van Konynenburs, Radiation Dust's :n Gianite Arund Emplacement Holes in the Spent-Fud TestClmax ifinal Repurt). Lawrence Livermure National Laboratory. Livermore, CA, UCRL-53580 (July 1984).

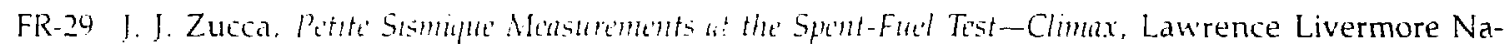
tional Laboratory. Livermort, CA, LCRL-73597 (July 1984).

FR-30 D. N. Montan and W. E. Bradkin, Heater Te'st 1, Climax Stock Gmite, Neriala, Lawrence Livermore National Laboratory, Livermore, CA, UCRL-53446 (October 1984).

FR-31 D. G. Wilder and J. L. Yow, Jr., Structural Geology Report, Spent-Fuel Test-Climax, Nevnda Test Site, Lawrence Livermore National Laboratory, Livermore, CA, UCRL-53381 (October 1984).

FR-32 W. C. Patrick, N. L. Rector, and I. J. Scarafintti, Instrumentation Report No. 3: Performance and Reliability of Insirumentation Deployed for the Spent-Fuel Test-Climax, Lawrence Livermore National Laboratory, Livermore, CA, UCRL-53637 (December 1984).

FR-33 F. J. Ryerson and J. M. Beiriger, Mintralugic and Petrologic Investigation of Post-Tesi Core Samples from the Spent-Fuel Test-Climax, Lawrence Livermore National Laboratory, Livermore, CA, UCRL-53625 (February 1985).

FR-34 T. R. Butkovich and W. C. Patrick, Post-Test Thermomechanical Calculations and Preliminary Data Analyses, Lawrence Livermore National Laboratory, Livermore, CA, UCRL-53688 (July 1985).

FR-35 W. C. Patrick, J. L. Yow, Jr., and M. C. Axelrod, Estimates of In Situ Deformability with an NX Boreliole Jack SFT-C-NTS, Lawrence Livermore National Laboratory, Livermore, CA, UCRL-53673 (December 1985).

FR-36 D. N. Montan and W. C. Patrick, Post-Test Thermal Calculations and Data Analyses for the Spent-Fuel Test-Climar, Lawrence Livermore National Laboratory, Livermore, CA, UCRL-53728 (September 1986).

FR-37 D. G. Wilder and J. L. Yow; Jr., Geomechanics of the Spent-Fuel Test-Climax, Lawrence Livermore National Laboratory, Livermore, CA UCRL-53767 (1986).

FR-38 W. C. Patrick, Spent-Fuel Test-Climax: An Ezaluation of the Technical Feasibility of Geologic Sturage of Spent Nuclear Fuel in Gramite - Excutioe Summary of Final Results, Law rence Livermore National Laboratory: Livermore, CA, UCRL-53762 (September 1986). 


\section{Informal Reports}

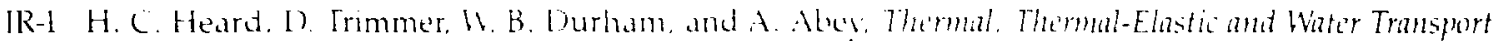

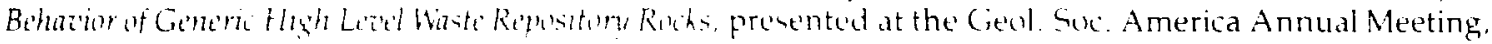
Atlanta, GA, November 17-20, 1980. Published as Lawrence Livermure National Laboratory, Livermore, CA. LCRL-8440+(1980).

IR-2 J. E. Durcan. P. A. House, and G. W. Wright. Spent-Fud Handling Sustem for a Geologic Stumat Test at the Neviada Test Site. pre'sented at the American Nuclear Society Meeting, Las Vegas, NV, June 1980. Published as Lawrence Livermore National i_aboratury, Livermure, CA, LCRL-83728 (May 1980).

IR-3 A. E. Abey and J. R. Washington, stressmeter Placement at Spent-Fuel Test in Climax Gramite, Lawrence Livermore National Laboratory, Livermsire, CA, LCID-18620 (May 1980).

IR-4 D. Isherwood, E. Raber. D. Coles and R. Stone, Program Plan: Field Radionuclide Migration Studies in Climax Granite, Lawrence Livermure National Laboratory, Livermore, CA, UCID-18838 (1980).

IR-5 L. Ramspott, L. Ballou, and W. Patrick, Status Report on the Spent-Fuel Test-Climax: A Test of Geologic Sturlge of High-Lerel Waste in Grartite, presented at the 110th Annual AIME Meeting, Chicago, IL, February 22, 1981. Published as Lawrence Livermore National Laburatory, Livermore, CA, UCRL-85516 (January 1981).

IR-6 F. E. Heuze, The Climax Granite Nevada Test Site, as Host for a Rock Mechanics Test Facility Related to the Geologic Disposal of High Level Nuclear Wastes, Lawrence Livermore National Laboratory, Livermore, CA, UCID-18946 (February 1981).

IR-7 R. Thorpe and J. Springer, Fracture Mapping for Radionuclide Migration Studies in the Climax Granite, Lawrence Livermore National Laboratory, Livermore, CA, UCID-19081 (May 1981).

IR-8 W. B. Durham and A. E. Abey, Thernal Properties of Rock Salt and Quartz Monzonite to $573 \mathrm{~K}$ and $50 \mathrm{MPa}$ Confining Pressure, presented at the 20th ASME-AIChE National Heat Transfer Conference, Milwaukee, WI, August 2-5, 1981. Published as Lawrence Livermore NationaI Laboratory, Livermore, CA, UCRL85191 (August 1981).

IR-9 J. Yow, Jr., and D. Wilder, Tape Extensometer Sensitivity and Reliability, presented at the 24th Annual Meeting of the Association of Engineering Geologists, Portland, OR, September 27-October 2, 1981. Published as Lawrence Livermore National Laboratory, Livermore, CA, UCRL-86100 (September 1981).

IR-10 R. C. Carlson, L. E. Page, L. Koons, and C. Sundbeck, Preliminary Report on Radiation-Induced Thermoluminescence in Climax Stock Quartz Monzonite, Lawrence Livermore National Laboratory, Livermore, CA, UCID-19229 (October 1981).

IR-11 F. A. Morrison, Jr., Scoping Analysis for Radionuclide Migration Test, Lawrence Livermore National Laboratory, Livermore, CA, UCID-19369 (January 1982).

IR-12 W. B. Durham, The Effect of Gamma Irradiation on the Strength of Climax Stock Quartz Monzomitc, Lawrence Livermore National Laboratory, Livermore, CA, UCRL-87475 (March 1982).

IR-13 E. Raber, D. Lord, and P. Burklund, Hydrologic Test System for Fracture Flow Stidies in Crystalline Rack, Lawrence Livermore National Laboratory, Livermore, CA, UCID-19405 (May 1982).

IR-14 D. Wilder, J. Yow, Jr., and R. Thorpe, Core logging for Site In'e'stigation and Instrumentrtion. Spent-Fu'l Test-Climax, Lawrence Livermore National Laboratory, Livermore, CA, UCID-19646 (May 1982). 
IR-15 W. C. Patrick, L. D. Ramspott, and L. B. Ballou, Expertmental and Calculational Results from the SpentFuel Test-Climax, presented at OECD Nuclear Energy Agency-Stripa 1982: In Situ Experiments in Granite Associated with Geological Disposial of Radionctive Wiste, Stockholm, Sweden, October 25-27, 1982. Published as Lawrence Livermore National Laboraterv, Livermore, CA, LCRL-88254 (October 1982).

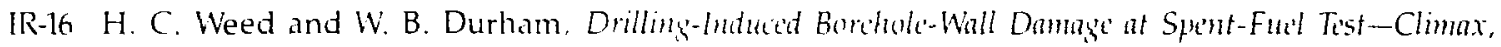
Lawrence Livermore National Laboratory, Livermore, CA, UCID-19672 (December 1982).

IR-17 R. A. Nyholm. Spent-Fuel Test-Climax Datin Atuphisition System Operations Manual, Lawrence Livermore National Laboratury: Livermore, CA, UCID-19834 (January 1983).

IR-18 G. L. Hage, BREAD, A CDC 7600 Pryzram Thut Prowese's Spent-Fud Test-Climax Data, Lawrence Livermore National Laboratory: Livermore, CA, LCID-19814 (April 1983)

IR-19 F. J. Rverson and B. I. Qualheim, Minerolugic and Petrolugio hinestigation of Pre-Test Core Somples from the Spent-Fuel Test-Climax, Lawrence Livermore Natimal Laboratory, Livernore, CA, UCID-19976 (December 1983).

IR-20 3. Beiriger and W. Durham, SEM Studits of Strissed and Iradiated Climax Stock Quart= Monzonite, Lawrence Livermore National Laboratory, Livermore, CA, UCID-20052 (February 1984).

iR-21 R. Thorpe, An Analysis of Fracturing in Hole UG2, SFT-C. Lawrence Livermore National Laboratory, Livermore, CA, UCID-20130 (June 1984).

IR-22 N. Mao, Overooring and Calibration of IRAD Gage Stressmeters at Spent-Fuel Test in Climax Granite, Lawrence Livermore National Laboratory, Livermore, CA, UCID-20318 (September 1984).

IR-23 G. Hage, A User's Guide to REVERT: A CDC 7600 Program for Converting SFT-C Data to Engineering Units, irith Corretions, Lawrence Livermore National Laboratory, Livermore, CA, UCID-30206 (October 1984).

IR-24 J. L. Yow, Jr., Geologic Structure Mapping Database, Spent-Fuel Test-Climax, Nevada Test Site, Lawrence Livermore Nationa! Laboratory, Livermore, CA, UCID-20301 (December 1984).

IR-25 J. M. Beiriger, W. B. Durham, and F. I. Ryerson, Physical and Chemical Change's to Rock Nenr Electrically Heated Boreholes at Spent-Fuel Test-Climax, Lawrence Livermore National Laboratory, Livermore, CA, UCID-20412 (January 1985).

IR-26 K. Raschke and T. Straume, Radiation Safety Considerations for a Test of Deep Geologic Storage of Spent Nuclear Fuel, submitted to Nuclear Science and Engineering, Lawrence Livermore National Laboratory, Livermore, CA, UCRL-92003 (January 1985).

IR-27 R. Thorpe and B. Qualheim, Logging of Post-Test and CCH Recort Core Samples for the Spent-Fucl TestClimax, Lawrence Livermore National Laboratory, Livermore, CA, UCID-20351 (February 1985).

IR-28 W. B. Durham, J. M. Beiriger, M. Axelrod, and S. Trett anero, The Effect of Gamma Irradiation on the Strength and Elasticity of Climax Stock and Westerly Granites, Lawrence Livermore National Laboratory, Livermore, CA, UCRL-92526 (March 1985).

IR-29 H. C. Ganow, Negrative Hysteresis Effect Obsered During Calibration of the UI.S. Bureau of Mines Borehole Deformation Gauge, Lawrence Livermore National Laboratory, Livermore, CA, UCID-20523 (August 1985).

IR-30 R. C. Carlson, Spent-Fue! Test-Climax: Technical Measurements, Data Management System, and Data Presentation, Lawrence Livermore National Laboratory, Livermore, CA, UCID-20712 (September 1985). 


\section{Journal Articles}

J-1 D. Trimmer, B. Bonner, H. C. Heard, and A. Duba, "Effect of Pressure and Stress on Water Transport in Intact and Fractured Gabbro and Granite," I. Geophys. Res. 85, 7059-7071 (1980). Also available as Lawrence Livermore National Laboratory, Livermore, CA, UCRL-83932 (September 1977).

J-2 H. C. Heard, "Thermal Expansion and Inierred Permeability of Climax Quartz Monzonite to $300^{\circ} \mathrm{C}$ and 27.6 MPa," Int. Jour. Rock Mech. Min. Sci. 17, 289-296 (1980). Also available as Lawrence Livermore National Laboratory, Livermore, CA, UCRL-83697 (December 1979).

J-3 D. G. Wilder and W. C. Patrick, "Geotechnical Status Report for Test Storage of Spent Reactor Fuel in Climax Granite, Nevada Test Site," Bull. Assoc. Eng. Geol. 18(4), 355-367 (1981). Also available as Lawrence Livermore National Laboratory, Livermore, CA, UCRL-85096 (November 1980).

J-4 H. C. Heard and L. Page, "Elastic Moduli, Thermal Expansion and Inferred Permeability of Two Granites to $350^{\circ} \mathrm{C}$ and $55 \mathrm{MPa}, " \mathrm{~J}$. Geophys. Res. 87, 9340-9348 (1982). Also available as Lawrence Livermore National Laboratory, Livermore, CA, UCRL-86603 (1981).

J-5 J. L. Yow, Jr., "Sources of Compass Error in Tunnel Mapping," Assoc. Eng. Geol. Bull. 19(2), 133-140 (1982). Also available as Lawrence Livermore National Laboratory, Livermore, CA, UCRL-86749 (September 1981).

J-6 R. Carlson, "Thermoluminescence for Self-Dosimetry in Climax Stock Quartz Monzonite," Nucl. Technol. 60, 244-252 (1983). Also available as Lawrence Livermore National Laboratory, Livermore, CA, UCRL-86627 (September 1981).

J-7 F. Heuze, W. Patrick, T. Butkovich, J. Peterson, R. V. de Ia Cruz, and C. F. Voss, "Rock Mechanics Studies of Mining in the Climax Granite," Int. J. Rock Mech. Min. Sci. 19, 167-183 (1982). Also available as Lawrence Livermore National Laboratory, Livermore, CA, UCRL-86968 (November 1981).

J-8 D. A. Trimmer, "Laboratory Measurements of Ultra-Low Permeability Geologic Materials," Rev. Sci. Instrum. 53, 1246-1254 (1982). Aiso available as Lawrence Livermore National Laboratory, Livermore, CA, UCRL-86722 (1982).

J-9 J. Harrar and E. Raber, "Borehole Collector for In Situ Chemical Analysis of Ground Water," Ground Water 20(4), 479-481 (1982). Also available as Lawrence Livermore National Laboratory, Livermore, CA, UCRL-87252 (February 1982).

J-10 W. B. Durham, J. M. Beiriger, and H. C. Weed, "A Rapid Technique for Counting Cracks in Granitic Rocks," Scanning Electron Microscopy /1985/I, 133-142 (1985). Also available as Lawrence Livermore National Laboratory, Livermore, CA, UCRL-90257 (January 1984).

J-11 W. C. Patrick and N. L. Rector, "Measurement of Displacement in Large Boreholes with a Strain Gauged Proving Ring," Experimental Techniques 9(2). Also available as Lawrence Livermore National Laboratory, Livermore, CA, UCRL-91360 (July 1984).

\section{Society and Symposium Proceedings}

SP-1 H. C. Heard, D. Trimmer, W. Lin, A. Duba, and B. Bonner, "Simultaneous Measurements of Permeability, Electrical Conductivity and Ultrasonic Velocity in Igneous and Metamorphic Rocks," Trans. Am. Geop. Union 46, 1113 (1980). Also available as Lawrence Livermore National Laboratory, Livermore, CA, UCRL-82389 (February 1979). 
SP-2 H. C. Heard, D. Trimmer, A. Duba, and B. Bonner, "Permeability of Generic Repository Rocks at Simulated In Situ Conditions. "Proc. Workshop on Low'-Flow, Low Permeability Measurements in Largely Impermeable Rocks (OECD Publication Center, Washington, DC, 1979). Also available as Lawrence Livermore National Laboratory, Livermore, CA, UCRL-82609 (April 1979).

SP-3 L. D. Ramspott and L. B. Ballou, "Test Storage of Spent Reactor Fuel in the Climax Granite at the Nevada Test Site," in M. E. Wacks and R. G. Post, Eds., Waste Management 80: The State of Waste Disposal Technology, Mill Tailings, and Risk Analysis Models 2, 515 (University of Arizona, Tucson, AZ, 1980). Also available as Lawrence Livermore National Laboratory, Livermore, CA, UCRL-83976 (Febi'uary 1980).

SP-4 D. N. Montan, "Thermal Analysis for a Spent Reactor Fuel Storage Test in Granite," Proc. Third International Symposium on the Scientific Basis for Nuclear Waste Management 3, 615-622 (1981). Also available as Lawrence Livermore National Laboratory, Livermore, CA, UCRL-83995 (September 1980).

SP-5 L. D. Ramspott, "The Spent-Fuel Test Project, Climax Granitic Stock, Nevada Test Site," Proc. International Symposium for Environmental Protection, Low Cost Storage \& Energy Savings (Rockstore 80). Also available as Lawrence Livermore National Laboratory, Livermore, CA, UCRL-85078 (October 1980).

SP-6 F. E. Heuze, "Geomechanics of the Climax 'Mine-By', Nevada Test Site," Proc. 22nd Symposium on U.S. Rock Mechanics, pp. 428-434 (Massachusetts Institute of Technology, Cambridge, MA, 1981). Also available as Lawrence Livermore National Laboratory, Livermore, CA, UCRL-85768 (March 1981).

SP-7 L. E. Page and H. C. Heard, "Elastic Moduli, Thermal Expansion and Inferred Permeability of Climax Quartz Monzonite and Sudbury Gabbro to $500^{\circ} \mathrm{C}$ and $55 \mathrm{MPa}$," Proc. 22nd U.S. Symposium on Rock Mechanics, pp. 97-104 (Massachusetts Institute of Techrology, Cambridge, MA, 1981). Also available as Lawrence Livermore National Laboratory, Livermore, C A, UCRL-85736 (March 1981).

SP-8 W. B. Durham and A. E. Abey, "The Effect of Pressure and Temperature on the Thermal Properties of a Salt and a Quartz Monzonite," Proc. 22nd U.S. Symposium on Rock Mechanics, pp. 79-84 (Massachusetts Institute of Technol ${ }_{0}$, Cambridge, MA, 1981). Also available as Lawrence Livermore National Laboratory, Livermore, CA, UCRL-85285 (June 1981).

SP-9 D. Isherwood, E. Raber, and R. Stone, "Site Characterization for Field Radionuclide Migration Studies in Climax Granite," in S. V. Topp, Ed., Scientific Basis for Nuclear Waste Management 6, 199-206, 1982. Also available as Lawrence Livermore National Laboratory, Livermore, CA, UCRL-86194 (June 1981).

SP-10 W. Patrick, D. Montan, and L. Ballou, “Near-Field Heat Transfer at the Spent-Fuel Test-Climax: A Comparison of Measurements and Calculations," Proc. OECD Nuclear Energy Agency Workshop in Near-Field Phenomena in Geological Repositories, pp. 147-160 (OECD, Nuclear Energy Agency, Paris, France, 1981). Also available as Lawrence Livermore National Laboratory, Livermore, CA, UCRL-86043 (August 1981).

SP-11 W. B. Durham and A. E. Abey, "Thermal Conductivity and Diffusivity of Climax Stock Quartz Monzonite at High Pressure and Temperature," in J. G. Hust, Ed., Thermal Conductivity 17, 459-468 (1983). Also available as Lawrence Livermore National Laboratory, Livermore, CA, UCRL-86619 Rev. 1 (November 1981).

SP-12 L. D. Ramspott, L. Ballou, and W. C. Patrick, "Status Report on the Spent-Fuel Test-Climax, NTS: A Test of Dry Storage of Spent-Fuel in a Deep Granite Location," in R. G. Post and M. E. Wackss, Eds., Waste Management 1982 3, 131-139 (University of Arizona, Tucson, AZ, 1982). Also available as Lawrence Livermore National Laboratory, Livermore, CA, UCRL-87448 (March 1982).

SP-13 J. Yow, Jr., and T. Butkovich, "Calculated and Measured Drift Closure During the Spent-Fuel Test in Climax Granite," Proc. 23rd Symposium on Rock Mechanics, Ch. 86, pp. 855-863 (University of California, Berkeley, CA, 1982). Also available as Lawrence Livermore National Laboratory, Livermore, CA, UCRL87179 (April 1982). 
SP-14 T. Butkovich, J. Yow, Jr., and D. Montan, "Influence of Heat Flow on Drift Closure During Climax Granite Spent-Fuel Test: Measurements," Proc. International Conference on Radioactive Waste Management, Winnipeg, Manitoba, Canada (1982). Also available as Lawrence Livermore National Laboratory, Livermore, CA, UCRL-87248 (September 1982).

SP-15 L. B. Ballou, "Handling Encapsulated Spent-Fuel in a Geologic Repository Environment," Radiouctive Waste Management 3, 463-472, 1AEA-CN-43/223 (International Atomic Energy Agency, Vienna, 1984). Also available as Lawrence Livirmore National Laboratory, Livermore, CA, UCRL-87872 (February 1983).

S?-16 J. L. Yow, Jr., and D. G. Wilder, "Planning Exploratory Drilling: The Effect of Blind Zones and Level of Logging Effort," Proc. 24th U.S. Symposium on Rock Mechanics, pp. 807-812 (Texas A\&M University, College Station, TX 1983). Also available as Lawrence Livermore National Laboratory, Livermore, CA, UCRL88374 (June 1983).

SP-17 W. C. Patrick and N. L. Rector, "Reliability of lnstrumentation in a Simulated Nuclear-Waste Repository Environment," Proc. International Symposium on Field Measurements in Geomechanics, K. Kovari, Ed., pp. 1431-1440, Zurich, Switzerland (1983). Also available as Lawrence Livermore National Laboratory, Livermore, CA, UCRL-88806 (June 1983).

SP-18 W. C. Patrick, N. L. Rector, and T. R. Butkovich, "The Application of Proving-Ring Technology to Measure Thermally Induced Displacements in Large Boreholes in Rock," Proc. 5th International Congress on Experimental Mechanics, pp. 189-196, Montreal, Quebec, Canada (1984). Also available as Lawrence Livermore National Laboratory, Livermore, CA, UCRL-88933 (March 1984).

SP-19 W. C. Patrick, "Operational and Technical Results from the Spent-Fuel Test-Climax," Proc. 31st Annual Technical Mee ing-Institute for Environmental Sciences, Las Vegas, NV (1985). Also available as Lawrence Livermore National Laboratory, Livermore, CA, UCRL-92065 (January 1985).

SP-20 W. C. Patrick, J. L. Yow, Jr., and M. C. Axelrod, "Observation of Borehole Deformation Modulus Values Before and After Extensive Heating of a Granitic Rock Mass," Proc. 26th U.S. Symposium on Rock Mechanics (South Dakota School of Mines and Technology, Rapid City, SD, 1985). Also available a: Lawrence Livermore National Laboratory, Livermore, CA, UCRL-91468 (February 1985).

\section{DOE Symposium Proceedings}

DSP-1 L. D. Ramspoti, "Climax Granite Test Results," Proc. Workshop on Thermomechanical Modeling for a Hardrock Waste Repository, F. Holzer and L. Ramspott, Eds., pp. 92-112, Lawrence Livermore National Laboratory, Livermore, CA, UCAR-10043 (1979). This article available as Lawrence Livermore National Laboratory, Livermore, CA, UCID-18502 (1979).

DSP-2 L. D. Ramspott, "Status of LLNL Granite Projects," Proc. ONWI/LBL Workshop on" Thermomechanical-Hydrochemical Modeling for a Hardrock Waste Repository, pp. 37-44, Lawrence Berke': Laboratory, Berkeley, CA (1980). Also available as Lawrence Livermore National Laboratory, Liverm ..., CA, UCRL-84613 (July 1980).

DSP-3 L. B. Ballou, "Field Testing at the Climax Stock on the Nevada Test Site: Spent-Fuel Test and Radionuclide Migration Experiments," Proc. 1980 National Waste Terminal Storage Meeting, pp. 208-210, Columbus, $\mathrm{OH}(1980)$. Also available as Lawrence Livermore National Laboratory, Livermore, CA, UCRL85047 (October 1980). 
DSP-4 L. Ballou, D. Isherwood, and W. Parrick, "Field Testing at the Climax Stock on the Nevada Test Site: Spent-Fuel Test and Radionuclide Migration Experiments," The Technology of High-Level Nuclear Waste Disposal, Adrances in the Science and Technology of the Management of High-Level Nuclear Waste 2, 53-75 (Office of Nuclear Waste Isolation annual publication DOE/TIC-4621, Oak Ridge, TN, 1981). Also available as Lawrence Livermore National Laboratory, Livermore, CA, UCID-14, 73 (June 1981).

DSP-5 W. Patrick and L. Baliou, "The Spent-Fuel Test-Climax: A Progress Report," Proc. NWTS Prog. Info. Meeting, DOE/NWTS-30, pp. 101-104, Las Vegas, NV (1982). Ilso available as Lawrence Livermore National Laboratory, Livermore, CA, UCRL-88174 (September 1982).

\section{Contractor Reports}

CR-1 R. Lingle and H. R. Pratt, Laboratory Measured Material Properties of Granodiorite Climax Stock, Nevada Test Site. Submitted to Lawrence Livermore National Laboratory by Terra Tek, Inc. (August 1978).

CR-2 H. R. Pratt, W. H. Hustrulid, and R. Simonson, Instrumentation Program for Rock Mechanics and SpentFuel Tests at the Nevada Test Site. Submitted to Lawrence Livermore National Laboratory by Terra Tek, Inc. (August 1978).

CR-3 H. Pratt, R. Lingle, and T. Schrauf, Laboratory Measured Material Properties of Quartz Monzonite, Climax Stock, Nevada Test Site. Submitted to Lawrence Livermore National Laboratory by Terra Tek, Inc. Published as Lawrence Livermore National Laboratory, Livermore, CA, UCRL-15073 (June 1979).

CR-4 T. Schrauf and M. Board, Instrument Selection, Installation, and Analysis of Data for the Spent-Fuel Mineby, Nevada Test Site, Climar Stock, Tr79-51. Submitted to Lavrrence Livermore National Laboratory by Terra Tek, Inc. Published as Lawrence Livermore National Laboratory, Livermore, CA, UCRL-15076 (July 1979).

CR-5 K. W. Cumpbell, Seismic Hazard Analysis for the NTS Spent Reactor Fuel Test Site. Submitted to Lawrence Livermore National Laboratory by Tera Corporation. Published as Lawrence Livermore National Laboratory, Livermore, CA, UCRL-15260 (1980).

CR-6 W. Quam and T. DeVore, Climax Spent-Fuel Dosimetry-Progress Report, September 1980-September 1981, EGG 1183-2432 and SANL 909-034. Submitted to Lawrence Livermore National Laboratory by EG\&G, Santa Barbara, CA. Published as Lawrence Livermore National Laboratory, Livermore, CA, UCRL-15419 (October 1981).

CR-7 P. Dutta, R. Hatfield, and P. Runstadler, Jr., Calibration Charrcteristics of IRAD Gage Vibrating Wire Stressmeter at Normal and High Temperature, Technical Report 80-2, vols. 1 and 2. Submitted to Lawrence Livermore National Laboratory by IRAD Gage, Lebanon, NH. Published as Lawrence Livermore National Laboratory, Livermore, CA, UCRL-15426 (October 1981).

CR-8 W. Quam and T. DeVore, Climax Spent-Fuel Dosimetry-Progress Report, September 1981-September 1982, EGG 1183-2455 and SANL 909-034. Submitted to Lawrence Livermore National Laboratory by EG\&G, Santa Barbara, CA. Published as Lawrence Livermore National Laboratory, Livermore, CA, UCRL-15419-1 (August 1982).

CR-9 J. B. Creveling, F. S. Shuri, K. M. Foster, and S. V. Mills, In Situ Stress Measurements at the Spent-Fuel Test-Climax Facility. Submitted to Lawrence Livermore National Laboratory by Foundation Sciences, Inc., Portland, OR. Published as Lawrence Livermore National Laboratory, Livermore, CA, UCRL-15628 (May 1984).

CR-10 W. Quam and T. DeVore, Climax Spent-Fuel Dosimetry Progress Report Sept. 82-Jan. 84, EGG 102822042. Submitted to Lawrence Livermore National Laboratory by EG\&G, Santa Barbara, CA. Published as Lawrence Livermore National Laboratory, Livermore, CA, UCRL-15419-2 (June 1984). 
CR-11 W. Quam, and T. DeVore. Climmax Spent-Full Dosimetry, Short Term Exposure, EGC; 11282-21141. Sub. mitted to Lawrence Livermore National Laboratory by EG\&C, Goleta, CA. Published as Lawrence I ivermore National Laboratory, Livermore, CA, UCRL-15419-3 (June 1984).

\section{Related Reports Published by Other Agencies}

OA-1 F. Maldonado, Summary of the Geology and Physical Properties of the Climax Stock. Nezada Test Site. U.S. Geological Survey Open File Report 77-356 (1977).

OA-2 Safety Asstsintent Document for the Spent-Fuel Handling and Packaging Program Demonstration at the Netrada Test Site, U.S. DOE repe:t NVO-198 (December 1978).

OA-3 J. C. Krogness, Materials Interaction Test Summary Description, Hanford Engineering Development Laboratory, Richland, WA, HEDL-TC-1331 Rev. 1(1981).

OA-4 F. Schmittroth, G. I. Neely, and J. C. Krogness, A Compurison of Measured and Calculated Decal/ Hent for Spent-Fuel Near 2.5 Years Cooling Time, Hanford Engineering Development Laboratory, Richland, WA, HEDL-7202 (September 1982).

OA-5 Safety Asse'ssment Document for the Spent Re'actor Fucl Goologic Storage Test in the' Climax Granite Stock at the Nevada Test Site, U.S. DOE report NVO-210 (January 1980).

OA-6 E. L. Majer, T. V. McEvilly, and M. S. King, "Monitoring an Underground Repository with Modern Seismological Methods," Inter. J. of Rock Mech. and Mining Sciences 18, 517-527 (1981).

OA-7 W. L. Ellis and J. E. Magner, Determination of the In Situ State of Stress at the Spent-Fud Test Climax Site, Climax Stock, Nezada Test Site, U.S. Geological Survey Open File Report $82-458$ (1982).

OA-8 E. Majer and T. McEvilly, Acoustic Emission and Wave Propagation Montitoring at the Spent-Fuel TistClimax, Laivrence Berkeley Laboratory, Berkeley, CA, LBL-17546 (April 1984).

\section{Documentary Film}

DF-1 L. B. Ballou and W. C. Patrick, Spent-Fuel Stornge in Granite a Final Report, a 17-minute color tilm Lawrence Livermore National Laboratory, Livermore, CA, film number PR-052 (1984). 